PACIFIC LINGUISTICS

Series A -82

\title{
PAPERS IN AUSTRONESIAN LINGUISTICS NO. 2
}

edited by

M. D. Ross

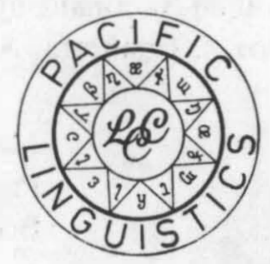

Department of Linguistics

Research School of Pacific Studies

THE AUSTRALIAN NATIONAL UNIVERSITY 
PACIFIC LINGUISTICS is issued through the Linguistic Circle of Canberra and consists of four series:

SERIES A: Occasional Papers

SERIES B: Monographs
SERIES C: Books

SERIES D: Special Publications

FOUNDING EDITOR: S.A. Wurm

EDITORIAL BOARD: K.A. Adelaar, T.E. Dutton, A.K. Pawley, M.D. Ross, D.T. Tryon

EDITORIAL ADVISERS:
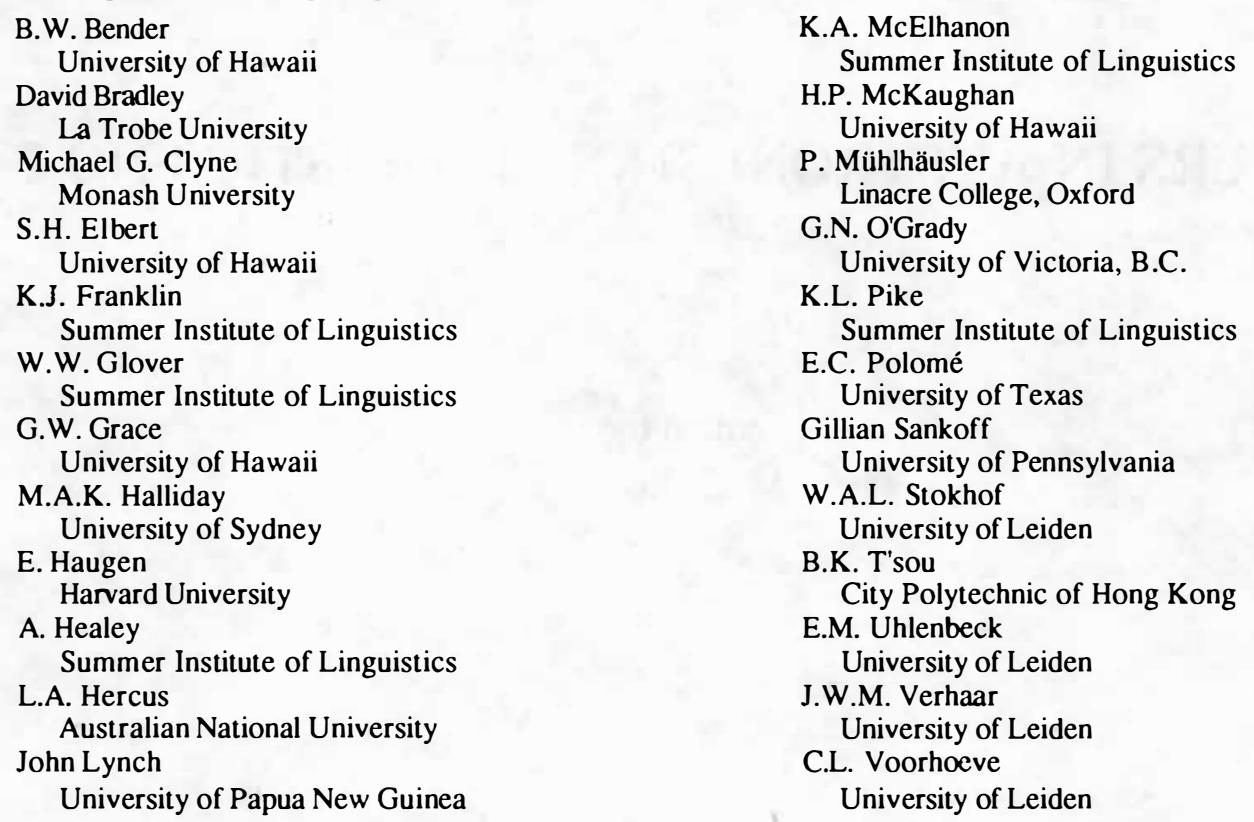

All correspondence concerning PACIFIC LINGUISTICS, including orders and subscriptions, should be addressed to:

\section{PACIFIC LINGUISTICS \\ Department of Linguistics \\ Research School of Pacific Studies \\ The Australian National University \\ G.P.O. Box 4, Canberra, A.C.T. 2601 \\ Australia}

Copyright $\odot$ The Authors

Copyedited by Joan Birnie

Typeset by Jeanette Coombes

First Published 1992

The editors are indebted to the Australian National University for assistance in the production of this series.

This publication was made possible by an initial grant from the Hunter Douglas Fund.
Maps drawn by Theo Baumann

Printed by A.N.U. Printing Service

Bound by F \& M Perfect Bookbinding 


\section{TABLE OF CONTENTS}

PREFACE

INTRODUCTION

ROBERT BLUST

On speech strata in Tiruray

SARAH BELL

On the order of nouns and modifiers in literary Cebuano

VIDEA P. DE GUZMAN

Morphological evidence for primacy of patient as subject in Tagalog

STEPHEN J. SCHOOLING

The phonology of Yuanga: a language of New Caledonia

BRYAN EZARD

Tawala derivational prefixes: a semantic perspective

$147-250$

Clif OlsON

Gumawana (Amphlett Islands, Papua New Guinea): grammar sketch and texts 


\section{PREFACE}

This Pacific Linguistics' Series A volume appears under a recently adopted policy whereby volumes are edited by members of the Editorial Board or other invited persons. This policy has been adopted to make cataloguing, bibliographic referencing, and finding volumes in libraries simpler. In the past these features were complicated by the facts that (i) there were many subseries under Series A, and (ii) all contributors to a Series A volume were listed as its authors so that anyone wishing to consult an article in a volume had to know under which author the volume was catalogued in order to find the volume. Now volumes will be listed under the editor's name. In adopting this policy, however, it should be pointed out that the editor's duties will vary from one volume to another. In some cases the editor will have little more to do with the production of the volume than a member of the editorial board would do in connection with the publication of volumes in our other series. In other cases the editor will play a major role in the production of the volume, by soliciting papers and reworking contributors' articles. In any event, the editor will be a specialist in the field represented by the volume, and his/her role will be indicated. In the case of the present volume, the editor's tasks included editing the text of Olson's paper, which had been written as part of his programme of language study and Bible translation with the Summer Institute of Linguistics. I am grateful to him for allowing me to edit it for publication.

Series A volumes will not be on specific themes. They will remain as they have always been - collections of individual papers. Any special thematic volumes will be published in Series C. We hope that this new policy will make life easier for our contributors, readers and other users.

M.D. ROSS 


\section{INTRODUCTION}

Of the six papers papers in this volume, three (Blust, Bell and De Guzman) concern languages of the Philippines and three (Schooling, Ezard and Olson) describe languages spoken in Melanesia. Map 1 shows the locations of these languages. Five of the papers (i.e. all except Olson's work) have for various reasons experienced a delay in publication, and they appear together here because the editors of Pacific Linguistics feel that all six make contributions to Austronesian linguistic studies which should be made available to scholars.

Blust's paper was received in 1988, and is a study of speech strata in Tiruray, a language of Mindanao in the southern Philippines. The term 'speech strata' is used when major portions of a language's lexicon are derived from a different, but genetically related, sources. Thus in Tiruray one stratum consists of natively inherited vocabulary, while the second is made up of items borrowed from another Austronesian source in the southern Philippines. Blust's study is in the tradition of Dyen's (1956) well-known paper on Ngaju Dayak (south Kalimantan), but the stratification of Tiruray is much less easily amenable to analysis than that of Ngaju Dayak, and Blust's fine-grained work is of particular importance for his discussion of analytical methods and for their application to difficult data. We know with reasonable certainty that there are many cases of lexical stratification in the Austronesian language family (and doubtless in other language families, too), but very few adequate analyses of stratification have appeared, and Blust's paper provides a model for such analysis. At the same time it establishes the genetic position of Tiruray and is also relevant to the debate on the genetic grouping of the Austronesian languages of the Philippines (Reid 1982; Zorc 1986).

Bell's paper, a revision of one originally written in 1979, examines apparently free variation in the structure of the noun phrase in written Cebuano (central Philippines), and finds that this variation is not as free as might appear. Indeed she finds that there are syntactic and semantic constraints on variation in noun phrase structure, and that Cebuano differs in this respect from Tagalog (to which it is quite closely related), in that the corresponding constraints in Tagalog are largely discourse-based. This paper complements a parallel study by Bell of Cebuano clause structure (Bell 1988).

De Guzman's contribution is a 1990 reworking of a paper written in 1979. It is commonly accepted that a canonically ergative language is one in which the patient of a transitive clause is treated in the same way as the subject of an intransitive clause, whilst in an accusative language it is the agent which has this privilege (Dixon 1987). On this basis, Tagalog is morphologically neither canonically ergative nor canonically accusative, since some intransitive verbs are morphologically similar to patient-subject transitives, while other intransitives resemble agent-subject transitives. Other means thus have to be used to characterise Tagalog verbal morphology, and De Guzman shows that there is a strong tendency for forms with a patient subject to be morphologically simpler than forms with an 
agent subject. This suggests that, morphologically at least, Tagalog has ergative tendencies. This finding supplements De Guzman (1988) and the work of a number of other scholars cited by De Guzman, who have argued on syntactic criteria that Tagalog is primarily an ergative language. Parallel arguments have been offered on discourse-based criteria by Coorman, Fox and Givón (1988).

The first of the three papers on languages spoken in Melanesia is Schooling's work, prepared in 1985, on the phonology of Yuanga, of northern New Caledonia. His paper is of interest in two respects. Firstly, he provides us with an account of the phonology of a New Caledonian language: in comparison with other regions within Oceania, relatively little has been published about the languages of this island, and only a fraction of published material is in English. Secondly, Schooling provides two different analyses of his data, one based on structuralist phonemics, the other on the prosodic analysis of the London School. The latter analysis is radical, but, as Schooling recognises, prosodic analysis is a major precursor of autosegmental phonology, and he uses Yuanga data to demonstrate the relationship between them.

Ezard's account of the classificatory prefixes of Tawala was written in 1982, but, apart from the short account in Ezard (1978), it has not been generally available. Tawala is a member of the Papuan Tip cluster of Westem Oceanic languages (Ross 1988: ch.6) and, as Capell (1943:237) noted, one of the interesting features of these languages is the use of 'classificatory' prefixes on verbs, indicating such semantic categories as the kind of instrument used to perform the action of the verb. Ezard's is almost the only account of these prefixes, and certainly the only detailed account. His careful examination of the interaction of semantic features in determining the use of classificatory prefixes not only provides a clear description of their functions in Tawala, but is also a satisf ying application of the kind of semantically based grammar developed by Dixon (1982).

Olson's sketch of Gumawana grammar is included here because of its interest from a comparative perspective. Gumawana (formerly known as Gumasi) is, like Tawala, a member of the Papuan Tip cluster, but its position within the cluster has long been unclear. Lithgow (1976) treated it as an isolate within the cluster. Ross (1988: ch.6) assumed the language to be more closely related to Kilivila of the Trobriand Islands to its north than to the languages of the D'Entrecasteaux Archipelago to its south. However, Olson's data and analysis show that its relationship is in fact somewhat closer to the languages to the south. At the same time, it has unique features whose diachronic status as retentions or innovations needs investigation and which may cast light on the history of the Papuan Tip cluster as a whole. Interestingly, the confusion about the genetic status of Gumawana has been only partly due to a shortage of data: the lexicon of Gumawana has two strata, and it is only now clear which stratum is probably native and which is acquired (probably from Kilivila). The language is thus a prime candidate for application of the strategies presented by Blust in his contribution to this volume.

M.D. ROSS 


\section{REFERENCES}

BELL, Sarah J., 1988, Voice and foreground/background in Cebuano. In McGinn, ed. 1988:427-440.

CAPELL, Arthur, 1943, The linguistic position of south-eastern Papua. Sydney: Australasian Medical Publishing Co.

COORMAN, Ann M., Barbard FOX and Talmy GIVÓN, 1988, The discourse definition of ergativity: a study of Chamorro and Tagalog texts. In McGinn, ed. 1988:387-426.

De GUZMAN, Videa P., 1988, Ergative analysis for Philippine languages: an analysis. In McGinn, ed. 1988:323-345.

DIXON, R.M.W., 1982, Where have all the adjectives gone? and other essays in semantics and syntax. Berlin: Mouton.

1987, Studies in ergativity: introduction. Lingua 71:1-16.

DYEN, Isidore, 1956, The Ngaju-Dayak 'old speech stratum'. Language 32:83-87.

EZARD, Bryan, 1978, Classificatory prefixes of the Massim cluster. In S.A. Wurm and Lois Carrington, eds Second International Conference on Austronesian Linguistics: proceedings, 1159-1180. PL, C-61.

LITHGOW, David R., 1976, Austronesian languages: Milne Bay and adjacent islands (Milne Bay Province). In S.A. Wurm, ed. New Guinea area languages and language study, vol.2: 441-523. PL, C-39.

McGINN, Richard, 1988, Studies in Austronesian linguistics. Athens, Ohio: Ohio University Center for International Studies, Center for Southeast Asia Studies.

REID, Lawrence A., 1982, The demise of Proto-Philippines. In Amran Halim, Lois Carrington and S.A. Wurm, eds Papers from the Third International Conference on Austronesian Linguistics, vol.2: 201-216. PL, C-75.

ROSS, M.D., 1988, Proto Oceanic and the Austronesian languages of Western Melanesia. PL, C-98.

ZORC, R. David, 1986, The genetic relationships of Philippine languages. In Paul Geraghty, Lois Carrington and S.A. Wurm, eds FOCAL II: Papers from the Fifth International Conference on Austronesian Linguistics, 147-173. PL, C-94. 


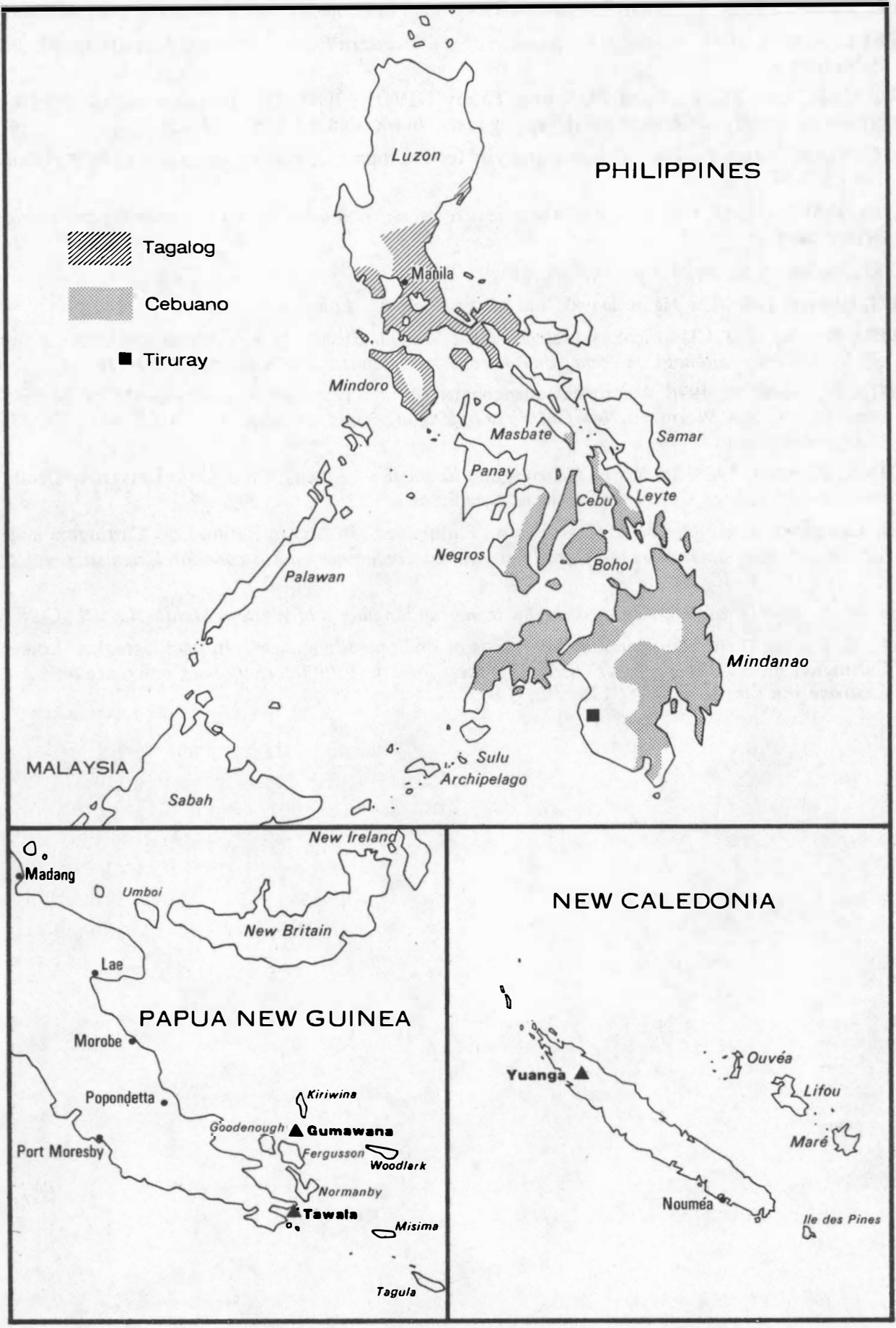




\title{
ON SPEECH STRATA IN TIRURAY
}

\author{
ROBERT BLUST
}

\section{INTRODUCTION}

The historical phonology of Tiruray was first examined by Conant in 1913. More recently Schlegel (1971), in his Tiruray-English dictionary, has drawn attention to a number of loanwords in the language. This paper ${ }^{1}$ attempts to deepen and extend both lines of inquiry. In agreement with Conklin (1955) it concludes that Tiruray belongs to a South Mindanao subgroup of Philippine languages which includes Tagabili and Bilaan. A consideration of the Tiruray reflexes of Proto Philippine reconstructions leads to the following noteworthy conclusions: (1) nearly half of all Tiruray vocabulary with a known Proto Philippine etymology has been borrowed, producing a number of etymological doublets and double reflexes of many proto-phonemes; (2) native and borrowed lexical items can be distinguished not simply by differing reflexes but by correlated differences of development which exhibit a high degree of mutual association, thus defining distinct 'speech strata'; (3) unlike the classic case of Ngaju Dayak the native speech stratum in Tiruray can be most confidently by identified by appeal to unique reflexes rather than to the basic:non-basic vocabulary distinction, since basic vocabulary has been borrowed on a large scale; (4) some of the non-native vocabulary of Tiruray is shared with Tagabili or Bilaan or both - this raises the perhaps unanswerable question whether in any given case a loan distribution is the product of recent independent borrowing of the same item ("parallel borrowing'), or a product of a single borrowing into Proto South Mindanao from an unknown source language; and (5) within the unambiguously native lexical stratum there have been several unconditioned phonemic splits and since these cannot be explained as products of borrowing they pose a direct challenge to the Regularity Hypothesis and lend support to the "lexical diffusion" model of phonological change advocated by Wang (1969).

\subsection{BACKGROUND}

Probably all languages have some loanwords, but the scope and structural consequences of lexical borrowing vary considerably. English, with its extensive loan vocabulary from Scandinavian, Latin, Greek and especially Norman French sources, owes much to foreign lexical influences. Mandarin Chinese, on the other hand, is a language with some loan translations but relatively few direct loans.

\footnotetext{
${ }^{1} R$. David Zorc read an earlier version of this manuscript and offered valuable suggestions for improvement. Needless to say, he does not necessarily accept all of its conclusions, and I alone am responsible for any shortcomings that remain.
} 
It is well known that extensive borrowing from a genetically related language can produce etymological doublets, as with English shirt and skirt or shell and skull, where the first reflex of each pair is native and the second borrowed. More generally, the Proto Germanic cluster ${ }^{*} s k$ appears as a voiceless palatal fricative in native English words, but as /sk/ in Scandinavian loans. When borrowing produces double reflexes of more than one protophoneme that can be correlated with one another we may speak of separate 'strata' in the lexicon of a language. In Austronesian linguistics this term (and its German equivalent: Sprachschicht) has been used to describe the historically distinct vocabulary layers of Ngaju Dayak of south-east Borneo (Dempwolff 1922, 1937; Dyen 1956). Thus, Ngaju Dayak reflects PAN ${ }^{*}-a,{ }^{*} e(s c h w a),{ }^{*} R,{ }^{*} q,{ }^{*}-D$ - and ${ }^{*} c$ in either of two ways (Dyen 1956:85).

$\begin{array}{lcl}\text { PAN } & (1) & (2) \\ a & \grave{e} & a \\ e & e, \grave{e} & a \\ R & h & r \\ q & \emptyset & h \\ D & r & d \\ c & s & c\end{array}$

\section{FIGURE 1: EVIDENCE FOR SPEECH STRATA IN NGAJU DAYAK}

The strata of the Ngaju Dayak lexicon are defined by consistent associations of diagnostic reflexes: in any given morpheme a reflex may belong to only one of these two sets. Hence *tiDuR > tiroh 'sleep', with stratum (1) reflexes of ${ }^{*} D$ and $* R$, but $* d a R a q>$ darah 'blood', with stratum (2) reflexes of ${ }^{*} R$ and ${ }^{*} q$, or the etymological doublets behat 'heavy' with stratum (1) reflexes of ${ }^{*} e$ and ${ }^{*} R$, but $s a$-barat 'as heavy as ', with stratum (2) reflexes of the same proto-phonemes. A similar situation has been reported (without the associated terminology) for Rotuman of the central Pacific (Biggs 1965), and more recently for Rennellese, a Polynesian Outlier language in the Solomon Islands (Blust 1987), and Mokilese of the eastem Caroline Islands in Micronesia (Rehg \& Bender 1988). ${ }^{2}$

The major purpose of this paper is to draw attention to two fairly well def ined speech strata in Tiruray of the southern Philippines. This undertaking is of interest for a least two reasons. Firstly, although it has been observed that Tiruray contains a number of loanwords, many unambiguous loans have been overlooked in past discussions, and the evidence of stratal correlations has gone totally unnoticed. Secondly, the problem of assigning lexical items to strata is more difficult in Tiruray than in Ngaju Dayak since Tiruray has borrowed a substantial amount of basic vocabulary and exhibits some apparently unconditioned phonemic splits both in native and in borrowed forms.

Tiruray (or Teduray) is spoken on the island of Mindanao, in the hill country along the eastern shore of Moro Gulf between Magindanao (or Maguindanao) on the south and Ilanun (or Iranon) and Maranao on the north (Map 2). Conklin (1955) placed it with Bilaan (or Blaan) and Tagabili (or Tboli) in a "Southem Philippine" group of languages which appears to diverge rather sharply from other languages of the archipelago. Thomas and Healey (1962) include Tiruray only tentatively with Bilaan and Tagabili in a "Southern Mindanao

\footnotetext{
${ }^{2}$ Some other cases of heavy borrowing, as that reported by Reid (1973) for Kankanay of the northern Philippines, show somewhat less clearly demarcated strata, as fewer sound changes distinguish the source and borrowing languages.
} 


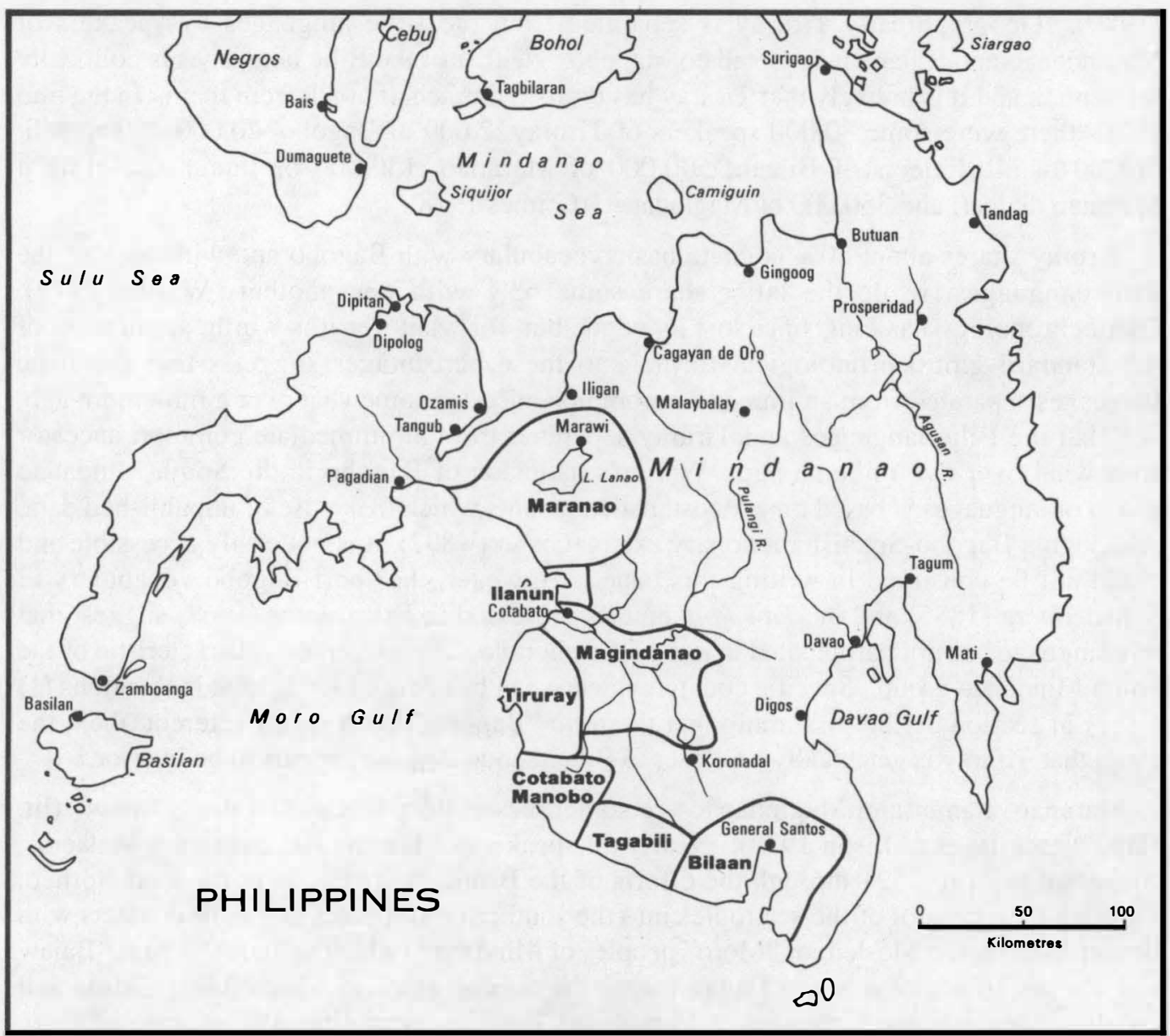

MAP 2: TIRURAY AND ITS NEIGHBOURS 
Family", which is said to be coordinate with the "Philippine Superstock" (comprising all other languages of the Philippines) on the one hand and with Malay and the Chamic languages of Vietnam on the other. According to Walton (1979) Tiruray forms one of three primary branches of a South Mindanao subgroup of Philippine languages. The second branch consists only of a language he calls "Bagobo", while the third ("Bilic") contains Tagabili and the various dialects of Bilaan. A similar view is expressed by McFarland (1980). Geographically Tiruray is separated from the Bilic languages by speakers of Magindanao and Kalamansig Cotabato Manobo. Neither of the Bilic languages is politically influential, and it is unlikely that Tiruray has borrowed much, if at all, from them. In the mid 1970s there were some 30,000 speakers of Tiruray, 7,000 of Bagobo, 20,000 of Tagabili, 76,000 of all dialects of Bilaan, 500,000 of Maranao, 150,000 of Ilanun (possibly a Maranao dialect) and 350,000 of Magindanao (Grimes 1978). ${ }^{3}$

Tiruray shares about $40 \%$ cognate basic vocabulary with Bagobo and with each of the Bilic languages, while the latter share some $63 \%$ with one another (Walton 1979). Glottochronology has long since lost its vogue but, for whatever it is worth, application of the standard glottochronological formula to these percentages suggests that the Bilic languages separated from an immediate common ancestor somewhat over a millenium ago, and that the Bilic languages and Tiruray separated from an immediate common ancestor somewhat over two millenia ago. Walton's inclusion of Bagobo in the South Mindanao group of languages is based on lexicostatistical counts which make use of unpublished data. Although a Bagobo-Spanish dictionary exists (Gisbert 1892), it is not easily accessible and could not be consulted in writing this paper. However, the short Bagobo vocabulary in Schadenberg (1885) and the Tuwaang epic as presented in Falcasantos (1967) suggest that this language has not participated in any of the phonological innovations characteristic of the South Mindanao group. Specific counterevidence can be adduced for at least innovations (1) - (11) in section 3.1.3. Assuming that the term "Bagobo" has a single referent, then, the claim that Tiruray is genetically no closer to Bilic than to Bagobo appears to be in error. ${ }^{4}$

Maranao, Ilanun and Magindanao are sometimes collectively called the "Danaw" (lit. "lake") languages (Allison 1979). Nearly all speakers of Danaw languages are Moslems, converted prior to 1521 through the efforts of the Brunei Sultanate in north-west Borneo. Through their control of the sea routes into the southern Philippines and their contacts with Brunei Malays, the Moslem or "Moro" peoples of Mindanao (which include the Sama-Bajaw and Tausug in addition to the Danaw) were the conduit through which foreign ideas and vocabulary entered the hinterland of Mindanao. The Tiruray traditionally maintained close trading relations with the Magindanao (Lebar 1975; Moore 1975). Moreover, although the Tiruray generally resisted the introduction of Islam, "Magindanao datus have traditionally exercised tenuous political control within portions of the southwestern Cotabato uplands inhabited by Tiruray and Manobos, an extenstion of long-standing trading relations between coastal Muslims and their pagan upland neighbors" (Lebar 1975:36). Given what we know of the political and cultural relations in the area of eastern Moro Gulf, then, the Danaw

\footnotetext{
${ }^{3}$ Allison (1979) reports approximately 250,000 speakers of Maranao, another 250,000 of Magindanao and 100,000 of Ilanun.

${ }^{4} R$. David Zorc has suggested to me why this confusing situation exists. The term "Bagobo" does in fact have two quite distinct referents. In its better known sense it refers to a Manono language represented in the publications of Schadenberg (1885), Gisbert (1892) and Falcasantos (1967). Walton (1979), however, uses the same term for a still undescribed South Mindanao language which Zorc prefers to call "Giangan".
} 
languages in general and Magindanao in particular are the most likely sources of Austronesian loanwords in Tiruray.

The historical phonology of Tiruray was described briefly by Conant (1913) and in passing by Charles (1974). A sketch of the synchronic phonology is provided by Post (1966). The largest published source of lexical material on Tiruray is Schlegel (1971). A special feature of Schlegel's dictionary is his attempt to mark loanwords wherever possible. The loans that he identifies fall into six categories: (1) Chinese, (2) English, (3) Hiligaynon, (4) Magindanao, (5) Spanish and (6) Tagalog. Schlegel (p.9) states clearly that the identification of loans in his dictionary was based upon "the subjective opinions of Tiruray speakers". To the extent that these identifications reflect a majority view in the Tiruray speech community it is clear that many loans from Danaw and other Philippine languages are no longer recognised as such by the Tiruray themselves.

To come to grips with the problem of speech strata we must examine Tiruray historical phonology in greater depth than has been done in earlier studies. So as to maximise the usefulness of reconstructions we will compare Tiruray (TIR) forms with forms attributed to Proto Philippines (Zorc 1971, plus some additional reconstructions of my own) rather than with the more remote Proto Malayo-Polynesian (PMP) or Proto Austronesian (PAN). In addition it will be useful to refer to two interstage proto-languages, Proto Danaw (the putative immediate ancestor of Maranao, Ilanun and Magindanao) and Proto South Mindanao (the putative immediate ancestor of Tiruray, Tagabili, the Bilaan dialects and Giangan, the last of which cannot be included for lack of published data). Proto Danaw (PD) reconstructions are taken in part from Allison (1979) and partly supplied by comparison of Maranao with other Austronesian languages. Proto South Mindanao (PSM) reconstructions are taken in part from Savage (1986), who uses material only from Tagabili and the Koronadal and Sarangani dialects of Bilaan, and partly supplied by independent comparison. 5

The generally accepted phoneme inventory of Proto Philippines (PPH) includes 20 consonants, 4 vowels and 4 diphthongs, as follows: ${ }^{*} p,{ }^{*} t,{ }^{*} k,{ }^{*} q,{ }^{*}$, ${ }^{*} b,{ }^{*} d,{ }^{*} j,{ }^{*} g$,

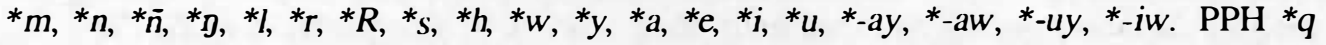
may have been a back velar (uvular) stop, but its most common reflex is a glottal stop. PPH *? was first recognised by Zorc (1982); it has fallen together with ${ }^{*} q$ in most languages, but is distinctly reflected in some. This symbol appears to cover more than one correspondence class, and its validity remains debatable. ${ }^{*} j$ is phonetically problematic and probably did not pattern with the other voiced stops and the nasals; it may have been a palatalised voiced velar stop. ${ }^{*} r$ evidently was apical and ${ }^{*} R$ uvular, while ${ }^{*} e$ was a mid to high central vowel. In

\footnotetext{
${ }^{5}$ Sources used for attested languages other than Tiruray are as follows. Tagabili (TBL): Forsberg and Lindquist (1955), plus a few examples from Lindquist, Forsberg and Healey 1959), and Reid (1971); Bilaan (BIL): Dean and Dean (1955), Abrams (1963), Reid (1971) - the dialects of Koronadal and Sarangani are distinguished as BIL(K) and BIL(S); Maranao (MAR): McKaughan and Macaraya 1967; Magindanao (MAG): Juanmarti 1892. Little Ilanun material appears to be available in print, apart from the limited corpus in Allison (1979) and the short vocabulary in Ray (1913). I have not had access to the Bilaan vocabulary in Montano (1885), nor to the unpublished manuscript on Sarangani Bilaan by Blackburn and McLachlin to which Savage (1986) refers. In citing material from all languages I omit the initial glottal stop and the written semivowels in the environments -iy $V$ - and $-u w V$-, since these can be supplied from context when intervocalic glottal stop is written.
} 
addition, stress was phonemic. Because none of the languages considered in this paper have retained stress contrasts, however, this feature of PPH reconstructions is ignored. ${ }^{6}$

\section{PROTODANAW}

Allison (1979) reconstructs 15 PD consonants and 4 vowels: ${ }^{*} p,{ }^{*} t,{ }^{*} k,{ }^{*} ?,{ }^{*} b,{ }^{*} d,{ }^{*} g$, ${ }^{*} m,{ }^{*} n,{ }^{*} \eta,{ }^{*} s,{ }^{*} l,{ }^{*} r,{ }^{*} w,{ }^{*} y,{ }^{*} a, *_{i}$ (hereafter $\left.{ }^{*} e\right),{ }^{*} i,{ }^{*} u$. In the description of his reconstructed phoneme inventory (p.57) he does not mention diphthongs, but in his

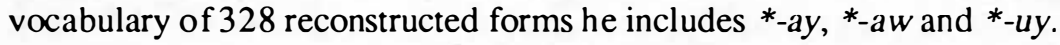

A comparison of Proto Danaw with Proto Philippines shows relatively few phonological changes. Those noted are as follows:

(1) $\mathrm{PPH} * h$ unconditionally disappeared (e.g. *hapuy $>$ *apuy 'fire', *duha $>$ *dua 'two').

(2) $\mathrm{PPH}^{*} q$ disappeared in initial position and between unlike vowels the first of which was high, but otherwise became *? (e.g. *qatay $>$ *atay 'liver', *liqeR $>$ *lig 'neck', *buqaya > buaya 'crocodile', *puqun $>{ }^{*}$ pu? ?un 'beginning, cause', *daqet $>{ }^{*}$ ra? 'bad', *baseq > *wasa? 'wet').

(3) Initially and intervocalically PPH ${ }^{*} b$ split into PD ${ }^{*} b$ and ${ }^{*} w$ without statable conditions. Maranao variants such as bata?, wata? 'child' and batu, watu 'stone' suggest that this change was incomplete in Proto Danaw. Following the change ${ }^{*} b>{ }^{*} w, P D{ }^{*} w$ generally disappeared before ${ }^{*} u$, with contraction of a resulting sequence of like vowels (e.g. *buliR > ulig 'bunch, cluster', *tubuq $>t u$ ?' 'grow'). In final position, and apparently after $* e, \mathrm{PPH}{ }^{*} b$ did not change.

(4) Parallel to the preceding development, $\mathrm{PPH} * d$ and $* j$ merged and then split into *d and ${ }^{*} r$ without statable conditions. Pre-PD ${ }^{*} r$ from PPH ${ }^{*} d,{ }^{*} j$ or ${ }^{*} r$ then became ${ }^{*}$ if a lateral occurred in the following syllable (e.g. *dalan $>*^{*}$ lalan 'path, road'). Similarly, PPH ${ }^{*}$ l became PD ${ }^{*} r$ if ${ }^{*} r$ occurred in the following syllable (e.g. *lujan $>{ }^{*}$ ruran "load, cargo'). In final position, and apparently after $* e, \mathrm{PPH}{ }^{*} d$ and $*^{*} j$ merged as PD ${ }^{*} d$.

(5) $\mathrm{PPH}{ }^{*} R$ became PD ${ }^{*} g$ (e.g. *Ratus $>{ }^{*}$ gatus 'hundred', *beRas $>{ }^{*}$ begas 'husked rice', *salaR > *salag 'nest').

(6) PPH prepenultimate *a which was or which came to be initial disappeared (e.g. *qabaRa > *waga 'shoulder', *qapeju > *pedu 'gall').

(7) $\mathrm{PPH} *$ disappeared if it was initial or if it came to be initial through loss of a laryngeal consonant (e.g. *enem $>{ }^{*}$ nem 'six', *hemay $>{ }^{*}$ may 'cooked rice').

(8) If *e came to follow another vowel, or if *a came to precede a high vowel word internally, each disappeared (e.g. *luheq $>*^{*} l u$ ? 'tears', *wahis $>*^{*}$ ig 'fresh water', *panahik > *panik 'climb', *lahud $>$ *ka-lud-an 'deep sea').

(9) PPH *-iw and *-uy merged as PD *-uy (e.g. *hapuy > *apuy 'fire', *laRiw > *laguy 'flee, run away').

6Juanmarti (1892) marks stress contrasts in a small number of Magindanao forms, as uni 'sced' (Sp. semilla), but uni 'to sound' (Sp. sonar). Allison (1979) reports no usc of contrastive stress in the daughter languages and does not reconstruct it for Proto Danaw. 
(10) PPH CVCCVC reduplications reduced to CVCVC by loss of the first member of the consonant cluster under certain conditions. Reduction generally (but now always) took place if both consonants were obstruents (e.g. *pakpak > ${ }^{*}$ papak 'wing', *kutkut > ${ }^{*} k u k u t$ 'claw, scratch '). If the first consonant was a nasal and the second a stop, reduction apparently never took place. Where the first consonant was a sonorant other than a nasal it sometimes was retained (e.g. *bulbul > *bulbul 'feathers, body hair').

Changes from Proto Danaw to the daughter languages are minor, largely involving the simplificaton of certain medial consonant clusters in Maranao, the loss of $\mathrm{PH} *$ in Ilanun and Magindanao and the change of $P D{ }^{*} r$ to Magindanao $N .{ }^{7}$

\section{PROTO SOUTH MINDANAO}

Savage (1986) reconstructs 16 PSM consonants and 4 vowels: ${ }^{*} p,{ }^{*} t,{ }^{*} q,{ }^{*},{ }^{*} b,{ }^{*} d,{ }^{*} g$, ${ }^{*} m,{ }^{*} n,{ }^{*} N,{ }^{*} s,{ }^{*} h,{ }^{*} l,{ }^{*} w,{ }^{*} y,{ }^{*} i,{ }^{*} i,{ }^{*} a,{ }^{*} u .{ }^{*} q$ is said to have been a glottal stop, ${ }^{*} N$ a velar nasal (hereafter written ${ }^{*} g$ ) and $*_{i}$ a high or mid central vowel (hereafter written ${ }^{*} e$ ), while ${ }^{*}$ (which occurs in none of the daughter languages) is left phonetically undefined. ${ }^{8}$ Inspection of the primary sources shows clearly that Savage's reconstruction is in need of revision.

For the correspondence $\operatorname{BIL}(\mathrm{K}) f: \operatorname{BIL}(\mathrm{S}) f:$ TDL $h$ in initial position, and $\operatorname{BIL}(\mathrm{K}) f$ : TBL $f$ elsewhere, Savage posits PSM ${ }^{*} p .{ }^{9}$ His arguments for doing so are based on pattern symmetry and some reported [p], [f] allophony in Sarangani Bilaan. However, the same arguments apply to the synchronic phonology of the languages compared, yet are not used to infer a phoneme $/ \mathrm{p} /$ in either Bilaan dialect nor in Tagabili. Moreover, reference to Savage's primary published source on Bilaan (Dean \& Dean 1955:fn.11) reveals that a stop allophone of /f/ was observed only in "two Spanish loans": pasinsya (paciencia) 'excuse', and patatas 'potato'. The argument from pattern symmetry similarly carries no weight, as it simply refers to the situation prior to the shift ${ }^{*} p>/ f /$, a change which clearly led to phonological restructuring. I see no grounds, then, for maintaining a PSM phoneme ${ }^{*} p$.

Savage also posits a flapped allophone of PSM ${ }^{*} d$ in intervocalic position. This claim appears to be based largely on the situation in Bilaan. Referring to BIL/d/, Dean and Dean (1955:314) report that "there is free variation between [d] and [r] alternants of this phoneme in intervocalic position in the speech of many speakers". According to Lindquist, Forsberg and Healey (1959:230), TBL /d/ generally is pronounced as a voiced stop, though "flapped [r] is found infrequently in intervocalic position and has been noted only in the speech of those who have had contact with another dialect, such as Ilocano or Ilongo". Neither Post (1966) nor Schlegel (1971) mention an intervocalic flapped allophone of TIR /d/. Indeed, flapping of $/ d /$ in any position would almost certainly have led to merger with $/ r /$. I assume, then, that PSM ${ }^{*} d$ was a stop in all positions.

\footnotetext{
7Juanmarti (1892) writes Magindanao/ $r$ / where Allison (1979) writes $/ 1 /$, as in ragum versus lagum 'needle'. In some cases Juanmarti gives doublets, as with ranaw, lanaw 'lake'.

${ }^{8}$ Savage (1986) describes PSM *' as "a laryngeal of indeterminate quality (possibly pharyngeal)". For a broader comparative perspective which suggests that Savage's ${ }^{*}$ should be written as ${ }^{*} q$ and his ${ }^{*} q$ as ${ }^{* 7} \mathrm{cf}$. Dyen (1953) and Zorc (1982).

${ }^{9}$ Tagabili reflects $\mathrm{PPH}{ }^{*} p$ - as / $/$ / in a handful of monosyllables that appear to be directly inherited (* ${ }^{*}$ paen $>$ /fan/ 'bait', *empu > /fu?/ 'great grandfather, great grandchild', *puqun 'base of a tree; beginning; cause' > /fun/ 'owner'). Savage does not consider these forms.
} 
As noted in the previous paragraph, Tiruray has a phoneme $/ r /$. TIR $/ r /$ derives historically from PPM ${ }^{*} d,{ }^{*} j,{ }^{*} r$ and ${ }^{*} R$, and contrasts with $\Lambda /$, which derives from PPH ${ }^{*} l$. Given these facts we have little choice but to assume that Proto South Mindanao had two contrasting liquids, ${ }^{*} l$ and ${ }^{*} r$.

Savage $(1986: 218, \mathrm{fn} .8)$ notes that errors in the transcription of the Bilaan vowels in his primary sources may vitiate his proposed reconstruction of four PSM vowels. Although the recognition of additional vowel correspondences is facilitated by the inclusion of Tiruray in PSM comparisons, it is clear from the data in Reid (1971) that Proto Bilic had at least *é (BIL(K) qéqél, BIL(S) yéqél, TBL qél 'water') and *o (BIL(K) dyoh, B IL(S) dyo, TBL dyoh 'bathe') in addition to the vowels posited by Savage. Examples of these vowels appear in Appendix 1.

In addition to consonants and vowels it appears necessary to reconstruct four final rising diphthongs of PSM: *-ay (BIL -ay, TBL -ay, TIR -ey), *-ey (BIL -i, TBL -ay, TIR -ey), *-aw (BIL -aw, TBL -aw, TIR -ew) and *-ew (BIL -u, TBL -aw, TIR -ew). However, as will be seen, *-ay and *-aw appear only in loans, all of which may have entered the South Mindanao languages after their separation from a common ancestor.

To summarise, I assume the following PSM phoneme inventory: consonants $t, k, q, ?, b$, $d, g, f, s, h, m, n, \eta, l, r, w$ and $y$, vowels $i, u, e ́, e, o$ and $a$; diphthongs ey and ew. Diphthongs ay and aw may have been present in some loanwords, but this remains a moot point.

The PPH sources of these phonemes can be seen in Appendix 1.

\subsection{SUBGROUPING AND RECONSTRUCTION}

Comparison with Bilaan and Tagabili supports an inference that several of the most distinctive historical developments in Tiruray, including some of its apparently unconditioned phonemic splits, already existed in Proto South Mindanao. The major innovations shared by these three languages are as follows: ${ }^{10}$

\subsubsection{LEXICAL INNOVATONS}

An examination of the material in Reid (1971) and in the available dictionaries shows a number of cognate sets that appear to be shared exclusively by Tiruray with Bilaan, Tagabili or both. Those noted are:

(1) armpit: TBL imak, TIR ima? (PPH *qidek);

(2) break: TBL tefok, TIR tefo?(PPH *baliq?);

(3) breast: BIL, TBL, TIR tutu? $\left(\mathrm{PPH}{ }^{*} s u s u\right)$;

(4) child: B IL(K) go?, TBL ga?, TIR ega? (Some other Philippine languages, such as Bontok, If ugao and Kallahan, have forms pointing to *upaq, but these appear to be distinct (PPH *anak, *bataq).);

(5) cook: BIL(K) tagah, TBL $t$-m-ogo, TIR togo (PPH *lutuq);

${ }^{10}$ Some of these innovations have already been pointed out in a fuller, prepublication version of Zorc (1986). 
(6) cut (slice meat): BIL.(K) faleh, BIL(S) f-n-ale, TIR féréh (PPH gelit?);

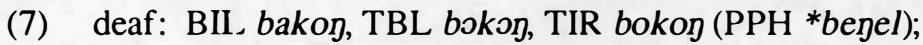

(8) deep: BIL(K) m-ᄁalam, BIL(S) m-nalam, TBL nelem, TIR nalen(?) (PPH *dalem);

(9) dream: BIL(K) kno, BIL(S) kna, TBL kena, TIR kena? (but also TIR kenakena 'talk in one's sleep') (PPH *taRa-qinep);

(10) exchange: TBL, TIR luluk (PPH *tuked);

(11) frog: BIL, TBL fak, TIR ef ak (PPH *bakbak);

(12) loincloth: BIL(K), TBL dowin, TIR dawin (PPH *bahaR);

(13) many: BIL de?e, TBL de?, TIR do?o (PPH *dakel);

(14) night: BIL buta刀, TBL, TIR bute刀 (PPH *Rabi?);

(15) pillow: $\mathrm{BIL}(\mathrm{S}), \mathrm{TIR}$ danan (PPH *qulunan);

(16) press down: TBL lenog, TIR reneg (PPH *dasek?);

(17) push: $\mathrm{BIL}(\mathrm{K})$ uluk, TIR uduk (PPH *turud);

(18) rattan: TBL lus, TIR deme-luas (PPH *quay);

(19) scar: BIL(K) la?os, BIL(S), TIR la?as, TBL lekes (PPH *piRlat, *ulat);

(20) skinny: BIL(K) lahon, BIL(S) lahan, TBL lehen, TIR lohon (PPH *ma-niwan);

(21) sniff: TBL s-em-luf, TIR serof (PPH *hajek);

(22) stab: BIL(K) tibeh, TBL tibo, TIR tiboh (PPH *saksak);

(23) urine: $\mathrm{BIL}(\mathrm{K})$ tlé?, BIL(S) klé?, TBL tle?é-l, TIR teré? (PPH *ihiq, *siqbu);

(24) weak: BIL(K) m-lunay, TBL m-ujoy, TIR lunay-lunay (PPH *ma-lumay).

In addition to the above a number of other cognate sets are shared by one or more South Mindanao languages with a few non-South Mindanao languages which are geographically contiguous or nearly so. Among the more noteworthy of these are:

(1) blanket: BIL, TBL kayab, TIR $k$-in-ayab, but Siocon Subanun (SubSc), Kalamansig Cotabato Manobo (MbKC), kayab 'blanket', Sarangani Manobo kayab 'modern blanket' (PPH *habel);

(2) burn: BIL(K) tam, BIL(S) $n$-tam, TBL $m$-tem, but MbKC temtem 'burn a field' (PPH *deket, *tutun);

(3) butterfly: BIL(K) kalboje, BIL(S) kalbani, TBL kbani, but SubSc kolombanoy (PPH *kali-bajban);

(4) chest (anat.): BIL kfe, TBL kfuh, but Binukid, Ilianen Manobo, MbKC kagpa $\left(\mathrm{PPH}{ }^{*}\right.$ dahdah, ${ }^{*}$ debdeb);

(5) coconut: BIL(K) ogit, TBL agit, TIR agit 'newly matured coconut', but Ilianen Manobo ahit $(\mathrm{PPH} *$ niuR);

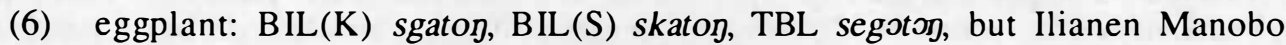

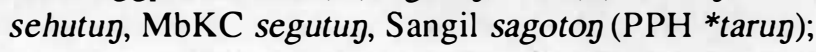


(7) feather: BIL, TBL, TIR lakay, but Sarangani Manobo lakay, Aborlan Tagbanwa lay 'tail feathers of a cock' (PPH *lawi);

(8) fence: BIL(K) labot, BIL(S), TBL labat, but Sindangan Subanun dlabat, SubSc glambat $(\mathrm{PPH} *$ qalad);

(9) floor: BIL(K) sa? $a^{2}$, BIL(S) sa?al, TBL se?el, TIR sa?ag, but Proto Manobo ${ }^{*} s a$ ?ag. These items appear to relfect PPH *saleR 'floor' with irregular loss of ${ }^{*}-I-$ (and subsequent insertion of glottal stop between like vowels). It is tempting to consider TIR sa?ag a Manobo loan, but phonological considerations prevent such a hypothesis in the case of the Bilic forms.

(10) lice (chicken): BIL(K), TBL, TIR sisif, but SubSc sisip (PPH *tuyaw?);

(11) long (object): BIL(K) taho?, BIL(S), TBL taha?, but Samal taha? (PPH *qanaduq);

(12) ring: BIL, TBL, TIR tisin, but MbKC tisin; from PPH *sinsin, with sporadic dissimilation;

(13) sand: BIL falak, TBL helek, TIR farek, but Dibabawon Manobo paek (PPH *qenay);

(14) strong: BIL m-gal, TIR bager, but Ilianen Manobo me-baher, MbKC me-bagel, Sangil me-bage? (PPH *ma-keseg);

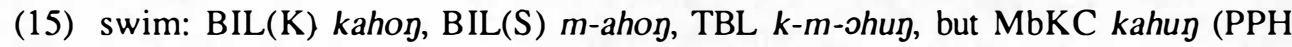
*laguy);

(16) termite: BIL kanok, but MbKC konok (PPH *anay);

(17) throat: BIL bkakon, TBL beklog(?), but MbKC bekokoy (PPH ?);

(18) woman: BIL, TBL, TIR libun, but Sindangan Subanun dlibun, SubSc glibun, Buludupi (Ray 1913) liun (PPH *ba-bahi);

(19) year: BIL(K) foli, BIL(S) fali, TBL halay, but MbKC sege-palay (PPH *taqun). This item clearly is based on the word for 'rice plant, rice in the field', presumably through reference to the cycle of growth and harvesting.

Some of the foregoing cognate sets undoubtedly acquired their attested distribution through borrowing. Kalamansig Cotabato Manobo in particular shares a number of forms with South Mindanao languages which it apparently does not share with other Manobo languages, and it is likely that these are a result of diffusion from some member of the South Mindanao group (probably Tiruray). However, in many of the above cognate sets borrowing is unlikely for semantic reasons, and the exclusively shared forms may point to a wider subgroup which includes the South Mindanao languages and various other languages of the southern Philippines. ${ }^{11}$

\footnotetext{
${ }^{11}$ Reid (1982:211) has proposed that the Bilic languages be cxcluded not only from a Philippincs subgroup, but even from the subgroup that 1 have elsewhere called "Malayo-Polynesian" (= extra-Formosan). His stated reasons for this proposal are that the languages in question are "Icxically...phonologically, morphologically and syntactically divergent". In addition: "Their antiquity is revcaled also in thcir phonology. Tboli is the only Philippine language (apart from Tagbanwa) which retains PAN * $q$ as a backed velar stop". Reid is an important scholar who has made lasting contributions to Philippine linguistics, but his proposal concerning the subgrouping of the South Mindanao languages appears to be without foundation. In effect, he treats the atypical features of the Bilic languages as retentions (since if they were innovations they would not be
} 


\subsubsection{SPORADIC SOUND CHANGES}

In general, agreement between languages in reflecting a sporadic change is less likely to be independent than agreement between languages in reflecting a regular sound change. Sporadic changes that are exclusively shared thus constitute powerful evidence that the languages which reflect them have undergone a period of common history apart from languages which do not. Several changes of this type are shared by Tiruray and the Bilic languages, as follows:

(1) $\mathrm{PPH} *$ depa $>$ PSM *dipa 'fathom', with sporadic *e $>*_{i}$ : TBL difu 'arm spread', TIR rifo 'the span of one's arms';

(2) $\mathrm{PPH} *$ talina $>$ PSM *kelina 'ear', with sporadic * $t>{ }^{*} k$, probably as a result of the elision of the prepenultimate vowel in rapid speech and unmarking of the resulting ${ }^{*} t l-$ cluster: BIL klige, TBL kelinu;

(3) $\mathrm{PPH}{ }^{*}$ ipen > PSM *kifen 'tooth', with the sporadic addition of ${ }^{*} k$-: BIL $k$ ifan, TIR kifen;

(4) PPH *lakaw > PSM *agew 'walk, go', with sporadic loss of the initial consonant: BIL(K) ogu 'go', BIL(S) m-agu, TBL m-ogow, TIR agew 'walk, go';

(5) $\mathrm{PPH} *$ dekdek $>$ PSM *edek 'pulverise, pound rice', with sporadic loss of the initial consonant: BIL(K) dak, BIL(S) m-dak, TBL $m$-dek, TIR edek;

(6) PPH *kuden > PSM *kureg 'cooking pot', with sporadic change of *-n to *B IL kulaj, TBL kulej, TIR kurey,

(7) $\mathrm{PPH}{ }^{*} \operatorname{taw} a R>\mathrm{PSM}{ }^{*} \operatorname{tabaR}$ 'to call', with sporadic change of * $w$ - to *- $b$-: TBL t-em-aba, TIR tabar.

In addition to the foregoing we might note the apparently sporadic change of $* I$ - in PPH *ludaq > PSM *duraq 'spit', which is reflected both by the South Mindanao languages and by the Danaw languages, and the semantic innovation PPH *abukay 'albino; white (of animals)' > PSM *bukay 'white'. Other examples (e.g. *dius $>{ }^{*}$ dioh 'bathe', *Rusuk > *rohok 'rib') can be found in Appendix 1.

\subsubsection{RECURRENT SOUND CHANGES}

Finally, there are a number of recurrent sound changes that are shared exclusively or almost exclusively by South Mindanao languages. I deliberately avoid the common

grounds for excluding Bilic from a Philippine subgroup). However, no argument whatever is offered for this interpretation, and widespread Philippine innovations that appear in one or more South Mindanao languages are not discussed (see Zorc 1986 for examples). By the same logic one could arbitrarily exclude many other languages from Malayo-Polyncsian despite their obvious membership in it: Kelabit of northern Sarawak shows no trace of medial prenasalisation, yet clearly subgroups with neighbouring languages that retain medial nasal clusters; the Chamic languages of mainland Southcast Asia show no trace of a prefix *man-, yet clearly subgroup with languages that do, ctc. Similarly, the distribution of languages which reflect PAN ${ }^{*} q$ as a velar - not "backed velar" - stop (e.g. Kalamian Tagbanwa and Tagabili of the Philippines, Moken of the Mergui Archipelago, Watubela of the east-central Moluccas, various (but not all) languages of the Admiralty Islands and New Caledonia) lends no support to the view that such languages are coordinate with the rest of Malayo-Polynesian. 
expression "regular sound change" for reasons that will become clear below. Those recurrent sound changes that are most distinctive for the South Mindanao group are: ${ }^{12}$

(1) $\mathrm{PPH} * p$ unconditionally shifted to PSM *f.

(2) PPH *- $k$ - became PSM *-g- in several of the most basic forms, but remained unchanged in others. In the pronouns $\mathrm{PPH}{ }^{*} k$ became PSM ${ }^{*} g$ even when initial. Where it became $\mathrm{PSM}^{*} \mathrm{~g}, \mathrm{PPH}{ }^{*} k$ merged with $\mathrm{PPH}{ }^{*} g$.

(3) $\mathrm{PPH} *_{-}^{*} \eta k$ - and heterorganic clusters of nasal plus $*^{*}$ in reduplicated monosyllables apparently became PSM *-k-.

(4) $\mathrm{PPH} *_{d}$ (which occurred in all positions) and $*_{j}$ (which did not occur word initially) merged as ${ }^{*} d$. This stop then came PSM ${ }^{*} r$ initially, intervocalically and finally in some forms, while in others it remained unchanged. Where they became PSM ${ }^{*} r, \mathrm{PPH}{ }^{*} d$ and ${ }^{*} j$ merged with $\mathrm{PPH}{ }^{*} r$ and ${ }^{*} R$. For convenience when discussing phonemes (not lexical items) $\mathrm{PPH} * d / j$ will be represented as ${ }^{*} d$ in the remainder of this paper.

(5) $\mathrm{PPH} *$-nd-and heterorganic clusters of nasal plus *d in reduplicated monosyllables apparently became PSM *-d-.

(6) $\mathrm{PPH}{ }^{*} s$ remained unchanged in initial position, but sometimes shifted to PSM $* \boldsymbol{h}$ in intervocalic. position, and almost always shifted to PSM ${ }^{*} h$ in final position.

(7) $\mathrm{PPH}{ }^{*}$-ns- and heterorganic clusters of nasal plus ${ }^{*} s$ in reduplicated monosyllables apparently became PSM *-s-.

(8) $\mathrm{PPH} * a, *_{i}$ and $*_{u}$ before a consonant in prepenultimate syllables merged with ${ }^{*} e$ (schwa). If this schwa was initial in PSM the entire first syllable disappeared in some forms ('gall', 'sting, smart') but not in others ('slave'). Where a PPH trisyllable with an initial vowel or laryngeal lacks a Tagabili cognate its PSM shape is ambiguous (e.g. 'shoulder'). Preceding a vowel PPH ${ }^{*} a,{ }^{*} i$ and ${ }^{*} u$ in this position did not change.

(9) $\mathrm{PPH} *_{-i}, *_{-}-u y$ and $*_{-i w}$ merged as PSM *-i.

(10) PPH high vowels generally were lowered before PPH $*_{-} q$ and $*_{-} R$, and occasionally were lowered before other final consonants $\left(*_{-} s, *_{-k}\right)$. If a high vowel of the same quality occurred in the preceding syllable is also lowered in accordance with a high harmony constraint.

(11) PPH medial consonant clusters, both in reduplicated monosyllables and in unreduplicated words, of ten were reduced by deletion of the first member. This could be a nasal (*dindin > *didin 'wall'), a liquid (*baRqay > *ba?an 'molar tooth') or an obstruent.

(12) PPH initial consonants were sporadically lost.

One other possible PSM innovation has been obscured by subsequent change. In Tiruray earlier ${ }^{*} l$ assimilated to ${ }^{*} r$ (from $\mathrm{PPH}{ }^{*} d,{ }^{*} j,{ }^{*} r$ or ${ }^{*} R$ ) anywhere within the same morpheme, as in PPH *lujan > TIR ruran 'load, cargo', *bulud > burur 'mountain', *lebuR $>$ rebur 'turbid, murky' or *liqe $R>$ ré?ér 'neck'. Since PSM ${ }^{*} I$ and ${ }^{*} r$ merged

\footnotetext{
${ }^{12}$ For examples the reader is referred to Appendix 1 . In addition, $\mathrm{PPH}{ }^{*} h$ disappeared unconditionally, and PPH * $q$ disappeared between unlike vowels when the first was high (e.g. PPh *buqaya > PSM *buaya 'crocodile', PPH *suqaR > PSM *suar 'thorn'). These changes are, on the whole, less distinctive than the twelve singled out for discussion.
} 
unconditionally in Bilaan and Tagabili it cannot be determined whether this change was present in Proto South Mindanao, or took place in the separate history of Tiruray. In reconstructing Proto South Mindanao I adopt the latter assumption.

Together these innovations consitute a substantial body of evidence that Bilaan, Tagabili and Tiruray have undergone a period of common development distinct from all other Austronesian languages (except, perhaps, from the still undocumented Giangan). Apart from superficial details such as the atypical development of /f/ in a Philippine language, perhaps the most striking feature of this set of data is the apparently sporadic character of many of the changes. In some cases the same types of irregularity can also be seen in comparisons between the South Mindanao languages themselves.

(1) ${ }^{*} k>$ /g/: PPH *paku > TIR fagew 'edible fem', but TBL hoku? 'edible wild fern', PPH *hikam > BIL igem, TBL igam, but TIR ikam 'mat', PPH *takaw > TBL m-nagaw, but BIL(K) toku, TIR fe-nakaw 'steal';

(2) ${ }^{*} d>$ /r/: PPH *depa > TIR rifo 'the span of one's arms', but TBL difu 'arm spread';

(3) $\quad *_{-s}>$ /h/: PPH *(ma)-nipis $>$ BIL(K) m-nifih, BIL(S) m-nifi, TBL lufi, but TIR nifis 'thin (objects)';

(4) Lowering of high vowels: PPH *piliq > TBL $m$-élék, but TIR f-em-ili? 'choose', $\mathrm{PPH} *$ lebuR > TBL lebol 'murky, riled, as a river after a heavy rain', but TIR rebur '(of water) dirty, murky, unclear', TIR eméh, but BIL, TBL mih 'sweet';

(5) Loss of initial consonants: PPH *manuk > BIL(K) anok, BIL(S) anuk, TBL onuk, but TIR manuk 'bird, chicken', PPH *tabeq > TBL abu?, but BIL tabe?, TIR towo?

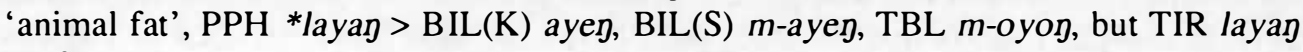
'to fly'.

The evidence presented in this section establishes the immediate genetic relationship of Tiruray, Tagabili and Bilaan beyond reasonable doubt. Although the wider relationships of the South Mindanao languages remain unclear, membership in a Philippines group seems almost certain and membership in a Southern Philippines group that includes the Manobo languages and possibly Subanun receives some lexical support. The often noted "aberrant" character of the South Mindanao languages is most simply explained as a product of their highly innovative nature rather than as a product of long separation from other languages in the Philippines.

\subsection{METHODOLOGICAL ISSUES}

In section 3.1 I have suggested a number of changes from PPH to PSM, and have proposed some PSM lexical reconstructions. Certain methodological issues arise in connection with these proposals, and these are addressed below.

\subsubsection{THE REGULARITY HYPOTHESIS AND BORROWING}

As noted in section 3.1, one of the most compelling types of evidence for the South Mindanao subgroup is the occurrence of exclusively shared sporadic changes. While sporadic changes are welcome as subgrouping evidence they play havoc with reconstruction, as they conflict with the "Regularity Hypothesis" upon which systematic diachronic inferences in phonology depend. As an alternative to acknowledging, for example, the 
unconditioned split of PPH *-k- to PSM *-g- or *-k-, we must find convincing evidence for at least one of three other hypotheses: (1) PPH had an additional velar stop which has previously been overlooked (hence *lak $i$ 'man, male', *sik $u$ 'elbow', but *tak $\mathbf{k}_{2} e d$ 'heel', ${ }^{*} h i k_{2}$ et 'to tie'); (2) the split of PPH ${ }^{*}-k$-is phonologically conditioned; (3) the split is due to borrowing.

Alternative (1) is rejected on the grounds that it violates the fundamental triangulation procedure of scientific inference. All successful scientific explanations, from the Newtonian theory of gravity to the double helix theory of the structure of DNA, posit a logical (hence non-observable) construct at the apex of the explanatory triangle which is justified solely by its ability to interrelate at least two independent and superficially disparate observations at the observational base (e.g. falling apples, orbits of the planets). The situation in comparative linguistics is no different. To justify the reconstruction of a new proto-phoneme we need evidence for the distinction from a least two primary branches of the collection of languages compared. Without this requirement the reconstruction of a new proto-phoneme does little more than transfer an unexplained change in a daughter language (the base of the triangle) onto its reconstructed ancestor (the apex).

Alternative (2) may offer a partial explanation for the splits of various PPH phonemes in South Mindanao languages. Despite differences of detail the changes PPH $*_{-}-k_{-}>\mathrm{PSM}^{*} \boldsymbol{-}_{-}$-, $\mathrm{PPH}{ }^{*} d>\mathrm{PSM} *^{*}$ and PPH $*_{-s(-)}>\mathrm{PSM}{ }^{*} h$ can all be seen as types of lenition. In intervocalic position lenition apparently was blocked following schwa. Phonetically this inhibiting condition is understandable. The schwa is shorter in duration than the other vowels, and in many of the languages of Indonesia and the Philippines obstruents that follow schwa are phonetically geminated (hence strengthened), thereby reducing the likelihood that they would undergo an otherwise general lenition process. For this reason we find such PPH minimal pairs as *besuR 'satiated' and *busuR 'hunting bow' reflected as TIR besor (with $/ \mathrm{s} /$ ) and bohor (with $/ \mathrm{h} /$ ) respectively.

Despite its value in suggesting why the changes $*_{-k-}>-g_{-}, *_{-} d->-r$ - and $*_{-} s->-h$ - have not taken place after schwa, alternative (2) fails to deal with the problem of apparent unconditioned splitting after vowels other than schwa. Similar problems arise in connection with the PSM reflexes of PPH *d in initial and final position.

We might then consider the possibility that PPH accentual contrasts are reflected in the South Mindanao languages as differences of 'fortis' versus 'lenis' consonant reflexes, where the fortis grades of ${ }^{*}-k-{ }^{*}{ }_{-} d$ - and ${ }^{*}-s(-)$ are $/ \mathrm{k} /, / \mathrm{d} /$ and $/ \mathrm{s} /$ respectively. Since lexical items with penultimate schwa tend to be oxytone, the appearance of fortis reflexes after a schwa may prove to be a special case of the more general condition that post-tonic obstruents are lenited, while pretonic obstruents are strengthened. Unfortunately spot checks reveal no clear correlation between the placement of PPH accent and the appearance of a fortis or lenis obstruent reflex in Tiruray. To illustrate only with reflexes of intervocalic ${ }^{*} k$, $\mathrm{PPH}$ paroxytones *abúkay 'albino', *túkud 'prop, support', *(la)láki 'man, male' and *siku 'elbow' yielded TIR / $\mathrm{k} /$ in the first two instances, but /g/ in the second two (see Appendix 1). Similarly, PPH oxytones *dakél 'big', *sekí 'foot, leg', *likúd 'back (anat.)' and *pakú 'edible fern' yielded $/ \mathrm{k} /$ in the first two instances, but $/ \mathrm{g} /$ in the second two. Examples could be multiplied.

A third prospect for phonological conditioning invokes medial prenasalisation. In forms such as PPH *dindin > PSM *didig 'wall' and PPH *kamansi > TIR kemasey 'breadfruit' it appears that prenasalised obstruents failed to lenite. Because PPH consonant clusters were 
reduced in PSM, the result is a single consonant reflex that differs from the normal intervocalic reflex precisely in exhibiting a fortis rather than a lenis reflex. As noted by Dempwolff (1934 - 1938) and others since, medial homorganic prenasalisation is of ten a sporadic process in Austronesian languages. Given these facts we might explain a reflex such as PPH *bukel 'bump, knob, protuberance' > TIR bukal 'bone' by positing a pre-PSM *bujkel. However, virtually no independent evidence can be offered for preconsonantal nasals that would be needed to reconcile the 'fortis' and 'lenis' reflexes of PPH intervocalic obstruents in the South Mindanao languages. Being posited solely to salvage the Regularity Hypothesis, such elements would be classic components of an ad hoc explanation.

This leaves borrowing as the only remaining alternative to recognising several unconditioned phonemic splits in the translation from Proto Philippines to Proto South Mindanao. As noted already, there is historical evidence to suggest that Tiruray has been in fairly intense contact with Magindanao. We might, therefore, consider borrowing from Magindanao (or other Danaw languages) as a possible explanation of the split of PPH $*_{-} k$ into PSM *- $h$ - and *-k-. Since no other language of the Philippines shows the first change we can eliminate it as a borrowed reflex. This leaves PSM *taked 'heel', *iket 'to tie', *bukel 'bone; knee' and *bukay 'white' as presumptive loans.

The first obstacle to adopting a hypothesis of borrowing in these four cases is the fact that the presumptive loans are found both in Tiruray and in Bilic. If borrowing took place in a single language ancestral to both branches (i.e. PSM) the event must have occurred some two millenia ago, hence at a time far antedating the rise of the Danaw languages to their historical position of regional influence. Alternatively, we could assume that the loans are more recent, but have entered the South Mindanao languages separately, a phenomenon that I will refer to as 'parallel borrowing'. Other things being equal, the probability that the same basic vocabulary items would be borrowed independently into two (or three) languages is clearly lower than the probability that they would be borrowed into only one language.

The second obstacle to adopting a hypothesis of borrowing in these four cases is the fact that every example is an item of basic vocabulary either by virtue of inclusion on the Swadesh 200-item lexicostatistical test list, or by virtue of a reasonable extension of the notion 'basic vocabulary' to include all body-part terms. If basic vocabulary is less likely to be borrowed than non-basic vocabulary we should hesitate to assume borrowing unless phonological irregularities require this explanation.

Finally, any serious hypothesis of borrowing requires a plausible source language. By 'plausible' we understand a source language which (1) is geographically not far removed from the borrowing language, (2) has a cognate form with the approximate phonemic shape (or an appropriate shape altered only by recent sound change), and (3) is spoken by a population that is known to have been culturally or politically influential in relation to speakers of the borrowing language.

For the meanings 'heel', 'to tie', 'bone; knee' and 'white' Allison (1979) reconstructs PD *palu, *iket, *talan; *aleb and *puti? respectively. In addition, for Maranao, McKaughan and Macaraya (1967) list bokai 'albino'. For the first item, then, there is no plausible Danaw source. A check of Reid (1971) shows only one other Philippine language with a reflex of *taked (Kalamansig Cotabato Manobo, which has borrowed heavily from a SM language, probably Tiruray). The nearest known potential source languages are Bario Kelabit and Long Anap Kenyah, spoken in the interior of north-west Borneo, with Bario Kelabit taked 'popliteal area, back of knee' and Long Anap Kenyah taket 'leg, foot'. There is, then, no 
plausible source language at all through which South Mindanao reflexes of PPH *taked 'heel' could be explained as loans. ${ }^{13}$

The second item could be a loan from some unknown prehistoric source into PSM, as many languages in the southern Philippines have a phonologically appropriate reflex of PPH *hiket.

For the third item we find BIL bukal, TBL bukol 'knee', TIR bukal 'bone'. Since the Tiruray item shows an irregular change $\left({ }^{*} e>/ a /\right)$ and differs in meaning from the Bilic forms, we might wish to treat the Bilic and Tiruray words as products of independent borrowings. Again, however, a check of Reid (1971) and the available dictionaries of Philippine languages uncovers no plausible source language.

For the fourth item Maranao has bokai 'albino', and Zorc (1971) posits PPH *bukay 'white (fowl, etc.)'. Forms such as Hanunoo abúkay 'white (chicken, crocodile); longish white eggplant', Bilol abúkay 'white parrot' indicate a PPH form *abukay 'white (of things normally some other colour)' in contrast to PPH *putiq 'white (normal colour term)'. In all available sources on the Bilic languages a reflex of *abukay is given as the ordinary term for 'white', and for Tiruray Schlegel (1971) gives futé? and bukay as synonyms. If reflexes of PPH *abukay have been borrowed into Bilaan, Tagabili and Tiruray, then, they have either undergone a parallel semantic shift in all three languages or the ancestral form was borrowed with such a semantic change in PSM.

In considering other apparently unconditioned phonemic splits in PSM the support for a borrowing hypothesis is equally shaky. We need look only at reflexes of PPH ${ }^{*}-s$. In one known case - that of PPH *Ratas > TBL, TIR gatas 'milk' - a cognate loanword, apparently from a Danaw language, is found in at least two South Mindanao languages. Given this fact we might explain the retention of ${ }^{*} s$ in PPH ${ }^{*} k a d u s>\operatorname{BIL}(\mathrm{K})$ kolus, BIL(S), TBL $k$ - $m$-alus, TIR karus 'to scratch, claw' as due to borrowing from a Danaw language (cf. PD *karus 'to scratch'). The difficulties already encountered with reflexes of PPH *-k-, however, must be faced again with this comparison. Firstly, if we adopt the simplest hypothesis - that ${ }^{*}$ karus was borrowed into PSM - we are suggesting a borrowing which must have antedated by many centuries the rise of the Danaw languages to their historical position of influence. Secondly, if we assume a most recent acquisition from a Danaw source we are forced to conclude that the word was borrowed independently by Bilaan, Tagabili and Tiruray. Although there is a parallel to such independent borrowing with gatas, the two cases are significantly different, since (1) 'scratch' is an item of basic vocabulary, and (2) Tiruray has a doublet ratah 'human breast milk' which confirms the loan status of gatas 'milk; to add milk to something', while no such etymological doublet of karus has yet been found.

To summarise, only one of the four Tiruray reflexes of PPH etyma which retain ${ }^{*}-k$ - as a voiceless stop (iket 'to tie') is a plausible loan, and it is a basic vocabulary item. The hypothesis that PPH *-k-split into PSM *-g-and *-k-through the introduction of loanwords is therefore highly problematic. Much of the same conclusion can be drawn with respect to the split of PPH $*_{-s}$ into PSM $*_{-} h$ and $*_{-s}$.

Despite the foregoing conclusion, proposed PSM reconstructions such as *taked 'heel' and *bukay 'white' exhibit double irregularities, since the expected reflexes of ${ }^{*}-k-$, ${ }^{*}$ - $d$ and

${ }^{13}$ Casiguran Dumagat, Mamanwa and Tausug retlect a variant *tiked. Although Reid 91971) cites tiked for Tagabili, Forsberg and Lindquist (1955) give only teked 'heel'. 
$*_{\text {-ay in PSM are }}^{*} g,{ }^{*} r$ and ${ }^{*} e y$. With very few exceptions (discussed in section 4.2 ) these irregular reflexes are repeatedly associated with one another and with other reflexes diagnostic of borrowed vocabulary, while the reflexes ${ }^{*}-k->{ }^{*} g,{ }^{*}-d>{ }^{*} r$ and $*_{-a}-{ }^{*} e y$ show a complementary set of associations. Multiple, correlated irregularities allow for only one reasonable explanation: borrowing. Despite the formidable difficulties that we must confront if we adopt a hypothesis of borrowing to account for a number of the phonological irregularities in South Mindanao languages, then, in many cases there appears to be no reasonable alternative.

Returning for a moment to the internal South Mindanao discrepancies mentioned at the end of section 3.1.3, a hypothesis of borrowing from a Danaw or other source could help to explain such forms as TIR ikam 'mat', fenakaw 'to steal', nifis 'thin', manuk 'bird, chicken' and layag 'to fly' if we assume that the Tiruray but not the Bilic forms are loans. However, in the case of TBL difu, TIR rifo 'fathom' (with -i-), TBL lebol, TIR rubur 'murky' (with $-l, r$ ) and BIL, TBL mih, TIR eméh 'sweet' (with - $h$ ) a borrowing hypothesis is of no use, since the forms in question contain reflexes which do not occur in any other language of the southern or central Philippines. Examples such as these strongly suggest that certain phonological changes which had begun in PSM continued to recruit new lexical items during the individual histories of the South Mindanao languages in the manner that Wang (1969) has called "lexical diffusion".

The methodological issues which arise in connection with South Mindanao reflexes of PPH *taked, *hiket, *bukel, *abukay and *kadus are complex and difficult to resolve. If we assume that these words are directly inherited we contradict the Regularity Hypothesis. If, on the other hand, we assume that they are loans we encounter a variety of problems, from lack of a plausible source language to the inherent improbability that the same basic vocabulary item would be borrowed independently into two or more closely related languages. We return to these issues in the discussion of Tiruray historical phonology in section 4 .

\subsubsection{RECONSTRUCTIONAL AMBIGUITIES}

The relatively large number of irregularities in the historical phonology of the South Mindanao languages creates two distinct types of indeterminacy in historical inferences. The first type affects the shape of reconstructions and the second their validity.

Type 1 can be illustrated by PPH *sakit > TIR agit 'painful'. Since the voicing of intervocalic ${ }^{*} k$ appears to be restricted to native vocabulary, there is little doubt that TIR agit is directly inherited. Because Bilic cognates are unknown, however, and because the changes in question could have occurred in the separate history of Tiruray, it is unclear whether the PSM form for 'painful' was *sakit, *sagit, *akit or *agit. Many PSM reconstructions which are supported by a single internal witness in conjunction with external evidence contain (generally unstated) ambiguities of this kind.

The second type of indeterminacy involves the identification of loanwords. A number of PSM reconstructions in Appendix 1 are based on a reflex only in Tiruray, for example, PPH *daRaq > PSM *dara? 'blood' (TIR dara?), PPH *huRas > PSM *urah 'wash' (TIR urah) and PPH *bituka > PSM *betuga 'large intestine' (TIR betugo). In these and similar cases we can be fairly certain that the South Mindanao form in question is not borrowed, as it exhibits one or more reflexes that are unique in the Mindanao region. Given this fact and the 
presence of cognate forms in both South Mindanao and non-South Mindanao witnesses, the presence of the form in PSM is assured even though it has survived in only one primary branch of the South Mindanao group. However, a similar lexical distribution without the presence of reflexes that are diagnostic of native vocabulary does not allow the unambiguous attribution of a proto-form to PSM. As a case in point, TIR feka (PPH *peka) 'disconnect' lacks known cognates in the Bilic languages and contains no reflexes which are diagnostic either of native or of borrowed vocabulary. If we assume that TIR feka is native we must posit PSM *feka 'disconnect'. However, given Maranao peka 'break, snap, as chains', the Tiruray form could equally well be a Danaw loan, in which case no support for PSM *feka exists. Such indeterminacies appear to be unresolvable in the present state of our knowledge.

\section{TIRURAY HISTORICAL PHONOLOGY}

Both Post (1966) and Schlegel (1971) recognise 16 consonant and 6 vowel phonemes in Tiruray. In Schlegel's orthography these are consonants /t, k, ?; b, d, g; m, n, g; f, s, h; l, r; $\mathrm{w}, \mathrm{y} /$ and vowels /a, e, é, i, o, u/. /f/ is described as a voiceless bilabial fricative, $/ \mathrm{r} / \mathrm{as}$ an alveolar trill varying freely with a homorganic flap, /e/ as a high central, and /é/ as a mid front vowel (Post 1966). In addition Schlegel writes nine word-final rising diphthongs: -/ay/, -/ey/, -/éy/, -/oy/, -/uy/, -/aw/, -/ew/, -/ow/ and -/iw/. Neither writer discusses these explicitly.

Schlegel (p.7) states that primary stress "falls on the penult or antepenult of polysyllabic bases, except when the vowels of those syllables are shortened, in which case stress is on the ultima".

Apart from the innovations in PSM that have already been mentioned, TIR has undergone the following relatively well-attested sound changes:

(1) $\mathrm{PSM}^{*} k$ - has sometimes become /g/.

(2) $\operatorname{PSM}^{*} q$ disappeared in initial position and generally became $/ ? /$ elsewhere.

(3) PSM *b has often become /w/ intervocalically. In initial position the same change occurs in four known examples. The lenition of PSM *- $b$-, unlike the lenition of PPH $*_{-k-}, *_{-} d-$ and $*_{-s-}$, was not blocked following schwa; rather, in etymologies such as $*^{*}$ lebey > luay 'bury' and *tebey $>$ tuon 'fell trees' $*_{-} b$ - became ${ }^{*} w$, and the sequence *-ew- then contracted to $/ \mathrm{u} /$.

(4) PSM *a is of ten reflected as TIR /o/.

(5) PSM * $-i$ and *- $u$ were diphthongised to -/ey/ and -/ew/ or -/ow/ (possibly two transcriptions of the same diphthong).

(6) PSM *-ay and *-aw of ten became -/ey/ and -/ew/, thus merging with $*_{-}-i$ and $*_{-} u$ respectively.

(7) (Schwa epenthesis). PPH *h disappeared in PSM, with contraction of a resulting sequence of like vowels or unlike vowels one of which was schwa. When such a contraction or any other change resulted in the reduction of an original disyllable to a monosyllable the original disyllabism was restored through schwa epenthesis: *bahaw > eba'? 'mouth', *buhek > ebuk 'head hair', *luheq > en-lo' 'teardrop', *tahep > etof 'winnow', *tau > etew 'person, human being', *tuhud > etur 'knee'. 
As can be seen from the above, Tiruray is phonologically a relatively innovative language. Apart from $\mathrm{PPH}{ }^{*} t,{ }^{*} q$ (which may have been a glottal stop), ${ }^{*} g$, the nasals and schwa, no phoneme, diphthong or internal vowel sequence has regularly remained unchanged. Moreover, a number of these innovations involve what appear at first sight to be unconditioned phonemic splits. A well-supported hypothesis of borrowing would help to explain why many of these double reflexes exist.

As evidence for large-scale borrowing we might look for (1) etymological doublets, (2) indications that one reflex is less frequently encountered in basic vocabulary, and (3) 'speech stratum' associations between given members of each pair of double reflexes. This approach yields results which are consistent with a hypothesis of much heavier lexical borrowing from the Danaw languages (not just Magindanao) than Schlegel recognises in his dictionary. In addition Tiruray shows evidence of relatively recent borrowing from non-Danaw (presumably Manobo) languages, as well as a distinct layer of what may be far older loans which it shares with the Bilic languages.

\subsection{MULTIPLE REFLEXES IN TIRURAY}

In order to classify Tiruray vocabulary into strata it will be necessary to state and to justify the conditions (1) under which vocabulary must be marked + native, (2) under which vocabulary must be marked -native, and (3) under which the provenance of lexical items is indeterminate.

There are several ways in which native vocabulary can be distinguished from non-native vocabulary in any language. Those which will be used here are the following:

\section{(1) UNIQUE REFLEXES}

Where a proto-phoneme exhibits more than one reflex without apparent phonological conditions one of the reflexes may be unique to the geographical area in question, while the other may be attested in other languages. A case in point is the development of PPH ${ }^{*} R$ to TIR $/ \mathrm{r} /$ or $/ \mathrm{g} /$. Tiruray is the only language in the central and southem Philippines which reflects ${ }^{*} R$ as $/ \mathrm{r} /$, whereas it is surrounded by languages (both Danaw and Manobo) which show the development ${ }^{*} R>/ \mathrm{g} /{ }^{14}$ It follows that $* R>/ \mathrm{r} /$ can occur only in native Tiruray words or in loans from outside the southern and central Philippines.

\section{(2) BASIC: NON-BASIC}

A word of any meaning can be borrowed, but the probability of borrowing is far smaller for lexical items that represent basic meanings than for those that represent non-basic meanings. It was primarily reference to the basic:non-basic distinction which Dyen (1956) used a guide to segregate the lexical strata of Ngaju Dayak (and, in so doing, to reverse Dempwolff's decision as to which stratum was native and which borrowed). ${ }^{15}$

\footnotetext{
${ }^{14}$ The only non-South Mindanao language in the southern and central Philippines known to reflect ${ }^{*} R$ as a liquid is Samal, which reflects ${ }^{*} R$ as $/ \mathrm{g} /, / \mathrm{h} /, / \mathrm{l} /$ and zero. The Samalan and South Mindanao peoples have no known history of contact, occupy almost completcly complementary ecological niches, and show little cvidence of linguistic borrowing from onc another.

${ }^{15}$ Dyen's discussion of Dempwolff's position ref crs only to a footnotc in the Vergleichende Lautlehre (1937). Although this footnotc mentions Dempwolf's 1922 publication on Ngaju Dayak and Aichele's theory of an ancient literary language in Bornco, it does not represent Dempwolffs vicws adequately. Dempwolff himself clearly states (1922:204) that the Ngaju reflexes ${ }^{*} e>/ \mathrm{a} /,{ }^{*} R>/ \mathrm{r} /$ and ${ }^{*} \mathrm{C}>/ \mathrm{h} /$ (as the reconstructions would now be represented) are due to borrowing from Malay ("alles Übernahmen aus dem Malaiischen").
} 
The notion 'basic vocabulary' does not, of course, define some fixed number of meanings such as those represented rather arbitrarily on the Swadesh 100- or 200-item lexicostatistical test lists. For present purposes 'basic vocabulary' will include all meanings on the Swadesh 100- and 200-word lists and the variant of the latter list used in Blust (1981), plus all other tems for body parts and substances, all pronouns, the numerals from 'one' to 'five' and the word for 'sick, painful', which is arbitrarily omitted from the Swadesh lists, and the word for 'how much/how many?', which in the Austronesian context is far more appropriate than the Swadesh 'how?'.

\section{(3) ETYMOLOGICAL DOUBLETS}

As noted earlier, etymological doublets sometimes provide clues to borrowing. Semantic differences between etymologically equivalent words may further indicate which form is native and which borrowed. Tiruray gatas 'milk; add milk to something' and ratah 'human breast milk' both reflect PPH *Ratas, but the semantic difference makes it clear even without other considerations that gatas is borrowed and ratah native.

\section{(4) PARALlEL BORROWING}

In general it is less probable that two or more languages which subgroup together have borrowed the same lexical item independently than that the item was borrowed once into their immediate common ancestor. Whatever force this argument may have is increased in the case of basic vocabulary, which on the whole is more resistant to borrowing than nonbasic vocabulary. Yet the issue is an empirical one, and reflexes diagnostic of borrowing may force us to conclude that the same items - even basic items - were borrowed independently in some cases.

\section{(5) STRATAL ASSOCIATIONS}

Proto-phonemes which have a single reflex cannot be used to distinguish native from nonnative vocabulary. In determining stratal associations our concern is thus exclusively with proto-phonemes which exhibit at least two apparently unconditioned developments. These developments will be called 'problematic reflexes'. Stratal associations can initially be established only in morphemes which have at least two differing problematic reflexes: for example, PPH *buku > TIR bugew 'node, joint, knuckle' establishes an association between ${ }^{*}-k->/ g /$ and $*_{-}^{*} u>/$ ew/, while PPH ${ }^{*} n i R u>$ TIR nigu 'winnowing basket' establishes an association between ${ }^{*} R>/ g /$ and ${ }^{*}-u / u /$. Once it is determined that a reflex is native (e.g. because it is unique), any other reflex which is stratally associated with it is automatically established as native, even in morphemes in which it is the sole problematic reflex. For example, since ${ }^{*}-k->/ g /$ is established as a marker of native vocabulary, ${ }^{*}-u$ $>$ /ew/ must have an equivalent value, not only in forms such as bugew where it is associated with *-k->/g/, but also in etymologies such as PPH *telu > TIR /telew/ 'three' where it is not.

\section{(6) NEED FOR A PLAUSIBLE SOURCE LANGUAGE}

If borrowing is assumed, a plausible source language for the proposed loan must be available. By 'plausible' is meant a language that is geographically contiguous (or which can be shown to have formerly been contiguous) to the borrowing language, which has a phonemically and semantically appropriate form of the word in question, and which is or has been in a position of cultural or political influence in the region. 
Before applying these principles to the Tiruray data it may be worthwhile to identify some types of 'noise' that will not figure in the main discussion.

\subsection{1 'NOISE' IN THE COMPARATIVE DATA}

Certain types of irregular change in Tiruray appear to have no direct bearing on the issue of borrowing, and these are noted briefly here.

In initial position PPH ${ }^{*} k$ occasionally is voiced, as with * $k a p a l>$ gefol 'thick', *ka-taqu-an > getuan 'knowing something', *kilala-an > gilolon 'recognisable', *kita-an > giton 'visible' and garatas 'paper' (Malay kertas, ultimately from Arabic). There appears to have been a greater tendency for ${ }^{*} k$ to undergo sporadic voicing in (unstressed) prepenultimate syllables than elsewhere. ${ }^{16}$ The wider Austronesian comparative picture suggests that all such examples manifest a more general and probably universal tendency for sporadic voicing cross-over in the velar stops which can be attributed to perceptual difficulties resulting from shortened voicing duration during velar, as opposed to pre-velar oral closure. Some sporadic instances of PPH ${ }^{*} g>T I R / k /$ evidently result from the same tendency. These relatively marginal changes are not to be equated with the quite common voicing of intervocalic ${ }^{*} k$ in native Tiruray words.

In two known forms, PPH *bahuq > ahu? 'smelly' and PPH *lisehaq > TIR lisaha? 'nit, louse egg', $\mathrm{PPH}{ }^{*} h$ is reflected as Tiruray $/ \mathrm{h} /$. These items cannot be native, nor can they be Danaw loans, since PPH ${ }^{*} h$ disappeared or became $* ?$ in Proto Danaw. The first item may be a Tagalog loan (with sporadic loss of the initial consonant); the second is most likely a Manobo loan (cf. Western Bukidnon Manobo liseha?'louse eggs'). ${ }^{17}$

PPH *e became TIR /a/ before a final glottal stop, but otherwise generally remained unchanged both in Tiruray and in the Danaw languages. However, in a small number of forms PPH *e became TIR /a/ before other final consonants, as in *bukel ' $k$ nob, protuberance' > bukal 'bone', *qitem > itam 'black', *lebeg 'bury' and *pasek > fasak 'stake'. A comparable change is perhaps seen in PPH *hasek > TIR ohok 'dibble' (with *e $>*_{a}$, followed by $*_{a}>/ \mathrm{o} /$ and vowel harmony). PPH *e regularly became B IL /a/ in the last syllable, but the Tiruray irregularities do not appear to be explainable as Bilaan loans (cf. BIL bukal 'knee' (not 'bone'), BIL fitam (not **itam) 'black', BIL(K) lbạ 'bury').

In three known cases penultimate *a has become TIR /e/: PPH *kapal > TIR gefol 'thick', *kesew 'rafters', *la(m)paw > lefew 'surpass'. A fourth etymology which may belong here is PPH *qahlu > TIR elew 'rice pestle'; alternatively PPH *qahlu may have been *qahelu.

In a few forms Tiruray shows an unexplained accretive final $/ \mathrm{h} /$ or glottal stop, as in PPH *eta > TIR etah 'rice husk', *leja > lejoh 'sesame' *tapa > TIR tafah 'to dry meat, make jerky', *kuRita > kurita? 'octopus' and *talina > kelino' 'ear'. Similar changes occur in some known loans, as in latah 'tin can' (Spanish lata), safi? 'Zebu' (Malay sapi 'ox'), and falsu? (Spanish falso). These irregularities thus might be taken as markers of borrowed forms. However, Tagabili also exhibits an accretive glottal stop in some apparently native words, as with PPH *paku > TBL hoku?, but TIR fagew 'edible fern'.

\footnotetext{
${ }^{16}$ Conant (1913:54) claimed that * $k$ - "regularly becomes $g$ in accentless prefixes and pronominal suffixes". However, he cites only onc example of this change in a prefix: ${ }^{*} k a->$ ge- "ordinal marker". The facts appear rather to support a claim that ${ }^{*} k$ - was sporadically voiced in prepenultimate (hence pretonic) position.

${ }^{17}$ Conant (1913), citing an earlier Spanish source, gives Tiruray lisa.
} 


\subsubsection{SPEECH STRATA IN TIRURAY}

Tiruray contains many unambiguous loans, a number of which have been identified by Schlegel (1971). Some of these are transparently foreign because they derive from nonAustronesian sources, as with the numerous loans from Spanish. ${ }^{18}$ Others are of Arabic or Sanskrit origin, transported by speakers of Malay first to Brunei and then to the southern Philippines, whence they passed from the languages of the coastal Muslims into the languages of the more traditional peoples of the interior. Examples of the latter include akar 'trick, crafty or cheating action' (Malay akal, ultimately from Arabic), fanday 'pertaining to midwifery, and by extension to other specialised skills' (Malay pandai, ultimately from Sanskrit), gafas 'cotton' (Malay kapas, ultimately from Sanskrit), laga? 'price' (Malay harga, ultimately from Sanskrit) and salam 'employ a prayer or charm as protection against frightening spirits' (Malay salam, ultimately from Arabic).

Somewhat more difficult for the non-specialist to recognise are Austronesian loans which followed the same route of transmission, as with adafan 'the area immediately in front of someone or something' (Malay hadap-an), kambin 'goat' (Malay kambin), ganti 'substitute for someone' (Malay ganti), gula? 'a sugar syrup made by boiling the juice squeezed from sugarcane' (Malay gula 'sugar'), guntig 'scissors' (Malay guntig), gunsi? 'key', (Malay kunchi), la-gari? 'saw, to saw' (Malay gergaji), sakali? 'only' (Malay se-kali 'all at one time'), samfay 'forward a message' (Malay sampai, sampai-kan), sumbag 'incest' (Malay sumbay), sundal 'whore' (Malay sundal) and timbak 'gun, shoot a gun' (Malay témbak

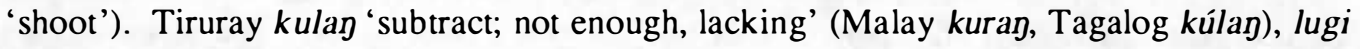
'give less than actual value in a commercial exchange' (Malay rugi, Tagalog lúgı) and sulat 'a letter; to write' (Malay surat, Tagalog súlat) cannot be directly inherited nor borrowed directly from Malay (as we would expect forms with $/ \mathrm{r} /$ ). Instead, they have been borrowed indirectly from Malay through a local language which shows ${ }^{*} r>/ 1 /$ (most likely Magindanao), or from Tagalog. Other words which are not ultimately Malay loans exhibit telltale signs which indicate that they were borrowed from various Philippine languages. PPH *sale $R$ 'floor' would have yielded TIR **sarer if it were directly inherited and regular; TIR sahig 'bamboo slat floor' can only be from Tagalog sahig 'floor', which shows a highly distinctive development. Similarly, the loss of ${ }^{*} b$ - in ulig 'a bunch' (PPH *buliR) points unambiguously to a Danaw source, and the retention of $\mathrm{PPH}{ }^{*} h$ in $a h u^{*}$ 'smelly, malodorous' (PPH *bahuq) and lisaha? 'louse egg' (PPH *lisehaq) points unambiguously to a non-Danaw source.

More subtle than the preceding is a pervasive problem of double reflexes in all the South Mindanao languages, but especially in Tiruray. The problem, which was already broached in connection with the reconstruction of Proto South Mindanao, can perhaps be framed most lucidly through comparison with Ngaju Dayak. Figure 1 presented the evidence for speech strata in Ngaju Dayak; as a first step towards determining speech strata in Tiruray Figure 2 presents the double reflexes of Tiruray in the same way. Regular conditioned changes are not considered further, and reflexes of PPH ${ }^{*} h$ are not included, as the few examples of ${ }^{*} h>$ $\mathrm{h} /$ in Tiruray loans ( $a h u^{\text {? }}$, lisaha $?$ have already been discussed.

\footnotetext{
${ }^{18}$ Schlcgel currently identifies most Spanish loans, but misses some, such as bayabas (Spanish guayaba) 'guava', kakaw (Spanish cacao, ultimatcly from Nahuatl) and nanas (Spanish ananas) 'pineapple', three New World plants introduced to Southeast Asia in post-European times. Similarly, Schlegel occasionally misidentifics Austronesian forms as Spanish, as with timcra 'Icad (metal)' and pantalan 'picr', both of which appear to be loans in Tiruray, but which derive from well-cslablished Austronesian sources *timeRaq and *pantar-an respectively.
} 


\begin{tabular}{clll} 
& PPH & \multicolumn{1}{c}{1} & \multicolumn{1}{c}{2} \\
1. & C- & $\mathrm{C}, \emptyset$ & $\mathrm{C}, \emptyset$ \\
2. & $-\mathrm{CC}-$ & $\mathrm{C}$ & $\mathrm{CC}$ \\
3. & $-k-$ & $g$ & $k$ \\
4. & $b-$ & $b, w$ & $b, w$ \\
5. & $-b-$ & $w$ & $b, w$ \\
6. & $d-$ & $d, r$ & $d, r$ \\
7. & $-d-$ & $r$ & $d, r$ \\
8. & $-d$ & $r$ & $d$ \\
9. & $-s-$ & $h$ & $s$ \\
10. & $-s$ & $h$ & $s$ \\
11. & $r$ & $r$ & $l, r$ \\
12. & $R$ & $r$ & $g$ \\
13. & $V_{3}$ & $e$ & $V / 3$ \\
14. & $i / u C$ & $e ́ / o$ & $i / u$ \\
15. & $-\mathrm{i} / u$ & $e y / e w$ & $i / u$ \\
16. & $-a(\mathrm{C})$ & $a, o$ & $a, o$ \\
17. & $-i w / u y$ & $e y$ & $i w / u y$ \\
18. & $-a y / a w$ & $e y / e w$ & $a y / a w$
\end{tabular}

\section{FIGURE 2: WELL-ATTESTED DOUBLE REFLEXES IN TIRURAY}

In conjunction with the text Figure 2 can be read as follows: (1) a PPH initial consonant sometimes disappeared, (2) PPH medial consonant clusters were sometimes reduced, (3) $\mathrm{PPH}$ intervocalic ${ }^{*} k$ following vowels other than schwa sometimes became $/ \mathrm{g} /$ and sometimes remained $/ \mathrm{k} /$; following schwa no change took place, (4-5) PPH non-final *b sometimes became $/ \mathrm{w} /$ and sometimes remained $/ \mathrm{b} /$; this change postdated the lenition of intervocalic ${ }^{*} k$, ${ }^{*} d$ and ${ }^{*} s$, and in intervocalic position was not blocked following schwa, (6-8) $\mathrm{PPH} * d$ (and non-initially also $*^{*}$ ) sometimes became $/ \mathrm{r} /$ and sometimes $/ \mathrm{d} /$; in intervocalic position this change was blocked after schwa, (9-10) PPH intervocalic *s following vowels other than schwa, and PPH final *s following any vowel normally became $/ \mathrm{h} /$, but occasionally remained /s/, (11) $\mathrm{PPH}{ }^{*} r$ sometimes remained $/ \mathrm{r} /$ and sometimes became /1/, (12) PPH ${ }^{*} R$ sometimes became /r/ and sometimes /g/, (13) PPH vowels in prepenultimate position sometimes became TIR schwa and sometimes remained unchanged, (14) PPH high vowels preceding a final ${ }^{*} q$ or ${ }^{*} R$ generally were lowered to the corresponding mid vowels, but sometimes did not change; before other final consonants $\mathrm{PPH}$ high vowels were lowered only rarely, (15) PPH high vowels in final position sometimes underwent breaking to diphthongs /ey/,/ew/ and sometimes remained unchanged, (16) PPH last syllable *a sometimes became /o/ and sometimes remained unchanged, (17) the PPH diphthongs *-iw and *-uy sometimes merged with $*_{-} i$ to become a new diphthong ley/ and sometimes remained unchanged, (18) the PPH diphthongs *-ay and *-aw sometimes merged with $*_{-i}, *_{-u}$ to become new diphthongs/ey/, /ew/ and sometimes remained unchanged.

The first difference between Figures 1 and 2 that is likely to strike the reader is the considerably greater length of the list for Tiruray, a consequence of the highly innovative phonological history of this language. However, it is yet to be determined whether all of the 
phonemic splits that appear in Figure 2 are diagnostic for borrowing. 19 In Ngaju Dayak the determination that one unconditioned reflex of a given proto-phoneme is native means ipso facto that the other is foreign. This follows from the fact that nearly all unconditioned phonemic splits in Ngaju Dayak are fairly transparent products of borrowing from Banjarese Malay. In Tiruray the determination of loans is made considerably more complex by (1) the occurrence of what must be considered either borrowed reflexes in a number of basic vocabulary items, or unconditioned phonemic splits in native Tiruray material, (2) the distribution of such problematic forms across all three South Mindanao languages and (3) in some cases the lack of a plausible source language to support a hypothesis of borrowing. As a result the determination that one unconditioned reflex of a proto-phoneme is native (e.g. $\left.{ }^{*} b->/ w /\right)$ does not necessarily mean that the other $\left({ }^{*} b->/ b /\right)$ is exclusively foreign. A consideration of these problems occupies us for the remainder of the paper.

\subsubsection{BASIC VOCABULARY}

In his approach to the problem of speech strata in Ngaju Dayak, Dyen (1956) appealed to the use of basic vocabulary to distinguish native from borrowed reflexes. While this approach was highly successful in the Ngaju Dayak case, in the case of Tiruray the facts are less straightforward and require other methods of dealing with the data. We need consider only two fairly well attested developments to make the point: the reflexes of PPH $* R$ and intervocalic ${ }^{*} k$.

In scanning Schlegel's dictionary I have identified 80 reflexes of $\mathrm{PPH}{ }^{*} R$, with the following distribution: (1) ${ }^{*} R>/ \mathrm{r} /: 44$ cases, (2) ${ }^{*} R>/ \mathrm{g} /: 36$ cases. Since ${ }^{*} R>/ \mathrm{r} /$ is a unique development in the region and ${ }^{*} R>/ \mathrm{g} /$ is commonplace, the first reflex is assumed to be native and the second borrowed. However, as will be seen, three instances of $* R>/ \mathrm{r} /$ are also probable loans, leaving the numbers at 41 and 36. Of the 41 examples of $* R>/ \mathrm{r} / 12$ (i.e. 29\%) are found in basic vocabulary: (1) *ikuR > igor 'tail', (2) *huRas > urah 'wash', (3) *ulaR > urar 'snake', (4) *uRat > urat 'vein, tendon', (5) *bibiR > béwér 'lip', (6) *daR aq > dara? 'blood', (7) *R atas > ratah 'human breast milk', (8) *Ratus > ratuh 'hundred', (9) *Rabun > rawen 'cloud', (10) *liqeR > ré?ér 'neck', (11) *Rusuk > rohok 'rib', (12) *qabaRa > wara 'shoulder'. Of the 36 examples of $* R>/ g / 8$ (i.e. $22 \%$ ) are found in basic vocabulary: (1) *ibeR > ibeq 'saliva', (2) *baRaq > baga?'lung', (3) *beRqat $>$ begat 'heavy', (4) *daRat > dogot 'sea', (5) *deRes > reges 'flow swiftly', (6) *Renaw > genaw 'cold', (7) *taRa-qinep > teginef 'dream', (8) *wahiR > wayeg 'water'. Although the absolute number of $* R>/ \mathrm{r} /$ reflexes is higher both overall and in basic vocabulary, the number of $* R>/ \mathrm{g} /$ reflexes in both categories is significant.

In examining reflexes of intervocalic ${ }^{*} k$ I ignore instances of ${ }^{*}-k$-following schwa, as there appears to be only one reflex in this environment. Keeping this qualification in mind I find the following distribution in Appendix 1: (a) ${ }^{*}-k->/ g /: 13$, (b) ${ }^{*}-k->/ k /: 24$. Since the voicing of intervocalic ${ }^{*} k$ is unique to the South Mindanao languages and the retention of ${ }^{*} k$ is commonplace, the first reflex is assumed to be native and the second borrowed. Of the 13

\footnotetext{
${ }^{19}$ In a few cases cognate sets which appear to be exclusively shared by the South Mindanao languages show phonotactic characteristics which are contrary to expectation, as with PSM *tuluq (not **toloq) 'breast', PSM *luas (not **luah) 'rattan' and PSM *laqas (not **laqah) 'scar'. The reasons for thesc phonological discrepancies are unknown, but such forms may indicate that unconditioned phonemic splitting as a result of "Icxical diffusion" has becn more common in the South Mindanao languages than I have suggested. If so, the role of borrowing as an explanation of unconditioned phonemic splits will be correspondingly reduced.
} 
instances of *-k- to /g/ 9 (i.e. 69\%) are found in basic vocabulary: (1) *lakaw > agew 'go, walk', (2) *sakit > agit 'painful', (3) *ikuR > igor 'tail', (4) *bituka 'large intestine' > betugo 'stomach', (5) *buku > bugew 'node, joint, knuckle', (6) *kanuku > kenugew 'nail, claw', (7) *likud > digur 'black (anat.)', (8) *laki > lagey 'man, male', (9) *siku > sigew 'elbow'. Of the 24 instances of ${ }^{*}-k->/ k / 6$ (i.e. 25\%) are found in basic vocabulary: (1) *hiket > iket 'to tie', (2) *bukel > bukal 'bone', (3) *abukay 'white (of things normally some other colour)' > bukay 'white (ordinary colour term)', (4) *dakel > dakel 'big', (5) *panakaw > fenakaw 'to steal', (6) *taked > taked 'heel'. In considering the reflexes of intervocalic ${ }^{*} k$ the significance of basic vocabulary becomes more evident: although the absolute number of retention of ${ }^{*} k$ is nearly twice that of intervocalic voicings, the latter are far more heavily concentrated in basic vocabulary. Nevertheless, the number of ${ }^{*}-k->/ k /$ reflexes in basic items is not insignficant either in absolute terms or in percentage. By comparison Dyen (1956:85) found only one item of basic vocabulary in Ngaju Dayak with a known etymology which had a reflex indicative of borrowing.

The foregoing observations make it clear that the use of basic vocabulary to distinguish native from borrowed forms is less straightforward in the Tiruray than in the Nga ju Dayak case, approximating more closely to what Biggs (1965) found regarding Polynesian loanwords in basic and non-basic sectors of the Rotuman lexicon. Although basic vocabulary is considered in the following discussion, the use of etymological doublets, unique reflexes and stratal associations plays a more pivotal role in segregating directly from indirectly inherited forms.

\subsubsection{ETYMOLOGICAL DOUBLETS}

There are a number of etymological doublets in Tiruray which provide evidence for the distinction between native and borrowed vocabulary. Those noted are: (1) PPH *be(g)kas 'undo, untie' > TIR bekah (native) '(of a spring trap) to spring', begkas (borrowed) 'to split, tear something along the seam', (2) PPH *Ratas 'milk; add milk to something', ratah (native) 'human breast milk', (3) PPH *sabuR > TIR sabug (borrowed) 'sow rice seed by broadcasting', (4) PPH *tabaj 'help, assist' > TIR tabaj (borrowed) 'physical or material assistance rendered', towog (native) 'help; to help', (5) PPH *tawaR 'to call' > TIR tabar (native) 'to call', tawag (borrowed) 'to call'. In addition PPH *hasek 'press down, cram into' > TIR asek (borrowed) 'to press down, to compact the contents of a container or a hole', ohok (native) 'to dibble, dibble stick' may involve the same morpheme. In most cases a plausible Danaw source for the presumed loan exists (MAG, MAR asek 'press down', MAR bejkas 'untie, undo', MAG, MAR gatas 'milk', MAG, MAR tabaj 'help, assist', MAG, MAR tawaๆ 'call, summon'). In one case (sabug) no plausible Danaw source is known.

Despite the relatively small number of etymological doublets in Tiruray these pairs of words serve to demonstrate the presence of previously overlooked loans from other Philippine languages, and at the same time provide clues as to which reflex is native and which borrowed (e.g. the glosses of gatas and ratah).

\subsubsection{UNIQUE REFLEXES}

A unique reflex is a reflex which is distinctive for a given geographical region. Unique reflexes are of great value in distinguishing native from borrowed vocabulary in so far as 
borrowed forms could not possibly contain them. However, we must always keep in mind the possibility that some loanwords may enter a geographical region from a distant but influential source. In the Philippines we know that many Malay loanwords have entered the languages of the coastal peoples and in some cases have diffused from them into the languages of interior groups who themselves have had no contact with Malays.

There appear to be seven unique PSM innovations which Tiruray inherits: (1) reduction of medial consonant clusters, (2) merger of PPH $*_{-} k$ - and $*_{-}-g$ - as /g/, (3) shift of PPH ${ }^{*}-s(-)$ to /h/ (except intervocalically after schwa), (4) merger of PPH ${ }^{*} d,{ }^{*} j,{ }^{*} r$ and ${ }^{*} R$ as $/ \mathrm{r} /,(5)$ merger of all vowels as schwa in prepenultimate syllables, (6) shift of PPH *iand *u to /é/ and $/ \mathrm{o} /$ respectively before final ${ }^{*} q$ and ${ }^{*} R$, with consequent height harmony for penultimate vowels with the same value for backness, (7) merger of PPH $*_{-i}, *_{-i w}$ and $*_{-u y}$ as PSM $*_{i}$, TIR /ey/. Three minor qualifications should be added: (a) Proto Danaw also reduced medial clusters if the first member was an obstruent; however, the reduction of nasal plus obstruent clusters in reduplicatd monosyllables and of homorganically prenasalised stops in nonreduplicated forms was regionally unique to the South Mindanao languages, (b) not all instances of PPH ${ }^{*} d$ and ${ }^{*} j$ became TIR $/ r /$, bu those that did merged with ${ }^{*} r$ and ${ }^{*} R$, and (c) prepenultimate *a merged with schwa in a few loanwords; in no known instance, however, did such a merger occur with $*_{i}$ or ${ }^{*} u$. Given the fact that they are shared by Tiruray with the Bilic languages and do not occur in unambiguous loans, these innovations can be taken as secure markers of native Tiruray material.

In addition to these unambiguously early innovations Tiruray shows several other innovations that postdate its separation from the Bilic languages. The most noteworthy of these are: (1) the shift of last-syllable *a to/o/ (with consequent vowel harmony), as in PSM * mata > TIR moto 'eye' and PPH *daRat > TIR dogot 'sea', and (2) the merger of PSM *-i and *-ey as /ey/ and of *-u and *-ew as /ew/, as in PSM *lagi > TIR lagey 'man, male', *farey $>$ farey 'rice', *sigu $>$ sigew 'elbow' and *agew $>$ agew 'go, walk'. A third change, PPH $*$ l > TIR /d/ before *i, is attested in only two known etymologies (*likud $>$ digur 'back (anat.)', *lindug > TIR dirug 'seek shelter'), neither of which has known Bilic cognates. For purposes of reconstruction I will assume that this change took place in the separate history of Tiruray. Although all three of these changes are distinctive, then, they may have postdated the introduction of some Danaw loans and are therefore of more dubious value as markers of native vocabulary.

\subsubsection{STRATAL ASSOCATIONS}

To economise on the presentation of data the discussion henceforth will refer to Appendix 1. The purpose of Appendix 1 is to focus on the evidence for speech strata in Tiruray through determining whether any two sound changes show significant associations. One unconditioned phonemic split, which is marked only when it is present so as to save the marking of over 300 lexical items in which it is absent, is change (1) in Figure 2. Tiruray clearly has lost the initial consonant in etymologies such as *lakaw > agew 'go, walk' and *sakit $>$ agit 'painful'. In addition Tiruray may have lost the initial consonant in *bunduk $>$ uruk 'peak, summit' and in *matay 'die, dead' > atey 'dying' (although at some stage in the history of Austronesian *matay appears to have been morphologically complex: ${ }^{*} m$-atay). It is tempting to seek a correlation between the loss of the original initial consonant in Tiruray and PPH accent (or stress). TIR agew, agit, uruk and atey all reflect etyma with final (oxytone) stress, and such words as lagey 'man, male', sawer 'to sow, broadcast seed', 
lowoh 'body' and sigew 'elbow', which have retained the initial consonant, reflect etyma with penultimate (paroxytone) stress. We might therefore conclude that initial consonants in native Tiruray words disappeared if the following vowel was unstressed. The difficulty with this explanation is that many native Tiruray words which reflect PPH oxytones have not lost the initial consonant, as with *likúd > digur 'back (anat.)', *Ratuis > ratuh 'hundred', *suláq $>$ solo? 'torch' and *baRáq > wara? 'abscess'. The mere fact that no word with initial accent has lost an initial consonant is not significant, as the change is too rare to make this partial correlation anything more than a product of chance. Moreover, etyma such as PPH *manúk 'chicken' and *tabéq 'fat, grease' retain the initial consonant in Tiruray, but have lost it in some or all of the Bilic cognates. Together with the facts in Tiruray these developments suggest the continued operation of tendencies already present in PSM, but incompletely carried out in any of its descendants. Finally, Tiruray has lost the initial

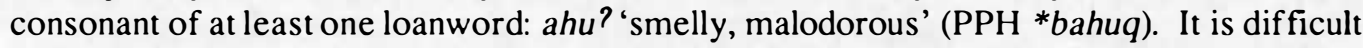
to avoid the conclusion that the loss of initial consonants in Tiruray is sporadic, and that it carries no weight as a clue to stratum assignment.

In general, if two proto-phonemes $\mathrm{A}$ and $\mathrm{B}$ each exhibit two apparently unconditioned reflexes $\mathrm{A} 1, \mathrm{~A} 2, \mathrm{~B} 1$ and $\mathrm{B} 2$ a hypothesis of borrowing should be able to demonstrate that one reflex of A (say A1) and one reflex of B (say B1) may co-occur in the same morpheme, but that other co-occurrences (as of A1 with B2 or A2 with B1) are disallowed. A case in point is PPH *Ratas > TIR ratah 'human breast milk', as against gatas 'milk; add milk to something', where an association of ${ }^{*} R>/ \mathrm{r} /$ and ${ }^{*}-s>/ \mathrm{h} /$ is found in the native reflex, and an assocation of ${ }^{*} R>/ \mathrm{g} /$ and ${ }^{*}-\mathrm{s}>/ \mathrm{s} /$ in the borrowed reflex. Such associations recur in other forms, as with *huRas > urah 'wash' (native) as against *beRas > begas 'polished, uncooked rice' (borrowed). Associations or correlations such as A1:B1 as against A2:B2 constitute evidence for speech strata. On the other hand, if both reflexes of a proto-phoneme are associated with a single reflex of the other proto-phoneme (A1/A2:B1) a hypothesis of borrowing breaks down. This is the case with loss of initial consonants in Tiruray, where both the loss and the retention of initial consonants are found in words with original final stress, and with the change ${ }^{*} k->/ g /\left({ }^{*}\right.$ lakáw $>$ agew, but ${ }^{*}$ likúd $>$ digur). It is also the case with the splits of initial ${ }^{*} b$ and ${ }^{*} d$, and of last-syllable $* a$, since each reflex of these protophonemes $(/ \mathrm{b} /$ and $/ \mathrm{w} /, / \mathrm{d} /$ and $/ \mathrm{r} /, / \mathrm{a} /$ and $/ \mathrm{o} /)$ is manifested in unambiguously native forms, in unambiguously foreign forms or in both.

\subsection{THE APPENDICES}

In the remainder of this paper we examine the material of Appendix 1 in an effort to determine (1) whether there is evidence of unconditioned phonemic splitting in Tiruray or whether the observations in question are better attributed to borrowing, and (2) if evidence of borrowing is found, which reflexes are native and which foreign. Appendix 2 offers some provisional suggestions as to possible sources of loanwords.

Appendix 1 offers a representative, but by no means complete list of reflexes of PPH reconstructions in Tiruray. PPH eytma preceded by an asterisk have more than one reflex. Alphabetically these are juxtaposed to facilitate comparison, except that TIR egas 'a slab of hard salt; the interior of the trunks or large branches of certain hardwood trees', tegas 'hard, obdurate' are conflated (hence the actual number of etymologies in Appendix 1 is 368). In most cases these etymological doublets correlate with differences of speech stratum, as with (21) *hasek > asek (foreign) and (22) *hasek > ohok (native). However, in (35) *teRas > 
egas, tegas, (169) *deRu > degu and (170)*deRu > regu, both variants are loans, while in (320) *tapa > tafah and (321) *tapa > tofo there are no diagnostic clues to stratum assignment for either variant. Preconsonantal nasals within parentheses are attested in some languages but not in others, and a hyphen marks a bound form $\left(*_{-}^{*} n i,-^{*} k u\right)$ or a morpheme boundary (*ka-wanan, *qali-matek).

A PSM etymon is posited wherever Tiruray has a unique reflex or a reflex that shows stratal associations with a unique reflex. Unique reflexes include distinctive recurrent changes such as $\left.*_{-k-}>/ \mathrm{g} /{ }^{*}{ }_{-}-s_{-}\right)>/ \mathrm{h} /$ or ${ }^{*} R>/ \mathrm{r} /$. In addition, where a distinctive irregularity appears both in Tiruray and in the Bilic languages the form is taken to be native whether a distinctive recurrent change is present or not, as with PPH *depa > PSM *difa > TIR rifo 'fathom' (with irregular penultimate vowel). A PSM etymon is not posited (1) where there are clear phonological criteria that the Tiruray form is a loan, or (2) where the stratum assignment is indeterminate and the form is not basic. It will be useful to consider each of these cases in turn.

Where there is clear phonological criteria that a Tiruray form is a loan, a PSM form is not reconstructed, as it is generally assumed that the loan entered Tiruray after the break-up of Proto South Mindanao. This assumption is most likely to be correct where only Tiruray has an irregular reflex, as with PPH *nipis > TIR nifis, but BIL(K) m-nifih, BIL(S) m-nifi, TBL lufi 'thin (objects)'. When one or more of the Bilic languages exhibits a corresponding irregularity we are confronted with a dilemma: whether to adopt the similar assumption that borrowing took place once in PSM, or the more complex assumption that borrowing took place independently in two or more of the South Mindanao languages.

There are certain cases where an assumption of parallel borrowing is necessary to explain the facts. Consider the data in Figure 3.

\begin{tabular}{|c|c|c|}
\hline Tiruray & Tagabili & English \\
\hline bayabas & beyabas & guava \\
\hline lamesa & lemisa & table \\
\hline makinah & mekina & machine \\
\hline sandalu & sendalu? & soldier \\
\hline adat & adat & custom \\
\hline kafal & kafal & ship, boat \\
\hline kambig & kambin & goat \\
\hline dagan & dagan & sell \\
\hline fintu? & hintu? & door \\
\hline guntin & guntig & scissors \\
\hline rugi & lugi & lose out \\
\hline safi? & safï? & cow \\
\hline abas & abas & chicken pox \\
\hline baga? & baga? & lung \\
\hline gatas & gatas & milk \\
\hline sarig & salig & depend on \\
\hline ranaw & lanaw & lake \\
\hline karus & kalus & scratch, claw \\
\hline bukay & bukay & white \\
\hline taked & taked & heel \\
\hline
\end{tabular}

FIGURE 3: SOUTH MINDANAO COMPARISONS INVOLVING KNOWN AND SUSPECTED LOANWORDS 
Items 1-4 are Spanish loans, yet exhibit correspondences that manifest a high degree of regularity. If we did not know their adventitious origin we might be tempted to reconstruct a PSM prototype for these sets. However, both semantic considerations and some degree of irregularity in the correspondences (prepenultimate /a/ rather than schwa in Tiruray, sporadic final laryngeals) probably would alert us to the error of this decision.

Items 5-12 demand a somewhat more difficult decision from the comparativist. There is good reason to believe that all of these items are Malay loans. In the case of 5 and 6 this is certain, as adat is ultimately of Arabic and kafal ultimately of Tamil origin. In the case of 7-12 all but dagan exhibit phonological irregularities which can be understood on the assumption that the items are loans which followed cluster reduction and lowering of high vowels before a final glottal stop in PSM, and diphthongisation of final high vowels in Tiruray. Again, semantic considerations provide some clues: items relating to commerce, the sea and non-indigenous animals (cow) are immediately suspect as foreign.

With 13-20 the task of distinguishing native from foreign lexical elements becomes more difficult. Not only are all of these items likely to reflect etyma that were present in PPH, but some of them represent basic meanings. We might dismiss TIR, TBL abas 'measles' on semantic grounds (since the disease is introduced), but what are we to do with baga? 'lung' in both languages?

One approach to this problem would take the following form. Since $* b->/ b /$ or $/ w /, * d$ $>/ \mathrm{d} /$ or $/ \mathrm{r} /$ and last syllable $* \mathrm{a}>/ \mathrm{a} /$ or $/ \mathrm{o} /$ all occur in unambiguously native forms (forms with unique reflexes) we cannot escape the conclusion that Tiruray shows some phonologically unconditioned splits which are not readily explainable through an appeal to borrowing. Given this conclusion, why should we not assume that $\mathrm{PPH} * R$ has also split unconditionally in Tiruray, and that one of the inherited reflexes $(/ g /)$ happens to be identical to the reflex in loans? There is even some marginal support for this hypothesis in the comparisons BIL(K) sa?l, BIL(S) sa?al, TBL se?el, but TIR sa?ag (with /g/) 'floor', TBL sala, but TIR salag (with/g/) 'nest' and BIL lite?, TBL lito? 'blood', TBL litok 'sap of tree', but TIR gito? (with /g/) 'a euphemistic substitute for blood in referring to a wound that is actually bleeding'. However, each of these comparisons can be explained on the assumption that Tiruray has borrowed its cognate (cf. Western Bukidnon Manobo sa?ag 'floor', gita? 'sap of tree' (often used as a euphemistic substitute for 'blood' in the languages of Indonesia and the Philippines), Western Bukidnon Manobo, Magindanao, Maranao salag 'nest'). The change of ${ }^{*} R$ to $/ \mathrm{g} /$ in a Tiruray lexical item, then, apparently must be taken as absolutely indicative of a loan. A similar case with reflexes of ${ }^{*}-k$ - is seen in BIL igem, TBL igam, but TIR ikam (with/k/) 'mat', a form which could have been borrowed from MAG, MAR ikam or any number of Manobo languages.

It is troubling to conclude that a body-part term such as baga? has been borrowed independently by two languages belonging to the same subgroup. Yet the conclusion that parallel borrowing of basic vocabulary has occurred in the South Mindanao languages is forced upon us repeatedly in considering the evidence. Although not a body part, milk is a bodily substance. Both Tiruray and Tagabili have borrowed the Danaw term gatas 'milk'. In Tagabili gatas evidently is generic. In Tiruray, judging from Schlegel's gloss, gatas refers only to animal milk, and contrasts with a native term ratah, which refers specifically to human breast milk. Perhaps only the latter should be considered basic, since only ratah refers to a substance produced by the human body. In this case the loan status of the 
Tiruray-Tagabili comparison is brought into focus by the retention of a directly inherited etymological doublet.

Item 16 in Figure 3 is a very straightforward comparison: TIR sarig 'depend upon someone, put confidence in someone': TBL salig 'trust; have confidence in'. Even if this item is a loan is it not simpler to attribute the loan to PSM rather than assume parallel borrowing in Tiruray and Tagabili? In this case semantic change provides a clue. PPH ${ }^{*} s a(n) d i R$ clearly meant 'lean against, lean on', referring to a physical activity. The south Mindanao reflexes show complete transfer of the original meaning to a figurative sense. Since MAR sarig 'trust, depend on; faith, confidence' shows the same semantic change and exhibits a regular phonological development it is simplest to assume that the Tiruray and Tagabili forms are Danaw loans.

With 17-20 the decisions become extremely difficult. All of these items exhibit phonological irregularities, yet all are found in Tiruray, Tagabili and Bilaan, and all represent meanings that are either on the Swadesh 200-item lexicostatistical test list or can be considered basic by a reasonable extension of that list (e.g. to include all body-part terms). Given their phonological irregularities we are tempted to regard items 17-20 as borrowed. Yet given their distribution over all three South Mindanao languages and their basic character we are tempted to regard them as native. If we consider items 17-20 to be native Tiruray forms we must recognise the following unconditioned phonemic splits: (1) $*_{-a w}>/$ ew/ or /aw/, (2) ${ }^{*}-s>/ \mathrm{h} /$ or $/ \mathrm{s} /$, (3) ${ }^{*}-k->/ g /$ or $/ \mathrm{k} /$, (4) ${ }^{*}$-ay $>/$ ey/ or $/$ ay/ and $(5){ }^{*}-d>/ \mathrm{r} /$ or $/ \mathrm{d} /$. Since we have already been forced to recognise that PPH ${ }^{*} b$-, ${ }^{*} d$ - and last-syllable ${ }^{*}$ a have split unconditionally in Tiruray why should we not assume additional unconditioned splits so as to avoid a problematic hypothesis of borrowing? The answer to this question comes from a consideration of stratal associations. The South Mindanao reflexes of both *bukay and ${ }^{*}$ taked show multiple irregularities $\left(*_{-k-}>/ \mathrm{k} /,{ }^{*}\right.$-ay $>/$ ay/, ${ }^{*}-d>/ \mathrm{d} /$ ) which manifest clear stratal correlations. The probability that a native form would exhibit more than one irregularity and that these irregularities would correspond to the developments in known loanwords is too small to be considered seriously. Items 17-20, then, as well as many other lexical items which exhibit similar diachronic irregularities, must be considered loans.

The foregoing conclusion leaves open the question of the age of such loanwords. Is it not too improbable to believe that the same basic vocabulary item has been borrowed independently by three different members of the same linguistic subgroup? With TIR ranaw, BIL, TBL lanaw 'lake' we might accept the claim that South Mindanao speakers have borrowed MAG, MAR ranaw, lanaw 'lake'. Danaw speakers are in control of the regions around both of the major lakes of Mindanao (Maranao around Lake Sultan Alonto, Magindanao around Lake Buluan). Yet South Mindanao speakers must surely have been familiar with lakes and must have had a word for 'lake' prior to the introduction of the word they now possess. Moreover, there is no apparent reason why South Mindanao speakers should borrow MAG, MAR karus 'scratch, claw'. Little published lexical material is available for Bilaan, and it is quite possible that Bilaan, like Tiruray and Tagabili, has baga? 'lung'. If so we would have little choice but to conclude that a basic vocabulary item has been borrowed into all three South Mindanao languages. Such an event, then, cannot be ruled out with reflexes of PPH *danaw and *kadus.

With items 19 and 20 we encounter still greater difficulties. PPH *abukay appears to have originally meant 'white, of things normally some other colour', referring prototypically to albinism or to white colouration in the feathers of cocks. MAR bukay 'albino' retains this 
sense, but all of the South Mindanao languages reflect a semantic innovation: BIL(K) bukoy, BIL(S), TBL, TIR bukay 'white (ordinary colour term)'. Since no other language is known to reflect *abukay with the meaning found in the South Mindanao languages there is no obvious source for this item if it is a loan. In such a case we are perhaps justified in assuming borrowing from a language which no longer exists. The problem recurs with reflexes of PPH *taked, as noted already in the discussion of Proto South Mindanao (section 3.2.1). For apparent loans such as TIR bukay and taked, then, it will be assumed that borrowing took place in PSM rather than in the separate histories of the South Mindanao languages, since no modern source is known.

When stratum assignment is indeterminate because a morpheme contains no diagnostic reflexes I adopt the following procedure. Considerations of diachronic phonology support the classification of some 130 of the 368 lexical items in Appendix 1 (i.e. 35.3\%) as native, 172 items $(46.7 \%)$ as foreign and 66 items $(18.0 \%)$ as indeterminate. The matter is different for basic items, where 55 out of $126(43.6 \%)$ must be considered native, 36 (28.6\%) foreign and $35(27.8 \%)$ indeterminate. It follows by extrapolation from cases in which a diagnostic reflex is available that for any given phonologically indeterminate non-basic form the probability is greatest that it is borrowed. Under these circumstances I posit no PSM etymon. In a number of cases (arek 'sniff', away 'canoe', olot 'basket') a plausible Danaw source is known (MAR arek 'kiss', awaj 'boat', alat 'basket'). Where a plausible Danaw source is not known it is assumed that the Tiruray word derives from another loan source. With basic items the opposite strategy is adopted: since the majority of basic items with a diagnostic reflex are native, phonologically indeterminate basic items are also assumed to be native, and I posit a PSM etymon. It must be kept in mind that such reconstructions are probabilistic, and that in any given case an etymon may be posited which did not exist, or an etymon may have existed where I posit none. PSM reconstructions are followed by a number code to indicate the distribution of known reflexes $(1=$ either Bilaan dialect, $2=$ Tagabili, 3 = Tiruray).

Tiruray forms in Appendix 1 are followed by (B) if they are regarded as basic. As already noted, I have extended the notion of basic vocabulary to include some items not on the Swadesh 100- or 200-item lexicostatistical test lists. Items are listed following the order in which they appear in Schlegel (1971). The omission of orthographic (but non-phonemic) glides $/ y /$ and $/ w /$ has caused some items to appear as though out of sequence.

The last two columns before the English glosses provide a schematic indication of the evidence for classifying a Tiruray form as native or as foreign. Phonological segments under the appropriate column refer to Figure 2, where further information is given. Thus, (1) PPH *abas $>$ TIR abas is regarded as foreign because the reflexes of ${ }^{*}-b$ - and ${ }^{*}$-s identify it as not directly inherited, while (7) PPH *lakaw > TIR agew is regarded as native because the reflexes of ${ }^{*}-k$ - and ${ }^{*}$-aw are markers of a directly inherited morpheme. Phonologically indeterminate reflexes are marked by a dash in each column.

Finally, of the 368 etymologies in Appendix 1, some 15 exhibit conflicting reflexes. The first problematic item is (5) PPH *aday > TIR adey 'ouch!'. If this form were native we would expect **arey; if it were foreign we would expect **aday. Given its meaning adey is not likely to be a loan. Moreover, exclamations not uncommonly resist sound changes so as to retain an expressive power that might otherwise be lost. I assume, then, that adey is native and has resisted the normal lenition of intervocalic ${ }^{*} d$ for expressive reasons. 
The second problematic item is (138) PPH *kamansi > kemasey 'breadfruit'. If this form were native we would expect ${ }^{*}$ kemahey; if it were foreign we would expect ${ }^{* *}$ kamansi. However, Tiruray reflects other plain and prenasalised obstruents differently (e.g. PPH *-d$>\mathrm{PSM}^{*} r$, TIR /r/, but PPH *-nd- or *-nd- > PSM *-d-, TIR /d/), and there is little comparative evidence to identify the regular reflex of PPH ${ }^{*}$-ns- in Tiruray. I assume, then, that kemasey is native.

The third problematic item is (149) PPH *kundur > kondor 'gourd'. If this form were native we would expect ${ }^{* *} k$ udur or possibly ${ }^{* *} k o d o r$, if it were foreign we would expect **kundur. I assume that TIR kondor is a loan, but am presently unable to identify a likely source.

The fourth problematic item is (155) PPH *kuRita > TIR kurita? 'octopus'. If this form were native we would expect ${ }^{* *} k e r i t a$ or perhaps ${ }^{* *} k e r i t o$; if it were a loan from any of the Danaw languages we would expect ${ }^{* *} k u g i t a$. However, Maranao kurita? 'octopus, cuttlefish, squid' itself shows irregularities indicative of borrowing, probably from Brunei Malay. We can assume, then, that this form was borrowed from Malay into Maranao, and thence from Maranao into Tiruray. It is worth noting that this hypothesis is independently supported by the need to assume borrowing for many words that belong to the same general semantic domain. Although the situation has changed in modern times, traditionally the Tiruray (like their Bilic relatives) were interior hill people who had little direct knowledge of the sea and its products. This historical fact is reflected linguistically in an entire panoply of terms relating to the sea which appear to be loans from Danaw, or occasionally other languages, signalled by the reflexes ${ }^{*} R>/ \mathrm{g} /,{ }_{-}-d>/ \mathrm{d} /$, non-dipthongisation of final high vowels, and the distinctive Danaw reduction of medial $*_{\text {-au- }}$ or ${ }^{*}$-ai- to the simple high vowel: (1) *daRat > dogot 'sea' (MAG lagat, MAR, Ilanun ragat; the stop in Tiruray suggests a non-Danaw source), (2) *kaRaj kagaj 'crab', (3) *ka-lahud > ke-lud-an 'deep water or open sea', kolud 'go toward deeper water, toward open sea' (MAR kaludan 'ocean, sea, lake', kalud 'off shore, far out at sea'), (4) *paRi > fagi 'stingray' (MAG, MAR pagi), (5) *butiti > butiti 'globefish' (MAR butiti), (6) *kemi > kemi 'suckerfish, remora', (7) *keti $>$ keti 'low tide', (8) *kurapu > kurafu 'large saltwater fish: Epinephel us sp.', (9) begel 'waves on the ocean' (MAR bagel 'ripple, wave'), (10) begison 'shark' (MAR bagisan, begisan). Also not worthy in this connection are PPH *peñu 'sea turtle, green turtle' > fenew 'a land turtle: Cyclemys amboinensis (Daudin)', where the native term for 'sea turtle' has been retained but altered in meaning, and *pawikan > fuikon 'large marine turtle', an apparent loan which has taken over the sense originally represented by *peñu.

The fifth problematic item is (196) PPH *panakaw > fenakaw 'to steal'. If this form were native we would expect ${ }^{* *}$ fenagew, if it were foreign we would expect ${ }^{* *}$ fanakaw. However, the treatment of prepenultimate /a/ in loanwords does not appear to be consistent: while /a/ is often retained unchanged in this position, it merged with schwa in (196) * panakaw > fenakaw (MAG manakaw, MAR panekew), (199) *kayaw > fejayaw 'invade, attack another tribe or country' (MAR payayaw 'engage in piracy'), (338) PPH *taRa-qinep $>$ teginef 'dream' (MAG, MAR taginep) and (340) PPH *tambuRi > temburi 'conch shell trumpet'. There seems to be no obstacle, then, to assuming that TIR fenakaw is a loan.

The sixth problematic item in Appendix 1 (199) was discussed with (196) in the preceding paragraph.

The seventh problematic item is (228) $\mathrm{PPH} *_{-}-k u>g u$ ' $\mathrm{I}$ '. If this form were native we would expect ${ }^{* *}$ gew; if it were foreign we would expect ${ }^{* *} k u$. Since bound pronouns are 
among the lexical items least likely to be borrowed, TIR -gu almost certainly is native. The failure of *-u to diphthongise in this form is paralleled in (38) PPH *-ni > eni 'this' and (174) $\mathrm{PPH} * d$-ini $>d i n i$ 'here'. Pronouns and locative adverbs as a group, then, appear to have resisted the diphthongisation of final vowels. A similar grammatically conditioned exception to an otherwise regular diphthongisation of final high vowels has been noted in Rejang of south Sumatra (Blust 1984b).

The eight problematic item is $(254) *$ muntay > muntey 'citrus fruit'. If this form were native we would expect ${ }^{* *}$ mutey, if it were foreign we would expect ${ }^{* *}$ muntay. I assume that TIR muntey is a loan, perhaps from a Manobo language, as the PPH diphthongs *ay and *-aw regularly became /ey/ and /ew/ and medial consonant clusters were preserved in Dibabawon, Ilianen, Tigwa and Western Bukidnon Manobo.

The ninth problematic item is (267) PPH *Rantaw > rantaw 'floating'. If this form were native we would expect ${ }^{* *}$ ratew; if it were borrowed we would expect **gantaw. However, PPH *Rantaw is based solely on the comparison of Tiruray rantaw with Bikol gátaw 'float just beneath the surface of the water'. Since this item contains a monosyllabic root (Blust 1988), the initial syllables of the Tiruray and Bikol forms - despite their correspondence may have no historical connection. The $/ \mathrm{r} /$ of TIR rantaw therefore need not be attributed to ${ }^{*} R$, but could derive from ${ }^{*} d$ or ${ }^{*} r$. I assume that this item is a loan, perhaps from a Manobo language, though a plausible source is yet to be found.

The tenth problematic item is (272) *lebuR > rebur 'murky, riled'. If this form were native we would expect ${ }^{* *}$ ruor; if it were borrowed we would expect **lebug. The final $/ \mathrm{r} /$ $\left(\right.$ from ${ }^{*} R$ ) eliminates any Danaw or Manobo source. At the same time TBL lebol 'murky, riled' shows the expected lowering of ${ }^{*} u$ before final ${ }^{*} R$, so the Tiruray form could not plausibly be a loan from Tagabili. I assume that this form is native, but am unable to explain the development either of the medial consonant or of the last vowel.

The eleventh problematic item is (273) PPH *daRami > regamey 'rice straw'. If this form were native we would expect ${ }^{* *}$ deramey or perhaps ${ }^{* *}$ reramey; if it were borrowed we would expect ${ }^{* *}$ dagami or ${ }^{* *}$ degami. The diphthongisation of the final vowel is thus in apparent conflict with the change ${ }^{*} R>/ \mathrm{g} /$. To reconcile these changes we could assume that PPH high vowels occasionally diphthongised in loanwords. However, there is no independent evidence to support such a claim. Next to ${ }^{*}$ daRami PPH had a doublet ${ }^{*}$ gaRami (inherited from PMP *gaRami, a form reflected in, for example, Ilokano garámi and Kelabit geramih 'rice straw, rice stubble'). I assume that TIR regamey is a native reflex of *gaRami, with metathesis of the first two consonants. TBL lami 'harvested rice field' lacks the entire first syllable and so cannot help to resolve the problem. A Bilaan cognate is unknown.

The twelf th problematic item is (313) PPH *tawaR >tabar 'to call'. If this item were native we would expect ${ }^{* *}$ tawar; if it were foreign we would expect **tawag. TIR tabar clearly is native, as it reflects the sporadic change of ${ }^{*}-w$ - to $/ \mathrm{b} / \mathrm{seen}$ also in TBL $t$-em-aba 'to call' and contrasts with the etymological doublet tawag 'to call', which presumably derives from MAG, MAR or Ilanun tawag. I am unable to suggest an explanation for the preservation of the historically secondary intervocalic stop, which should have lenited in Tiruray.

The thirteenth problematic item, (338) PPH *taRa-qinep > teginef 'dream', has already been discussed in connection with (196) PPH *panakaw > fenakaw. 
The fourteenth problematic item is (340) PPH *tambuRi > temburi 'conch shell trumpet'. If this term were native we would expect **teburey, if it were borrowed from a language in the southern or central Philippines we would expect ${ }^{* *}$ tambugi. MAG, MAR tambuli? 'giant conch shell' show an irregular development which is suggestive of borrowing. The most plausible immediate source of the Danaw form is Tagalog tambúli? 'bugle made out of horn or large shell'. However, the Tagalog form itself exhibits irregularities indicative of borrowing, probably from Brunei Malay. Indeed, it was the complex, undetected history of borrowing of this form which led Dempwolff (1938) to incorrectly reconstruct *tamburi (with ${ }^{*} r$ rather than ${ }^{*} R$ ). The phonological development of PMP ${ }^{*}$ tambuR $i$ in Philippine languages suggests the following historical events: (1) the reflex of PMP *tambuRi probably disappeared in Proto Philippines (no directly inherited Philippine forms have yet been found), (2) a loan from a language in which ${ }^{*} R$ became $/ r /$ was introduced into Tagalog and perhaps some other languages of the central Philippines, (3) this loan then diff used to the Danaw languages, among others, and (4) a second wave of borrowing from a non-Philippine source introduced temburi into Tiruray. Apart from its inherent complexity there are two problems with this scenario: Malay, the most likely source of temburi, has buri, with an irregular loss of the first syllable, and there is little evidence that any of the Malay loans in Tiruray were borrowed directly from Malay as opposed to being mediated by a Danaw source. This item, then, remains problematic despite the overwhelming probability that it is a loan. Tentatively I assume that it derives from a non-standard dialect of Malay in which the first syllable was not lost.

The last problematic item in Appendix 1 is (342) PPH *timeRaq > timera 'lead (metal)'. If this item were native we would expect ${ }^{* *}$ temera? or ${ }^{* *}$ temero?; if it were borrowed from a language in the southern or central Philippines we would expect ${ }^{* *}$ timga? or **tinga? Not accounted for in either case is the loss of $*_{-} q$. As with temburi it is tempting to consider timera a Malay loan. Since PMP *- $q$ became Malay $/ \mathrm{h} /$ and $\mathrm{PPH}{ }^{*} h$ was lost in Tiruray, the $\mathrm{h} / \mathrm{of}$ Malay loans presumably would disappear, as indeed we have already seen with adafan 'the area immediately in front of someone or something' (Malay hadap-an). The difficulty with this hypothesis is that the Standard Malay reflex of *timeRaw is timah. Minangkabau timarah 'tin, lead' shows that some Malay dialects or some languages closely related to Malay retain the original trisyllabic shape of this morpheme, but it is unknown whether this is true of Brunei Malay, the most likely source of TIR timera.

In Appendix 2 I have made some attempt to identify the sources of the proposed loans in Appendix 1. Although the historical sources suggest that Magindanao was the most important contact language for Tiruray within the past century or two, the Magindanao dictionary of Juanmarti (1892) is not nearly as complete as the Maranao dictionary of McKaughan and Macaraya (1967). For reasons of documentary completeness alone, then, a Maranao source may often be found when the actual borrowing was from Magindanao. However, we must not underestimate the importance of Maranao, and perhaps Ilanun, as sources of loans in Tiruray. And, as already noted, some recent Austronesian loans are clearly from non-Danaw sources such as Tagalog and probably certain Manobo languages. Forms such as taked 'heel' or bukay 'white' raise the issue of how to account for apparent loans that have no plausible source language. Both the number of basic vocabulary items borrowed and the lack of a plausible modern source language for certain forms suggest that PSM was in intimate and prolonged contact with some other Austronesian language in the southern Philippines which left no modern descendants. 


\section{CONCLUSIONS}

Based on the 368 etymologies in Appendix 1 the following general conclusions appear justified:

(1) Those Tiruray lexical items for which a PPH etymon is proposed are assigned to one of three categories, as follows: (1) native forms, $130=35.3 \%$; (b) foreign forms, $172=46.7 \%$; (c) indeterminate forms, $66=18.0 \%$.

(2) The 126 items in Appendix 1 which can be classified as basic fall into the following categories: (1) native forms, $55=43.6 \%$; (b) foreign forms, $36=28.6 \%$; (c) indeterminate forms, $35=27.8 \%$.

(3) The native speech stratum in Tiruray can most confidently be identified through the use of unique reflexes rather than through use of the basic:non-basic vocabulary distinction.

(4) In association with unique reflexes such as $*_{-}-k_{-}>/ \mathrm{g} /,{ }^{*}-s(-)>/ \mathrm{h} /,{ }^{*} R>/ \mathrm{r} /,{ }^{*}-i$,

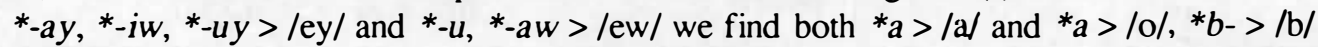
and ${ }^{*} b->/ \mathrm{w} /,{ }^{*} d->/ \mathrm{d} /$ and $* d->/ \mathrm{r} /$. Since these phonemic splits cannot be explained through an appeal to phonological conditions or to borrowing they must be regarded as unconditioned. Such examples appear to be products of lexical diffusion (Wang 1969).

(5) Changes such as $*_{-k}->/ \mathrm{k} /{ }^{*}{ }_{-}-\mathrm{s}(-)>/ \mathrm{s} /,{ }^{*} R>/ \mathrm{g} /, *_{-}-\mathrm{i} / \mathrm{i} /,{ }^{*}-u>/ \mathrm{u} /,{ }^{*}$-ay $>/$ ay $/$ or $*_{\text {-aw }}>$ /aw/ cannot be considered unconditioned phonemic splits, since they show clear stratal associations with one another that point to indirect inheritance.

(6) Some of the non-native forms that are found in Tiruray and in Bilaan or Tagabili (or both) may have been borrowed into Proto South Mindanao. Others almost certainly entered the South Mindanao languages through parallel borrowing.

(7) Although many loans in Tiruray are of clear Danaw derivation, many others must derive from other languages. In some cases there is no extant source for a given loan that is shared by Tiruray and the Bilic languages. Such cases (such as reflexes of PPH *abukay or *taked) may reflect borrowing into PSM from a prehistoric source language that left no modern descendants. As for the many Danaw loans in Tiruray (and the Bilic languages, insofar as they are documented), Maranao would seem to be at least as important a source as Miagindanao.

To comment briefly, startling as it may appear, conclusion (1) probably is conservative. Appendix 1 includes only one item that Schlegel marks as a loan (timera, which he incorrectly lists as Spanish). Except for the three items with ${ }^{*} R>/ r$ / (kurita?, temburi and timera), all likely Malay loans, both those noted earlier and many that space has not permitted me to mention, have been omitted. Moreover, only Philippine forms with a PPH etymology are considered, although many other likely loans occur, such as TIR asad 'load a gun' (MAR asad 'measure, load'); TIR eled 'sink' (MAR led 'drown'); TIR ined 'country, nation, neighbourhood, place' (MAR ined 'place, country, town, city'); TIR, MAR baba? 'do intentionally, provoke'; TIR, MAR kubig 'bamboo Jew's harp'; TIR fakay 'possible, permitted' (MAR pakay 'willingness; approve, accept'); TIR guket 'snarl, tangle' (MAR guket 'chaotic condition'); TIR lafis 'cheat one's business partner by not dividing the profits equally' (MAR lapis 'deficit, loss'); TIR sukay 'wage(s)' (MAR sukay 'pay, salary, fare; hire'); TIR, MAR sukug 'boom of a sail'; TIR suggud 'brideprice' (MAR suggud 'pay alimony, dowry, brideprice'); TIR, MAR tukid 'share, distribute'; TIR tuges 'to fish in the 
ocean' (MAR tuges 'to fish'); and TIR, MAR tundug 'follow, chase', to mention only a few. The result is a set of etyma that with very few exceptions can safely be attributed to PPH. In conclusion, the claim that nearly $47 \%$ of Tiruray vocabulary is borrowed not only is justified, but this figure almost certainly is lower that the actual percentage of loans in the total Tiruray vocabulary, which may well exceed $50 \%$.

Given the fact that I have adopted the concept 'basic vocabulary' rather than the actual set of forms on either the Swadesh 100- or 200-item lexicostatistical test lists, one could quibble with the claim that nearly $29 \%$ of Tiruray basic vocabulary consists of loans. However, restricting ourselves only to the 86 items in Appendix 1 that actually appear on the Swadesh 200-word list we obtain very nearly the same results: (a) native forms, $36=41.9 \%$; (b) foreign forms, $25=29.1 \%$; (c) indeterminate forms, $25=29.1 \%$. We can conclude with some confidence, then, that nearly $30 \%$ of Tiruray basic vocabulary has been borrowed.

The foregoing conclusion should make it clear why the identification of speech strata in Tiruray is methodologically so unlike the similar problem in Ngaju Dayak. Among the forms marked as basic in Appendix 1, PPH *-k-becomes /g/ (the native reflex) in 9 items and remains $/ \mathrm{k} /$ in 8 others. Even when it is determined that two of the latter reflexes occur in the non-diagnostic environment following schwa we are left with 9 instances of ${ }^{*}-k->/ g /$ and 6 of ${ }^{*}-k->/ \mathrm{k} /$. The situation with regard to reflexes of intervocalic and final ${ }^{*} s$ is nearly the same (one instance of ${ }^{*} s>/ s /$ following schwa, 7 of ${ }^{*} s>$ /s/ following other vowels and 6 of ${ }^{*} s>/ \mathrm{h} /$ ). Reflexes of ${ }^{*} R$ fare only slightly better (11 examples of ${ }^{*} R>/ \mathrm{r} /, 7$ of ${ }^{*} R>$ $/ g /$ ). Such a situation hardly encourages the use of basic vocabulary as a primary tool for distinguishing native from borrowed lexical items.

With reference to conclusion (6) parallel borrowing must be assumed to account for those non-Austronesian loans which are shared by Tiruray and Tagabili, since they could have entered these languages only after they separated from a common ancestor. Surprisingly, a number of Danaw and other Philippine loans also appear to have been borrowed independently by Tiruray and Tagabili. Where the lexical items in question refer to useful introduced items of material culture this parallelism is not difficult to explain. However, where the items in question are of a more general character (e.g. TIR sarig, TBL salig 'depend on') the reasons for parallel borrowing are far less clear. In such cases we are confronted with a situation reminiscent of drif $t$, with this difference: in drift the continued operation of inherited structural pressures favours parallel developments after two languages have separated from a common ancestor, while in parallel borrowing the predisposing factors for parallelism must be sought in the sociocultural setting rather than in the structure of the borrowing languages.

Differences in sociocultural setting may also help to explain another puzzling observation. Ngaju Dayak has borrowed so heavily from Banjarese Malay that clearly discernible speech strata were recognised very early (Dempwolff 1922:203ff., 1937). Yet the basic vocabulary has remained almost untouched by loan influences. Tiruray, on the other hand, has borrowed nearly $30 \%$ of its basic vocabulary. What can account for such striking differences in the degree to which basic vocabulary is exempt from the effects of heavy borrowing?

Finally, this paper should make it clear that a great deal remains to be done in the study of intra-Austronesian loans. Pallesen (1985) has provided extensive documentation of linguistic convergence between Tausug and Sama-Bajaw. This important work and the present study document two quite independent instances of massive borrowing between 
languages on or near the island of Mindanao. Undoubtedly cases of equally significant borrowing will be identified in time among other languages in the Philippines, or elsewhere in the Austronesian world.

APPENDIX 1: Tiruray reflexes of Proto Philippine reconstructions ${ }^{1}$

\begin{tabular}{|c|c|c|c|c|c|c|}
\hline & PPH & PSM & Tiruray & Native & Foreign & English \\
\hline 1. & abas & -23 & abas & & $b, s$ & pockmarks \\
\hline 2 . & abay & - & abay & & $b, a y$ & side-by-side \\
\hline 3 . & akaw & - & akaw?akaw & & $k, a w$ & stilts \\
\hline 4. & hakup & - & akuf & & $k$ & scoop with hands \\
\hline 5. & aday & adey 3 & adey & ey & (d) & ouch! \\
\hline 6. & hapuy & afi 123 & afey (B) & ey & & fire \\
\hline 7 . & lakaw & agew 123 & $\operatorname{agew}(\mathrm{B})$ & g,ew & & walk, go \\
\hline 8. & sakit & agit 3 & $\operatorname{agit}(\mathrm{B})$ & $g$ & & painful \\
\hline 9 . & ambaw & - & ambaw (B) & & CC, aw & rat \\
\hline 10. & ampun & - & amfun & & $\mathrm{CC}$ & ask pardon \\
\hline 11. & anay & ane $y$ & aney & ey & & termite \\
\hline 12. & apsej & - & ansed & & $\mathrm{CC}$ & underann odour \\
\hline 13. & qã̃ud & qanur 2,3 & $\operatorname{anur}(\mathrm{B})$ & $r$ & & float, drift \\
\hline 14. & anay & ajey 3 & $\operatorname{agey}(\mathrm{B})$ & ey & & come, go \\
\hline 15. & akak & $\operatorname{arak} 3$ & arak & $r$ & & lead by the hand \\
\hline 16. & hajek & -23 & arek & - & - & sniff, kiss \\
\hline 17. & harimaw & - & arimaw & & $a, a w$ & tiger, lion \\
\hline 18. & arud & - & arud & & $d$ & scrape, shave off \\
\hline 19. & alud & alur 13 & arur & $-r$ & & boat, raft \\
\hline 20. & hasay & - & asaj & & $s$ & gills \\
\hline 21. & *hasek & - & asek & & $s$ & press, cram \\
\hline 22 . & ${ }^{*}$ hasek & ahek 23 & ohok & $h$ & & dibble \\
\hline 23. & qatep & qatep 123 & $\operatorname{atc} f(B)$ & - & - & roof \\
\hline 24. & $m$-atay & m-atey 123 & $\operatorname{atcy}(\mathrm{B})$ & ey & & die, dying \\
\hline 25. & atis & - & atis & & $s$ & sweetsop \\
\hline 26. & qabaj & -123 & awaj & - & - & canoe $^{2}$ \\
\hline 27. & habel & -123 & awel & - & - & weave cloth \\
\hline 28. & qabu & qabu 13 & awew (B) & ew & & ashes \\
\hline 29. & beqbeq & ebaq 13 & $e b a^{2}(\mathrm{~B})$ & - & - & mouth \\
\hline 30. & $q e b c l$ & qebel 23 & $e b c l(\mathrm{~B})$ & 一 & - & smoke \\
\hline 31. & buhek & buek 123 & ebuk (B) & - & - & head hair \\
\hline 32. & dedep & - & ekel & - & - & embrace \\
\hline 33. & dekdek & edek 123 & edek (B) & - & - & to pound \\
\hline 34. & hepat & efat 123 & $e f o t(\mathrm{~B})$ & - & - & four \\
\hline 35. & ${ }^{*}$ leRas & - & (t)egas & & $g, s$ & hardwood \\
\hline
\end{tabular}

\footnotetext{
${ }^{1}$ Numbers following a PSM reconstruction indicate the distribution of reflexes (where $1=$ either Bilaan dialect, 2 = Tagabili and 3 = Tiruray). Where no PSM reconstruction is proposed numbers indicate the distribution of presumptive loans. Thus PPH *abas, PSM - 23 indicates that a borrowed reflex of PPH *abas is found both in Tagabili and in Tiruray.

2Probably a Danaw loan, as TBL owo 'ship' does not show the anticipated change * $q->\mathrm{k} /$.
} 


\begin{tabular}{|c|c|c|c|c|c|}
\hline 36. heRet & - & eget & & $g$ & tight \\
\hline 37. qahlu & elu 13 & elew & $e, e w$ & & rice pestle \\
\hline 38. -ni & -ni 123 & eni (B) & & $i$ & this \\
\hline 39. sesep & esef 123 & $\operatorname{esef}(\mathrm{B})$ & - & - & suck \\
\hline 40. lesuy & -123 & esuy & - & - & rice mortar \\
\hline 41. tau & etew 123 & etew (B) & ew & & person \\
\hline 42. tuhud & tuur 3 & etur (B) & $r$ & & knee \\
\hline 43. ibeR & - & ibeg (B) & & $b, g$ & saliva \\
\hline 44. hikam & igam 12 & ikam & & $k$ & $\mathrm{mat}^{3}$ \\
\hline 45. hiket & -13 & $i k e t(\mathrm{~B})$ & & $k$ & to tie \\
\hline 46. hipaR & ifar3 & ifar & $r$ & & opposite side \\
\hline 47. ipes & - & ifes & & $s$ & cockroach \\
\hline 48. ikuR & igor 3 & igor(B) & $g, o, r$ & & tail \\
\hline 49. inem & inem 3 & inem (B) & - & - & to drink \\
\hline 50. hiRup & irof 3 & irof & $r$ & & $\operatorname{sip}$ \\
\hline 51. ijug & irup 123 & irug (B) & - & - & nose \\
\hline 52. qitem & qitem 123 & itam (B) & - & - & black $^{4}$ \\
\hline 53. ituq & - & $i t u^{?}$ (B) & & $u$ & dog \\
\hline 54. hiup & iuf 123 & $\operatorname{iuf}(\mathrm{B})$ & - & - & to blow \\
\hline 55. alat & -3 & olot & - & - & basket \\
\hline 56. qunuq & qonoq 3 & ono? & $o$ & & beads, necklace \\
\hline 57. anak & anak 3 & onok (B) & - & - & of fspring, cgg \\
\hline 58. ubi & - & $u b i$ & & $b, i$ & yam, sweet potato \\
\hline 59. ukap & - & ukof & & $k$ & rice chaff \\
\hline 60. upaw & - & ufaw & & $a w$ & bald \\
\hline 61. qulu & qulu 123 & ulew (B) & ew & & head \\
\hline 62. buliR & - & ulig & & $\emptyset, i, g$ & bunch, cluster \\
\hline 63. hunus & unuh 3 & unuh & $h$ & & pull out, extract \\
\hline 64. huRas & urah 3 & urah (B) & $r, h$ & & wash \\
\hline 65. UlaR & ular3 & $\operatorname{urar}(\mathrm{B})$ & $-r$ & & snake $^{5}$ \\
\hline 66. uRat & urat 123 & urat (B) & $r$ & & vein, tendon \\
\hline 67. bunduk & uruk 3 & uruk & $\mathrm{C}$ & & pcak, summit \\
\hline 68. huaR & uar3 & uar & $r$ & & vinc: Flagellaria sp. \\
\hline 69. babuy & - & babuy & & $-b-, u y$ & pig \\
\hline 70. bakhaw & - & bakaw & & $k, a w$ & mangrove \\
\hline 71. bakul & - & bakul & & $k$ & basket \\
\hline 72. badak & - & badak & & $d$ & jackfruit \\
\hline 73. badup & - & baduy & & $d$ & bolo \\
\hline 74. $b a R a q$ & -23 & baga? (B) & & $g$ & lung \\
\hline 75. balu & balu 123 & balew & ew & & widow(cr) \\
\hline 76. banaR & banar 23 & banar & $r$ & & vine: Smilax sp. \\
\hline 77. bantay & - & bantay & & CC, ay & guard \\
\hline 78. banug & - & banug & - & - & eagle, hawk \\
\hline 79. baykay & - & bankay & & CC, ay & corpse \\
\hline
\end{tabular}

${ }^{3} \mathrm{BIL}$ igem, TBL igam 'woven mat' are assumed to be directly inherited; TIR ikam is assumed to be a loan. ${ }^{4}$ The Bilic languages reflect ${ }^{*} p$-item, presumably from earlier ${ }^{*} p V$-qitem.

${ }^{5}$ TIR urar may reflect PPH * gule $j$ 'maggot, caterpillar' (cf. BIL ulad 'snake'). MAG ular 'snake' almost certainly is a Malay loan (cf. Allison 1979: PD *nipay 'snake'). 


\begin{tabular}{|c|c|c|c|c|c|c|}
\hline 80. & $b a R a h$ & bara 23 & bara & $r$ & & ember \\
\hline 81. & habaRat & barat 23 & barat & $r$ & & west wind \\
\hline 82. & batu & batu 123 & batew (B) & ew & & stone \\
\hline 83. & bauR & baur 3 & bawer & $r$ & & spring of a trap \\
\hline 84. & bayad & -23 & bayad & & $d$ & pay \\
\hline 85 . & bayuR & - & bayug & & $g$ & tree: Pterospermum sp \\
\hline 86. & ${ }^{*} b e(\eta) k a s$ & bekah 3 & bekah & C, $h$ & & undo, spring (a trap) \\
\hline 87. & ${ }^{*} b e(\eta) k a s$ & - & bejkas & & $\mathrm{CC}, s$ & split, tear along seam \\
\hline 88. & beken & beken 3 & beken (B) & - & - & no, not \\
\hline 89. & beRas & - & begas & & $g, s$ & husked rice \\
\hline 90. & beRqat & - & begat (B) & & $g$ & heavy \\
\hline 91. & beli & beli 123 & beley (B) & ey & & buy \\
\hline 92. & beniq & bcnéq 23 & bené? & $e$ & & seed rice \\
\hline 93. & bepis & bejéh 3 & bejéh & $e, h$ & & open the lips \\
\hline 94. & besuR & besor 123 & besor & $r$ & & satiated \\
\hline 95. & betu & betu 3 & betew & ew & & blister, callus \\
\hline 96. & bituka & betuga 3 & betugo (B) & $e, g$ & & intestines, stomach \\
\hline 97. & bebiR & bébér3 & béwér (B) & $e, r$ & & lip \\
\hline 98. & birbir & bébér 3 & béwêr & $e$ & & rim, edge \\
\hline 99. & sida & -ra 13 & $b e-r o(\mathrm{~B})$ & - & - & they \\
\hline 100. & bitbit & - & bibit & & $-b-$ & carry in the hand \\
\hline 101. & biRaq & bira? 23 & bira? & $r$ & & taro: Alocasia sp. \\
\hline 102. & bisa & - & bisa & & $s$ & poison \\
\hline 103. & bisu & - & bisu & & $s, u$ & deaf \\
\hline 104. & bihaR & - & biag & & $g$ & take captive \\
\hline 105. & baRqay & ba?ą 23 & bo? & $\mathrm{C}$ & & molar tooth \\
\hline 106. & bibay & bibay 123 & biwog(B) & 一 & - & left side \\
\hline 107. & busuR & bohor 123 & bohor & $h, o, r$ & & hunting bow \\
\hline 108. & buluq & bolog 3 & bolo? & $o$ & & k.o. bamboo \\
\hline 109. & bunuq & bonoq 3 & bono?(B) & $o$ & & kill \\
\hline 110. & batay & - & botog & 一 & - & $\log$, tree trunk \\
\hline 111. & bukbuk & - & bubuk (B) & & $-b$ & dust \\
\hline 112. & bulbul & - & bubul (B) & & $-b-$ & feather \\
\hline 113. & bukel & bukal 123 & bukal(B) & & $k$ & bone \\
\hline 114. & bukaq & - & buka? & & $k$ & wide open \\
\hline 115. & bukay & bukay 123 & bukay (B) & & $k, a y$ & white \\
\hline 116. & bujiq & - & budi? & & $d, i$ & fish eggs \\
\hline 117. & buku & bugu 3 & bugew (B) & g, ew & & node, joint \\
\hline 118. & bulaR & 一 & bulog & & $g$ & cataract of the eye \\
\hline 119. & buni & buni 13 & buney (B) & ey & & to hide \\
\hline 120. & buntud & - & buntud & & $\mathrm{CC}, d$ & mound \\
\hline 121. & bujig & -3 & buritg & - & - & charcoal \\
\hline 122. & bujaq & -3 & buro?buro? & 一 & 一 & foam, bubbles \\
\hline 123. & bulud & bulur 123 & buru(B) & $-r$ & & mountain, hill \\
\hline 124. & butiR & butér 3 & butér & $e, r$ & & wart \\
\hline 125. & butiti & - & butiti & & $u,-i$ & globefish \\
\hline 126. & kabeg & - & kabcg & & $b$ & fruit-bat \\
\hline 127. & kabiR & 一 & kabig & & $b, i, g$ & attract a following \\
\hline
\end{tabular}




\begin{tabular}{|c|c|c|c|c|c|}
\hline 128. kaRaJ & - & kagas & & $g$ & crab \\
\hline 129. karabaw & - & karabaw & & $v_{3}, b, a w$ & water buffalo \\
\hline 130. kadus & -123 & karus (B) & & $s$ & scratch \\
\hline 131. kahiw & kayu 123 & kayew (B) & ew & & wood, tree \\
\hline 132. qijan & -123 & ked-iron (B) & 一 & 一 & when? \\
\hline 133. $k e(m) p i s$ & - & kefis & & $s$ & stunted, dwarfed \\
\hline 134. kelaq & - & kela? & 一 & 一 & crack \\
\hline 135. talina & kelina 123 & keligo?(B) & $k$ & & ear \\
\hline 136. ka-lahud & - & keludan & & $-\emptyset-, d$ & open sea 6 \\
\hline 137. ka-lahud & - & kolud & & $-d$ & go towards open se \\
\hline 38. kamansi & kemasi 3 & kemasey & C, ey & $(s)$ & breadfruit \\
\hline 39. kemi & - & kemi & & $-i$ & suckerfish, remora \\
\hline 140. kanuku & kenugu 123 & kenugew (B) & $e, g, e w$ & & claw, fingernail \\
\hline 41. kerud & - & kerud & & $d$ & scrape \\
\hline 142. kasaw & kesew 3 & kesew & ew & & rafter \\
\hline 143. ketas & - & $\operatorname{ketas}(\mathrm{B})$ & & $s$ & cut \\
\hline 144. keti & 一 & keti & & $i$ & low tide \\
\hline 145. qipen & kifen 13 & kifen (B) & $k$ & & tooth \\
\hline 146. ki(m)pes & - & kifes & & $s$ & shrink \\
\hline 147. kiday & - & kilay (B) & & ay & eyebrow \\
\hline 148. kiras & kirah 3 & kirah & $h$ & & scar \\
\hline 149. kundur & - & kondor & $(o ?)$ & $\mathrm{CC}$ & gourd \\
\hline 150. kulit & kulit 123 & kulit(B) & - & - & skin \\
\hline 151. kulat & - & kulot & - & - & mushroom \\
\hline 152. kurapu & - & kurafu & & $v_{3},-u$ & marine fish \\
\hline 153. kuray & - & kuray & & $-a y$ & grain of wood \\
\hline 154. kuden & kureg 123 & kured & D & & cooking pot \\
\hline 155. kuRita & 一 & kurita? & (r) & $u$ & octopus \\
\hline 156. qudaj & -3 & $k$-uroj & - & - & shrimp \\
\hline 157. kutu & kutu 123 & kutew (B) & ew & & louse \\
\hline 158. ka-wanan & kewanan 123 & kuonon (B) & - & 一 & right side \\
\hline 159. dahun & daqun 123 & $d a^{?} u n$ & - & - & leaf \\
\hline 160. dakel & -3 & dakel (B) & & $k$ & big \\
\hline 161. dakep & dagef 3 & dagef & $g$ & & scize, abduct \\
\hline 162. dalu & dalu 3 & dalew & ew & & jealousy \\
\hline 163. daRaq & daraq 3 & dara?(B) & $r$ & & blood \\
\hline 164. dalij & dalir 123 & darir (B) & $-r$ & & root \\
\hline 165. daRum & darum 123 & darum & $r$ & & needle \\
\hline 166. daqtaR & datar 23 & datar & $r$ & & nat land, plain \\
\hline 167. deket & -23 & deket & - & - & paste, glue \\
\hline 168. de(ク)kit & - & dekit & 一 & - & joined lengthwise ${ }^{7}$ \\
\hline 169. *deRu & - & degu & & $g, u$ & rumble, roar \\
\hline 170. * deRu & - & regu & & $g, u$ & snore \\
\hline 171. deRa & dera 3 & dera & $r$ & & have hurt feelings \\
\hline 172. digdin & didig 13 & didin & $\mathrm{C}$ & & wall \\
\hline
\end{tabular}

${ }^{6}$ With the distinctive Danaw loss of *a before a high vowel.

${ }^{7}$ If from *degkit this form must be nątive; if from *dekit its source is indeterminate. 


\begin{tabular}{|c|c|c|c|c|c|c|}
\hline 173. & $\operatorname{dipaR}$ & difar3 & difar & $r$ & & other side \\
\hline 174. & likud & ligur3 & $\operatorname{digur}(\mathrm{B})$ & $g, r$ & & back (anat.) \\
\hline 175. & dilaq & dilaq 123 & $\operatorname{dila}^{?}(\mathrm{~B})$ & - & - & tongue \\
\hline 176. & $d$-ini & $\operatorname{dini} 123$ & $\operatorname{dini}(\mathrm{B})$ & & $(-i)$ & here \\
\hline 177. & lindur & $\operatorname{linug} 3$ & dinu & $\mathrm{C}$ & & seek shelter \\
\hline 178. & daRat & - & $\operatorname{dog} o t(\mathrm{~B})$ & & $g$ & sea \\
\hline 179. & dalan & dalan 23 & dolon (B) & - & - & road \\
\hline 180. & ludaq & -123 & dura?(B) & - & - & spit \\
\hline 181. & pakpak & fafak 123 & fafak (B) & - & - & wing \\
\hline 182. & paku & fagu 23 & fagew & g,ew & & edible fem \\
\hline 183. & $p a R i$ & - & fagi & & $g, i$ & stingray \\
\hline 184. & paliq & - & fali? & & $i$ & wound \\
\hline 185. & panaq & fanaq 123 & fana?(B) & - & - & shoot an arrow \\
\hline 186. & pantaw & - & fantaw & & CC, aw & sleeping attic \\
\hline 187. & pantay & - & fantay & & $\mathrm{CC}, a y$ & level \\
\hline 188. & pajay & farey 123 & farey & ey & & rice-plant \\
\hline 189. & pasek & - & fasak & & $s$ & stake \\
\hline 190. & peka & 一 & feka & - & - & disconnect \\
\hline 191. & pekuq & - & feku? & & $u$ & bend \\
\hline 192. & qapeju & fedu 23 & fedew (B) & ew & & gall \\
\hline 193. & qape jiq & fedéq 23 & fedé? & $e$ & & sting, smart \\
\hline 194. & dius & dioh 123 & fe-dioh (B) & $h$ & & bathe \\
\hline 195. & piliq & féléq 2 & $\int-c m-i l i ?(\mathrm{~B})$ & & $i$ & choose \\
\hline 196. & panakaw & -123 & fenakaw (B) & (e) & $k, a w$ & steal \\
\hline 197. & peñu & fenu 123 & fenew & ew & & turtle \\
\hline 198. & penuq & fenoq 123 & feno? & $o$ & & full \\
\hline 199. & kayaw & - & fegayaw & (e) & aw & attack in war \\
\hline 200. & pipi & fifi 123 & fifey (B) & ey & & cheek \\
\hline 201. & pija & fira 123 & firo-y(B) & - & - & how much/many? \\
\hline 202. & pia & fia 123 & fio $(\mathrm{B})$ & - & - & good \\
\hline 203. & paqa & faqa 23 & fo? $?$ ? (B) & - & - & thigh \\
\hline 204. & puluq & foloq 123 & folo? & $o$ & & len \\
\hline 205. & paga & fana 23 & fogo $(\mathrm{B})$ & - & - & bifurcation, branch \\
\hline 206. & palaj & falar 123 & foror (B) & $-r$ & & palm of the hand \\
\hline 207. & pukas & $\dot{-}$ & fukas & & $k, s$ & release \\
\hline 208. & puda & fura 123 & furo (B) & - & - & red \\
\hline 209. & pusej & - & fused (B) & & $s, d$ & navel \\
\hline 210. & pusuq & - & fusu? & & $s, u$ & banana blossom \\
\hline 211. & putiq & futéq 3 & futé?(B) & é & . & white \\
\hline 212. & putus & - & futus & & $s$ & woman's hair knot \\
\hline 213. & pawikan & 一 & fuikon & & $k$ & large marine turte \\
\hline 214. & puyu & - & fuyufuyu & & $-u$ & climbing perch \\
\hline 215. & Rakit & - & gakit & & $g, k$ & raft, tie together \\
\hline 216. & gadup & -23 & gaduy & & $d$ & green, blue \\
\hline 217. & Rapus & - & gafus & & $g, s$ & restrain \\
\hline 218. & ${ }^{*}$ Ratas & -23 & gatas & & $g, s$ & milk, add milk \\
\hline 219. & ${ }^{*}$ Ratas & ratah 3 & ratah (B) & $r, h$ & & human breast milk \\
\hline 220. & haRedan & - & gedan & & $g$ & ladder \\
\hline
\end{tabular}


221. Renaw

222. taqu

223. gilu

224. gisgis

225. bituqen

226. $k a$

227. kamu

228. $-k u$

229. guris

230. guyud

231. labu

232. labuq

233. laki

234. lapkaw

235. lasuq

236. layaR

237. lekas

238. lepas

239. Ia $(\mathrm{m})$ paw

240. letiq

241. liqi

242. libas

243. ligis

244. hadiRi

245. qali-matek

246. lima

247. linis

248. lapuy

249. lawas

250. lebey

251. luqnaw

252. minana

253. mata

254. muntay

255. naRa

256. natuq

257. ribu

258. nipis

259. niRu

260. naya

261. najam

262. nunuk

263. rasuk

264. danaw

265. randut

266. rantas

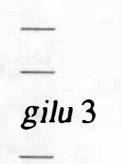

ga 13

gamu 23

$-k u 13$

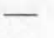

-

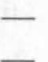

lagi 123
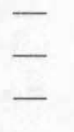

$-$$$
\text { - }
$$

lefew 3

letéq23

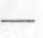

-

riri 3

matek 2

lima 123

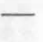

lawah 123

lebey 123

lunew 123

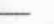

mata 123

nara 3
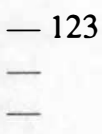

-

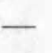

rahuk 3

$-123$
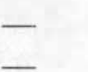

genaw (B)

ge-tu-on (B)

gilew

gisgis

gito?on (B)

go (B)

gom (B)

gu (B)

guris

guyud

labu?

labu?

lagey (B)

lankaw

lasu?(B)

layag

lekas

lefas

lefew

leté?

li? $i$

libos

ligis

liley

limatek

limo (B)

linis

loguy (B)

lowoh (B)

luag

lunew (B)

minana

moto (B)

muntey

nara

natu?

nibu

nifis (B)

nigu

nojo

norom

nunuk

rahuk

ranaw (B)

randut

rantas g, aw cold

$a>\emptyset \quad$ know

ew rheumatic pain

CC, $s \quad$ scrape

$V_{3}$ star

g

g

g

(u)

$s$

$d$

$b, u$

$b, u$

g, ey

you (sg.)

you (pl.)

I

line, stripe

drag, sled

gourd

drop anchor

man, male

CC, aw tall

$s, u \quad$ penis

$g \quad$ sail

$\boldsymbol{s} \quad$ undress

$s \quad$ pass by

surpass

thunderclap

taboo

$-i$

$b, s$

$s$

$-1-$, ey

$v_{3}$

fruit tree: Spondias sp.

heavy roller

house post ${ }^{8}$

leech

five

clean

swim

body

bury

green

$v_{3} \quad$ mouth of a river

eye

citrus fruit

tree: Pterocarpus sp.

u

egg yolk

$b, u \quad$ thousand

$s \quad$ thin (of materials)

$g, u \quad$ winnowing basket

k.o. rattan

tame, gentle

strangler fig

enter

$\begin{array}{ll}\text { aw } & \text { lake } \\ \mathrm{CC} & \text { uproot }\end{array}$

CC, $s \quad$ cut lashings

${ }^{8}$ With unexplained ${ }^{*} R>/ 1$. 


\begin{tabular}{|c|c|c|c|c|c|c|}
\hline 267. & Rantaw & - & rantaw & (r) & CC, aw & floating \\
\hline 268. & dasek & - & rasek & & $s$ & press against, crowd \\
\hline 269. & Ratus & ratuh 123 & ratuh (B) & $r, h$ & & hundred \\
\hline 70. & Rabun & rabun 123 & rawen $(\mathrm{B})$ & $r$ & & cloud \\
\hline 71. & dayuq & -23 & rayu?(B) & & $u$ & far \\
\hline 72. & lebuR & lebur 23 & rebur & $-r$ & $b, u$ & murky, roiled \\
\hline 73. & daRami & (ga)rami 23 & regamey & ey & (g) & rice straw \\
\hline 74. & deRes & - & $\operatorname{reges}(\mathrm{B})$ & & g, $s$ & flow swiftly \\
\hline 75. & liqeR & liqer 123 & ré?êr (B) & $\hat{e},-r$ & & neck \\
\hline 276. & qudipen & qerifen 123 & rifen & - & - & slave, servant \\
\hline 77. & depa & difa 23 & rifo & $i$ & & fathom \\
\hline 278. & Rusuk & rohok 123 & rohok $(\mathrm{B})$ & $r, h$ & & rib \\
\hline 79. & Rumaq & rumaq 123 & ruma? & $r$ & & house, sheath \\
\hline 280. & lujan & -23 & ruran & - & - & load, cargo \\
\hline 81. & luqaR & luqar 3 & ruar & $-r$ & & loose, spacious \\
\hline 82. & duha & rua 123 & nuo (B) & - & - & two \\
\hline 83. & ${ }^{*} s a b u R$ & - & sabug & & $b, g$ & sow, broadcast seed \\
\hline 84. & ${ }^{*} s a b u R$ & sabur 3 & sawer & $r$ & $s$ & sow, broadcast seed \\
\hline 85. & sakay & - & sakay & & $k$ & bowlegged \\
\hline 86. & saksak & - & saksak (B) & & $\mathrm{CC}$ & stab \\
\hline 287. & sagin & -123 & sagin & 一 & 一 & banana \\
\hline 288. & salaR & salar2 & salag & & $g$ & nest \\
\hline 289. & sampaw & - & samfaw & & CC, aw & waterfall \\
\hline 290. & $s a(n) d i R$ & - & sarig & & $g$ & lean on, trust \\
\hline 291. & sayaw & 一 & sayaw & & $a w$ & leap, dance \\
\hline 292. & sebu & - & sebaw & & $b$ & extinguish a fire \\
\hline 293. & sedaq & - & $\operatorname{sedo}^{?}(\mathrm{~B})$ & - & - & fish \\
\hline 294. & sanclaR & selar 23 & serar & $-r$ & & to fry \\
\hline 295. & siki & seki 3 & $\operatorname{sckey}(\mathrm{B})$ & ey & & leg \\
\hline 296. & sarapay & -23 & serafay & - & - & harpoon, trident \\
\hline 297. & siku & sigu 123 & sigew $(\mathrm{B})$ & g, ew & & elbow \\
\hline 298. & silaq & silaq 123 & $\operatorname{sila}^{?}(\mathrm{~B})$ & - & - & lightning \\
\hline 299. & suluq & soloq 23 & solo? & $o$ & & torch \\
\hline 300. & subaq & - & suba? & & $b$ & go upstream \\
\hline 301. & suksuk & - & suksuk & & $\mathrm{CC}$ & insert, wedge in \\
\hline 302. & sukub & - & sukub & & $k$ & portable fish trap \\
\hline 303. & suRuq & 一 & sugu? & & $g, u$ & command, messenger \\
\hline 304. & suliq & - & suli? & & $i$ & hit back \\
\hline 305. & supiq & supe? 3 & sujé? & é & & harelip \\
\hline 306. & suja & -23 & suro & 一 & 一 & pitfall spikes \\
\hline 307. & suqaR & suqar 123 & suar & $r$ & & thom \\
\hline 308. & sujud & -23 & surud & & $d$ & fine-toothed comb \\
\hline 309. & taban & - & taban & & $b$ & loot, bounty \\
\hline 310. & tabay & - & tabay & & $b$ & brackish \\
\hline 311. & ${ }^{*}$ tabay & - & tabay & & $b$ & help, assist \\
\hline 312. & *tabay & tabag 23 & towoI & $w$ & & help, assist \\
\hline 313. & ${ }^{*}$ tawaR & tabar23 & tabar & $r$ & & to call \\
\hline 314. & ${ }^{*} \operatorname{tawaR}$ & - & tawag & & $g$ & to call \\
\hline
\end{tabular}




\begin{tabular}{|c|c|c|c|c|c|}
\hline 315. tabas & - & tabas & & $b, s$ & cut, shape \\
\hline 316. $t a(m) b e j$ & - & tabed & & $b, d$ & wind around \\
\hline 317. taked & taked 123 & taked (B) & & $k, d$ & heel \\
\hline 318. ta( $(\eta) k e p$ & - & takef & & $k$ & catch, trap \\
\hline 319. takep & - & takef & & $k$ & fold double \\
\hline 320. *tapa & - & tafah & - & - & to dry meat \\
\hline 321. *tafa & - & tofo & 一 & - & dry over a fire \\
\hline 322. taRad & -23 & tagad & & $g$ & wait \\
\hline 323. takub & tagub 3 & tagub & $g$ & & cover, enclose \\
\hline 324. talaw & - & talaw & & aw & cowardly \\
\hline 325. talih & tali 13 & taley $(\mathrm{B})$ & ey & & rope, cordage \\
\hline 326. talun & - & talun (B) & - & - & fallow land, forest \\
\hline 327. taman & -23 & $\operatorname{taman}$ & - & - & until \\
\hline 328. tamben & - & tamben & & $\mathrm{CC}$ & block, stop up \\
\hline 329. tambis & - & tambis & & $\mathrm{CC}, s$ & fnuit tree \\
\hline 330. $\operatorname{tanaR}$ & $\operatorname{tanar} 3$ & tajar & $r$ & & elope \\
\hline 331. tapkis & - & tagkis & & $\mathrm{CC}, s$ & parry a blow \\
\hline 332. tajaw & tajew 3 & tanew & ew & & rice bug \\
\hline 333. tapkap & - & taggaf & & $\mathrm{CC}$ & receive, accept \\
\hline 334. tasik & - & tasik & & $s$ & saltwater, salty \\
\hline 335. tebuR & - & tebug & & $b, u, g$ & stagnant pool \\
\hline 336. tebus & - & tebus & & $b, s$ & ransom \\
\hline 337. teRep & - & tegef & & $g$ & tree like breadf ruit \\
\hline 338. taRa-qinep & - & tegine $f(\mathrm{~B})$ & & $\emptyset, g$ & dream \\
\hline 339. telu & telu 123 & telew (B) & ew & & three \\
\hline 340. tambuRi & - & temburi & $(r)$ & $\mathrm{CC}, i$ & conch shell trumpet \\
\hline 341. tikup & - & tikuf & & $k$ & encircle \\
\hline 342. timeRaq & - & timera & (r) & $v_{3}$ & lead (metal) \\
\hline 343. timus & - & timus (B) & & $s$ & salt \\
\hline 344. tindeg & - & tindeg (B) & & $\mathrm{CC}$ & stand \\
\hline 345. sigsin & tisin 23 & tisin & $t$ & & finger ring \\
\hline 346. taytay & - & titay & & ay & bridge \\
\hline 347. tuqu & taqu 23 & to?ow (B) & ow & & true \\
\hline 348. tuduq & toroq 23 & toro? & $o$ & & point at \\
\hline 349. tabeq & -13 & towo? $(\mathrm{B})$ & - & - & fat, grease \\
\hline 350. tebeg & -3 & tuon & - & - & to fell trees \\
\hline 351. tukud & - & tukud & & $k, d$ & prop, support \\
\hline 352. tukug & - & tukug & & $k$ & tailless (fowls) \\
\hline 353. tudaq & - & tuda? (B) & & $d$ & throw \\
\hline 354. tuRiq & - & tugi? & & $g, i$ & lie, falsehood \\
\hline 355. tumpuk & - & tumfuk & & $\mathrm{CC}$ & to pile \\
\hline 356. taneq & taneq 12 & tuna?(B) & & $u$ & earth, soil \\
\hline 357. tunas & tunah 3 & tunah & $h$ & & new sprout \\
\hline 358. tunaw & tupew 3 & tunow & ow & & biting mite \\
\hline 359. tuptup & - & tuptur & & $\mathrm{CC}$ & bamboo internode \\
\hline 360. tultul & -23 & tutul & - & - & story \\
\hline 361. tuaji & tuari 23 & tuarey $(\mathrm{B})$ & ey & & younger sibling \\
\hline 362. walu & walu 123 & walew & ew & & eight \\
\hline
\end{tabular}




$\begin{array}{lllllll}\text { 363. } & \text { qabaRa } & \text { (qe)bara 3 } & \text { wara(B) } & r & & \text { shoulder } \\ \text { 364. beReq } & \text { bareq 3 } & \text { wara? } & r & & \text { abscess } \\ \text { 365. baRiw } & \text { bari } 23 & \text { warey } & r \text {, ey } & & \text { stale, tainted } \\ \text { 366. wahiR } & \text { é?ér } 12 & \text { wayeg(B) } & & \mathrm{g} & \text { water } \\ \text { 367. abaka } & \text { baga 3 } & \text { wogo } & \mathrm{g} & & \text { hemp }\end{array}$

\section{APPENDIX 2: Possible sources of Tiruray loans}

The following sources of proposed Austronesian loanwords in Tiruray can be suggested. SU = source unknown.

1. TIR abas 'measles': MAG abas 'measles', MAR abas 'chicken pox';

2. TIR abay 'side-by-side': MAR abay 'go by the side, alongside';

3. TIR akaw?akaw 'stilts': SU;

4. TIR akuf 'the contents of one's two cupped hands': MAR akup 'scoop with both hands';

5. TIR ambaw 'the common field rat': probably a Manobo loan (cf. e.g. Kalagan, Sarangani Manobo ambaw 'rat');

6. TIR amfun 'an expression asking indulgence for something about to be said': MAG ampun 'pardon';

7. TIR ansed 'underarm perspiration odour': MAR ansed 'offensive body odour';

8. TIR arimaw 'lion': MAG arimaw 'tiger', MAR arimaw 'lion';

9. TIR arud 'shave flat a length of split rattan': SU;

10. TIR asag 'gills of a fish': MAG, MAR asag 'gills';

11. TIR asek 'press down, compact the contents of a container or hole': MAG asek 'tamp down earth, compress the contents of a sack to make room for more', MAR asek 'press';

12. TIR atis ‘sweetsop: Annona squamosa L.': MAR atis 'sugar apple: Annona squamosa L.';

13. TIR egas 'a slab of hard salt; the hard interior of the trunks or large branches of certain hardwood trees': MAG gas 'heartwood', MAR gas 'hard part of log';

14. TIR tegas 'hard, obdurate': MAG tegas 'strong, hard', MAR tegas 'harden, solidify; salt obtained from boiling and evaporation; white-grained hard wood';

15. TIR eget 'holding something tightly': MAR get 'lose breath, choke out breath' (?);

16. TIR ibeg 'saliva': SU;

17. TIR ikam 'mat': MAG ikam 'mat';

18. TIR iket 'to tie': MAG iket 'rope, lashings', iket-an, MAR iket 'to tie';

19. TIR ifes 'cockroach': MAG ipes 'rachitic animal' (= cockroach?);

20. TIR itu?'dog': SU;

21. TIR ubi 'sweet potato': MAG, MAR ubi 'sweet potato';

22. TIR ukof 'rice chaff': MAG, MAR ukap 'chaff';

23. TIR ufaw 'bald head': MAG, MAR upaw 'bald head'; 
24. TIR ulig 'a bunch'; MAG, MAR ulig 'bunch, as of bananas';

25. TIR babuy 'domestic pig': MAR beboy 'pig' (?) (probably from a non-Danaw, nonMoslem source);

26. TIR bakaw 'mangrove': MAG, MAR bakaw 'mangrove';

27. TIR bakul 'small basket used by saltwater fishermen to store their line and hook': SU;

28. TIR badak 'jackfruit': MAG badak 'jackfruit';

29. TIR badug 'an all-purpose bolo': MAR baruy 'bolo, machete' (?) (possibly borrowed before ${ }^{*}-d->/ r /$, or from a non-Danaw source);

30. TIR baga?'lung': MAG, MAR baga?'lung';

31. TIR bantay 'a guard': MAG bantay, MAR banta-bantay 'watchman, guard';

32. TIR bankay 'corpse': MAG, MAR bajkay 'corpse';

33. TIR bayad 'payment; to pay': MAG bayad 'debt', MAR bayad 'pay, payment, debt';

34. TIR bayug 'a tree: Pterospermum divorsifolium BIm.': SU;

35. TIR benkas 'split, tear something along the seam': MAR begkas 'untie, undo; break an agreement';

36. TIR begas 'polished, uncooked rice': MAG begas 'rice', MAR begas 'cooked rice';

37. TIR begat 'weight', em-begat 'heavy': SU (possibly from a Manobo language);

38. TIR bibit 'carry by hand': MAG bibit-en 'take with the hands', MAR bibit 'carry in the hand';

39. TIR bisa 'poisonous; poison': MAG, MAR bisa 'poison, venom';

40. TIR bisu 'temporary impairment of hearing': MAG, MAR bisu 'deaf';

41. TIR biag 'kidnap, enslave': MAG, MAR biag 'abduct, kidnap';

42. TIR bubuk 'road dust; toasted and pounded corn kernels': MAR bubuk 'face powder; wood weevil' (?);

43. TIR bubul 'body hair, feathers': MAR bulbul, bumbul 'feathers, fur, hair' (?);

44. TIR buka? 'wide or (when speaking of a piece of land) large': SU;

45. TIR bukay 'white': SU;

46. TIR bukal 'bone': SU;

47. TIR budi? 'unfertilised fish eggs': MAR budi?'egg of fish';

48. TIR bulog 'a white opaque growth near the pupil of the eye': MAR bulag 'cataract of the eye';

49. TIR buntud 'mound, termite mound': SU;

50. TIR butiti 'globefish: Tetradon lunaris BI.': MAR butiti 'fish with air-filled entrails';

51. TIR kabeg 'giant fruit-bat: Pteropus vampyrus lenensis Mearns': MAG, MAR kabeg 'bat';

52. TIR kabig 'the extent (geographical or social) of a leader's following, jurisdiction or authority': Tagalog kábig 'vassal, subject, follower';

53. TIR kagaj 'type of edible crab, found in swamps': Cebuano kágag 'kind of small crab of muddy areas near the shore' (?); 
54. TIR karabaw 'carabao, water buffalo': MAG, MAR karabaw 'carabao, water buffalo’;

55. TIR karus 'to claw, to scratch with fingernails or claws': MAG, MAR karus 'to scratch';

56. TIR kefis ('of animals or persons only) stunted in growth, dwarfed': SU;

57. TIR keludan 'deep water or open sea': MAR kalodan 'ocean, sea, lake';

58. TIR kolud 'go toward deeper water, toward open sea': MAR kalod 'offshore, far our at sea' (in both this and the preceding example the Tiruray word exhibits the distinctive Danaw reduction of *-au- to $/ \mathrm{u} /)$;

59. TIR kemi 'suckerfish, remora': SU;

60. TIR kerud 'a lenticular iron scraper for shredding coconut meat': MAR kerud 'scrape (as a coconut)';

61. TIR ketas 'cut something with a knife': SU;

62. TIR keti 'low tide': SU: MAG keti 'flacid, feeble, languid' undoubtedly is cognate but differs substantially in meaning;

63. TIR kifes 'shrink': MAG, MAR kipes 'shrink';

64. TIR kilay 'eyebrow': MAG kilay 'eyebrow';

65. TIR kondor 'a common gourd: Lagenaria leucantha (Duch.) Rusby': SU;

66. TIR kurafu 'large saltwater fish: Epinephelus sp.': MAG kulapu 'immature growth stage of the carp' (?) (if from Magindanao the Tiruray form must have been borrowed before the change $\left.{ }^{*} r>/ 1 /\right)$;

67. TIR kuray '(or wood) a prominent, visible grain': MAR kuray 'whorl of grains of wood';

68. TIR kurita? 'octopus': MAR kurita? 'octopus, cuttlefish, squid' (ultimately from Malay);

69. TIR dakel 'big': SU;

70. TIR degu 'the rumbling of distant thunder, etc.': MAG degu 'groan, moan', MAR degu 'grunt';

71. TIR regu 'snore': MAR regu 'groan';

72. TIR dogot 'a body of saltwater, an ocean': MAG dagat, ragat, MAR ragat 'sea, ocean';

73. TIR fagi 'a ray fish': MAG, MAR pagi 'stingray';

74. TIR fali?' a wound': MAG, MAR pali?'wound, cut';

75. TIR fantaw 'sleeping attic': MAR pantaw 'porch, balcony' (?);

76. TIR fantay 'level': Tagalog pantáy 'of the same height or level';

77. TIR fasak 'a stake driven into the ground for the purpose of tying an animal': MAG pasek 'wedge, quoin', MAR pasek 'post, pillar';

78. TIR feku' 'to bend': MAG, MAR peku?' bent, bend';

79. TIR femili? 'select, choose': MAR pili?, pamimili? 'choose';

80. TIR fenakaw 'to steal': SU;

81. TIR fejayaw 'to invade, attack another tribe or country': MAR pajayaw 'engage in piracy'; 
82. TIR fukas 'to release from debt or hardship; to release an animal from the yoke': MAG, MAR pukas 'free, give up, disjoin, disengage';

83. TIR fused 'umbilical cord, navel': MAG, MAR pused 'navel';

84. TIR fusu? 'banana blossom': MAR pusu? 'banana flower';

85. TIR futus 'a woman's hair knot, worn at the back of the head': SU, probably from a Manobo language (cf. Western Bukidnon Manobo putus 'woman's hair knot, worn at the back of head');

86. TIR fuikon 'large marine turtle': MAG pawikan 'sea turtle', MAR pawikan 'giant turtle';

87. TIR fuyufuyu 'a climbing perch': SU;

88. TIR gakit 'tie together objects floating in the water': MAR gakit 'string together boats for wedding, make a raft';

89. TIR gadu 'blue': MAG, MAR gaduy 'green' (?);

90. TIR gafus 'to physically restrain some person from some action, usually violent': MAG gapus 'restrain, check the motion or progress of', MAR gapus 'stop or restrict movement of angry person';

91. TIR gatas 'milk; add milk to something': MAG, MAR gatas 'milk';

92. TIR gedan 'ladder': SU;

93. TIR genaw 'cold': SU (possibly from a Manobo language: cf. Western Bukidnon Manobo genew, Sarangani Manobo genaw 'cold');

94. TIR getuon 'knowing something': MAG katawan 'know', MAR katawan 'known, recognised; know';

95. TIR gisgis 'to scratch or scrape something': MAG gigis 'scrape' (?) (if from Magindanao this item must have been borrowed prior to the reduction of medial clusters in reduplicated monosyllables);

96. TIR gito?on 'star': SU;

97. TIR guris 'a stripe': MAG guris, kuris 'stroke, line, dash';

98. TIR guyud 'a sled': MAG guyud 'drag along the ground', MAR guyud 'pull, transport by sled or cart';

99. TIR labu? 'the common gourd, Lagenaria leucantha (Duch.) Rusby': MAG labu? 'white calabash';

100. TIR labu? 'drop anchor': MAR labu? 'anchor' (MAG labuh 'anchor a boat' appears itself to be a loan from Malay);

101. TIR laykaw 'tall': SU;

102. TIR lasu?'(taboo) the penis': SU;

103. TIR layag 'a sail; to sail': MAG, MAR layag 'sail' (the Magindanao variant layar is evidently itself a loan from Malay);

104. TIR lekas 'change clothes, undress': MAR lekas 'undress';

105. TIR lefas 'pass by, go beyond a certain place': MAR lepas 'pass by';

106. TIR $l i$ ? $i$ 'a proscribed food': MAR $l i$ ? i 'taboo';

107. TIR libos 'a tree bearing edible fruit: Spondias purpurea Linn.': SU; 
108. TIR ligis 'a heavy roller, made of a log and pulled by a work animal': MAR ligis 'trample, run over', ligis-a ' 'crusher, grinder' (?);

109. TIR limatek 'leech': MAG, MAR limatek 'leech';

110. TIR linis 'to clean': Tagalog línis 'cleanliness', mag-línis 'to clean';

111. TIR lonuy 'to swim': MAG, MAR lanuy 'to swim';

112. TIR minaya 'mouth of a river': MAG, MAR minana 'outlet, mouth of river or stream';

113. TIR muntey 'a kabuyau: Citrus hystrix DC': MAG muntay 'lemon';

114. TIR natu?'egg yolk': SU;

115. TIR nibu 'thousand': MAG gu-ibu 'thousand' (?);

116. TIR nifis 'thin, as paper': MAG, MAR nipis 'thin, flat';

117. TIR nigu 'woven winnowing tray': MAG, MAR nigu 'winnowing tray';

118. TIR ranaw 'lake': MAG, MAR ranaw, lanaw 'lake';

119. TIR randut 'uproot, pull out': SU;

120. TIR rantas 'cut away wrapped lashings': MAR rantas 'cut';

121. TIR rantaw 'floating': SU;

122. TIR rasek 'to press against, to crowd': MAR dasek 'press' (borrowed as dasek, with subsequent change ${ }^{*} d->/ \mathrm{r} /$ ?);

123. TIR rayu? 'far, distant': SU;

124. TIR reges '(of water) flowing swif tly with a strong current': MAG, MAR reges 'water current';

125. TIR sabug 'to sow rice seed by broadcasting': SU;

126. TIR sakag 'bow-legged': Tagalog sakán 'bow-legged';

127. TIR saksak 'pierce, stab': MAR saksak 'tear, split, cut into small pieces' (?);

128. TIR salag 'nest': MAG, MAR salag 'nest';

129. TIR samfaw 'waterfall': MAG sampaw 'waterfall';

130. TIR sarig 'depend upon someone, put confidence in someone': MAR sarig 'trust, depend on';

131. TIR sayaw 'jump over something': MAR sayaw 'jump, dance, leap';

132. TIR sebaw 'put something hot into water so that it sizzles, or to put water in a fire': MAR sebu 'sudden change from hot to cold temperature, temper metal, sizzle, boil' (?);

133. TIR suba?'go upstream': MAG suba?'ascend a river', MAR suba?'follow course of river';

134. TIR suksuk 'lodge an object by inserting it in a place where it will be held securely': MAR suksuk 'wedge in, put in between';

135. TIR sukub 'type of mudfish trap': MAR sukub 'movable trap for mudfish';

136. TIR sugu' 'a messenger; to send a messenger': MAG, MAR sugu?'command, order';

137. TIR suli? 'to return 'tit for tat': MAG suli? 'take revenge', MAR suli? 'hit back';

138. TIR surud 'a fine-toothed comb': MAG, MAR surud 'comb'; 
139. TIR taban 'spoils or winnings; to win in fighting or betting': MAG, MAR taban 'win, winnings; beat';

140. TIR tabay '(of water) tasting slightly salty': MAR tabay a ig 'fresh water';

141. TIR tabay 'physical or material assistance rendered': MAG, MAR tabaj 'help, aid, support';

142. TIR tabas 'the scraps cut off when a piece of cloth is trimmed': MAR tabas 'cut with scissors';

143. TIR tabed 'wind something around something else': SU;

144. TIR taked 'heel': SU;

145. TIR takef 'kind of eel trap': MAR takep-an 'trap for eel';

146. TIR takef 'to double something, to make it twice as much': MAG takep 'double the price of merchandise', MAR takep 'double, multiply';

147. TIR tagad 'pause briefly in one's activity, wait': SU;

148. TIR talaw 'cowardly, af raid to fight': MAG, MAR talaw 'coward';

149. TIR tambeg 'stop a small flow of water by setting an impediment': SU;

150. TIR tambis 'a tree: Eugenia aquea Burm. f.': MAR tambis 'tree with pink fruit: Syzygium Samarangense /Blm./ Merr. and Perry';

151. TIR tankis 'to parry, to turn something aside': MAG, MAR tankis 'parry, turn aside';

152. TIR tangaf 'receive, accept': MAR tankap 'accept';

153. TIR tasik 'salty': MAG tasik 'water that is filtered through cinders in making salt';

154. TIR tawag 'to call': MAG, MAR tawag 'call, summon';

155. TIR tebug 'a stagnant pool of water; to make a pool to hold water': SU;

156. TIR tebus 'to bargain for a charm with one who has the desired charm or knowledge; always requires some offering in return': MAG tebus 'ransom, redeem';

157. TIR tegef 'tree bearing edible fruit: Artocarpus elastica Reinw.': Western Bukidnon Manobo tegep 'the sap of this tree, Artocarpus elastica, is used for birdlime; the fruit, similar to breadfruit, is cooked and eaten'. This item is not reported for either Magindanao or Maranao. It may be a Manobo loan, but the choice of Western Bukidnon Manobo as a source is dictated solely by the fact that more information is available for this language than for other Manobo languages.

158. TIR teginef 'dream': MAR taginep 'dream';

159. TIR temburi 'shell trumpet': SU;

160. TIR tikuf 'encircle': MAR tikup 'surround, encircle';

161. TIR timera 'lead (metal)': SU;

162. TIR timus 'salt; add salt to food': MAG, MAR timus 'salt';

163. TIR tindeg 'to stand': MAG tindeg 'stand, rise', MAR tindeg 'to stand';

164. TIR titay 'bridge': MAG, MAR titay 'bridge';

165. TIR tukud 'a vertical support, a prop; to support by tukud': MAG, MAR tukud 'post, support';

166. TIR tukug '(of birds) tailless': MAG tukug 'tailless (bird)'; 
167. TIR tuda? 'to throw': SU;

168. TIR tugi?' a lie, a false promise': SU;

169. TIR tumfik 'to pile': SU (possibly from Tagalog tumpók 'heap, pile');

170. TIR tuna? 'earth, ground, soil; to wallow': MAR tuna? 'wallow in mud; watery mud';

171. TIR tuytuy 'an intemode of bamboo used as a container': SU;

172. TIR wayeg 'water': SU (probably a Manobo loan: cf. Kalamansig Cotabato Manobo wayig 'water').

\section{REFERENCES}

ABRAMS, Norman, 1963, Historical development of Bilaan vowels and some consonant reflexes in Bilaan and related dialects. The Philippine Sociological Review 11:147-154.

ALliSON, E. Joe, 1979, Proto-Danao: a comparative study of Maranao, Maguindanao, and Iranon. Papers in Philippine linguistics, No.10, 53-112. PL, A-55.

BIGGS, Bruce, 1980, Direct and indirect inheritance in Rotuman. Lingua 14:383-415.

BLUST, Robert, 1980, Austronesian etymologies. Oceanic Linguistics 19:1-181.

1981, Variation in retention rate among Austronesian languages. Paper presented at the Third International Conference on Austronesian Linguistics, Denpasar, Bali, January, 1981.

1984a, Austronesian etymologies - II. Oceanic Linguistics 22-23:29-149.

1984b, On the history of the Rejang vowels and diphthongs. Bijdragen tot de Taal-, Land-en Volkenkunde 140:422-450.

1987, Rennell-Bellona /1/and the "Hiti' substratum. In Donald C. Laycock and Werner Winter, eds $A$ world of language: papers presented to Professor S.A. Wurm on his 65th birthday, 69-79. PL, C-100.

1988, Austonesian root theory: an essay on the limits of morphology. Amsterdam: John Benjamins.

CHARLES, Mathew, 1974, Problems in the reconstruction of Proto-Philippine phonology and the subgrouping of the Philippine languages. Papers of the First International Conference on Comparative Austronesian Linguistics, 1974-Proto-Austronesian and Western Austronesian. Oceanic Linguistics 13:457-509.

CONANT, Carlos Everett, 1908, ' $\mathrm{f}$ ' and ' $\mathrm{v}$ ' in Philippine languages. Bureau of Science, Division of Ethnology Publications 5/5, Part 3:135-141. [Reprinted in Gonzalez, Llamzon and Otanes 1973:213219.]

1913, Notes on the phonology of the Tirurai language. JAOS 33/1:150-157.

CONKLIN, Harold C., 1955, Preliminary linguistic survey of Mindanao. University of Chicago, Philippine Studies Program (mimeographed).

DEAN, James and Gladys DEAN, 1955, The phonemes of Bilaan. The Philippine Journal of Science 84:311-322.

DEMPWOLFF, Otto, 1922, Entstehung von Nasalen und Nasalverbindungen im Ngaju (Dajak). Zeitschrift für Eingeborenen-Sprachen 13:161-205.

1934-1938, Vergleichende Lautlehre des austroncsischen Wortschatzes. I. Induktiver Aufbau einer indonesischen Ursprache, Supplement 15 (1934), 2. Deduktive Anwendung des Urindonesischen auf austronesische Einzelsprachen, Supplement 17 (1937), 3. Austronesisches Wörtcrverzeichnis, Supplement 19 (1938). Zeitschrift für Eingeborenen-Sprachen. Bcrlin: Dietrich Reimer.

DYEN, Isidore, 1953, The Proto-Malayo-Polynesian laryngeals. Baltimore: Linguistic Society of America.

1956, The Ngaju-Dayak 'Old Speech Stratum'. Language 32:83-87.

FALCASANTOS, Luz Arce, 1967, The philosophy of life of the Bagobos as reflected in the "Tuwaang" (a fragment epic cycle). MA thesis, University of Santo Tomas.

FORSBERG, Vivian and Alice LINDQUIST, 1955, Tagabili vocabulary. Manila: Summer Institute of Linguistics; Bureau of Public Schools; Institute of National Language. 
GISBERT, Mateo, 1892, Diccionario Bagobo-Español, Español-Bagobo. Manila.

GONZALES, Andrew B., Teodoro LLAMZON and Fe OTANES, eds 1973, Readings in Philippine linguistics. Manila: Linguistic Society of the Philippines.

GRIMES, Barbara F., ed., 1978, Ethnologue. 9th edition. Huntington Beach, California: Wycliffe Bible Translators.

JUANMARTI, Jacinto, 1892, Diccionario Moro-Maguindanao-Español y diccionario Español-MoroMaguindanao. Manila.

LEBAR, Frank M., 1975, “Magindanao". In Lebar, ed. 1975:35-36.

LEBAR, Frank M., ed., 1975, Ethnic groups of insular Southeast Asia, vol.2: Philippines and Formosa. New Haven: Human Relations Area Files Press.

LINDQUIST, Alice, Vivian FORSBERG and Alan HEALEY, 1959, The phonemes of Tagabili. The Philippine Journal of Science 88/1:225-243.

McFARLAND, Curtis D., 1980, A linguistic allas of the Philippines. Study of Languages of Asia and Af rica monograph series no.15. Tokyo: Institute for the Study of Languages and Cultures of Asia and Africa.

McKaUghaN, Howard P. and Batua A. MACARAYA, 1967, A Maranao dictionary. Honolulu: University of Hawaii Press.

MONTANO, Joseph, 1885, Rapport à M. le Ministre de l'Instruction Publique sur une mission aux Philippines. Archives des Missions Scientifiques et Littéraires. Troisième Série, 11:271-479. Paris: Imprimerie Nationale.

MOORE, Grace Wood, 1975, Tiruray. In Lebar, ed. 1975:41-45.

PALLESEN, A. Kemp, 1985, Culture contact and language convergence. Manila: Linguistic Society of the Philippines.

POST, Ursula R., 1966, The phonology of Tiruray. The Philippine Journal of Science 95:563-575.

RAY, Sidney H., 1913, The languages of Borneo. The Sarawak Museum Journal 1/4:1-196.

REHG, Kenneth L. and Byron W. BENDER, 1988, Lexical transfer from Marshallese to Mokilese: a study in intra-Micronesian borrowing. Paper presented at the Fifth International Conference on Austronesian Linguistics, Auckland, New Zealand, January 11-16, 1988.

REID, Lawrence A., 1973, Kankanay and the problem *R and ${ }^{* 1}$ reflexes. In Andrew B. Gonzalez, ed. Parangal kay Cecilio Lopez: essays in honor of Cecilio Lopez on his seventh-fifth birthday, 51-63. Quezon City: Linguistic Society of the Philippines.

1982, The demise of Proto-Philippines. In Amran Halim, Lois Carrington and S.A. Wurm, eds Papers from the Third International Conference on Austronesian Linguistics, vol.2, 201-216. PL, C-75.

REID, Lawrence, A., ed., 1971, Philippine minor languages: word lists and phonologies. Oceanic Linguistics special publication No.8. Honolulu: University of Hawaii Press.

SAVAGE, T. Dale, 1986, A reconstruction of Proto-Southern Mindanaon. Studies in Philippine Linguistics 6/2:181-223.

SCHADENBERG, Alexander, 1885, Die Bewohner von Süd-Mindanao und der Insel Samal. Zeitschrift für Ethnologie 17:8-37, 45-57.

SCHLEGEL, Stuart A., 1971, Tiruray-English lexicon. University of California Publications in Linguistics, No.67. Berkeley.

THOMAS, David and Alan HEALEY, 1962, Some Philippine language subgroupings: a lexicostatistical study. Anthropological Linguistics 4/9:21-33.

WALTON, Charles, 1979, A Philippine language tree. Anthropological Linguistics 21:70-98.

WANG, William S- Y., 1969, Compcting changes as a cause of residue. Language 45:9-25.

ZORC, R. David, 1971, Proto-Philippine finder list. Typescript.

1982, Where, O where, have the laryngeals gone? Austronesian laryngeals re-examined. In Amran Halim, Lois Carrington and S.A. Wurm, eds Papers from the Third International Conference on Austronesian Linguistics, vol.2, 111-144. PL, C-75.

1986, The genetic relationships of Philippine languages. In Paul Geraghty, Lois Carrington and S.A. Wurm, eds FOCAL II: papers from the Fif th International Conference on Austronesian Linguistics, vol.2, 147-173. PL, C-94. 


\title{
ON THE ORDER OF NOUNS AND MODIFIERS IN LITERARY CEBUANO
}

\author{
SARAH BELL
}

\section{INTRODUCTION}

Wolff (1965:220-221) notes that in Cebuano noun phrases, two constituents $\mathrm{X}$ and $\mathrm{Y}$ linked by $n g a^{1}$ can occur in either order, $X$ nga $Y$ or $Y n g a X$, save that $X$ must come first if $\mathrm{X}$ is a demonstrative or an independent genitive, or if $\mathrm{X}$ is an adjective and $\mathrm{Y}$ is a verbal phrase. In this paper, I examine the conditions under which one order or the other is found.

Because of differences in their distribution, adjectives, with their modifiers and complements, and non-adjectival relative clauses are treated separately. I classify as a nonadjectival relative clause any constituent linked to a noun by nga and containing a base with verbal affixes, verb- or clause-modif ying adverbs (including na 'already', pa 'still, yet' and attitudinal particles such as unta 'hopefully') or the existential marker $y .{ }^{2}$

In this study, I have taken as my primary source of data three stories published in the Bisaya magazine:

\section{SK: 'Mga Salingsing sa Kaaghop' (The Offshoots of Kindness) by Mariano F. Manus, ACMDC, Lutopan, Toledo City (25 Oct. 1978) \\ LDP: 'Ang Limos Dili alang sa Patay' (Alms are not for the Dead) by Ruben B. Legorio, 088-A Quezon Avenue, Dipolog City (8 Nov. 1978)}

\footnotetext{
${ }^{1}$ I follow the customary Cebuano orthography. Stress and word-final glottal stops, although phonemic, are not indicated. A sequence of two vowels represents vowels separated by a glottal stop. A sequence of consonant, hyphen, and vowel represents a consonant, glottal stop and vowel. $O$ and $u$ are not phonemically distinct, and neither are $i$ and $e$. The combination $n g$ represents a velar nasal, not a sequence of $n$ and $g$.

I use the following abbreviations: ACC - accusative case, ACT - active voice, CAUS - causative marker, EXC - exclusive, GEN - genitive case, INC - inclusive, INS - instrumental voice, LN linker, NLN number linker, NOM - nominative case, OBJ - objective voice, OBL - oblique case, REF - referential voice. If several English words are used to gloss a single Cebuano morpheme, they are connected by full stops. Glosses of successive morphemes in a word are connected by hyphens.

${ }^{2}$ It is quite posssible that adjective modifiers and clausal modifiers are different surface realisations of similar underlying structures or are different allo-forms of the same form. It is because of differences in their predominant order that I treat them separately.
}

There are a few cases whose correct categorisation is unclear. For example, in

$\begin{array}{llll}\text { ang walay } & \text { kasingkasing nga magtiayon (SK) } \\ \text { NOM not.existential hean } & \text { LN couple }\end{array}$

the heartless couple (i.e. the couple that had no heart)

does walay kasingkasing retain the clausal structure clearly indicated by wala+y+noun phrase, or has it fused into a single adjective? 
HAK: 'Hulata ako sa Kalagkalag' (Wait for me on All Souls' Day) by Rolando P. Rosell, Philippine Port Authority, Butuan City (15 Nov. 1978)

Occurrences of modified noun phrases in the ten readings in Wolff (1967) are also taken into account.

Sections 2 and 3 deal with noun phrases containing adjectives. I argue in section 2 that the noun, not the first constituent, is the head in a modified noun phrase. In section 3 the order of nouns and adjectives is examined. The predominant order is found to be with the adjectives before the noun. Four conditions favouring postnominal position of the adjective are identified.

The order of noun and non-adjectival relative clauses is discussed in section 4 . The predominant order is with the relative clause following the noun. Restrictions on the use of prenominal position for relative clauses are given.

Finally, in section 5, the results of this study are compared with Schachter and Otanes' (1972:118-119) observations about the order of nouns and modifiers in Tagalog.

\section{DETERMINING THE HEAD OF NOUN PHRASES}

In Cebuano, as in other Philippine languages, an adjective may precede or follow the noun in a noun phrase. ${ }^{3}$

(1) a. ug blangko nga mga papel

ACC blank LN PL paper

blank papers

b. sa papel nga blangko

ACC paper LN blank

the blank papers

It would seem uncontentious to claim that the head of a noun phrase consisting of a noun and an adjective is the noun. Such an analysis is required by theories which project the category of a phrase from the category of the head, and this is indeed the analysis proposed for Tagalog by Schachter and Otanes (1972:118-131).

However, another analysis has also been proposed for noun phrases in Philippine languages. In his study of Ivatan, Reid (1966:95-96) analyses whichever element comes first as the head, with the linker plus the second element as an exocentric, relator-axis modifying phrase. If his analysis were transferred to Cebuano, blangko 'blank' would be the head of (1a) and the example would more accurately be glossed as 'some blank things that are papers', while papel 'paper' would be the head of ( $1 \mathrm{~b})$.

It therefore becomes necessary to determine which element is the head in modified noun phrases in Cebuano. It is possible to argue from noun phrases containing adjectives denoting polar opposites, to use Leech's (1974:108-110) term, and from identity of sense

\footnotetext{
${ }^{3}$ It should be noted that Wolff $(1965: 60-61,65-66)$ provides frames for distinguishing nouns and adjectives. Of course, as in other languages, a word may belong to several word classes. Bata, for example, is a noun meaning 'child' as well as an adjective meaning 'young'. Also, adjectives may sometimes be used as substantives.
} 
anaphora that the noun is the head in Cebuano noun phrases containing modifiers, no matter whether the noun or the modifier comes first.

\subsection{ARGUMENT BASED ON POLAR OPPOSITES}

In Cebuano, there are examples of $\mathrm{A}+\mathrm{N}$ and $\mathrm{N}+\mathrm{A}$ sequences in which the noun cannot be taken to modify the adjective. These examples involve adjectives which denote members of polar oppositions. Polar opposites express contrasts along a scale between extremes. As Leech (1974:109) puts it, "This middle ground implies the existence of a norm - and it is important to observe that the norm is object-related - that is, it can shift its position on the scale according to the object being categorized". As has been pointed out since the time of Aristotle, the fact that the norm is object-related accounts for the fact that while one can conclude from "This is a grey elephant" that "This is a grey animal", one cannot conclude from "This is a small elephant" that "This is a small animal".

Like other languages, Cebuano has pairs of adjectives which express polar oppositions. Taas 'tall' and mubo 'short' are such a pair. Taas and mubo can be used to describe trees and flagpoles, buildings, people, tables and noses, among other things. It can be shown that because of the shifting norm, taas cannot be taken to be the head of either of the two noun phrases below, which occur in a paragraph about looking for a small table: 4

(2) a. daghang taas nga mga lamisa many.LN tall LN PL table many tall tables

b. ang mga lamisa nga taas

NOM PL table LN tall the tall tables

Suppose first that taas is the head and that it is used substantively. Then the sense of the phrase would be 'a tall thing that is a table', but tables, even tall tables, are not tall in a world which includes trees, buildings and flagpoles. If taas is the head, then, it is not being used substantively.

Suppose next that taas is the head and lamisa is the modifier specifying, say, the manner, respect or extent to which taas can be applied to an object. Then taas is being used to refer to something, not necessarily a table, which is 'tall as a table' or 'tall for a table'. The fact is, however, that the noun phrases in (2) are used to refer to tables and nothing else.

The set of objects determining the norm for the polar adjective is stated by the noun, and no interpretation with the adjective as head makes sense. The noun, then, is the head whether it precedes or follows the adjective.

\subsection{ARGUMENT FROM IDENTITY OF SENSE ANAPHORA}

The same conclusion follows from semantic and syntactic observations regarding identity of sense anaphora.

\footnotetext{
4Judgments of grammaticality of those examples which are not quoted from the stories come from various Cebuano speakers: Roberto Bantilan, Leonardo Tiro, Jr and Mrs Nora Bawasanta, all from northem Mindanao, and Jessica Sanson from Cebu. I would like to thank all these people for their patience and help.
} 
When a speaker has referred to one member of a class denoted by a noun or noun plus modifiers, he may want to refer to another member of the same class, another individual to which the noun, or noun and modifier, can be applied. Some languages use ellipsis or some pro-form so that the designation of the class does not have to be repeated. In English, one is used, as in (3).

(3) I have a red wool jacket, and Ingrid has a black one.

In (3), one is replacing either 'wool jacket' or simply 'jacket', that is, it is replacing the head, possibly with a modifier. ${ }^{5}$

In Cebuano, identity of sense is shown by ellipsis, as in (4).

$\begin{array}{lllllll}\text { Gibasa } & k 0 & \text { ang } & \text { nobela } & \text { ni } & \text { Bok } & \text { ug gibasa usab } \\ \text { OBJ.read } & \text { 1SG.GEN NOM novel } & \text { GEN } & \text { Bok and OBJ.read also }\end{array}$

\section{ni Tomas ang kang Hermosisima.}

GEN Tomas NOM OBL Hermosisima

I read Bok's novel and Tomas read Hermosisima's.

In the last noun phrase, ang kang Hermosisima, a noun is missing between the two case markers, ang and kang. The missing noun is nobela, which I assume no one would deny is the head of ang nobela ni Bok. As in English, then, the reduced noun in the second occurrence corresponds to the head of the first occurrence.

Now in Cebuano, when the adjective is omitted its sense is not carried over into the following noun phrase, whether the adjective precedes or follows the noun. For example, in neither of the sentences in (5) is there any implication that the skirt is red.

(5) a. Nagpaguhit si Perla ug pulang sinina ug nagpaguhit ACT.C.sew NOM Perla ACC red.LN dress and ACT.C.sew ako usab ug saya. 1SG.NOM too ACC skirt

Perla had a red dress made, and I had a skirt made.

b. Sa duha ka adlaw nga milabay, nahuman na ang OBL two NLN day LN ACT.pass OBJ.finish already NOM sinina nga pula, pero wala pa mahuman ang saya. dress LN red but not yet OBJ.finish NOM skirt In two days, the red dress had been finished, but the skirt was not yet finished.

On the other hand, when the noun is omitted, its sense is determined from the noun in the preceding noun phrase, whether the noun or the adjective comes first. Thus, mubo 'short' is understood as referring to a table in both sentences in (6).

(6) a. Sa tindahan, adunay daghang taas nga mga

OBL store there.existential many.LN tall LN PL

lamisa apan usa lamang ang mubo.

table but one only NOM short

In the store, there were many tall tables, but just one short one.

\footnotetext{
${ }^{5}$ The fact that a place-holding dummy like one can be the head of a noun phrase shows clearly that heads cannot be identified with whatever has the greatest communicative value.
} 
b. Ang mga lamisa nga taas maayong gitukod, pero ang

NOM PL table LN tall good.LN OBJ.make but NOM

mubo haguka.

short poorly.made

The tall tables were well made, but the short one was poorly made.

In (4) we saw that it is the element corresponding to the head of the first noun phrase which is omitted in identity of sense anaphora. From (5) and (6) we see that the omitted element is lamisa, which corresponds to the noun of the first noun phrase. It follows that the noun lamisa, not the adjective taas, is the head of the first noun phrase, no matter whether the adjective precedes or follows the noun. Once again, the noun is the head and the adjective is the modifier, regardless of order.

\section{THE ORDER OF NOUNS AND ADJECTIVES}

Having established that the noun is the head of the noun phrase and the adjective is the modifier no matter whether the adjective precedes or follows the noun, we examine when each order occurs.

\subsection{FREQUENCY OF PRENOMINAL AND POSTNOMINAL ADJECTIVES}

Adjectives usually appear before the noun. Table 1 gives the number of occurrences of adjectives and noun combinations in the stories considered, counting repeated noun phrases only once.

TABLE 1: FREQUENCY OF PRE- AND POSTNOMINAL ADJECTIVES

\begin{tabular}{|lcc|}
\hline Story & A+N & N+A \\
\hline SK & 53 & 7 \\
LDP & 18 & 2 \\
HAK & 15 & 2 \\
Wolff & 84 & 17 \\
Total & 170 & 28 \\
\hline
\end{tabular}

From Table 1 it is clear that the order $\mathrm{A}+\mathrm{N}$ is strongly predominant; however, the order $\mathrm{N}+\mathrm{A}$ is also well represented.

\subsection{CONDITIONS AFFECTING THE ORDER OF NOUNS AND ADJECTIVES}

\subsubsection{ADJECTIVES WHICH MUST BE PRENOMINAL}

Wolff (1965:220-221) notes that demonstratives and independent genitives must precede the noun. We can add to Wolff's list mao 'same, aforementioned' in its use as a modifier and the adjective lain 'different' in one of its meanings.

Mao has a number of uses. It introduces a result, enters into various idioms, and indicates that a noun phrase's referent is the one to which a predicate is properly attributed. 
(See Wolff 1972:678-679.) It is also used before a noun to indicate that the noun refers to the same referent mentioned previously.

(7)

$$
\begin{aligned}
& \text { ang maong mga singgit } \\
& \text { NOM aforementioned.LN PL shout } \\
& \text { the same shouts / those shouts }
\end{aligned}
$$

In this use, it never follows the noun.

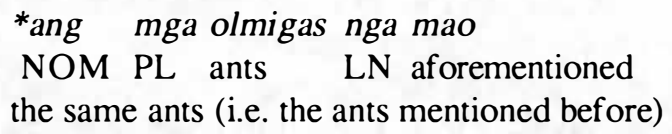

Similarly, lain in its meaning 'another, a different' always occurs before the noun.

(9)

$$
\begin{aligned}
& \text { ang laing Kalagkalag } \\
& \text { NOM another.LN All Souls' Day } \\
& \text { another All Souls' Day }
\end{aligned}
$$

In this sense, lain never occurs after the head.

\subsubsection{CONDITIONS FAVOURING POSTNOMINAL POSITION}

The examples of postnominal adjectives fall into four clear groups: (a) adjectives which take complements, (b) adjectives indicating species, (c) adjectives in a repeated noun phrase, and (d) adjectives used non-restrictively.

(a) ADJECTIVES WHICH TAKE COMPLEMENTS

Adjectives which take noun phrases as complements invariably follow the noun.

(10) a. sa usa ka layag nga puno sa hagin (Wolff, R10) OBL one NLN sail LN full GEN wind a sail full of wind

b. *sa puno sa hangin nga layag

OBL full GEN wind LN sail

a full-of-wind sail

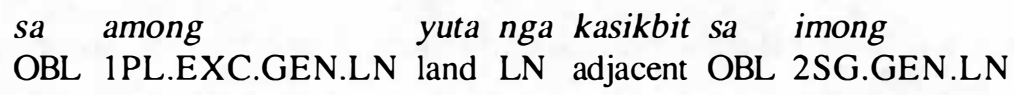

asyenda (SK)

hacienda

our land, which was adjacent to your hacienda

$$
\begin{aligned}
& \text { ang usa ka sakayan nga kulang sa trepulante (HAK) } \\
& \text { NOM one NLN vehicle LN lacking OBL crew } \\
& \text { a vessel lacking a crew }
\end{aligned}
$$

ang usa ka pamilyanga kulang sa amahanong paggiya NOM one NLN family LN lacking OBL fatherly guidance

a family lacking a father's guidance 
However, an author may treat quite a complex phrase as a single unit by hyphenating it and placing it before the head.
sa dili-makaog-iro
nga kasaba

(SK)

OBL not-able.to.be.eaten.GEN-dog LN scolding a scolding that a dog wouldn't take

(b) ADJECTIVES INDICATING SPECIES

Adjectives indicating species or type tend to follow the noun.

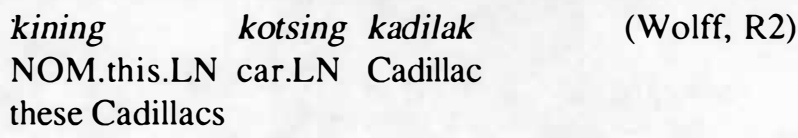

(Wolff, R2)

$$
\text { ug usa ka puno nga lubi (Wolff, R6) }
$$

ACC one NLN trunk $\mathrm{LN}$ coconut a coconut tree

$$
\text { upat ka punoan nga saging (Wolff, R6) }
$$

sa ihong bakikihon (Wolff, R10)

ACC shark.LN spotted.shark the spotted shark

ang dalagang bukidnon

NOM maiden.LN of.the.mountain

(Wolff, 25B9) the mountain girl

$$
\begin{array}{ll}
\text { sa tawong hakog } \\
\text { GEN people.LN } \\
\text { of greedy } \\
\text { greedy people }
\end{array}
$$

$$
\text { (Wolff, } 25 \mathrm{~B} 9)
$$

In the light of later observations, it is important to note that this tendency holds of both non-restrictive and restrictive modification. From the context it is clear that the modifier is not restrictive in (15), but that the modifiers are restrictive in (16) - (20).

Two cautions should be noted. Firstly, while there is a tendency for species to follow, there is no invariable rule that it must, as shown for example by (21).

$$
\begin{aligned}
& \text { mga baliting mga kahoy } \\
& \text { PL banyan.LN PL tree } \\
& \text { banyan trees }
\end{aligned}
$$$$
\text { (Wolff, R2) }
$$

Secondly, at least some of these phrases may be examples of nouns in apposition rather than of adjectives modifying nouns. If so, the examples would follow the normal pattern of appositives with the more specific following the less specific, as in (22).

\footnotetext{
6I treat the modifiers in examples (19) and (20) as indicating species because both noun phrases are used to state the genus in generic sentences.
} 


$$
\text { ang magtiayong Don Ambrosio ug Donya Leonila }
$$

NOM couple.LN Don Ambrosio and Doña Leonila the couple, Don Ambrosio and Doña Leonila

\section{(c) ADJECTIVES IN REPEATED NOUN PHRASES}

The third factor which favours postnominal position for adjectives is contextual. When a noun and adjective are repeated shortly after they have been used before, the adjective may switch from prenominal to postnominal position. This was the case with the examples in (1) of section 2. The switch is also shown in (23), which occurs shortly after (21), and in examples (24) and (25).

kanang kagoyng baliti (Wolff, R2)
NOM.that.LN tree.LN banyan
those banyan trees

a. 'type B' nga dugo
type B LN blood
type B blood
b. 'g dugong 'type B'
ACC blood.LN type B
type B blood

Again, the change in order of head and modifier when the noun phrase is repeated is a tendency, not a hard-and-fast rule.

\section{(d) ADJECTIVES USED NON-RESTRICTIVELY}

All the remaining postnominal adjectives in the stories are used non-restrictively. ${ }^{7}$ For example, consider (25).

$$
\begin{aligned}
& \text { sa mga ang-ang nga marnol } \\
& \text { OBL PL steps LN marble } \\
& \text { on the marble steps }
\end{aligned}
$$

In this example the marble is not mentioned to help make clear which steps are being referred to. It is used, rather, to strengthen the impression of the extravagant luxury of the house being described. In such non-restrictive use the adjective of ten follows the noun.

This fact may help to explain the fact that adjectives used with proper names and pronouns are always postnominal. Given that proper names and pronouns are inherently referential, adjectives describing them are always used non-restrictively.

\footnotetext{
${ }^{7}$ It is sometimes difficult to determine whether a modifier is used restrictively or not. For example, one of the characters in (SK) steals money from some stores, which are described as:

sa katindahanan sa lungsod nga gipamiyaan sa nangikyas nga mga Insek (SK)

OBL store-collective OBL city LN abandon.REF GEN ACT.flee LN PL Chinese

from the stores in the city which had becn abandoned by the fleeing Chinese

If all the Chinese shopkecpers fled, then nangikyas 'flecing' and gipamiyaan sa nangikyas nga mga Insek 'abandoned by the flecing Chincse' are both used non-restrictively. If not, they are both being used restrictively. The question cannot be settled by looking either at form or at context.
} 
(26)

kaming makaluluoy
NOM.1PL.EXC.LN pitiful
we miserable ones

$(\mathrm{SK})$

we miserable ones

However, the tendency for non-restrictively used adjectives to follow the noun does not fully explain the apparent prohibition on prenominal position for adjectives applied to proper names and pronouns precisely because it is a tendency, not a firm rule. Adjectives used nonrestrictively may also precede the noun, as in (27).

$$
\begin{aligned}
& \text { sa maanindot nga lungon } \\
& \text { OBL beautiful LN coffin } \\
& \text { the beautiful coffin }
\end{aligned}
$$

When (27) occurs, only one cof fin is in evidence. The adjective does not serve to determine reference and is therefore used non-restrictively, despite its position before the noun.

\subsection{SUMMARY OF THE POSITION OF ADJECTIVES}

Adjectives generally occur in prenominal position. An adjective with a noun phrase complement, however, can only occur after the head noun. Otherwise, an adjective used restrictively follows the noun only if it identifies a species or type or if it appeared in prenominal position not long before. Adjectives used non-restrictively must follow pronouns and, apparently, proper names. Otherwise, adjectives used non-restrictively may follow, but usually precede, the noun.

\section{ORDER OF NOUNS AND NON-ADJECTIVAL RELATIVE CLAUSES}

\subsection{FREQUENCY OF PRE- AND POSTNOMINAL POSITION FOR NON-ADJECTIVAL RELATIVE CLAUSES}

As can be seen from the table below, relative clauses more frequently follow than precede nouns.

TABLE 2: FREQUENCY OF PRE- AND POSTNOMINAL RELATIVES

\begin{tabular}{|lcc|}
\hline Story & $\mathrm{N}+\mathrm{RC}$ & $\mathrm{RC}+\mathrm{N}$ \\
\hline SK & 71 & 15 \\
LDP & 54 & 15 \\
HAK & 26 & 5 \\
Total & 151 & 35 \\
\hline
\end{tabular}

Relative clauses which follow the noun present no special problems and will not be discussed here, but see the appendix for examples found in the stories.

\subsection{RELATIVE CLAUSES IN PRENOMINAL POSITION}

Prenominal relative clauses generally consist of a single verb. 
(28)

$$
\text { ang nagdilaab nga kalayo }
$$

NOM ACT.blaze.up LN fire the fire, which was blazing up

$$
\begin{array}{llll}
\text { sa } & \text { nagdali } & \text { niyang } & \text { bana } \\
\text { OBL } & \text { NOM.hurry } & \text { 3SG.GEN.LN } & \text { husband }
\end{array}
$$
to her hurrying husband

(30) sa makapakitbisa-atay nga huwes dekutsilyo OBL ACT.C.revolt-liver LN massacre of civilians the revolting massacre of civilians

(31) sa magbukal nga tubig

OBL ACT.boil LN water in boiling water

$$
\begin{aligned}
& \text { sa gidunol nga dos pesos (LDP) } \\
& \text { ACC OBJ.hand LN two pesos } \\
& \text { the two pesos being handed [to him] } \\
& \text { sa gihayang lawas ni Mila (LDP) }
\end{aligned}
$$

(34) miabot nga usa ka puting punerarya (HAK)

ACT.arrive LN one NLN white.LN hearse

a white hearse which had [just] arrived

$$
\text { sa naggilakgilak nga lungon (HAK) }
$$

OBL ACT.sparkle LN coffin the coffin, sparkling all over

However, adverbial particles and other verb modifiers do occur in relative clauses in prenominal position.

$$
\begin{aligned}
& \text { sa nangamig nang lawas (LDP) } \\
& \text { ACC ACT.grow.cold already.LN body } \\
& \text { the already cold body } \\
& \text { sa bag-ong nanggula } \quad \text { nga mga mantalaan }{ }^{8} \\
& \text { OBL new-LN ACT.come.out LN PL magazine } \\
& \text { the magazines which had just started coming out }
\end{aligned}
$$

Moreover, pronouns are found in relative clauses before the noun.
kining
inyong
gilimos nga salapi
NOM.this.LN 2PL.GEN-LN OBJ-alms LN money this money, given by you as alms

$$
\begin{aligned}
& \text { ang gipugas niyang kaaghop } \\
& \text { NOM INS.sow } 3 \text { SG.GEN.LN kindness } \\
& \text { the kindness sowed by him }
\end{aligned}
$$

(LDP)

\footnotetext{
${ }^{8}$ Example (37) comes from 'Katitikang Binisaya-3' (Visayan Literature-3) by Marcel M. Navarra, Tuyom, Carcar, Cebu, published in Bisaya (29 Nov. 1978).
} 
Although pronouns are found in relative clauses which precede the noun, the stories contain no examples of relative clauses before the noun with non-pronominal complements, and such relative clauses may well be excluded from prenominal position in Cebuano, as they are in Kapampangan (Mirikitani 1972:199).

Relative clauses do not appear before proper names, but, of course, they may follow them.

$$
\begin{aligned}
& \text { *si nagdali nga Perto } \\
& \text { NOM ACT.hurry LN Perto } \\
& \text { (the hurrying Perto) }
\end{aligned}
$$

(41) ni Melinda nga nadukahan

GEN Melinda LN REF.drowse

by Melinda, who was drowsy

Non-adjectival relative clauses in prenominal position are relatively infrequent and are highly restricted, consisting at most of a verb, adverbs and pronominal complements of the verb. They do not appear before proper names. They may be used either non-restrictively, as in (36), or restrictively, as in (38).

\section{COMPARISON WITH TAGALOG}

The conditions on pre- and postnominal modifiers in Cebuano and Tagalog differ. According to Schachter and Otanes (1972:118-131), modifiers in Tagalog behave as follows:

1. Non-restrictive: always follow the head

2. Restrictive:

(a) If the information in modifier and noun is equally new, postnominal position is preferred.

(b) If the information in the modifier is unpredictable while the information in the noun is predictable, prenominal position is preferred. ${ }^{9}$

(c) Otherwise, either order is possible, but postnominal position is used if the modifier is very long or if it might cause ambiguity in prenominal position.

These conditions contrast with the situation in Cebuano as follows:

1. Non-restrictive: may precede or follow head

2. Restrictive: must precede head unless:

(a) the adjective phrase contains noun phrase complements, in which case it must follow;

(b) the head is a pronoun (or, possibly, a proper name), in which case the adjective must follow;

(c) the adjective and head are both repeated (and hence equally predictable) in which case either order is possible, but postnominal order is preferred;

\footnotetext{
${ }^{9}$ In other words, more rhematic material precedes more thematic material.
} 
(d) the adjective indicates a species or type, in which case either order is possible.

One further difference between Tagalog and Cebuano is that Tagalog permits more complex relative clauses to appear before the noun than Cebuano does.

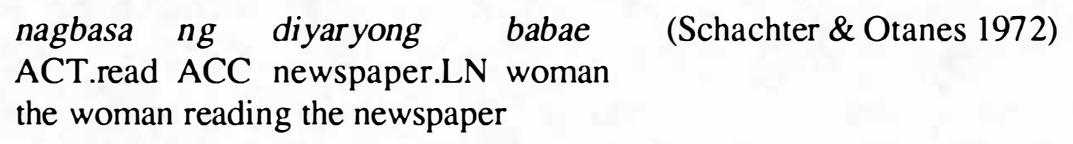

However, since postnominal position is preferred if the modifier is complex, relative clauses with non-pronominal complements will usually follow the noun in Tagalog, as they always do in Cebuano.

\section{APPENDIX}

Modified noun phrases in SK, LDP and HAK which are not given in the text are listed below. Following each is an indication of whether the modifier is restrictive ( $r$ ), nonrestrictive (u) or unclear (?). Each noun phrase is listed only once. If a noun phrase contains several modifiers or contains a modified noun phrase, a different number is written before each modifier. (As before, only relative clauses and adjectives are considered.)

\section{A. SK}

1. $\mathrm{A}+\mathrm{N}$

(1) ang kabos nilang mga silingan

NOM poor 3PL.GEN.LN PL neighbour their poor neighbours

(2) sa daotan nilang mga buhat

ACC evil 3PL.GEN.LN PL do

their evil deeds

(3) sa adunahang magtiayon

GEN wealthy.LN couple

of the wealthy couple

(4) sa harianong panimalay

OBL royal.LN household the lordly mansion

(5) sa tumang kahimuot

OBL extreme.LN pleasure

with extreme pleasure

(6) ang alaot nga magtiayon

NOM wretched LN couple

the unfortunate couple

(7) sa huhamugaway [sic] nilang mga silingan

OBL comfortable 3PL.GEN PL neighbours

for their comfortably well-off neighbours 
(8) 'g laing trabaho

a different job

(9) ang maong salapi

NOM mentioned.LN money

that same money

(10) sa hilabihang kawadon

GEN greatest.LN poverty

of extreme poverty

(11) sa palarang magtiayon

GEN fortunate.LN couple

of the fortunate couple

(12) sa maong nilang negosyo

OBL mentioned.LN 3PL.GEN.LN business

their (aforementioned) business

(13) sa mangtas nga magtiayon

GEN cruel LN couple

by the cruel couple

(14) sa mao nilang paagi

GEN mentioned.LN 3PL.GEN.LN way

by these same ways of theirs

(15) ang tanang yuta

NOM all.LN land

all the land

(16) ang laing hinungdan

NOM other.LN reason

another reason

(17) ang mga kabos nga manananto

NOM PL poor LN interest.payer

the impoverished interest-payers

(18) ang alaot nga manananto

NOM wretched LN interest.payer

the destitute interest-payer

(19) ang hilabihang kahiubos

NOM greatest.LN humiliation the greatest humiliation

(20) sa dakong pangihanglan sa kuwarta OBL great.LN needing ACC money the great need of money

(21) ang kabos nga magtiayon

NOM poor LN couple the poor couple 
(22) ang tinuod tang sabot

NOM true our.LN agree

our true agreement

(23) sa singkuwenta porsinto nga tanto

OBL fifty per.cent $\mathrm{LN}$ interest

fifty per cent interest

(24) sa maong yuta

ACC mentioned.LN land that land

(25) sa maong kamatuoran

OBL mentioned.LN evidence

that evidence

(26) y laing mga papeles sa pagpalit other.LN PL documents GEN purchase other documents of purchase

(27) ang maong mga papeles

NOM mentioned.LN PL documents

those documents

(28) ang sinalbahis nga buhat

NOM beastly LN do

this inhuman deed

(29) sa sapiang magtiayon

GEN monied.LN couple

the monied couple

(30) ang maong mga pulong ni Perto

NOM mentioned.LN PL word GEN Perto these words of Perto's

(31) sa halagyong lalawigan

OBL far.PL.LN province

in distant provinces

(32) y mga sulugoong babaye ug lalaki

PL servant.LN woman and man serving men and women

(33) sa halapad nga hawanan sa sala

OBL broad LN open.space GEN livingroom the broad livingroom

(34) ang hilabihang kainit

NOM greatest.LN heat

the extreme heat

(35) y tinuod nga bahandi sa tawo true LN wealth GEN person the true wealth of man 
(36) ang mahal nga bahandi ning kalibotan

(r)

NOM dear LN wealth GEN.this.LN world

the wealth to be held dear in this world

(37) ' $g$ daghang mga ilimon

ACC many.LN PL things.to.drink

many drinks

(38) sa kataposang gutlo sa among kinabuhi

OBL last.LN instant GEN 1PL.EXC.GEN.LN life

to the last minute of our lives

2. $\mathrm{N}+\mathrm{A}$

(1) sa mga utang nilang kabubuton

ACC PL debt 3PL.GEN moral

their moral indebtedness

3. $\mathrm{N}+\mathrm{RC}$

(1) sa singgit nga migilis sa kahilom sa kagabhion

GEN shout LN ACT.tear ACC quiet GEN night of a shout that tore the quiet of the evening

(2) kang Perto ${ }^{1}$ nga nahiunlod sa ${ }^{2}$ halawom nga

OBL Perto LN ACT.sink OBL deep LN

paghinanok

sound.sleep

Perto, who was sunk in a deep sleep

(3) sa dapit nga gigikanan sa singgit

OBL place LN REF.from GEN shout

the place that the shout came from

(4) si Perto nga miyugyog kang Melinda

NOM Perto LN ACT.shake ACC Melinda

Perto, who shook Melinda

(5) kalayo nga nakaugdaw na sa katunga sa kosina fire LN ACT.burn.up already ACC half GEN kitchen

fire, which had already burned to ashes half the kitchen

(6) ang kayugot nga gibati sa tanan tang mga NOM outrage LN OBJ.feel GEN all 1PL.INC.GEN PL

silingan gumikan kasalbahis nianang magtiayona

neighbour because.of atrocities GEN.this.LN couple.specific

the anger that is felt by all our neighbours on account of the atrocities of that couple

(7) Tawo usab sila nga linalang sa Dios. person also 3PL.NOM LN creature GEN God They are also people, creatures of God. 
(8) sa ngalan sa Dios nga naglalang kanila

OBL name GEN God LN ACT.create 3PL.ACC in the name of God, who created them

(9) nianang mga tawo nga mananap ug balatian OBL.that PL person LN animal ACC feeling those people, who are animals in feelings

(10) sa balay nga nasunog OBL house LN OBJ.burn the house that was burning

(11) ni Donya Leonila nga nahadagandagan sulod-gula sa GEN Doña Leonila LN ACT.run.run inside-outside OBL ilang lagwerta samtang nagdanguyngoy 3PL.GEN.LN yard while ACT.wail

Doña Leonila, who kept running in and out of their yard, wailing

(12) 'g tubig nga among ipanghimasaw ACC water LN 1PL.EXC.GEN.LN INS.rinse.body water that we'll use to rinse with

(13) nilang mga silingan nga nagtanga ug naghinan-aw 3PL.GEN.LN PL neighbours LN ACT.stay.put and ACT.look-at

lamang sa nagbanuos sa kalayo only ACC ACT.rage GEN fire their neighbours, who were staying put and just watching the raging of the fire

(14) laing singgit nga nasawod sa pandungog ni other.LN shout LN ACT.pour.into ACC hearing GEN

Perto

Perto

another shout that poured into Perto's hearing

(15) ang kantidad nga ilang madawat sa matag adlaw

NOM quantity LN 3PL.GEN.LN OBJ.receive OBL every day the amount they received every day

(16) y mga oras sa pagkaon nga ila lamang

PL hour GEN eating LN 3PL.GEN only.LN

sagulohon

skip.a.meal.OBJ

meal times that were just skipped by them

(17) ang ilang mga silingan nga natandog sa

NOM 3PL.GEN.LN PL neighbour LN OBJ.touch GEN

kapait sa ilang kahimtang

bittemess GEN 3PL.GEN.LN situation

their neighbours who were touched by the bittemess of their situation 
(18)

ang palwa nga iyang gilingkoran

$(\mathrm{r})$

NOM palm frond LN 3SG.GEN.LN sit.on.REF

the palm frond that he was sitting on

(19) sa iyang uyoan nga tigbuhat ug kandela sa

GEN 3SG.GEN.LN uncle LN maker ACC candles OBL

simbahan sa ilang lungsod

church OBL 3PL.GEN.LN city

his uncle, who was a maker of candles in the church in their city

(20) ang tanang kuwarta nga abot sa simbahan

NOM all.LN money LN stay OBL church

all the money that remained in the church

(21) ang daghang salapi nga nahipos ni Ambrosio

NOM many.LN money LN OBJ.gather GEN Ambrosio

the great amount of money which had been gathered up by A mbrosio

ang salapi nga ilang nahipos

NOM money LN 3PL.GEN.LN OBJ.gather

the money that had been gathered up by them

ug 'cash' 'nga tinangkilan sa ${ }^{2}$ makabuktot

ACC cash LN point.of.attachment ACC ACT.bend.back

nga tanto

$\mathrm{LN}$ interest

cash, to which was attached backbending interest

(24)

y kabos nga makapasilong sa harianon nilang poor LN ACT.take.shelter OBL royal 3PL.GEN.LN

panimalay

household

poor (people) who could take shelter in the lordly house

(25)

ang kuwarta nga ilang pahulaman

NOM money LN 3PL.GEN.LN CAUS.borrow.REF

the money that they let be borrowed

(26) sa kuwarta nga ilang luwatan

GEN money LN 3PL.GEN.LN let.out.REF

the money that they let out

(27) sa panahon nga ilang gitakda sa pagpabayad

GEN time LN 3PL.GEN.LN OBJ.period OBL repayment the time that was set by them as the period for repayment

(28) sa mga manghulam nga nagilaid sa hilabihang

GEN PL ACT.borrow LN ACT.stagger OBL extreme.LN

kawadon

poverty

the borrowers who staggered under the load of extreme poverty 
(29) ang mahinayak pagsulod sa ilang lagwerta nga NOM ACT.easy entering OBL 3PL.GEN.LN yard LN dili makatuman sa ilang gibaod not ACT.fulfill ACC 3PL.GEN.LN OBJ.rule those who easily got into their yard who weren't able to obey their rules

(30) sa kuwarta nga itanto sa mga manghulam

OBL money LN INS.interest GEN PL ACT.borrow the money paid as interest by the borrowers

(31) sa iyang asawa lnga nagungaw sa GEN 3SG.GEN.LN wife LN ACT.be.on.point.of.death OBL kamatayan gumikan sa usa ka ${ }^{2}$ grabing sakit death because.of OBL one NLN grave.LN illness his wife, who was on the brink of death from a grave illness

(32) sa Don pa ${ }^{1}$ nga mikuha ug blangko nga mga papel ( $1 \mathrm{u}),(2 \mathrm{u} ?)$ say Don say LN ACT.take ACC blank LN PL paper said the Don, who took some blank papers

(33) ang kabos nga magtiayon ${ }^{1}$ nga makabayad sa kuwarta NOM poor LN couple LN ACT.pay ACC money

${ }^{2}$ nga ilang nahulaman uban sa ${ }^{3}$ tagaliog nga LN 3PL.GEN.LN borrow.REF with OBL up.to.neck LN tanto niini $(1 \mathrm{u}),(2 \mathrm{r}),(3 \mathrm{u})$ interest GEN.this the poor couple who were able to pay the money that had been borrowed by them together with the neck-high interest on it

(34) sa adlaw nga gitakda sa pagbayad

OBL day LN OBJ.set.period OBL payment the day that had been set for payment

(35) sa mga papel nga gipirnahan niya

ACC PL paper LN REF.sign 3SG.GEN

the papers that had been signed by him

(36) ang kantidadsa kuwarta nga ilang nahulam

NOM quantity GEN money LN 3PL.GEN.LN OBJ.borrow the amount of money that had been borrowed by them

(37) ang salapi nga among nahulaman NOM money LN 1PL.EXC.GEN.LN REF.borrow the money borrowed by us

(38) si Don Ambrosio nga nagmugtok ang dagway NOM Don Ambrosio LN ACT.scowl NOM face Don Ambrosio, whose face was scowling 
(39) y laing mga papeles sa pagpalit nga gilig-on other.LN PL documents GEN purchase LN OBJ.seal

sa notaryo sa usa $k a$ abogado

GEN notary GEN one NLN lawyer

other bills of sale which were sealed by a lawyer's notary

(40) ang ${ }^{1}$ labing mangtas nga alimatok ${ }^{2}$ nga nagsupsop

NOM most.LN cruel LN leech LN ACT.suck

sa ${ }^{3}$ daginotong katigaynan sa mga kabos (1r),(2r),(3u)

ACC frugal.LN possession GEN PL poor

the most savage leech that sucks up the frugal possessions of the poor

(41) y Dios nga nagtanaw sa inyong buhat

God LN ACT.look.at ACC your.LN do

a God who sees your deeds

(42) sa mga luha sa mga kabos nga inyong

ACC PL tear GEN PL poor LN 2PL.GEN.LN

gipahilak

OBJ.C.cry / INS.C.cry(?)

the tears of the poor, whom you have caused to weep (or the tears of the poor, which you have caused to be shed)

(43) si Perto nga mitindog ug mitulisok kang

NOM Perto LN ACT.stand and ACT.reproach ACC

Don Ambrosio

Don Ambrosio

Perto, who stood and reproached Don Ambrosio

(44) ang kayugot ni Perto nga dugay nang nahanaw

NOM hatred GEN Perto LN long already ACT.vanish

Perto's hatred, which had vanished long ago

(45) ni Donya Leonila nga nagpadayon pagsinggit ug

GEN Doña Leonila LN ACT.continue shouting and

pakitabang

asking.help

Doña Leonila who was continuing to shout and beg for help

(46) sa Donya pa nga mitagbo ug migakos kaniya

say Doña say LN ACT.go.meet and ACT.embrace 3SG.ACC

sa iyang paghiabot sa ganghaan sa pergola

OBL 3SG.GEN.LN arriving OBL gate GEN pergola

said the Dona, who met and embraced him upon his arrival at the gate to the . pergola

(47) ni Perto nga naghangos

GEN Perto LN ACT.have.trouble.breathing

Perto, who was gasping for breath 
(48)

ang iyang mga tiil nga mitikang sa mga ang-ang

NOM 3SG.GEN.LN PL feet LN ACT.step OBL PL step

nga manmol

LN marble

his feet which stepped on the marble steps

(49) sa 'paralysis' ${ }^{1}$ nga mitakboy kaniya human siya

OBL paralysis LN ACT.afflict ACC.he after 3SG.NOM

atakeha sa grabe ${ }^{2}$ nga 'highblood'

$(1 r),(2 u)$

attack.OBJ GEN grave LN high.blood.pressure

the paralysis that had afflicted him after he had been attacked by a grave case

of high blood pressure.

(50) ang 'napuot nga aso ${ }^{2}$ nga nakahatag ug kalisod

NOM airless LN smoke LN ACT.give ACC difficulty

sa iyang pagginhawa

OBL 3SG.GEN.LN breathing

the airless smoke that gave him trouble breathing

(51) sa lawak nga nahimutangan ni Don Ambrosio

OBL room LN place.REF GEN Don Ambrosio

the room that Don Ambrosio was located in

(52) si Don Ambriso [sic] nga gilaboklabok na sa kayayo

NOM Don Ambriso LN OBJ.scorch already GEN fire

Don Ambriso, who was being repeatedly scorched by the fire

(53) sa kayalo ${ }^{1}$ nga dala sa ${ }^{2}$ nagkayong mga agipo

GEN fire LN bring GEN ACT.burn.LN PL ember

${ }^{3}$ nga nanugpa kaniya

$(\mathrm{lr}),(2 \mathrm{u}),(3 \mathrm{r})$

LN ACT.alight 3SG.OBL

the fire that was brought by the buming embers that were landing on him

(54) sa tibuok lawak nga ilang gigikanan

OBL whole room LN 3PL.GEN.LN REF.go.from

in the whole of the room they'd just left

sa traysikol nga gimaneho sa iyang anak

OBL tricycle LN OBJ.operate GEN 3SG.GEN.LN child a tricycle driven by his son

(56) sa mga sayop nga among nahimo kaninyo OBL PL wrong LN 1PL.EXC.GEN.LN OBJ.make 2PL.OBL

ug ingon sa atong silingan

and like OBL 1PL.INC.GEN.LN neighbour

the wrongs that we have done you and also our neighbours

(57) ang katalagman nga midamgat kanamo

NOM fate LN ACT.reach 1PL.EXC.OBL

the fate which has reached us 
(58) ug usa ka traktora ${ }^{1}$ nga pagadumalahon sa tawo ACC one NLN tractor LN manage.OBJ GEN person ${ }^{2}$ nga among sinuholan

LN 1PL.EXC.GEN.LN pay.wages.REF a tractor which will be operated by a man who will be paid by us

(59) sa kuwarta nga inyong nahulaman OBL money LN 2PL.GEN.LN REF.borrow the money that you borrowed

(60) sa balay nga among ipatukod

OBL house LN 1PL.EXC.GEN.LN INS.C.build the house that we are having built

(61) ang mga pulong nga nanglibkas sa mga ngabil NOM PL word LN ACT.slip.out OBL PL lips sa adunahang magtiayon

GEN wealthy couple the words that slipped out of the lips of the wealthy couple

(62) sa ${ }^{1}$ hilabihang kalipay ${ }^{2}$ nga miawas sa balatian OBL greatest.LN happiness LN ACT.spill OBL feeling ni Perto ug ni Melinda GEN Perto and GEN Melinda the very great happiness that overflowed in Perto's and Melinda's feelings

4. $\mathrm{RC}+\mathrm{N}$

(1) ang inutaw nga mga papel de bank

NOM ironed LN PL paper bank the ironed bank-notes

(2) ang linapwaan nga mga plata

NOM sterilised LN PL coin the sterilised coins

(3) ang nagublo nga kalayo

NOM ACT.flare.up LN fire the up-flaring fire

(4) sa makabungog nilang pagpaganansiya

OBL ACT.deafen 3PL.GEN.LN interest their deafening interest / their extreme interest

(5) ang naghingapin nilang kadelikado

NOM ACT.exceed.limit 3PL.GEN.LN delicateness their delicateness, which went to excess

(6) sa nagsilaob nga balay OBL ACT.bum LN house the burning house

(7) sa ${ }^{1}$ nanglugpad nga mga baga ug sa ${ }^{2}$ nagkayo nga GEN ACT.fly.PL LN PL spark and GEN ACT.burn LN 
mga agipo

$(\mathrm{lu} ?),(2 \mathrm{u} ?)$

PL wood.with.glowing.tip

by the flying sparks and the buming embers

(8) sa gihigdaan nga kama

OBL lie.on. REF LN bed

on the bed being lain on

B. LDP

1. $\mathrm{A}+\mathrm{N}$

$\begin{array}{lll}\text { (1) ang tibuok niyang } & \text { kalawasan } \\ \text { NOM whole } & \text { 3SG.GEN.LN flesh.collective }\end{array}$

his whole body

(2) ang ${ }^{1}$ mugbong angang sa ${ }^{2}$ sementadong hagdan

$(1 \mathrm{u}),(2 \mathrm{u})$

NOM small.PL.LN step GEN cement.LN stairway

the small steps of the cement stairs

(3) sa tuo niyang kamot

OBL right 3 SG.GEN.LN hand

with his right hand

(4) ang kataposan kong paglaom nga mabuhi pa si

NOM last my.LN hope LN ACT.live still NOM

Komare Mila ninyo

compadre Mila 2PL.GEN

my last hope that your Compadre Mila will live

(5) 'g gamay mga kantidad

ACC small PL quantities

even small amounts

(6) sa sementong bongbong

OBL cement.LN wall

the cement wall

(7) sa sementong salog

OBL cement.LN floor

the cement floor

(8) sa labing daling panahon

OBL most.LN quick.LN time

in the shortest possible time

(9) matingad-ong sukot

surprised-LN question

a surprised question

(10) ang luya ug luyloy nga mga abaga

NOM weak and limp LN PL shoulder

the weak, limp shoulders 
(11) sa kataposang pangadye

OBL last.LN novena

the last day of the novena

(12) ug hilaw nga pahiyom

ACC raw LN smile

an unnatural smile

(13) ang patay niyang lawas

NOM dead 3SG.GEN.LN body

her dead body

2. $\mathrm{N}+\mathrm{A}$

(1) $y$ dugo nga 'type B'
blood LN type B
type B blood

3. $\mathrm{N}+\mathrm{RC}$

(1) ug 'type B nga dugo nga balig 2000cc

ACC type B LN blood LN worth $2000 \mathrm{cc}$

2000cc's worth of type B blood

(2) sa doktor nga namahid usab sa singot

GEN doctor LN ACT.dry also ACC sweat the doctor, who was also drying his sweat

(3) ni Mila nga naghigda sa katre

GEN Mila LN ACT.lie OBL bed

Mila, who was lying on the bed

(4) ning ${ }^{1}$ maong gidaghanon sa dugo ${ }^{2}$ nga gipangayo

this mentioned.LN amount GEN blood LN OBJ.beg.for

sa doktor alang sa iyang asawa

$(1 r),(2 r)$

GEN doctor for OBL 3SG.GEN.LN wife

this same quantity of blood that had been requested by the doctor for his

[Efren's] wife

(5) sa tigulang nga hangtod karon wala pa niya kabayri

OBL old LN until now not yet 3SG.GEN REF.pay the old (man) whom he hadn't yet been able to pay

(6) y mga kabtangan pang ikabaligya

PL thing.collective still.LN INS.sell things that could still be sold

(7) sa anak niini nagsuka-kalibang

OBL child GEN.this ACT.vomit-diarrhoea

his child, who had an intestinal disorder

(Note the lack of a linker)

(8)
sa 'luban niyang
mga silingan ${ }^{2}$ nga iya
OBL other 3SG.GEN.LN PL neighbour LN 3SG.GEN 
nang natabangan niadto

already.LN help.REF then

$(1 r),(2 r ?)$

his other neighbours who had been helped by him before

(9) ang 'stretcher' 'nga gikargahan ug ${ }^{2}$ minatay nga

NOM stretcher LN load.REF ACC dying LN

pasyente

patient

a stretcher that was loaded with a dying patient

(10) ang iyang mga silingan ug kauban sa

NOM 3SG.GEN.LN PL neighbour and companions OBL

trabaho sa pantalan nga nanaginom

work OBL dock LN ACT.PL.drink

his neighbours and fellow workers at the dock, who were drinking

(11) ni Pisoy nga namula ang nawong sa giinom

GEN Pisoy LN ACT.red NOM face OBL OBJ.drink

niini

GEN.this

Pisoy, whose face was red from what he'd drunk

(12) ni Efren nga namahid sa singot sa iyang

GEN Efren LN ACT.dry ACC sweat OBL 3SG.GEN.LN

nawong

face

Efren, who was drying the sweat from his face

(13) ug usa ka baso nga way sagol

ACC one NLN glass LN there.is.no mixture

a glass of unmixed spirits

(14) g dugo nga balig 2000cc

ACC blood LN worth $2000 \mathrm{cc}$

2000cc's worth of blood

(15) ni Efren nga namulong

GEN Efren LN ACT.speak

Efren, who was speaking

(16) y mahikap sa balay nga sarong kong

OBJ.touch OBL house LN justly.LN 1SG.GEN.LN

\section{ikabaligya}

INS.sell

(things) that can be touched at the house that can properly be sold by me
ang duha ko
karon ka mga anak nga

NOM two 1SG.GEN now NLN PL child LN

nahibilin sa balay

OBJ.leave OBL house

my two children now, who have been left at the house 
(18) sa iyang mga silingan nga dili pa lang GEN 3SG.GEN.LN PL neighbours LN not still only dugay iyang gipangtabangan long 3SG.GEN.LN REF.help

his neighbours, who had been helped by him not long before

(19) ang 'ultimong baboy ${ }^{2}$ nga ilang binuhi ni Mila NOM last.LN pig LN 3PL.GEN raised GEN Mila their last pig raised by Mila

(20) si Iya Masing nga ganina dang naminaw sa NOM Iya Masing LN recently then.LN ACT.listen.to ACC iyang gipanagsultihan

3SG.GEN.LN REF.PL.speak

Iya Masing, who had just listened to (the replies of) those to whom he had spoken

(21) ning kalisod nga iya karong giatubang

OBL.this.LN difficulty LN 3SG.GEN now.LN OBJ.face this hardship that was not faced by him

(22) mga silingan ${ }^{1}$ nga sa ${ }^{2}$ miaging adlaw iyang PL neighbours LN OBL ACT.pass.LN day 3SG.GEN.LN natabangan $(1 \mathrm{u} ?),(2 \mathrm{r})$ REF.help neighbours who had been helped by him in past days
sa dugong gikinahanglan niini alang sa

ACC blood.LN OBJ.need GEN.this for OBL

iyang asawa

3SG.GEN.LN wife

the blood needed by him for his [Efren's] wife

sa Hepe nga miabot na diay gikan sa

GEN Chief LN ACT.arrive already really from OBL

gitambongan niining komperensiya

REF.attend GEN.this.LN conference

the Chief, who had arrived back from the conference attended by him

(25) sa Hepe, ${ }^{1}$ kinsa gitaplakan sa ${ }^{2}$ hilabihan usab nga .

GEN Chief who REF.cover GEN greatest also LN

\section{kahikurat}

astonishment

the Chief, who was covered with extreme astonishment

(Note the use of the interrogative pronoun kinsa. Nga is also possible here, but kinsa is said to be better.)

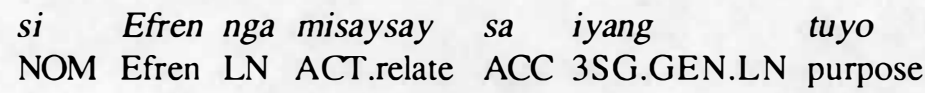


ngadto sa Hepe

thither OBL Chief

Efren, who told his purpose to the Chief

(27) sa mga luha nga magiyahay pagpalugwa sa

OBL PL tear LN ACT.one.by.one forcing.way.out OBL

iyang mga mata

3SG.GEN.LN PL eye

the tears that forced their way out of his eyes one by one

(28) sa Hepe 'nga mipikpik sa abaga ni Efren

GEN Chief LN ACT.pat ACC shoulder GEN Efren

2nga karon miluom na paghilak

LN now ACT.repress already crying

$(1 \mathrm{u}),(2 \mathrm{u})$

the Chief, who patted the shoulder of Efren, who had now repressed his

crying

(29) ang tanan binilanggo nga mikabat ug napulog

NOM all prisoner LN ACT.amount.to ACC ten

siyam ka buok

nine NLN piece

all the prisoners, who amounted to 19 in number

(30) sa trakdekarga nga ang Hepe mismo ang nangunay

OBL freight.truck LN NOM Chief himself NOM ACT.do.personally

pagmaneho

operating

a freight truck that the one personally driving was the Chief himself

(Note that this relative clause violates the restriction that only subjects can be relativised.)

(31) ang ospital nga mga lima tingali ka kilometro ang NOM hospital LN PL five perhaps NLN kilometre NOM

gilay-on

distance

the hospital, which was about five kilometres away

(32) sa akong mga silingan nga kanhi akong OBL 1SG.GEN.LN PL neighbour LN formerly ISG.GEN.LN

natabangan sa ilang mga kalisod

REF.help OBL 3PL.GEN.LN PL difficulty

my neighbours, who had been helped by me before in their troubles

(33) si Efren nga wala mobulag pagtutok sa ilang NOM Efren LN not ACT.cease staring OBL 3PL.GEN.LN

gidulngan

REF.approach

Efren, who had not ceased to stare forward 
(34) ang sakyanan nga misulod na karon sa ospital

NOM vehicle LN ACT.go.in already now OBL hospital the vehicle that had already reached the hospital

(35) ang mga binilanggong sakay niini

NOM PL prisoner.LN riding OBL.this

the prisoners who were riding in it

(36) Efren nga ingog giibtag tunok

Efren LN as.if REF.pull.out.ACC thom

Efren, who (felt) as if he'd just had a thorn pulled out of him

sa doktor ${ }^{1}$ nga nagundog sa kalid sa katre ${ }^{2}$ nga

GEN doctor LN ACT.stand OBL side GEN bed LN

gihigdaan sa iyang asawa ${ }^{3}$ nga binukotan na

REF.lie GEN 3SG.GEN.LN wife LN covered already

sa puting habol

GEN white.LN blanket

the doctor, who was standing beside the bed on which was lying his wife, who was covered with a white blanket

(Note that the main point of the sentence, that Efren's wife is dead, is conveyed in the third, non-restrictive relative clause.)

(38) si Efren nga migakosgakos sa nangamig nang

NOM Efren LN ACT.embrace ACC ACT.cold already.LN

lawas sa iyang asawa

body GEN 3SG.GEN.LN wife

Efren, who kept hugging the body of his wife, which was already cold

(39) sa doktor nga mipikpik sa abaga ni Efren

GEN doctor LN ACT.pat ACC shoulder GEN Efren

the doctor, who patted Efren's shoulder

(40) ang mga silingan ni Efren nga nanaka sa

NOM PL neighbour GEN Efren LN ACT.climb.up OBL

iyang balay aron pagduaw sa gihayang

3SG.GEN.LN house in order visiting ACC OBJ.lay.out.LN

lawas ni Mila

body GEN Mila

Efren's neighbours who came to his house to visit Mila's laid-out body

(41) mga silingan nga kanhi pulos nakatagamtam sa

PL neighbour LN formerly fully ACT.experience ACC

iyang mga panagang

3SG.GEN.LN PL help

neighbours who had all formerly experienced his help

(42) sa plato ${ }^{1}$ nga gitungtong ibabaw sa ${ }^{2}$ gamayng talad

OBL plate LN OBJ.place on.top OBL small.LN table the plate that was placed on top of a small table 
(43) y laing duha ka tawong miabot

other.LN two NLN person.LN ACT.arrive

another two people who had just arrived

(44) sa plato nga gisudlan sa mga limos

OBL plate LN REF.put.into ACC PL alms

the plate into which alms were put

(45) ni MrLopez nga mipabuhot sa iyang abano

GEN Mr Lopez LN ACT.exhale ACC 3SG.GEN.LN cigar

Mr Lopez, who exhaled the smoke from his cigar

(46) ni Efren ${ }^{1}$ nga karon ingon ug nahubsan na sa GEN Efren LN now as if REF.dry.out already ACC

mga luha ug nagpangagot ang mga ngipon 2 nga

$\mathrm{PL}$ tear and ACT.grind NOM PL tooth LN

miatubang sa kadaghanan

ACT.face ACC multitude

Efren, who was as if all his tears were dried out and whose teeth were grinding as he faced the multitude

(47) si Iya Masing nga hilaw kaayo ang nawong NOM Iya Masing $\mathrm{LN}$ raw very NOM face

Iya Masing, whose face was very embarrassed

(48) kang Mila nga patay na

OBL Mila LN dead already

Mila, who is dead now

(49) sa salaping papel nga nangaliring ug

GEN money.LN paper LN ACT.cause.rustling.sound and

nanglupad sa hawanan sa balay

ACT.fly OBL broad.space GEN house

the paper money, which whirled and flew about the living-room of the house

4. $\mathrm{RC}+\mathrm{N}$

(1) ang inyong mga tinagoang salapi

NOM 2PL.GEN.LN PL hidden.LN money

your hidden money

(2) ang nagtibugok nga mga singot

NOM ACT.form.into.bead LN PL sweat

the sweat, which was forming beads

(3) niadto lang ganing miaging bulan that.OBL only even.LN ACT.pass.LN month just that very past month

(4) y gitambongan kunong komperensiya

REF.attend reportative.LN conference

a conference that they said he was attending 
(5) sa namatay niyang asawa

GEN ACT.die 3SG.GEN.LN wife his dead wife

(6) sa namulapula nilang salapi

ACC ACT.be.red 3PL.GEN.LN money

their red-coloured banknotes

C. HAK

1. $\mathrm{A}+\mathrm{N}$

(1) ang patayng lawas sa imong amahan NOM dead.LN body GEN 2SG.GEN.LN father the dead body of your father

(2) sa silangan nga dapit

GEN neighbour LN place neighbouring places

(3) sa layong dapit

OBL far.LN place

in a distant place

(4) sa dakong krus

OBL big.LN cross

at the big cross

(5) sa mabudhion mong gugma

GEN treacherous 2SG.GEN.LN love your treacherous love

(6) y buhing handomanan

alive.LN souvenir

a living reminder

(7) sa buhi kong lawas

ACC alive ISG.GEN.LN body

my living body

(8) sa kataposang higayon

(r)

OBL last.LN opportunity

the last chance

(9) sa laing linalang

OBL other.LN creature another creature

2. N+A: all occurrences were discussed in the text.

3. $\mathrm{N}+\mathrm{RC}$

(1) ang barko nga iyang gisakyan

NOM ship LN 3SG.GEN.LN REF.ride

the ship he was travelling on 
(2) ang kasakit nga iyang gibati

NOM pain LN 3SG.GEN.LN OBJ.feel the pain felt by her

(3) sa iyang anak nga uhaw kaayo sa amahanong

OBL 3SG.GEN.LN child LN thirsty very OBL fatherly.LN

mga pagpangga

PL love.and.care

her child, who was very thirsty for a father's loving care

(4) ug mga barungbarong duol sa sementaryo ${ }^{1}$ nga ${ }^{2}$ sarang

ACC PL huts near OBL cemetery LN adequate.LN

kapasilongan sa ilang mga ${ }^{3}$ tindang ilimnon,

shelter OBL 3PL.GEN.LN PL sold.LN drinks

sumsoman ug kandela

snacks and candles

huts near the cemetery, which were adequate shelter for the drinks, snacks and candles sold by them (or for their sale of drinks, snacks and candles?)

sa mga tagibalangay niya nga nanglangkaw

GEN PL fellow.townsmen 3SG.GEN LN ACT.emigrate

ug layo

ACC far

her fellow-townsmen who had emigrated far away

(6) kada puwerto nga dunggoan ni Ronaldo

each port LN REF.land.at GEN Ronaldo

each port that Ronaldo landed at

uban ang iyang hulagway 'nga makuha sa

with NOM 3SG.GEN.LN photo LN OBJ.take OBL

2nagkalainlaing mga dapit

ACT.be.different.LN PL place

with a photograph of him taken in the different places

(8) ang pipila $k a$ pulong nga nahisulat sa mga gipadala

NOM several NLN word LN OBJ.write OBL PL INS.send

ni Ronaldo ngadto kang Rebecca

GEN Ronaldo thither OBL Rebecca

some of the sentences that were written in the [letters] sent by Ronaldo to Rebecca

(9) ang paguto nga gitisok niya sa iyang

NOM belief LN OBJ.implant 3SG.GEN OBL 3SG.GEN.LN

anak

child

the belief which she had implanted in her child

(10) niadtong bata nga gipakatawo mo

GEN.that.LN child LN OBJ.give.birth 2SG.GEN 
niining kalibotan

$(r)$

OBL.this.LN sexual.activity

that child who was bom of you as a result of this sexual activity

(11) ang usa ka anak lnga nagampo sa kalipay

NOM one NLN child LN ACT.pray OBL happiness

sa kalag sa usa ka amahan ${ }^{2} n g a$ ania pa

GEN soul GEN one NLN father LN here still

magtikawtikaw sa kalibotan

ACT.move.around OBL world

a child who is praying for the happiness of the soul of a father who is still moving about here on earth

(12) niadtong batang nagluhod atubangan sa dakong

that.OBL.LN child.LN ACT.kneel facing OBL big.LN

krus

cross

that child who was kneeling before the big cross

(13) si Cheng nga nahibulong kaayo

NOM Cheng LN ACT.be.surprised very

Cheng, who was very surprised

(14) ang matuod nga tawo nga naghatag kanimo ug

NOM actual LN person LN ACT.give 2SG.OBL ACC

kinabuhi

life

the actual person who gave you life

(15) si Rebecca nga nagtan-aw kanila

NOM Rebecca LN ACT.look-at 3PL.OBL

Rebecca, who was watching them

(16) sa amahan ug anak nga karon lang magkailhanay

ACC father and child LN now only ACT.get.to.know.each.other the father and son who were only now getting to know each other

(17) sa kagamingaw ngadto sa amahan nga gibati sa ACC loneliness thither OBL father LN OBJ.feel GEN iyang anak

3SG.GEN.LN child

the loneliness for the father that was felt by her child
sa panyo
nga gikuot
niya
sa bolsa

OBL handkerchief LN OBJ.pull.out 3SG.GEN OBL pocket

sa iyang karsones

GEN 3SG.GEN.LN trousers

a handerchief that he pulled out of the pocket of his trousers 
(19) sa amahan nga ginapangita ni Cheng

OBL father LN OBJ.seek GEN Cheng

the father that Cheng had been seeking

(20) niadtong bag-ong ilubong atol sa adlaw sa

OBL.that.LN new-LN INS.bury.LN coincide OBL day GEN

mga nangamatay

PL ACT.die

the new one-to-be-buried that coincided in time with the day of the dead

(21) kadtong babayeng nagluto

NOM.that.LN woman.LN ACT.wear.black

that woman who was wearing black

(22) ang usa ka batang babaye nga sama ug edad

NOM one NLN young.LN female LN same age

$$
\text { sa iyang anak }
$$

OBL 3SG.GEN.LN child

a girl who was the same age as her child

(23) y mananambal nga makaayo pa doctor LN ACT.good still

doctor that could make him well again

(24) sa tawong mitaliwan

OBL person.LN ACT.finish

the man who had finished his course

(25) ug tagsa ka buok handomanan nga bisa kanus-a

ACC each NLN piece reminder LN even.if whenever

dili gayod malaksi diha sa tagsatagsa nila

not indeed OBJ.erase there OBL each.one 3PL.GEN

ka handurawan

NLN imagination

for each a reminder that would never be erased from the imagination of either

4. $\mathrm{RC}+\mathrm{N}$

(1)
sa naghinobra
nilang
mga kalipay
GEN ACT.go.to.excess 3PL.GEN.LN PL happiness
their happiness, which went to excess

\section{REFERENCES}

LEECH, Geoffrey, 1974, Semantics. Harmondsworth, Pclican Books.

MIRIKITANI, Leatrice, 1972, Kapampangan syntax. Oceanic Linguistics Special Publication 10. Honolulu.

REID, Lawrence A., 1966, An Ivatan syntax. Oceanic Linguistics Special Publication 2. Honolulu.

SCHACHTER, Paul and Fe T. OTANES, 1972, Tagalog reference grammar. Los Angeles:

University of California Press. 
WOLFF, John U., 1965, Cebuano Visayan syntax. PhD thesis, Yale University. University Microfilms, Ann Arbor, Michigan.

1967, Beginning Cebuano, Part II. New Haven: Connecticut, Yale University Press.

1972, Dictionary of Cebuano Visayan, Data Paper Number 87, Southcast Asia Program. Ithaca, New York: Department of Asian Studies, Corncll University. 


\title{
MORPHOLOGICAL EVIDENCE FOR PRIMACY OF PATIENT AS SUBJECT IN TAGALOG
}

\author{
VIDEA P. DE GUZMAN
}

\section{INTRODUCTION}

There have been studies on Tagalog, a major language of the Philippines, that present strong pieces of evidence, both syntactic and psychological, for the non-universality of agent as subject. Schachter $(1976,1977)$, for instance, shows that there are reference-related properties for subject (i.e. grammatical subject, which may be an agent or a patient or some other nominal) as well as role-related properties (i.e. a nominal, being an agent, may undergo certain rules whether it is a grammatical subject or not). Cena (1977) discusses a whole array of syntactic structures where the patient is preferred to appear as the grammatical subject over a co-occurring agent. Along the same vein, in a language acquisition study by Galang (1982), she concludes that children learning Tagalog verbs acquire the patient or object focus first before the agent focus forms of the active verbs. In support of these studies, this paper will show that the morphological structure of verbs also indicates the primacy of patient or object over agent or experiencer as subject. Subject is taken here as that nominal in a predicative construction identified as the focus marked by ang/si or manifested by the nominative form of pronouns (referred to as the absolutive form in an ergative approach).

The thesis of this paper ${ }^{1}$ is that a verb in its basic or unmarked morphological form indicates a basic structure and, concomitantly, a more basic relation exists between that verb form and the nominal that co-occurs with it as the subject of the sentence. This thesis draws from the theory of markedness which considers the unmarked form of an opposition as the more productive or regular form (Hyman 1975:145-146). More recently, in Mayerthaler's theory of Natural Morphology (Klausenburger 1986:328-329), he conceives of markedness as matching the principle of constructional iconicity. This principle states that "what is semantically more should also be constructionally more". From this principle, we can draw that an overt morphological marking signifies a corresponding semantic marking. Thus, where a verb stem is more complex in internal structure than another related form, it is perceived as projecting more semantic information and, therefore, is not a basic or primary structure.

While it is true that languages with an accusative system have agents as subject of unmarked verbs and, conversely, the verbs are more complex in structure when the co-

\footnotetext{
${ }^{1}$ This is a revised version of a paper read at the Linguistic Society of America Annual Meeting in Los Angeles, California, 1979.
} 
occurring patient is subject, there are languages where the reverse obtains. Tagalog is one such language. Although it has transitive verb stems consisting of roots that can take either the active voice affix -um-, or one of the patient voice affixes -in, -an or $i$-depending on the subclass the verb belongs to, the interesting fact is that there are a number of subclasses of other transitive verb stems of the same simple structure that would only allow the patient to be the subject of the sentence. For the related verb form to inflect for the agentive voice, if this is at all permissible, the stem has to assume a more complex, derived form. In fact, the number of subclasses exhibiting this latter characteristic far exceeds that of the former. The simple underived class of transitive verbs preferring a patient subject extends over to other subcategories of lexically derived verb stems and to other so-called pseudo-verb forms. To show this, however, we have to refer to the inflection system of Tagalog verbs. In this presentation, the relevant aspect to be dealt with is the distinction between the agentive or the experiencer versus the patient or the objective voice forms of transitive verbs, in order to describe pointedly the difference between the two distinct forms. ${ }^{2}$ For the purposes of this paper, I do not deal with the other non-agentive or non-objective voice forms.

\section{TAGALOG VERB INFLECTION}

Tagalog verbs inflect for voice and aspect (Schachter \& Otanes 1972; de Guzman 1978). Transitive verbs that take the affix -um-co-occur with the agent nominal as the subject. The same verb stems take -in, -an or $i$, depending on the subcategory, to indicate patient or objective voice, that is, the patient is the subject of the sentence. For example:

\begin{tabular}{|c|c|c|c|c|c|c|c|}
\hline (1) $\mathrm{a}$. & $\begin{array}{l}\text { humiram } \\
\text { borrowed } \\
\text { [+agtv }]^{3}\end{array}$ & ang & $\begin{array}{l}\text { bata } \\
\text { child } \\
\text { [+NOM] } \\
\text { [+Agt] }\end{array}$ & $n g$ & $\begin{array}{l}\text { libro } \\
\text { book } \\
\text { [+ACC] } \\
\text { [+Pat] }\end{array}$ & sa & $\begin{array}{l}\text { aklatan } \\
\text { library } \\
\text { [+OBL] } \\
\text { [+Loc] }\end{array}$ \\
\hline
\end{tabular}

the child borrowed a book from the library

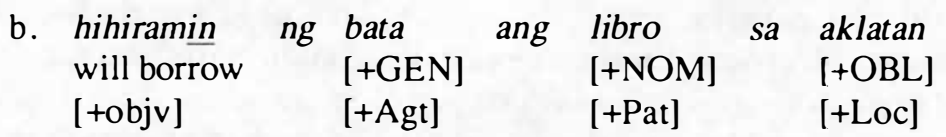

the book will be borrowed by the child from the library / the child will borrow the book from the library

There are other verb roots which are similarly marked for the agentive and the objective (patient) voices. Some of them are as follows:

${ }^{2}$ Transitive verbs treated here are those verbs that co-occur at lcast with an agentive or an experiencer and a patient or an object nominal.

${ }^{3}$ The following abbreviations are used throughout the paper:

a. Case relation/semantic role

$\begin{array}{llll}\text { Agt } & \text { Agent } & \text { NOM } & \text { nominative } \\ \text { Pat } & \text { Patient } & \text { GEN } & \text { genitive } \\ \text { Loc } & \text { Location } & \text { OBL } & \text { oblique } \\ \text { Exp } & \text { Experiencer } & \text { ACC } & \text { accusative } \\ \text { Obj } & \text { Object } & & \end{array}$

b. The features [+caus] and [-caus] stand for causative and non-causative, respectively; [+agtv] for agentive; [+exp] for experiential; [+inch] for inchoative; [+objv] for objective. 


$\begin{array}{ll}\text { tumulong/tulungan } & \text { to help } \\ \text { umabuloy/abuluyan } & \text { to contribute } \\ \text { kumuha/kunin } & \text { to get } \\ \text { bumili/bilhin } & \text { to buy }\end{array}$

tumanggap/tanggapin kumain/kainin uminom/inumin to receive

to eat

to drink

Notice that with verbs of this type, there appears to be no discernible structural basis for choosing one or the other nominal phrase to function as subject. Both the agent and the patient are possible candidates, and in both instances the verb structure is equally simple, that is, it consists of a simple verb stem or root plus its voice affix.

Yet the more interesting groups of verbs, because they are more revealing and thus more informative, are the subclasses of transitive roots that allow the patient voice marked by -in, -an or $i$ - but which never allow the formation of an agentive counterpart simply by adding the affix -um-. Some of these are listed below.

Ditransitive verbs

$\begin{array}{llll}\text { tanungin } & \text { to ask } & \text { ibigay } & \text { to give } \\ \text { sabihin } & \text { to say } & \text { ilagay } & \text { to put } \\ \text { iutos } & \text { to command } & \text { isauli } & \text { to return } \\ \text { ituro } & \text { to teach } & \\ \text { (*tumanong, }{ }^{*} \text { sumabi, }{ }^{*} \text { umutos } \text { etc.) } & & \end{array}$

(4) Simple transitive verbs

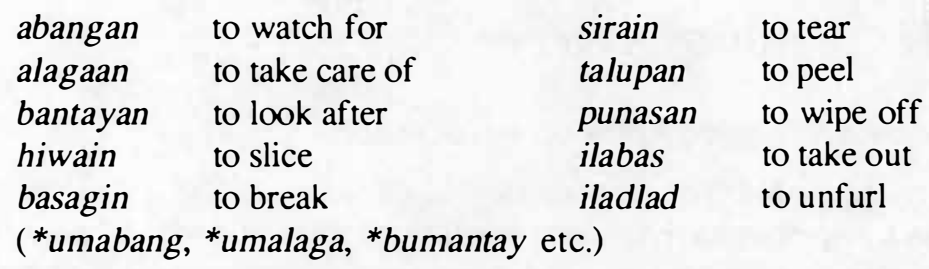

The agentive counterpart of these verb stems is better known as the mag-verbs, e.g. magtanong, magturo, mag-abang, madhiwa, magtalop etc.

In previous studies (Schachter \& Otanes 1972; Ramos 1974), mag-verbs have usually been analysed as consisting of the active voice affix mag- + verb base, with mag- being treated as one unit complementing the active voice affix -um-. A reanalysis of these verbs instead into an active affix $m-+$ pag- verb stem, however, captures two structural relationships which are concealed in the former analysis (De Guzman 1978). Firstly, $m$ rather than mag-is phonologically a closer and more viable altemant form of the voice affix -um-. It can apply generally not only to pag-stems but to pang-and paki-stems as well, morphophonemically resulting in mag-, mang- and maki-respectively, via a full nasal assimilation process. Secondly, in the same manner that a verb root can inflect for the agentive or the non-agentive voice, a pag-stem verb which derives from a verb root or another derived stem can also inflect for the agentive, the benefactive and the locative. For example, the derived stem pagluto (from pag- + luto) has the inflected forms magluto, ipagluto and paglutuan for the agentive, benefactive and locative voices respectively.

The class of pag-verb stems, then, designated for the agentive voice, among others, has a more complex morphological structure than the corresponding class of root forms which inflect for the patient voice. 


\section{DERIVED TRANSITIVE AND CAUSATIVE VERB STEMS}

It may be shown further that intransitive verbs marked by -um-, which take either a cooccurring object or an agent (actor in some literature) as the case may be, when transitivised take two different forms to inflect for the agentive and for the patient or objective voices. By conversion, the derived transitive form is identical to the intransitive root; but this transitive root form does not allow an agentive form without using a pag-stem as base. Compare the verb forms below:

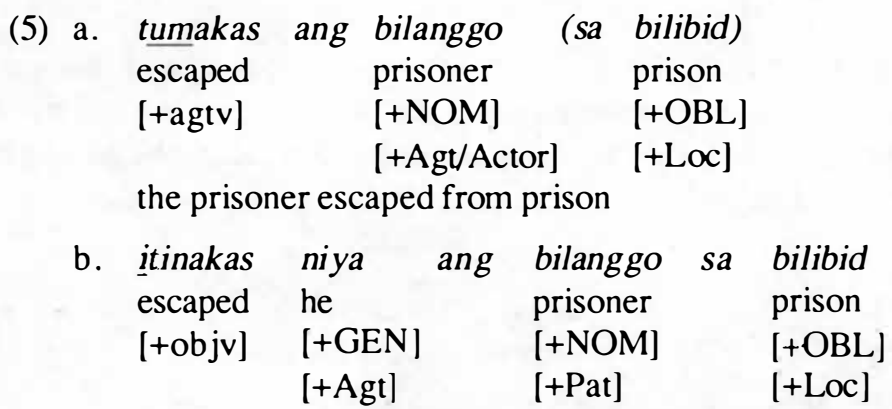

the prisoner was taken away/smuggled by him from prison (lit. the prisoner was escaped by him from prison)

$\begin{array}{clllll}\text { c. nagtakas } & \text { siya } & \text { ng } & \begin{array}{l}\text { bilanggo } \\ \text { prisoner }\end{array} & \text { sa } & \text { bilibid } \\ \text { [+agtv] } & \text { he } & & \text { prison } \\ & \text { [+NOM] } & \text { [+ACC] } & \text { [+OBL] } \\ & \text { [+Agt] } & \text { [+Pat] } & \text { [+Loc] }\end{array}$

he took away/smuggled a prisoner out of prison

Like the pag-stems derivable from roots listed in (3) and (4), the agentive voice form nagtakas in (5c) has a pag-stem derived from the derived transitive root takas in (5b), which manifests the patient voice, which in turn is derived from the intransitive root takas in (5a). Some other examples of derived transitive verbs, where a simple root takes the patient as subject and the corresponding pag-stem takes the agent as subject, are as follows:

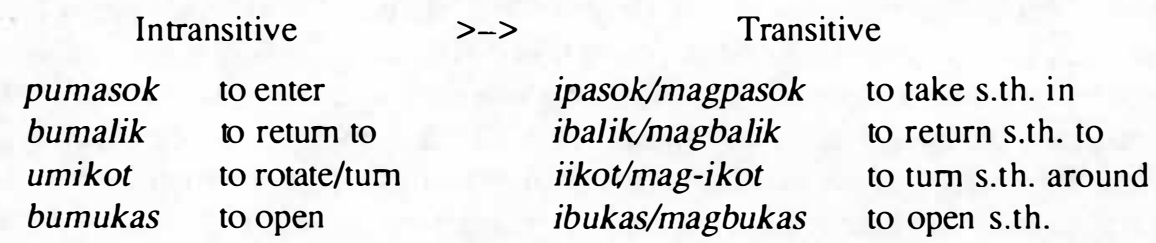

The type of derivation exhibited in the process of transitivisation above, that is, introducing an agent to perform the act indicated by the verb upon a patient, is analogous to another more general process of derivation known as causativisation. A derived causative verb stem is marked with the prefix pa-; it can be derived from an intransitive verb stem, a transitive one or another causative stem. The derived form pa- + verb root is the simplest structure of causative verb stems, and while this form inflects for the patient-as-subject, it never does for the agent. To make the causative verb stem capable of co-occurring with the newly introduced agent (sometimes referred to as causer) as subject, the only alternative way is to rederive the non-agentive causative stem into the agentive stem with the affix pag-. Inflected

${ }^{4}$ The completed aspect form of the [ $m$ - + pag-stem] verb is expressed by the replacement of initial $m$ - with $n-$. 
for the agentive voice, the verb will have the form $[m-+[$ pag- $[$ pa- + verb root $]]]$. To illustrate:

(7) a. bumagsak ang bunga

fell/dropped fruit

[-caus] [+NOM]

[-agtv] [+Obj]

the fruit fell

b. pababagsakin niya ang bunga

will-make-fall he fruit

[+caus] [+GEN] [+NOM]

[+objv] [+Agt] [+Pat]

he will make the fruit fall
c. nagpabagsak siya ng bunga
[+caus] [+NOM] [+ ACC]
[+agtv] [+Agt] [+Pat]

he made a fruit fall

Similar forms can be created from transitive root sources, as in the following:

$\begin{array}{llll}\text { (8) a. } \begin{array}{lll}\text { bumili } \\ \text { bought }\end{array} & \begin{array}{l}\text { nanay } \\ \text { mother }\end{array} & \begin{array}{l}\text { damit } \\ \text { dress }\end{array} \\ \text { [-caus] } & \text { [+NOM] } & \text { [+ACC] } \\ \text { [+agtv] } & \text { [+Agt] } & \text { [+Pat] }\end{array}$

mother bought a dress

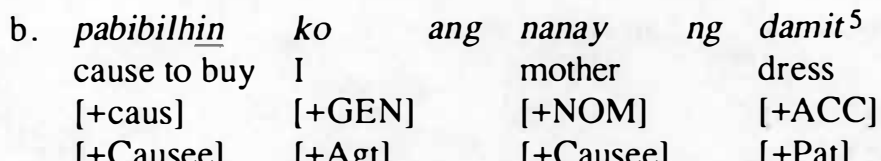

I will make mother buy a dress

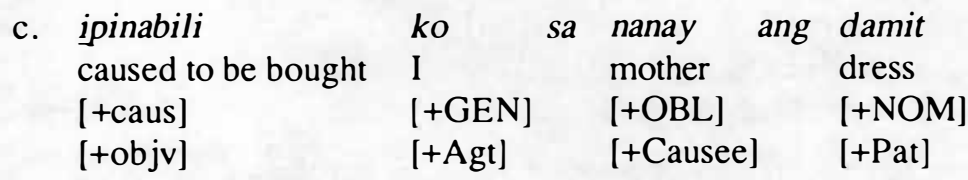

I had mother buy the dress

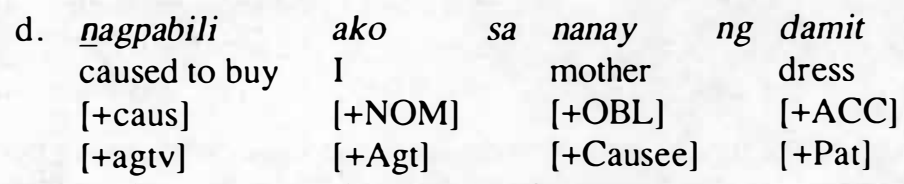

I asked mother to buy a dress (for me)

\section{PSYCHOLOGICAL OR EXPERIENTIAL VERBS}

With psychological or experiential verbs, the experiencer in place of an agent co-occurs with an object or stimulus instead of a patient. Unlike the patient nominal, which is

\footnotetext{
5 It will be observed that the nominal marked [+Causee] co-occurring with the causative verb functions like that of a patient or object as shown by the objective voice marker -in.
} 
semantically the object affected by the action the agent performs on it, the object co-occurring with a psychological verb is unaffected; it is acting as a stimulus responsible for what the experiencer perceives or feels. If we assume that the agent is more primary than the patient in being used as the grammatical subject, we would likewise expect the experiencer to be primary over that of the object in this type of transitive verb. Correspondingly, the morphological structure of the experiencer (or dative) voice form should be simpler than that of the relative objective voice form. We find these assumptions true of only a small subclass of verbs which may be labelled emotion verbs. The structure may be described as consisting of the affix ma- + root. For example:

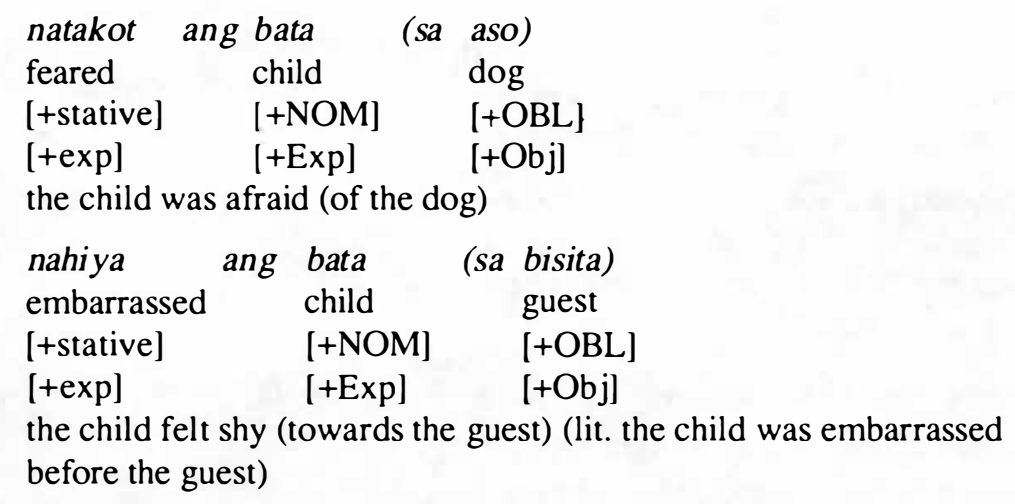

$\begin{array}{llc}\begin{array}{l}\text { nahiya ang } \\ \text { embarrassed }\end{array} & \begin{array}{l}\text { bata } \\ \text { child }\end{array} & \begin{array}{r}\text { (sa bisita) } \\ \text { guest }\end{array} \\ \begin{array}{l}\text { [+stative] } \\ \text { [+exp] }\end{array} & \text { [+NOM] } & \text { [+OBL] } \\ \text { [+Exp] } & \text { [+Obj] }\end{array}$

To show the corresponding objective voice forms of the verbs above, we have the following sentences in which the verb forms are made up of a more complex structure [[ka- stem]+ -an]:

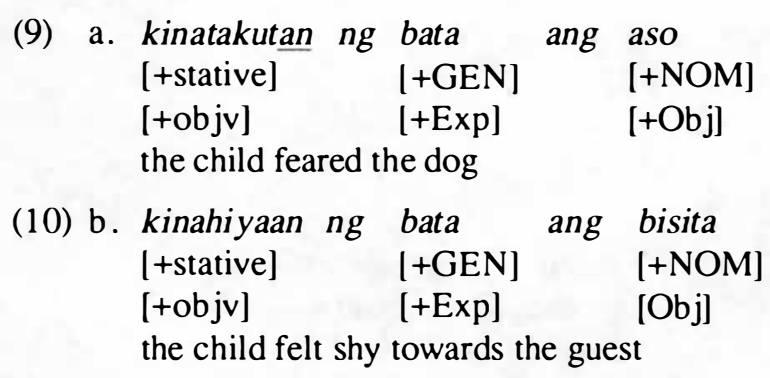

Other verbs that belong to this category of emotion verbs are as follows:

$\begin{array}{llll}\text { magalit } & \text { be angry with } & \text { mayamot } & \text { be annoyed with } \\ \text { matuwa } & \text { be delighted with } & \text { masuya } & \text { be satiated with } \\ \text { mainis } & \text { be irritated with } & \text { masuklam } & \text { be disgusted with }\end{array}$

On the other hand, the majority of psychological verbs have the same form, ma- + root, but they select the object nominal as the grammatical subject. To make the co-occurring experiencer subject of the sentence, the affix ma- has to attach to the more complex stem form with the $k$ a- prefix. $^{6}$ We can compare the objective voice forms with [ma- + root] and the corresponding experiencer forms with $[m a-+[k a-s t e m]]$ in the following examples:

\footnotetext{
${ }^{6}$ Note that the prefixes ma- and maka- are not identified as voice affixes but as derivationals indicating a stative or a psychological type of verb. It will be observed that both the objective and experience voice forms manifest this ma- affix. The expericncer form is considered more complex in that it can be analysed as ma- +
} 
(12)
a. nakita
saw
[+stative]
[+objv]
ng mga
bata
PLURAL child
ang palabas
$[+\mathrm{GEN}]$
[+Exp]
show
[+NOM]

the children saw the show / the show was seen by the children
b. nakakita ang mga bata ng palabas
saw
[+stative]
[+exp]

\begin{tabular}{|c|c|}
\hline & $\begin{array}{l}\text { child } \\
\text { [+NOM] } \\
\text { [+Exp] }\end{array}$ \\
\hline
\end{tabular}

the children saw a show

Other verbs that fall into this subclass, showing their objective and experiencer voice forms with the same structure as above, are as follows:

$\begin{array}{ll}\text { marinig/makarinig } & \text { to hear } \\ \text { matanaw/makatanaw } & \text { to see/view } \\ \text { maalala/makaalala } & \text { to remember } \\ \text { mabatid/makabatid } & \text { to know } \\ \text { mahalata/makahalata } & \text { to detect from someone's behaviour } \\ \text { maramdam }(a n) / \text { makaramdam } & \text { to feel or sense something }\end{array}$

It appears that the more complex verb form with [ma- + [ka-stem]] is distinct enough to identify the experiencer (or dative) voice in contrast with the simpler object voice form I ma+ root]. This complex voice form is therefore seen as being analogous to the agentive voice in which the ma-affix seems to correspond to a psychological feature, that is, stative or emotion or perception, and the distinction in terms of the structure of the stem, whether a root or a $k a$-stem, to which this ma- affix is attached signals the difference between objective and experiencer voice forms respectively. Thus, in transitive active verbs as well as in transitive psychological verbs, the patient or the objective voice form is invariably simpler in internal structure, that is, root + affix or affix + root, than the agentive or experiencer counterpart, which usually takes an affix + affixed-stem (with pag-, pang-, paki- or ka-).

\section{TRANSITIVE VERBS DERIVED FROM ADJECTIVES AND NOUNS}

Similar to derived transitive and causative verbs, transitive verbs which are derived from adjectives and nouns occur in their simplest stem form when the co-occurring grammatical subject is the patient or object and not the agent. For example:

\begin{tabular}{|c|c|c|c|}
\hline & & & to scare s.o. \\
\hline galit & anger & galitin & to make s.o angry \\
\hline inis & contempt & inisin & $\begin{array}{l}\text { to irritate s.o./to make s.o. } \\
\text { contemptuous }\end{array}$ \\
\hline gulat & surprise & gulatin & to surprise s.o. \\
\hline
\end{tabular}

ka-stem; ka-stems can also be inflected for other voices. For a discussion of this analysis, see De Guzman (1978:151-158). 
Verbs of use

\begin{tabular}{|c|c|c|c|}
\hline adobo & a braised dish & adobohin & to make/cook into a braised dish \\
\hline & wood & huyl & to use as firewood \\
\hline ara & plow & araruhin & to plow in/to use a plow on s.th. \\
\hline $\begin{array}{l}\text { kumot } \\
\text { martilyo }\end{array}$ & $\begin{array}{l}\text { blanket/sheet } \\
\text { hammer }\end{array}$ & $\begin{array}{l}\text { kumutin } \\
\text { martilyuhin }\end{array}$ & $\begin{array}{l}\text { to use a blanket/sheet } \\
\text { to hammer s.th. }\end{array}$ \\
\hline
\end{tabular}

(16) Verbs of affect

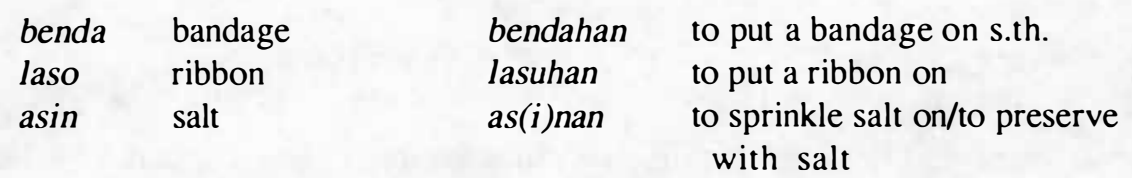

From the above examples, it does not seem coincidental that such transitive verbs in root form occur more frequently than their corresponding pag-or pang-active forms, as the case may be. They parallel those transitive verbs which do not have corresponding active voice forms such as transitive verbs derived from inchoative verbs as follows:

\begin{tabular}{lllll}
\multicolumn{2}{c}{ Adjective $>->$} & \multicolumn{2}{c}{ Inchoative $>->$} & \multicolumn{1}{c}{ Transitive } \\
ma-laki big & $l-u m-a k i$ & to become big & lakih-an to make s.th. big \\
ma-tamis sweet & $t$-um-amis & to become sweet & tamis-an to make s.th. sweet \\
ma-alat salty & um-alat & to become salty & alat-an to make s.th. salty
\end{tabular}

In turn, these transitive verbs which derived from inchoative verbs, which in turn derived from adjectives, are akin to the causative counterpart of inchoative verbs which in their simplest forms also take the patient as subject. For example:

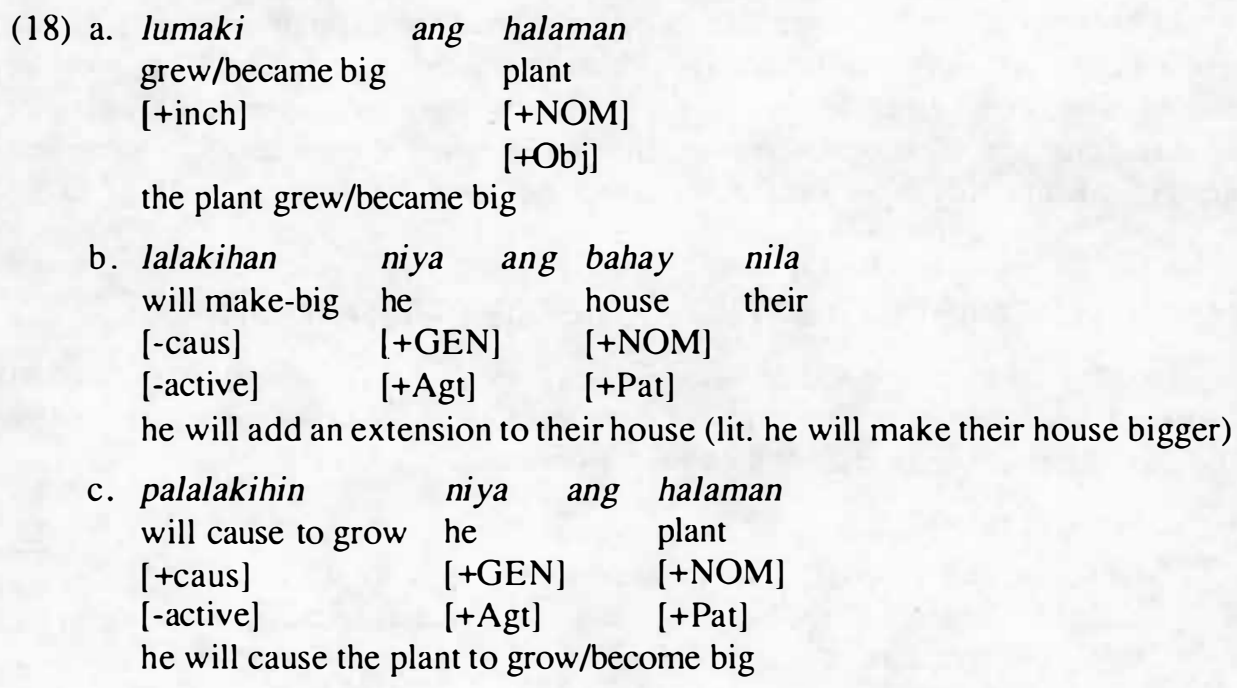

\section{PSEUDO-VERBS}

Finally, a class of semantically stative verbs, identified as pseudo-verbs for being unmarked for voice (Schachter \& Otanes 1972:384f.), never co-occurs with the agent or the experiencer as subject. They are usually subjectless. However, the one possibility of its taking a subject is when the patient or object is made definite. Thus: 
(19)
a. gusto ko
ng ubas
like
I
[+stative] [+GEN]
grapes
I like grapes
[+Exp]
$[+\mathrm{ACC}]$
[+Obj]

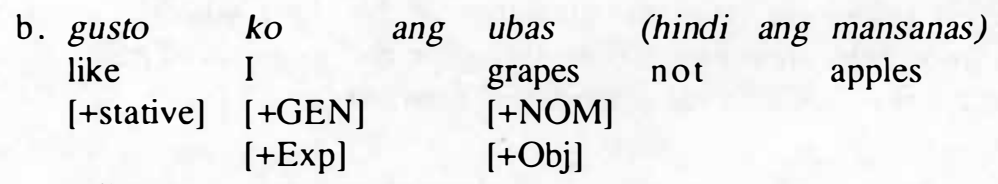

I like the grapes (not the apples)

Some other pseudo-verbs which exhibit the same syntactic behaviour are:
ibig want/desire
nais desire
ayaw don't like/don't want
kailangan need

Another set of state verbs similar in form to the preceding type can occur without a voice affix only when the patient is the co-occurring subject. For example:

$\begin{array}{llll}\begin{array}{l}\text { akay ni } \\ \text { led-by-hand }\end{array} & \text { Berto ang } & \begin{array}{l}\text { bata } \\ \text { child }\end{array} \\ \text { [-caus] } & \text { [+GEN] } & \text { [+NOM] } \\ \begin{array}{l}\text { [+stative] } \\ \text { the child is led by the hand by Berto }\end{array} & \text { [+Agt/Exp] }\end{array}$

(22)

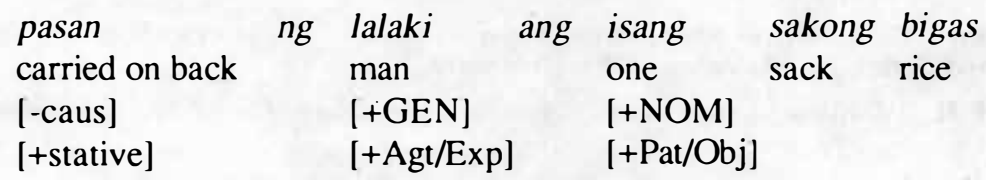

a sack of rice is carried on his back by the man

Other verbs of this type are as follows:

$\begin{array}{llll}\text { hawak } & \text { held in hand } & \text { ari? } & \text { possessed; owned } \\ \text { dala } & \text { carried } & \text { sakop } & \text { covered; included; in domain of } \\ \text { taban } & \text { handled; grasped } & \text { mahal } & \text { loved }\end{array}$

\section{CONCLUSION}

From the point of view of morphological formation, voice inflection in particular, the analysis of the agentive voice form as consisting of the allomorph $\mathrm{m}$ - (an alternant of the active voice affix -um-) plus a pag-stem provides a clear contrast in structural complexity with that of the patient voice form which is made up of the voice affix -in, -an or $i$ - and a root. Likewise with state verbs that take [ma- + root] versus [ma- $+k a-$ stem] to indicate an objective voice and an experiencer voice respectively, the form is obviously comparatively simpler than the latter. In sum, based on the number of subtypes of verbs that have been presented here showing the objective or patient voice forms as being simpler or less marked in internal structure than their corresponding agentive or experiencer voice forms, if such forms are permitted, it is safe to conclude that morphologically, the patient or object is the nominal favoured or preferred to function as the grammatical subject in a Tagalog predicative sentence. 
One implication that may be drawn from this conclusion with reference to typology is that Tagalog, manifesting verb roots that take either agent or patient as subject as well as verb roots that take only patient as subject, may be regarded synchronically as a mixed ergativeaccusative type, that is, where the patient as subject co-occurs with the unmarked or least marked verb stem; and that the development of the accusative system started with the active affix -um- operating in certain classes of transitive verbs along with the creation of a productive activisation rule. This rule presumably gave rise to pag-and pang-stems and, simultaneously, to the alternant af fix $m$ - of the earlier active voice affix $-u m-.^{7}$

\section{REFERENCES}

CENA, R.M., 1977, Patient primacy in Tagalog. Paper read at the Linguistic Society of America Winter Meeting, Chicago, Illinois.

De GUZMAN, Videa P., 1978, Syntactic derivation of Tagalog verbs. (Oceanic Linguistics Special Publication No.16). Honolulu: The University Press of Hawaii.

1988, Ergative analysis for Philippine languages: an analysis. In R. McGinn, ed. 1988:323-245.

GALANG, Rosita G., 1982, The acquisition of Tagalog verb morphology: linguistic and cognitive factors. Philippine Journal of Linguistics 13/2:1-15.

GERDTS, Donna B., 1988, Antipassives and causatives in Ilokano: evidence for an ergative analysis. In R. McGinn, ed. 1988:295-321.

H YMAN, Larry M., 1975, Phonology: theory and analysis. New York: Holt, Rinehart and Winston.

KLAUSENBURGER, Jurgen, 1986, Two aspects of morphological naturalness. The Canadian Journal of Linguistics 31/4:327-342.

McGINN, R., ed., 1988, Studies in Austronesian linguistics. Monographs in International Studies, Southeast Asia Series, No.76. Athens: Ohio University.

MATTHEWS, P.H., 1974, Morphology: an introduction to the theory of word-structure. London: Cambridge University Press.

RAMOS, Teresita V., 1974, The case system of Tagalog verbs. PL, B-27.

ROWSELL, Lorna V., 1983, An ergative analysis of Kapampangan. MA thesis, Department of Linguistics. The University of Calgary.

SCHACHTER, Paul, 1976, The subject in Philippine languages: topic, actor, actor-topic, or none of the above? In C.N. Li, ed. Subject and topic, 491-561. New York: Academic Press.

1977, Reference-related and role-related properties of subjects. In P. Cole and J. Sadock, eds Syntax and Semantics, vol.8: Grammatical relations, 279-306. New York: Academic Press.

SCHACHTER, Paul and Fe T. OTANES, 1972, Tagalog reference grammar. Los Angeles: University of California Press.

${ }^{7}$ There are recent works that analyse Tagalog and other Philippine languages as belonging to the ergative type of languages (Gerdts 1988; De Guzman 1988; Rowsell 1983), and consequently the terms used in those papers for the nominal case marking do not correspond to the labels in this paper. 


\title{
THE PHONOLOGY OF YUANGA, A LANGUAGE OF NEW CALEDONIA
}

\author{
STEPHEN J. SCHOOLING
}

\section{INTRODUCTION}

\subsection{DEMOGRAPHY}

The Yuanga language is spoken in the northem region of the island of New Caledonia, which is a French Overseas Territory situated 1,500 kilometres to the east of the coast of Australia.

According to the more recent statistics (published in 1976) Yuanga is spoken by approximately 2,000 people. The Gomen dialect of Yuanga is spoken by the 800 people who live on the western coastal plain of the island in the vicinity of the village of KaalaGomen, and it is this dialect that is described here. ${ }^{1}$ Two other major dialects of Yuanga can be phonologically distinguished from the Gomen dialect by the absence of the interdental fricative and the retroflexed stops. Nonetheless, all three dialects are mutually intelligible and are recognised by local people, and other linguists, as belonging together in contradistinction to other neighbouring languages. One dialect (population 550) is spoken in the valley of the river Diahot in the environs of the Catholic Mission Station at Bondé, 30 kilometres due north of Gomen. A community which originated from the Bondé area moved eastwards at some point in the past and is now living at St Paul on the north-east coast of the island, near the village of Pouébo. The other important dialect (population 420) is spoken in the region

\footnotetext{
${ }^{1}$ The data for this study were gathered over a period of five months in 1982 and 1983 in the village of Paita, which is located three miles to the east of the small town of Kaala-Gomen.

The research was conducted under the auspices of the Summer Institute of Linguistics and in cooperation with the Melanesian Cultural Institute of Noumea, New Caledonia. I am grateful to the Territorial Government and the Western Administrative Sub-Division for the permission to undertake this enterprise.

I would also like to express my appreciation to the chief of the Gomen region, the chiefs of Paita and Baganda, and the Council of Elders and the people of Paita for their gracious welcome and spontaneous generosity throughout the length of our stay with them. We are particularly indebted to the Teinweiawe family for the loan of their house, and also to Pastor Pidjot Teinweiawe, Chief Bealo Teity, Deacon Caina Teity and Mr Mangoulou Teinweiawe for their infinite patience and great devotion to the task of revealing to us the intricacies of their language.

Last, but by no means least, is my wife, Janice, to whom I owe an immeasurable debt, not only for her practical help in the collection of data during our stay at Paita, but also for her unswerving support throughout every stage of this project.
} 
known as Paimboas, in the central mountain chain 15 milometres to the east of the GomenBondé axis. (See Schooling 1982:13) and Rivierre (1981) for maps of the region.)

The language takes its name from a river which crosses the plain near Gomen. In this region in which the name originated, Yuanga is pronounced [Ouaßa]. It is also known locally as phwa jua 'the language (lit. mouth) of Oua'.

\subsection{LINGUISTIC CLASSIFICATION AND HISTORY OF RESEARCH}

According to the classificatory work undertaken by Haudricourt $(1951,1971)$ and Rivierre (1972), Yuanga belongs to the Austronesian family of languages, as do all the languages of New Caledonia. As far as internal classification is concerned, Haudricourt (1971) has classified Yuanga with the languages of the extreme north of New Caledonia.

In the course of his surveys Haudricourt $(1968,1971)$ noted some idiosyncratic features of the Gomen dialect of Yuanga, namely the presence of four degrees of aperture in the system of vowels and two orders of apical consonants in the consonantal system. Since that time Coyaud (1975) and Michailovsky (1982) of the Centre National de Recherches Scientifiques of Paris have conducted further research on the dialect of Yuanga spoken at Bondé and Paimboas, but no other work has been undertaken on the Gomen dialect, apart from the reference in Leenhardt (1946) whose monumental work still remains the point of departure for all linguistic research in New Caledonia.

The early Catholic missionaries also undertook basic linguistic work and in 1893 a catechism was published in the Bondé dialect. Local people report that the Paris Missionary Society printed some portions of the New Testament in the Gomen dialect in the 1930s but at the present time there are no copies in current use. At about the same time Protestant pastors also prepared a liturgy in the same dialect, which is still sometimes used.

\subsection{THEORETICAL FRAMEWORK OF PRESENTATION}

The purpose of this paper is to describe the phonology of the Gomen dialect of the Yuanga language. In sections 2--4 a model of linguistic analysis variously known as the 'Structure-Function' or the 'Syntagmatic Model' is used to analyse and describe the data.

This model was first conceived of by J.T. Bendor-Samuel, following training at the University of London and fieldwork conducted in South America, as a practical descriptive methodology for trainee linguists, and it was developed and refined over many years of teaching at the British School of the Summer Institute of Linguistics. In its fully developed form, the model clearly belongs to the structuralist tradition and has particularly clear affinities with the tagmemic approach developed by K.L. Pike (1967) and E.V. Pike (1976). It has been exemplified by numerous descriptions of natural languages, such as those by Callow (1962), Meier, Meier and Bendor-Samuel (1975), Naden (1973), Thomas (1978) and Nicole (1979). The model itself has been presented in some detail by Naden (1971) and more recently by Nicole (1981).

It is the hope of all of us who were involved in this work that this phonological study will not be an end in itself but merely one step towards a more practical goal, namely the preparation of a practical orthography for the Yuanga language. 
The syntagmatic approach to linguistics recognises three distinct levels of linguistic reality, each of which is viewed as an essentially autonomous hierarchy of ranks. The three levels are the phonological, the syntactic and the semantic, with the phonological hierarchy being the level which is of interest in this presentation. The lowest rank of the phonological hierarchy is that of the phoneme, which is used in the classical sense of the term, and as such it forms the focal point upon which the entire description of the phonology of a language hinges.

Within the perspective of this model the number of distinct ranks within the hierarchy is not universal but is language specific. In the analysis of Yuanga, reference is made to the following ranks which are listed in ascending order: phoneme, syllable, phonological word, phonological phrase and intonation group.

The second major characteristic of the model is that each unit used in the analysis of a language is defined in terms of its structure and its function. The structure of a unit, which pertains to any given rank of the hierarchy, is defined in terms of units which belong to the next lower rank, and its function is defined in terms of its role or position in the next higher rank of the hierarchy. Thus for example, the structure of the unit called a syllable is described in terms of phonemes, units of the next lower rank, while its function is described in terms of its place in the next higher rank, that of the phonological word in the case of Yuanga. The structure of the phoneme cannot, by definition, be described in terms of smaller units since it already belongs at the lowest rank of the hierarchy, and so it is described instead in terms of its phonetic realisation in different contexts. Units of any rank are grouped into types on the basis of similarity of structure and into classes on the basis of similarity of function.

In this study the phoneme rank is dealt with in considerable detail, whereas the higher level ranks are presented in much less detail, and in some cases the hypotheses propounded are subject to subsequent verification.

In section 6 the same data is reappraised from the perspective of the model of Prosodic Analysis and then, very briefly, from the more recent perspective of Autosegmental Phonology.

\section{A PHONEMIC ANALYSIS OF YUANGA}

\subsection{DEFINITION OF A PHONEME}

In the context of the Syntagmatic Model being used for this analysis, the phoneme is the smallest contrastive unit in the phonological system of a language. Since it constitutes the lowest level of the hierarchy, it is not composed of lower level units, but it can be described in terms of the acoustic and articulatory parameters which define its phonetic manifestation as it occurs in different positions in a syllable or phonological word.

There are two primary classes of phoneme, namely consonants and vowels. This distinction is based not only on phonetic features but also on functional differences. All phonemes function as components of syllables which are the units comprising the next higher level in the phonological hierarchy. In general, however, a consonant functions as the margin of the syllable while a vowel functions as its nucleus. 


\subsection{THE CONSONANTAL PHONEMES}

The consonantal system of Yuanga can be analysed in terms of three types of articulation and three zones of articulation. The three types of those of closure, nasality and aspiration, while the three zones are labial, apical or central, and dorsal. These three zones can in turn be subdivided into eight more precise points of articulation. All of the above information is summarised graphically in Table 1, while the phonetic realisation of each phoneme is described in section 2.2.1.

TABLE 1: THE CONSONANT PHONEMES

\begin{tabular}{|c|c|c|c|c|c|c|}
\hline & labial & $\begin{array}{l}\text { BIAL } \\
\text { labio-velar }\end{array}$ & interdental & $\begin{array}{l}\text { APICAL } \\
\text { postdental }\end{array}$ & palatalised & DORSAL \\
\hline $\begin{array}{l}\text { STOPS } \\
\text { unaspirated } \\
\text { OR A L } \\
\text { aspirated }\end{array}$ & $\begin{array}{l}p \\
p h\end{array}$ & $\begin{array}{l}p w \\
p h w\end{array}$ & th & thr & $\begin{array}{l}\text { ty } \\
\text { thy }\end{array}$ & $\begin{array}{l}k \\
k h\end{array}$ \\
\hline NASAL & $m p$ & $m p w$ & $n t$ & $n t r$ & nty & $n k$ \\
\hline $\begin{array}{l}\text { CONTINUANTS } \\
\text { unaspirated } \\
\text { OR A L } \\
\text { aspirated }\end{array}$ & $\begin{array}{l}f \\
f h\end{array}$ & $\begin{array}{l}\text { wh } \\
\text { wh }\end{array}$ & $j$ & $\begin{array}{l}l \\
(l h)\end{array}$ & $\begin{array}{l}y \\
y h\end{array}$ & $\begin{array}{l}x \\
h\end{array}$ \\
\hline $\begin{array}{l}\text { unaspirated } \\
\text { NASAL } \\
\text { aspirated }\end{array}$ & $\begin{array}{l}m \\
m h\end{array}$ & $\begin{array}{l}m w \\
m h w\end{array}$ & & nhy & ny & $n g$ \\
\hline
\end{tabular}

In addition to the phonemes displayed in Table 1, the speakers of Yuanga also use the phonemes $/ \mathrm{s} /$ and $/ \mathrm{r} /$. However these phonemes occur only in words borrowed from European languages, for example:

$$
\begin{array}{ll}
\text { /siro/ } & \text { soft drink (from French sirop) } \\
\text { /kirikèt/ } & \text { cricket }
\end{array}
$$

It is to be noted that in Yuanga, as in most Oceanic languages, the voiced-voiceless correlation is not relevant. Consequently, these terms are not used in Table 1 nor in the technical descriptions of the phonemes, except in those cases where voicing is a nonphonemic characteristic of certain variants. A general statement can be made to the effect that all oral stops are voiceless except in intervocalic position, where voiced variants usually occur. The oral continuants are generally voiced, especially in intervocalic position, but there is a tendency towards free variation in word-initial position. All the nasals, both stops and continuants are voiced.

The postdental stops are produced with a retroflex articulation and the symbol $/ \mathrm{j} / \mathrm{is}$ realised phonetically as $[\theta]$. It is probable that $/ \mathrm{h} /$ does not occur as an independent phoneme in the speech of the majority of present-day speakers of Yuanga (as explained in section 4.4.2).

Haudricourt (1971:364) makes a distinction between retroflex interdental nasals (both aspirated and unaspirated) for the Gomen dialect of Yuanga. In the course of this present 
study, however, no evidence was found for this contrast. The apical nasals which were noted normally had an interdental realisation, although they can also optionally have a dental realisation.

The Gomen dialect is unique among the dialects of Yuanga in that consonants only appear in pre-nuclear position in the syllable, functioning as syllable onset, and never in postnuclear position, functioning as syllable coda.

\subsubsection{TECHNICAL DESCRIPTION OF THE CONSONANTS}

In this section the phonetic realisation of each of the consonant phonemes is described. Examples of each of the contrasts are presented in section 3, while intervocalic variants are discussed and exemplified in section 4.3. Difficulties experienced in the choice of terms, such as aspiration, are explained in section 4.4.

All the phonemes in Yuanga are produced with egressive lung air. All the consonants are interpreted as being phonologically voiceless (as stated in section 2.2 above).

\section{STOPS}

Labial order

/p/ is an unaspirated bilabial stop [p].

It may have a voiced realisation [b] in intervocalic position.

/ph/ is an aspirated bilabial stop [ $\left.\mathrm{p}^{\mathrm{h}}\right]$.

/pw/ is an unaspirated labio-velar stop $\left[\mathrm{p}^{\mathrm{w}}\right]$.

It may have a voiced realisation $\left[\mathrm{b}^{\mathrm{w}}\right]$ in intervocalic position.

$/ \mathrm{mp} / \quad$ is a prenasalised bilabial stop [mb].

$/ \mathrm{mpw} / \quad$ is a prenasalised labio-velar stop [ $\left.\mathrm{mb}^{\mathrm{w}}\right]$.

Apical order

It is an unaspirated interdental stop [t].

It may have a voiced realisation [d] in intervocalic position.

$/$ th/ is an aspirated interdental stop $\left[\mathrm{t}^{\mathrm{h}}\right]$.

/tr/ is an unaspirated retroflexed stop [t ].

It may have a voiced realisation [d] or a flapped realisation [ $\mathrm{r}]$ in intervocalic position.

/thr/ is an aspirated retroflexed stop [ $[\mathrm{h}]$.

/ty/ is an unaspirated apico-alveolar palatalised stop [ $\left.\mathrm{t}^{\mathrm{j}}\right]$.

It may have a voiced realisation $\left[\mathrm{d}^{\mathrm{j}}\right]$ in intervocalic position.

/thy/ is an aspirated apico-alveolar palatalised stop [ $\left.\mathrm{t}^{\mathrm{jh}}\right]$.

$\mathrm{ht} / \quad$ is a prenasalised interdental stop [ $\left.{ }^{\mathrm{n}} \mathrm{d}\right]$.

/ntr/ is a prenasalised retroflexed stop [ $\left.{ }^{\mathrm{n}} \mathrm{d}\right]$.

/nty/ is a prenasalised apico-alveolar palatalised stop [ $\left[{ }^{\mathrm{n}} \mathrm{d}\right]$. 
Dorsal order

$\mathrm{kJ} \quad$ is an unaspirated velar stop [k].

In intervocalic position it may be realised interchangeably as a stop or as a voiced $[\gamma]$ or voiceless $[\mathrm{x}]$ velar fricative.

$\mathrm{kh} / \quad$ is an aspirated velar stop $\left[\mathrm{k}^{\mathrm{h}}\right]$.

/nk/ is a prenasalised velar stop [ $\mathrm{g}$ ].

\section{CONTINUANTS}

Labial order

/f/ is an unaspirated labio-dental fricative.

Its phonetic realisation is voiced [ $\mathrm{v}]$.

/fh/ is an aspirated labio-dental fricative.

Its phonetic realisation can be voiced $\left[\mathrm{v}^{\mathrm{h}}\right]$ or voiceless [ $\left.\mathrm{f}^{\mathrm{h}}\right]$.

/w/ is an unaspirated labio-velar oral approximant [w].

/wh/ is an aspirated labio-velar oral approximant $\left[\mathrm{w}^{\mathrm{h}}\right]$.

$/ \mathrm{m} / \quad$ is an unaspirated bilabial nasal continuant $[\mathrm{m}]$.

$/ \mathrm{mh} / \quad$ is an aspirated bilabial nasal continuant $\left[\mathrm{m}^{\mathrm{h}}\right]$.

$/ \mathrm{mw} /$ is an unaspirated labio-velar nasal continuant $\left[\mathrm{m}^{\mathrm{w}}\right]$.

/mhw/ is an aspirated labio-velar nasal continuant $\left[\mathrm{m}^{\mathrm{w}^{\mathrm{h}}}\right]$.

\section{Apical order}

/j/ is an unaspirated interdental fricative $[\theta]$.

It may have a voiced realisation [ $\delta]$ in intervocalic position.

N/ is an unaspirated apico-alveolar lateral continuant. Its phonetic realisation is normally voiced [1].

(lh) is an aspirated lateral but probably is not an integral part of the phonological system of Yuanga. (See section 4.4.2 for a discussion of this symbol.)

$/ \mathrm{n} / \quad$ is an unaspirated interdental nasal continuant $[\mathrm{n}]$.

/nh/ is an aspirated interdental nasal continuant $\left[\mathrm{n}^{\mathrm{h}}\right]$.

$/ y / \quad$ is an unaspirated palatal approximant $[\mathrm{j}]$.

/yh/ is an aspirated palatal approximant $\left[\mathrm{j}^{\mathrm{h}}\right]$.

/ny/ is an unaspirated nasal continuant with a palatalised apico-alveolar articulation [n]

/nhy/ is an aspirated nasal continuant with a palatalised apico-alveolar articulation $\left[\boldsymbol{j}^{\mathrm{h}}\right]$. 
Dorsal order

$\mid \mathrm{x} / \quad$ is an unaspirated velar fricative $[\mathrm{x}]$.

It may have a voiced realisation $[\gamma]$ in intervocalic position.

$\mathrm{h} / \quad$ is a laryngeal fricative $[\mathrm{h}]$.

Its realisation is always voiceless but in intervocalic position it is usually deleted.

/ng/ is an unaspirated velar nasal continuant [ $\mathrm{g}]$.

\subsection{THE VOCALIC PHONEMES}

In the Gomen dialect there are twelve contrastive vowel qualities, of which seven are oral and five are nasal. They are distinguished by four degrees of aperture for the oral vowels and three degrees of aperture for the nasals. The distinction between the second and third degrees of aperture is not contrastive when the vowels are nasalised. The lips are spread for the front vowels and rounded for the back vowels, with this distinction being irrelevant for the vowel formed by the maximum degree of aperture. The vocalic system is schematically presented in Table 2, and the phonetic description of the phonemes follows.

The circumflex is used in both phonemic and phonetic notation to denote the strong, contrastive type of nasalisation, while the tilde is used to mark non-contrastive nasalisation in phonetic script.

TABLE 2: THE VOWEL PHONEMES

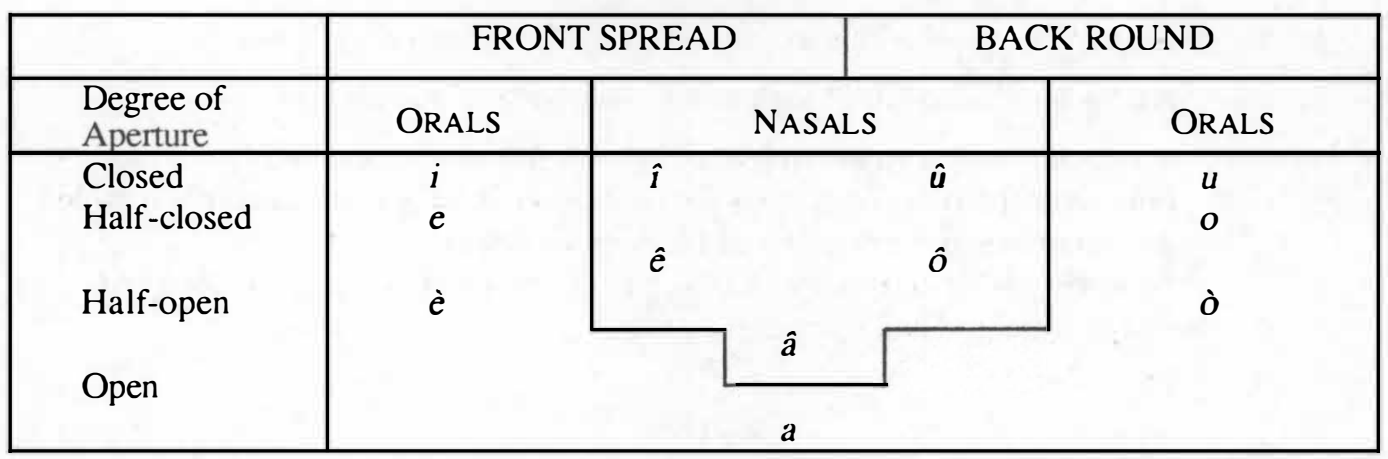

Vowel length is also contrastive, and in principle all vowels can be either short or long (see section 4.5.3).

\subsubsection{TECHNICAL DESCRIPTION OF THE VOWELS}

(A complete set of examples of all the phonemes will be found in section 3.)

Oral vowels

il is a front spread vowel with minimum degree of aperture [i]. 
le/ is a front spread vowel with a half-closed degree of aperture [e].

Following all palatalised stops and (in principle) the palatalised oral continuants, the realisation of /e/ is more closed and slightly backed [l].

Examples:

$\begin{array}{lll}\text { /tyi/ } & {\left[\mathrm{t}^{\mathrm{i}}\right]} & \text { pawpaw tree } \\ \text { /tye/ } & {\left[\mathrm{t}^{\mathrm{j}} \mathrm{l}\right]} & \text { wood } \\ \text { /-ntye/ } & {\left[{ }^{\mathrm{n}} \mathrm{d}^{\mathrm{j}} \mathrm{l}\right]} & \text { third person singular possessive }\end{array}$

le/ is a front spread vowel with a half-open degree of aperture $[\varepsilon]$.

Following the palatalised stops and the oral palatalised continuants the realisation of $/ \mathrm{e} /$ is more closed and is very similar to the normal pronunciation of $/ \mathrm{e} /$.

Following another vowel the realisation of $/ \mathrm{e} / \mathrm{is}$ much more closed and resembles the realisation of /e/. It is probable that there is neutralisation of the /e/ - /e/ contrast in this context. Thus far no examples have been found to disprove this hypothesis.

Examples:

\begin{tabular}{|c|c|c|}
\hline /tyè(nU)/ & {$[\mathrm{tje}(\mathrm{nũ})]$} & (my) food \\
\hline /ntyènAV & [ndjenã] & there/that's right \\
\hline /yèpwa/ & {$\left[j e b^{w} a\right]$} & when \\
\hline /kaè/ & [kae] & pumpkin \\
\hline
\end{tabular}

The capital letters in the above examples (and likewise in any other examples) represent archiphonemes (see section 4.2.4).

/a/ is a central vowel with maximum degree of aperture [a].

$\mathrm{lu} / \quad$ is a back rounded vowel with minimum degree of aperture [u].

/o/ is a back rounded vowel with a half-closed degree of aperture [o].

Following the labio-velar stops the realisation of $/ \mathrm{o} /$ is more markedly rounded and resembles the realisation of the pure [o] vowel.

Following other consonants $/ \mathrm{o} /$ has a realisation which is less rounded and more centralised and resembles [Q].

Examples:

$\begin{array}{lll}/ \mathrm{mpo} / & {\left[\mathrm{mb}^{\mathrm{b}}\right]} & \text { a wall } \\ / \mathrm{mpwo} / & \left.\mathrm{mb}^{\mathrm{w}} \mathrm{o}\right] & \text { rotten }\end{array}$

/o/ is a back rounded vowel with a half-open degree of aperture [0].

Following labio-velar stops and labio-velar nasal continuants, the realisation of $\mathrm{fo} /$ is more sharply rounded and even more closed than the pure vowel [0].

Following other consonants the pronunciation is more relaxed open and centralised than the pure [0].

Following another vowel the realisation of $/ 0 /$ is much more closed and resembles $|0|$ or even [Q]. It is probable that there is neutralisation of the contrast $/ \mathrm{o} /-\mathrm{o} /$ in this context.

Examples:

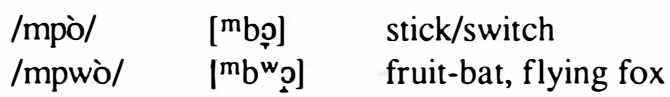




\begin{tabular}{|c|c|c|}
\hline$/ \mathrm{mO} /$ & [mõ] & left (direction) \\
\hline$/ \mathrm{mwO} /$ & {$\left[\mathrm{m}^{\mathrm{w}} \tilde{\mathrm{D}}\right]$} & pot \\
\hline$/ \mathrm{mhO} /$ & {$\left[\mathrm{m}^{\mathrm{h}} \tilde{\tilde{D}}\right]$} & we three (inclusive) \\
\hline$/ \mathrm{mhwO} /$ & {$\left[\mathrm{m}^{\mathrm{hw}} \tilde{\mathrm{D}}\right]$} & wrinkle \\
\hline$/ \mathrm{kaO} /$ & [kao] & flood \\
\hline
\end{tabular}

Nasal vowels
[il
is a front spread nasal vowel with a minimum degree of aperture [î].
lel
is a front spread nasal vowel with a half-open degree of aperture [ê].
la I is a central nasal vowel with a maximum degree of aperture [â].
lu/ is a back rounded nasal vowel with a minimum degree of aperture [û].
/o/ is a back rounded nasal vowel with a half-open degree of aperture [ô].

\subsection{SUMMARY}

Using this phonemic model of analysis and description, the phonological system of the Gomen dialect of Yuanga is analysed as having 39 consonant phonemes, of which 37 are native to the language and two are due to borrowing from other sources. In addition, it has 12 basic vowel phonemes and a total inventory of 24 , since all the vowels can be either short or long.

\section{EVIDENCE FOR THE PROPOSED ANALYSIS}

A phoneme is by definition a unit of surface contrast. It is, therefore, identified and defined in terms of the pattems of contrast which exist between it and other phonemic units in a given language. Consequently, an analysis of a phonological system into phonemes is supported by data which illustrate a contrast between the members of the set of phonemes which have been posited.

The following data, therefore, are presented to support the analysis set out in section 2 . It is presented in phonemic form unless otherwise marked by square brackets.

The glosses which are enclosed in parentheses are to be interpreted as 'a kind or species of ...'. Additional information in parentheses indicates a specification or clarification of the meaning given.

\subsection{CONSONANTAL OPPOSITIONS}

\subsubsection{LABIAL ORDER}

Stops: /p, ph, pw, phw, mp, mpw/

$\begin{array}{llll}p a & \text { pebble } & p i & \text { fish egg } \\ \text { pha } & \text { lung } & p h i & \text { excrement } \\ p w a & \text { rain } & p w i o ̀ ~ & \text { fish net } \\ \text { phwa } & \text { hole } & \text { phwiò } & \text { oldest (child) }\end{array}$




$\begin{array}{llll}\text { mpa } & \text { instrument } & \text { mpi } & \begin{array}{l}\text { we two (exclusive) } \\ \text { (idiomatic form) }\end{array} \\ \text { mpwa } & \text { on } & \text { mpwi } & \text { blind }\end{array}$

Continuants: /m, mh, mw, mhw, f, fh, w, wh/

\begin{tabular}{|c|c|c|c|}
\hline$m A$ & and & $m I$ & ripe, red \\
\hline$m h A$ & (liana) & $m h I$ & we two (inclusive) \\
\hline$m w A$ & house & $\begin{array}{l}\text { tyimwI } \\
\text { timI }\end{array}$ & $\begin{array}{l}\text { to hold } \\
\text { to paint }\end{array}$ \\
\hline$m h w A$ & we (inclusive) & $m h w I$ & shy \\
\hline$f a$ & gift & finI & $\begin{array}{l}\text { vertical post } \\
\text { (house construction) }\end{array}$ \\
\hline fha & to speak & fhi & to pass wind \\
\hline wa & to sing & wi & where? \\
\hline wha & big & whili & to drag \\
\hline
\end{tabular}

\subsubsection{APICAL ORDER}

Stops: /t, th, tr, thr, ty, thy, nt, ntr, nty/

$\begin{array}{llll}\begin{array}{l}\text { ta } \\ \text { tra }\end{array} & \begin{array}{l}\text { table } \\ \text { grammatical word } \\ \text { (e.g. hòmpwò tra kò } \\ \text { 'trousers') }\end{array} & \begin{array}{l}t i \\ \text { tri }\end{array} & \begin{array}{l}\text { who? } \\ \text { tea }\end{array} \\ \text { thra } & \text { bald, pandanus } & \text { thri } & \text { fete for the big chief } \\ \text { taa } & \text { to dig } & & \\ \text { thaa } & \text { red pepper } & t h i & \text { to comb } \\ \text { thraa } & \text { bad } & n t i & \text { (tree) } \\ \text { nta } & \text { what? } & n t e & \text { fork } \\ \text { ntra } & \text { ashes } & \text { ntree } & \text { wind } \\ \text { ntya } & \text { garbage } & \text { Intye } & \text { him, her } \\ \text { tya } & \text { mark of indirect object } & \text { tye } & \text { wood, tree } \\ \text { tyatya } & \text { daddy } & \text { tyi } & \text { pawpaw tree } \\ \text { tyAmpwo } & \text { to wake up } & \text { tyEmpi } & \text { our (two exclusive) food } \\ \text { thyamwA } & \text { banana } & \text { thyipwe } & \text { to sneeze } \\ \text { thyapwi } & \text { lack of food } & \text { thyèpwe } & \text { square banana }\end{array}$

Continuants: /n, nh, ny, nhy, j, l, y, yh/

$\begin{array}{llll}n A & \text { from (direction) } & n I & \text { to (direction) } \\ n U & \text { I } & n h I & \text { (hard stone) } \\ n h U & \text { to crumble } & \text { nyIntyi } & \text { (ant) } \\ n y A n g A & \text { fete for ... } & \text { nyO } & \text { fruit-bat's nest } \\ \text { nyAnyA } & \text { mummy } & \text { nhyAtu } & \text { good soil } \\ \text { nhyAle } & \text { to crush in hand } & & \\ \text { nhy } A & \begin{array}{l}\text { grammatical word } \\ \text { (direct object) }\end{array} & & \end{array}$




$\begin{array}{llll}\text { yAnke } & \text { to pick up } & \text { yòò } & \text { ironwood tree } \\ \text { yala } & \text { to rinse dishes } & \text { yhòò } & \text { older brother } \\ \text { yaja } & \text { name } & \text { kòyò } & \text { to lose } \\ \text { ya } m w A & \text { to roof a house } & \text { èjò } & \text { he has the itch (illness) } \\ \text { yhamwA } & \text { I do not know } & \text { èlò } & \text { yes } \\ \text { ja } & \text { plate } & \text { la } & \text { they, their }\end{array}$

\subsubsection{DORSAL ORDER}

Stops: /k, kh, nkJ

$\begin{array}{ll}k a & \text { year } \\ \text { èka } & \text { interrogative word }\end{array}$

$k i \quad$ pain

$\begin{array}{llll}\text { (è) } k h a & \text { (he) presses } & k h i & \text { to break, hurt } \\ \text { kınka } & \text { to laugh } & n k i & \text { to cry } \\ \text { kikha } & \text { to burn fields } & j A n k i & \text { brain } \\ k a i & \text { with (person) } & & \\ \text { khai } & \text { to pull } & & \end{array}$

Continuants: /ng, x, h, $\emptyset]$

$\begin{array}{llll}n g A & \begin{array}{l}\text { grammatical word } \\ \text { (e.g. nyA ngA ajo } \\ \text { fete for the chief) } \\ \text { tail }\end{array} & \text { ngAngI } & \text { to put teeth on edge } \\ \begin{array}{l}\text { thing } A \\ \text { xa }\end{array} & \begin{array}{l}\text { time word (past) } \\ \text { kixa }\end{array} & \text { nothing } & \begin{array}{l}\text { to close eyes } \\ \text { (i.e. to pray) }\end{array} \\ \text { ha } & \text { or } & \text { hi } & \text { hand, branch } \\ \text { a } & \text { to go } & i & \text { where? (person) } \\ \text { hai } & \text { no } & & \\ \text { ai } & \text { heart } & & \end{array}$

\subsection{VOCALIC OPPOSITIONS}

\subsubsection{ORAL VOWELS}

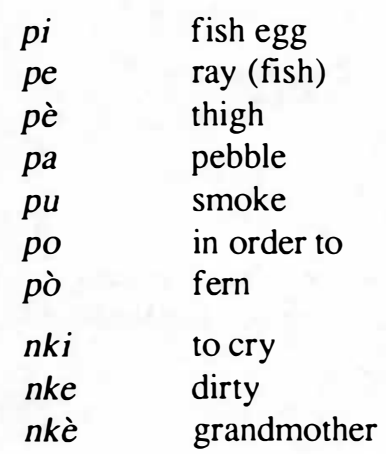

$\begin{array}{ll}k u & \text { place } \\ k o & \text { chicken } \\ k o ̀ & \text { the bush } \\ k a & \text { year }\end{array}$

mpè banyan tree

mpa instrument 


\subsubsection{NASAL VOWELS}

$\begin{array}{llll}w i & \text { where? } & k i & \text { pain } \\ w \hat{i} & \text { strong } & k \hat{\imath} & \text { oyster } \\ \text { trè } & \text { day } & k e & \text { basket } \\ \text { trê } & \text { to run } & k \hat{e} & \text { father } \\ l a & \text { they } & k a & \text { year } \\ \text { lâ } & \text { those there } & k \hat{a} & \text { to shout } \\ \text { pu } & \text { smoke } & k u & \text { place } \\ \text { pû } & \text { green } & k \hat{u} & \text { hard ground } \\ \text { trò } & \text { night } & k \grave{o} & \text { the bush } \\ \text { trô } & \text { mat } & k o ̂ & \text { dried fruit }\end{array}$

\subsubsection{VOCALIC LENGTH}

As noted previously there is a contrast between long and short vowels. The following data provide evidence for this contrast.

Oral vowels

\begin{tabular}{|c|c|c|c|}
\hline $\begin{array}{l}\text { pi } \\
\text { pii }\end{array}$ & $\begin{array}{l}\text { fish eggs } \\
\text { to break (bread) }\end{array}$ & $\begin{array}{l}\text { tyi } \\
\text { tyii }\end{array}$ & $\begin{array}{l}\text { pawpaw tree } \\
\text { skin }\end{array}$ \\
\hline $\begin{array}{l}\text { we } \\
\text { wee }\end{array}$ & $\begin{array}{l}\text { water } \\
\text { juice }\end{array}$ & $\begin{array}{l}\text { nke } \\
\text { nkee }\end{array}$ & $\begin{array}{l}\text { dirty } \\
\text { melody }\end{array}$ \\
\hline 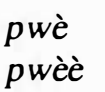 & $\begin{array}{l}\text { to be born } \\
\text { entrance }\end{array}$ & $\begin{array}{l}\text { wè } \\
\text { wèè }\end{array}$ & $\begin{array}{l}\text { personal name } \\
\text { root }\end{array}$ \\
\hline $\begin{array}{l}\text { mpa } \\
\text { mpaa }\end{array}$ & $\begin{array}{l}\text { instrument } \\
\text { black }\end{array}$ & $\begin{array}{l}\text { ta } \\
\text { taa }\end{array}$ & $\begin{array}{l}\text { table } \\
\text { to dig }\end{array}$ \\
\hline $\begin{array}{l}\text { mpu } \\
\text { mpuu }\end{array}$ & $\begin{array}{l}\text { green fruit } \\
\text { shoulder }\end{array}$ & $\begin{array}{l}n U \\
n U U\end{array}$ & $\begin{array}{l}\text { I } \\
\text { torch }\end{array}$ \\
\hline $\begin{array}{l}\text { po } \\
\text { poo }\end{array}$ & $\begin{array}{l}\text { to fill } \\
\text { to bind, link }\end{array}$ & $\begin{array}{l}\text { to } \\
\text { too }\end{array}$ & $\begin{array}{l}\text { time marker (future) } \\
\text { to crawl }\end{array}$ \\
\hline $\begin{array}{l}\text { jò } \\
\text { jòò }\end{array}$ & $\begin{array}{l}\text { (illness) } \\
\text { to swim }\end{array}$ & $\begin{array}{l}\text { ntrò } \\
\text { ntròò }\end{array}$ & $\begin{array}{l}\text { cloud } \\
\text { leaf }\end{array}$ \\
\hline $\begin{array}{l}\text { kò } \\
\text { kòò }\end{array}$ & $\begin{array}{l}\text { the bush } \\
\text { upright, leg }\end{array}$ & & \\
\hline
\end{tabular}

Nasal vowels

Thus far in the course of data collection very few unambiguous examples of lexemes with long vowels have been noted. The following is a list of the data which are available at this stage of research. 


$\begin{array}{llll}k \hat{i} & \text { oyster } & \text { ta } & \text { table } \\ k \tilde{i ̂} & \text { to snivel } & \text { tââ } & \text { to squirt water } \\ w \hat{e} & \text { owl } & k h o ̂ & \text { cord, rope } \\ w \hat{e} \hat{e} & \text { hat } & k h o ̂ o ̂ ~ k e & \text { basket handle }\end{array}$

\section{PROBLEMS OF INTERPRETATION AND OTHER THEORETICAL ISSUES}

\subsection{PROBLEMS OF INTERPRETATION}

Certain segments and sequences of segments, even though they can be accurately described from a phonetic point of view, are nonetheless ambiguous when considered from a phonological point of view because the same data could, in theory, be interpreted in a number of different ways. In addition, different theoreticians approach the same data differently using different criteria to guide their choice of interpretation. In this section a number of theoretical issues raised by the Yuanga data are discussed and the reasons for the interpretations adopted are presented.

\subsubsection{COMPLEX CONSONANTS}

There are five types of complex consonant which are open to alternative interpretations, namely the palatalised, labio-velar, retroflexed and prenasalised consonants. The first four can be interpreted as single complex consonants $/ \mathrm{C} /$, or as sequences of two (or even three in the case of aspiration combined with another feature such as labialisation or retroflexion) consonants $/ \mathrm{CC} /$ or $/ \mathrm{CCC} /$. In addition, the first three can also be interpreted as being sequences of one (or two) consonants followed by one (or two) vowels /CV/, /CVV/ or /CCV/. For example, an aspirated consonant can be interpreted as a consonant followed by $/ \mathrm{h} /$ or as a consonant followed by a voiceless vowel homorganic with the next vowel. Likewise a labialised or palatalised consonant can be interpreted as a consonant followed by $\mathrm{/w} /$ or $/ \mathrm{y} /$ or as a consonant followed by $/ \mathrm{u} /$ or $/ \mathrm{i} /$, and a retroflexed consonant can be interpreted as a sequence of consonant plus $/ \mathrm{r} /$.

The preferred interpretation is that of a single complex consonant $/ \mathrm{C} /$, although, for reasons of facility of typographical reproduction, the phonemes are represented by digraphs and trigraphs, namely: /ph/, /phw/, /tr/,/ty/etc.

This unitary interpretation is based largely on the canonical structure of the syllable in Yuanga. On the basis of all the unambiguous data available, the only syllable pattern which occurs in the Gomen dialect and which contains a consonant is the /CV/ pattern. Consequently, any interpretation of the complex consonants which involves a /CC/ pattern would violate this pattern and is, therefore, to be rejected.

Likewise, any interpretation which involves a /CV/ or /CVV/ sequence is also to be rejected, because in certain words this would result in a /CVV/ sequence. Even though sequences of two consecutive vowels occur in unambiguous data, sequences of three vowels do not, and so any interpretation which creates such an unattested sequence is to be avoided. The interpretation of the complex consonants as single segments / C/ avoids all these difficulties and accounts for all the data, but at the cost of multiplying the number of consonant phonemes. 
The prenasalised stops are also interpreted as single segments $/ \mathrm{C} /$ for exactly the same reasons, since the choice of either $/ \mathrm{VC} /$ or $/ \mathrm{CC} /$ is ruled out. Another possibility is that the nasal phone be interpreted as a separate phonemic segment which belongs to a different syllable than the following stop; that is to say that it would be interpreted as a syllabic nasal. This solution avoids the difficulties mentioned above but it involves positing a new syllable type to cover the syllabic nasal. There is no justification for such a procedure, especially as the interpretation of the prenasalised stops as a single segment accounts for all the data without the need to propose additional syllable types.

Even though the phonetic realisation of the prenasalised stops is voiced, the phonemic notation uses the symbols for the voiceless stops, namely: $/ \mathrm{mp} /, / \mathrm{nt} /$ and $/ \mathrm{nk} /$. This is in an effort to formalise the true generalisation about Yuanga that the phonemic system does not use voicing as a feature to distinguish between phonemes. The comparable distinction in the case of the stops is between voiceless stops and prenasalised stops rather than between voiceless and voiced stops, hence the above choice of notation avoiding the use of additional symbols, namely those for the non-pertinent voiced stops.

\subsubsection{THE SEMIVOWELS AND [h]}

The semivowels $[w]$ and $[y]$, and $[h]$ also raise some questions of interpretation. As the name 'semivowel' suggests, $[\mathrm{w}]$ and $[\mathrm{y}]$ can just as easily be interpreted as vowels as they can be as consonants, depending on their function in a given language. In Yuanga it is clear that the semivowels and $[\mathrm{h}]$ function as consonants in that they occur only in the prenuclear position in the syllable. Such an interpretation does not entail the creation of any new syllable types not otherwise attested, whereas the alternative solution (treating them as vowels) would create a new /VVV/ syllable pattem which is not otherwise attested.

\subsubsection{VOWEL SEQUENCES}

Certain [VV] sequences are ambiguous because when one of the two close vowels [i] or [u] occurs in either of the two positions it could feasibly be interpreted as a semivowel, functioning as a consonant. Thus, three interpretations of such sequences are possible, namely /VV/, /CV/ or /VC/, with the consonant being either /w/ or /y/.

The / $\mathrm{VC} /$ solution can be immediately rejected since a primary characteristic of the Gomen dialect is the fact that it has no closed syllables.

The /CV/ solution likewise is not suitable since there is contrast between close vowels occurring at the beginning of [VV] sequences and their equivalent semivowels, and also between consonant plus close vowel and palatalised and labialised stops. For example:

\begin{tabular}{|c|c|c|c|c|}
\hline [tia] & to push & $\begin{array}{l}\text { contrasts with } \\
\text { and with }\end{array}$ & $\begin{array}{l}{\left[\mathrm{t}^{\mathrm{j}} \mathrm{a}\right]} \\
{\left[\mathrm{t}_{\mathrm{i}}^{\mathrm{j}}\right]}\end{array}$ & $\begin{array}{l}\text { indirect object } \\
\text { to dance }\end{array}$ \\
\hline & to call out & contrasts with & {$\left[m^{w} a\right]$} & he \\
\hline & to blow & contrasts with & [wi] & where? \\
\hline & soon & contrasts with & [jo) & ironwood \\
\hline
\end{tabular}

It is clear, then, that for Yuanga the vocalic segments in the left-hand column should not be interpreted as a sequence of consonant and vowel but rather as a sequence of two vowels. 
This choice has the confirming advantage of harmonising with other unambiguous sequences of vowels, such as /aè/, /aò/, /oè/ and /ea/, which also occur in the Gomen dialect.

The geminate vowels are also ambiguous in that they can be interpreted as single complex segments $/ \mathrm{Vv} /$ or as sequences of two identical segments /VV/. The latter solution is favoured on the grounds of economy, since it does not require the introduction of any new vowel phonemes.

\subsection{NEUTRALISATION AND BIUNIQUENESS}

A phoneme is a contrastive unit defined in terms of its patterns of opposition to other phonemes in a language. Consequently, when the regular pattems of contrast break down for some reason, these have to be carefully noted. Neutralisation is the term used to describe those situations where patterns of contrast which are attested in a given language break down, or are neutralised, in a particular phonological context. Neutralisation affects a number of different phonemes in Yuanga as described below.

\subsubsection{THE LABIAL CONSONANTS}

There is neutralisation of the opposition between the labial consonants and the labio-velar consonants in the environment preceding the high close back vowel /u/, in favour of the labial consonants. For example:

$\begin{array}{lllll}\text { /pò/ } & \text { fem } & \text { is in contrast with } & \text { /pwò/ } & \text { turtle } \\ \text { /mpo/ } & \text { wall } & \text { is in contrast with } / \mathrm{mpwo} / & \text { rotten } \\ \text { /mpò/ } & \text { stick } & \text { is in contrast with } & / \mathrm{mpwò} / & \text { fruit-bat } \\ \text { /mO/ } & \text { left } & \text { is in contrast with } & / \mathrm{mwO} / & \text { pot }\end{array}$

The words in the left column below occur in Yuanga but the ones on the right do not:

$\begin{array}{lll}\text { /pu/ } & \text { smoke } & * / \mathrm{pwu} / \\ \text { /phu/ } & \text { fly away } & * / \mathrm{phwu} / \\ \text { /mpu/ } & \text { green fruit } & * / \mathrm{mpwu} / \\ \text { /mU/ } & \text { behind } & * / \mathrm{mwU} /\end{array}$

\subsubsection{THE DORSAL CONSONANTS}

In word-initial position $/ \mathrm{k} /$ is in contrast with $/ \mathrm{x} /$. In intervocalic position, however, there can be neutralisation of this contrast with $/ \mathrm{k} /$ being realised as $[\mathrm{x}]$ or $[\gamma]$ and $/ \mathrm{x} /$ also being realised as $[\mathrm{x}]$ or $[\mathrm{\gamma}]$. The presence of the feature of voicing in an intervocalic position is a natural phenomenon and (as shown later) is a regular occurrence in Yuanga. The difficulty which arises in this case is that, instead of the intervocalic reflex of $/ \mathrm{k} /$ being $[\mathrm{g}]$, as might be expected by analogy with the other stops (cf. section 4.3), it is in fact a fricative. The result of this neutralisation is that the reflex of phoneme $/ \mathrm{k} /$ may be considered to be identical with the reflex of phoneme $/ x /$ in the same environment, and this violates the principle of biuniqueness which is fundamental of structuralist theory. To put it in Bloch's terms (1941), the above coincidence of the reflexes of two different phonemes in the same environment is an example of complete overlapping, which, according to Bloch, is not acceptable in a valid phonological description. 
Before blindly sacrificing symmetry and congruity on the altar of biuniqueness, however, it is necessary to understand the practical considerations which led Bloch to repudiate complete overlapping. His argument is that when a hitherto unknown language is being studied, if phoneme /A/ and phoneme /B/ can have the same reflex [C] in the same environment, then, if the linguist finds an occurrence of reflex $|\mathrm{C}|$ how can he know if it is an occurrence of / $\mathrm{A} /$ or an occurrence of $/ \mathrm{B} /$ ? The answer is that he cannot know; and so, for reasons of accuracy and consistency, Bloch insisted on the prohibition of an analysis which allows complete overlapping.

In the case of Yuanga however, the above difficulties do not arise and the analyst can always know when $[\mathrm{x}]$ or $[\mathrm{y}]$ are reflexes of $/ \mathrm{k} /$ and when they are reflexes of $/ \mathrm{x} /$. This is because the medial reflexes are free variants which depend mainly on the style of speech. Thus in fast speech the distinction between $/ \mathrm{k} /$ and $/ \mathrm{x} /$ tends to be blurred in intervocalic positions, but in slow deliberate speech the difference between them is quite clear. There is, therefore, no difficulty in consistently distinguishing between the two different phonemes. for example, in each of the following words or phrases the intervocalic $/ \mathrm{k} / \mathrm{may}$ be pronounced as $[\mathrm{x}]$ or $[\mathrm{\gamma}]$ in fast speech, but it is always realised as $[\mathrm{k} \mid$ in slow speech:

$\begin{array}{lll}\text { /hê-kòlò/ } & \text { family } & \text { (lit. contents of home) } \\ \text { /kòò kai/ } & \text { second (child) } & \begin{array}{l}\text { (lit. standing behind) } \\ \text { /mwO-kAmpu/ }\end{array} \\ \text { church } & \text { (lit. house sacred) } \\ \text { /mpwò-kAmpu/ } & \text { Sunday } & \text { (lit. time sacred) } \\ \text { /mpa-kunI/ } & \text { finally } & \text { (lit. thing to finish) } \\ \text { /nU kOmpwè/ } & \text { I say } & \end{array}$

As a general rule then, the contrast between $/ k /$ and $/ x /$ is neutralised in intervocalic position in favour of $/ x /$. This fact harmonises with data from neighbouring languages and dialects; for example, Haudricourt (1963:6) cites data indicating that such an intervocalic neutralisation occurs between all stops and their homorganic fricatives in the neighbouring language of Kumak, and according to my observations the same is true of the dialect of Yuanga spoken at Bondé.

At the same time, however, it must be noted that the contrast between $/ \mathrm{k} /$ and $/ \mathrm{x} /$ is maintained in slow speech in those situations when the segment in question occurs at the beginning of a word or morpheme, even though it occurs intervocalically in terms of the linear flow of speech. In such cases, as in the examples given above, it is possible to reconstruct whether the underlying phoneme is $/ \mathrm{k} /$ or $/ \mathrm{x} /$.

In conclusion, one further point can be made with regard to the problem of $/ \mathrm{k} /$ and $/ \mathrm{x} /$. At the present point in time, even though the distinction between $/ \mathrm{k} /$ and $/ \mathrm{x} /$ is becoming blurred in certain contexts, the native speaker of Yuanga nonetheless still maintains a distinction between the two phonemes and is able to consistently produce the distinctive realisation of each of them in a deliberate style of speech. I have argued that this fact is sufficient justification for maintaining an analysis that on the surface violates the principle of biuniqueness. However, it is reasonable to suppose that after a period of several generations the knowledge of this distinction may be lost. In that case, there would be no way of accurately assigning a particular example of the phone to its 'correct' phoneme, and so at that time a different analysis would be necessary to account for the phonological system of the language as it would be after the period of change. In other words, languages change and, consequently, different analyses are necessary at different stages in a language's history. During the in-between stages when change is in process, the language itself may be a bit 
inconsistent and 'fuzzy round the edges' as Vachek (1964) proposes and so, as Vachek also implies, linguists should not be apologetic if their analyses reflect such linguistic realities. The above analysis is a case in point and lends credence to Vachek's proposals.

\subsubsection{THE ASPIRATED CONSONANTS}

In spite of all that was stated in section 4.2.2, it is possible to find in the Gomen dialect of Yuanga the phone $[\mathrm{k}]$ in word-medial position, as is evidenced by the following examples:

$\begin{array}{ll}\text { [kika] } & \text { burn the fields } \\ \text { [ako] } & \text { three (people) } \\ \text { [pwoko] } & \text { three (animals) } \\ \text { [haikã }{ }^{\text {mbu }} \text { ] } & \text { very cold }\end{array}$

However, this medial velar phone has been interpreted as the medial allophone of $/ \mathrm{kh} /$ rather than as a reflex of $/ \mathrm{k} /$ for the following combination of reasons.

In the case of / kikha/, all native speakers consulted insisted that the medial phone should be realised as a strong aspirated consonant, that is, as $/ \mathrm{kh} /$.

Haudricourt (1971:384) and Rivierre (1972) indicate that /-khò/ 'three', with an aspirated velar stop, is to be found in many languages of New Caledonia.

Finally, Michailovsky (1982:3) reports that in the dialect of Yuanga spoken at Bondé, the free form /khampu/ 'cold', with an aspirated velar stop, is used even though this word does not currently occur in the Gomen dialect.

This interpretation - that the aspirated velar stop is realised phonetically as an unaspirated stop in medial position - is further borne out by the only other example available of an aspirated stop in medial position:

$\begin{array}{llll}\text { /thumEnO/ } & \text { to move (walking) } & \text { is realised as } & \text { [ } \mathrm{t}^{\mathrm{h}} \text { umẽnō] } \\ \text { /pèthumEnO/ } & \text { to walk about }, & \text { is realised as } & \text { [petumẽnō] }\end{array}$

while

/katUmpi/ quickly is realised as [kadũmbi].

These cases where the unaspirated voiceless phone occurs as a reflex of two different phonemes (the aspirated and unaspirated stop) is another example of overlap, but in this case it is only partial overlap, as the identical reflexes occur in different environments. Since the overlap is only partial, it is always possible to unambiguously identify the phoneme which the phone is representing, and so the analysis presented above is acceptable within the theoretical framework proposed by Bloch (1941).

No examples of aspirated nasals in medial position have yet been found, which means that in practice there is neutralisation of the opposition between aspirated and unaspirated nasals in this position. Haudricourt (1968:233) and Rivierre (1972:312) have proposed that the aspirated consonants in New Caledonian languages are derived from reduplicated syllables in an earlier form of the ancestral language(s). If this is true, it is not surprising that there are not a large number of examples of aspirated consonants generally, and it is even less surprising that there are hardly any examples of medial aspirated consonants. Further data collection may produce more examples, in which case the above hypotheses would need to 
be double-checked against the new data. (See also section 4.4.1 for further comments on the term 'aspiration').

\subsubsection{THE VOWELS}

The opposition between oral and nasal vowels is neutralised in two different environments, namely in the environment preceding prenasalised stops and also in that following nasal continuants. In these cases the neutralised segment has a phonetic realisation that is halfway between the normal realisation of the oral and nasal vowels. That is to say, it carries a very light nasalisation which can be quite noticeable if the syllable happens to be stressed, but its realisation is, nonetheless, still quite distinct from that of a normal nasal vowel.

It is in cases like these that the concept of the archiphoneme can be very valuable. The Syntagmatic Model still defines an archiphoneme in the broad sense espoused by the early members of the Prague School (Vachek 1966:60) and, consequently, Nicole (1981:65) states that an archiphoneme is an abstract unit which is the sum of the characteristics of two or more distinct phonemes. This definition leads to the rather unnecessary position that an archiphoneme should be posited in every case of neutralisation and, not surprisingly, this methodological redundancy has been rejected by most other linguists, including later members of the Prague School.

Pike (1967:301), however, also still uses the term, but with a more restricted definition. He only invokes the concept in cases (such as the one under discussion) where the phone which occurs in the neutralising environment has a realisation which is phonetically half way between the normal realisation of the respective phonemes in their contrastive environments.

Neutralisation which is manifested by a phonetically intermediate form poses a particular problem for analysts. This is because it is not possible to assign the phone which occurs in the neutralising environment to one phoneme or the other without making an arbitrary choice which masks the phonetic reality. In such a case, the archiphoneme as defined by Pike comes into its own, for by using this convention to represent the neutralised phonemes it is possible to state with formal clarity that the neutralisation so marked is one which is not in favour of one phoneme or the other, but is manifested by a phonetically intermediate form.

Thus, for Yuanga, the presence of one of the five vowel archiphonemes /I, E, A, U, O/ indicates that the phonetic realisation of that segment involves a light degree of nasalisation, which sets it apart from the normal realisaton of both oral and nasal vowels when they occur in non-neutralising environments.

The situation in Yuanga is reminiscent of the case of nasalisation in French described by Schane in his paper, 'The phoneme revisited' (1971). From the French data Schane (p.505) drew the principle that, if on the surface a feature is contrastive in some environments but not in others, then that feature is lost where there is no contrast.

If this principle were applied to the Yuanga data it could be argued that the phonemically nasalised vowels are the residual result of a process which took place in the following manner:

(1) nasalisation of vowels preceding nasals: $\mathrm{VN}>\tilde{\mathrm{V} N}$

(2) loss of nasals in syllable-final position: $\bar{V} N \$>\bar{V} \$$ 
The first step is a simple case of assimilation and the second also has plausibility, in that the nasalisation of the vowel makes the final nasal redundant. However, in contexts where a nasalised consonant is retained (i.e. in syllable-initial position), the nasal contrast is carried by the consonant and is non-contrastive in the vowel. In such cases, according to Schane's principle, the vowel would tend to lose the non-contrastive feature and become denasalised. This would result, at least in an intermediate stage of the process, in the lightly nasalised vowel which currently occurs in Yuanga.

The application of this principle to Yuanga is complicated by the fact that it is necessary to assume that there never was any vocalic nasalisation contrast following nasal continuants or preceding nasalised stops (or that it has been lost), since contrastive nasalised vowels do not currently occur in those positions. This is not an entirely unreasonable hypothesis, but it is still speculative and there is no evidence currently available to either support or refute it.

It should also be noted that Schane approaches the data in his article from a diachronic perspective, which makes it only marginally relevant to the present paper, which is purely synchronic in nature. In any case, this whole question of nasalisation is taken up again in section 6 , where some more satisfactory proposals will be presented.

\subsection{CONSONANTAL VARIANTS}

In section 2 it was noted that most of the unaspirated consonants have voiced variants which occur in intervocalic position. This is, of course, a very natural phonological phenomenon and its manifestation in Yuanga is exemplified below.

$/ \mathrm{p} /$

$\begin{array}{llll}\text { /hopo/ } & \text { eat } & \text { is realised as } & \text { [hobo] } \\ \text { /tyopa/ } & \text { horse } & \text { is realised as } & \text { [tjoba] } \\ \text { /upi/ } & \text { buy } & \text { is realised as } & \text { [ubi] }\end{array}$

$/ \mathrm{pw} /$

/ntyipawa/ number of is realised as [ $\left.{ }^{n}{ }^{j} j^{j} b^{w} a\right]$

/thyapwi/ lack of is realised as [ $\left.\mathrm{tjhab}^{\mathrm{i}} \mathrm{i}\right]$

/V

/pota/ do is realised as [poda]

/ponIta/ how many? is realised as [ponīda]

/ $\mathbf{r} /$

/pètròli/ see again is realised as [pedoli]

/ntròtrò/ yesterday is realised as [ndodo]

(The flap [ $[$ r] is another intervocalic variant of /tr/, but according to some speakers this is a 'deformation' characteristic of the young people.)

/ty/

/utyal arrive is realised as [udja]

/ityo/ you (singular) is realised as [idjo] 
/j/

/ajo/ chief is realised as [aðo]

/yaja/ name is realised as [jaða]

/xل

/ôxè/ again is realised as [ôyè]

/kixal nothing is realised as [kiya]

h/

As might be expected $/ \mathrm{h} /$ is not voiced intervocalically but is instead lost entirely:

$\begin{array}{llll}\text { /ntyahò/ } & \text { river } & \text { is realised as } & {\left[{ }^{n} \mathrm{~d}^{j} \mathrm{a} a\right]} \\ \text { /nAA hinU/ } & \text { give to me } & \text { is realised as } & \text { [nãā inū] }\end{array}$

All of the above examples are variants which are dependent on the style of speech, the voiced variants occurring in normal speech and the voiceless form occurring in slow deliberate speech.

In section 4.2.2 above it was noted that $/ \mathrm{k} /$ is an exception to this generalisation in that its medial variant is a fricative rather than a voiced stop. Nonetheless, the natural tendency to voicing still comes into play as the variant fricative is often voiced rather than voiceless.

The intervocalic variant of the aspirated stops is the unaspirated version of the same consonant (as noted in section 4.2.3).

\subsection{PROBLEMS OF NOTATION AND DESCRIPTION OF THE CONSONANTS}

\subsubsection{THE TERM 'ASPIRATION'}

The terms 'aspirated' and 'unaspirated' have been used in this analysis in order to describe a set of distinctions which are very pervasive and significant for the phonological system of Yuanga. The reasons for using this particular pair of terms are two-fold: firstly, because on the phonetic level the segments in question are regularly aspirated, and secondly, in order to maintain a certain congruity and comparability with descriptions of other languages of New Caledonia by other researchers, who have consistently used these terms (e.g. Haudricourt 1963, 1971).

It should be noted, however, that in comparing the pronunciation of different speakers and even different pronunciations by the same speaker it was found that the noticeable expiration of air, which is the classical sign of aspiration, did not always appear to be present when so-called aspirated consonants were produced. At the same time, it was clear that all such consonants were produced with a greater degree of force and effort than their so-called unaspirated counterparts, which suggests that tems such as 'fortis' and 'lenis' may be more appropriate for describing this set of distinctions.

The use of the terms 'fortis' and 'lenis' has recently been brought under scrutiny by Jaeger (1983). She is not entirely in favour of these terms, since she considers that the variation in so-called 'force of articulation' is not of primary importance in distinguishing between sounds of this type. She proposes instead that consonants which have traditionally been distinguished by the terms 'fortis' and 'lenis' can be more accurately described in terms of a combination of three phonetic features, namely duration, variation in voicing, and 
variation in the type of closure. On the basis of the evidence that she adduces from Zapotec (Mexico) and Jawoñ (Australia), Jaeger proposes, firstly, that fortis consonants are longer than their lenis counterparts; that they tend to be consistent in the type of voicing used, with a tendency to be voiceless and aspirated; and thirdly, that there is no variation in the type of closure used, so that stops are always stops and affricates always affricates etc.

It is noteworthy that, to a large extent, the Yuanga data fit this pattern, with the aspirated consonants fitting Jaeger's description of fortis consonants, and the unaspirated ones fitting her description of lenis consonants. Very little can be said about the question of duration since there is hardly any clearcut evidence currently available. Suffice it to say that syllables with aspirated or fortis consonants have always been subjectively perceived as being longer than syllables with unaspirated consonants (cf. section 4.5.3). The very limited number of spectrograms that are available support this perception, but they do not show that the fortis consonants themselves are longer in duration than the lenis ones. It can be stated with confidence, however, that the aspirated consonants always have the same type of voicing, whether initial or medial (cf. section 4.2.3), that they are almost invariably aspirated and that the stops, at least, are voiceless. In addition, the type of closure is always the same, regardless of the position of the consonant in the word. The only exception to this is /fh/ which can be voiced, although it is usually voicelsss. The unaspirated consonants, on the other hand, act just like Jaeger's lenis consonants. For example, there is variation in voicing in that voiceless stops are voiced intervocalically (cf. section 4.3), and variation in type of closure in that $/ \mathrm{k} /$ is produced with a fricative articulation in medial position (cf. section 4.2.2).

A further piece of evidence which suggests that New Caledonian languages may have the same features as those described by Jaeger is related to the historical source of the consonants in question. In Jaeger's study (1983:187) the fortis consonants are reputedly derived from consonant clusters, while Haudricourt (1968) has proposed that the New Caledonian aspirated (or fortis) consonants are derived from reduplicated syllables. Both cases lend credence to the proposal that duration may be a crucial difference between the two types of consonant.

The significance of Jaeger's proposals, if they are held to be correct, lies in the fact that they support the view that terms such as 'aspirated' and 'unaspirated' may not be totally accurate descriptions of the primary phonetic features of the consonantal system of Yuanga. Clearly, more research and analysis needs to be done on this topic in order to unambiguously define the phonetic realisation of the so-called aspirated and unaspirated consonants in Yuanga. In addition, it would be of considerable value to compare and contrast all the occurrences of aspiration in New Caledonian languages to see if there are certain features which always occur, and then to compare these with similar features in Australian languages, such as that studied by Jaeger.

\subsubsection{THE ORAL CONTINUANTS}

The pair of phonemes $/ \mathrm{f} /$ and $/ \mathrm{fh} /$ are rather unusual but are nonetheless characteristic at least of the Gomen dialect of Yuanga. There is some free variation in the pronunciation of /fh/. Middle-aged people pronounce it as a voiceless labio-dental fricative, but younger people tend to pronounce it with a slight degree of voicing. In either case, there is a pronounced aspiration or 'scraping' in the throat which gives the sound its distinctive colouring. In an intervocalic position the pronunciation is slightly voiced by all speakers, in 
line with the generalisation noted above regarding the voicing of medial variants. However, even intervocalically the 'aspiration' is still present which distinguishes it from the pronunciation of $/ \mathrm{f} /$, which is always pronounced as a voiced labio-dental fricative but without any 'aspiration' or scrape. (The symbol/f/ was chosen to represent this phoneme rather than the symbol $/ \mathrm{v} /$ in order to underscore the fact that within the phonological system of Yuanga the primary distinction is between voiceless aspirated segments and voiceless unaspirated segments, and that the voicing correlation is not relevant.)

In Table 1 the symbol $I h$ is marked in parentheses in order to indicate that it is probably not a phoneme of Yuanga as it is currently spoken, even though by symmetry it fits neatly into the system. In the speech of one particular person at Paita a distinction is made between $\Lambda /$ and $/ \mathrm{lh} /$, but this distinction is not recognised - either at the level of production or at the level of perception - by a total of ten other people with whom this question was investigated. It is fairly certain then, that this phoneme should not be counted as part of the phoneme inventory for Yuanga. Even if the aspirated form of $/ \mathrm{l} /$ were heard in the speech of a larger number of people, it would still not be necessary to posit a new phoneme, since /1/ always occurs in medial positions while the aspirated form, when it occurs, always occurs in wordinitial position.

The same speaker mentioned above also recognises a distinction between the interdental fricative $/ \mathrm{j} /$ and its voiced counterpart, but again this distinction is not recognised by any other person with whom it was checked. The fact of the matter would appear to be that the voiced version of the fricative only appears in intervocalic positions, which is entirely in keeping with the general trend of medial voicing in Yuanga. It is, therefore, merely a contextually conditioned variant of $/ \mathrm{j} /$.

The examples of variants noted in this section are of interest in that they are probable examples of interference from another indigenous language of New Caledonia. Such cases of outside influence on a phonological system are not easy to recognise by a non-native analyst, but it is important to seek them out if an analysis of a given language is to be truly accurate. In this case the outside language is probably Drehu, which is spoken on the island of Lifou. This language was the first to have an orthography, and in the 1930)s pastors from there came to Paita, prepared an alphabet and began to teach children of that era to read. In that orthography a distinction is made between $/ \mathrm{l} /$ and $* / \mathrm{lh} /$ and between $/ \mathrm{j} /$ and its voiced counterpart. According to Sam (1982), Drehu has both /l/ and /lh/ as distinct phonemes, as well as both voiced and voiceless interdental fricatives. It is reasonable to suppose, therefore, that the pastors' knowledge of their own language influenced their orthography decisions for Yuanga. Suffice it to say that the person cited above, who makes the idiosyncratic distinctions described there, learned to read in the pastors' school of that era and went on to become fluent in Drehu himself. It is possible also, that the difference in the pronunciation of $/ \mathrm{fh} /$ by the older and younger generations dates from the same period, for a voiceless labio-dental is quite common in Drehu and would have been the nearest equivalent to the /fh/ of Yuanga, whereas / $/ \mathrm{in}$ Drehu is a recent and relatively rare borrowed phoneme.

\subsubsection{THE PALATALISED CONSONANTS}

The phonetic realisation of these phonemes (with the exception of $/ y /$ and $/ y h /$ ) is not that of a consonant with a single point of articulation but that of a complex consonant with the primary closure between or behind the teeth and the secondary closure at the palate. The phoneme symbols have been chosen expressly in order to try to formally express this fact. 


\subsubsection{THE LABIALISED VELAR CONSONANTS}

The phonemes $/ \mathrm{kw} /$ and $/ \mathrm{nkw} /$ also occur in the Yuanga language, although they have not been included in the main phoneme inventory. They are of a rather peripheral nature in that they only occur in a limited number of proper names, as follows:
/kwamanta/ topographical name
/nkwatintyi/
/nkwamahatai/ $\}$ names of clans
/nkwapama/
/we nkwa/
lit. river of Gwa (otherwise known as Ouegoa a village in the Bondé dialect area).

The word /kwau/ 'dog' also occurs in both the Gomen and Bondé dialects, but it is possible that this is a relatively recent borrowing of a word of Polynesian origin, namely kuau 'the young of an animal'.

The evidence cited above suggests that these phonemes were once an integral part of the phonological system of Yuanga, but for some reason they have disappeared from common usage even though they have remained fossilised in some proper names, and even though they still occur in other languages including Pwapwâ, the language spoken in the region immediately to the south of Gomen.

Haudricourt (1951) has traced the evolution of the old labio-velars in the languages of New Caledonia, but the reason why they were not retained in Yuanga is much less obvious than the fact of their actual absence.

Simons (1982) and Schooling (1981) have documented evidence which suggests that language change in Oceania may have been greatly affected generally by a system of word taboo, and in particular by a prohibition on the utterance of personal names. Naturally enough the prohibition was especially strong in the case of chiefs' names, and one can only assume that it would have been even stronger in the case of the names of gods or important ancestors. There is abundant evidence which indicates that this system of name taboo was practised throughout New Caledonia and that it is still part of the social system at the present time, although in a relatively weak form. Coyaud (1975) collected a number of traditional stories in the Bondé dialect region, and from these it appears that the leading ancestor of the Yuanga people was a personage by the name of $n G$ wa or Goa (cf. the place name Ouegoa cited above). It is reasonable to suppose, therefore, that at an earlier stage in the history of the language there was a prohibition against uttering any word which sounded anything like the name $n G w a$ and, as a result, all such words disappeared from the language apart from the few proper names mentioned above.

According to one speaker of the Gomen dialect, the phoneme */hw/ could also be included in the phonological system of Yuanga, since he recognises a difference between all the following words:

$\begin{array}{ll}\text { /wa/ } & \text { song } \\ \text { /wha/ } & \text { big } \\ * / h w a / & \text { fig tree } \\ \text { /hoa/ } & \text { moming }\end{array}$

This issue has not yet been satisfactorily resolved, but the evidence collected thus far suggests that the distinction between $/ \mathrm{wh} /$ and $/ \mathrm{hw} /$ is an idiosyncratic variation which is not 
recognised by other members of the community. For this reason, /hw/ has not been included in the main inventory of phonemes.

\subsection{FEATURES OF THE VOWELS}

\subsubsection{DEGREE OF APERTURE}

The vowels /e/, /e/, /o/ and /o/ have a tendency to be pronounced with a degree of articulation which is closer than the symbolisation might suggest. Since the functional load of the $/ \mathrm{e} /-\mathrm{e} /$ and $/ \mathrm{O} /-\mathrm{O} /$ oppositions is fairly low, the difference in pronunciation between these two pairs of phonemes is of ten only very slight, with the consequence that, in isolation, the pronunciation of $/ \mathrm{e} /$ and $/ \mathrm{o} /$ can easily be confused with that of $/ \mathrm{e} / \mathrm{and} / \mathrm{o} /$ respectively.

\subsubsection{THE NASAL VOWELS}

Only five nasal vowels have been distinguished for the Gomen dialect of Yuanga, even though Michailovsky (1982) considers that there are seven distinct nasal vowels in the Bondé dialect.

In the Gomen dialect the four phones $[\hat{e}],[\hat{\varepsilon}], \mid \hat{o}]$ and $[\hat{\jmath} \mid$ can be distinguished phonetically, but phonologically it is a case of contextual conditioning, with the closer phones being produced following stops and the more open phones being produced following continuants. For example:

$\begin{array}{llll}\text { /trê/ } & \text { to run } & \text { may be realised as } & \text { [trê] } \\ / \mathrm{kê} / & \text { father } & \text { may be realised as } & {[\mathrm{kê}]} \\ / \text { thôni/ } & \text { to close } & \text { may be realised as } & \text { [thôni] }\end{array}$

but:

$\begin{array}{llll}\text { /hê/ } & \text { contents } & \text { is always realised as } & \text { [hê] } \\ \text { /hô/ } & \text { new } & \text { is always realised as } & \text { [hô] } \\ \text { /wô/ } & \text { boat } & \text { is always realised as } & \text { [wô] }\end{array}$

Since there is no opposition between the members of the two pairs of phones, there is a tendency towards free variation between them, especially, of course, if there is a switch between fast and slow styles of speech. In general, the more open variants appear to be the more frequent.

\subsubsection{VOCALICLENGTH}

In principle all the vowels can be either short or long. This vocalic lengthening has a clear contrastive function in monosyllabic words (as evidenced by the data presented in section 3 ). However, the function of vocalic length in polysyllabic words is much less clear, especially as no unambiguous minimal pairs have yet been isolated.

One of the reasons for this lack of clarity may be that this is another example of a feature of the language which is in the process of change. The evidence for this is that there is a considerable amount of idiosyncratic variation in both the realisation and the perception of length among native speakers of Yuanga. This suggests that the feature of length may be in 
the process of losing its contrastive function, at least for the Gomen dialect. For example, at Paita some speakers of Yuanga pronounce the word /pa/ 'pebble' with a short vowel, while others pronounce it with a long vowel. Some people make a distinction between /pwòpa/ 'four' (inanimate) with a short final vowel, and /pwò paa/ 'little pebble' with a long final vowel, and some make a distinction between /pa/ 'pebble' with a short vowel and /paa/ 'war' with a long vowel.

A further factor which adds to the difficulty of obtaining a clear-cut analysis, but which in itself may be the reason why vocalic length is losing its distinctive function, is that word stress appears to be primarily marked on a phonetic level by a lengthening of the vowel of the accented syllable. For the vast majority of lexical items, stress predictably falls on the penultimate syllable and therefore would not be marked in a phonemic transcription. In addition, the vowels following the so-called aspirated consonants tend to be phonetically long due to the force with which these consonants are pronounced.

It can be seen from this brief résumé of the data that the whole question of vocalic length in Yuanga is fraught with difficulty and uncertainty, and a more complete and definitive analysis will only be possible after more field research has been undertaken.

Three degrees of vocalic length have been noted for a few lexical items in Yuanga by Haudricourt (1968:223) and Michailovsky (1982:10), and also for the neighbouring language of Caaqac by Hollyman (1962:49). It has not yet been satisfactorily demonstrated that this distinction is still recognised by the present-day speakers of the Gomen dialect. Even if this distinction were found to be still pertinent, it would not be necessary to posit a new phonemic feature to account for the second degree of length, since all the examples noted by Haudricourt and Michailovsky involve the two close vowels /i/ and /u/. In such a situation it would be feasible on a phonological level to interpret the second vowel as a semivowel functioning as a consonant in the pre-nuclear position of a second syllable. Thus the example [ $\mathrm{t}$ jiii] 'louse' could be interpreted as a two syllable word /tyi.yi/.

\section{THE HIGHER LEVEL UNITS}

\subsection{THE SYLLABLE}

The syllable is the distributional unit which consitutes the next higher rank of the phonological hierarchy above the rank of the phoneme. In terms of its structure, it is composed of phonemes which function as nucleus and periphery of the syllable. Vocalic phonemes (V) function as the obligatory nucleus of the syllable and consonant phonemes (C) function as the optional pre-nuclear margin of the syllable. The syllable functions as a component of the phonological word.

\subsubsection{UNAMBIGUOUS SYLLABLE TYPES}

In the Gomen dialect of Yuanga, there are two types of syllable which are unambiguous. They are distinguished on the basis of their different structures.

Type $1: \mathrm{V}$

The first type consists of a vocalic nucleus without any consonantal support. For example:

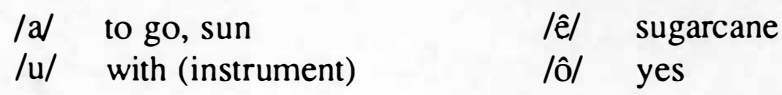


This type of syllable may be divided into at least two classes on the basis of a difference in function:

Class 1 is composed of the phoneme /a/. This class of syllable may function in any position in the phonological word.

Class 2 is composed of the phonemes $/ \mathrm{i}, \mathrm{e}, \mathrm{u}, \mathrm{o} /$. This class of syllable may not function as the stressed nucleus of the phonological word if it is immediately preceded by another vowel in the same word (see also section 5.2.2).

At this stage of research it is not possible to assign the phonemes $/ \mathrm{e} / \mathrm{and} / \mathrm{o} /$ to one class or the other with absolute certainty, although it is probable that they belong in Class 1 .

\section{Type 2 : CV}

The second type of syllable consists of a vocalic nucleus supported by a consonant in the pre-nuclear position. For example:

$\begin{array}{llll}/ \mathrm{pu} / & \text { smoke } & \text { /jinè/ } & \text { rat } \\ / \mathrm{mu} / & \text { behind } & \text { /kala/ } & \text { run away } \\ \text { /nò/ } & \text { fish } & & \end{array}$

The syllable type CVC occurs in other dialects of Yuanga but not in the Gomen dialect.

In principle all the short vowels, whether oral or nasal, can function in a syllable of Type 1. The exceptions are /û/, for which no unambiguous data have yet been found, and the oral vowels $/ \mathrm{o} / \mathrm{and} / \mathrm{e} /$. It is possible that there is neutralisation of the contrast between $/ \mathrm{e} / \mathrm{and} / \mathrm{e} /$, and $/ \mathrm{o} /$ and $/ \mathrm{o} /$ in this type of syllable in favour of the more open vowels (cf. section 2.3.1).

No unambiguous examples of long vowels standing alone without consonantal support have yet been found which suggests that long vowels are not the same type of unit as short vowels. This supports our hypothesis that long vowels should not be interpreted as a single complex unit but rather as a sequence of two units (see section 4.1.3).

All consonants and all vowels can occur in syllables of Type 2, with a distributional gap such that no aspirated nasal consonants have been found in word-medial position.

\subsubsection{AMBIGUOUS SYLLABLE PATTERNS}

It was established in section 4.1.3 that all vowel sequences, whether geminate vowels or heterogenous vowels, are to be interpreted as sequences of two vocalic phonemes. As a result of this segmental interpretation, there are three ambiguous syllable patterns: CVVV, CVV and VV, of which the last two can be combined into a single formula: (C)VV. These patterns can be interpreted either as additional syllable types or as sequences of syllables of Types 1 and 2 .

The best hypothesis for the (C)VV sequence is that it should be interpreted as a sequence of two syllables: (C)V.V. This interpretation has the advantage of economy in that it does not entail the addition of any new syllable type, whereas the alternative interpretation - CVV as a single syllable - would mean that this latter pattern would have to be incorporated into the system as a distinct syllable type. 
Further evidence supporting the preferred interpretation was obtained by measuring the length of the ambiguous CVV pattern on a sound spectrograph. It was found that the VV sequence was exactly twice as long as a single vowel, which clearly supports the view that a VV sequence should be interpreted as a sequence of two units rather than as one single complex unit. It can also be noted that a long vowel is also the same length as a sequence of two non-homorganic vowels which also lends credence to the hypothesis subscribed to above that long vowels should be interpreted as VV sequences.

In the case of the CVVV patterns all the examples have a close vowel in either the first or the second vowel position. Such vowels can be interpreted as semivowels and therefore as single consonants, or as part of complex consonant phonemes. Such an interpretation again commends itself by virtue of economy, in that it avoids the necessity of positing any new syllable structures.

The following are some examples of ambiguous syllable patterns followed by their proposed phonological interpretation:

\begin{tabular}{|c|c|c|c|c|c|}
\hline CVVV: & $\begin{array}{l}\text { [kuau] } \\
{[\text { [ eiu] }}\end{array}$ & $\begin{array}{l}\text { dog } \\
\text { to remain }\end{array}$ & $\begin{array}{l}\text { interpreted as } \\
\text { interpreted as }\end{array}$ & $\begin{array}{l}\text { /kwau/ } \\
\text { /treyu/ }\end{array}$ & $\begin{array}{l}(\mathrm{CV} . \mathrm{V}) \\
(\mathrm{CV} . \mathrm{CV})\end{array}$ \\
\hline CVV: & $\begin{array}{l}\text { [mbua] } \\
{\left[\mathrm{mb}^{w} \mathrm{a}\right]} \\
{\left[\mathrm{ha}^{\mathrm{m} \mathrm{b}^{\mathrm{w}}} \mathrm{xc}\right]} \\
{[\mathrm{kac}]} \\
\text { [haibo] } \\
\text { [haxai] }\end{array}$ & $\begin{array}{l}\text { to call out } \\
\text { head } \\
\text { to guard } \\
\text { pumpkin } \\
\text { much } \\
\text { big }\end{array}$ & $\begin{array}{l}\text { interpreted as } \\
\text { interpreted as } \\
\text { interpreted as } \\
\text { interpreted as } \\
\text { interpreted as } \\
\text { interpreted as }\end{array}$ & $\begin{array}{l}\text { /mpua/ } \\
\text { /mpwa/ } \\
\text { /hambwòè/ } \\
\text { /kaè/ } \\
\text { /haipo/ } \\
\text { /haxai/ }\end{array}$ & $\begin{array}{l}\text { (CV.V) } \\
\text { (CV) } \\
\text { (CV.CV.V) } \\
\text { (CV.V) } \\
\text { (CV.V.CV) } \\
\text { (CV.CV.V) }\end{array}$ \\
\hline
\end{tabular}

\subsection{THE PHONOLOGICAL WORD}

The phonological word is the distributional unit which constitutes the next higher rank of the phonological hierarchy above the rank of the syllable. In terms of its structure, it is composed of syllables which function as the stress-bearing nucleus and as the non-stressbearing periphery of the phonological word. The phonological word is the domain for the placement of word stress and it functions as a component of the phonological phrase.

\subsubsection{THE STRUCTURE OF THE PHONOLOGICAL WORD}

The phonological word is composed of an obligatory nucleus which comprises a stressbearing syllable, an optional pre-nuclear margin which may be composed of between one and three syllables, and an optional post-nuclear margin or coda which consists of a single syllable. If a pre-nuclear margin occurs, then a post-nuclear margin must also occur. The syllables which occur in the word margins are, by definition, unstressed.

In addition to the presence of one stressed syllable, a phonological word can be identified by the fact that it is the smallest phonological unit which can stand alone as a complete meaningf ul utterance, and also by the related fact that its borders are marked by points in the flow of speech where pauses may occur.

Syllables of Type 1, Class 1 and Type 2 may occur in any position in the phonological word except that no more than two syllable nuclei may occur in succession without an 
intervening consonant. The only example of a five-syllable word which has been noted thus far is composed entirely of syllables of Type 2 .

\subsubsection{THE PHONOLOGICAL WORD AS THE DOMAIN FOR STRESS PLACEMENT}

Word stress in Yuanga falls on the penultimate syllable of the phonological word. Since its placement is predictable it does not have a distinctive or phonemic function, but it does have a demarcative function in that its presence marks off one phonological word from another.

From a phonetic point of view word stress is characterised by extra expiratory force which results in a lengthening of the vocalic nucleus of the stressed syllable. It should be noted that aspirated consonants are produced with a simlar kind of pulmonary force and have the same lengthening effect on the following vowel. Consequently, the presence of an aspirated consonant in an unstressed syllable can camouflage the word stress, as the two syllables bear a very similar degree of phonetic force. For example, in the word /pèthumènò/ 'to walk about' the second and third syllables both appear to be phonetically stressed, but the second syllable has an aspirated consonant and it is the third one (i.e. the penultimate one) which bears the word stress.

A number of methods are used in Yuanga for augmenting the lexicon by creating new words. Affixation is one of these methods, but it is also quite common to find compound words which are the result of conjoining what were formerly two phonological words into one unit. In such cases, the compound words retain the same number of stressed syllables as their component words, and are consequently marked by at least two word stresses, as is exemplified by the words listed below. In these, as in the other examples in this section, the stressed syllable is the one following the apostrophe:

$\begin{array}{lll}\text { /'mpwò'kAmpu/ } & \begin{array}{l}\text { Sunday } \\ \text { church }\end{array} & \text { (lit. occasion sacred) } \\ \text { /'mwO'kAmpu/ house sacred) } \\ \text { /mwOntra'laè/ } & \text { village } & \text { (lit. house of whiteskin) }\end{array}$

There is one class of interrogative words which do not follow the usual pattern of stress placement but, for a reason which has yet to be elucidated, have the stress appearing on the ante-penultimate syllable:

$\begin{array}{ll}\text { ranIta/ } & \text { how many? (animate) } \\ \text { /pwònIta/ } & \text { how many? (inanimate) } \\ \text { rènIta/ } & \text { when? } \\ \text { /wènIta/ } & \text { how long? }\end{array}$

In those cases where there is a sequence of two contiguous vocalic nuclei, that is to say either a sequence of two syllables of Type 1 (V.V) or a sequence of a syllable of Type 2 followed by a syllable of Type 1 (CV.V), the stress only falls on the first of the two syllables, as indicated in the following examples:

$\begin{array}{lll}\text { /'ui/ } & \text { to blow } & \text { 'V.V } \\ \text { /mpua/ } & \text { to call out } & \text { 'CV.V } \\ \text { /mwOntra'laè/ } & \text { village } & \text { 'CV.CV.'CV.V } \\ \text { /ha'xai/ } & \text { big } & \text { 'CV.'CV.V }\end{array}$


In the preceding examples, the stress falls in the expected position, on the penultimate syllable. However, in other words this restriction on the stress placement causes the stress to fall on a syllable other than the penultimate. For example:
rhaipo/
much
'CV.V.CV
raiyu/
to inhabit
'V.V.CV

There is, nonetheless, an exception to this restriction in that the open vowel /a/ can carry stress even if it is in second position in a sequence of two vowels, and so in the following examples the stress appears in the usual place:

$\begin{array}{lll}\text { /e'amwA/ } & \text { where? (specific) } & \text { V.'V.CV } \\ \text { /ju'angA/ } & \text { Yuanga } & \text { CV.'V.CV }\end{array}$

It is on the basis of such data that Syllable Type 1 was divided into two classes in section 5.1.1.

\subsubsection{EXAMPLES OF PHONOLOGICAL WORD TYPES}

Phonological words in Yuanga can be divided into six types on the basis of their different structures.

Type 1: One Syllable

$\begin{array}{lll}\text { IV } & \text { where? } & \mathrm{V} \\ \text { /mA } & \text { sick } & \mathrm{CV} \\ \text { /mpwa/ } & \text { head } & \mathrm{CV}\end{array}$

Type 2: Two Syllables

$\begin{array}{lll}\text { rèa/ } & \text { from where? } & \text { V.V } \\ \text { rajo/ } & \text { chief } & \text { V.CV } \\ \text { rjala/ } & \text { question } & \text { CV.CV } \\ \text { r tòè/ } & \text { to throw } & \text { CV.V }\end{array}$

Type 3: Three Syllables

$\begin{array}{lll}\text { raiyu/ } & \text { to inhabit } & \text { V.V.CV } \\ \text { /e'amwA/ } & \text { from where? } & \text { V.V.CV } \\ \text { /E'ntòa/ } & \text { seed } & \text { V.CV.V } \\ \text { /a'tyòmU/ } & \text { teacher } & \text { V.CV.CV } \\ \text { /ju'angA/ } & \text { Yuanga } & \text { CV.V.CV } \\ \text { /hA'nkanA/ } & \text { now } & \text { CV.CV.CV } \\ \text { /pè'haje/ } & \text { different } & \text { CV.CV.CV } \\ \text { /ja'xòè/ } & \text { to try } & \text { CV.CV.V }\end{array}$

Type 4: Four Syllables
/atya'mAnti/
wise man
/wai'mAnI/
to tie yam leaves
together
V.CV.CV.CV
CV.V.CV.CV 
no example available

/trètrE'mpwau/

/pèha'jenI/

Type 5: Five Syllables

/pènAmpu'lunI/ round

difference

CV.CV.V.CV

CV.CV.CV.V

CV.CV.CV.CV

collection of

traditional gifts

CV.CV.CV.CV.CV

Type 6: Compund words
/'mwO'kAmpu/
church
'CV.'CV.CV

\subsubsection{THE PHONOLOGICAL WORD AND THE GRAMMATICAL WORD}

The term 'word' is used in two distinct ways in this model of analysis. It is used to label a rank on the level of the syntactic hierarchy (see section 1.3) as well as on the level of the phonological hierarchy, as has been discussed in the preceding paragraphs. It is important, therefore, to distinguish between these two uses of the same term.

In the majority of cases a phonological word in Yuanga is identical with its correlative grammatical word. This is not always the case, however, since some grammatical units such as prepositions and pronouns, which may be analysed as words on the syntactic level, do not bear word stress and in that unstressed form cannot stand alone as autonomous phonological words.

In such cases, then, a string of segments which may be analysed as two or three grammatical words may only constitute a single phonological word, as the following examples of Type 3 phonological words illustrate:

\section{kòò 'kai nU/ upright behind me (i.e. the second child) \\ /nU 'kOmbwè/ I say}

On the basis of data collected thus far, it appears that a single grammatical morpheme may be composed of a phonological word which is a maximum of three syllables in length. Any phonological words which are more than three syllables in length can be correlated with more than one morpheme.

\subsection{THE PHONOLOGICAL PHRASE}

The phonological phrase is composed of phonological words and constitutes the next higher rank in the hierarchy above the level of its constituents. The distinctive characteristics of the phonological phrase are the demarcative accent and minimal intonation patterns. The phonological phrase functions as a constituent of the intonation group which is the next higher rank in the hierarchy. 


\subsubsection{THE DEMARCATIVE ACCENT}

In each phrase there is one phonological word, which is normally the one with a verbal function at the grammatical level of the language and which is marked off from the other constituents of the phrase by a noticeably higher pitch. If the word in question is several syllables in length, the peak of the phrase accent coincides with the stressed syllable of the word.

Pitch can be used to differentiate between two different utterances when it occurs as part of an intonation contour, but otherwise pitch has no contrastive, phonemic function in the phonology of Yuanga.

\subsubsection{INTONATION PATTERNS}

Thus far only the verb basic intonation patterns for indicative and imperative statements and for interrogatives have been analysed and described. Doubtless there are other pattems which still remain to be discovered and defined.

The indicative statements and the interrogative phrases which are marked by an interrogative word have an intonation contour which rises at the point of the demarcative accent, and then falls towards the end of the phrase.

Imperatives have an intonation contour very similar to that of the indicative statements. The main difference is that the rising part of the contour begins nearer the beginning of the phrase and rises more sharply and higher before falling towards the end of the phrase.

The interrogatives which are not marked by an interrogative word have a rising contour at the very end of the phrase as well as at the point of the demarcative accent.

The following phrases exemplify the intonation patterns enumerated above. The demarcative accent is indicated by a single slash preceding the syllable in question, and the pitch contour is graphically represented above the string of segments.

Intonation contour for marked interrogatives and indicative statements
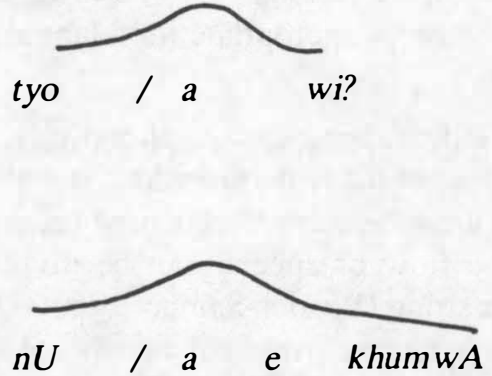

You go where?

(Where are you going?)

I (am) going to Koumac.

Imperative intonation contour

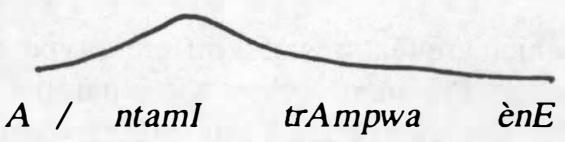

Come in (and) sit down here. 
Intonation contour for unmarked interrogatives

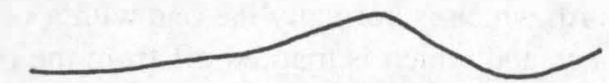

tyo tomA A / ntamwA mOnO? (Are) you going to come back tomorrow?

The above examples are, as stated, examples of phrases. However, it should be noted that they are also examples of minimal intonation groups. In general, intonation is considered to be a feature of the intonation group which is the next higher level in the hierarchy above the phonological phrase. However, since the research thus far has not included an exhaustive analysis of the features of the highest ranks of the phonological hierarchy, the basic intonation features which have been noted thus far are included at the phrase rank, in order to make the analysis as complete as possible at this stage.

\section{AN ALTERNATIVE ANALYSIS}

\subsection{THE PROSODIC APPROACH TO PHONOLOGICAL ANALYSIS}

A classical phonemic approach to phonology can produce a very reasonable analysis of a language such as Yuanga, as has been demonstrated in the preceding sections. It accounts for the phonic data accurately enough and produces a symmetrical systematisation of the phonology of the language which is satisfying and, to a large extent, satisfactory. In particular, the formal presentation reveals certain generalities of the language such as the dichotomy between stops and continuants and between oral and nasal segments, as well as the pervasive presence of aspiration.

In terms of economy, however, a segmental phonemic analysis is not at all satisfactory in that it leads inevitably to the positing of at least 37 consonant phonemes and 12 vowel phonemes. Not surprisingly, some other generalisations, such as the fact that only labial consonants are labialised and only apical consonants are retroflexed or palatalised, also get lost among the sheer mass of symbols.

The prosodic approach to phonology, however, which was first propounded by J. R. Firth (1948) of the London School and further expounded by Robins (1957) and Lyons (1962), offers a different theoretical model which is particularly appropriate for a language such as Yuanga.

As Lyons (1962:129) has pointed out, the prosodic approach to phonology is characterised by the fact that it is two-dimensional. The first of the two dimensions is that of the phonematic units, which are segmental in nature and are ordered in a sequential fashion. The phonematic units represent the way in which the flow of speech can be divided vertically, producing what has been likened to beads on a string (Bendor-Samuel 1960:348). They are not to be equated with classical phonemes but rather as the paradigmatic units of the consonant and vowel systems of a given language. As such, they function as fillers for the consonant and vowel slots within the framework of the syllable of the language. Conventionally, the alphabetic letters $p, t, k$, etc. are used to represent the consonants and $a$, $e, i$, etc., to represent the vowels.

The second dimension is that of the prosodies, which are features of a different type, not unlike Harris's (1944) simultaneous long components. Phonically, they occur parallel to, but not specifically in a one to one relationship with, the phonematic units. The prosodies 
reflect the wave-like nature of language (cf. Pike 9176:45), in that they represent features which are manifested horizontally in the flow of speech and which may, as a consequence, have an effect on more than one of the segmental phonematic units. As the phonematic units indicate the paradigmatic phonological relationships, so the prosodies indicate the syntagmatic relationships. By means of this dichotomy it is possible to divide and describe the phonetic material in terms of two systems which are different in nature but complementary in explanatory power. For further exposition of the Prosodic Approach, reference can be made to Palmer (1970) which combines a lucid summary of the theory with an anthology of important articles on the subject.

When this method of analysis was applied to the Yuanga data it was possible to reduce the phoneme inventory to six consonants and seven vowels at the cost of proposing five prosodies and without sacrificing any of the symmetry or uniformity of the system.

\subsection{THE BASIS FOR AND RESULTS OF A PROSODIC ANALYSIS OF YUANGA}

In the course of the analysis of the Yuanga data, pieces of evidence came to light which indicate that certain features of the sound system, such as nasalisation and labialisation, affect more than one segment at a time. The features involved are precisely those which, according to Robins (1957:4), of ten lend themselves to a prosodic analysis.

As noted in section 2, the palatalised consonants have an effect on the following front vowels which causes them to have a more closed realisation than those in non-palatalised syllables. In actual fact, this is true of the back vowels as well, for in the early stages of data collection the word/tyo/ 'you' was often transcribed as [tiu].

In a similar way the labialised consonants also have an effect on the following vowel, in that the rounding and closeness of the back vowels in particular is emphasised in a labialised environment. The nasalised consonants affect their neighbouring vowels by giving them a slight nasal colouration and by cancelling the opposition between nasal and oral vowels. A tentative hypothesis that the vowels following aspirated consonants tend to be slightly breathy, more intense and marginally longer than their unaspirated counterparts was confirmed by a sound spectrograph analysis.

All this evidence taken together indicates that many of the phonetic features of Yuanga are not purely segmental in nature. Rather, they are characterised by the fact that they co-occur, not just with single segments, but with a whole string of segments. Consequently, an analysis in terms of prosodies can more effectively describe such features and more adequately reveal the true nature of the phonological system of the language.

Using this system, then, Yuanga is considered to have just seven segmental vocalic phonematic units - i, e, è, $a, u, o$, and $\grave{o}$ - and six consonantal phonematic units (all of which have a voiceless phonetic realisation) which can be schematised as follows:

\section{LABIAL APICAL DORSAL}

$\begin{array}{llll}\text { Stops: } & \boldsymbol{p} & t & k \\ \text { Continuants: } & f & j & \boldsymbol{x}\end{array}$


In addition to the above phonematic units there are five prosodies which, in combination with the above segmental units and with each other, produce the same number of possible contrasts as the preceding phonemic analysis.

The prosodies and their respective abbreviations are as follows:

$\begin{array}{ll}\text { Aspiration } & \text { (A) } \\ \text { Labialisation } & \text { (L) } \\ \text { Retroflexion } & \text { (R) } \\ \text { Palatalisation } & \text { (P) } \\ \text { Nasalisation } & \text { (N) }\end{array}$

Apart from two particular cases which will be discussed later, the prosodies of Yuanga described in this section are all examples of what Robins (1957:4) calls 'syllable prosodies', which means to say that the syllable is the domain of the prosody. To put it in other words, the sequence of phonematic units which form a syllable also comprise the maximum linear extent of the effect of any given prosody. Since this is so, it can be stated at the outset that all the prosodies can occur with any of the vocalic phonematic units which form the obligatory nucleus of syllables. The only exception is that the back close vocalic segment $u$ does not occur in the same syllable as the labialisation prosody. In addition, there are restrictions on the number of vocalic contrasts which can occur in close proximity to a nasalisation prosody but these are noted in detail in section 6.3. All the prosodies can occur with either Syllable Type 1, consisting of a single vocalic segment, V, or Syllable Type 2, consisting of vocalic segment plus a preceding consonantal segment, $\mathrm{CV}$.

There are, however, a variety of restrictions on the co-occurrence of the prosodies and the consonantal phonematic units. It should be noted, nonetheless, that these restrictions are not entirely arbitrary but in most cases merely eliminate unnatural phonetic combinations.

Thus it is that the retroflexion prosody and the palatalisation prosody only occur with the apical stop $t$ and, apart from the fossilised forms noted in section 4 , the labialisation prosody only occurs with the labial stop $p$. The aspiration and nasalisation prosodies have a broader distribution, in that aspiration occurs with all the consonantal segments except $j$ and $x$, and nasalisation occurs with all the stops.

These latter two prosodies are also unique in that they can co-occur in combination with any of the other prosodies or with each other, and they can also occur together in a three-fold combination with labialisation or palatalisation. A listing of the possible combinations and the syllable types in which they can occur is given below using the formal abbreviations.

Possible combinations

$A$ and $\mathrm{L}$

$A$ and $R$

$A$ and $P$

$\mathrm{N}$ and $\mathrm{L}$

$\mathrm{N}$ and $\mathrm{R}$

$\mathrm{N}$ and $\mathrm{P}$

$\mathrm{A}$ and $\mathrm{N}$

$\mathrm{A}$ and $\mathrm{N}$ and $\mathrm{L}$

$\mathrm{A}$ and $\mathrm{N}$ and $\mathrm{P}$
Syllable types

1 and 2

2 only

1 and 2

1 and 2

1 and 2

1 and 2

1 and 2

2 only

2 only 
The application of the first four prosodies to the data is very straightforward as is evidenced by the following examples. The prosodic notation is given in the right hand column.

\begin{tabular}{|c|c|c|}
\hline [pwe] & fishing line & is written \\
\hline$\left[\mathrm{t}^{\mathrm{h}} \mathrm{i}\right]$ & to comb & is written \\
\hline$\left[\mathrm{tje}^{\mathrm{je}}\right]$ & tree & is written \\
\hline e] & night & is written \\
\hline
\end{tabular}

The nasalisation prosody, however, is considerably more complex and is discussed next. (More examples of all the prosodies are given in section 6.4.)

\subsection{THE NASALISATION PROSODY}

\subsubsection{THE PROBLEM}

The difficulty with the nasalisation prosody lies in the fact that there are, in effect, three types of nasalisation in Yuanga. Firstly, there is the type of nasalisation commonly known as prenasalisation which operates in combination with a following consonantal segment. In Yuanga it also has an effect on the immediately preceding vocalic segment (if any) in the same word, in that it provokes a neutralisation of the contrast between the two sets of vowels of an intermediate degree of aperture ( $e, \grave{e}$ and $o, \grave{o})$.

Secondly, there are the nasal consonants $m, n$, etc., which in Yuanga have the same neutralising effect as noted above but, in this case, on the following vowel (i.e. the one in the same syllable) rather than on the preceding one.

Thirdly, vocalic units can be nasalised providing a possibility of contrast between oral vocalic segments and nasal vocalic segments. The presence of this type of nasalisation causes the same vocalic neutralisation as mentioned above, but since such nasal/oral contrast only occurs following oral consonants, it clearly cannot be analysed as the same type of nasalisation as in the previous two categories. Normally this type of nasalisation only affects the vocalic phone in question; however there is some evidence that it can affect the preceding phone as well, especially if it is a semivowel. For example /wî/ 'strong' can be optionally

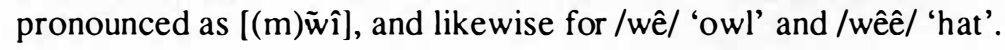

Although sharing certain similarities, these three types of nasalisation are nonetheless different and are not reducible to a single feature or process. This means that they have to be accounted for in three different ways with an independent analysis for each one.

\subsubsection{POSSIBLE SOLUTIONS}

Within the confines of the prosodic approach, there are two possible solutions for each type of nasalisation: to interpret the nasalisation as a segmental feature, which would entail positing additional phonematic units; or to interpret it as a prosody.

In the case of prenasalisation, a segmental interpretation would result in three additional phonematic units such as $m b$, nd and $n G$, or $m p, n t$ and $n k$. If a prosodic approach is taken, 
the fact that the nasalisation affects two contiguous segments which are in different syllables needs to be accounted for and handled in a satisfactory manner.

In the second case the segmental approach would involve the positing of three nasal phonematic units, $m, n$ and $n g$. The difficulty with applying the prosodic approach in this case is that the prosody is phonetically manifested in three different ways, with labial, apical and velar points of articulation respectively. These different points of articulation would have to be clearly indicated in some way within the limits of the prosodic formalism.

The third category - the nasalised vowels - also lends itself to a prosodic analysis. However, if a prosodic approach were chosen for more than two of the categories of nasalisation, then a way would have to be found to distinguish them so that each occurrence of a given prosody could be properly identified.

If a segmental approach were chosen for the third category (the nasalised vowels), there are two possible options. The most straightforward one would be to follow the example of the phonemic analysis and posit five additional nasal vocalic phonematic units. An altemative approach would be to interpret the nasalised vowel as an oral vowel followed by a nasal consonant on the phonological level which is realised phonetically as a nasalised vowel. On a diachronic level this is a very reasonable hypothesis, for it is known that other dialects of Yuanga, as well as other related languages, have nasal consonants in syllable-final position, even though there are no data immediately to hand which would indicate that this was also once true of the Gomen dialect. However, on a synchronic level it is a much less attractive proposition, for the necessary corollary of creating a closed syllable type, CVN or CVC, far from encapsulating a true generalisation about the dialect, in effect masks a unique fact about the dialect, namely, that it does not have any closed syllables.

\subsubsection{THE PREFERRED SOLUTION}

It would be possible to use a combination of segmental and prosodic solutions to account for the three types of nasalisation but the preferred solution is to treat them all as prosodies. This is clearly the most consistent solution for an analysis based on the Prosodic Model, and it is also the most economical, as it does not require the introduction of any new phonematic units or syllable types. All it requires is the splitting of the nasalisation prosody into three parts, which has the effect of adding two more syllable prosodies to the inventory for Yuanga. Since each of the three prosodies is different, it is necessary to distinguish them, but this can be done by the simple expedient of assigning a different number, $\mathrm{N}^{1}, \mathrm{~N}^{2}$ and $\mathrm{N}^{3}$, to each of them.

Prosody $\mathrm{N}^{1}$ therefore, refers to the prenasalisation prosody. In this case the nasalisation affects the stop consonants, producing on the phonetic level a strong nasal effect and a concomitant voicing of the stop. As mentioned above, it also causes the preceding vowel (if any) in the same word to be lightly nasalised and the usual contrast between the vowels of an intermediate degree of aperture ( $e, \grave{e}$ and $o, \grave{o})$ to be neutralised. The fact that this prosody affects segments in two different syllables can be adequately taken into account by introducing the concept of focus (discussed in some detail in section 6.3.4). The notation for this prosody is as follows:

[mba] instrument is written $\begin{gathered}\mathrm{N}^{l} \\ \mathrm{pa}\end{gathered}$ 
Prosody $\mathrm{N}^{2}$ is the notation for the analysis of the features which were treated as nasal consonants in the phonemic analysis and which are phonetically realised as nasal continuants. In this case the prosody does not act upon or in combination with another consonant, as was the case with $\mathrm{N}^{1}$, but it is phonetically manifested as a single nasal consonant in its own right. The prosody also affects the following vowel in exactly the same way as the preceding vowel is affected by prosody $\mathrm{N}^{1}$. In the case of $\mathrm{N}^{2}$ the point of articulation also has to be stipulated. This can be done by using one of the existing phonematic units, with the choice between the appropriate stop and the approximate continuant being somewhat arbitrary. However, in order to minimise any possible confusion between $\mathrm{N}^{1}$ and $\mathrm{N}^{2}$, the symbols for the continuant phonematic units were chosen to fulfill this function. Thus the notation for prosody $\mathrm{N}^{2}$ is as follows:

\section{[ma] and is written $\stackrel{\mathrm{N}^{2}}{\mathrm{fa}}$}

The third category of nasalisation which affects vocalic segments is labelled $\mathrm{N}^{3}$. A word with a nasalised vowel would consequently be transcribed as follows:

\section{[kê] father is written $\stackrel{\mathrm{N}^{3}}{k e}$}

As noted above, this prosody produces on the phonetic level a strong nasalisation of the vowel and the nasalisation of any preceding semivowel. It also has the same neutralising effect on the intermediate aperture vowels as the other two prosodies.

It should also be noted, in conclusion, that these three nasal prosodies cannot co-occur in the same syllable.

\subsubsection{THE CONCEPT OF FOCUS}

In his article on Sanskrit, W.S. Allen (1951) develops the concepts of focus and of linear extension as applied to prosodic features. His difficulty in Sanskrit was that the feature of retroflexion, which is typical of certain so-called retroflex consonants in Indic languages, seemed to have an effect on other segments which were sometimes separated from the retroflex consonant by several intervening segments. At that time none of the current explanations for this phenomenon were at all satisfactory and so Allen invoked the twodimensional notions of the London School and proposed, in the first instance, that retroflexion should be abstracted from the linear sequence of phones and treated as a prosody.

He then went on to propose that any given prosody will have a focal point which will normally coincide with the occurrence of the consonants which, in Sanskrit, are particularly marked by their retroflex articulation. From this focal point the effects of the prosody can spread in either direction along the linear dimension until its influence is halted by the occurrence of what Allen (1951:943) calls a "palatographically interfering articulation'. This is a segment which is produced with an articulation which is specifically not retroflex. Any segments in between these two articulations will, to a lesser or greater extent, be affected by the prosody, and they will also have, by definition, a non-interfering articulation. Thus in the Sanskrit example labial consonants, vowels and semivowels can occur within the domain of the retroflex prosody, while a dental consonant would mark the limit of the linear extension of the prosody. For example, in the following word there are two retroflex 
prosodies, whose extent is marked by the underlining, which are separated by an interfering dental nasal. The geminate nasal at the end of the word has a retroflexed articulation.

\section{Sanskrit: $\stackrel{\mathrm{R}}{\mathrm{R}}$ parinirvinna-}

The same principles can also be applied to the Yuanga data. For the majority of the prosodies, the limit of their linear extension conveniently coincides with the contiguous syllable boundaries and so Robin's (1957) category of syllable prosody remains appropriate, even though the effective cause of the limitations on the extent of the prosody is almost certainly due to the presence of an interfering segment which happens to occur at a syllable boundary, rather than any quality inherent in the juncture between syllables itself. An additional advantage of not being tied too closely to Robins's category of syllable prosodies is that it leaves the door open to the possibility of perceiving that in some cases a single prosody may affect a whole word or a polysyllabic component of a word, as in the following example:

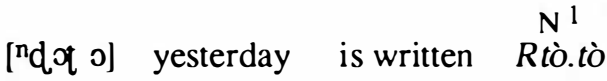

In this case, following Lyons's (1962) notation, the position of the retroflexion symbol $(R)$ indicates that both of the syllables in the word are marked by retroflexion in an identical manner, whereas only the first syllable is marked by the nasalisation prosody. This possibility is mentioned to indicate where further research is necessary, but it will not be developed further here.

It is clear, however, that Allen's concept of focus is particularly pertinent to the understanding of the prenasalisation prosody $\left(\mathrm{N}^{1}\right)$ which spreads in both directions from the focal point but does not end at a syllable boundary in either direction. Whereas in our notation syllable boundaries can conveniently be used to mark the extent of prosodies $\mathrm{N}^{2}$ and $\mathrm{N}^{3}$, in the case of $\mathrm{N}^{1}$ a system such as Allen used needs to be appended, as is illustrated in the following example:

[kūndo] to drink is written $\frac{\mathrm{N}^{1}}{\text { u.tò }}$

In this example the letter of the prosody symbol is vertically aligned with the focal point of the prosody and the horizontal line marks its linear extension, since $k$ is a non-nasal consonant and $o$ is an oral vowel. From the data collected thus far it has become clear that only oral vowels occur after prenasalised stops. One piece of evidence for this is that such contrasts as /nke/ 'dirty' and /nkè/ 'grandmother' occur, where the neutralisation always associated with nasalisation elsewhere does not occur. This makes it possible to state with some confidence that the vowel following an $\mathrm{N}^{1}$ prosody always acts as an interfering segment.

In addition to dealing very neatly with the problem raised by the $\mathrm{N}^{1}$ prosody, Allen's concept of focus and linear extension also accounts for another phenomenon which occurs in Yuanga but which has been skated over up until now. It has been noted elsewhere that sequences of two vowels are possible in Yuanga and that they have been interpreted as sequences of two syllables. It is clear however, that prosodies which are inherent in a preceding consonant carry over to some extent onto the second vowel of the sequence. Having understood Allen's extension of the Prosodic Model this phenomenon is entirely in keeping with prosodic features of language, for it is to be expected that a prosody will affect 
any segment which is not separated from the focal point of the prosody by an interfering segment. This is the case with the two vowel sequences in the following example:

\section{[thaa red pepper is written $\frac{A}{\text { ta.a }}$}

In this particular example the second vowel is phonetically marked by a slight degree of breathiness. The notation using the solid line indicates that there is only one prosodic focal point. This means that the second syllable is affected by the prosody to a lesser extent than the first syllable and, as a consequence, the phonetic manifestation of the prosody is not the same in both syllables. If the phonetic manifestation were identical in both syllables, it would be due to the presence of two prosodic foci as in the following hypothetical example:

*[thaha] would be written * A A

The Yuanga data is significantly different from Allen's in one respect, in that two or three prosodies can co-occur with the same focal point or they can overlap so that one particular segment may fall within the domain of two different prosodies. This fact, however, still does not create any major theoretical difficulty. It implies that some segments are susceptible to being affected by more than one prosody. Using Allen's terminology, it is possible to state that they are non-interfering segments with regard to more than one prosody and, as a consequence, overlap is to be expected if two or more prosodies are operative in close proximity. (Examples of co-occurring and overlapping prosodies are given in section 6.4.)

\subsection{EXAMPLES OF YUANGA DATA USING PROSODIC NOTATION}

In the examples given in this section the following notational conventions are used:

(1) The letter code of the prosodies is vertically aligned with the phonematic unit which marks the focal point of the prosody in the segmental dimension.

(2) The linear extension of the prosodies normally coincides with the syllable boundaries which are marked by a full stop. The linear extension is marked by a solid line in those cases where it does not coincide with syllable boundaries.

In order to facilitate comparison of the two analyses, the phonemic transcription is given in the left-hand column. The phonetic realisation of the examples is not reiterated here as it can be easily derived from the descriptions of the phonemes given in section 2 .

\subsubsection{EXAMPLES OF SINGLE PROSODIES}

Aspiration:

$\begin{array}{ccc}\text { pha } & \text { lung } & \begin{array}{l}\text { A } \\ p a\end{array} \\ & & \\ \text { kha } & \text { to press } & \begin{array}{l}\text { A } \\ k a\end{array} \\ & & \text { A } \\ \text { fha } & \text { to speak } & \text { fa } \\ & & \text { A } \\ \text { ha } & \text { or } & a\end{array}$


Labialisation:

\begin{tabular}{|c|c|c|}
\hline$p w a$ & rain & $\begin{array}{l}\mathrm{L} \\
p a\end{array}$ \\
\hline kapwa & not & ka.pa \\
\hline da & to open mouth & $\frac{\mathrm{L}}{a \cdot a}$ \\
\hline wòjò & crowbar & $\begin{array}{l}\mathrm{L} \\
\text { ò.jò }\end{array}$ \\
\hline
\end{tabular}

Retroflexion:

$\begin{array}{lll}\text { tri } & \text { tea } & \begin{array}{l}\mathrm{R} \\ t i\end{array} \\ \text { atru } & \text { two (animate) } & \begin{array}{c}\mathrm{R} \\ \text { a.tu }\end{array} \\ & & \mathrm{R} \\ \text { la } & \text { they } & \mathrm{a} \\ & & \mathrm{R} \mathrm{R} \\ \text { tròli } & \text { to find } & \text { tò.i }\end{array}$

Palatalisation:

\begin{tabular}{|c|c|c|}
\hline tyi & pawpaw tree & $\stackrel{\mathrm{P}}{t i}$ \\
\hline tyatya & (or: & $\begin{array}{r}\mathrm{P} \quad \mathrm{P} \\
\text { ta.ta } \\
\text { Pta.ta) }\end{array}$ \\
\hline yaji & to cover & $\begin{array}{l}\mathrm{P} \\
\text { a.jii }\end{array}$ \\
\hline kòyò & to lose & kò.ò \\
\hline
\end{tabular}

Nasalisation:

\begin{tabular}{|c|c|c|}
\hline & & $\underline{N}^{1}$ \\
\hline$n t a$ & what? & \\
\hline$k I n k a$ & to laugh & $k \overline{i \cdot k a}$ \\
\hline$m I$ & ripe & $\mathrm{N}^{2}$ \\
\hline & & $\mathrm{N}^{2}$ \\
\hline$n A A$ & to give & ja.a \\
\hline$n g A m A$ & the remainder & $\begin{array}{l}\mathrm{N}^{2} \mathrm{~N}^{2} \\
\text { xa.fa }\end{array}$ \\
\hline$\hat{o}$ & yes & $\begin{array}{l}\mathrm{N}^{3} \\
\mathrm{O}\end{array}$ \\
\hline kâ & to shout & $\begin{array}{l}\mathrm{N}^{3} \\
k a\end{array}$ \\
\hline
\end{tabular}




\subsubsection{EXAMPLES OF CO-OCCURRENT PROSODIES}

Aspiration and labialisation:

$\begin{array}{cll} & & \mathrm{A} \\ \text { phwa } & \text { hole } & \mathrm{L} \\ & & \text { pa } \\ & & \mathrm{A} \\ \text { phwiò } & \text { the eldest } & \frac{\mathrm{L}}{\text { pi.ò }} \\ & & \mathrm{A} \\ \text { wha } & \text { big } & \mathrm{L} \\ & & \mathrm{a} \\ & & \mathrm{A} \\ \text { whili } & \text { to drag } & \text { L R } \\ & & \text { i.i }\end{array}$

Aspiration and retroflexion:

$\begin{array}{lll} & & \mathrm{A} \\ \text { thra } & \text { bald } & \mathrm{R} \\ & & \text { ta } \\ & & \mathrm{A} \\ \text { thròli } & \text { shell } & \mathrm{R} \mathrm{R} \\ & & \text { tò. } i\end{array}$

Aspiration and palatalisation:

thyamwA banana

$$
\begin{aligned}
& \text { A L } \\
& P \quad N^{2} \\
& \text { ta.fa }
\end{aligned}
$$

A

P. L

thyipwe to sneeze ti.pe

Nasalisation and labialisation:

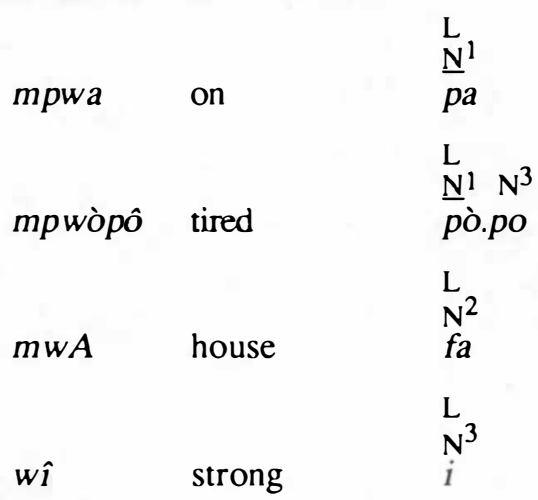

This notation indicates that the labialisation and the nasalisation prosody co-occur simultaneously and that the vowel is the focal point of the prosodies. If this is correct it goes a long way towards explaining, from a phonetic point of view, why the variant [mw̃î] sometimes occurs (cf. section 6.3.1), as this is a natural result of trying to produce a nasal and a labial sound at the same time. 
Nasalisation and retroflexion:

$\begin{array}{lll} & & \mathrm{R} \\ \text { ntra } & \text { ashes } & \frac{\underline{\mathrm{N}}^{1}}{\text { ta }} \\ & & \mathrm{T} \\ & & \underline{\mathrm{N}}^{1} \mathrm{R} \\ \text { ntròtrò } & \text { yesterday } & \text { tò.tò } \\ & & \mathrm{R} \\ & & \mathrm{N}^{3} \\ \text { lâ } & \text { those } & \mathrm{a}\end{array}$

Nasalisation and palatalisation:
ntya dirt $\quad \frac{\mathrm{P}}{\underline{N}^{1}}$
nyAnya mother $\begin{aligned} & \mathrm{P} P \\ & \mathrm{~N}^{2} \mathrm{~N}^{2} \\ & \text { ja.ja }\end{aligned}$

No example is available for $\mathrm{P}$ and $\mathrm{N}^{3}$ combined.

Nasalisation and aspiration:

$\begin{array}{lll} & & \mathrm{A} \\ \text { nhU } & \text { to crumble } & \mathrm{N} \\ & & j u \\ & & \mathrm{~A} \\ & & \mathrm{~N}^{3} \\ \text { hâ } & \text { already } & a\end{array}$

Nasalisation, aspiration and labialisation:

$\begin{array}{lll} & & \mathrm{A} \\ & & \mathrm{L} \\ \mathrm{N} h w A & \text { we (inclusive) } & \mathrm{Na} \\ & & \mathrm{A} \\ & & \mathrm{L} \\ & & \mathrm{N}^{2} \mathrm{~N}^{2} \\ \text { mhwAnU moon } & \text { fa.ju }\end{array}$

Nasalisation, aspiration and palatalisation:
A
$P$
nhyAtu good soil ja.tu

\subsubsection{EXAMPLES OF OVERLAPPING PROSODIES}

Overlapping only occurs with the $\mathrm{N}^{1}$ prosody.

$$
\text { ènOmpau very good } \quad \text { è.jo.pau } \frac{\mathrm{N}^{2}}{\mathrm{~N}^{1}}
$$




$\begin{array}{lll}\text { ènUnta } & \text { up there } & \begin{array}{c}\frac{\underline{N}^{2}}{j \underline{u} t a} \\ N^{1}\end{array} \\ m A n k u & \text { correct } & \frac{\underline{N}^{2}}{\frac{f a \cdot k u}{N^{1}}}\end{array}$

At this point a modification can be made to the general statement set out above in section 6.2 with regard to the occurrence of the nasalisation prosody in particular syllable types. With the division of the nasalisation prosody into three categories, the following more specific statement can be made: prosodies $\mathrm{N}^{1}$ and $\mathrm{N}^{2}$ only occur with Syllable Type 2, while prosody $\mathrm{N}^{3}$ can occur with both syllable types.

\subsubsection{SUMMARY}

The above examples illustrate how a wide variety of features, and combinations of features, can be represented using the Prosodic Approach. In the case of Yuanga the notation reveals clearly the simple syllable structure which is basic to the language. In addition, it reveals that despite the apparent complexity of the system of consonantal contrasts there are, in fact, only a very small number of phonematic units which actually function in the consonant slot of the syllable. The other phonetic features of Yuanga, such as nasalisation and labialisation, are clearly seen to be non-segmental in nature. Their function is not to fill a slot in the syllable structure but rather to give a particular colouration to the syllable as a whole by operating in parallel with the segmental components of the syllable. The prosodic method of analysis and notation, then, graphically reveals the fundamental difference between these two types of phonological feature in Yuanga.

\subsection{WORD, PHRASE AND SENTENCE PROSODIES}

In section 5 a brief analysis was made of the phonological features of higher level units such as the word, phrase and sentence. Although it is not possible within the limits of this paper to develop this at any length, it should be noted that the prosodic model can also account for features such as stress, phrase accent, tone (if any) and intonation, and would treat them as prosodies of the unit in question. Thus, for example, stress in Yuanga would be analysed as a prosody of the word, for although it does not have any contrastive function in the classical phonemic sense of the word it does have a clear demarcative function, as it is a phonological means of distinguishing one word from another. Using Allen's (1951) conceptualisation again, it could be said that stress is a prosody whose linear extension is bounded by the juncture between words. All the syllables of a word fall within the domain of the stress prosody because, if one syllable is the focal point of the prosody, then by definition all the other syllables in the word will be of a lesser intensity and of a shorter length than the stressed syllable. Thus, in a very real way the stress prosody affects all the syllables of a word, not just the stressed syllable.

In a phonemic analysis stress in Yuanga would, in effect, be relegated to a peripheral position in the analysis because it is not semantically contrastive and is, therefore, 'nonphonemic'. With the prosodic model, however, such a distinction is redundant and stress would take its place on a par with all other prosodies. Such an analysis undoubtedly does greater justice to the true role of stress within the phonological system. 
In a similar manner intervocalic voicing could be analysed as another word prosody, phrase accent would be analysed as a prosody of the phonological phrase, and intonation as a prosody of the sentence. As a consequence, it can be seen that the prosodic approach to phonology is capable of taking account of the whole range of phonological features with considerable economy and clarity.

\subsection{PROSODIC ANALYSIS AND AUTOSEGMENTAL PHONOLOGY}

The purpose of section 6 has been primarily to review the phonology of Yuanga from the perspective of Prosodic Analysis and, as a consequence, to bring new light to bear on the exact nature of this particular sound system. It is of interest to note in conclusion, however, that these same data can also be analysed, with very similar results, by using the methodology known as 'Autosegmental Phonology', which has been developed by J.A. Goldsmith (1976).

Although of very different parentage, Prosodic Analysis and Autosegmental Phonology have a remarkable amount in common. According to Palmer (1970:ix-xv), the prosodic approach to phonology, as developed by Firth and his colleagues, had three particularly remarkable characteristics. Firstly, it was a radical alternative to the structuralist-type approach to phonology of the day in that it proposed a phonological analysis that was not based primarily on segmentation into phonemes. Secondly, in place of the phoneme, Firth used the word as his base unit and incorporated features of the word into his phonological analysis. At the same time he also emphasised the importance of the syllable, and it is in relation to their function within the syllable that the segmental phonematic units are described and derive their significance. Thirdly, although he did not develop it in any great detail, Firth recognised the interdependence of grammar and phonology and considered that an analysis should attempt to integrate these different aspects of linguistic reality rather than arbitrarily keeping them apart, as was the common practice within American structuralism.

These are, of course, the very same issues which have been taken up and developed, apparently independently, by the Generative school of linguistics. Chomsky himself (1964) rejected the rigid phoneme-based approach to phonology of the structuralists and proposed instead his alternative Transformational Generative approach, which is notable for its close integration of grammar and phonology. Proponents of Natural Generative Phonology have championed the cause of the syllable (Hooper 1972) and the word (Vennemann 1974) as units which are important for, and even basic to, linguistic analysis.

Autosegmental Phonology itself is, of course, one of the most recent developments of phonological theory from within the Generative tradition. Goldsmith's innovation arose out of the fact that the Generative model cannot neatly and conveniently represent essentially non-segmental phonological features such as tone. His solution (Goldsmith 1976:i) is to posit "parallel tiers of segments (or 'autosegments')" which can be used to represent as many different phonological features as are present in the phonic data.

The basic tier of units which occur in all representations is that of the so-called "atomic units" (Goldsmith p.16), although they are usually simply referred to as segments. As with Firth's phonematic units, they are represented by alphabetic letters. In this case, however, in line with traditional generative phonology they represent and symbolise all the appropriate distinctive feature specifications of the segment in question, except for those features represented by another tier of autosegments. Phonological features which cannot adequately 
be expressed by single segments, as defined in terms of a matrix of distinctive features, are assigned to another tier and are represented by an abbreviation appropriate to the feature in question. Such a tier is appropriate if a segment needs to be marked with two features which are mutually exclusive in distinctive feature characterisation. An example of this would be a contour tone which may have to be characterised as both '+ high' and '- high' simultaneously. A second tier is also appropriate if there is a feature, such as nasalisation, which occurs simultaneously with or affects more than one segment. Thus in the following example given by Goldsmith (p.23), a word with low tone on the first syllable, high tone on the second syllable and a low-high contour tone on the third would be represented by two tiers of autosegments:<smiles>[3H][Te][Tl]</smiles>

The relationship between the two tiers is overtly marked by lines of association. The role of these lines is important, and Goldsmith developed a formal definition for making the associations which he called 'the well-formedness condition'. In the case of the above example which deals with tone, this condition reads (p.27):

(1) All vowels are associated with at least one tone;

All tones are associated with at least one vowel.

(2) Association lines do not cross.

In addition, it can be noted that complex features can be indicated by having two association lines leading to a single segment as in the case of the contour tone above.

It is not possible within the scope of this paper to give a full autosegmental analysis of Yuanga. The purpose is merely to make passing reference to a current, distinctive development in phonological theory and to underscore the proposal, made elsewhere in this paper, that a single set of data can profitably be viewed from more than one perspective. Nonetheless, by demonstrating how the feature of nasalisation would be handled it is possible to give an indication as to how the other features would be handled as well. The interested reader can easily pursue this issue further on the basis of the examples given.

Autosegmental Phonology is a rule-based theory, although the detailed development of the rules for Yuanga will not be dealt with here. The process of analysis involved applying the universal 'well-formedness condition' and then the non-universal rules which need to be developed for each specific language. These latter rules define how and when the extra lines of association are drawn in those cases where more than one line leads to a single segment or autosegment. Once such rules have been applied to the Yuanga data, the result is as indicated in the following examples. For ease of reference the phonemic, prosodic and autosegmental representations will all be given together.

Prenasalisation:

Phonemic:

/kUntò/ to drink

Prosodic:

$$
\frac{N^{1}}{k u . t o ̀ ~}
$$

Autosegmental:

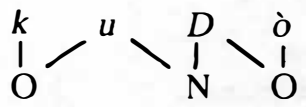


In this notation $\mathrm{O}$ indicates 'oral' and $\mathrm{N}$ indicates 'nasal'. The upper case $D$ represents a segment with all the feature specifications of an $/ \mathrm{n} /$ except for nasality. The presence of two association lines leading to the $D$ indicates that the segment is complex: in this case it is a prenasalised stop (i.e. part nasal, part oral). The two lines leading to the $u$ have similar significance, in that this segment is part oral and part nasal, being neither identical with an oral vowel nor identical with a nasal vowel.

Nasal consonants:

Phonemic

Prosodic:

Autosegmental:

\section{/nU/}

$\mathrm{N}^{2}$

ju

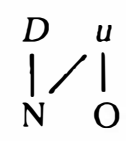

Nasalised vowels:

$\begin{array}{lcl}\text { Phonemic: } & \text { /pû/ } & \text { green } \\ & \mathrm{N}^{3} & \\ \text { Prosodic: } & \mathrm{pu}\end{array}$

Autosegmental:<smiles>N[AlH]O</smiles>

It can be seen from these examples that the basic conceptualisation of Prosodic Analysis and Autosegmental Phonology is almost identical, with merely the form of notation being different. Both conceive of a basic string of unitary segments linked in parallel with another set of features which are more fluid in their extension along the linear plane. Clearly there also are some differences, but these largely hinge around whether a particular relationship or feature is explicitly marked in the notation or whether it is implicit in the definition of one of the symbols. For example, in the prosodic analysis the interfering segments are not explicitly marked, although their presence is implied by the absence of any prosodic marking. In the autosegmental analysis all the segments are explicitly marked as to whether they are oral or nasal.

Another significant difference is that the autosegmental analysis only posits a single feature of nasalisation, while three nasalisation prosodies are required with the prosodic approach. This is somewhat counterbalanced by the fact that the autosegmental analysis requires the additional upper case symbols to represent the information which is inherent in the definition of the three prosodies. This means that what is gained by reducing all occurrences of nasalisation to a single feature is counteracted by enlarging the inventory of segmental units.

Finally, in defence of the phonemic analysis, even though the presence of two types of features is not explicitly expressed in the notation, as it is in the other two analyses, nonetheless, in this particular case, the fact that nasalisation affects the contiguous vowel as well as the consonant is indicated by the presence of the archiphoneme. 
Needless to say, a lot more work could be done to develop the implications and the relative value of each of the analyses. Suffice it to say at this point that different analyses of the same data are possible; none can be rejected a priori as having no relevance, for each of them, in its own way, gives an accurate account of the sound system of Yuanga and, potentially at least, is capable of doing so for any natural language.

\section{CONCLUSION}

The main purpose of this article has been to present with as much clarity and plenitude as possible a description of the phonological system of one of the dialects of the language of Yuanga. The intrinsic value of such an exercise lies in the fact that this language has not previously been described in such detail, and in the fact that the languages of New Caledonia are almost completely unknown to linguists of the English-speaking world.

In the interests of giving the most complete picture possible, it was deemed appropriate to approach the data from two different perspectives, and this also raises an issue of general interest. The first approach, that of the Syntagmatic Model, concentrates on segmentation. In doing so, it reveals how many individual segments are required to account for the system of phonemic contrasts which are inherent in Yuanga. The approach of Prosodic Analysis or Autosegmental Phonology puts less emphasis on segmentation and demonstrates that the same phonic data can be perceived from another perspective. In this case, both segmental and non-segmental features are perceived as occurring simultaneously and in complementation with each other.

The fact that the same data can be viewed from more than one perspective does not necessarily undermine the theoretical foundations of linguistic analysis in general, nor, even, of one particular model of analysis. The fact of the matter is that all reality can be studied and perceived from different points of view. This universal is illustrated by what are known as 'ambiguous drawings' which, for example, may be seen as a beautiful woman or as an old crone, depending on how the eye interprets the web of interrelationships of the lines in the drawing.

The fact of more than one perspective (provided that it is accurate in its representation of reality) does not imply that one perspective is correct, or true, and that all the rest are illusory. It implies rather that truth may be greater, and more inclusive, than a single isolated viewpoint would have us believe. The inadequacy of a particular perspective, or theoretical model, may lie not in the fact that it presents a false picture of reality but merely in that it presents a partial and incomplete picture of reality. The quest for a complete and, by definition, true picture of linguistic reality, then, does not involve the elimination of all competing models bar one, but rather in the appreciation of the insights which each of the relevant models can bring to bear on the language being studied.

The value of a particular model may, in fact, lie more in its specific aim or practical application. The stated aim of the Syntagmatic Model, as with many phonemic models, is to provide the linguistic foundations for producing a practical orthography of a hitherto unwritten language (Nicole 1981; Pike 1947). In such cases, an analysis which reduces all the phonological contrasts to a set of segments is a very valuable starting point for organising an appropriate but economical alphabet.

The results of a prosodic or autosegmental analysis, on the other hand, do not lend themselves quite so readily to the uni-dimensional requirements of an alphabet-based 
orthography, although such analyses may, arguably, be more appropriate than a phonemic analysis if a syllabary were the goal, rather than an alphabet. The strengths of both prosodic and autosegmental analyses lie less in their application to practical problems such as orthography preparation and more in their theoretical insightfulness into the universal nature of language. Both the Prosodic Model and Autosegmental Phonology reveal the fact that speech is not a simple linear collection of discrete utterances but rather a complex interaction of various types of sounds, many of which occur simultaneously rather than sequentially.

A phonemic approach then, provides the valuable service of reducing a complex multilevel system to a single segmental plane suitable for transcription into the uni-dimensional milieu of alphabetic writing; but it does so at the cost of over-simplification. Prosodic analysis and autosegmentalisation preserve and portray the complex web of relationships inherent in a phonological system, such as that of Yuanga, but at the cost of being notationally more cumbersome and, possibly, of less immediate value in other more practical fields.

Viewing linguistic reality from all possible viewpoints is almost certainly a practical impossibility and even using more than one approach in any given study may, generally, be more than the human frame can bear. Nonetheless, it is salutary to realise that such a multidimensional view of reality is theoretically possible. Such a realisation can help an analyst choose the approach which is the best suited to his specific goal in undertaking research. In addition and above all, such a realisation helps to keep all discoveries in perspective and to promote the healthy and humbling prerequisite to all scientific research: that no one methodology and no one tradition has a monopoly on truth.

\section{REFERENCES}

ALLEN, W.S., 1951, Some prosodic aspects of retroflexion and aspiration in Sanskrit. Bulletin of the School of Oriental and African Studies 13:939-946.

BENDOR-SAMUEL, John T., 1958, Structure and function of the verbal piece in Jebero. PhD dissertation, University of London.

1960, Some problems of segmentation in the phonological analysis of Tereno. Word 16:348-355.

1961, The verbal piece in Jebero. Word 17, Supplementary Monograph 4.

1963, A structure-function description of Terena phrases. Canadian Journal of Linguistics 8:59-70.

BOLLI, M., 1976, Etude prosodique du Dan (Blossé). Abidjan: University of Abidjan ILA and Socićté Internationale de Linguistique.

BLOCH, Bernard, 1941, Phonemic overlapping. American Speech 16:278-284. (Reprinted in Makkai, ed. 1972:66-70.)

CALLOW, John C., 1962, The Apinayć language. PhD disscrtation, University of London.

CHAPMAN, W.H., 1971, Introduction to practical phonetics. Horsleys Green: Summer Institute of Linguistics.

CHOMSKY, Noam, 1964, The nature of structural descriptions. Current Issues in Linguistic Theory, 65110. The Hague: Mouton. (Reprinted in Makkai, ed. 1972:401 -423.)

COYAUD, M., 1975, Matćriaux conccrnant la langue juang. Nouméa: ORSTOM. (Mimeograph.)

DUBOIS, Jean, Mathée GIACOMO, Louis GUESPIN, Christiane MARCELLESI, Jean-Baptiste MARCELLESI and Jean Pierre MEVEL, 1973, Dictionnaire de linguistique. Paris: Larousse.

DYEN, Isidore, 1971, The Austronesian languages and Proto-Austronesian. In Scbeok, cd. 1971:5-54.

FIRTH, J.R., 1948, Sounds and prosodies. Transactions of the Philological Society, 127-152. (Reprinted in Makkai, cd. 1972:252-263.) 
GOLDSMITH, John A., 1976, Autosegmental phonology. Bloomington: Indiana University Linguistics Club.

HARRIS, Zellig S., 1944, Simultaneous components in phonology. Language 20/181-205. (Reprinted in Makkai, ed. 1972:115-133.)

HAUDRICOURT, André G., 1951, Variations paralléles en Mélanésien. Bulletin de la Société de Linguistique de Paris 48/1:140-153.

1963, La langue des Nenemas et des Nigoumak. (Te Reo Monograph.) Auckland: Linguistic Society of New Zealand.

1968, La langue de Gomen et la langue de Touho. Bulletin de la Société de Linguistique de Paris 63:208235.

1971, New Caledonia and the Loyalty Islands. In Sebeok, ed. 1971:359-396.

HAUDRICOURT, André G., Jean-Claude RIVIERRE, Françoise RIVIERRE, C. MOYSE-FAURIE, Jacqueline de la FONTINELLE, 1979, Les langues mélanésiennes de Nouvelle Calédonie. (Collection Eveil 13.) Nouméa: Direction de l'Enseignement Catholique.

HOLl YMAN, K.J., 1962, Premiére esquisse de la phonologie du Caaqac. Te Reo 5:41-51. Auckland: Linguistic Society of New Zealand.

HOOPER, Joan Bybee, 1972, The syllable in phonological theory. Language 48:525-540.

1976, Introduction to natural generative phonology. New York: Academic Press.

JAEGER, Jeri J., 1983, The fortis/lenis question: evidence from Zapotec and Jawoñ. Journal of Phonetics 11:177-189.

LEENHARDT, Maurice, 1946, Langues et dialectes de l'Austro-Mélanésie. (Travaux et Mémoires de l'Institut de l'Ethnologie 46.) Paris: Musée de l'Homme.

LYONS, John, 1962, Phonemic and non-phonemic phonology: some typological reflections. IJAL 28:127-134. (Reprinted in Makkai, ed. 1972:275-281.)

MAKKAI, Valerie Becker, ed. 1972, Phonological theory: evolution and current practice. New York: Holt, Rinehart and Winston.

MEIER, Paul, Inge MEIER and John T. BENDOR-SAMUEL, 1975, A grammar of Izi, an Igbo language. Norman OK: Summer Institute of Linguistics.

MICHAILOVSKY, Boyd, 1982, Une écriture pour le Yuaanga de Bondé. Paris: Centre National de Recherches Scientifiques. (Mimeograph.)

NADEN, Anthony Joshua, 1971, Introduction to phonemic analysis. Horsleys Green: Summer Institute of Linguistics. (Mimeograph.)

1973, The grammar of Bisa: a synchronic description of the Lebir dialect. PhD dissertation, University of London.

NICOLE, Jacques, 1979, Phonologie et morphophonologie du Nawdm. Lomé, Togo: Université du Bénin and la Société Internationale de Linguistique.

1981, Introduction à l'analyse phonologique. Paris: Société Internationale de Linguistique.

OZANNE-RIVIERRE, Francoise and André G. HAUDRICOURT, 1982, Dictionnaire thématique des langues de la région nord de la Nouvelle Calédonie. (LACITO Documents 4.) Paris: SELAF.

PALMER, F.R., ed., 1970, Prosodic analysis. Oxford: OUP.

PIKE, Eunice V., 1976, Phonology. In Ruth M. Brend and Kenneth L. Pike eds Trends in linguistics: tagmemics, vol.1: Aspects of the field. (Studies and Mongraphs 1:45-83.) The Hague: Mouton.

PIKE, Kenneth L., 1947, Phonemics: a technique for reducing languages to writing. Ann Arbor: University of Michigan.

1967, Language in relation to a unified theory of the structure of human behavior. 2nd rev. edn. The Hague: Mouton.

REVIERRE, J.-C., 1972, Les tons de la langue de Touho (Nouvelle Calédonie). Bulletin de la Société de Linguistique de Paris 67/1:301-316.

1973, Phonologie comparée des dialectes de l'extrême-sud de la Nouvelle Calédonie. (LACITO 5.) Paris: SELAF. 
1980, La langue de Touho: phonologie el Grammaire du Cèmuhî. (LACITO 38.) Paris: SELAF.

1981, New Calcdonia. In S.A. Wurm and Shirô Hattori, eds Language atlas of the Pacific area, map 17, part 1: New Guinea area, Oceania, Australia. Canberra: The Australian Academy of the Humanities, in collaboration with the Japan Academy. PL, C-66.

ROBINS, R.H., 1957, Aspects of prosodic analysis. Proceedings of the University of Durham Philosophical Society 1:1-12. (Reprinted in Makkai, cd, 1972:264-274.)

SAM, Léonard, 1982, Le Drehu. Nouméa: CTRDP. (Mimeograph.)

SCHANE, Sanford A., 1971, The phoneme revisited. Language 47:5()3-521.

SCHOOLING, Stephen .J., 1973a, A phonetic investigation of Wolof (Senegal). Coleraine UK: New University of Ulster.

1973b, A phonemic analysis of Japanese. Horsleys Green: Summer Institute of Linguistics.

1978, A phonological study of Atché (Ivory Coast). Horsleys Grecn: Summer Institute of Linguistics.

1981, A linguistic and sociolinguistic survey of French Polynesia. Hamilton NZ: Summer Institute of Linguistics.

1982, A sociolinguistic survey of New Caledonia. Hamilton NZ: Summer Institute of Linguistics.

SEBEOK, Thomas A., ed., 1971, Current trends in linguistics, vol.8: Linguistics in Oceania. The Hague: Mouton.

SERVICE DE LA STATISTIQUE, 1976, Recensement du 23 avril 1976. Nouméa.

SIMONS, G.F., 1982, Word taboo and comparative Austronesian linguistics. In Amran Halim, Lois Carrington and S.A. Wurm, eds Papers from the Third International Conference on Austronesian Linguistics, vol.3: Accent on variety, 157-226. PL, C-76.

THOMAS, Elaine, 1978, A grammatical description of the Engenni language. Dallas: Summer Institute of Linguistics and University of Texas at Arlington.

VACHEK, Josef, 1964, On some basic principles of "classical" phonology. Zeitschrift für Phonetik, Sprachwissenschaft und Kommunikationsforschung 17:409-431. (Reprinted in Makkai, cd. 1972:424441.)

1966, The Linguistic School of Prague. Bloomington: Indiana Univcrsity Press.

VENNEMANN, Theo, 1974, Words and syllables in natural gencrative grammar. In Anthony Bruck, A. Fox and Michael W. La Galy Papers from the Parasession on natural phonology, 346-374. Chicago: Chicago Linguistic Society. 


\title{
TAWALA DERIVATIONAL PREFIXES: A SEMANTIC PERSPECTIVE
}

\author{
BRYAN EZARD
}

The most urgent need in semantics is for fresh empirical evidence obtained by painstaking study of concrete lexical data. (Weinreich 1966:473)

\section{INTRODUCTION}

Derivational prefixes are probably the most complex aspect of Milne Bay languages. Even though they are central to a thorough knowledge of these languages, they have of ten received only cursory treatment by linguists. This present study is the first systematic treatment of these prefixes. ${ }^{1}$

The Austronesian languages of the Milne Bay area have a reputation for being rather simple - and this is probably true enough for 90 per cent of day-to-day communication. However, mastery of the remaining 10 per cent involves an effort out of all proportion to its frequency. An examination of the dictionaries of Milne Bay and beyond (details are given in

${ }^{1}$ I wish to acknowledge my deep sense of gratitude to various individuals who played a significant role in the formative processes of this paper, produced as partial fulfilment of the requirements for the degree of Master of Arts of the Australian National University.

Firstly, my debt to the Tawala people, and Yailo Robert in particular, is incalculable. The people of Diwinai and Labe villages have always made me most welcome - getting out the pandanus mats and sharing their lives with me.

Without the encouragement of my Summer Institute of Linguistics colleagues - Drs Ray Johnson, Robert Litteral and Ken McElhanon - it is doubtful if I would ever have ventured along the course I have now come to the end of.

The excitement of 'frontier' discovery - shared by Professor Dixon and the staff of the Linguistics Department, The Faculties, Australian National University - has been a conducive atmosphere in which to pursue the intricacies of linguistics. Special appreciation is extended to Drs Avery Andrews and Timothy Shopen for their contribution to my MA thesis.

I am especially indebted to John Lynch, Professor of Linguistics at the University of Papua New Guinea, who gave generously of his time to read two earlier drafts and whose overall and detailed suggestions resulted in numerous improvements.

Finally, to Janet, my wife, constant companion, finest critic, detailed editor and typist of the many drafts of the material in this paper go my deepest appreciation. Without her help and encouragement I could not have started, let alone finished such an undertaking.

Financial assistance was gratefully received during 1981 and 1982 from a Commonwealth of Australia Postgraduate Award, and during my Papua New Guinea field trip, February to June 1982, from an Australian National University scholarship. 
Appendices 1 to 6 ) reveals that a single root with two or more different prefixes is commonly recorded without any clear distinction in its glosses. The dictionaries and grammars also reveal a trite treatment of the derivational prefixes, with little or no effort being made to give accurate definitions, and little or no attention being paid to data which do not conform to the usual 'causative' definition. This paper, then, reveals something of the detail that needs to be controlled in order to productively use the Tawala derivational prefixes.

The Tawala derivational prefixes (wi, lu, li, wo and om) are added to roots in order to derive new verbs. There appear to be no restrictions as to which part of speech can be 'verbalised' by the addition of one of these prefixes. A general meaning associated with the respective prefixes has been suggested in section 4 (see Table 5) but these meanings do not enable us to predict the precise meaning a root should have with a given prefix. Although the general meanings of derivational prefixes are not productive in a formal way, all is not chaos, because a given prefix usually has a precise meaning when applied to a specific semantic class. The discovery of the correspondence between the meanings of the prefixes and the various semantic classes has thus reduced a formidable array of data to a manageable corpus (sections 3 and 4).

This present study handles not much more than the tip of the iceberg. Or, to use a more appropriate metaphor suggested by my language helper, Yailo, ${ }^{2}$ we have criss-crossed the jungle with a few paths and discovered the general topography of the area while many details remain hidden, waiting for future discovery. While I am aware that much work remains undone, the very fact of exposing a difficult area will hopefully encourage others to take up the challenge. Tawala pref ixes need a treatment as detailed as Wierzbicka's (1980) treatment of the Russian instrumental case, which seeks the general core meaning of the case and the pattems divergent from the general meaning.

\subsection{ThE Tawala Situation}

The data presented in this paper are predominantly from the Diwinai dialect, the central dialect of the Tawala language. Tawala is spoken by some 10,000 people living around the shores of Milne Bay and nearby islands of the easternmost tip of Papua New Guinea (see Map 3). It includes the dialects referred to in earlier literature as the separate languages of Basilaki, Bohila?i (Bohira?i), Kehelala (Keherara) and Tavara, ${ }^{3}$ but does not include Maiwara (as suggested by Dutton 1973), which is a dialect closely related to the Taupota language, though most Maiwara people have some knowledge of Tawala as a second language.

To understand the growing importance of the Tawala language we need to look briefly at the history of the Milne Bay Province from the time of European settlement. In the early days, a number of forces worked against the use of Tawala (the people themselves say the language was dying). This attitude is seen in the constant misspelling of place names by outsiders, as seen in the language names given above. Today, however, the language is undergoing a revival, and may well become a lingua franca of the province in the years to come.

\footnotetext{
${ }^{2}$ No words could express my debt to Yailo Robert, my 'older brother' and co-translator. He has paticntly helped me to gain insight into the treasures of his language and culture since we first commenced working together in 1974.

${ }^{3} r$ and $v$ do not appear in any present-day Tawala dialects; these sounds reflect Dobu and Suau spelling.
} 


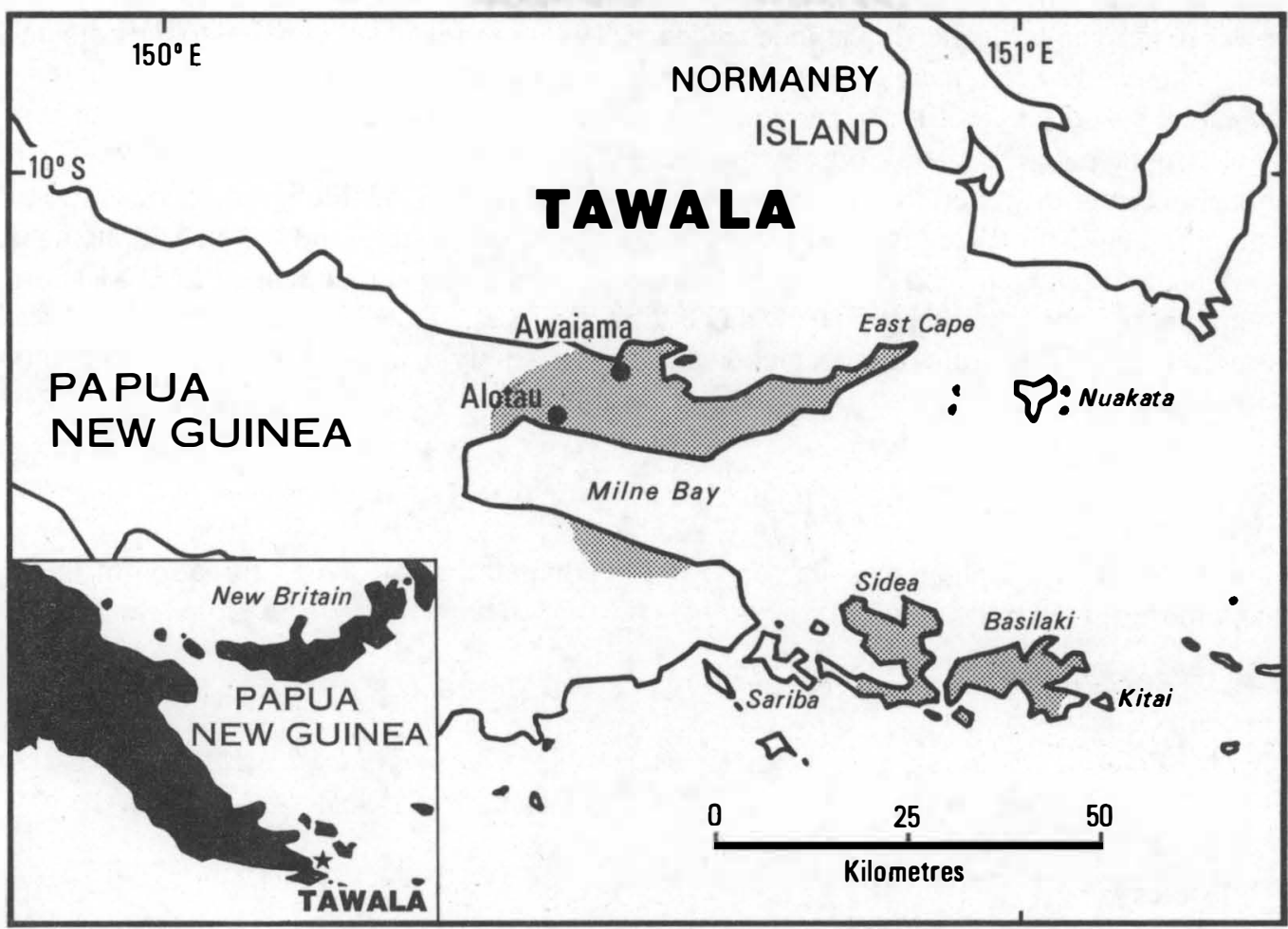

MAP 3: THE TAWALA LANGUAGE AREA

The first consistent contact with the outside world began in the last decades of the nineteenth century with the commencement of three Christian missions, each working in the Tawala language area but not using the Tawala language (see Map 1). From the south, the Kwato mission (an off-shoot of the London Missionary Society) moved into Milne Bay using the Suau language. From the north-west the Anglicans moved along the north coast towards East Cape using the Wedau language. From the north came the Dobu-speaking Methodists, establishing work first on the East Cape Peninsula and later extending to the islands to the south. Though some efforts were made at producing Tawala literature, work was predominantly in the three church languages. The Tawala people thus began to look on their own language as unimportant. This conclusion was reinforced by the government operations being centred at Samarai in the Suau language area, with Suau commonly used by government of ficers having contact with the people. In the early 1930s Catholic work began in the area, centred at Sideia. Over the years some work was done by them in the Tawala language, but only in a token way in comparison with the literature available in the other church languages of the area. However, later moves in government circles changed the scene.

In the mid 1960s the hopelessly overcrowded island of Samarai was abandoned as the administrative headquarters of the Milne Bay Province in favour of the mainland centre of Alotau on the north coast of Milne Bay, within the Tawala language area. This changeover 
was completed in 1976 with the opening of the intemational wharf at Alotau. The transfer of power to indigenous leadership at independence (1975) has relegated Samarai to the colonial past. There have been many results of this change of location, but none more important than the effect it had on the Tawala people, who have a new-found sense of the importance of their language. A United Church minister active in the Alotau area during the early changeover period reported a swing to the use of the vernacular in church services (pers. comm.). Today the swing is almost complete, with Tawala hymns and the New Testament available and popular, and church services mostly in the Tawala language. In 1981 some young people published the first Tawala newspaper - Geka Tuwega (This is News). What is more, people from other language areas are increasingly using Tawala in their contacts with the local people.

\subsection{TAWALA PHONOLOGY}

The following 20 phonemes are found in the Diwinai dialect. (A justification of these phonemes is given in Ezard and Ezard 1974).

TABLE 1: TAWALA PHONEMES - POINT AND MANNER OF ARTICULATION

CONSONANTS

\begin{tabular}{|c|c|c|c|c|}
\hline & & Bilabial & Dental & Velar \\
\hline \multirow{2}{*}{ Plosives } & voiceless & $p$ & $t$ & $k$ \\
\hline & voiced & $b$ & $d$ & $g$ \\
\hline \multirow{2}{*}{ Labialised plosives } & voiceless & & & $k w$ \\
\hline & voiced & & & $g w$ \\
\hline Grooved fricative & & & $s$ & \\
\hline Nasals & & $m$ & $n$ & \\
\hline
\end{tabular}

Retroflex lateral

$\begin{array}{ccc}\text { Alveolar } & & \\ & & \\ & 1 & \\ & y & h\end{array}$

VOWELS

$\begin{array}{cccc} & \text { Front } & \text { Central } & \text { Back } \\ \text { High } & i & & u \\ \text { Low } & e & a & o\end{array}$

NOTES:

(1) The $s / t$ distinction has been recently introduced as a result of contact with English. Historically, $s / \underline{i}$ and $t$ elsewhere. 
(2) There is negligible phonetic variation of Tawala phonemes.

(3) Tawala has only one closed syllable type, ending in $m$. No $m u$ syllables are found, and the $m$ closed syllable has historically developed from $m u$. (The Yamalele language of Fergusson Island has $m u$ in some dialects with corresponding $m$ in others - see J. Ezard 1970).

\subsection{WIDER LINGUISTIC RELATONS}

Much work waits to be done on the classification of Tawala, and of Milne Bay languages generally. However, the overall position can be presented in outline. At the lowest level Tawala's closest relations lie along the north-east coast of eastern Papua (Ross 1988:191, 195).

Lithgow (1976) assigned 40 Milne Bay languages to 12 families. While non-lexical data were referred to by Lithgow, his classification rests predominantly on the basis of lexicostatistics. The statistics, no doubt, reflect the synchronic situation well enough, but do not constitute a genetic classification. In addition, no attempt was made to account for extensive and widespread borrowing through the Kula and other trading ventures (Ezard, B. 1977) and for word taboo (Simons 1982), not to mention other fundamental problems involved in lexicostatistical studies themselves (McElhanon 1971).

At the highest level, Milne Bay languages, along with all the Austronesian languages of Papua New Guinea and island Melanesia, belong to a major subgroup of the Austronesian language family set up by Dempwolff $(1927,1937)$ on a comparative phonological basis, and in recent years referred to as 'Oceanic'. Dyen (1965) questioned the cohesiveness of the Oceanic subgroup, but his lexicostatistics also failed to take into account the extreme distortion of the Melanesian data caused by word taboo, small isolated societies and contact situations involving disparate Papuan languages. Almost all Oceanic linguists today accept the validity of the Oceanic subgroup.

The most recent study to include the prehistory of the Oceanic languages of the Milne Bay area is Ross (1988), which is based on phonological and morphosyntactic comparisons. He argues that the Oceanic languages of Papua New Guinea and the western Solomon Islands fall into four large 'clusters' of languages. Three of these, the Meso-Melanesian, North New Guinea and Papuan Tip clusters, are tentatively attributed to a single Westem Oceanic grouping. The latter is the result of diffusion from the probable Proto-Oceanic homeland area, which occurred after Oceanic speakers had departed for the Admiralties and eastem Oceania.

The Papuan Tip cluster includes all the Oceanic languages of Milne Bay identified by Lithgow (1976) together with a few related languages located on the coast of the Oro Province (to the north-west of the Milne Bay Province) and the Oceanic languages of central Papua (Ross 1988:190-212). The cluster divides into two networks of languages, which Ross calls Nuclear Papuan Tip and Peripheral Papuan Tip. The former includes all the Oceanic languages of the mainland in the Milne Bay and Oro Provinces, and the languages of the D'Entrecasteaux archipelago and various islands close to the mainland. Within the Nuclear Papuan Tip network are several communalect chains, one of which is the AreTaupota chain. This chain of languages includes the Are and Taupota families identified by Lithgow and stretches along the coast of the Oro and Milne Bay Provinces from ArifamaMeniafia on Cape Nelson at its north-western extreme to Tawala at its south-eastem end. 


\subsection{METHOD}

Too many supposedly empirical studies of language employ an 'anecdotal' approach, where a hypothesis is considered established if a half-dozen good examples are culled from the vast stock of possible examples. Under this method counter examples are simply ignored. Often relatively few counter examples are even discovered; the research worker in seeking to prove the theory he is working on elicits supportive material without any thought as to whether he is dealing with central, peripheral or even slightly aberrant language material.

Of course there will always be the need for broad studies which look at the universal features of a large number of languages. But such studies will always be plagued with superficiality and, like an earlier breed of Latin-based studies, an inescapable bias.

The Tawala derivational prefixes, not to mention the relationship between semantics and syntax, are so exceedingly complex that every effort needs to be taken to avoid theoretical and cultural bias. Every effort must also be made to let the language speak for itself, and avoid forcing data into an alien mould. Accordingly, I chose to work from a corpus of 30 texts which had previously been transcribed and reduced to a concordance by computer (in November 1979). After excluding the main person/number markers, 14,441 entries appear in the concordance, representing the multiple occurrence of 2,021 key words. Once the various forms in which a word may appear are accounted for, I estimate that the corpus for this paper consists of a vocabulary approaching 1,000 words, including 460 different verbs, 383 of which I discussed in an earlier paper (Ezard, B. 1980b). The 87 verbs I omitted occur for the most part only once in the text, and not enough was known of their semantics to make their inclusion profitable there.

The texts represent a wide variety of male and female speakers, from teenagers to a very old man respected for his 'pure' speech. This, together with three distinct dialects (Kehelala, Diwinai and Labe) and a wide variety of discourse genre (stories, instruction, narrative etc.) guarantees a fairly representative cross-section of the Tawala language forms. Because of the difficulty of recording spontaneous conversations, most of the texts are 'formal' monologues spoken into the tape-recorder. However a number of impromptu speeches at public gatherings are also represented.

The 383 verbs looked at in B. Ezard (1980b) were sorted into semantic classes with methods and results reported (a summary is presented in section 4.3). This was the point from which I commenced work on this present study.

From the full list of 460 verbs, the derivational prefixes which occur with them number as follows:

$\begin{array}{ll}\text { wi } & 81 \\ l u & 56 \\ l i & 20 \\ \text { wo } & 16 \\ \text { om } & 35\end{array}$

With a total of 208 out of 460 verbs, we get an idea of the important role played by derivational prefixes in Tawala verb derivation. I examined each prefix to determine its area of meaning but drew no fresh conclusions. I then compared the lists with an eye to the use of more than one prefix to a root. I drew up a chart (similar to those in section 4) of the 55 
roots which I knew to occur with more than one prefix and included all the material I had collected in connection with the previous paper (Ezard, B. 1978). At this stage 124 boxes were filled in, averaging only $2 \frac{1}{4}$ prefixes per root. Keeping in mind that only roots with two or more prefixes were placed in this chart, this was not an encouraging score. In fact, I was advised at this stage that my search may prove vain, as the prefixes appeared to be nonproductive. At this point I retumed to the field to collect more data and to find, if possible, a key that would enable me to use the derivational prefixes productively - a key that would unlock some pattem in the function of the prefixes. I had several lines of enquiry in mind, but the one which was to prove successful was the concept of 'the priority of semantics' in which the prefixes function in pattems according to their semantic fields (see section 3.1).

My initial aim of trying to fill in the blanks in the chart was successful (at least for the four main prefixes - om did not pattern well with the others), with an increase to an average of more than three prefixes per root. It soon became obvious, however, that I could not contain all the relevant data for each root in a single line of a chart so I devised and duplicated blank charts which enabled me to record over 100 pieces of relevant information for each root. The filling in of these charts proved very time-consuming but was eventually completed for the original 55 roots, plus 23 other roots which suggested themselves in the course of the investigation. I then devoted several weeks to an examination of these data from various theoretical standpoints, including the priority of semantics (see section 3.1) which began to show a little promise at this stage, as I attempted to bring together charts from the same semantic fields.

The next period of elicitation proved to be very exciting with almost daily discoveries of new semantic fields in which the prefixes functioned in a regular manner (see section 4). At this point Yailo, my language helper, who had previously had little idea of what I was trying to achieve, began to actively cooperate in discovery procedures. As soon as I could suggest two parallel forms belonging to a single semantic field he was able to suggest further examples - proving the practical value of the 'priority of semantics' concept. By this method the corpus increased to 562 verbs derived from 162 roots (listed in section 4, Charts 1-19).

Increasingly the picture became clear, that in so far as two roots share significant semantic components so the verbs derived from the application of the derivational prefixes were completely predictable. In line with this insight, the data were again transferred, this time onto charts in which roots belonging to a single semantic field could be displayed together (similar to those in section 4). The meanings a given prefix has with the various roots of a semantic field were then checked for homogeneity. One problem became apparent with the method at this point. Often a prefix can be used with a semantic field with more than one meaning. However, once a particular meaning surfaced in an elicitation session, it was difficult to change focus. Only by retuming to a list at a later date was there much likelihood of discovering new areas of meaning. I took this step in only a handful of cases.

Another caution needs to be stated about some of the meanings contained in section 4 . Many of these derived verbs are of low frequency of occurrence and probably represent the personal idiolect of Yailo. He would sometimes preface his remarks by saying something like, "I think it probably means such-and-such". Checking some of the material with other language speakers confirmed the individual nature of some material. However, as these checks were made in the Labe dialect, the distinctions may be dialectal.

A final problem is also apparent. It is not easy for anyone, untrained in the art, to define words, especially obscure words, in his own language. I constantly encouraged Yailo to 
illustrate the differences between words by putting them into sentences or even stories. Doubtless, at many points I may have missed the point of the story and have biased the meaning by failing to understand the full cultural significance of what I was told. Exposure of this problem will probably have to wait until Tawala linguists begin to write about their own language from an internal cultural perspective.

Whatever the weaknesses may be, this paper outlines how hundreds of derived verbs can be controlled, and texts interpreted. That much work remains to be done is obvious, but at least a start has been made.

\subsection{TERMINOLOGY}

Various terms used throughout the paper are in need of definition and explanation. Unfortunately there are many discrepancies in the terminology of linguists. For my own terminology I revert to some of the fundamental works in the field of morphology of the Tagmemic school.

\subsubsection{ROOTS AND STEMS}

In their chapter 'Tagmemes and Construction below the Word Level', Elson and Pickett (1964:79) define 'roots' as "single morphemes which function as the nucleus of words". The term 'stem' "is used to refer to either single morphemes (roots, simple stems) or to morpheme sequences (derived stems)". Hence a single morpheme carrying the basic meaning of the resultant word is a root. A Tawala illustration may be helpful:

$$
\begin{aligned}
& \text { I-lata. } \\
& \text { he-grow } \\
& \text { He grew. }
\end{aligned}
$$

Lata is the root carrying the basic meaning of the word, and also forms the simple stem in this word. If we now add a derivational prefix (DP) to the root we derive the form wi-lata 'to cause to grow'. This is a transitive stem:

$$
\begin{aligned}
& \text { I-wi-lata-ya. } \\
& \text { he-DP-grow-it } \\
& \text { He emphasised the point. }
\end{aligned}
$$

In (1) the word is built by adding an inflectional prefix $i$ to a simple stem lata. In (2) the word is built by adding an inflectional prefix $i$ and suffix ya to a derived stem wilata which is composed of a derivational prefix wi and a root lata.

\subsubsection{DERIVATIONAL AND INFLECTIONAL PREFIXES}

We now turn to the distinction we have assumed above between derivational and inflectional prefixes. Halle (1973:6) calls into question the theoretical relevance of the distinction between derivational and inflectional morphology: 
The examples discussed above have been chosen from the domain that traditionally has been called derivational morphology. As far as I can tell facts that traditionally have been treated under the separate heading of inflectional morphology must be handled in completely parallel fashion to those discussed above.

In Tawala it is essential to distinguish derivational from inflectional prefixes (see section 2.5.2) and it thus seems wise to follow the traditional terminology. The distinguishing features between the two classes of affix as outlined in Nida (1949:99) proved useful in establishing the distinction for Tawala prefixes. A summary of these (and other) features relevant to the Tawala distinction is presented in Table 2. However it is not my purpose to pursue the matter further, as the theoretical distinction is largely irrelevant to the main argument of derivational prefixes. (The inflectional prefixes are largely set out in section 2 and the derivational prefixes in section 4.)

While each inflectional prefix has a single function, derivational prefixes have a variety of functions in Austronesian languages; in Tawala and other Milne Bay languages the functions and variety have reached a high degree of utility.

Finally it should be noted that reduplication of stems with derivational prefixes follows different rules from reduplication of word roots (see sections 2.5 and 2.5.1).

\section{GRAMMATICAL FOUNDATIONS}

Owing to the word-class-changing nature of the derivational prefixes it is essential to start by setting up the major word classes (2.1).

Certain features of the verb morphology also need to be outlined in this section to facilitate an understanding of derivational prefixes and the examples which illustrate their usage, since inflectional prefixes are always present in Tawala sentences $(2.2-2.7)$.

\subsection{WORD CLASSES}

From earliest times linguists have been aware of the fluid nature of many Austronesian roots which are used here as a verb, there as a noun or perhaps an adjective. Codrington (1885:102) comments:

It is not that there is a complete absence of such special forms of Verb or Noun; but that the same word [i.e. root] without any change of form may be in use as almost any of the Parts of Speech. The use of the word, not its form, commonly declares its character...

This phenomenon is apparently a language universal (cf. Bloomfield 1935:196), however its high frequency of occurrence in Austronesian forces itself on the linguists' attention. A Tawala example using the borrowed word pati 'putty' illustrates the situation nicely: 4

\footnotetext{
${ }^{4} \mathrm{Abbreviations} \mathrm{used} \mathrm{in} \mathrm{this} \mathrm{paper} \mathrm{are} \mathrm{as} \mathrm{follows:} \mathrm{CP}$ - classificatory prefix, DAT - dative, DP - derivational prefix, EXC - exclusive, INC - inclusive, INST - instrument, INT - intentive aspect, IRR - irrealis aspect, FUT - future, N - noun, NEG - negative, O - object, PRES - present, PROG - progressive aspect, R root, RED - reduplication, RFX - reflexive, s.o. - someone, s.th. - something, TC - transitive concord, V verb.
} 
TABLE 2: SUMMARY OF DISTINGUISHING FEATURES OF TAWALA INFLECTIONAL AND DERIV ATIONAL PREFIXES

\begin{tabular}{|c|c|c|}
\hline & Inflectional prefixes & Derivational prefixes \\
\hline $\begin{array}{l}\text { Semantic } \\
\text { features }\end{array}$ & $\begin{array}{l}\text { (1) Never involve a change in word-class membership } \\
\text { (2) Single predictable }{ }^{1} \text { meaning } \\
\text { (3) Uniform meaning with all roots they occur with } \\
\text { (4) Their domain extends beyond the word; } \\
\text { i.e. they show relationships between words }\end{array}$ & $\begin{array}{l}\text { (1) Often change word-class membership } \\
\text { (2) Meaning dependent on semantics of root } \\
\text { (see sections } 3 \text { and 4) } \\
\text { (3) Derive new stems } \\
\text { (4) Their domain does not extend beyond the word }\end{array}$ \\
\hline $\begin{array}{l}\text { Morpho- } \\
\text { syntactic } \\
\text { features }\end{array}$ & $\begin{array}{l}\text { (1) Unrestricted to specific roots } \\
\text { (2) Belong to the outer periphery }{ }^{2} \\
\text { (3) Normally a single invariant form }\end{array}$ & $\begin{array}{l}\text { (1) Restricted to certain roots } \\
\text { (2) Inner periphery } 2 \text { - never occur first in word } \\
\text { (3) Multiple form depending on aspect } \\
\text { (see section 5.2) }\end{array}$ \\
\hline
\end{tabular}

1'Predictable' needs qualifying - it is predictable within the framework of the culture - not necessarily cross-culturally.

2 'Inner' and 'outer' periphery refer to the position affixes take in relation to the core or root of a word. 
(3) (a) stative verb

Wam i-pati.

boat it-putty

The boat has been patched.

(b) transitive verb

Kuka u-na-pati- $\emptyset$

sail you.SG-INT-putty-it

Patch the sailing boat!

(c) noun

Dimdim hai pati u-na-waya.

foreigner their putty you.SG-INT-take

Take the foreigners' glue.

(d) adjective

wam patipati-na

boat putty-its

putty for the boat

A second example illustrates the same phenomenon using a common Tawala root bagibagi 'work':

(4) (a) intransitive verb

Ta-bagibagi.

we.INC-work

Let's do some work.

(b) transitive verb

Nima-hi-yei hi-bagibagi-ye-ya.

hand-their-INST they-work-DAT-it

They worked it with their hands.

(c) noun

Hai bagibagi i-kokoe.

their work it-finish

Their work is finished.

(d) adjective

Meyagai bagibagi-na.

village work-its

Work for the village.

Sapir (1921:117ff.) noted that traditional classification of words into parts of speech "is only a vague, wavering approximation to a consistently worked out inventory of experience". Thus, the part of speech "outside the limitations of syntactic form is but a will o' the wisp". Consequently, he considers that interlanguage correspondence of parts of speech is not "of the slightest interest to the linguist". R.M.W. Dixon (1977:19), however, considers that such relationships are not entirely arbitrary; "It is a fact", he observes, "that inter-language class correspondences are made, on an intuitive basis, and are valuable". 
The unrestricted data of a living language are so vast that in setting up word classes it is essential to distinguish between which are typical of their parts of speech and those which are atypical. In other words, we need a working hypothesis which enables us to handle all the data but at the same time distinguish basic data from that which is non-basic. R.M.W. Dixon (1976:347) suggests a suitable tool for our purpose:

...a language contains a set of basic norms - semantic, morphological, and maybe even phonological norms - from which it deviates in different ways and to different degrees a great deal of the time.

An application of this type of reasoning to parts of speech is given in Lyons (1977:440) (cf. Schachter 1985):

The thesis that will be maintained here is that the semantic...part of the traditional definitions of the parts-of-speech define for each part-of-speech, not the whole class, but a distinguished subclass of the total class. Each such semantically defined subclass is focal within the larger class...

Failure to observe basic norms in language results in great confusion. Without the concept a single counter example is sufficient to destroy an argument. However, by observing basic norms we are able to sort out relevant counter examples from those which are aberrant and mere red herrings.

It is true that certain nouns have underlying verbal notions, but this does not detract from the fact that the core notion of nouns in English is 'persons, places and things'.

Thus we conclude that a part of speech is established on the basis of a characteristic subset of the whole class. Having defined the subset most characteristic of the class, we are then able to define the entire class as the class which includes the defined subset, and all other words which behave in the same way as the described subset.

To consider each use of a root as a separate lexeme, in line with traditional views, is to destroy the unity of the root. Rather there is a need for a thorough examination of all word roots in order to ascertain the potential performance and restrictions of each one, and accordingly assign each to a particular subclass. Lack of space prohibits such a classification in this paper.

We now look briefly at the core notional content of Tawala nouns, adjectives and verbs, setting up classes which will later correlate with various morpho-syntactic data presented in the relevant sub-sections of section 4 .

\subsubsection{THE CORE NOTIONAL CONTENT OF NOUNS}

Concrete 'objects' form the core notional content of nouns functioning only as nouns. In order for these noun roots to function as verbs, a derivational prefix must be added to them (see section 4.1). On the other hand, abstract nouns function as verbs or nouns without the use of derivational prefixes. The following noun classes are clearly distinguished in Tawala.

(a) Persons only function as nouns. These include proper names (Mika, Yailo), person referent words (lawa 'person', bada 'man') and relationship terms (amau 'my father', natuta 'our (inclusive child'). Human referent and relationship terms are typically reduplicated for plural. 


$\begin{array}{llll}\begin{array}{lll}\text { keduluma } \\ \text { oloto }\end{array} & \text { woman } & \text { kedukeduluma } & \text { women } \\ \text { hinau } & \text { my mother } & \text { ololoto } & \text { males } \\ \text { nouwe }^{5} & \text { my sister } & \text { hinahinau } & \text { my mothers } \\ & \text { nounouwe } & \text { my sisters }\end{array}$

Relationship terms are marked for inalienable possession:

$\begin{array}{ll}\text { goga-u } & \text { my grandparen } / \text { grandchild } \\ \text { nou-we } & \text { my sister } \\ \text { amama-ta } & \text { our (inclusive) fathers }\end{array}$

(b) Places also only function as nouns. Included here are proper names (Diwinai, Labe) and place referent words (meyagai 'village', huhuna 'bay').

$$
\begin{aligned}
& \text { Mika e-ge-gae } u \text { meyagai. } \\
& \text { Mika he.PRES-PROG-ascend to village } \\
& \text { Mika is going to the village. }
\end{aligned}
$$

(6) Tauna Diwini-yei i-nei.

him Diwinai-from he-come

He comes from Diwinai.

(7) Ta-nae hoi tawali.

we.INC-go to reef

Let's go to the reef.

(c) Body parts of animals (including humans) and living things also only function as nouns. Like human relationship terms they are reduplicated for plural and marked for inalienable possession:

$\begin{array}{llll}\text { ae- } u & \text { my leg } & \text { aeae- } u & \text { my legs } \\ \text { nima-na } & \text { his hand } & \text { nimanima-na } & \text { his hands } \\ \text { lugu-na } & \text { its leaf } & \text { lugulugu-na } & \text { its leaves } \\ \text { laga-na } & \text { its branch } & \text { lagalaga-hi } & \text { their branches }\end{array}$

(d) Things (animate or inanimate) are signalled by referent terms (neula 'coconut', motamota 'worms'). They have no special inflectional morphology.

\subsubsection{THE CORE NOTIONAL CONTENT OF ADJECTIVES}

The Tawala open class of adjectives includes all the universal semantic types (Dixon, R.M.W. 1977) with the exception of the 'human propensity' class, which forms a special closed class of words (section 4.4).

Most adjectives form opposition sets:

(a) Value:

$$
\text { dewadewana good apapoena bad }
$$

(b) Dimension:

baneina big habuluna small

$5_{u \rightarrow} w e / u$ 
(c) Age:

odubona old wouna new

(d) Speed:

bambamna slow sagesagena fast

(e) Physical property:

hayahayana dry niginigina wet

Colour and some physical property adjectives form complementary sets:

wakewakekena 'white', waididibalena 'black', kayakayana 'red' etc.

gugouna 'sweet', waigolana 'bitter', tululuwana 'sour' etc.

\subsubsection{THE CORE NOTIONAL CONTENT OF VERBS}

(a) Events (actions and processes) are typically expressed by verbs in Tawala.

(8) Lawa i-nae.

person he-go

The man went.

(9) Logaloga he-lupa-lupa.

children they.PRES-PROG-jump

The children are jumping.

(10) Liyapa i-lalana.

mat it-dry

The mat dried.

(11) Mayau amaka i-lata.

tree already it-grow

The tree has already grown.

(b) States are typically expressed by the use of stative verbs (a verbal form of adjective).

(12) Amaka i-dumalu.

already it-straight

It [the problem] has already been fixed.

(13) A-togo po a-yeuyeu.

I-wash and I-clean

I washed and I am clean.

(14) Dobu i-gobu.

village it-dirty

The village is dirty.

(15) Lawa hi-dewadewa.

person they-good

The people are good. 


\subsection{INFLECTIONAL PREFIXES}

The distinction between Tawala inflectional and derivational prefixes was established in the introduction (section 1.5.2). The verbal inflectional prefixes are used for the categories of person, number, tense and aspect, and are given only cursory treatment here as a full treatment is irrelevant to the purpose of this paper.

\subsubsection{PERSON, NUMBER AND TENSE}

TABLE 3: THE PERSON/NUMBER PREFIXES

\begin{tabular}{|c|c|c|}
\hline Nerson & Singular & Plural \\
\hline 1 & $a-$ & ta- (INC) \\
& & to- $(\mathrm{EXC})$ \\
\hline 2 & $u-(e-)$ & $o-$ \\
\hline 3 & $i-(e-)$ & $h i-(h e-)$ \\
\hline
\end{tabular}

The above table sets out the various prefixes associated with person and number. These prefixes are obligatory whenever a stem is used as a verb. The forms in brackets are used when the situation context is in the present tense. Person/number categories not marked for present tense are distinguished purely on contextual grounds.

Only two examples of these prefixes are given at this point as there are numerous examples elsewhere.

(16) Awai i

yam e-an-ani?

what our.EXC food it.PRES-PROG-eat

What keeps eating our food?
To-hopu
u Modewa.
we.EXC-descend to Modewa

We went down to Modewa.

Tense is further marked by the future particle apo and the completive particle amaka. Apo marks probable state as opposed to improbable state apega (from apo (future) and ega (negative), but it is also important in marking tense, especially in the first person).

Amaka i-nei.

already he-come

He has already come.

(19) Apo a-ne-hi.

FUT I-come-towards.hearer

I will come.

\footnotetext{
Apega a-peu.

FUT.NEG I-fall

I won't fall.
} 


\subsubsection{ASPECT}

There are three aspects in Tawala, marked by prefixes which follow the person/number prefixes.

na intentive aspect, including commands

ta irrealis aspect, including negatives

$\emptyset \quad$ realis aspect

The remaining aspect (progressive) is marked by reduplication (handled in section 1.5). The irrealis aspect $t a$ is marked with all persons and numbers, but intentive aspect na does not productively occur with first person prefixes. ${ }^{6}$ The unmarked form, a zero morpheme, is normally not glossed in the examples.

(a) Intentive aspect (na):

$$
\begin{aligned}
& \text { Ap(o) u-na-peu! } \\
& \text { FUT you.SG-INT-fall } \\
& \text { You'll fall! } \\
& \text { U-na-hopu! } \\
& \text { you.SG-INT-descend } \\
& \text { Get down! }
\end{aligned}
$$

(b) Irrealis aspect (ta):

$$
\begin{aligned}
& \text { Apo a-ta-nei? } \\
& \text { FUT I-IRR-come } \\
& \text { Can't I come? (I couldn't come, could I?) }
\end{aligned}
$$

$$
\begin{aligned}
& \text { Ega a-ta-peu. } \\
& \text { NEG I-IRR-fall } \\
& \text { I didn't fall. }
\end{aligned}
$$

(c) Simple realis aspect (unmarked)

$$
\begin{aligned}
& \text { I-peu. } \\
& \text { he-fall } \\
& \text { He fell. } \\
& \text { Amaka to-hopu. } \\
& \text { already we.EXC-descend } \\
& \text { We already went down. }
\end{aligned}
$$

\subsection{DERIVATIONAL PREFIXES OF VERBS}

Derivational prefixes (wi, lu, li and wo) attach directly to the root in order to form derived verb stems:

$\begin{array}{llll}\text { wi-neula } & \text { rub oil on } & \text { (neula } & \text { mature coconut) } \\ \text { lu-mayau } & \text { collect firewood } & \text { (mayau } & \text { fire/firewood) }\end{array}$

\footnotetext{
${ }^{6}$ The na occurs in vestigial form with the om prefix, e.g. ta-n(a)-om-hoe 'let's go'. The word to-na-i-baabani 'we will chat' (Labe dialect) may also be an example of a vestigial form, or it may be another morpheme I have not yet tracked down, c.g. Hau malatom to-na-i-baabani yaka a-paliweleya 'If we talk tomorrow I will tell him'.
} 


$$
\begin{aligned}
& \text { li-dao-ya lengthen something (daodao- long) } \\
& \text { wo-geleta be revealed (geleta arrive) }
\end{aligned}
$$

Only cursory treatment is given the stative prefix (om) which is far less productive and apparently less complex than the other derivational prefixes.

Derivational prefixes have of ten been referred to as 'causative' prefixes. As these prefixes are of ten clearly not causative it seems wiser to avoid this traditional usage in preference for a more generic term, hence the choice of 'derivational' prefixes. I have previously (Ezard, B. 1978) referred to them as 'modal' prefixes following Capell (1943), but even Capell recognised that the term was 'not satisfactory'. Pawley (1972:39) uses the term "transformative affixes" for a broader class than the Tawala derivational prefixes. This term would be adequate; however, the term 'derivational' is useful in pointing out the syntactic nature of these prefixes in deriving new verbs.

As the initial part of the stem (simple or derived) normally undergoes reduplication (see section 2.5) for progressive aspect, the derivational prefixes are involved in morphological change. However, they are quite irregular in this respect (see section 2.5.2).

\subsection{CLASSIFICATORY PREFIXES}

In B. Ezard (1978) I outlined the form and function of Tawala classificatory prefixes which do not entirely fit into either the inflectional or derivational class of prefix (see Table 2). The following examples illustrate something of the range of classificatory prefixes (data from Ezard, B. 1978):

(a) Instrumental prefixes

$\begin{array}{llll}\begin{array}{l}\text { tu-hedali } \\ \text { guna-loloya }\end{array} & \text { break something by knocking } & \begin{array}{l}\text { (hedali } \\ \text { (loloya }\end{array} & \text { break something) } \\ & \text { tear something) }\end{array}$

(b) Declaration prefixes

kawa-moina proclaim something true (moina true)

pali-weleya tell something (wele give)

(c) Movement prefixes

$\begin{array}{llll}\text { welu-lui } & \text { disappear inside } & \text { (lui } & \text { enter) } \\ \text { tu-hopu } & \text { descend a little } & \text { (hopu } & \text { descend) }\end{array}$

Tawala classificatory prefixes share the semantic features of inflectional prefixes in that:

(1) they do not normally involve a change in word class membership;

(2) they have completely predictable meaning;

(3) they have a uniform meaning with all roots;

(4) some show relationships between words.

However, morphosyntactically the classificatory prefixes are akin to the derivational prefixes in that:

(1) they are restricted to certain roots - even more than derivational prefixes;

(2) they belong to the inner periphery;

(3) they change form according to the aspect of the verb. 
The main morphological distinction between classificatory and derivational prefixes is that the latter do not follow the regular forms for reduplication which apply elsewhere in the language (see section 2.5.2) whereas the classificatory prefixes follow normal reduplication patterns (see section 2.5.1).

The greatest affinity of the classificatory prefixes is the compound verbs; however, this present paper is not the place to develop this theme. The classificatory prefixes are included here only because of their relationship to derivational prefixes. Data on classificatory prefixes are included where relevant in section 4 (e.g. motion verbs 4.3 .1 ) as they strengthen the 'priority of semantics' thesis.

\subsection{REDUPLICATION}

As outlined in B. Ezard (1980a), reduplication is used for a number of separate functions in Tawala. For the purposes of this paper we are interested in one function only: progressive aspect. All active verbs have a special form for progressive aspect, which for most stems, including most derived stems (formed with compound stems or classificatory prefixes), has a reduplicated form. On the other hand, for derived stems formed with the derivational prefixes, the progressive aspect does not consist of a reduplicated form but is formed by the substitution of a separate form of the prefix.

\subsubsection{STANDARD VERBS}

The actual form of reduplication of normal verbs is determined by the phonetic shape of the stem.

(a) Complete reduplication

Verbs whose roots commence with a CVCV pattern nomally reduplicate the first two syllables. As most Tawala roots have this pattern, this is the most common form of reduplication.

$\begin{array}{llll}\text { hopu } & \text { go down } & \text { hopuhopu } & \text { be/keep going down } \\ \text { hune } & \text { praise } & \text { hunehune } & \text { keep praising } \\ \text { geleta } & \text { arrive } & \text { gelegeleta } & \text { be/keep arriving } \\ \text { hagu } & \text { help } & \text { haguhagu } & \text { keep helping } \\ \text { wele } & \text { give } & \text { welewele } & \text { keep giving }\end{array}$

(b) Partial reduplication

There are two types of partial reduplicaton, firstly for verbs which commence with CVV and secondly for verbs which commence with a vowel (V).

(i) Verbs which have a CVV pattern at the beginning of the root, where the second vowel is higher than the first, are normally reduplicated by prefixing the root with the consonant plus the second (high) vowel. (The aspectual meanings have been omitted in the following examples, but they follow the same pattern as the examples above.)

$\begin{array}{lll}\text { gae } & \text { gegae } & \text { go up } \\ \text { houni } & \text { hunouni } & \text { put something } \\ \text { beiha } & \text { bibeiha } & \text { search } \\ \text { tou } & \text { tutou } & \text { cry }\end{array}$


However, a few verbs take a vowel other than the second vowel of the root:

$\begin{array}{lll}\text { nei } & \text { nenei } & \text { come } \\ \text { peu } & \text { pipeu } & \text { fall }\end{array}$

The small number of verbs having both vowels at the same level (both high or both low, see section 1.2) show complete reduplication:

$\begin{array}{lll}\text { hoe } & \text { hoehoe } & \text { open } \\ \text { woe } & \text { woewoe } & \text { paddle } \\ \text { bui } & \text { buibui } & \text { turn over }\end{array}$

To keep the exceptions together, the following $\mathrm{CVCV}$ verbs have partial reduplication:

$\begin{array}{lll}\text { hale } & \text { hahale } & \text { throw } \\ \text { niye } & \text { niniye } & \text { bring something } \\ \text { waya } & \text { wiwaya } & \text { take something }\end{array}$

(ii) Verbs which commence with a vowel form their reduplication by repeating the first VC:

$\begin{array}{lll}\text { apuya } & \text { apapuya } & \text { cook something } \\ \text { eno } & \text { eneno } & \text { sleep } \\ \text { am } & \text { amam } & \text { eat } \\ \text { uma } & \text { umuma } & \text { drink } \\ \text { atuna } & \text { atatuna } & \text { rain }\end{array}$

(c) Vowel reduplication

When the first two syllables of a stem are the same, the first vowel is reduplicated to form the progressive aspect:

$\begin{array}{lll}\text { totogo } & \text { tootogo } & \text { be ill } \\ \text { guguya } & \text { guuguya } & \text { preach } \\ \text { tatawa } & \text { taatawa } & \text { tremble } \\ \text { teteya } & \text { teeteya } & \text { cross/bridge something } \\ \text { kiki } & \text { kiiki } & \text { strangle something (dog) }\end{array}$

\subsubsection{DERIVED VERBS}

All verbs form their progressive aspect following the above rules except those with derivational prefixes. The verbs in Tawala which incorporate derivational prefixes distinguish between punctiliar and progressive aspect by using a separate set of prefixes, as set out in Table 4.

TABLE 4: PREFIXES MARKING ASPECT CHANGE ON THE VERB

\begin{tabular}{|c|c|}
\hline Punctiliar apsect & Progressive aspect \\
\hline$w i$ & $i$ \\
$l u$ & lau \\
$l i$ & lai \\
wo & woo \\
om & yam \\
\hline
\end{tabular}


Examples:

\begin{tabular}{|c|c|}
\hline $\begin{array}{l}\text { hi-wi-tona } \\
\text { he-i-tona } \\
\text { hi-i-tona }\end{array}$ & $\begin{array}{l}\text { they fought } \\
\text { they are fighting } \\
\text { they were fighting }\end{array}$ \\
\hline $\begin{array}{l}\text { hi-lu-mayau } \\
\text { hi-lau-mayau }\end{array}$ & $\begin{array}{l}\text { they gathered wood } \\
\text { they were gathering wood }\end{array}$ \\
\hline $\begin{array}{l}\text { hi-li-bolu } \\
\text { hi-lai-bolu }\end{array}$ & $\begin{array}{l}\text { they sat talking } \\
\text { they were sitting talking }\end{array}$ \\
\hline $\begin{array}{l}\text { hi-wo-dadani } \\
\text { hi-woo-dadani }\end{array}$ & $\begin{array}{l}\text { they touched it } \\
\text { they were touching it }\end{array}$ \\
\hline $\begin{array}{l}\text { hi-(o)m-poya } \\
\text { hi-yam-poya }\end{array}$ & $\begin{array}{l}\text { they applied heat/magic } \\
\text { they were applying heat/magic }\end{array}$ \\
\hline
\end{tabular}

(For full paradigms and further details of the progressive aspect of derivational verbs see B. Ezard 1978.)

\subsection{FOCUS OF VERBS}

When I set out to write this paper I had in mind handling the derivational prefixes from a syntactic point of view, placing special emphasis on the causative nature of the prefixes. However, I became so engrossed by the insights gained from the concept of the priority of semantics (section 3) that I soon found I had more material than I could adequately handle without even touching on syntax. Consequently, the syntax of Tawala derivational prefixes must wait for another paper. However an outline of certain problems needs to be presented here to facilitate an understanding of the Tawala data in section 4.

Tawala verbs are of three basic types: stative, intransitive and transitive. The following definitions depend in part on Pawley (1973:126f.).

STATIVE:

In stative verbs the subject experiences or is in the state of the verb, for example, 'good', 'happy', 'soft', 'red'. These verbs are usually closely related to a cognate adjectival form.

$$
\begin{aligned}
& \text { Dobu gobugobu-na. } \\
& \text { village dirty-its } \\
& \text { A dirty village. }
\end{aligned}
$$

$$
\begin{aligned}
& \text { Houga daodao-na. } \\
& \text { ume long-its } \\
& \text { A long time. }
\end{aligned}
$$

Dobu i-gobu.

village it-dirty

The village is dirty.

Houga i-dao.

time it-long

It is a long time.

\section{INTRANSITIVE:}

With intransitive verbs the subject not only undergoes the action but with animate beings can be thought of as causing it as well. Most intransitive verbs involve movement or posture, for example, ‘jump', 'go', 'walk', 'stand', 'fly', 'lie down', 'sleep'. These verbs do not have related adjectival usage. 
(29)

Tewela i-eno.

child it-sleep

The child slept.

(30)

$$
\begin{aligned}
& \text { Wam i-nae. } \\
& \text { boat it-go } \\
& \text { The boat went. }
\end{aligned}
$$

\section{TRANSITIVE:}

Transitive verbs may be defined as those verbs which potentially have an object - the experiencer/patient of the action - for example, 'obey', 'eat', 'cut', 'kick', etc. There are two distinct forms of many verbs which have, in the past, been referred to as transitive and intransitive forms of a root. The problem with this traditional interpretation is that many of the 'intransitive' forms can take objects!

$$
\begin{aligned}
& \text { Ta-nae polo ta-lugowada. } \\
& \text { we.INC-go pig we.INC-steal } \\
& \text { Let's go pig-stealing. }
\end{aligned}
$$
Ta-nae Kama a polo ta-lugowad(a)-i. we.INC-go Kama his pig we.INC-steal-O
Let's go and steal Kama's pig.

Example (31) is the 'intransitive' and (32) the 'transitive' form of the sentence. The real distinction here is obviously not between transitive and intransitive verbs, but between a specific and non-specific object. In (31) there is no specific object in mind, but in (32) there is. In discussing this same phenomenon in Misiman, Callister and Callister (1979) use the terms 'action focus' (31) and 'referent focus' (32) which seem to capture the distinction nicely, though I use the terms 'action focus' and 'object focus' in this paper.

However, the situation is complicated by the fact that many transitive verbs do not have an action focus form and hence are always marked for specific object, which as a result loses its markedness and becomes simply a transitive object agreement marker.

In addition to the above problem there are various classes of transitive verbs, depending to a large degree on the phonetic shape of the root involved. These classes are briefly as follows:

(a) Verb roots ending in $i$; these have no action focus form. The plural is formed by adding -hi to the unchanged root:

$\begin{array}{lll}\text { Singular } & \text { Plural } & \\ \text { lawi } & \text { lawi-hi } & \text { hit something } \\ \text { hapi } & \text { hapi-hi } & \text { cut/chop something } \\ \text { houni } & \text { houni-hi } & \text { put something } \\ \text { gowadi } & \text { gowadi-hi } & \text { hide something }\end{array}$

(b) Roots ending in ta; these form the object focus by replacing ta with $h i$ in the singular, and adding a second $-h i$ for the plural:

$\begin{array}{lll}\text { Action focus } & \text { Object focus (plural) } & \\ \text { limaamata } & \text { limaamahi(-hi) } & \text { wake something } \\ \text { ugota } & \text { ugohi(-hi) } & \text { plant something } \\ \text { momota } & \text { momohi(-hi) } & \text { hold something tightly }\end{array}$


(c) In the Labe dialect, two-syllable roots add -ya for singular and -hi for plural specific object. In the Kehelala dialect - $n i$ is added for the singular instead of -ya. Lying midway between these two dialects, Diwinai shows a good deal of fluctuation between these two forms. Certain words show a definite preference, for example, huma-ya 'he wrapped it', $i$ huwe-ni 'he blew it'; however, for one form or the other, many have free fluctuation between speakers or even between utterances of a single speaker. (Wherever possible my language helper has accommodated himself to the Labe dialect, as that is where we have done most of our linguistic and translation work in recent years.) Only a small number of the roots with more than two syllables follow the same pattern; however, as most Tawala roots have two syllables, this is by far the most common morphological pattern:

$\begin{array}{lll}\text { Singular } & \text { Plural } & \\ \text { gale-ya } & \text { gale- } h i & \text { see something } \\ \text { tala-ya } & \text { tala- } h i & \text { cut something } \\ \text { wilupa-ya } & \text { wilupa- } h i & \text { let something go } \\ \text { gwae-ya } & \text { gwae-hi } & \text { make water muddy }\end{array}$

(d) Three-syllable roots replace the final vowel with $i$ for object focus forms and add -hi for the plural object:

\begin{tabular}{lll} 
Action focus & \multicolumn{2}{l}{ Object focus (plural) } \\
toula & touli(-hi) & load something \\
tagona & tagoni(-hi) & cross over something \\
(wi)towolo & (wi)towoli(-hi) & stand something up \\
(lu)yadaga & (lu)yadagi(-hi) & hit something
\end{tabular}

One of the common functions of Tawala derivational prefixes is to transform stative and intransitive verbs into causative (and thus transitive) verbs. Hence many of the data contained in section 4 have endings falling into the classes just described.

\subsection{THE DATIVE SUFFIX}

Sometimes Tawala verbs do not specify a direct involvement with their 'object' but a more indirect relationship. This indirect relationship is marked with the dative suffix -e, which is a first-order suffix followed by a transitive suffix (section 2.6). The dative involves indirect relationships, including actions carried out with an instrument and also reflexive action upon oneself. The phonetic output of -e changes according to environment in the following ways:

(a)

$$
\begin{aligned}
& e \rightarrow\left\{\begin{array}{c}
\text { ye } \\
g e
\end{array}\right\} / i_{-} \\
& \text {(-ye -ge may be a dialectal distinction - } \\
& \text { most examples in my data have -ye) } \\
& \left.\left.\rightarrow \text { ge } /\left\{\begin{array}{c}
\mathrm{V} \\
\text { +grave }
\end{array}\right] \text { c } \begin{array}{c}
\mathrm{C} \\
\text { +grave } \\
+ \text { nasal }
\end{array}\right] \quad \text { (V) }\right\}
\end{aligned}
$$


(b) Assimilation also takes place before the dative prefix:

$$
\left[\begin{array}{c}
v \\
\text {-high } \\
\text {-back }
\end{array}\right]+\mathrm{e} \rightarrow \mathrm{e}
$$

Examples:

\begin{tabular}{|c|c|}
\hline bagibagi-ye-ya & work at something \\
\hline pali-ye-ya & scold someone \\
\hline luwohepali-ge-hi & hit four items (with spear) \\
\hline geno-ge-ya & worry about something \\
\hline otu-ge-ya & call to someone \\
\hline wiwom-ge-ya & warm something \\
\hline winima-ge-ni & put gloves on (hands) \\
\hline lugowad(a)-e-ya & hide oneself \\
\hline widakul(e)-e-ya & gravel an area \\
\hline
\end{tabular}

Something of the force of the dative/transitive distinction can be seen with the two minimal pairs that have come to light:

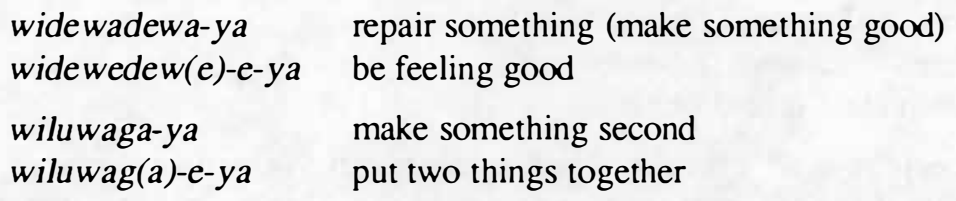

While the following examples are not minimal pairs they do illustrate various meanings of the dative:

\begin{tabular}{|c|c|}
\hline $\begin{array}{l}\text { winima-ge-ni } \\
\text { lunima-ni }\end{array}$ & $\begin{array}{l}\text { put gloves on (hands) } \\
\text { hit his hand }\end{array}$ \\
\hline $\begin{array}{l}\text { wigapola-ya } \\
\text { lugapol(a)-e-ya }\end{array}$ & $\begin{array}{l}\text { make someone rich } \\
\text { become rich }\end{array}$ \\
\hline $\begin{array}{l}\text { luwohepali-ge-hi } \\
\text { wowohepali-ge-ni }\end{array}$ & $\begin{array}{l}\text { hit four items (with spear) } \\
\text { gather/hold four }\end{array}$ \\
\hline
\end{tabular}

It will be noted that a large proportion of the above examples involve derivational prefixes (more examples are to be found in the charts of section 4). However, in line with the purpose of this paper, no systematic treatment of this aspect of the syntax is attempted.

\section{THEORETICAL FOUNDATIONS}

This section looks briefly at three theoretical questions upon which this thesis rests: the relationship between syntax and semantics (3.1); the concept of semantic fields (3.2); and the problem of cross-cultural studies, with reference to world view (3.3).

\subsection{THE PRIORITY OF SEMANTICS}

In seeking to unravel the complex world of Tawala derivational prefixes, I set as one of my goals to examine them in the light of possible underlying semantic strata - investigating 
whether the syntax of the prefixes is in some way dependent on the underlying semantics of words. It was with increasing excitement that I realised that this was indeed the nature of the case, and that I had discovered a key to unlock at least some of the mysteries of derivational prefixes. But this is to anticipate our conclusion.

American linguists from Bloomfield to Chomsky were fascinated with the ideal of autonomous grammar - grammar which could be enunciated without recourse to meaning. to study the objective forms of language was considered the truly scientific method, and as "most linguists are...anxious...to lay claim to being scientists" (Haas 1978:207) this model has had a pervasive influence on the course of linguistic events. In his Syntactic Structures Chomsky (1957):

...took the view that the grammatical rules could be established and formalized without making any appeal to sameness and difference of meaning or to any other semantic notions. In this respect, grammar was held to be autonomous and independent of semantics. (Lyons 1977:409)

Chomsky (p.15) distinguished grammatical from meaningful sentences with his now famous example:

Sentences (1) and (2) are equally nonsensical, but any speaker of English will recognise that only the former is grammatical.

(1) Colorless green ideas sleep furiously.

(2) Furiously sleep ideas green colorless.

It is important to keep in mind a second aspect presented in Syntactic Structures. Not only did Chomsky stress the independent nature of syntax, he also stressed the importance of the syntactic-semantic relationship (p.93):

There is no aspect of linguistic study more subject to confusion and more in need of clear and careful formulation than that which deals with the points of connection between syntax and semantics.

While Chomsky defined the connection between syntax and semantics in narrow terms, assigning only a secondary role to semantics, and biased research "heavily in favour of syntactic solutions to problems" (Jackendoff 1972:2), yet he did open the door to semantics. The result has been an ever-increasing, worldwide interest in semantics both from within the generative framework and from those working along totally separate lines.

One such line of research is that outlined by R.M.W. Dixon (1977) in his seminal paper 'Where have all the adjectives gone?'. The underlying principle of his paper is 'the priority of semantics'. Dixon (p.24) outlines this principle:

We work from the assumption that the syntactic properties of a lexical item can largely be predicted from its semantic description. Semantics is thus held to be prior to syntax. The ways in which syntactic properties can be predicted on the basis of semantic representation are complex, and are not yet fully understood...

The correlation between semantics and syntax is seen from the fact that once the meaning of a new word is learnt we are able to use it in a variety of syntactic structures with a high degree of accuracy. Chomsky (1965:58) himself was forced on the basis of this correlation to postulate a language-acquisition device which enables the child to master the complexities of generative grammar in his daily life: 
It seems plain that language acquisition is based on the child's discovery of what from a formal point of view is a deep and abstract theory - a generative grammar of his language - many of the concepts of which are only remotely related to experience by long and intricate chains of unconscious quasiinferential steps.

Instead of postulating a language acquisition mechanism by which the complexities of experience are mapped onto an inf inite set of sentences, Dixon (1977:24) starts with a totally different model in which the mature speaker:

On the basis of his semantic competence, and his understanding of the general connections between semantic types and semantic properties in that language... immediately knows how to use the word in a syntactically acceptable manner. That it, he is able to predict its syntactic properties on the basis of the semantic specification.

In section 4 I present some strong strong expirical evidence from the Tawala language in support of Dixon's thesis. The data suggest the general principle that in so far as two words share significant semantic components so their syntax overlaps.

\subsection{SEMANTIC FIELDS}

In the first passage quoted from R.M.W. Dixon (1977) above, we find the term 'semantic description' ("the syntactic properties of a lexical item can largely be predicted from its semantic description").

The semantic description of lexical items is a complex matter which has exercised the minds of many capable scholars this century. For the purposes of this paper it is necessary to examine three areas of semantic description:

(a) The part of speech from which each verb is derived is relevant in determining the meaning of derived forms. Word classes are set up on the basis of a cluster of morphosyntactic features associated with a core notional meaning. This aspect of the semantic description has been partially handled for the open word classes in the grammar section (2.1). Throughout section 4 data are presented on the basis of the part of speech of the underlying root (for a summary see Table 7), commencing with the three open word classes and followed by the three closed word classes. In the process of this presentation further aspects of the word classes are presented.

(b) The valency of roots and the changed valency of derived forms is handled briefly in the introduction to section 4 (see Table 8 for a summary). The magnitude of the subject and the already bulging dimensions of this paper mean that a systematic treatment of this aspect of the prefixes must wait for a future paper.

(c) The semantic field of roots is of vital importance. While we look at this aspect in detail in section 4 (see Table 5 for a summary) we turn now to examine the terminology of the subject.

A semantic field (or domain) consists of a set of words which are related to each other by sharing a common significant component. It is quite feasible for a single word to belong to more than one domain, as illustrated by Lehrer (1974:7): 
...glass 'a container' would be studied along with cup, bowl, mug, vase, and other container words to see how these items contrast. Glass 'the material' is compared to brick, concrete, plastic, wood, etc.

The Tawala word gaima 'stone' belongs to three semantic fields, and in each case it takes at least one derivational prefix appropriate to the domain.

(i) As a type of ground covering, gaima falls into the same semantic field as dakule 'gravel' and bubu 'sand'. By prefixing the derivational prefix wi to these roots we get stative stems indicating 'a condition of being covered by something':

Dobu i-wi-gai-gaima.

village it-DP-PROG-stone

The village is very stony.

(34) Niha i-wi-dakule.

salt it-DP-gravel

The beach is pebbly.
Numa i-wi-bubu.
house it-DP-sand
The floor is covered with sand.

(ii) As a type of weapon gaima takes the derivational prefix wo indicating 'to hold in the hand ready for throwing':

(36) Hewa-hewali he-woo-gaima.

PL-youth they.PRES-DP.PROG-stone

The youths are holding stones.

Bada e-woo-higeyala.

man he.PRES-DP.PROG-spear

The man is holding a spear.

(iii) As a common legendary item into which culture heroes of ten turn, gaima is used with li- $(-y a)$ indicating 'to turn into something'.

(38) Bada i-li-gaima-ya.

man he-DP-stone-RFX

The man became a stone.

$$
\begin{array}{ll}
\text { Neula } & \text { i-li-ginah(i)-i. } \\
\text { coconut } & \text { it-DP-sago-RFX }
\end{array}
$$

The coconut palm became a sago palm.

(40) Yakoyako i-li-gumaguma-ya.

shell it-DP-hermit.crab-RFX

The shell-fish became a hermit crab.

Perchonock and Werner (1969: quoted in Lehrer 1974:18) conducted studies in Navaho food classification which led to the conclusion that there are usually several legitimate classifications of words into semantic fields within a speech community:

It is interesting that people, without exception so far, agree to the rightness of another person's classification even though it differs considerably from their own. This seems to indicate that there are several different culturally accepted 
ways of categorizing Navaho food, and that each member of the society is implicitly aware of nearly all of them.

It is not my purpose to become embroiled in the semantic field debate. Suffice to say that my exposure to the Tawala data has led me to a strong affirmation of Spence (1961:105) when he states that the association of words is "looser, more complex, and more unpredictable than most field theorists are prepared to admit". While the concept of "the priority of semantics', along with that of semantic fields, has unlocked considerable areas of Tawala syntax, yet there are sufficient 'idiomatic' exceptions and residue data (section 4.7) to forestall complacency and remind us that I may have done little more than scratched the surface in seeking to fully understand the semantic-syntactic connection of just one small area of grammar.

\subsection{SEMANTIC FIELDS: INDICES OF WORLD VIEW}

In examining the semantic fields of an exotic culture, one becomes accutely aware that the domains have little in common with one's native language. Lyons (1977:250) agrees that the grammatical and lexical structure of a language will reflect the specific interests and attitudes of the culture in which it operates. He warns us, however, against thinking "that every grammatical and lexical distinction must be correlated with some important difference in the patterns of thought of the society using the language". While keeping this warning in mind we can feel more confident in dealing with semantic fields than with isolated words as an index of world view. An example of a domain which introduces us to something of the emotional world of the Tawala people is the domain which I refer to as 'the ritual chants' domain. Prior to discovering this linguistic domain I had experienced certain emotionally charged chants in the Tawala culture, but did not realise that they were tied together into a single semantic field (by a unique usage of a derivational prefix) until I was collecting the data for my MA thesis. I hope the following brief account of these words reveals something of the Tawala world, so strange to an outsider. In each case the prefix lu is used with the reduplicated form of the root.

(i) lu-hoehoe (lit. to make hoe)

The chant is used when making sago, in order to keep up rhythm and morale during long hours of chopping - "Hoe...hoe...hoe...". The importance of this cultural trait has been immortalised in the sago myth:

...Lizard's adze was chopping and he was chanting (luhoehoe), "Hoe...hoe...hoe...hoe...". His friend stood listening and exclaimed, "Wow, whose voice sounds so good?". Then Possum went down to his friend and said..."Oh Friend, your voice sounded really good; perhaps we should follow this custom of yours since it is so good. Your voice sounded melancholic and your chopping beautiful". (Yailo Robert)

(ii) lu-bahabaha (lit. to make words)

A ritualised boasting or denouncing of another party. For several minutes the boaster keeps throwing one hand and leg into the air and yelling at the top of his voice sentiments such as, "You complete and utter idiots, how could you fail in such a simple thing? When we (exclusive) did it last year it was a complete success. You idiots, you complete imbeciles..." 


\section{(iii) lu-otuotu (lit. to make calls)}

This high pitched call, somewhat akin to the Australian 'cooee' is used to communicate short messages through the jungle. "My friend." Reply, "Ooo". "I'm going down to the river." Reply, "Oooo" ('I understand - I got your message').

\section{(iv) lu-hiyahiyawa (lit. to make countings) or tou-baha (to cry words)}

The ritualised wailing, accompanied by tears, practised at the death of a friend or relative. The mourner recounts the past glories that the two shared. "Oh my brother, we walked the trails together; my brother, we hunted pigs in the bush. Oh, my brother, my brother..."

\section{(v) wi-lulougo ${ }^{7}$ (lit. to make singing)}

A ritualised call, used either to notify one's arrival at a hamlet or as a kind of yodelling by a group of young men walking along the jungle trails. (Even as I wrote these notes the bush was reverberating with such beautiful two-part harmonies, but it is in the middle of the night that these calls are especially beautiful.)

It should be noted that these examples illustrate a semantic field of a set of derived verbs, whereas our main interest in this paper is the semantic fields of underived roots (discussed in detail in section 4). Semantic fields are of two kinds. Firstly, there are those areas of meaning which are based on the nature of things: numbers, colours, size, body parts etc. These will tend to have recognisable parallel focal points in all cultures (cf. Berlin \& Kay 1969; Dixon, R.M.W. 1977). However, where the human mind is less tied by the nature of things, and allowed to construct its own world, we discover divergent paths which have little or nothing in common across unrelated cultures. An exceptionally good illustration of this point is the fusion of person and deixis in Kawi (Becker \& Oka 1974).

The area of verbs gives ample freedom for thought and language-specific approaches, particularly in the types of semantic domain functioning as grammatical groups. We would not expect the categories set up for English to be more than a very rough guide to the categories of another language. This is certainly true for Tawala, where almost all the residue data belong to the verb class. Doubtless there are a number of interesting semantic fields which, when discovered, will reduce these data to a degree of order.

\section{TAWALA DATA}

In this section we examine Tawala derivational prefixes in detail. In particular we investigate the meanings attached to these prefixes when used with various roots to derive verbs. In discussing the priority of semantics (section 3.1 ) the general principle was stated: in so far as two words share significant semantic components, so their syntax overlaps. The data listed in chart form in this section illustrate this thesis.

We can identify a general meaning for each prefix, but these meanings are not sufficient to predict the semantic effect a prefix will have with a given root. However, in addition to assigning general meanings for each prefix, the roots are divided into 16 semantic fields with which each prefix has separate specific meanings. Thus while the general meaning of the $l u$ prefix is to derive a verb which 'involves physical contact or movement', the specific meaning of lu with body parts is 'to hit a body part' and with a cultural item it is 'to collect

${ }^{7}$ The prefix wi replaces $l u$ here, as the reduplicated form of lougo already involves one $l u$ prefixed to the root. 
TABLE 5: SEMANTIC FIELdS ANI TAWALA DERIVATIONAL PREFIXES

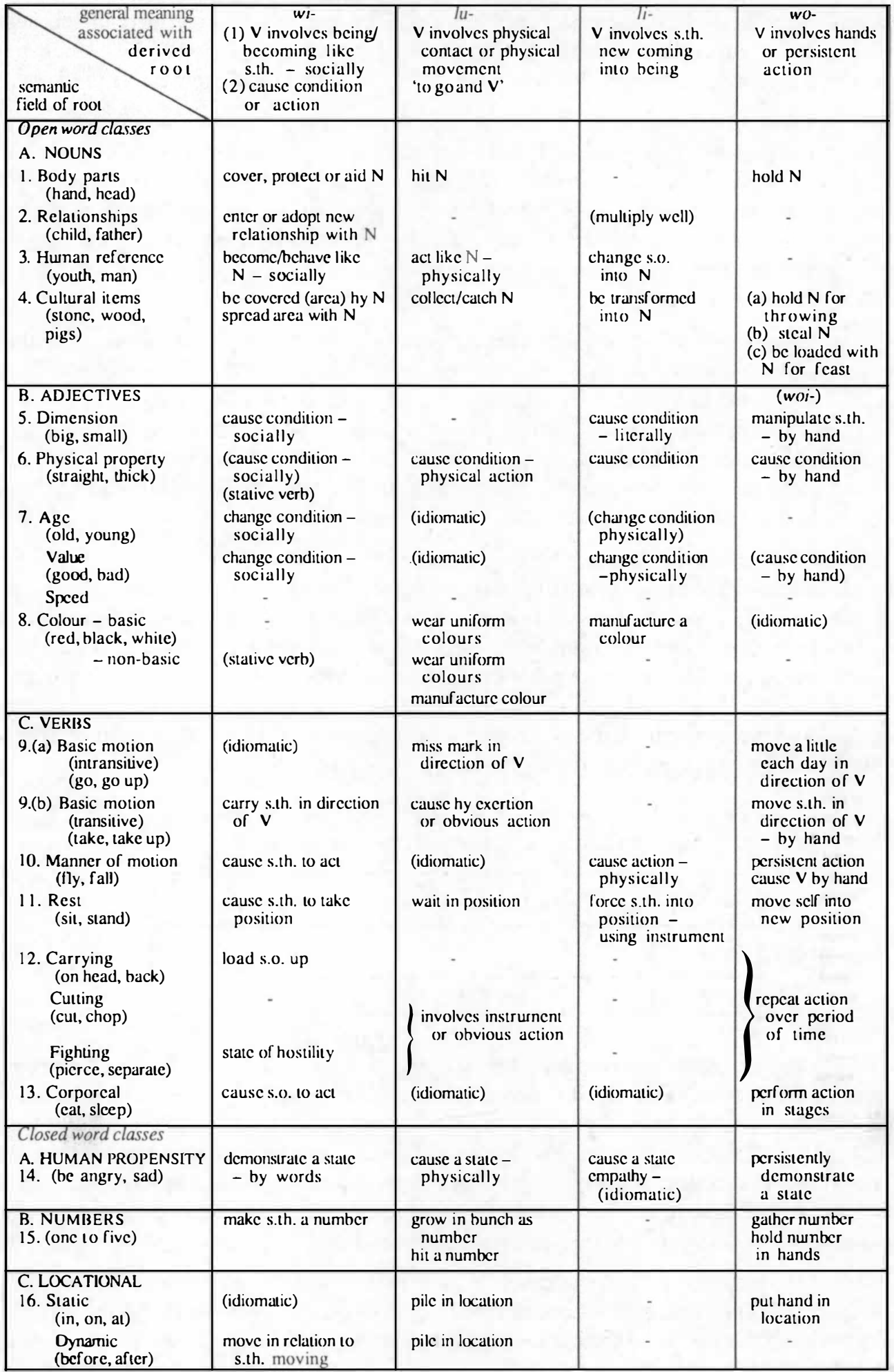


an item'. The general meanings are set out in Table 5 at the head of each column under the respective prefixes. The specific meanings for each prefix are contained in the cells corresponding to the various semantic fields listed in the left-hand column. Each line represents a semantic field, with the specific meanings listed under the respective prefixes.

The positing of general meanings facilitates discussion in the following sections, as specific meanings need to be related to the general meaning. In her discussion of cases, Wierzbicka (1980:xix) warns against the idea of a single "common meaning" as being "too general to have any predictive value". This is a valid observation, and it will be noted that on more than one occasion two quite distinct meanings have been proposed. This process is taken a step further in Table 7 where separate common meanings are proposed for each of the six word classes involved.

While Table 5 appears rather complicated, it is in fact considerably simpler than the data it represents, which consist of almost 500 derived verbs (based on 135 separate roots). These data, together with the residue data of 68 derived verbs (based on 27 roots), are listed individually in Charts 1-17 and represent an almost impossible memory load, if they had to be individually learned. Charts $1-16$ present 90 per cent of the Tawala data in systematic form and these data are summarised in Table 5, with the numbers in the left-hand column corresponding to the charts where the data are presented.

What is posited in Table 5 is that every semantic field has its own unique syntacticsemantic combination of derivational prefixes associated with it. Table 6 sets out how the system works. $\mathrm{X}, \mathrm{Y}$ and $\mathrm{Z}$ represent three semantic fields, and $\mathrm{A}, \mathrm{B}, \mathrm{C}$ and $\mathrm{D}$ represent the form-function complex of the resultant derived verbs; $A$ always represents the presence of the same prefix etc. The subscript number represents the same or different meaning with a given prefix depending on whether the same or a different number is used with a given letter. Thus $A_{1}, A_{2}$ represents the same prefix but a different meaning; $A_{1}, B_{1}$ would of course involve a different meaning because a different prefix is involved.

TABLE 6: A FORMAL REPRESENTATION OF THE SEMANTIC-SYNTACTIC RELATIONSHIP

\begin{tabular}{|c|llll|}
\hline$X$ & $\mathrm{~A}_{1}$ & $\mathrm{~B}_{1}$ & & $\mathrm{D}_{1}$ \\
\hline $\mathrm{Y}$ & $\mathrm{A}_{1}$ & $\mathrm{~B}_{1}$ & & $\mathrm{D}_{2}$ \\
\hline $\mathrm{Z}$ & & $\mathrm{B}_{2}$ & $\mathrm{C}_{1}$ & $\mathrm{D}_{2}$ \\
\hline
\end{tabular}

Table 6 demonstrates that semantic fields $X$ and $Y$ have a very similar use of prefixes. They not only use the same set of prefixes ( $A, B$ and D, with $C$ absent) but also have the same meaning with $\mathrm{A}$ and $\mathrm{B}$, though a different meaning with $\mathrm{D}$. If $\mathrm{X}$ and $\mathrm{Y}$ did not have separate $D$ meanings, it would be possible to collapse the two semantic fields into a single $X Y$ domain. As it is, the 'priority of semantics' hypothesis would lead us to expect that $X$ and $\mathrm{Y}$ do in fact belong to closely related semantic fields, and this is the very type of situation which occurs over and over again in the Tawala data.

When $\mathrm{Y}$ is compared with $\mathrm{Z}$ we appear to have two very different semantic fields. Only at one point (D2) do the two sets of derived verbs overlap. This would be typical of a situation where the semantic domains have almost nothing in common. Again the Tawala data present this type of data at many points. 
Thus the lines in Table 5 should be viewed as a type of code for each semantic field, listing the combination of prefixes used with that field together with the resultant meanings. Table 8 presents the supplementary syntactic side of the relationship, but more details on that aspect are given below.

Certain generalisations which may be stated about the use of derivational prefixes are contained in Table 5, but tend to be overlooked in the mass of detail. Table 7 captures these generalisations by listing a common meaning for each prefix with each part of speech. These meanings are not as vague as the general meanings presented in Table 5; however, they are not as complex as the specific meanings either.

Working cross-culturally, it is of ten difficult to know how far to press various common meanings. For example, in Table 5 the verbs derived from nouns with the wi prefix (top left-hand cells) mostly share the common meaning of 'become like item'. Those include 'the covering of a body part' - a glove, for example, appears to become like a hand; similarly when 'an area is covered with items' it becomes like the item - for example, sandy or stony. In a similar vein it is tempting to think of developing new relationships, including adoption, as also in some way involving a 'becoming like the real relationship'. Insights of this nature are discussed under the respective semantic classes below, but should be regarded as hypotheses rather than data, as they present data according to my analysis and not as presented by a native speaker of the language.

Table 7 is an advance on Table 5 as it presents a separate common meaning for each word class, instead of attempting to give a single general meaning for all word classes.

Having mastered this relatively simple table, students would have at their command some 90 per cent of the specific meanings contained in Table 5, and would be in a strong position to tackle the more idiomatic meanings found in the 16 semantic fields. All this is in line with the theoretical claim made above (section 3.1) that once the meaning of a new word is learnt the speaker of the language is able to use it in a variety of syntactic structures with a high degree of accuracy. The fact that a table of common meanings is able to be drawn up on the broad basis of word classes is a confirmation of the thesis that this section seeks to affirm: in so far as two words share significant semantic components so their syntax overlaps. The very fact that two words belong to the same word class is an indication that they do share significant components: the nouns (of this section) are all 'concrete' objects; the adjectives are qualities; the verbs, mostly events etc.

Table 8 is to be read parallel to Table 5 and presents the syntactic data, including the valency changes involved in the use of derivational prefixes. The syntactic formulae represent the forms in which data were collected and no claim is made with respect to other possible formulae; in fact, I have discovered since returning from the field that some data collected previously in texts have different syntax from the more recently collected data. Hence, examples occasionally differ from the systematic presentation of data.

This paper concentrates largely on the semantics of the Tawala derivational prefixes, leaving aside their syntax. While no attempt is made to systematically handle the syntax, clues to its nature are presented at the head of each column of each chart, throughout this section, summarising the syntax of the listed forms: 
TABLE 7: THE COMMON MEANING OF DERIVATIONAL PREFIXES

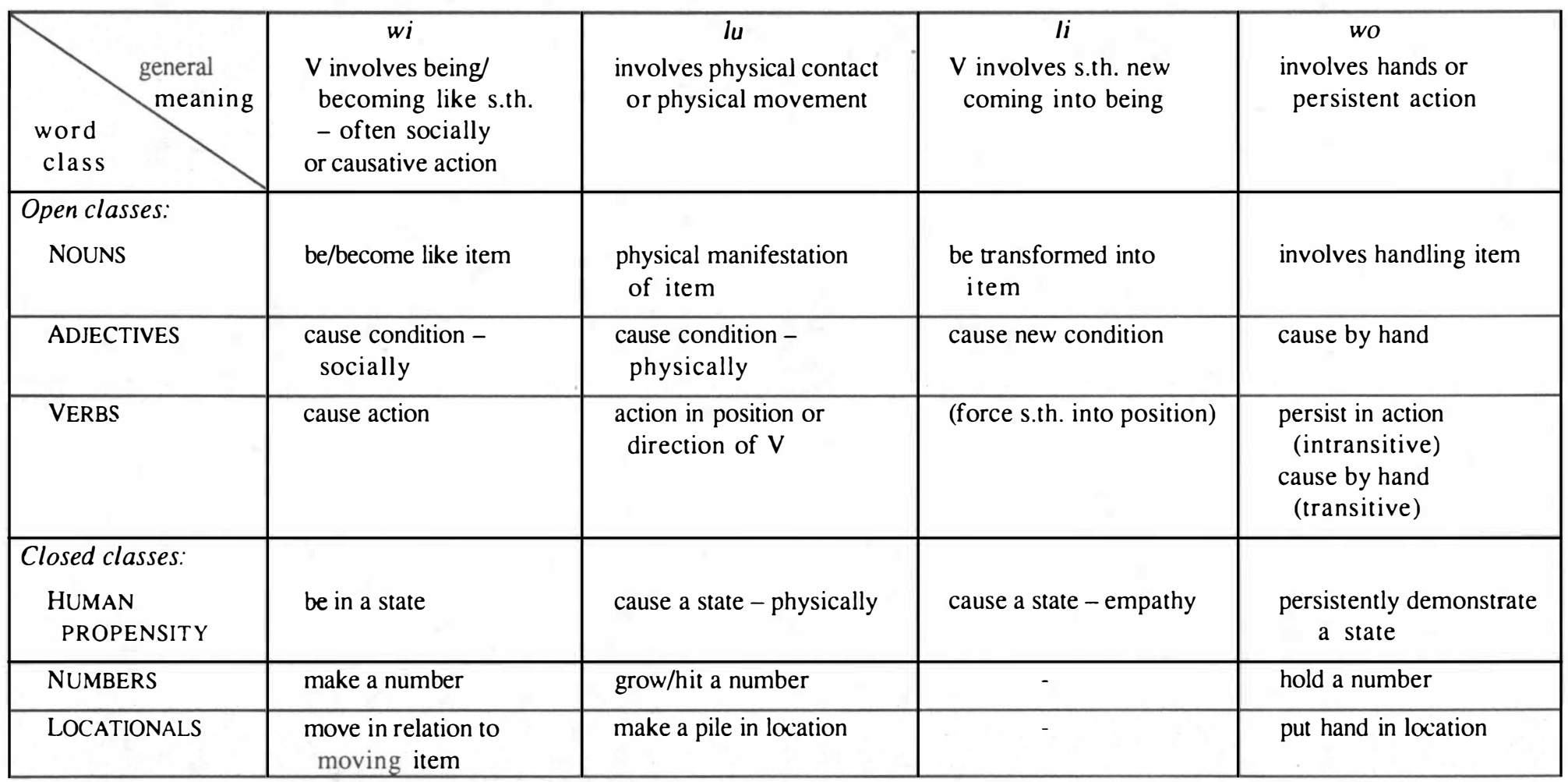


TABLE 8: SYNTACTIC SUMMARY OF TAWALA DERIVATIONAL PREFIXES

\begin{tabular}{|c|c|c|c|c|}
\hline & wi- & Iu- & li- & wo- \\
\hline NOUNS & & & & \\
\hline I. Body parts & $w i-\mathrm{R}-\mathrm{DAT}-\mathrm{O}$ & lu-R-O & - & $w o \cdot \mathrm{R}-\mathrm{O}$ \\
\hline 2. Relationship & $\begin{array}{l}\text { wi-R-na } \\
\text { wi-R-DAT-O } \\
\text { wi-RED-R-na }\end{array}$ & & $\left(l i-\right.$ RED-R- $\left.-{ }_{n a}^{\text {DAT-O }}\right)$ & - \\
\hline 3. Human reference & $w i-\mathrm{R}$ & Iu-RED-R & li-R-RFX & - \\
\hline 4. Cultural items & $w i-(\mathrm{RED})-\mathrm{R}$ & $l u-\mathrm{R}$ & li-R-RFX & $\begin{array}{l}\text { (a) } \&(b)^{1} \text { wo-R } \\
\text { (b) } \&(c)^{1} \text { wo-R-RFX }\end{array}$ \\
\hline ADJECTIVES & & & & \\
\hline 5. Dimension & $w i-\mathrm{R}-\mathrm{O}$ & - & li-R-O & woi-R-O \\
\hline 6. Physical propeny & $\begin{array}{l}\text { wi-R } \\
\text { wi-RED-R-O }\end{array}$ & $l u-\mathrm{R}-\mathrm{O}$ & li-R-O & $w o(i)-R-D A T-O$ \\
\hline $\begin{array}{l}\text { 7. Age } \\
\text { Valuc } \\
\text { Specd }\end{array}$ & $w i-\mathrm{R}-\mathrm{mc}\left\{\begin{array}{l}m e \\
\mathrm{RFX}\end{array}\right.$ & $(I u-\mathrm{R}-(\mathrm{DAT}-\mathrm{O}))$ & li-(RED)-R-O & (woi-R-O) \\
\hline 8. Colour: basic & - & $l u-\mathrm{R}$ & li-R-O & $w o-\mathrm{R}$ \\
\hline non-basic & $w i-\mathrm{R}$ & $\left\{\begin{array}{l}l u-\mathrm{R} \\
\text { lu-R-DAT-O }\end{array}\right.$ & - & - \\
\hline VERBS & & & & \\
\hline $\begin{array}{l}\text { 9.(a) Basic motion } \\
\text { (intransitive) }\end{array}$ & (wi-(RED)-R) & $l u-\mathrm{R}$ & - & $w o \cdot \mathrm{R}$ \\
\hline $\begin{array}{l}\text { 9.(b) Basic motion } \\
\text { (transitive) }\end{array}$ & $w i-\mathrm{R}-(\mathrm{DAT})-\mathrm{O}$ & lu-R-(DAT)-O & - & wo-R-(DAT)-O \\
\hline 10. Manner of motion & $w i-\mathrm{R}-\mathrm{O}$ & $\begin{array}{l}\text { lu-R } \\
\text { lu-RED-R-DAT-O }\end{array}$ & li-R-O & wo-R-(DAT-O) \\
\hline 11. Rest & $w i-\mathrm{R}-\mathrm{O}$ & $\begin{array}{l}\text { lu-R } \\
\text { lu-R-(DAT)-RFX }\end{array}$ & li-R-O & $\begin{array}{l}\text { wo-R } \\
\text { woi-R-O }\end{array}$ \\
\hline $\begin{array}{l}\text { 12. Carrying } \\
\text { Cutting } \\
\text { Fighting }\end{array}$ & $\begin{array}{l}w i-\mathrm{R} \\
\text { (wi-RED-R) } \\
w i-(\mathrm{RED})-\mathrm{R}\end{array}$ & $\begin{array}{l}(l u-\mathrm{R}-\mathrm{O}) \\
\text { lu-R-O } \\
\text { lu-R-O }\end{array}$ & - & $\begin{array}{l}w o-\mathrm{R}-\mathrm{O} \\
w o-\mathrm{R}-\mathrm{O} \\
\text { wo-R-O }\end{array}$ \\
\hline 13. Corporcal function & $w i-\mathrm{R}-(\mathrm{O})$ & lu-RED-R & li-R-O & $w o \cdot \mathrm{R}$ \\
\hline $\begin{array}{l}\text { 14. HUMAN } \\
\text { PROPENSITY }\end{array}$ & wi-S-(O) & Iu-S-(DAT)-O & li-S-O & $w o-R\left(\left\{\begin{array}{l}\text { DAT-O } \\
O\end{array}\right)\right.$ \\
\hline 15. NUMBERS & $\begin{array}{l}\text { wi-R-na } \\
\text { wi-R-DAT-O }\end{array}$ & $\begin{array}{l}\text { lu-R-(na) } \\
\text { lu-R-DAT-O }\end{array}$ & - & wo-R-DAT-O \\
\hline $\begin{array}{l}\text { 16. LOCATIONALS } \\
\text { Static } \\
\text { Dynamic }\end{array}$ & $\begin{array}{l}(w i-\mathrm{R}) \\
w i-\mathrm{R}\end{array}$ & $\begin{array}{l}\text { lu-R } \\
(I u-R)\end{array}$ & - & $(w o-R)$ \\
\hline
\end{tabular}

KEY

(formula) formula found with only a minority of roots

( ) morpheme occurs with some roots only

$\left\{\begin{array}{l}x \\ y\end{array}\right.$ either $x$ or $y$

${ }^{1}(\mathrm{a}),(\mathrm{b})$ and (c) as in Table 5 Cultural items. 
(a) RED is used when the resultant verb involves a group of items or group activity. (The various forms which reduplication takes are set out in section 2.5.)

(b) $\mathrm{O}$ at the end of the syntactic formula shows that the resultant verb has an object suffix (where the object is specific). Unmarked verbs have action focus; they may be intransitive or transitive (with a non-specific object). (For further details, including the suffixes associated with the various verb classes, see section 2.6.)

(c) DAT before $\mathrm{O}$ marks the dative suffix (for details see section 2.7).

(d) The na suffix which occurs with a number of the derived forms seems to be a vestigial suffix of the prederived root $(\mathrm{R})$.

(e) $m e\left\{\begin{array}{c}m e \\ \mathrm{O}\end{array}\right\}$ adverbial particle meaning 'again'; meme is the action focus form and $m e \mathrm{O}$ the object form."

(f) woi- is a stronger form than wo-, typically used with adjective roots and always resulting in transitive, object focus verbs. wo- typically, but not always, results in an intransitive or action focus verb, for example:

wo-towolo to assume standing position

woi-towol-i to stand something up

Table 8 is thus a convenient presentation of the syntactic formulae in one place to facilitate comparison and further study of the problem.

\subsection{NOUN CLASSES}

All the Tawala nouns taking derivational prefixes belong to those concrete nouns which make up the core notional content of the word class. The derivational prefixes make use of four semantic fields within Tawala nouns: body parts, relationship terms, human reference and cultural items. This list differs in detail from the noun classes set up on the basis of a core notional content (2.1.1) in that 'places' is omitted and 'persons' is subdivided into relationship terms and human reference. Independent evidence for the empirical nature of these classes is presented in Table 9, where the morphosyntactic distinctions between these four noun classes are tabulated.

TABLE 9: MORPHOSYNTACTIC DISTINCTIONOF SEMANTIC NOUN CLASSES

\begin{tabular}{|c|c|c|}
\hline Semantic type & $\begin{array}{l}\text { (1) obligatory 'inalienable } \\
\text { possession' marker }\end{array}$ & $\begin{array}{l}\text { (2) reduplication of } \\
\text { root for plural }\end{array}$ \\
\hline 1. Body parts & + & - \\
\hline 2. Relationship terms & + & + \\
\hline 3. Human reference & - & + \\
\hline 4. Cultural things & - & - \\
\hline
\end{tabular}

The details of the morphosyntactic data are discussed under the respective noun classes below. 
Verbs derived from nouns show a high degree of homogeneity in their resultant meaning. $W i$ indicates a becoming like the item, lu involves a physical manifestation or bringing forth of the item, $l i$ involves a transformation into the item and wo involves handling the item. The specific outworking of these common meanings is discussed under the respective semantic fields $(4.1 .1-4.1 .4)$.

There is thus considerable evidence for the priority of semantics in verbs derived from nouns. In all cases, the absence of a form is explainable on the grounds of a missing significant semantic component; for example, while one can "hold stones, sand and gravel in the hand to throw' it is not possible to hold water in the same way (4.1.4). In a similar vein, animals, being a rather homogenous group, are more closely aligned morphosyntactically than the list of human reference terms (4.1.3) which, as we would expect, show a number of morphosyntactic discrepancies.

\subsubsection{BODY PARTS}

Most Austronesian languages are characterised by at least two classes of possession: "some nouns take a possessive suffix added directly to the stem, others add it not to the stem but to a particle placed usually before it" (Capell 1976:16). Items which take the possessive suffix are usually referred to as "inalienable possessions" (Lynch 1973). Included in this semantic class are body parts, personal attributes and biological relationships. In Tawala, the suffixes are as follows:

TABLE 10: THE INALIENABLE POSSESSION SUFFIXES

\begin{tabular}{|c|c|c|}
\hline \multirow{2}{*}{1} & Singular & \multicolumn{2}{|c|}{ Plural } \\
\cline { 2 - 3 } & $u \sim w e^{1}$ & $\begin{array}{l}\text { ta (INC) } \\
\text { iyai (EXC) }\end{array}$ \\
\hline 2 & $m$ & $m i$ \\
\hline 3 & na & hi \\
\hline
\end{tabular}

${ }^{1} u \rightarrow w e / u_{-}$

Something of the range of meanings of this class can be seen in the following examples. The term 'biological relationship' includes the parts of plants and also kinship terminology:

$\begin{array}{ll}\text { nima-u } & \text { my hand } \\ \text { lugu-na } & \text { its leaf } \\ \text { hina-ta } & \text { our (inclusive) mother } \\ \text { nou-we } & \text { my sibling of opposite sex } \\ \text { gowa-hi } & \text { their name/s } \\ \text { kamna-na } & \text { his health, disposition }\end{array}$

Note that the concepts of name, health and disposition are considered body parts by the Tawala people, not as abstract nouns as we would consider them in English.

The body-part class of nouns is further characterised by a unique set of derivational prefixes as set out in Chart 1. It will be noted that the meanings in the chart are consistent, so that a Tawala speaker would easily be able to productively use any body part not listed in Chart 1. 


\begin{tabular}{|c|c|c|c|c|c|}
\hline root & & $\begin{array}{l}\text { wi-R-DAT-O } \\
\text { to cover, protect or aid }\end{array}$ & $\begin{array}{l}\text { lu-R-O } \\
\text { to hit a body part }\end{array}$ & $\begin{array}{l}l i \\
-\end{array}$ & $\begin{array}{l}\text { wo-R-O } \\
\text { to hold a body part }\end{array}$ \\
\hline$a e-$ & leg & $\begin{array}{l}\text { wiaegeni } \\
\text { put on shoes etc. }\end{array}$ & $\begin{array}{l}\text { luaeni } \\
\text { hit its leg }\end{array}$ & - & $\begin{array}{l}\text { woaeni } \\
\text { hold its leg }\end{array}$ \\
\hline taniga- & ear & $\begin{array}{l}\text { witanigageni } \\
\text { put on hearing aid etc. }\end{array}$ & $\begin{array}{l}\text { lutanigani } 1 \\
\text { hit its ear }\end{array}$ & - & $\begin{array}{l}\text { wotanigani } \\
\text { hold its earr }\end{array}$ \\
\hline mata- & eye & $\begin{array}{l}\text { wimatageni } \\
\text { put on glasses etc. }\end{array}$ & $\begin{array}{l}\text { lumatani } 2 \\
\text { hit its eye }\end{array}$ & - & - \\
\hline giu- & tail & - & $\begin{array}{l}\text { lugiuni } \\
\text { hit its tail }\end{array}$ & - & $\begin{array}{l}\text { wogiuni } \\
\text { hold its tail }\end{array}$ \\
\hline ununu- & head & $\begin{array}{l}\text { wiununugeni } \\
\text { put on hat }\end{array}$ & $\begin{array}{l}\text { Iuunununi } \\
\text { hit its head }\end{array}$ & - & $\begin{array}{l}\text { wounununi } \\
\text { hold its head }\end{array}$ \\
\hline nima- & hand & $\begin{array}{l}\text { winimageni } \\
\text { put on gloves etc. }\end{array}$ & $\begin{array}{l}\text { lunimani }{ }^{3} \\
\text { hit its hand }\end{array}$ & - & $\begin{array}{l}\text { wonimani } \\
\text { hold its hand }\end{array}$ \\
\hline hipu- & buttocks & - & $\begin{array}{l}\text { luhipuni } \\
\text { hit its buttocks }\end{array}$ & - & $\begin{array}{l}\text { wohipuni } \\
\text { hold its buttocks }\end{array}$ \\
\hline tolotolo- & ribs & - & $\begin{array}{l}\text { lutolotoloni } \\
\text { hit its side }\end{array}$ & - & $\begin{array}{l}\text { wotolotoloni } \\
\text { hold its side }\end{array}$ \\
\hline
\end{tabular}

\section{CHART 1: DERIVATIONAL PREFIXES WITH BODY PARTS}

'The form lutanigana is an idiom 'to listen'.

${ }^{2}$ This verb has an idiomatic meaning 'to talk face to face'. POC *mata is reconstructed with the meaning 'face' as well as 'eye', so this type of idiom has been around a long time.

${ }^{3}$ The form lunimana is an idiom 'to hold hands'. 
The wi prefix with body parts is used to derive verbs which involve placing a cover, protection or aid on a body part:

$$
\text { wi-ae-ge-ni put on a shoe etc. (ae foot/leg) }
$$

Thus, used with 'leg' the combination can mean 'the use of shoes, underwater flippers and also cricket pads (there is no separate word for foot). In line with the proposed common meaning 'become like item', a cover, protection or aid used with a body part does indeed become like the body part.

The lu prefix with a body part is used to derive a verb which refers to hitting that body part:

$$
\text { lu-tanigan-i hit his ear (tanigana his ear) }
$$

The notes to Chart 1 refer to three additional idiomatic meanings. This combination of $l u$ with a body part relates to the common meaning 'the physical manifestation of item', in that hitting a body part is to draw everyone's attention to that part, thus point it out in an obvious way.

There are no examples of $l i$ used with a body part.

The wo prefix with a body part is used to derive verbs in which the animal or human is held by that body part:
wo-giun-i hold its tail
(giuna its tail)

As it is not possible to hold an animal by its eye, there is a gap in the data at this point. The common meaning 'involves handling item' differs little from the specific meaning, 'to hold body part'.

Typical examples:

$$
\begin{aligned}
& \text { Natani unuhau i-wi-ununu-ge-ni. } \\
& \text { Nathan hat he-DP-head-DAT-it } \\
& \text { Nathan put the hat on. }
\end{aligned}
$$

Am kwasikwasi-gei u-na-lu-giun-i!

your.SG machete-INST you.SG-INT-DP-tail-it

Hit it on the tail with your machete!

Polo-na hi-wo-ae-ni.

pig-that they-DP-leg-it

They held the pig's leg(s).

\subsubsection{RELATIONSH IP TERMS}

The subclass of nouns involving human and animal relations is distinguished by inalienable possession suffixes (for details see 4.1.1) and by reduplication. Reduplication is used with nouns referring to humans, to mark plural. Reduplication morphology is productive for all open word classes (the details are handled in section 2.5).

Some examples of reduplication with relationship terms:

$\begin{array}{llll}\text { amana } & \text { his father } & \text { amamana } & \text { his fathers } \\ \text { gogata } & \text { our (inclusive) grandparent } & \text { googata } & \text { our grandparents } \\ \text { natum } & \text { your (singular) child } & \text { natunatum } & \text { your children }\end{array}$


The derivational prefixes are not highly productive with this semantic field; $w i$ is the only productive prefix, though $l i$ has a two-fold idiomatic use.

Chart 2 presents three separate, though related, uses of wi with relationship terms, involving the concepts:

(a) to enter a new biological relationship
wi-ama
become a father
(ama father) ${ }^{8}$

(b) to call someone by a kin term or to adopt a new relationship

wi-amana call someone father (amana his father)

(c) to develop relationships with others (church term)

wi-amamana gain new fathers (amamana his fathers)

The distinction between these three meanings rests on only slight differences of form, and a thorough treatment of the grammar would perhaps reduce these to productive grammatical distinctions. While example (46) below does not appear to have anything to do with the church, it is so connected in the minds of the people, as such wandering around in the dark was unthinkable in pre-Christian times. The form *wi-tulana for 'becoming a friend' (bilogical relationship) is omitted as it would involve a logical contradiction. The absence of the forms *wi-tugona 'become older brother' and *wi-tewela 'become younger brother' reflect the relative unimportance of these relationships in the Tawala culture. The relationships of all these meanings to the common meaning 'become like item' is quite obvious, in that adopting a new relation, say a child, is for that person to become like one's child.

Li occurs with two roots ('child' and 'grandchild') in reference to the progeny of pigs, if they had bred prolifically:

$$
\text { li-go-o-gana have many grandchildren (gogana his grandchild) }
$$

When a person dies, a female pig is set aside for producing offspring which will all be used at a mortuary feast in honour of the dead person. If in two generations the pigs number over 20 the original hog and sow will be said to have produced a large progeny. Even though these uses are idiomatic, they are in line with the common meaning of 'being transformed into item' or in this case into many items.

The retention of the third person singular suffix na with most of the intransitive examples in Chart 2 is apparently a vestigial affix reflecting the fact that relationship terms never occur by themselves. We cannot have 'a sister' in Tawala, but only 'someone's sister'.

Typical examples:

$$
\begin{aligned}
& \text { Ega nou-we ma a-wi-nouna. } \\
& \text { not sister-my but I-DP-sister } \\
& \text { She's not my sister, but I call her sister. }
\end{aligned}
$$

$$
\begin{aligned}
& \text { Bada-na amaka wawine i-wi-gogan-e-ya. } \\
& \text { man-that already woman he-DP-grandparent-DAT-her } \\
& \text { The man treated the woman as his grandmother. }
\end{aligned}
$$

\footnotetext{
${ }^{8}$ Ama 'father' and hina 'mother' are the only exceptions to the rulc that relationship terms cannot occur without the possessive suffix.
} 


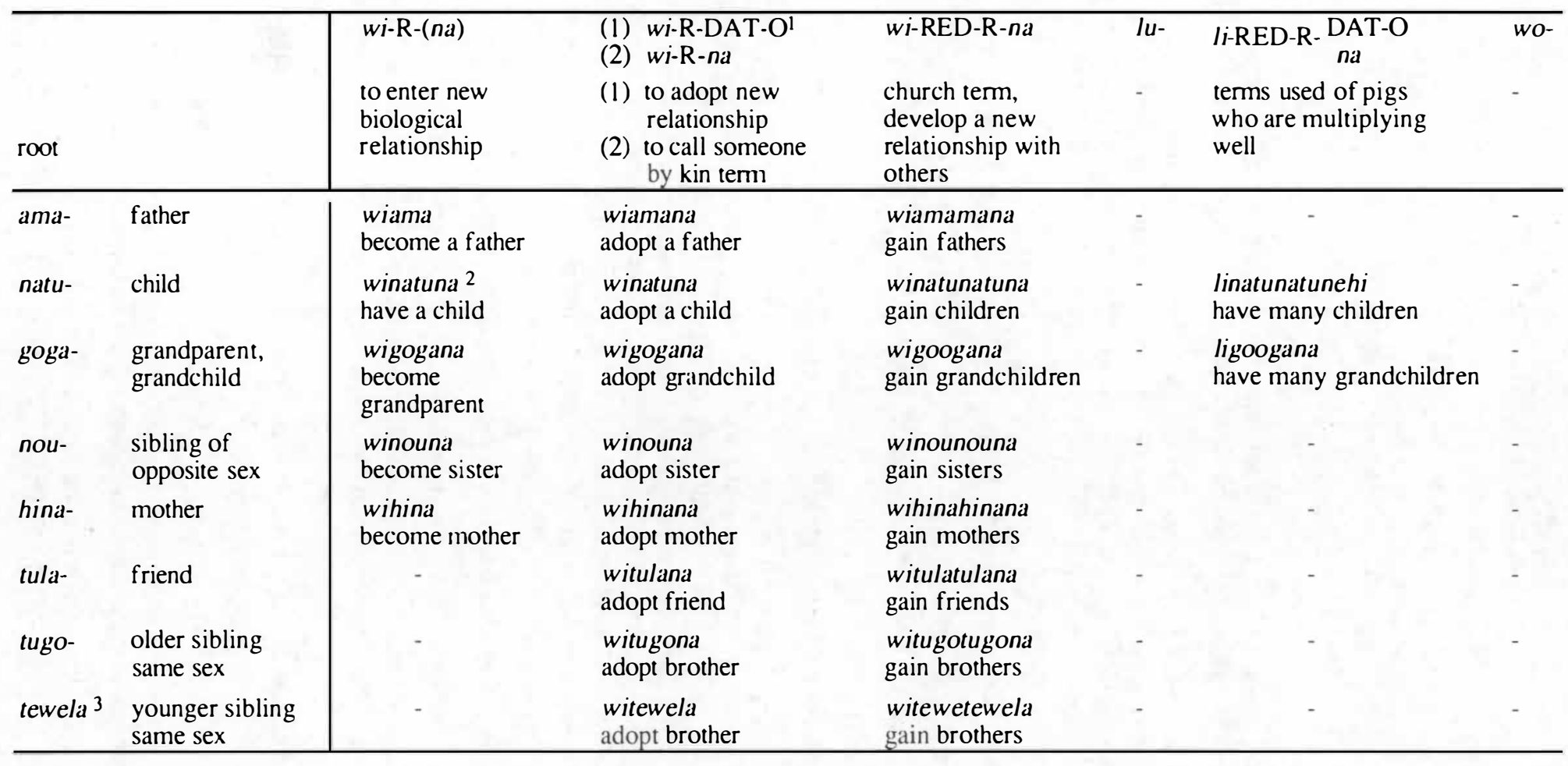

CHART 2: DERIVATIONAL PREFIXES WITH RELATIONSHIP TERMS

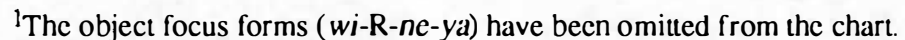

$2 \mathrm{cf}$. wigunaguna 'to give birth'.

${ }^{3}$ Tewela 'child-brother' is used with alienable possession only. 
(46)

I-didibal-ei meka po meka ta-nae po ta-wi-tula-tulana... it-dark-at where and where we.INC-go and we.INC-DP-RED-friend When it is dark, wherever we go we are all friends...

Polo hi-li-natu-natu-ne-hi.

pig they-DP-RED-child-DAT-RFX

The pigs (hog and sow) have a large progeny.

\subsubsection{HUMAN REFERENCE TERMS}

As with relationship terms (4.1.2), human reference terms are generally reduplicated for plural. The reduplicated forms are incorporated into Chart 3 as they are somewhat irregular.

This semantic field is less homogeneous than those we have examined so far, as is revealed by the number of gaps in the data and the idiomatic meanings presented in Chart 3 . The semantic shift between 'man' and 'male' is greater than between the two body parts 'arm' and 'leg'. Hence it is not surprising that the human reference terms should prove to be less regular than the body-part terms.

The prefix wi with human reference terms has two distinct meanings:

(a) to become the item

$$
\text { wi-bada become a man (bada man) }
$$

(b) behave like the item (socially)

wi-keduluma be like a woman (child with a deep cough) (keduluma woman)

In both cases we see a direct relationship between these specific meanings and the common meaning, 'become like item'. Chart 3 presents data which mostly have meaning (a); however, this meaning is not possible with 'female' and 'male' and hence the second meaning is the only possibility with these items. When the second meaning is used, the implication is that the 'action' is verbal or some other social form of behaviour, as opposed to the $l u$ form which would imply physical action. The only word for acting like a foreigner is that of physical action rather than a social adaptation. This seems to embody the insight that most cross-cultural adaptation is a fairly superficial affair.

The prefix lu with human reference terms has the meaning 'act like the item':

$$
\text { lu-hewahewali act like a youth (swing ams etc.) (hewali youth) }
$$

As has just been mentioned, this implies physical action - often a caricature of the way the thing is normally done. This is very close to the common meaning, 'physical manif estation of item'.

The prefix li with human reference terms involves the meaning of 'someone being turned into someone else':

$$
\text { li-wawineya change into a woman (wawine woman) }
$$

With the male/female items, the meaning necessarily involves a change of sex. Once again these meanings are very close to the common meaning 'be transformed into item'.

No occurrence of wo with human reference terms has been found. 


\begin{tabular}{|c|c|c|c|c|c|c|}
\hline root & & $\begin{array}{l}\text { RED-R } \\
\text { plural }\end{array}$ & $\begin{array}{l}\text { wi-R } \\
\text { (1) to become N } \\
\text { (2) to behave like N } \\
\text { (socially) }\end{array}$ & $\begin{array}{l}\text { lu-RED-R } \\
\text { to act like } \mathrm{N}\end{array}$ & $\begin{array}{l}\text { li-R-O } \\
\text { to change s.o. }{ }^{1} \\
\text { into } \mathrm{N}\end{array}$ & wo-R \\
\hline$\overline{\text { bada }}$ & $\operatorname{man}$ & babada & $\begin{array}{l}\text { wibada } \\
\text { become a man }\end{array}$ & $\begin{array}{l}\text { lubabada } \\
\text { act like men }\end{array}$ & $\begin{array}{l}\text { libadaya } \\
\text { make s.o. a man }\end{array}$ & - \\
\hline keduluma & woman & kedukeduluma & $\begin{array}{l}\text { wikeduluma } \\
\text { become a woman }\end{array}$ & $\begin{array}{l}\text { lukedukeduluma } \\
\text { act like women }\end{array}$ & $\begin{array}{l}\text { likedulumaya } \\
\text { make s.o. a woman }\end{array}$ & - \\
\hline hewali & youth & hewahewali & $\begin{array}{l}\text { wihewali } \\
\text { become a youth }\end{array}$ & $\begin{array}{l}\text { luhewahewali } \\
\text { act like youths }\end{array}$ & - & - \\
\hline guguhini & maiden & guuguhini & $\begin{array}{l}\text { wiguguhini } \\
\text { become a maiden }\end{array}$ & $\begin{array}{l}\text { luguuguhini } \\
\text { act like maidens }\end{array}$ & - & - \\
\hline tewela & child & logaloga & $\begin{array}{l}\text { witewela } \\
\text { become a child }\end{array}$ & - & $\begin{array}{l}\text { litewelaya } \\
\text { make s.o. a child }\end{array}$ & - \\
\hline lawa & person & - & $\begin{array}{l}\text { wilawa } \\
\text { become a person } \\
\text { (idiom-become } \\
\text { populated) }\end{array}$ & - & $\begin{array}{l}\text { lilawaya } \\
\text { make s.o. a person }\end{array}$ & - \\
\hline wawine & female & wiwine & $\begin{array}{l}\text { wiwawine } \\
\text { be effeminate }\end{array}$ & $\begin{array}{l}\text { luwawine } 2 \\
\text { dress prettily }\end{array}$ & $\begin{array}{l}\text { liwawineya } \\
\text { change to female }\end{array}$ & - \\
\hline oloto & male & ololoto & $\begin{array}{l}\text { wioloto } \\
\text { behave as male. }\end{array}$ & $\begin{array}{l}\text { luoloto } \\
\text { dress handsomely }\end{array}$ & $\begin{array}{l}\text { liolotohi } \\
\text { change to male }\end{array}$ & - \\
\hline (mi)dimdim & foreigner & - & - & $\begin{array}{l}\text { lumidimdim } \\
\text { act like foreigners }\end{array}$ & $\begin{array}{l}\text { lidimdim } \\
\text { give s.o. white skin }\end{array}$ & - \\
\hline meyameya & infant & - & $\begin{array}{l}\text { wimeyameya } \\
\text { become an inf ant }\end{array}$ & $\begin{array}{l}\text { lume yameya } \\
\text { act like infants }\end{array}$ & - & - \\
\hline
\end{tabular}

CHART 3: THE DERIVATIONAL PREFIXES WITH HUMAN REFERENCE TERMS

'Luwawine also has a transitive form luwawineya 'to rape a woman'.

${ }^{2}$ The concept involves work on the part of an agent. 
Typical examples:

$$
\text { E-lau-gonu po amaka i-wi-keduluma. }
$$

she.PRES-DP.PROG-cough and already she-DP-woman

She has a (deep) cough and sounds like an old woman.

(49) Dawida amaka i-wi-hewali.

David already he-DP-youth

David has already become a young man.

(50) Bada i-wi-hewali-meme.

man he-DP-youth-again

The man appeared as a youth again.

\section{Lectures hi-wawala po kikeina dobu i-wi-lawa.}

lectures they-start and little village it-DP-person

The lectures started and gradually the place became more populated.
Tu manini a baha-gei polo i-li-lawa-ya.
person power his word-from pig it-DP-person-RFX
At the magician's word the pig became a person.

\subsubsection{CUltUral itemS}

The final semantic field within the noun class is a large class of 'cultural items'. Items belonging to this group share no special morphosyntactic features apart from the distinctive set of derivational prefixes (Chart 4). Semantically, the cultural items are natural resources which involve no cultivation and are complete entities in themselves and not parts of constructions. Thus the group does not include cultivated food items or materials used in the construction of houses etc. Coconuts are not an exception to the cultivation rule as the planting of coconuts is a remote process carried out years before their collection and use.

Subclasses along mineral, vegetable and animal lines are required to explain distinctive uses with the derivational prefixes, but are not sufficiently distinctive to set up separate noun classes, nor is there any independent morphosyntactic evidence for their status as independent noun classes.

Chart 4 summarises the use of derivational prefixes with cultural items. The wi prefix derives intransitive verbs with the meaning of an area covered by the item - mineral and vegetable subclass:

$$
\text { wi-gai-gaima be covered with stones (gaima stone) }
$$

or an area containing an excessive number of the item - animal subclass:

$$
\text { wi-itala be infested with rats (itala rat) }
$$

A transitive form of this verb involves covering an area with the item - mineral subclass only, as the other semantic fields do not lend themselves to being 'spread out':

$$
\text { wi-bubu-ge-ya spread sand on ground (bubu sand) }
$$

The common meaning 'be like item' corresponds to the fact that if an area is covered with an item, then it is indeed like the item. 
The prefix lu with cultural items always involves collecting the items:
lu-mayau collect firewood
(mayau tree)

In English we use the separate lexical items 'catch' and 'hunt' when 'collecting' animals:

lu-polo hunt pigs (polo pig)

The common meaning of 'physical manifestation of item' is achieved with this class by bringing the collected items back to the village for all to see.

The prefix li has the single meaning 'be/become transformed into item' with this group of items:

$$
\text { li-gaima-ya become a stone (gaima stone) }
$$

This meaning is the prototypical common meaning of $l i$ with nouns.

The prefix wo has a distinctive use with each of the subclasses.

(a) Mineral - 'hold item for throwing' - these are typical weapons:

$$
\text { wo-gaima hold a stone } \quad \text { (gaima stone) }
$$

(b) Vegetable - 'steal item' - these items, particularly betel nut, are the most commonly stolen items in the culture:

$$
\text { wo-beda steal betel nut (beda betel palm) }
$$

(c) Animal - 'be loaded with item to take to a feast' - meat is always the most popular food at a feast:
wo-iyana-ya be loaded with fish
(iyana fish)

Meanings (a) and (b) are intransitive and (c) is transitive with a reflexive suffix. It is also possible to use (b) items with a transitive sense similar to (c) meanings, but not vice versa. All three of these meanings conform directly to the common meaning involves handling item'.

Meanings have not been supplied under each derived stem in Chart 4 as the meanings generally conform to those at the heading of the column; exceptions are recorded in the footnotes.

Typical examples:

(a) Mineral

(53) Dobu i-wi-gai-gaima.

village it-DP-RED-stone

The village ground is covered in stones.

(54) Hi-gale-ya ma bada amaka i-li-gaima-ya.

they-look-him but man already he-DP-stone-RFX

They looked but the man had tumed into a stone.

\footnotetext{
Ta-nae ta-lu-dubu.

we.INC-go we.INC-DP-sand

Let's go and get sand.
} 


\begin{tabular}{|c|c|c|c|c|c|c|}
\hline root & & $\begin{array}{l}\text { wi-(RED)-R } \\
\text { (intransitivc) } \\
\text { (a)\&(b) (area) to be } \\
\text { covcred by itcm } \\
\text { (c) (arca) to suppon } \\
\text { an excessive number } \\
\text { of itcms }\end{array}$ & $\begin{array}{l}\text { wi-(RED)-R-DAT-O } \\
\text { (transitive) } \\
\text { to spread itcm on } \\
\text { ground }\end{array}$ & $\begin{array}{l}\text { Iu-R } \\
\text { (a)\&(b) to collect } \\
\text { item } \\
\text { (c) to hunt/catch item }\end{array}$ & $\begin{array}{l}\text { li-R-RFX } \\
\text { to be/become } \\
\text { itcm }\end{array}$ & $\begin{array}{l}\text { (a) \&(b) wO-R } \\
\text { (c) wo-R-RFX } \\
\text { (a) to hold itcm for } \\
\text { throwing } \\
\text { (b) to steal itcm } \\
\text { (c) to be loaded with } \\
\text { itcms to take to a feast }\end{array}$ \\
\hline \multicolumn{7}{|l|}{ (a) Mincral } \\
\hline gaima & stonc & wigaigaima & wigaigaimeya & Iugaima & ligaimaya & wogaima \\
\hline bubu & sand & wibubu & wibubugcya & Iububu & libubuya & wobubu \\
\hline dakulc & gravel & widakulc & widakulcya & ludakule & lidakuleya & wodakulc \\
\hline goila & water & wigoigoila & wigoilcya & lugoila & ligoilaya & - \\
\hline \multicolumn{7}{|c|}{ (b) Vegctablc } \\
\hline ginahi & sago & wiginahi & - & luginahi I & liginahi & woginalii \\
\hline mayau & Irec & wimayau & - & lumayau & limayauya & womayau \\
\hline$b e d a$ & betcl nut & wibcda & - & lubeda & libedaya & wobcda \\
\hline gaga & pсppcr ${ }^{2}$ & wigaga & - & lugaga & ligagaya & wogaga \\
\hline neula & coconut & wincula 3 & - & luncula & lineulaya & woncula \\
\hline \multicolumn{7}{|l|}{ (c) Animal } \\
\hline polo & pig & wipolo & - & lupolo & lipoloya & wopoloya \\
\hline hagwai & possum & wilhagwai & - & Iuhagwai & lihagwaiya & -4 \\
\hline sigapa & wallaby & wisigapa & - & lusigapa & lisigapaya & wosigapaya \\
\hline kiu & bird & wikiu & - & lukiu & likiuya & wokiuya \\
\hline buncbunc & pigcon & wibuncbunc & - & Iubunebune & libunebuncya & wobunebuneya \\
\hline iyana & fish & wiiyana & - & luiyanas & liiyanaya & woiyanaya \\
\hline yakoyako & sheil & wiyakoyako & - & luyakoyako 6 & liyakoyakoya & woyakoyakoya \\
\hline kamkam & chicken & wikamkam & - & Iukamkam & likamkamya & wokamkamya \\
\hline kedewa & dog & wikedewa & - & lukedewa & likcdcwaya & wokedewaya \\
\hline itala & rat & wiitala & - & luitala & liitalaya & woitalaya \\
\hline gumaguma & hermit crab & wigumaguma & - & lugumaguma & ligumagumaya & wogumagumaya \\
\hline
\end{tabular}

CHART 4: DERIVATIONAL PREFIXES WITH CULTURAL ITEMS

' 'to process sago'.

2'Pepper' refers to the vine whose hot fruit and leaves are eaten with bctel nut.

3 Wineula also has the meaning 'to rub oil on something'.

${ }^{4}$ Wo prefix with hagwai does not take reflexive suffix, and means 'to act like a possum' - Tarzan iwohagwai nae. 'Tarzan flies like a possum'

s'to pull fish in".

6'to gather and break open shell for eating'. 
(56) Hewali i-wo-gaima.

youth he-DP-stone

The youth held a stone (ready to throw).

(b) Vegetable

(57) Naka dobu i-wi-ginahi duma.

that area it-DP-sago really

There are many sago palms at that place.

(58) Yakoyako i-li-gumaguma-ya.

shell it-DP-hermit.crab-RFX

The shell became a hermit crab.

(59) To-nae to-lu-mayau.

we.EXC-go we.EXC-DP-tree

We are going to collect firewood.

(60) To-lu-mayau-pahi-yai.

we.EXC-DP-tree-very-RFX

We really loaded ourselves with wood.

(c) Animal

(61) Dobu i-wi-hagwai duma.

village it-DP-possum really

The village is really infested with possums.

(62) Bada i-baha po kedewa i-li-polo-ya.

man he-talk and dog it-DP-pig-RFX

When the man spoke the dog became a pig.

(63) Pusi i-lu-itala po i-(a)m-am.

cat it-DP-rat and it-PROG-eat

The cat caught the rat and was eating it.

(64) To-wo-polo-pahi-yai.

we.EXC-DP-pig-many-RFX

We are really loaded with pigs (for the feast).

\subsection{ADJECTIVE CLASSES}

Adjectives form a distinctive open word class in Tawala, already introduced on semantic grounds (2.1.2). There is morphosyntactic evidence for distinguishing between the universal semantic classes set up by R.M.W. Dixon (1977:31). A summary of the data is inluded in Table 12. The type of semantic opposition has also been included in the table as these data help to distinguish the classes. The data on which Table 12 is based are set out in the remainder of this introductory section. Following that, the distinctive use of derivational prefixes with each of the adjectival classes is demonstrated (4.2.1 - 4.2.4). In all, six adjectival classes are recognised: physical property, dimension, value, age, speed and colour. A seventh, aberrant class set up by Dixon (1977) - the human propensity class - has been assigned to its own closed class (4.4) as this class has nothing to do with adjectives in Tawala. 
Adjectives follow the noun, if one is present, and they always mark the person/number of the noun they refer to, see Table 11. The form of these suffixes is identical to the inalienable possession suffixes (Table 10). Thus Tawala adjectives can be viewed as an extension of the concept of 'body parts' to include a person's attributes.

TABLE 11: ADJECTIVAL SUFFIXES

\begin{tabular}{|c|c|c|}
\hline \multirow{2}{*}{1} & Singular & Plural \\
\cline { 2 - 3 } & $u \sim w e^{1}$ & ta (INC) \\
& & iyai (EXC) \\
\hline 2 & $m$ & $m i$ \\
\hline 3 & na & hi \\
\hline
\end{tabular}

${ }^{1} u \rightarrow w e / u_{-}$.

(65) Bada dewadewa-m.

man good-your.SG

You are a great man.

(66) Lawa moina-u.

person true-my

I am a truthful person.

(67) Keyalu banei-hi.

casuarina big-their

They are large casuarina trees.

TABLE 12: SOME DISTINGUISHING FEATURES OF TAWALA ADJECTIVES

\begin{tabular}{|l|c|c|c|c|c|}
\hline & \multicolumn{3}{|c|}{ A. MORPHOSYNTAX } & \multicolumn{2}{c|}{ B. SEMANTIC OPPOSITION } \\
\hline Semantic type & $\begin{array}{c}\text { Reduplicated } \\
\text { form }\end{array}$ & $\begin{array}{c}\text { Plural } \\
\text { form }\end{array}$ & $\begin{array}{c}\text { Use with } \\
\text { wai- }\end{array}$ & $\begin{array}{c}\text { Antonym } \\
\text { pair }\end{array}$ & $\begin{array}{c}\text { Complement } \\
\text { sets }\end{array}$ \\
\hline Physical property & \pm & - & $\mp$ & \pm & $\mp$ \\
Dimension & \pm & \pm & - & + & - \\
Value & \pm & - & - & + & - \\
Age & - & - & - & + & - \\
Speed & + & - & - & + & - \\
Colour & + & - & + & - & + \\
\hline
\end{tabular}

KEY: + all; \pm most; $\subsetneq$ few; - none. 


\section{A. MORPHOSYNTACTIC DATA}

(a) Reduplicated forms

By far the majority of Tawala adjectives have a reduplicated form (for morphological details see section 2.5). Many adjectives are synchronically still derived from unreduplicated stems:

$\begin{array}{llll}\text { dewa } & \text { custom } & \text { dewadewana } & \text { good } \\ \text { tahaya } & \text { path } & \text { tahatahayana } & \text { first (lead) } \\ \text { hogoya } & \text { be full } & \text { hogohogoyana } & \text { full }\end{array}$

The fact that the age class of adjectives and also certain other adjectives do not have a reduplicated form is not accidental. Reduplication in Tawala typically refers to repetition of activity or a plural number of items (Ezard, B. 1980a). The age adjectives do not fit this classification - 'old' and 'new' are single events, happening only once. Similarly the unreduplicated nature of many other items can be explained within this framework. 'Big' and 'small' are unreduplicated, whereas items which have the qualities 'good', 'bad', 'fast',

- 'slow' demonstrate these qualities over and over again - hence the reduplicated forms.

(b) Plural forms

Dimension adjectives are distinguished in that they do not have lexical reduplication in the singular, but do have reduplicated forms for plural marking. The situation is somewhat complicated by the use of suppletive forms which make it impossible to say whether we are dealing with lexical or morphological reduplication:

$\begin{array}{llll}\text { habulu-na } & \text { small (singular) } & \text { muhomuho-hi } & \text { small (plural) } \\ \text { banei-na } & \text { big (singular) } & \text { balubalu-hi } & \text { big (plural) }\end{array}$

(c) Use of intensifier wai-

Wai- has the general meaning 'to be in the extreme or permanent condition of...' It is thus roughly equivalent to the English 'very' when used with adjectives. Two usages need to be distinguished:

(i) Obligatory use of wai-

Colour and certain physical condition adjectives have the prefix as an adjectiviser. The following examples have been noted:

Physical property

$\begin{array}{llll}\text { wai-dubudubuna } & \text { sandy } & \text { (dubu } & \text { dust) } \\ \text { wai-goigoilana } & \text { watery } & \text { (goila } & \text { water) } \\ \text { wai-donadonana } & \text { homy/thorny } & \text { (dona } & \text { tusk/horn) }\end{array}$

Colour

$\begin{array}{llll}\text { wai-didibalena } & \text { dark } & \text { (didibala } & \text { night) } \\ \text { wai-idaidagana } & \text { green } & \text { (idagana } & \text { unripe) } \\ \text { wai-kanikaniyogana } & \text { yellow } & \text { (kaniyogana } & \text { ginger used for yellow dye) }\end{array}$

(ii) Optional use of wai-

Certain adjectives take wai- as an intensifier with the implication 'to be in a more permanent or extreme condition of...' or 'to have the intrinsic nature of...': 
Physical property

$\begin{array}{llll}\begin{array}{l}\text { gigeimana } \\ \text { wai-gigeimana }\end{array} & \begin{array}{l}\text { stony } \\ \text { completely covered with stones }\end{array} & \text { (gaima } & \text { stone) } \\ \begin{array}{l}\text { gomugomuna } \\ \text { wai-gomugomuna }\end{array} & \begin{array}{l}\text { broken } \\ \text { hinged, swinging }\end{array} & \text { (gomu } & \text { to snap) } \\ \begin{array}{l}\text { holiholina } \\ \text { wai-holiholina }\end{array} & \begin{array}{l}\text { wound (fish line) } \\ \text { wound (spring) }\end{array} & \text { (holi } & \text { to pull in) }\end{array}$

Colour

$\begin{array}{ll}\text { wakewakekena } & \text { whitish } \\ \text { wai-wakewakekena } & \text { completely white } \\ \begin{array}{l}\text { dubadubana } \\ \text { wai-dubadubana }\end{array} & \text { blackish } \\ \text { completely black } \\ \text { kayakayana } & \text { reddish (e.g. cow) } \\ \text { wai-kayakayana } & \text { completely red (e.g. car) }\end{array}$

Note that the distinction between obligatory and optional use of wai- with colour fits neatly into the Berlin and Kay (1969) hierarchy (see section 4.2.4).

\section{B. SEMANTIC OPPOSITIONS}

(a) Antonyms

The denial of one term implies the assertion of its opposite. The following antonym pairs are typical, but not exhaustive. It will be noted that the opposites are not necessarily parallel to English antonym pairs (e.g. Tawala 'smooth - hard', English 'smooth - rough').

Physical property

$\begin{array}{llll}\text { bigabigana } & \text { muddy } & \text { gigimeina } & \text { stony } \\ \text { hegohegoyana } & \text { smooth } & \text { kapakapalana } & \text { hard } \\ \text { koyakoyana } & \text { flat } & \text { bibituna } & \text { spherical }\end{array}$

Dimension

$\begin{array}{llll}\text { awawana } & \text { thin } & \text { potopotona } & \text { thick } \\ \text { daodaona } & \text { long } & \text { kukuna } & \text { short } \\ \text { baneina } & \text { big } & \begin{array}{l}\text { habuluna } \\ \text { (cf. kikeina) }\end{array} & \text { small }\end{array}$

The following three sets are exhaustive:

Value

$\begin{array}{llll}\begin{array}{l}\text { dewadewana } \\ \text { yeuyeuna }\end{array} & \text { good } & \text { apapoena } & \text { bad } \\ \text { clean } & \text { gobugobuna } & \text { dirty } 9\end{array}$

Age

odubona old wouna new

${ }^{9}$ This opposition literally bclongs to physical property, but in valuc judgements of a person's worth and customs these words are normally used. 
Speed
sagesagena
fast
bambamna slow

Antonym pairs can also be formed by negativising the topic-comment clause, but this falls outside the realm of this paper.

(b) Complementary sets

Here we have contrastive sets of words. Only two sets are presented here, but others would not be difficult to elicit.

Colour

$\begin{array}{llll}\text { waididibalena } & \text { black } & \text { waiuguguwana } & \text { dark } \\ \text { kayakayana } & \text { red } & \text { waikanikaniyogana } & \text { yellow } \\ \text { waidaidagana } & \text { green } & \text { wakewakekena } & \text { white } \\ \text { waikulikulina } & \text { mottled } & & \end{array}$

Taste

$\begin{array}{llll}\text { gugouna } & \text { sweet } & \text { tululuwana } & \text { tart/sour } \\ \text { tomatomana } & \text { tasteless } & \text { dagidagihana } & \text { tasty } \\ \text { wainihana } & \text { salty/tasty } & \text { waigolana } & \text { bitter/salty (excessive) }\end{array}$

Dixon (1977:31) remarks that "complements provide absolute descriptions, antonym pairs...are always 'relative' to some implicit norm". While there is truth in this comment, the word 'absolute' is perhaps a little strong to describe the amount of salt in a particular bowl of soup. Some sets are better regarded as continuums.

\subsubsection{DIMENSION ADJECTIVES}

The semantic field of dimension adjectives has a distinctive set of derivational prefixes, with closest affinities to the related semantic field of physical property. Chart 5 sets out the use of three derivational prefixes with dimension adjectives.

$W i$ is a causative prefix when used with dimension adjectives:

$$
\text { wi-dao-ya to lengthen something (dao long) }
$$

The derived verb has social overtones - it is a talk or a meeting which is prolonged or cut short. These verbs are thus prototypical examples of the common meaning 'cause condition - socially'.

No examples of this semantic field used with the prefix $l u$ have been discovered.

The prefix li results in another causative verb:

$$
\text { li-habulu-ya to reduce something (habulu small) }
$$

This time the derived verb is to be taken literally - it is a house which is extended, or a canoe which is reduced in size. This specific meaning agrees well enough with the common meaning of $l i$ 'to cause new condition'.

The prefix woi (see p.180, explanation (f)) involves manipulating an item by hand: woi-dao-ya let out a line (i.e. lengthen it) (dao long) 


\begin{tabular}{|c|c|c|c|c|c|}
\hline $\operatorname{root}^{1}$ & & $\begin{array}{l}\text { wi-R-O } \\
\text { cause condition } \\
\text { - socially }\end{array}$ & lu- & $\begin{array}{l}\text { li-R-O } \\
\text { cause new condition } \\
-(\text { physical })\end{array}$ & $\begin{array}{l}\text { woi-R-O } \\
\text { manipulate s.th. by hand }\end{array}$ \\
\hline daodaona & long & $\begin{array}{l}\text { widaoya } \\
\text { lengthen s.th. } \\
\text { (e.g. talk) }\end{array}$ & - & $\begin{array}{l}\text { lidaoya } \\
\text { lengthen s.th. } \\
\text { (e.g. house) }\end{array}$ & $\begin{array}{l}\text { woidaoya } \\
\text { to let s.th. out }\end{array}$ \\
\hline kukuna & short & $\begin{array}{l}\text { wikikuya } \\
\text { run s.th. short } \\
\text { (e.g. meeting) }\end{array}$ & - & $\begin{array}{l}\text { likikuya } \\
\text { shorten s.th. } \\
\text { (e.g. canoe) }\end{array}$ & $\begin{array}{l}\text { woikukuya } \\
\text { take s.th. in }\end{array}$ \\
\hline baneina $^{2}$ & big & $\begin{array}{l}\text { wilataya } \\
\text { emphasise s.th. } \\
\text { (e.g. point of view) }\end{array}$ & - & $\begin{array}{l}\text { lilataya } \\
\text { increase s.th. } \\
\text { (e.g. land) }\end{array}$ & $\begin{array}{l}\text { woilataya }{ }^{3} \\
\text { adopt child (cause it } \\
\text { to grow) }\end{array}$ \\
\hline habuluna ${ }^{4}$ & small & $\begin{array}{l}\text { wihabuluya } \\
\text { make light of s.th. }\end{array}$ & - & $\begin{array}{l}\text { lihabuluya } \\
\text { reduce s.th. } \\
\text { (e.g. payment) }\end{array}$ & $\begin{array}{l}\text { woihabuluya } \\
\text { take s.th. in }\end{array}$ \\
\hline
\end{tabular}

\section{CHART 5: DERIVATIONAL PREFIXES WITH DIMENSION ADJECTIVES}

${ }^{1}$ The root is underlined.

${ }^{2}$ The adjective baneina (plural balubaluhl) is a suppletive form; lata is the productive root.

${ }^{3}$ The intransitive form wolata means 'to grow a little each day'.

${ }^{4}$ Plual muhomuhohi. 
This meaning is in line with the common meaning 'cause by hand' in that a translation of this type (e.g. 'cause the line to grow by hand') would be accurate enough even if somewhat awkward.

Typical examples:
A baha i-wi-dao-ya. his talk he-DP-long-it He spoke for a long time.

A numa i-popo-ya po i-li-dao-ya.

his house he-join-it and he-DP-long-it He joined a section onto his house and lengthened it.

Boga i-dao duma, yawai a-woi-kuku-ya. sea it-long really line I-DP-short-it The line went down too deep so I shortened it.
Lampa u-na-woi-habulu-ya!
lamp you.SG-INT-DP-short-it
Tum the lamp down!

\subsubsection{PHYSICAL PROPERTY ADJECTIVES}

This semantic field is quite close to the dimension adjectives discussed above (4.2.1). The main distinguishing features involve some small morphosyntactic details discussed in the introduction to this section (see Table 12) and the use of the lu prefix with physical property adjectives. Other distinctions of meaning can be seen by comparing Charts 5 and 6 . Chart 6 sets out the uses of the derivational prefixes with dimension adjectives.

The wi prefix has two meanings, each applying to only two out of six roots:

(a) to cause a condition - socially:

$$
\text { wi-kadidili to strengthen a relationship (kadidili strong) }
$$

(b) to be in a temporary condition:
wi-bigabiga to be muddy
(bigabiga muddy)

The first of these meanings agrees with the most common meaning, "cause condition socially'. The second (stative) meaning of wi occurs from time to time and is productive with some semantic fields.

The prefix with physical property adjectives involves more than the common meaning 'cause condition - physically' as the items in the data involve 'a strenuous or violent action in order to cause the condition':

$$
\text { lu-pilipili crumple a hard object (pilipili tangled) }
$$

The li prefix involves 'causing a condition' but does not always follow the common meaning 'to cause a new condition'. Sometimes the derived verb is to be taken literally (e.g. 'to sharpen something') at other times metaphorically:

li-dumalu-ya pay off debt (lit. straighten it) (dumalu straight) 


\begin{tabular}{|c|c|c|c|c|c|}
\hline root $^{1}$ & & $\begin{array}{l}\text { (1) wi-R-O } \\
\text { (2) wi-R } \\
\text { (1) cause condition } \\
\text { - socially } \\
\text { (2) temporary condition } \\
\text { (stative verb) }\end{array}$ & $\begin{array}{l}\text { lu-(RED)-R-O } \\
\text { cause condition } \\
\text { - violent action }\end{array}$ & $\begin{array}{l}\text { li-R-O } \\
\text { cause new condition }\end{array}$ & $\begin{array}{l}\text { wo(i)-(RED)-R-DAT-O } \\
\text { cause condition } \\
\text { - involves hands }\end{array}$ \\
\hline kamkamna & sharp & - & - & $\begin{array}{l}\text { likamya } \\
\text { sharpen s.th. }\end{array}$ & $\begin{array}{l}\text { woikamkamya } \\
\text { feel s.th. sharp }\end{array}$ \\
\hline bigabigana & muddy & $\begin{array}{l}\text { wibigabiga } \\
\text { be muddy }\end{array}$ & $\begin{array}{l}\text { lubigabigaya } \\
\text { make s.th. muddy }\end{array}$ & $\begin{array}{l}\text { libigabigaya } \\
\text { cause s.th. to be muddy }\end{array}$ & $\begin{array}{l}\text { woibigabigaya } \\
\text { muddy s.th. }\end{array}$ \\
\hline dumadumaluna & straight & - & - & $\begin{array}{l}\text { lidumaluya } \\
\text { pay off debt }\end{array}$ & $\begin{array}{l}\text { woidumaluya } \\
\text { straighten s.th. }\end{array}$ \\
\hline kapakapalana & hard & $\begin{array}{l}\text { wikapalaya } \\
\text { harden s.th. }\end{array}$ & - & $\begin{array}{l}\text { likapalaya } \\
\text { harden s.th. (by the sun) }\end{array}$ & $\begin{array}{l}\text { woikapakapalaya } \\
\text { harden s.th. }\end{array}$ \\
\hline kadikadidilina & strong & $\begin{array}{l}\text { wikadidili } \\
\text { strengthen s.th. }\end{array}$ & $\begin{array}{l}\text { lukadikadilith } \\
\text { hit s.th. hard }\end{array}$ & $\begin{array}{l}\text { likadidilit) } \\
\text { cause } s . \text { th. to harden } \\
\text { by adding s.th. }\end{array}$ & $\begin{array}{l}\text { wokadidiliyeni } \\
\text { hold s.th. tightly }\end{array}$ \\
\hline pilipilina & $\begin{array}{l}\text { tangled/ } \\
\text { crumpled }\end{array}$ & $\begin{array}{l}\text { wipilipili } \\
\text { be tangled }\end{array}$ & $\begin{array}{l}\text { Iupilipilit) } \\
\text { crumple a hard object }\end{array}$ & $\begin{array}{l}\text { lipilipilith } \\
\text { cause s.o. problems }\end{array}$ & $\begin{array}{l}\text { wopilipilith } \\
\text { crumple a soft object }\end{array}$ \\
\hline
\end{tabular}

CHART 6: DERIVATIONAL PREFIXES WITH PHYSICAL PROPERTY ADJECTIVES

${ }^{1}$ The root is underlined. 
The wo(i) prefix (see p.180, explanation (f)) normally follows the common meaning 'to manipulate something by hand':

wo-kadidili-ye-ni hold something tightly (kadidili strong)

But on one occasion there is no causative sense:

wo-kamkam-ya feel something sharp (kam sharp)

Typical examples:
Nugonugo-na i-wi-kapala-ya.
heart-his he-DP-hard-it
He resolutely made up his mind.
Fael-gei a-li-kam-ya.
file-with I-DP-sharp-it
I sharpened it with a file.
Om keliko u-woi-bigabiga-ya.
your.SG cloth you.SG-DP-mud-it
You muddied your clothes (with your dirty hand).

\begin{abstract}
Pepa nima-u-gei a-wo-pilipili.
paper hand-my-with I-DP-crumple
\end{abstract}
I screwed up the paper with my hands.

\subsubsection{AGE, VALUE AND SPEED ADJECTIVES}

The age, value and speed adjectives are three quite distinct classes, but are handled here in a section as they are each a small closed class of items and hence conveniently fit on a single page chart. The three classes are distinguished by the absence or presence of the various derivational prefixes (as well as morphosyntactic distinctions - introduced above, Table 12), rather than by distinct meanings attached to the prefixes.

The speed adjectives are the only class of adjectives to take no derivational prefixes at all. The age adjectives do not take the wo(i) prefix, but otherwise share the same prefixes as the value adjectives.

The wiprefix is used with age and value adjectives to signify a changed condition:

$$
\text { wi-wou-meme be renewed (wou new) }
$$

This is a stative verb with the age adjectives but a causative verb with the value adjectives:

$$
\text { wi-yeuyeu-ne-ya make something clean (yeuyeu clean) }
$$

Thus the latter semantic field agrees more closely with the common meaning 'cause condition - socially' than does the former. All these verbs have strong social overtones.

The lu prefix occurs with only a minority of age and value adjectives, and the resulting verbs have distinctly idiomatic meanings:
lu-gobu
be unkempt
(gobu dirty)
lu-odubo-ge-ni follow tradition
(odubona old)

These are only indirectly related to the common meaning 'to cause condition (physically)'. 


\begin{tabular}{|c|c|c|c|c|c|}
\hline $\operatorname{root}^{1}$ & & $\begin{array}{l}\text { wi-R-me me } \\
\text { RFX } \\
\text { change condition } \\
\text { - socially }\end{array}$ & $\begin{array}{l}\text { lu-R-(DAT-O) } \\
\text { idiomatic }\end{array}$ & $\begin{array}{l}\text { li-(RED)-R-O } \\
\text { cause new } \\
\text { condition to s.th. }\end{array}$ & $\begin{array}{l}\text { wo(i)-R-(O) } \\
\text { cause s.th. } \\
\text { with hands }\end{array}$ \\
\hline \multicolumn{6}{|l|}{$\overline{\text { Age }}$} \\
\hline wouna & new & $\begin{array}{l}\text { wiwou-meme } \\
\text { be renewed }\end{array}$ & - & $\begin{array}{l}\text { liwouya } \\
\text { renew, repair s.th. }\end{array}$ & - \\
\hline odubona & old & $\begin{array}{l}\text { wiodubo-meme } \\
\text { return to old custom }\end{array}$ & $\begin{array}{l}\text { luodubogeni } \\
\text { follow tradition }\end{array}$ & - & - \\
\hline \multicolumn{6}{|l|}{ Value } \\
\hline gobugobuna & dirty & $\begin{array}{l}\text { wigobugena-meya }{ }^{2} \\
\text { dirty oneself }\end{array}$ & $\begin{array}{l}\text { lugobu } \\
\text { be unkempt }\end{array}$ & $\begin{array}{l}\text { ligobugobuya } \\
\text { dirty s.th. }\end{array}$ & $\begin{array}{l}\text { woigobuya } \\
\text { dirty s.th. }\end{array}$ \\
\hline yeuyeuna & clean & $\begin{array}{l}\text { wiyeuyeu-meya } \\
\text { clean oneself }\end{array}$ & - & $\begin{array}{l}\text { liyeuyeuya } \\
\text { clean s.th. }\end{array}$ & $\begin{array}{l}\text { woyeuyeu } \\
\text { make s.th. clean }\end{array}$ \\
\hline dewadewana & good & $\begin{array}{l}\text { widewadewaya } \\
\text { make s.th. good } \\
\text { (with magic) }\end{array}$ & - & $\begin{array}{l}\text { lidewadewaya } \\
\text { make s.th. good }\end{array}$ & $\begin{array}{l}\text { woidewadewaya } \\
\text { fix s.th. }\end{array}$ \\
\hline \multicolumn{6}{|l|}{ Speed } \\
\hline bambamna & & - & - & - & - \\
\hline sagesagena & & - & - & - & - \\
\hline
\end{tabular}

Chart 7: Derivational PREFIXES WITH AGE, VALUE AND SPEED ADJECTIVES

${ }^{1}$ The root is underlined.

${ }^{2}$ Meya is the reflexive form and represents the only examples I have. Gena (transitive concord marker) is required before the reflexive form. 
The li prefix is used in line with its common meaning and involves 'to cause something to enter a (new) condition'.

$$
\text { li-wou-ya renew something (wou new) }
$$

The wo(i) prefix is used only with the value adjectives, and the examples have meaning 'to cause something with the hands'.

$$
\text { woi-gobu-ya dirty something (gobu dirty) }
$$

Typical examples:
ta-wi-wou-meme.
our.INC disposition we.INC-turn.over-them we.INC-DP-new-again
Let's change our ways and start again.

(77) Ta-wi-gobu-ge-na-me-ta. we.INC-DP-dirty-DAT-TC-again-RFX

We corrupt ourselves (by bad thoughts).

(78) Gibson meyagai i-li-yeuyeu-ya.

Gibson village he-DP-clean-it

Gibson kept the grounds tidy.

(79) Hi-lu-odubo-ge-ni.

they-DP-old-DAT-it

They follow the old (traditional) ways.

(80). Hiwape i-lu-gobu babana ago-na i-hilage.

widow she-DP-dirty because spouse-her he-die

A widow neglects her appearance because her husband has died.
Om luilui u-woi-gobu-ya nima-gei.
you.SG shirt you.SG-DP-dirty-it hand-INST
You have dirtied your shirt with your hands.

\subsubsection{COLOUR ADJECTIVES}

As pointed out in section 4.2 colours form a clearly distinguished class of adjectives on morphosyntactic as well as semantic grounds. Further evidence for the distinctive nature of adjectives is presented in Chart 8 which reveals a number of fundamental differences from the above data on the other classes of adjectives.

(a) The roots, and hence the derived forms, are always reduplicated in form.

(b) The meaning 'to be dressed in uniform' is a unique usage of the lu prefix, confined to the semantic field of colour.

The prefixes show clearly a distinction between the primary colours, red, black and white (there is even a word for 'coloured' - lugilugiluma - literally 'to be carved', which involves red, black and white paints), and the secondary colours, green/blue, yellow, mottled etc. Thus Tawala preserves as a grammatical distinction what in some languages is a lexical distinction (Berlin \& Kay 1969). In addition, the secondary colours all have the fossilised prefix waibefore their root in their basic lexical form, whereas wai with other adjectives is more typically an intensifier, as it is in fact with the primary colours (see $4.2 \mathrm{~A}$. (c)). 
The distinctive set of derivational prefixes is set out in Chart 8.

The wi prefix does not occur with the primary colours, and with the secondary colours does not occur with the most common meaning but with a secondary stative meaning which occurs occasionally throughout the data, but at this point occurs systematically with all the secondary colours:

$$
\text { wi-idaidaga to be green (waiidaidagana green) }
$$

The $l u$ prefix is used intransitively with all colours to refer to a group of people dressed in uniform:

$$
\text { lu-wakewakeke be dressed in white (cricketers) (wakewakekena white) }
$$

In addition, the secondary colours have a transitive use of lu being a causative verb:

$$
\text { lu-idaidag-e-ya make something green (waiidaidagana green) }
$$

Only the second of these meanings concurs with the common meaning 'to cause condition (physically)'.

Curiously, the gap left in the primary colour verbs by not using $l u$ in the transitive sense 'to make something a colour' is filled by $l i$ :

$$
\text { li-kayakaya-ya make something red (kayakayana red) }
$$

$L i$ is the causative verb with primary colours. This agrees well enough with the common meaning 'to cause new condition' but I can offer no explanation as to why the two semantic fields should have a different form at this point.

Only two verbs occur with wo:

$\begin{array}{lll}\text { wo-kayakaya } & \text { hold firebrand (in the dark) } & \text { (kayakayana } \\ \text { wo-dubadubana } & \text { become black } & \text { (dubadubana black) }\end{array}$

These appear to be completely idiomatic with little relationship to the common meaning 'to cause by hand'. Even though the former meaning involves holding something, the verb appears rather to emphasise the fact that the colour shines brightly in the dark.

Typical examples:

(82) Yada i-wi-gomigomida duma. sky it-DP-green/blue really The sky is really blue.

(83) I-li-wakewakeke-ya kabudala uyahinei. it-DP-white-it sun from It was bleached from the sunlight.

(84) Tu wipanipani hi-lu-kayakaya. people bound they-DP-red The prisoners were all dressed in red.

(85) A-wi-neula po a-wo-dubaduba. I-DP-coconut and I-DP-black I rubbed oil on myself and became black. 


\begin{tabular}{|c|c|c|c|c|c|c|}
\hline root & & $\begin{array}{l}\text { wi-R } \\
\text { state }\end{array}$ & $\begin{array}{l}\text { lu-R } \\
\text { wear uniform colours }\end{array}$ & $\begin{array}{l}\text { lu-R (DAT)-O } \\
\text { make a colour }\end{array}$ & $\begin{array}{l}\text { li-R-O } \\
\text { make a colour }\end{array}$ & $\begin{array}{l}\text { wo-R } \\
\text { idiomatic }\end{array}$ \\
\hline \multicolumn{7}{|l|}{ Primary colours: } \\
\hline kayakayana & red & - & $\begin{array}{l}\text { lukayakayaya } \\
\text { be dressed in red }\end{array}$ & - & $\begin{array}{l}\text { likayakayaya } \\
\text { makc s.th. red }\end{array}$ & $\begin{array}{l}\text { wokayakaya } \\
\text { hold fire-brand in dark }\end{array}$ \\
\hline dubadubana & black & - & $\begin{array}{l}\text { ludubadubaya } \\
\text { be dressed in black }\end{array}$ & - & $\begin{array}{l}\text { lidubadubaya } \\
\text { make s.th. black }\end{array}$ & $\begin{array}{l}\text { wodubaduba } \\
\text { become black }\end{array}$ \\
\hline wakewakckcna & whitc & - & $\begin{array}{l}\text { luwakewakcke } \\
\text { be dressed in whitc }\end{array}$ & - & $\begin{array}{l}\text { liwakcwakckcya } \\
\text { make s.th. whitc }\end{array}$ & - \\
\hline \multicolumn{7}{|l|}{ Sccondary colours: } \\
\hline waiidaidagana & $\begin{array}{l}\text { bluc/ } \\
\text { green }\end{array}$ & $\begin{array}{l}\text { wiidaidaga } \\
\text { be green }\end{array}$ & $\begin{array}{l}\text { luidaidaga } \\
\text { be dressed in green }\end{array}$ & $\begin{array}{l}\text { luidaidagcya } \\
\text { make s.th. grcen }\end{array}$ & - & - \\
\hline waigomigomidana & $\begin{array}{l}\text { bluc/ } \\
\text { green }\end{array}$ & $\begin{array}{l}\text { wigomigomida } \\
\text { be grcen }\end{array}$ & $\begin{array}{l}\text { lugomigomida } \\
\text { be dressed in grcen }\end{array}$ & $\begin{array}{l}\text { lugomigomidaya } \\
\text { makc s.th. green }\end{array}$ & - & - \\
\hline waikanikaniyogana & ycllow & - & $\begin{array}{l}\text { lukanikaniyoga } \\
\text { be dressed in yellow }\end{array}$ & $\begin{array}{l}\text { lukanikaniyogaya } \\
\text { make s.th. yellow }\end{array}$ & - & - \\
\hline waimagomagololona & orange & $\begin{array}{l}\text { wimagomagololo }{ }^{1} \\
\text { be orangc }\end{array}$ & $\begin{array}{l}\text { lumagomagololo }{ }^{2} \\
\text { all be dressed in } \\
\text { dance skirts }\end{array}$ & - & - & - \\
\hline waikulikulina & mottled & $\begin{array}{l}\text { wikulikuli }^{3} \\
\text { be mottled }\end{array}$ & $\begin{array}{l}\text { lugilugiluma } \\
\text { be dressed in mottled } \\
\text { colours }\end{array}$ & $\begin{array}{l}\text { lugilugilumcya }{ }^{4} \\
\text { makc s.th. mottled }\end{array}$ & - & - \\
\hline
\end{tabular}

\section{CHART 8: DERIVATIONAL PREFIXES WITH COLOUR ADJECTIVES}

${ }^{1}$ Used of bright sunscts.

2Orange dye is used in making magololo- special dancing skirts.

${ }^{3}$ Used of pigs, dogs and cats that have mottled/patches of colour.

${ }^{4} \mathrm{I}$ am not surc whether this is a suppletive form, separate words or a mixing of dialects. It means to paint something red, black and white.

The two forms are diachronically related. 


\subsection{VERB CLASSES}

Much more work needs to be done on verbs. The following data reveal a few patterns with very basic verbs, but the general picture beyond these is rather messy, especially when the residue (Chart 17) is included in the picture. In addition, while there is some evidence for derivational prefixes being used along semantic lines, there is very little evidence that these semantic fields are verb classes which play any other function in the grammar.

While linguists are in general agreement as to the presence of verbs in all languages (Sapir 1921:119; Bloomfield 1935:198), work on subclasses within verbs, as part of a general theory of language, has been largely neglected.

R.M.W. Dixon (1971:461) presents seven sets of verbs distinguished on the syntactic as well as the semantic properties of 250 Dyirbal verbs:

(1) Verbs of position, including 'go', 'sit', 'lead', 'take', 'throw', 'pick up', 'hold', 'empty out', and so on.

(2) Verbs of affect, including 'pierce', 'hit', 'rub', 'burn', and so on.

(3) Verbs of giving.

(4) Verbs of attention: 'look', 'listen', 'take no notice'.

(5) Verbs of speaking and gesturing: 'tell', 'ask', 'call', 'sing', and so on.

(6) Verbs dealing with other bodily activities; a residue set including 'cry', 'laugh', 'blow', 'copulate', 'cough', and so on.

(7) Verbs of breaking, that are 'meta' with respect to verbs in other sets, and can also have specific meanings: 'break', 'fall', 'peel'.

Subsequent work by Dixon has led to an extended semantic listing, based largely on English, but useful in the search for verb classes in other languages as well.

The following examples are selected from among the best data correlating semantics with phonetic shape in Tawala (Ezard, B. 1980b). It will be noted that the categories tend to be far more specific than those presented in Dixon (above). In applying derivational prefixes in the following sections, it has also been necessary to posit small, specialised subclasses within these classes. While the lists are tentative they are not anecdotal in that B. Ezard (1980b) systematically presents all 383 verbs of the pilot study in one list or another.

\section{A. VERBS OF MOTION}

These verbs mostly require an animate subject and rarely take an object.

(a) Generic verbs of motion involve a CVV pattern, which is relatively rare (only about ten words) in Tawala, but these words are among the most common in everyday use:

$\begin{array}{ll}\text { nae } & \text { go } \\ \text { nei } & \text { come } \\ \text { gae } & \text { go up, ascend } \\ \text { gei } & \text { come up }\end{array}$

These are presented in Table 13. 
TABLE 13: MOTION WITH RESPECT TO SPEAKER

\begin{tabular}{|l|c|c|}
\hline & Away from speaker & Towards speaker \\
\hline neutral & nae & nei \\
\hline ascending & gae & gei \\
\hline
\end{tabular}

In addition, the motion-towards-speaker verbs distinguish motion towards speaker from motion towards hearer.

TABLE 14: DIRECTION OF MOTION WITH RESPECT

TO SPEAKER AND HEARER

\begin{tabular}{|l|c|c|}
\hline & Towards speaker & Towards hearer \\
\hline neutral & nei & nehi \\
\hline ascending & gei & gehi \\
\hline
\end{tabular}

These verbs are all +control; there is also a CVV motion verb which is -control:

peu fall

(b) Specific verbs of motion (two-syllable intransitive words):

$\begin{array}{ll}\text { hala } & \text { dance } \\ \text { dala } & \text { crawl } \\ \text { lupa } & \text { jump, fly } \\ \text { hopu } & \text { go down, descend }\end{array}$

(c) Specific verbs of motion involving speed (three-syllable intransitive words ending in lili):

$\begin{array}{ll}\text { bulili } & \text { run } \\ \text { kalili } & \text { hurry westwards }\end{array}$

(d) Motion involving a starting point $\longmapsto$ (a rather random group):
lowo run away
gelu get on board
wi-yoli sink, drown
wo-mahili leave (involves speed?)

(e) Motion involving a specified end point

(another fairly random group

- though a preference for two-syllable words is evident):

$\begin{array}{ll}\text { talu } & \text { land (on perch) } \\ \text { yato } & \text { land (on perch, airstrip) } \\ \text { gota } & \text { arrive (at beach) } \\ \text { geleta } & \text { arrive (generic) } \\ \text { wialoni } & \text { meet (storm) (negative connotation) }\end{array}$


(f) Verbs involving passing a middle point (three-syllable words ending in $n a-a$ rare form):

$\begin{array}{ll}\text { tagona } & \text { go across (mountain) } \\ \text { damana } & \text { to across (bay) }\end{array}$

B. VERBS OF EFFECT

These verbs mostly involve a human subject, and are controlled action verbs.

(a) Intransitive verbs involving action on many small objects. We here meet with the remaining derivational prefix (om) in one of its productive domains:

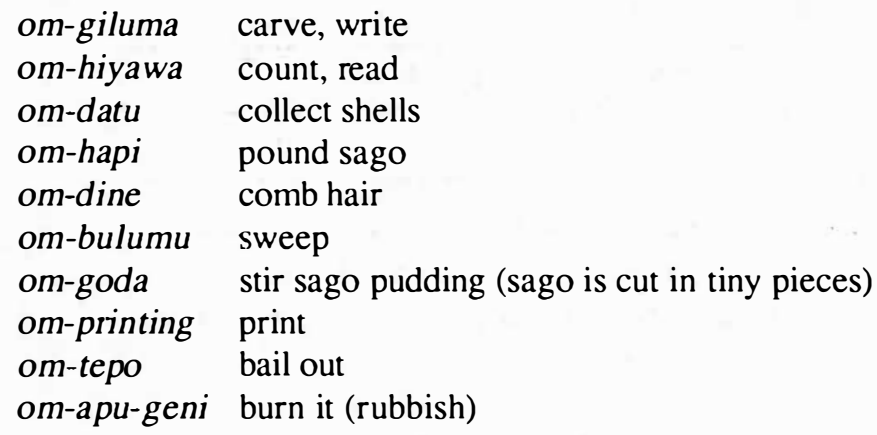

(b) Transitive verbs involving a radical transformation of the object ( $-i$ transitive form):

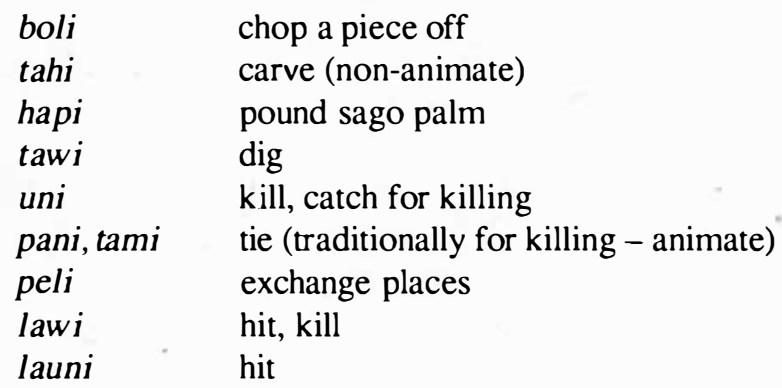

(c) Transitive verbs involving isolating part from whole; of ten take a non-animate object (two-syllable words with -ya transitive form):

$\begin{array}{ll}\text { toneya } & \text { spear } \\ \text { kahaya } & \text { separate } \\ \text { hepaya } & \text { lift up } \\ \text { pohaya } & \text { put in a basket } \\ \text { talaya } & \text { cut (lengthwise) } \\ \text { teleya } & \text { leave (food) for later } \\ \text { libeya } & \text { throw (rubbish) into the sea } \\ \text { guduya } & \text { shut, close } \\ \text { hoeya } & \text { open } \\ \text { dewaya } & \text { make, do } \\ \text { higuya } & \text { fill } \\ \text { humaya } & \text { wrap }\end{array}$




$\begin{array}{ll}\text { buyoya } & \text { squeeze out } \\ \text { buhuya } & \text { drill } \\ \text { gutaya } & \text { share } \\ \text { wogoya } & \text { hold } \\ \text { wilaya } & \text { mix }\end{array}$

(d) Repeated actions involving an instrument (another use of CVV pattern):

$\begin{array}{ll}\text { woe } & \text { paddle } \\ \text { wao } & \text { dig holes for planting }\end{array}$

(e) Verbs involving prolonged or continuous activity. The intransitive forms seem to be statives with the subject referring to the patient. The addition of the transitive suffix $-i$ also marks the fact that the patient is now the object (three-syllable words with $i$ transitive form):

$\begin{array}{ll}\text { ulona }-i & \text { cook } \\ \text { lelega }-i & \text { line up } \\ \text { toula }-i & \text { collect, load up } \\ \text { yaluma }-i & \text { mend fish net } \\ \text { upuma }-i & \text { pile up } \\ \text { hiyawa }-i & \text { count, read } \\ \text { hiwoga }-i & \text { pour out, unload } \\ \text { giluma }-i & \text { carve, write } \\ \text { didina }-i & \text { sew } \\ \text { guluwa }-i & \text { bury }\end{array}$

$\begin{array}{ll}\text { I-ulona. } & \text { A-ulon-i. } \\ \text { it-cook } & \text { I-cook-it } \\ \text { It is cooking. } & \text { I am cooking it. }\end{array}$

\section{CORPOREAL VERBS}

(a) Life-sustaining functions. There are to my knowledge only four VCV verbs, and three of these form the following set, a single semantic field of life-sustaining functions: ${ }^{10}$

$\begin{array}{ll}\text { eno } & \text { sleep } \\ \text { uma } & \text { drink } \\ \text { ani } & \text { eat (intransitive form am) }\end{array}$

(b) Verbs involved in taking something into the body (verbs involving a special use of the lu prefix):

$\begin{array}{llll}\text { lu-bogahu } & \text { smoke (tobacco) } & \text { (bogahu } & \text { smoke) } \\ \text { lu-haba } & \text { chew (betel nut) } & \text { (haba } & \text { red) } \\ \text { lu-yawahi } & \text { breathe, inhale } & \text { (yawata } & \text { breath) } \\ \text { lu-tanigana } & \text { listen, hear } & \text { (taniga- } & \text { ear) }\end{array}$

(c) Verbs involving a slowing down of bodily activity (the wi prefix in these examples is no longer productive as there is no meaning attached to the root apart from them):

${ }^{10}$ The remaining VCV verb is otu 'call'. 


$\begin{array}{ll}\text { wiyuwa } & \text { pain } \\ \text { wiyagohina } & \text { rest } \\ \text { wiyohi } & \text { fast } \\ \text { wikamna dewadewa } & \text { to get better) }\end{array}$

These data reveal that seemingly random features such as syllable patterns, word length and transitivising patterns are used with certain semantic fields, while other related semantic fields systematically use different patterns. Thus we see evidence for a correlation between form and meaning. To know the form of a word is to limit the semantic field to which it could belong. To know the semantic field of a word that is 'on the tip of the tongue' is to be able to predict its likely form - thus we see further evidence for the priority of semantics. The following sections dealing with the derivational prefixes make use of a number of the semantic fields illustrated in the above lists, demonstrating further the value of these semantic-syntactic correlations.

\subsubsection{MOTION VERBS}

Three classes of motion verbs are distinguished in Charts 9(a) and 9(b) on the basis of morphosyntactic distinctions. Two of these classes agree closely with the semantic fields set up above on a phonetic-syntactic-semantic basis. The remaining class involves an irregular lui 'enter' which did not occur in my original data, though luiya 'to put on clothing' was placed in a semantic field, but not with the motion verbs. The area of motion verbs is one of the most complex areas of Tawala verb morphology as the charts show.

In the first place there is a fully productive set of transitive and intransitive derived verbs with most of the prefixes. In the second place the transitive forms distinguish between transitive and dative forms. Finally, there are numerous classificatory prefixes associated with this group of words. Two of these prefixes have been included in the charts owing to their irregular nature and idiomatic usage with Class 2 and Class 3. The common meanings of these prefixes are:

hu to move deliberately, or with effort

tu to move a little or move something with the foot

It is possible that these prefixes are moving in the direction of becoming productive derivational prefixes, as they have more complex meanings than the usual classificatory prefixes and their single syllable form is more typical of derivational prefixes than the usual two syllable classificatory prefixes. In addition $h u$ has a parallel form to $l u$ for the progressive aspect (hau). However, these prefixes are not highly productive, occurring mainly with the motion verbs listed in this section.

Each of the three classes has a quite distinct use of the derivational prefixes. These prefixes with basic motion verbs (intransitive foms) are set out in Chart 9(a). The transitive forms are found in Chart 9(b).

(a) The prefix $w i$ is not highly productive and has a series of meanings:

$\begin{array}{llll}\text { wi-ne-nae } & \text { try to go } & \text { (nae } & \text { go) } \\ \text { wi-gae } & \text { to thatch (house) } & \text { (gae } & \text { ascend) } \\ \text { wi-ge-gae } & \text { argue } & \text { (gae } & \text { ascend) }\end{array}$

These are only connected to the common meaning 'to cause action' in a vague way. 
On the other hand $l u$ is a highly productive prefix, except with Class 3 motion verb. With Class 1 the derived verb has a meaning closely related to the common meaning 'action in direction of verb'.

$$
\text { lu-gae shoot high (gae ascend) }
$$

There are no examples of the use of the liprefix.

The woprefix is fully productive with all roots. With Class 1 roots this involves 'moving a little each day', which is in line with the common meaning for verb roots 'persist in action'.
wo-hopu
move down a little each day
(hopu
descend)

Class 2 roots have a variety of idiomatic meanings:

$\begin{array}{llll}\text { wo-geleta } & \text { reveal something } & \text { (geleta } & \text { arrive) } \\ \text { wo-damana } & \text { hand things over } & \text { (damana } & \text { cross bay) } \\ \text { wo-tagona } & \text { follow } & \text { (tagona } & \text { cross mountain) }\end{array}$

(b) The use of derivational prefixes with the same set of basic motion verb roots, but this time with object focus, transitive forms (cf. section 2.6) are set out in Chart 9(b).

The prefix wi is highly productive (in contrast to the action focus forms). With most roots these verbs involve carrying an item in the direction indicated by the verb (i.e. 'cause something to go') and are thus in line with the common meaning 'to cause verb':

$$
\text { wi-hopu-ni put something down (hopu descend) }
$$

With a few roots the meaning is somewhat idiomatic:

$\begin{array}{llll}\text { wi-gelete-ya } & \begin{array}{l}\text { sing an item } \\ \text { (cause something to appear) }\end{array} & \text { (geleta } & \text { arrive) } \\ \text { wi-tagon-i } & \begin{array}{l}\text { wind twine over something } \\ \text { (cause something to go over) }\end{array} & \text { (tagona } & \text { cross mountain) } \\ \text { wi-gei-ni } & \begin{array}{l}\text { put roof up } \\ \text { (cause something to go up) }\end{array} & \text { (gae } & \text { ascend) }\end{array}$

A distinction which is found a number of times in Chart 9(b) is between transitive (object focus) and dative forms; normally the dative involves an instrument or a less direct contact with the object (cf. section 2.7):

$\begin{array}{lll}\text { wi-daman- } i & \text { bridge a gap } & \text { (transitive) } \\ \text { wi-daman-e-ya } & \text { carry something across } & \text { (dative) }\end{array}$

The prefix lu involves an exerted or obvious action, which is an extension of the common meaning 'action in direction of the verb':
lu-hopu-ne-ya push something down
(hopu descend)

Only one of these verbs is idiomatic:

$$
\text { lu-gelet-e-ya be revealed/understood (geleta arrive) }
$$

As with the intransitive forms there are no transitive motion verbs with the prefix li. Transitive motion verbs which take the dative ending usually are able to replace this with an ablative form: 
$\begin{array}{lll}\text { lu-hopu-ne-ya } & \text { push something down } & \text { (dative) } \\ \text { lu-hopu-niyai } & \text { pull something down } & \text { (ablative) }\end{array}$

The prefix wo is used with the sense 'to move something by hand in the direction of the verb', which conforms to the common meaning of wo for transitive verbs 'cause by hand':

wo-hopu-ne-ya push something down (hopu descend)

Again a single idiom is found in this group:

wo-tagon- $i$ follow someone (tagona cross mountain)

Typical transitive and intransitive examples of the prefixes with the three classes of motion verbs are as follows:

Class 1:

Tau a-ne-nae numa a-wi-gae.

myself I-PROG-go house I-DP-ascend

I am going to (thatch) a house.

(In answer to question, 'What are you going to do?')

(88) Numa ta-wi-gei-ni!

house we.INC-DP-come up-it

Let's thatch the roof!

(89) U-na-tu-hopu!

you.SG-INT-DP-descend

Move down a bit!

(90) U-na-tu-hopu-ne-ya.

you.SG-INT-DP-descend-TC-it

Shove it down! (with your feet)

(91) A-lu-hopu duma po polo a-lupate-ya.

I-DP-descend really and pig I-miss-it

I shot too low and missed the pig.

(92) Nima-m u-na-lu-hopu-ne-ya!

hand-your.SG you.SG-INT-DP-descend-TC-it

Put your hand down a bit!

Class 2:

Hiyamoni tapu-na i-lu-gelet-e-ya.

grass different-its it-DP-arrive-DAT-RFX

A different type of grass appeared.

(94) Amaka ta-lu-gelet-e-ya.

already we.INC-DP-arrive-DAT-it

We already understood it.

(95) Lawa i-wo-gelet-e-na-me-ya.

person he-DP-arrive-DAT-TC-again-it

The man showed himself. 


\begin{tabular}{|c|c|c|c|c|c|c|c|}
\hline root & & $\begin{array}{l}\text { wi-(RED)-R } \\
\text { idiomatic }\end{array}$ & $\begin{array}{l}\text { Tu-R } \\
\mathrm{Cl} 1 \text { miss mark in } \\
\text { direction of } \mathrm{V} \\
\mathrm{Cl} 2 \text { idiomatic }\end{array}$ & Ii- & $\begin{array}{l}\text { WO-R } \\
\text { Cl } 1 \text { move a bil } \\
\text { each day } \\
\text { Cl } 2 \text { idiomatic }\end{array}$ & $\begin{array}{l}\text { lu-R } \\
\text { Cl } 1 \text { move a little } \\
\text { Cl } 2 \text { unknown } \\
\text { Cl } 3 \text { idiomatic }\end{array}$ & $\begin{array}{l}\text { hu-R } \\
\mathrm{Cl} 1 \text { move deliberately } \\
\mathrm{Cl} 2 \text { involves stepping }\end{array}$ \\
\hline \multicolumn{8}{|l|}{ Class 1} \\
\hline nac & go & $\begin{array}{l}\text { winenac } \\
\text { try to go }\end{array}$ & $\begin{array}{l}\text { lunae } \\
\text { shoot further }\end{array}$ & - & $\begin{array}{l}\text { wonac } \\
\text { move on }\end{array}$ & $\begin{array}{l}\text { tunac } \\
\text { move on }\end{array}$ & $\begin{array}{l}\text { hunac } \\
\text { move away }\end{array}$ \\
\hline nci & come & - & $\begin{array}{l}\text { lunc-i/hi } \\
\text { shoot towards }\end{array}$ & - & $\begin{array}{l}\text { wonc-i/hi } \\
\text { move towards }\end{array}$ & $\begin{array}{l}\text { lunc-ihi } \\
\text { move towards }\end{array}$ & $\begin{array}{l}\text { hunc-i/ii } \\
\text { move towards }\end{array}$ \\
\hline \multirow[t]{2}{*}{ gac } & ascend & $\begin{array}{l}\text { wigac } \\
\text { thatch }\end{array}$ & $\begin{array}{l}\text { lugac } \\
\text { shoot high }\end{array}$ & - & $\begin{array}{l}\text { wogac } \\
\text { move up }\end{array}$ & $\begin{array}{l}\text { lugac } \\
\text { move up }\end{array}$ & $\begin{array}{l}\text { hugac } \\
\text { move up }\end{array}$ \\
\hline & & $\begin{array}{l}\text { wigcgac } \\
\text { arguc }\end{array}$ & $\begin{array}{l}\text { lugegac } \\
\text { be bigheaded }\end{array}$ & & & & \\
\hline gci & comc up & - & $\begin{array}{l}\text { lugc-i/hi } \\
\text { shoot high, } \\
\text { shoot closer }\end{array}$ & - & $\begin{array}{l}\text { wogc-i/ho } \\
\text { move up towards }\end{array}$ & $\begin{array}{l}\text { lugc-i/hi } \\
\text { move up towards }\end{array}$ & $\begin{array}{l}\text { hugc-i/ii } \\
\text { move up towards }\end{array}$ \\
\hline hорu & descend & - & $\begin{array}{l}\text { luhopu } \\
\text { shoot down }\end{array}$ & - & $\begin{array}{l}\text { wohopu } \\
\text { move down }\end{array}$ & $\begin{array}{l}\text { tuhopu } \\
\text { move down }\end{array}$ & $\begin{array}{l}\text { huhopu } \\
\text { move down }\end{array}$ \\
\hline \multicolumn{8}{|l|}{ Class 2} \\
\hline gclcta & arrivc (up) & - & $\begin{array}{l}\text { lugclcta } \\
\text { arrive after long walk }\end{array}$ & - & $\begin{array}{l}\text { wogcleta } \\
\text { revcal s.th. }\end{array}$ & tugclcta ${ }^{2}$ & $\begin{array}{l}\text { hugclcta } \\
\text { walk homc }\end{array}$ \\
\hline damana & cross (bay) & - & $\begin{array}{l}\text { ludiumana } \\
\text { inherit, cross over }\end{array}$ & - & $\begin{array}{l}\text { wodiumiena } \\
\text { hand things over }\end{array}$ & ludamana & $\begin{array}{l}\text { hudamana } \\
\text { step across }\end{array}$ \\
\hline tagona & $\begin{array}{l}\text { cross } \\
\text { (mountain) }\end{array}$ & - & - & - & $\begin{array}{l}\text { wotagona } \\
\text { follow }\end{array}$ & tutagona & $\begin{array}{l}\text { hutagona } \\
\text { step over }\end{array}$ \\
\hline Class 3 & & & & & & & \\
\hline Iui & enter & - & - & - & wolui ${ }^{2}$ & $\begin{array}{l}\text { tului } \\
\text { move into bush }\end{array}$ & - \\
\hline
\end{tabular}

CHART9(a): INTRANSITIVE BASIC MOTION VERBS WITH DERIVATIONAL PREFIXES

'For -i/-hi distinction sec section 2.6(a).

${ }^{2}$ Meanings have been omitted with ccrtain verbs as I am not sure what the combination means. 


\begin{tabular}{|c|c|c|c|c|c|c|c|}
\hline root & & $\begin{array}{l}\text { wi-R-(DAT)-O } \\
\text { carry s.th. in } \\
\text { direction of } \mathrm{V} \\
\text { idiomatic }\end{array}$ & $\begin{array}{l}\text { lu-R-(DAT)-O } \\
\text { causc by excrtion } \\
\text { or obvious action }\end{array}$ & li- & $\begin{array}{l}\text { wo-R-O } \\
\text { move s.th. in } \\
\text { direction of } \mathrm{V} \\
\text { by hand }\end{array}$ & $\begin{array}{l}\text { lu-R-O } \\
\text { move s.th. by } \\
\text { foot }\end{array}$ & $\begin{array}{l}\text { hu-R-O } \\
\text { use effort to move s.th. }\end{array}$ \\
\hline \multicolumn{8}{|l|}{ Class I } \\
\hline nac & go & winecneni & $\begin{array}{l}\text { luniycni } \\
\text { push s.th. }\end{array}$ & - & $\begin{array}{l}\text { woniycni } \\
\text { push s.th. }\end{array}$ & $\begin{array}{l}\text { luniycni } \\
\text { push s.th. }\end{array}$ & $\begin{array}{l}\text { huniyeni } \\
\text { push s.th. }\end{array}$ \\
\hline nei & & takc/bring & $\begin{array}{l}\text { lunciyai } \\
\text { pull s.th. }\end{array}$ & - & $\begin{array}{l}\text { wonciyai } \\
\text { pull s.th. }\end{array}$ & $\begin{array}{l}\text { lunciyai } \\
\text { ptill s.th. }\end{array}$ & $\begin{array}{l}\text { huneiyai } \\
\text { pull s.th. }\end{array}$ \\
\hline gae & ascend & $\begin{array}{l}\text { wigcini } \\
\text { put root up } \\
\text { (cause s.th. }\end{array}$ & $\begin{array}{l}\text { lugiycni } \\
\text { push s.th. up }\end{array}$ & - & $\begin{array}{l}\text { wogiycni } \\
\text { push s.th. up }\end{array}$ & $\begin{array}{l}\text { lugiycni } \\
\text { push s.th. up }\end{array}$ & $\begin{array}{l}\text { hugiycni } \\
\text { push s.th. up }\end{array}$ \\
\hline gci & come up & to ascend) & $\begin{array}{l}\text { lugciyai } \\
\text { pull s.th. up }\end{array}$ & - & $\begin{array}{l}\text { wogciyai } \\
\text { pull s.th. up }\end{array}$ & $\begin{array}{l}\text { lugeiyai } \\
\text { pull s.th. up }\end{array}$ & $\begin{array}{l}\text { hugciyai } \\
\text { pull s.th. up }\end{array}$ \\
\hline hopu & descend & $\begin{array}{l}\text { wihopuni } \\
\text { put s.th. down }\end{array}$ & $\begin{array}{l}\text { luhopuneya } \\
\text { push s.th. down }\end{array}$ & - & $\begin{array}{l}\text { wohopuncya } \\
\text { push s.th. down }\end{array}$ & $\begin{array}{l}\text { luhopuneya } \\
\text { push s.th. down }\end{array}$ & $\begin{array}{l}\text { huhopuncya } \\
\text { push s.th. down }\end{array}$ \\
\hline & & & $\begin{array}{l}\text { luhopuniyai } \\
\text { pull s.th. down }\end{array}$ & & $\begin{array}{l}\text { wohopuniyai } \\
\text { pull s.th. down }\end{array}$ & $\begin{array}{l}\text { tuhopuniyai } \\
\text { pull s.th. down }\end{array}$ & $\begin{array}{l}\text { huhopuniyai } \\
\text { pull S.th. down }\end{array}$ \\
\hline \multicolumn{8}{|l|}{ Class 2} \\
\hline gcleta & arrive (up) & $\begin{array}{l}\text { wigclctcya } \\
\text { sing an item }\end{array}$ & $\begin{array}{l}\text { lugeletcya } \\
\text { be revealed, } \\
\text { understand s.th. }\end{array}$ & - & $\begin{array}{l}\text { wogelctcya } \\
\text { reveal s.th. in hands }\end{array}$ & lugclcteyal & $\begin{array}{l}\text { hugcletcya } \\
\text { sing a number of items }\end{array}$ \\
\hline damana & cross (bay) & $\begin{array}{l}\text { widamani } \\
\text { bridge a gap }\end{array}$ & $\begin{array}{l}\text { ludamani } \\
\text { cross on s.th. }\end{array}$ & - & $\begin{array}{l}\text { wodamani } \\
\text { carry across }\end{array}$ & $\begin{array}{l}\text { ludamani } \\
\text { step across }\end{array}$ & $\begin{array}{l}\text { hudamani } \\
\text { jump s.th., step across }\end{array}$ \\
\hline & & $\begin{array}{l}\text { widamaneya } \\
\text { carry s.th. across }\end{array}$ & $\begin{array}{l}\text { ludamaneya } \\
\text { pour from one to another }\end{array}$ & - & $\begin{array}{l}\text { wodamancya } \\
\text { pass s.th. across }\end{array}$ & $\begin{array}{l}\text { ludamaneya } \\
\text { push s.th. across }\end{array}$ & $\begin{array}{l}\text { hudamancya } \\
\text { lift s.th. across }\end{array}$ \\
\hline tagona & $\begin{array}{l}\text { cross } \\
\text { (mountain) }\end{array}$ & $\begin{array}{l}\text { witagoni } \\
\text { wind twine } \\
\text { over s.th. }\end{array}$ & - & - & $\begin{array}{l}\text { wolagoni } \\
\text { follow s.o. }\end{array}$ & $\begin{array}{l}\text { tutagoni } \\
\text { follow s.o. }\end{array}$ & $\begin{array}{l}\text { hutagoni } \\
\text { jump over s.th. }\end{array}$ \\
\hline & & & $\begin{array}{l}\text { lutagoneya } \\
\text { throw s.th. over }\end{array}$ & - & $\begin{array}{l}\text { wolagoncya } \\
\text { push hands over s.th. }\end{array}$ & $\begin{array}{l}\text { tutagoneya } \\
\text { push s.th. over }\end{array}$ & $\begin{array}{l}\text { hutagoncya } \\
\text { lift s.th. over }\end{array}$ \\
\hline Class 3 & & & & & & & \\
\hline lui & enter & $\begin{array}{l}\text { wiluiya } \\
\text { wear clothes }\end{array}$ & - & - & - & - & - \\
\hline
\end{tabular}

CHART 9(b): TRANSITIVE BASIC MOTION VERBS WITH DERIVATIONAL PREFIXES

${ }^{1}$ Meaning is omitted because I omitted to elicit it.

${ }^{2}$ The expected meaning 'to step over something' is carried by the verb tulagoni. 
(96)

A-hu-geleta $u \quad$ yu numa.

I-DP-arrive my at house

I am going home.

(97) Wam-gei (*tete-gei) e-lau-daman-i.

boat-by bridge-by he.PRES-DP.PROG-cross-it

$\mathrm{He}$ is crossing the bay by boat (*bridge).

Wam-gei (tete-gei) e-hau-daman-i.

boat-by bridge-by he.PRES-DP.PROG-cross-it

$\mathrm{He}$ is using the boat to get across. (He is using the bridge to go across.)

CLASS 3:

Polo i-tu-lui.

pig it-DP-enter

The pig went into the bush.

(100) Am pilipou u-na-lui-ya.

your.SG trousers you.SG-INT-enter-it

Put on your trousers!

\subsubsection{MANNER-OF-MOTION VERBS}

A small class of motion verbs, perhaps belonging to a manner-of-motion subclass of motion verbs, is presented in this section. A comparison of these data with the basic motion verbs reveals some similarities in that they also take the classificatory prefixes discussed in connection with basic motion verbs, and yet there are some basic differences. The most basic one is the lack of a productive transitive-intransitive relationship. In addition these manner-of-motion verbs are highly productive with the $l i$ prefix, whereas none of the basic motion verbs are at all productive with $l i$. The four verbs seem to belong to three or even four separate semantic fields on the basis of the distinctive use they make of the derivational prefixes. These data are set out in Chart 10.

The wi prefix occurs with two of the manner-of-motion verbs with the meaning 'to cause something to act', which conforms with the common meaning 'to cause action':

$$
\begin{array}{llll}
\text { wi-lupa-ya } & \text { let something go } & \text { (lupa } & \text { jump) } \\
\text { (cause it to jump) } & &
\end{array}
$$

The lu prefix is used intransitively with only a single root:

$$
\text { lu-dala creep forward (dala crawl) }
$$

This meaning conforms to the common meaning 'action in position of verb'.

The transitive use of $l u$ occurs with two of the four roots under examination, both of which appear to be idiomatic, having little to do with the common meaning quoted in the previous sentence.

lu-dala-ge-ya drop one's hand lu-bulili-ye-ya hit faster

(dala crawl)

(bulili run, hasten) 


\begin{tabular}{|c|c|c|c|c|c|c|}
\hline root & & $\begin{array}{l}\text { wi-R-O } \\
\text { cause s.th. to act }\end{array}$ & $\begin{array}{l}\text { lu-R } \\
\text { action in } \\
\text { position of } \mathrm{V}\end{array}$ & $\begin{array}{l}\text { lu-(RED)-R-DAT-O } \\
\text { action in position of } \mathrm{V}\end{array}$ & $\begin{array}{l}\text { li-R-RF } \\
\text { cause violent } \\
\text { action }\end{array}$ & $\begin{array}{l}\text { wo-R-(DAT-O) } \\
\text { persistent action } \\
\text { (intransitive) } \\
\text { hands involved } \\
\text { (transitive) }\end{array}$ \\
\hline lupa & fly, jump & $\begin{array}{l}\text { wilupaya } \\
\text { let s.th. go }\end{array}$ & - & $\begin{array}{c}- \\
\text { spring s.th. }\end{array}$ & $\begin{array}{l}\text { lilupaya } \\
\text { keep going up }\end{array}$ & wolupa \\
\hline dala & crawl, lean & $\begin{array}{l}\text { widalaya } \\
\text { cause s.th. to } \\
\text { take crawling } \\
\text { position }\end{array}$ & $\begin{array}{l}\text { ludala } \\
\text { creep forward }\end{array}$ & $\begin{array}{l}\text { ludalageya } \\
\text { drop one's hands }\end{array}$ & $\begin{array}{l}\text { lidalaya } \\
\text { knock to crawling } \\
\text { position }\end{array}$ & $\begin{array}{l}\text { wodala(nae) } \\
\text { grope (forward) } \\
\text { in the dark }\end{array}$ \\
\hline peu & fall & $\begin{array}{l}\text { wipeuni } 1 \\
\text { drop }\end{array}$ & - & - & $\begin{array}{l}\text { lipeuya } \\
\text { topple s.th. or s.o. }\end{array}$ & $\begin{array}{l}\text { wopeu } \\
\text { drop s.th. }\end{array}$ \\
\hline bulili & run, hasten & - & - & $\begin{array}{l}\text { lubulibuliyeya } \\
\text { hit faster }\end{array}$ & - & $\begin{array}{l}\text { wobulibuliyeya } \\
\text { grab s.th. } \\
\text { quickly }\end{array}$ \\
\hline
\end{tabular}

CHART 10: DERIVATIONAL PREFIXES WITH MANNER-OF-MOTION VERBS

${ }^{1}$ Data from Ross 1983:38. 
The li prefix involves causing an action violently, which conforms to the common meaning 'force something into position':

$$
\text { li-dala-ya knock to crawling position (dala crawl) }
$$

However, in one case it is the resulting action which is violent:

$$
\begin{array}{llll}
\text { li-lupa-ya } & \begin{array}{l}
\text { spring something } \\
\text { (cause something to jump) }
\end{array} & \text { (lupa jump) }
\end{array}
$$

The wo prefix conforms to the common meaning for intransitive forms 'persistent action':

$$
\text { wo-lupa keep going up (lupa jump) }
$$

and for transitive forms 'cause by hand':

$\begin{array}{lll}\text { wo-peu (peu fall) } & \\ \text { (cause something to fall) } & & \end{array}$

This last example is an action focus form of the transitive verb and hence has no definite suffix (cf. section 2.6).

Typical examples:

(101) Kiu nima-u-gei a-wi-lupa-ya.

bird hand-my-from I-DP-jump-it

I let the bird go.

(102) U-na-lu-dala!

you.SG-INT-DP-crawl

Crawl forward!

(103) Ega u-na-wo-buli-bulili apo nima-m i-na-ala-hi!

NEG you.SG-INT-DP-PROG-run FUT hand-your.SG it-INT-bum-it

Don't grab it too quickly, it will bum your hand!

(104) Premier hi-li-peu-ya.

premier they-DP-fall-it

They have toppled the Premier (from office).

\subsubsection{VERBS OF REST}

Our data contain five 'verbs of rest' which function as a fairly homogenous group. A comparison with motion verbs reveals that these two semantic fields overlap. Though I have no data for how this class functions with classificatory prefixes, my feeling is that a Tawala analyst may well assign these verbs to a subclass of motion verbs because the concept of motion is strong especially when used with derivational prefixes. However, the meanings associated with these prefixes have their own quite distinctive uses.

Eno with the meaning 'to lie down' clearly functions with this group; it is also found with a different set of meanings with the corporeal function verbs (4.3.5).

The use of the derivational prefixes with the verbs of rest are set out in Chart 11.

The wi prefix is used with the sense 'to cause something to take a position'. The common meaning 'cause action' seems appropriate enough in view of the fact that these are 'verbs of rest':

$$
\text { wi-towol-i stand something (towolo be standing) }
$$




\begin{tabular}{|c|c|c|c|c|c|c|c|}
\hline root & & $\begin{array}{l}\text { wi-R-O } \\
\text { cause s.th. } \\
\text { to take } \\
\text { position }\end{array}$ & $\begin{array}{l}\text { lu-R } \\
\text { wait in a } \\
\text { position }\end{array}$ & $\begin{array}{l}\text { lu-R-(DAT)-RFX } \\
\text { move quickly } \\
\text { to position }\end{array}$ & $\begin{array}{l}\text { li-R-O } \\
\text { force s.th. into } \\
\text { position } \\
\text { - instrument } \\
\text { involved }\end{array}$ & $\begin{array}{l}\text { wo- } \mathrm{R} \\
\text { move into } \\
\text { new position }\end{array}$ & $\begin{array}{l}\text { woi-R-O } \\
\text { move s.th. by } \\
\text { hand }\end{array}$ \\
\hline towolo & be standing & $\begin{array}{l}\text { witowoli } \\
\text { stand s.th. }\end{array}$ & $\begin{array}{l}\text { lutowolo } \\
\text { stand poised } \\
\text { with spear etc. }\end{array}$ & $\begin{array}{l}\text { lutowologeni } \\
\text { stand quickly }\end{array}$ & $\begin{array}{l}\text { litowoli } \\
\text { lever up s.th. }\end{array}$ & $\begin{array}{l}\text { wotowolo } \\
\text { assume standing } \\
\text { position }\end{array}$ & $\begin{array}{l}\text { woitowoli } \\
\text { stand s.th. }\end{array}$ \\
\hline tugula & be sitting & $\begin{array}{l}\text { wituguli } \\
\text { sit s.th. }\end{array}$ & $\begin{array}{l}\text { lutugula } \\
\text { sit fishing }\end{array}$ & $\begin{array}{l}\text { lutuguli } \\
\text { sit quickly }\end{array}$ & $\begin{array}{l}\text { lituguli } \\
\text { force down }\end{array}$ & $\begin{array}{l}\text { wotugula } \\
\text { assume sitting } \\
\text { position }\end{array}$ & $\begin{array}{l}\text { woituguli } \\
\text { sit s.th. }\end{array}$ \\
\hline tagela & $\begin{array}{l}\text { swivel on } \\
\text { fixed point }\end{array}$ & $\begin{array}{l}\text { witageli } \\
\text { swivel s.th. }\end{array}$ & $\begin{array}{l}\text { lutagela } \\
\text { lean to one side }\end{array}$ & $\begin{array}{l}\text { lutageli } \\
\text { move quickly to } \\
\text { one side }\end{array}$ & $\begin{array}{l}\text { litageli } \\
\text { knock over }\end{array}$ & $\begin{array}{l}\text { wotagela(nae) } \\
\text { stagger (along) }\end{array}$ & $\begin{array}{l}\text { woitageli } \\
\text { push to one } \\
\text { side }\end{array}$ \\
\hline wahala & be leaning & $\begin{array}{l}\text { wiwahali } \\
\text { lean s.th. }\end{array}$ & $\begin{array}{l}\text { luwahala } \\
\text { lean on s.th. }\end{array}$ & - & $\begin{array}{l}\text { liluwahali } \\
\text { knock down } \\
\text { to leaning } \\
\text { position }\end{array}$ & - & $\begin{array}{l}\text { woiluwahali } \\
\text { lean s.th. }\end{array}$ \\
\hline eno & $\begin{array}{l}\text { be lying } \\
\text { down }\end{array}$ & $\begin{array}{l}\text { wienoya } \\
\text { lie s.th. } \\
\text { down }\end{array}$ & $\begin{array}{l}\text { lueno } \\
\text { rest head on } \\
\text { hand }\end{array}$ & $\begin{array}{l}\text { luenogeya } \\
\text { be woken when } \\
\text { almost asleep }\end{array}$ & $\begin{array}{l}\text { lienoya } \\
\text { knock s.th. } \\
\text { down }\end{array}$ & $\begin{array}{l}\text { woeno } \\
\text { begin to sleep }\end{array}$ & $\begin{array}{l}\text { woienoya } \\
\text { lie s.th. down }\end{array}$ \\
\hline
\end{tabular}


The lu prefix with verbs of rest has two almost contradictory meanings. When the verb is intransitive it has the meaning 'to wait in a position':

$$
\text { lu-tugula sit (fishing) (tugula be sitting) }
$$

With a transitive form (reflexive) the meaning is 'to move quickly to a position':

$$
\text { lu-tugul-i sit quickly (tugula be sitting) }
$$

This distinction seems to capture both aspects of the common meaning 'action in position and direction of verb'.

The $l i$ prefix with verbs of rest incorporates not only the common meaning 'force something into position' but the added dimension of implying the use of an instrument:

$$
\text { li-towol-i lever up something (towolo be standing) }
$$

The wo prefix involves a unique meaning, 'to move into a new position'. Here the 'persistence' involves the ongoing result of the action, rather than the repetition of an action usually involved in the wo prefix. A set of transitive forms associated with the verbs of rest take the stronger woi prefix, normally associated with adjectival roots (see sections 4.2.1 4.2.3). This is presumably because these verbs have a stative component found also with the adjective class. This is a good example of a shared semantic component (even across word classes) resulting in shared syntactic components. These forms have the meaning 'to move something by hand', in line with the normal common meaning associated with transitive verbs, 'to cause by hand':

wo-eno-ya lie something down (eno be lying down)

Typical examples:

(105) Kiwou-gei a-li-towol-i.

stick-with I-DP-stand-it

I stood it up with my stick.

(106) Gaima a-lu-tugul-e-u.

stone I-DP-sit-DAT-RFX

I dodged the stone.

(107) Motaka a wili i-wi-tage-tagel-i.

car its wheel it-DP-PROG-swivel-it

He was turning the driving wheel.

(108) Kedewa a-lau-laun-i po a-li-eno-ya.

dog I-PROG-hit-RF and I-DP-lie.down-it

I kept hitting the dog and eventually I knocked it down.

\subsubsection{VERBS OF EFFECT}

All the verbs of effect have been placed in a single chart (12) for convenience of comparison. There are three distinct semantic fields involved - verbs of carrying, cutting and fighting - and even these divisions seem to be too broad to account for the distinctive use of prefixes. Derivational prefixes are not over-productive with verbs of carrying and cutting, hence the numerous blanks in these sections of the chart. The fighting verbs appear 
to be more of a cohesive group with all forms being fully productive, except with $l i$ which is never used with verbs of effect.

Chart 12 lists data from all three semantic domains.

The wi prefix has separate meanings with each class of effect verbs. With the carrying verbs it occurs only with those verbs which list specific ways of carrying. With these verbs it means 'to load someone up'. This usage is in line with the common meaning 'to cause action':

$$
\begin{array}{lll}
\text { wi-awal-i } & \begin{array}{l}
\text { load on shoulder } \\
\text { (cause someone to carry) }
\end{array}
\end{array}
$$

There is only a single idiomatic use of wi with verbs of cutting:

$$
\text { wi-talatala cut area of grass (tala cut) }
$$

The fighting verbs have a stative meaning with the wi prefix. While this is not the most common meaning, it is not the first time we have met this meaning with verb roots:

$$
\text { wi-tona to be fighting (tona pierce) }
$$

The lu prefix has a single idiomatic use with verbs of carrying:

$$
\text { lu-awal-i carry on shoulder (awala- shoulder) }
$$

This verb is derived from the body part awalana 'his shoulder', and the $l u$ is required because awali is often used in a generic sense 'to carry' and thus lu-awali is used in line with the common meaning of $l u$ 'action in position of verb' to stress the use of the shoulder. With verbs of cutting and fighting $l u$ is productive and its meaning involves the use of an instrument or-an open obvious action. This is a distinctive use of $l u$ and is limited to verbs of effect:

lu-gomu-ya break something with a stick (gomu snap)

lu-kaha-ya separate something into piles (kaha separate, divide)

As stated above $l i$ is never used with verbs of effect.

The woprefix is used with all verbs of effect to indicate that an action is repeated over and over. This meaning is of course in line with the common meaning 'persist in an action':

wo-boli keep cutting pieces off (boli cut off)

Typical examples:

(109) Kopala u-na-wi-awali-u. copra you.SG-INT-DP-shoulder-me Put this bag of copra on my shoulder!

(110) Wam-gei apo a-wo-toul-i. boat-with FUT I-DP-collect-it I will collect the load with my boat.

(111) Yailo nugonugo-u i-wo-waya. Yailo mind-my he-DP-take Yailo persuaded me. 


\begin{tabular}{|c|c|c|c|c|c|}
\hline \multicolumn{2}{|l|}{ root } & $\begin{array}{l}\text { (1) wi-R } \\
\text { (2),(3) wi-(RED)-R } \\
\text { (1) load s.o. up } \\
\text { (2) idiomatic } \\
\text { (3) 'statc' of s.th. }\end{array}$ & $\begin{array}{l}\text { IU-R-O } \\
\text { (1) idiomatic } \\
\text { (2),(3) involves } \\
\text { instrument or obvious } \\
\text { action }\end{array}$ & - & $\begin{array}{l}\text { wo-R-O } \\
\text { repcat action over period } \\
\text { of time }\end{array}$ \\
\hline \multicolumn{6}{|c|}{$\begin{array}{l}\text { (1) Carrying } \\
\text { (a) specific }\end{array}$} \\
\hline awali & $\begin{array}{l}\text { carry on } \\
\text { shoulder }\end{array}$ & $\begin{array}{l}\text { wiawali } \\
\text { load on shoulder }\end{array}$ & $\begin{array}{l}\text { luawali } \\
\text { carry on shoulder }\end{array}$ & - & $\begin{array}{l}\text { woawali } \\
\text { carry a number of things }\end{array}$ \\
\hline naba & carry on head & $\begin{array}{l}\text { winaba } \\
\text { loan on hcad }\end{array}$ & - & - & $\begin{array}{l}\text { wonabaya } \\
\text { carry a number of things }\end{array}$ \\
\hline gedu & carry on back & $\begin{array}{l}\text { wigedu } \\
\text { load on back }\end{array}$ & - & - & $\begin{array}{l}\text { wogedu } \\
\text { carry a number of things }\end{array}$ \\
\hline \multicolumn{6}{|c|}{ (b) on vehicle } \\
\hline touli & collect & - & - & - & $\begin{array}{l}\text { wotouli } \\
\text { kecp collecting things }\end{array}$ \\
\hline \multicolumn{6}{|c|}{ (c) generic } \\
\hline waya & takc & - & - & - & $\begin{array}{l}\text { wowaya } \\
\text { takc }\end{array}$ \\
\hline houni & put & - & - & - & $\begin{array}{l}\text { wohouni } \\
\text { put }\end{array}$ \\
\hline \multicolumn{6}{|c|}{$\begin{array}{l}\text { (2) Cutting } \\
\text { (a) specilic }\end{array}$} \\
\hline hapi & chop & - & $\begin{array}{l}\text { luhapi } \\
\text { (i) cut onesclf } \\
\text { (ii) beckon s.o.' }\end{array}$ & - & $\begin{array}{l}\text { wohapi } \\
\text { (kecp) chopping sago }\end{array}$ \\
\hline & cut off & - & - & - & $\begin{array}{l}\text { woboli } \\
\text { kecp cutting things off }\end{array}$ \\
\hline lala & cut & $\begin{array}{l}\text { witalatala } \\
\text { cut arca of grass }\end{array}$ & $\begin{array}{l}\text { Iutalaya } \\
\text { cut s.th. }\end{array}$ & - & $\begin{array}{l}\text { wotalaya } \\
\text { kecp cutting things }\end{array}$ \\
\hline \multicolumn{6}{|c|}{ (b) snapping } \\
\hline gomu & snap & - & $\begin{array}{l}\text { lugomuya } \\
\text { brcak s.th. with stick }\end{array}$ & - & $\begin{array}{l}\text { wogomuya } \\
\text { kecp breaking things }\end{array}$ \\
\hline \multicolumn{6}{|c|}{ (3) Fighting } \\
\hline tona & picrec & $\begin{array}{l}\text { witona } \\
\text { be fighting }\end{array}$ & $\begin{array}{l}\text { lutonaya } \\
\text { poke with stick }\end{array}$ & - & $\begin{array}{l}\text { wotonaya } \\
\text { kecp poking things }\end{array}$ \\
\hline kaha & $\begin{array}{l}\text { scparatc, } \\
\text { divide }\end{array}$ & $\begin{array}{l}\text { wikahakilla } \\
\text { be separated (fight) }\end{array}$ & $\begin{array}{l}\text { lukahaya } \\
\text { separate into piles }\end{array}$ & - & $\begin{array}{l}\text { wokahaya } \\
\text { kecp scparating things }\end{array}$ \\
\hline gawiya & fight & $\begin{array}{l}\text { wigawiya } \\
\text { be warring/at war }\end{array}$ & $\begin{array}{l}\text { lugawiycya } \\
\text { fight in a pack }\end{array}$ & - & $\begin{array}{l}\text { wogawiya } \\
\text { kecp lighting }\end{array}$ \\
\hline
\end{tabular}

\section{CHART 12: DERIVATIONAL PREFIXES WITH VERBS OF EFFECT}

'The hand is dropped from above the head to onc's side. 
(112)

Kasi u-na-wele-u po a-wi-tala-tala.

knife you.SG-INT-give-me and I-DP-PROG-cut

Give me a grass knife and I will cut (the grass).

Ginahi a-wo-hapi ma o-na-nae po o-na-lu-neula.

sago I-DP-chop and you.PL-INT-go and you.PL-INT-DP-coconut

I'll chop the sago so you go and collect coconuts.

(114) Baubau hi-wo-boli.

bamboo they-DP-cut

They cut the bamboo (over several days).

(115) Lawa-na ago-na mite-hi

person-that spouse-his together-them

hi-woo-gawi-ye-na-me-hi.

they-DP.PROG-fight-DAT-TC-again-RFX

The man and his wife are always fighting.

\subsubsection{CORPOREAL FUNCTION VERBS}

The three verbs of corporeal function show a reasonable degree of homogeneity, though a degree of divergence is to be expected from the diverse semantics incorporated in the three verbs.

Chart 13 sets out the uses of derivational prefixes with the members of this semantic field.

The wi prefix always involves causing someone to act, which is in line with the common meaning 'to cause action':

$$
\text { wi-eno-ya put someone to sleep (eno sleep) }
$$

The lu prefix is used in only a single idiomatic sense with this group:

$$
\text { lu-eno-eno lazy person (eno sleep) }
$$

The uses of the li prefix are also idiomatic:

$$
\begin{array}{llll}
\text { li-eno-ya } & \text { lay out a dead body } & \text { (eno } & \text { sleep) } \\
\text { li-uma-ya } & \text { cause someone to choke by hitting them } & \text { (uma } & \text { drink) }
\end{array}
$$

The wo prefix is fully productive, 'to do something little by little', which is in line with the common meaning 'to persist in action':

wo-ani eat something in stages (ani eat something)

Typical examples:

(116) Logaloga iyana a-wi-ani-hi.

children fish I-DP-eat-them

I fed the children fish.

(117) Hi-nae hi-li-eno-ya. they-go they-DP-lie-it

They sent to lay out the dead body. 


\begin{tabular}{|c|c|c|c|c|c|}
\hline root & & $\begin{array}{l}\text { wi-R-(O) } \\
\text { cause s.o. to act }\end{array}$ & $\begin{array}{l}\text { lu-RED-R } \\
\text { idiomatic }\end{array}$ & $\begin{array}{l}\text { li-R-O } \\
\text { idiomatic }\end{array}$ & $\begin{array}{l}\text { wo-R } \\
\text { do s.th. little by little }\end{array}$ \\
\hline$a n i^{1}$ & $\begin{array}{l}\text { bite, } \\
\text { eat s.th. }\end{array}$ & $\begin{array}{l}\text { wiani } \\
\text { feed s.th. to s.o. }\end{array}$ & - & - & $\begin{array}{l}\text { woani } \\
\text { eat s.th. in stages }\end{array}$ \\
\hline$a m^{1}$ & eat, dine & wiam & - & - & $\begin{array}{l}\text { woam } \\
\text { eat in stages (i.e. feast) }\end{array}$ \\
\hline eno & $\begin{array}{l}\text { sleep, } \\
\text { lie down }\end{array}$ & $\begin{array}{l}\text { wienoya } \\
\text { put to sleep }\end{array}$ & $\begin{array}{l}\text { luenoeno } \\
\text { lazy }\end{array}$ & $\begin{array}{l}\text { lienoya } \\
\text { lay out dead body }\end{array}$ & $\begin{array}{l}\text { woeno } \\
\text { sleep in stages }\end{array}$ \\
\hline uma & drink & $\begin{array}{l}\text { wiumaya } \\
\text { give s.o. drink }\end{array}$ & - & $\begin{array}{l}\text { liumaya } \\
\text { cause s.o. to choke } \\
\text { on liquid by hitting } \\
\text { them }\end{array}$ & $\begin{array}{l}\text { wouma } \\
\text { drink in stages } \\
\text { (i.e. get drunk) }\end{array}$ \\
\hline
\end{tabular}

\section{CHART 13: DERIVATIONAL PREFIXES WITH VERBS OF CORPOREAL FUNCIION}

'Ani is the object focus form. Am is the action focus form. This is the only case in Tawala where this distinction is lexicalised. 

(118)
$\begin{array}{llll}\text { Hanali } & \text { uyahina } & \text { yaniyani o-n(a)-upum-i ma } \\ \text { food.house at } & \text { food } & \text { you.PL-INT-heap-it then }\end{array}$
o-na-wo-am.
you.PL-INT-DP-eat
Pile the food in your storehouse to eat over the following months.
(119) Hi-wo-uma po hi-buuwa.
they-DP-drink and they-mad
They kept drinking and got drunk.

\subsection{HUMAN PROPENSITY CLASS}

With human propensity words we begin looking at closed word classes - classes which are no longer open to the productive introduction of new items, unlike nouns, adjectives and verbs (cf. example (3) above). The human propensity class is treated by R.M.W. Dixon (1977) as one of his seven universal classes of adjectives. The remaining six adjective classes all appear as adjectives in Tawala (see section 4.2).

Human propensity is expressed in Tawala by a unique class of idiomatic words. Each lexical item is composed of a compound stem in which the first element is a body part and the second a descriptive root. There are over 70 lexical items connected with nugo 'heart', for example:

$\begin{array}{lll}\begin{array}{l}\text { nugo-gului } \\ \text { nugo-dubu }\end{array} & \text { forget } & \text { (heart-bury) } \\ \text { nugo-dumoli } & \text { be sad } & \text { (heart-dust) } \\ \text { nugo-hegohegoya } & \text { be unruffled by others } & \text { (heart-calm) } \\ \text { nugo-apapoe } & \text { be angry } & \text { (heart-smooth) } \\ \text { nugo-kadidili } & \text { have strong convictions } & \text { (heart-bad) } \\ \text { (heart-hard) }\end{array}$

Caution is needed in the translation of such idioms. It would be all too easy to think of nugo-kadidili (heart-hard) as '*lacking in pity' and thus being an undesirable quality (as early missionaries did), whereas it really means just the opposite - 'to have a stable character'. Once, at a funeral, I heard a man from a neighbouring language saying over and over again that he was nugo-apapoe (heart-bad) 'angry' when he meant nugo-dubu (heart-dust) 'sad'. I later discovered that the equivalent idiom (heart-bad) in his Bunama language did in fact mean 'sad'.

There are about ten words connected with hini 'skin', for example:

$\begin{array}{lll}\text { hini-dagihana } & \text { have sexual desire } & \text { (skin-tasty) } \\ \text { hini-doodola } & \text { be promiscuous } & \text { (skin-touchy?) } \\ \text { hini-maya } & \text { be ashamed } & \text { (skin-feel?) }\end{array}$

There are even fewer words connected with mata 'eye':

$\begin{array}{lll}\text { mata-kaya } & \text { be fighting sleep } & \text { (eye-red) } \\ \text { mata-maga } & \text { be promiscuous } & \text { (eye-many) } \\ \text { mata-pota } & \text { be sleep } & \text { (eye-shut) }\end{array}$

This category should probably be considered a formal part of speech in its own right, as these words are unique in semantics, form and morphosyntactic structure. 
A weakness of Dixon's (1977) paper arises from the shortage of languages with an open class of adjectives as his sample. In his data only Dyirbal and English had open classes. There appears to be no a priori reason why all languages with open adjectival classes should follow English and Dyirbal in assigning all seven semantic types to the adjective semantic class. Yet for a strongly adjective-dominated language, Dixon (p.62) believes "the seven types are exclusively associated with a single part of speech, the adjective class".

However, Tawala and other languages of Milne Bay assign human propensity to a special class which probably should be regarded as a separate part of speech in its own right. A study of the properties of the human propensity class in English (for summary see Dixon 1977:32, Table 1) reveals that this class differs from the other classes in a number of important ways:

(a) Unlike all other adjective semantic classes, human propensity does not typically form antonym pairs or complement sets.

(b) Derivation with un- is highly productive only with the human propensity class (e.g. 'unkind', 'unhappy' etc.)

(c) The use of the -ish suffix is rare with the human propensity class, but productive elsewhere.

There are other distinct differences presented in Dixon's paper, but sufficient has been said to show that we are dealing with a distinct subclass of adjectives in English.

In footnote 51 Dixon (p.78) makes reference to Yidiny, a northem neighbour of Dyirbal:

This language has an open class of adjectives, covering almost exactly the same semantic ground as the Dyirbal class. But Yidiny has some HUMAN PROPENSITY nouns - e.g. birmbir 'jealousy' - from which adjectival forms can be derived by the comitative suffix - $d y_{i}$ 'with'.

Again we find a language giving special treatment to the human propensity class.

The Tawala data may thus point us in the right direction to correctly interpret the English, Dyirbal and Yidiny. It is possible that human propensity may occur as a subclass of verbs or nouns, even in an adjective-dominated language; or the properties of the class may be such that it requires being assigned to a part of speech of its own, which is how I have placed human propensity in Tawala. This also helps solve the problem of classifying this class as verbs, when a number of the stems are in fact nouns and can only function as verbs by the addition of derivational prefixes.

The psychological words in Chart 14 have been chosen to illustrate the human propensity class. They fall into two classes:

Class 1 are stative verbs, and all undergo a transformation similar to the following example:

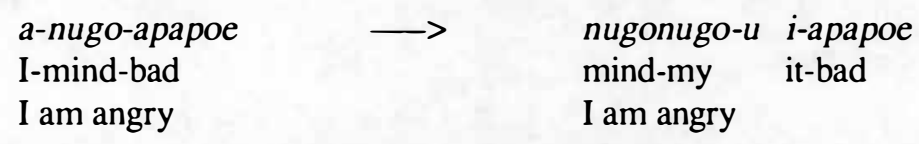

In the second form the 'agent' takes less responsibility; it literally means 'my mind is angry'. Class 2 are nouns and can only function as verbs by the addition of a derivational prefix, for example: 


$\begin{array}{lll}\begin{array}{l}\text { nugoneina } \\ \text { ignorance }\end{array} & \longrightarrow \text { i-wi-nugoneina } \\ \text { ignorance } & \text { he-DP-ignorance } \\ \text { he was ignorant }\end{array}$

These two classes are useful in distinguishing various uses of derivational prefixes as seen in Chart 14.

The wi prefix with Class 1 seems to mean 'to demonstrate a state by words'. This is an extension of the common meaning 'to be in a state':

$$
\text { wi-nugodewadewa-hi show them peace (nugodewadewa show peace) }
$$

With Class 2 words the wi prefix is used with the common meaning 'to be in a state':

$$
\text { wi-nugoneina be ignorant (nugoneina ignorance) }
$$

The lu prefix means 'to cause a state - by actions' which is the common meaning as it applies to all human propensity words which take the prefix:

$$
\text { lu-nugoapapoe-ge-hi make them angry (nugoapapoe anger) }
$$

The li prefix is used with Class 1 stems with the meaning 'to cause a state - by empathy' which is also the common meaning for this prefix. 'Empathy' involves the inspiration and encouragement of seeing an example, and hence the encouragement of others to follow that example:

$$
\text { li-nugohegoya-hi cause contentment (nugohegoya contentment) }
$$

With Class 2 stems $l i$ is not productive and the meanings are idiomatic:

$\begin{array}{llll}l i-n u g o n e i n a-h i & \text { be ignorant about things } & \begin{array}{l}\text { (nugoneina } \\ \text { (nugoemota }\end{array} & \begin{array}{l}\text { ignorance) } \\ \text { unity of mind) }\end{array}\end{array}$

With the wo prefix both Class 1 and Class 2 stems have the common meaning 'to persistently domonstrate a state':

$\begin{array}{llll}\text { wo-nugodubu } & \text { keep mouming } & \begin{array}{l}\text { (nugodubu } \\ \text { (nugoneina }\end{array} & \begin{array}{l}\text { sadness) } \\ \text { ignorance) } \\ \text { (persist in ignorance) }\end{array}\end{array}$

Typical examples:

(120) Ma lawa ugoli-hi tauna i-wi-nugodubu po ugoli-n-ei also people to-them himself he-DP-sadness and to-it-from

lawa hi-nugodubu.

people they-sadness

He was so sad that he made the people sad.

(121) Tu wi-nugototogo o-na-lu-nugotootogo. person DP-poor you.PL-INT-DP-mercy To the poor, show mercy.

(122) Tauna tu nugodewa yaka i-wi-nugodewadewa-hi. himself person peace consequently he-DP-peace-them $\mathrm{He}$ is a peaceful person and so showed them how to be peaceful. 


\begin{tabular}{|c|c|c|c|c|c|}
\hline stem & & $\begin{array}{l}\text { wi-S- }\left(\mathrm{O}^{1}\right) \\
\text { Cl } 1 \text { demonstrate a } \\
\text { state by words }{ }^{2} \\
\text { Cl } 2 \text { stative verb }\end{array}$ & $\begin{array}{l}\text { lu-S-(DAT)-O } \\
\text { causc statc - by actions }\end{array}$ & $\begin{array}{l}\text { li-S-O } \\
\text { Cl I cause a state } \\
\text { - by empathy } \\
\mathrm{Cl} 2 \text { idiomatic }\end{array}$ & 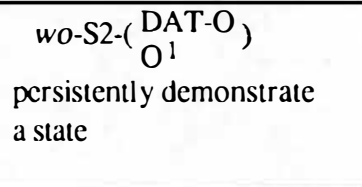 \\
\hline $\begin{array}{l}\text { Class 1 } \\
\text { nugodewa }\end{array}$ & peace & $\begin{array}{l}\text { winugodewadcwa(hi) } \\
\text { show peace }\end{array}$ & $\begin{array}{l}\text { lunugodewadcwahi } \\
\text { make them peaceful }\end{array}$ & $\begin{array}{l}\text { linugodewadewahi } \\
\text { cause peace }\end{array}$ & $\begin{array}{l}\text { wonugodcwa(ya) } \\
\text { kcep showing pcacc }\end{array}$ \\
\hline nugoapapoc & anger & $\begin{array}{l}\text { winugoapapoc(nihi) } \\
\text { show anger }\end{array}$ & $\begin{array}{l}\text { lunugoapapocgchi } \\
\text { make them angry }\end{array}$ & $\begin{array}{l}\text { linugoapapochi } \\
\text { cause anger }\end{array}$ & $\begin{array}{l}\text { wonugoapapoc(gcya) } \\
\text { kcep showing anger }\end{array}$ \\
\hline nugohcgoya & contentment & $\begin{array}{l}\text { winugohcgoya(hi) } \\
\text { show contentment }\end{array}$ & $\begin{array}{l}\text { lunugohegohegoyahi } \\
\text { make them content }\end{array}$ & $\begin{array}{l}\text { linugohegoyahi } \\
\text { cause content }\end{array}$ & $\begin{array}{l}\text { wonugolnegoya( ya) } \\
\text { kecp showing contentment }\end{array}$ \\
\hline nugogului & forget & $\begin{array}{l}\text { winugogului } \\
\text { forget words }\end{array}$ & $\begin{array}{l}\text { lunugoguluilii } \\
\text { make them forget }\end{array}$ & $\begin{array}{l}\text { limugogului } \\
\text { cause things to be forgotten }\end{array}$ & $\begin{array}{l}\text { wonugogului } \\
\text { forget little by little }\end{array}$ \\
\hline nugodubu & sadness & $\begin{array}{l}\text { winugodubu } \\
\text { show sadness }\end{array}$ & - & $\begin{array}{l}\text { linugodubui } \\
\text { cause sadness }\end{array}$ & $\begin{array}{l}\text { wonugodubu(gcya) } \\
\text { kecp mouming }\end{array}$ \\
\hline Class 2 & & & & & \\
\hline nugoncina & ignorance & $\begin{array}{l}\text { winugoncina } \\
\text { be ignorant of word }\end{array}$ & - & $\begin{array}{l}\text { limugoncinahi } \\
\text { be ignorant of things }\end{array}$ & $\begin{array}{l}\text { wonugoncinat } \\
\text { be slow to leam }\end{array}$ \\
\hline nugocmota & singlencss & $\begin{array}{l}\text { winugocmola } \\
\text { agree }\end{array}$ & $\begin{array}{l}\text { lunugocmoti } \\
\text { work together }\end{array}$ & $\begin{array}{l}\text { linugocmotalii } \\
\text { bring them together }\end{array}$ & $\begin{array}{l}\text { wonugocmota(hi) } \\
\text { bring people closer logether }\end{array}$ \\
\hline nugoluwaluwaga & uncertainty & $\begin{array}{l}\text { winugoluwaluwaga } \\
\text { be uncertain of right } \\
\text { thought }\end{array}$ & $\begin{array}{l}\text { lunugoluwaluwaga } \\
\text { be uncertain about actions }\end{array}$ & - & $\begin{array}{l}\text { wonugoluwaluwaga } \\
\text { follow two paths, be } \\
\text { schizophrenic }\end{array}$ \\
\hline nugotologo & poverty & $\begin{array}{l}\text { winugotologo } \\
\text { be necdy }\end{array}$ & $\begin{array}{l}\text { lunugotootogo } \\
\text { show mercy }\end{array}$ & - & - \\
\hline nugotuhu & thought & $\begin{array}{l}\text { winugoluhu } \\
\text { think }\end{array}$ & - & - & $\begin{array}{l}\text { wonugoluhu(ya) } \\
\text { keep thinking }\end{array}$ \\
\hline
\end{tabular}

\section{CHART 14: DERIVATIONAL PREFIXES WITH HUMAN PROPENSITY CLASS}

${ }^{1} H i$ is plural form 'them' i.c. 'pcople'.

${ }^{2}$ These have an optional transitive form, given in brackets. 
(123) Bada i-wi-nugohegoya-u.

man he-DP-content-me

The man calmed me down.

(124) A-laun-i po a-li-nugoapapoe-ya.

I-hit-him and I-DP-anger-him

I hit him and made him angry.

\subsection{NUMBERS}

Tawala numbers are a small closed class of words somewhat aligned to adjectives, but showing several distinctive features (cf. section 4.2):

(a) They are not marked for subject-person agreement, unlike adjectives:

(125) Bada banei-hi hi-nae.

man bid-their they-go

The big men went.

(126) Hai tonuga hi-nae.

their three they-go

The three (men) went.

(b) They do not have a reduplicated form, unlike most adjectives.

(c) They function as nouns, both by themselves and with alienable possession clitics:

(127) Luwaga he-ma-mae.

two they.PRES-PROG-stay

There are two remaining.

(128) Omi wohepali o-na-nae.

you.PL four you-INT-go

You four will go.

There are five basic numbers in Tawala:

$\begin{array}{ll}\text { emois/emota } & \text { one } \\ \text { luwaga } & \text { two } \\ \text { tonuga } & \text { three } \\ \text { wohepali } & \text { four } \\ \text { nim(a) i-tutu } & \text { five } \\ \text { hand it-joint } & \end{array}$

Grammatically, any number higher than that is referred to as gogo-na 'together-its'. Referentially it is possible to continue counting by combinations of these basic numerals plus the concept of olotoi-hilage 'twenty' (literally 'male he-finish'):

$\begin{array}{lll}\operatorname{nim}(a) \text { i-tutu po emosi } & \text { six } \\ \text { hand it-joint and one } & \\ \text { nima luwaga hi-tutu po luwaga } & \text { twelve } \\ \text { hand two they-joint and two } & \\ \text { nima tonuga hi-tutu po tonuga } & \text { eighteen } \\ \text { hand three they-joint and three } & \end{array}$




\author{
oloto emosi i-hilage po wohepali twenty-four \\ male one he-finish and four
}

Numbers represent the most perfect semantic-syntactic correlation I have discovered in Tawala. In section 3 the general principle was proposed: in so far as two words share significant semantic components so their syntax overlaps. The corollary is also true: in so far as two words have significantly separate components, to that extent their syntax is likely to diverge. Tawala numbers are a paradigmatic example of these principles. The numbers 'two' to 'five' do not differ in any significant way, semantically, and consequently they do not differ in their grammar. Nor are there any of the idiomatic uses found in most charts in this section. The number 'one' differs significantly from the other numbers semantically, involving such significant components as 'leadership', 'priority' and 'excellence' as well as 'number'. The resultant grammatical forms also differ at a number of points. The number 'beyond five' is a different, more generic concept than the specific numbers 'one' to 'five', and its grammar diverges quite significantly in line with the semantic distinction.

Charts 15(a) and 15(b) set out the details of the grammatical forms derived from derivational and classificatory prefixes respectively.

\title{
(a) Derivational prefixes
}

The wi prefix with a number forms an ordinal number which functions as an adjective, agreeing with the noun it follows in person and number:

$\begin{array}{llll}\text { wi-emosi-na } & \text { first } & \text { (emosi one) } \\ \text { wi-luwaga-na } & \text { second } & \text { (luwaga } & \text { two) }\end{array}$

The wi prefix also derives a transitive verb meaning 'to make something a number' which is considered the common meaning for these roots. These meanings are similar to the 'cause action' meaning common to verbs derived with wi:

$\begin{array}{lll}\text { wi-emot-e-ya } & \text { pile things together } & \text { (emota one) } \\ \text { wi-luwag-e-ya } & \text { make something second } & \text { (luwaga two) }\end{array}$

The prefix $l u$ is used with two different syntactic frames, involving the meaning 'to grow together in a bunch' and 'hit or spear a number'. These uses are similar to the meaning associated with nouns, 'to hit noun' and 'to collect item':
lu-luwaga-na
grow in a bunch of two
(luwaga two)
lu-luwag-e-hi
hit or spear two
(luwaga two)

The prefix lidoes not occur with numbers.

The prefix wo is used with the meaning 'to gather a number' or 'to hold a number in that hand'. This latter meaning is a common meaning of wo with a number of word classes:
wo-luwag-e-ya gather two
(luwaga two)

\section{(b) Classificatory prefixes}

Data are included in Chart 15(b) for the use of numbers with classificatory prefixes and the little-used om derivational prefix, because of the distinctive nature of these prefixes with numbers. Thus while there is nothing particularly distinctive in the use of derivational prefixes in distinguishing this semantic field of roots, there certainly is with the following prefixes. 
The prefix om is, of course, a derivational prefix, largely omitted from this thesis because of its failure to be productively used with most of the roots introduced in this section. With numbers it is productive and has the distinctive meaning 'number to be caught on a hook':

$$
\text { hi-(o)mluwaga two were caught (luwaga two) }
$$

The four classificatory prefixes are used with the following meanings:

$\begin{array}{llll}t u & \text { step on a number, cover number with feet } & \\ \text { tu-luwag-e-hi } & \text { step on two items } & \text { (luwaga } & \text { two) } \\ \text { tape } & \text { break something a number of times, break a number } \\ \text { tape-luwag-e-ya } & \text { break it twice } & \text { (luwaga } & \text { two) } \\ \text { hage } & \text { number go alone } & & \\ \text { hage-luwaga } & \text { two go alone } & (\text { luwaga } & \text { two) } \\ \text { ne } & \text { number go along together } & & \\ \text { ne-luwa-luwaga } & \text { two go together } & (\text { luwaga } & \text { two) }\end{array}$

Typical examples:
He-ne-nae
mi dimdim
po
they.PRES-PROG-go from across.the.sea and

he-tu-tu-luwa-luwaga.

they.PRES-PROG-CP-RED-two

They (husband and wife) are acting like Europeans and walking together.

(130) Iyeta emois $i$ kokoe ma wi-luwaga-na uyahina...

day one it finish then DP-two-its at

On the second day...

(131) Mika iyana i-lu-tonug-e-hi.

Mika fish he-DP-three-DAT-them

Mike caught three fish with one throw of the spear.

(132) Kama ma Yailo hi-hage-luwaga.

Kama and Yailo they-CP-two

Kama and Yailo have gone alone.

\subsection{LOCATIONALS}

This small closed class of words includes those words referred to as 'position adjectives' by Dixon. He notes (1977:74):

POSITION can be justified as a further semantic type associated with the class

Adjective in English but is most frequently dealt with through Adverbs in other languages, even, when they do have an open Adjective class.

In Tawala they are neither adjectives nor adverbs, but a closed class in their own right. Like adjectives, abstract nouns, inalienable nouns, etc. they are suffixed for person and number agreement of the noun they follow. However, they also stand absolutely as locational nouns by the addition of the prefix $u$ 'to, in, at'. The following examples demonstrate something of the range of usage of locationals: 


\begin{tabular}{|c|c|c|c|c|c|c|c|}
\hline cardinal number & & $\begin{array}{l}\text { wi-R-na } \\
\text { ordinal number }\end{array}$ & $\begin{array}{l}\text { wi-R-DAT-O } \\
\text { make s.th. a number }\end{array}$ & $\begin{array}{l}\text { lu-R-DAT-ya } \\
\text { na } \\
\text { grow in bunch }{ }^{2}\end{array}$ & $\begin{array}{l}\text { Iu-R-DAT-O } \\
\text { hit or spear a } \\
\text { number }\end{array}$ & li- & $\begin{array}{l}\text { wo-R-DAT-O } \\
\text { gather a number } \\
\text { hold a number in } \\
\text { hands }\end{array}$ \\
\hline emosi/emota ${ }^{3}$ & one & wiemosina $^{4}$ & wiemoteya $^{5}$ & luemotana & luemosigeya(-ni) & - & woemoteya \\
\hline luwaga & Iwo & wiluwagana & wiluwageya & Iuluwagana & Iuluwagehi & - & woluwageya \\
\hline tonuga & three & witonugana & witonugeya & lutonugana & lutongehi & - & wotonugeya \\
\hline wohepali & four & wiwohepalina & wiwohepaligeya & luwohepalina & luwohepaligehi & - & wowoheraligeni ${ }^{6}$ \\
\hline nimitutu & five & winimitutuna & winimitutugeya & Iunimitutugeya & Iunimitutugehi & - & wonimitutugeya \\
\hline gogona & together & - & -7 & -8 & lugogonehi 9 & - & wogogoni \\
\hline
\end{tabular}

\section{CHART 15(a): DERIVATIONAL PREFIXES WITH NUMBERS}

'The identical paradigm applies to hana 'to hold a number with tecth' or 'to bitc a number'.

${ }^{2}$ Thesc have stative meaning - wiluwageya 'to grew together' ctc.

${ }^{3}$ Dialect/age-group distinction, but also the two forms have separate usage with prefixes.

${ }^{4} T$ ahatahayana is used for 'first (on trail), be leader'.

5 Wicmotcya means 'to pilc things together'.

${ }^{6} T$ his $n i$ is only a free variant (dialectal) but I have maintained the irregularity as that is how I collected the data.

${ }^{7}$ This concept is handled by muli-na 'behind' (lit. 'back-its').

${ }^{8}$ This concept is handled by puli-na 'bunch' (lit. 'bunch-its').

${ }^{9}$ Lugoluhi is used for 'felling a bunch of coconuts with a stone'. 


\begin{tabular}{|c|c|c|c|c|c|c|}
\hline root & & $\begin{array}{l}\text { (o)m-R } \mathrm{R}^{1} \\
\text { number to be } \\
\text { caught on hook }\end{array}$ & $\begin{array}{l}\text { ru-R } \\
\text { step on a number, } \\
\text { cover number } \\
\text { with feet }\end{array}$ & $\begin{array}{l}\text { tape-R-DAT-O } \\
\text { break s.th. a number } \\
\text { of times, break a } \\
\text { number }\end{array}$ & $\begin{array}{l}\text { hage-R } \\
\text { number to go } \\
\text { alone }\end{array}$ & $\begin{array}{l}\text { ne-RED- }{ }^{3} \\
\text { number to go } \\
\text { along together }\end{array}$ \\
\hline emosi/emota $^{4}$ & one & i'memosi & tuemoteni & tapeemoteya & hageemota & neemoemota \\
\hline luwaga & two & hi'mluwaga & tuluwagehi & tapeluwageya & hageluwaga & neluwaluwaga \\
\hline tonuga & three & hi'mtonuga & tutonugehi & tapetonugeya & hagetonuga & netonutonuga \\
\hline wohepali & four & hi'mwohepali & tuwohepaligehi & tapewohepaligeya & hagewohepali & newohewohepali \\
\hline nimitutu & five & hi'mnimitutu & tunimitutugehi & tapenimitutugeya & hagenimitutu & neniminimitutu \\
\hline gogona 5 & together & hi'mgogona & tugogonehi & tapegogoni & gelugelu $^{6}$ & negogona \\
\hline
\end{tabular}

CHART 15(b): SOME CLASSIFICATORY PREFIXES WITH NUMBERS

${ }^{1}$ I have included the fully inflected form because of vowel loss and the change from singular to plural. Ona 'number to be caught in net' can substitute for om but does not suffer vowel loss.

${ }^{2}$ The paradigm also applies to tupa 'to hit number'.

${ }^{3} \mathrm{Gc}$ 'to cling, go up together' substitutes for $n c$.

${ }^{4} \mathrm{Dialect/agc-group} \mathrm{distinction,} \mathrm{but} \mathrm{also} \mathrm{the} \mathrm{two} \mathrm{forms} \mathrm{have} \mathrm{separate} \mathrm{usage} \mathrm{with} \mathrm{prefixes.}$

${ }^{5}$ Gogona, not being a number, does not always follow the formulac for numbers.

${ }^{6}$ Gelugelu - probably from the root gelu 'to get on board'. 
numa hine-na

house inside-its

...numa u-hine-na house at-inside-its

I-nae u-hine-na. he-go to-inside-its

u-hine-u

in-inside-my the inside of a house

(it is) inside the house

He went inside (it).

inside me

There are two separate classes of locationals:

Class 1 static relationship locations

depict the relationship between items which are stationary.

Class 2 dynamic relationship locationals

depict the relationship between items which are moving.

This semantic distinction is paralleled by differing usage of derivational prefixes, set out in Chart 16.

With static locationals the wi prefix is used with a single root and has an idiomatic meaning:

$$
\text { wi-tepa pretend (tepa on top) }
$$

However, with the dynamic locations the wi prefix is productive and means 'move in relation to something':

$$
\text { wi-muli follow (muli behind) }
$$

The lu prefix is productive with both classes of locationals in the sense 'to make a pile in location':
lu-hine-ni pile inside
(hine . inside)

The dynamic aspect is retained with the Class 2 locationals in that the pile is made in respect to (i.e. after) the marriage process:

$$
\text { lu-muli pile (gift)made after marriage (muli behind) }
$$

The li prefix is never productive with these roots.

The wo prefix is used only with static locationals and has the sense 'to put hand in location':

$$
\text { wo-gabola put hand undemeath (gabola under) }
$$

Typical examples:

U-na-tahae-ya po a-wi-muli. you.SG-INT-lead-it and I-DP-behind You go first and I will follow.

(134) Ba-bada hi-wo-tepa-ni.

RED-man they-DP-top-him

The elders laid hands on him. 


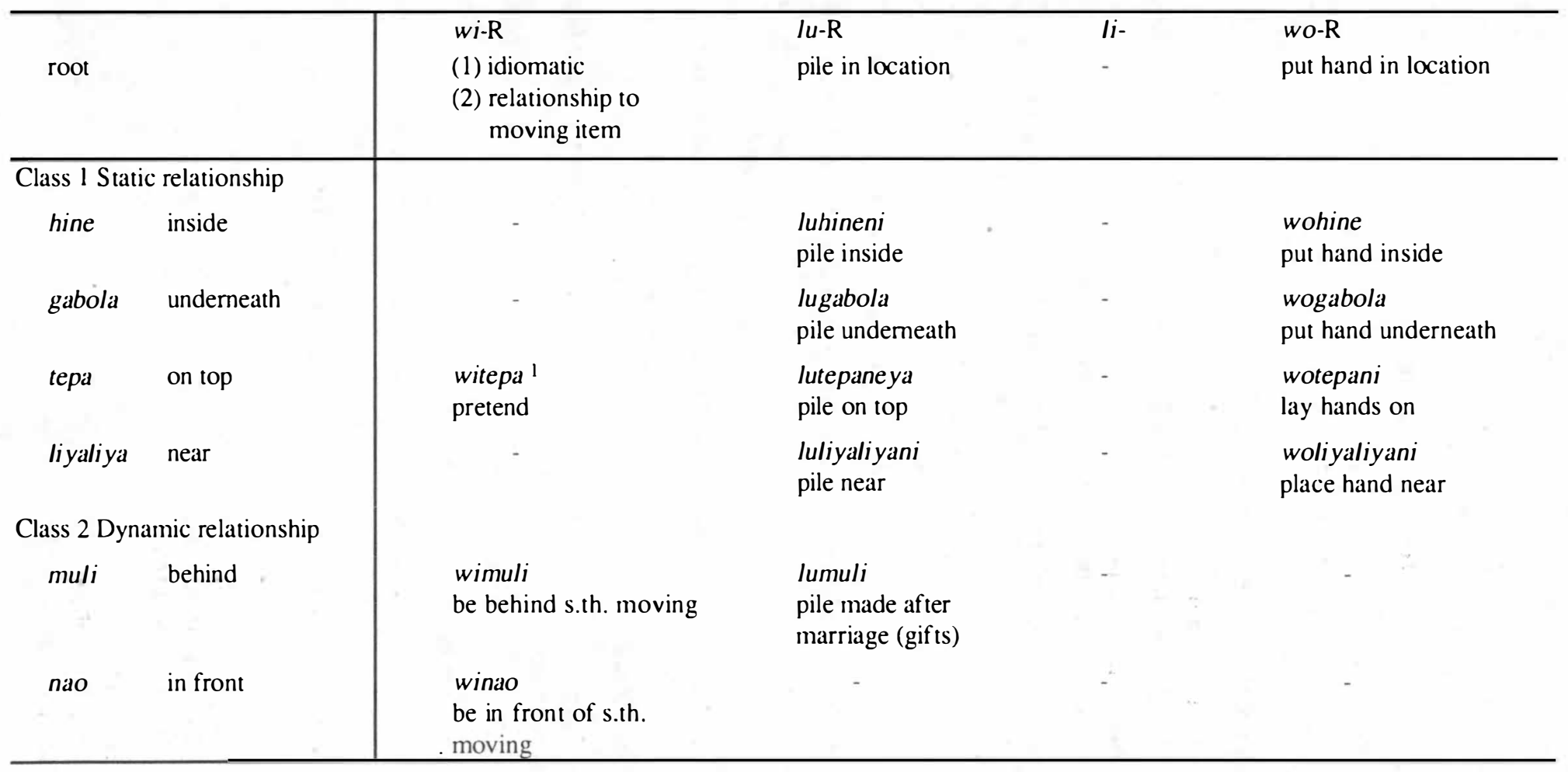

\section{CHART 16: DERIVATIONAL PREFIXES WITH LOCATIONALS}

'This is probably tepa used in the sense of 'face' i.c. wi-tcpa 'to make a face'. 

Yaniyani hi-lu-tepa-ne-ya.
food they-DP-top-DAT-it
They piled food on top.

\subsection{RESIDUE}

Chart 17 contains those roots which have been found to be productive with the derivational prefixes, but have not, as yet, been assigned to classes such as have been handled in Charts 1-16.

An examination of the data contained in Chart 17 reveals that the roots consist almost entirely of verbs (both transitive and intransitive) and that many of the meanings of the derived forms are similar to those encountered with the more regular data, though there are also many idioms. With the 'priority of semantics' hypothesis, we would expect roots coming from a wide range of semantic fields to appear to have an almost random use of derivational prefixes with a wide variety of form and meaning, and this is indeed what we have with Chart 17, which contrasts sharply with the order found in all the charts based on items from a single semantic field. Thus we find here a negative confirmation of the hypothesis in the lack of correlation between semantics and syntax.

Almost half of the roots contained in the residue are among the verbs of highest occurrence in everyday conversation. In addition the verbs derived from these roots of ten have quite distinctive meanings not yet encountered in the regular data. The combination of these two facts was largely responsible for early lack of progress in controlling derivational prefixes. With a systematic approach to a larger corpus of data the residue was able to be viewed in perspective and assigned a relatively unimportant role in the resultant schema.

As detailed comments on all 26 roots of Chart 17 would involve a very lengthy and somewhat tedious end to this data section, I have, instead, selected four of the most common roots to illustrate the major conclusions which can be drawn.

(a) bagibagi work

This word is so common that it is of ten the first word people recognise as a recurring partial when listening to Tawala. It is basically the noun 'work', though it does occur in restricted contexts as a verb:

$\begin{array}{lll}\text { Ta-bagibagi! } & \text { but not: } & { }^{* H i-b a g i b a g i} \\ \text { we.INC-work } & & \text { they-work } \\ \text { Let's work! } & & \end{array}$

The wi prefix is used with the unique meaning 'to use a tool' and includes the sense of the English 'to borrow':

(137) Ilama a-wi-bagibagi-ye-ya mayau ugoli-na.

axe I-DP-work-DAT-it tree at-it

I am using the axe to cut the wood.

This meaning has been found with only one other word. It is another residue word belonging to a closely related semantic field:

$$
\text { wi-hagu-ge-ya to use something (hagu help) }
$$


The root bagibagi does not occur with the $l u$ and $l i$ prefixes, however, it does occur with wo, where it functions as a verbaliser. The usual meaning, where the derived verb 'involves hands or persistent action', has been lost and the verb is simply the generic verb 'to work':

$$
\begin{aligned}
& \text { Apo lawa ega i-na-wo-bagibagi... } \\
& \text { FUT person NEG he-INT-DP-work } \\
& \text { If a person won't work... }
\end{aligned}
$$

(139) Kewokewou a-wo-bagibagi-ye-ni.

canoe I-DP-work-DAT-it

I made a canoe.

(b) baha talk

This root does not occur with the wi prefix, but it does with the other three prefixes. The form derived with $l u$ means 'to boast' and in line with the general meaning 'verb involves physical movement' the person 'boasting' uses wild gesticulations (see section 3.3 for a fuller definition).

(140) Bada e-lau-baha-baha. man he.PRES-DP.PROG-RED-talk

The man is boasting.

With the li prefix baha is used with the meaning 'cause someone to start talking':

(141) Natani ba-bada e-lai-baha-hi.

Nathan RED-men he.PRES-DP.PROG-talk-them

Nathan caused the men to start talking.

This meaning of 'to start something' is found with only one other root, which also belongs to the residue:

li-dagu-ya start something

$$
\begin{array}{ll}
\text { (dagu } & ? \\
\text { widagudagu } & \text { wriggle) }
\end{array}
$$

The wo prefix with baha is used in line with the common meaning 'persist in action' and means 'to continually boast or complain':

(142) Bagibagi e-woo-bahe-bah-e-ya.

work he.PRES-DP.PROG-RED-talk-DAT-it

$\mathrm{He}$ is always complaining about the work (to be done).

(c) hilage be finished, die

This root has a distinction between the wi and li prefixes not attested with any other roots:

$$
\begin{array}{ll}
\text { wi-hilage } & \text { kill by sorcery } \\
\text { li-hilage } & \text { kill physically }
\end{array}
$$

The first meaning is in line with the common meaning which occurs with adjectives, 'to cause condition (socially)', as 'social' action of ten involves the spoken word, which is also true of sorcery. However, it is most unusual to have li used for 'physical contact' (the general meaning of $l u$ ). However, this may be because $l u$ already had an idiomatic meaning of its own:

lu-hilage be exhausted 
The meaning with wo is also similar to that with $l u$, except that the implication in line with the common meaning is that the state is the result of persistent action:

wo-hilage be wom out

The following examples present hilage with the four prefixes in the order presented above:

Lawa tula-na balau-gei i-wi-hilage-ni.

person friend-his sorcery-INST he-DP-die-him

The man killed his friend by sorcery.

Mika kamkam ilama-gei i-li-hilage-ni.

Mika chicken axe-INST he-DP-die-it

Mika killed the chicken with an axe.

A-lu-hilage.

I-DP-die

I am exhausted. (after pushing a car)

(146) Wiyuwa-na a-wo-hilage.

pain-that I-DP-die

I am worn out with the pain.

(d) hogoya be full

The prefixes wi and $l i$ with this root change the stative verb into the active form:

$\left.\begin{array}{l}\text { wi-hogoya } \\ \text { li-hogoya }\end{array}\right\} \quad$ fill something

The distinction between these two forms is difficult to pin down, but lihogoya, in addition to meaning 'to fill something', also means 'to pour out':

(147) Goila hipuli i-li-hogoya babana tanki i-gunanagili. water ground it-DP-fill because tank it-break

The water poured out on the ground because the tank got a hole in it.

The following examples illustrate the distinction between these two verbs:

Goila/baketi u-na-wi-hogoya.

*Goila/baketi u-na-li-hogoya. water/bucket you-INT-DP-fill water/bucket you-INT-DP-fill

Fill the water/bucket.

(149) Goila hoi baketi u-na-wi-hogoya / *u-na-li-hogoya. water in bucket you-INT-DP-fill / you-INT-DP-fill Fill the bucket with water.

(150) Baketi goil(a)-ei u-na-li-hogoya / *u-na-li-hogoya. bucket water-INST you-INT-DP-fill / you-INT-DP-fill Fill the bucket with water.

The prefixes $l u$ and wo do not occur with this root. 


\begin{tabular}{|c|c|c|c|c|c|}
\hline root & & $W 1-$ & Iu- & Ii- & wo- \\
\hline$\overline{\text { bagibagi }}$ & work & $\begin{array}{l}\text { wibagibagi } \\
\text { usc a tool }\end{array}$ & - & - & $\begin{array}{l}\text { wobagibagi } \\
\text { work }\end{array}$ \\
\hline baha & talk & $=$ & $\begin{array}{l}\text { lubahat } \\
\text { boasti }\end{array}$ & $\begin{array}{l}\text { libahaya } \\
\text { start s.o. talking }\end{array}$ & $\begin{array}{l}\text { wobahabaha } \\
\text { continually boast, } \\
\text { complain }\end{array}$ \\
\hline daada & dawdlc & $\begin{array}{l}\text { widaadaya } \\
\text { walk s.o. }\end{array}$ & - & - & $\begin{array}{l}\text { wodaada } \\
\text { practisc walking }\end{array}$ \\
\hline dadana & inspect & $\begin{array}{l}\text { widadani } \\
\text { try s.th. }\end{array}$ & $\begin{array}{l}\text { ludadani } \\
\text { test s.o. }\end{array}$ & - & - \\
\hline (dagu) & - & $\begin{array}{l}\text { widaguya } \\
\text { move s.th. }\end{array}$ & - & $\begin{array}{l}\text { lidaguya } \\
\text { start s.o. }\end{array}$ & - \\
\hline gayo & be in water & $\begin{array}{l}\text { wigayoya } \\
\text { immerse s.th. }\end{array}$ & - & $\begin{array}{l}\text { ligayoya } \\
\text { wel s.th. }\end{array}$ & - \\
\hline guyau & chicf & $\begin{array}{l}\text { wiguyougcya } \\
\text { treat as chicf }\end{array}$ & $\begin{array}{l}\text { luguyoguyougcya } \\
\text { ridiculc, mock }\end{array}$ & - & - \\
\hline hagu & help & $\begin{array}{l}\text { wihagugcya } \\
\text { usc s.th. }\end{array}$ & - & - & $\begin{array}{l}\text { wohaguya } \\
\text { help s.o. in task }\end{array}$ \\
\hline halcya & throw s.th. & $\begin{array}{l}\text { wihalcya } \\
\text { remove s.th. }\end{array}$ & $\begin{array}{l}\text { luhalcya } \\
\text { exchange places } \\
\text { with s.o. }\end{array}$ & - & $\begin{array}{l}\text { wohaleya } \\
\text { lct s.th. go }\end{array}$ \\
\hline hсpa & beach boat & $\begin{array}{l}\text { wihcpaya } \\
\text { run boat aground }\end{array}$ & $\begin{array}{l}\text { luhcpaya } \\
\text { dig up vegetables }\end{array}$ & - & $\begin{array}{l}\text { wohepaya } \\
\text { raise s.th. }\end{array}$ \\
\hline hilagc & $\begin{array}{l}\text { dic, be } \\
\text { finished }\end{array}$ & $\begin{array}{l}\text { wihilagcni } \\
\text { kill - sorcery }\end{array}$ & $\begin{array}{l}\text { luhilagc } \\
\text { be cxhausted }\end{array}$ & $\begin{array}{l}\text { lihilagcni } \\
\text { kill - physically }\end{array}$ & $\begin{array}{l}\text { wohilage } \\
\text { be wom out }\end{array}$ \\
\hline hiyawi & count s.th. & $\begin{array}{l}\text { wihiyawi } \\
\text { read s.th. }\end{array}$ & $\begin{array}{l}\text { luhiyadiyyawa } \\
\text { recount the past }\end{array}$ & - & $\begin{array}{l}\text { wohiyahiyawa } \\
\text { read/count rapidly }\end{array}$ \\
\hline hocya & open s.th. & - & $\begin{array}{l}\text { luhochoc } \\
\text { be unticd }\end{array}$ & - & $\begin{array}{l}\text { wohocya } \\
\text { dismantle s.th. }\end{array}$ \\
\hline hogoya & be full & $\begin{array}{l}\text { wihogoya } \\
\text { fill s.th. }\end{array}$ & - & $\begin{array}{l}\text { lihogoya } \\
\text { pour out on ground }\end{array}$ & - \\
\hline holi & pull in & $\begin{array}{l}\text { wiholahola } \\
\text { sexual intercourse }\end{array}$ & $\begin{array}{l}\text { luholi } \\
\text { furl a sail }\end{array}$ & $\begin{array}{l}\text { liholi } \\
\text { scalter s.th. to } \\
\text { multiply it }\end{array}$ & $\begin{array}{l}\text { woholi } \\
\text { take s.th. from a } \\
\text { holc }\end{array}$ \\
\hline hunaya & $\begin{array}{l}\text { urge s.o. } \\
\text { on }\end{array}$ & - & - & $\begin{array}{l}\text { lihunaya } \\
\text { urge s.o. by } \\
\text { actions }\end{array}$ & $\begin{array}{l}\text { wohunahunaya } \\
\text { urge with whispers }\end{array}$ \\
\hline lawi & jerk s.th. & $\begin{array}{l}\text { wilawi } \\
\text { hit/kill s.th. }\end{array}$ & $\begin{array}{l}\text { Iulawi } \\
\text { break s.th. off with } \\
\text { hooked stick }\end{array}$ & $7 \quad-$ & $\begin{array}{l}\text { wolawi } \\
\text { break s.th. off by } \\
\text { hand }\end{array}$ \\
\hline lougo & $\begin{array}{l}\text { sing, yank } \\
\text { a line }\end{array}$ & $\begin{array}{l}\text { wilougo } \\
\text { knock }\end{array}$ & - & $\begin{array}{l}\text { lilugoya } \\
\text { hit s.th. again }\end{array}$ & $\begin{array}{l}\text { wolougo } \\
\text { persist in hitting }\end{array}$ \\
\hline pati & be patched & $\begin{array}{l}\text { wipati } \\
\text { stick s.th. }\end{array}$ & - & $\begin{array}{l}\text { lipati } \\
\text { stick s.th. up }\end{array}$ & $\begin{array}{l}\text { wopati } \\
\text { stick many things }\end{array}$ \\
\hline pili & be rolled & $\begin{array}{l}\text { wipilipili } \\
\text { spcilk riddles }\end{array}$ & $\begin{array}{l}\text { lupilipili } \\
\text { hit with instrument }\end{array}$ & $\begin{array}{l}\text { lipilipili } \\
\text { make miskiakc }\end{array}$ & $\begin{array}{l}\text { wopilipili } \\
\text { crumple s.th. }\end{array}$ \\
\hline popoya & join s.th. & - & $\begin{array}{l}\text { lupopoya } \\
\text { join string }\end{array}$ & - & - \\
\hline poyaya & heal s.th. & $\begin{array}{l}\text { wipoya } \\
\text { be/become hot }\end{array}$ & $\begin{array}{l}\text { lupoyaya } \\
\text { apply heal/medicine } \\
\text { to s.o. }\end{array}$ & $\begin{array}{l}\text { lipoyaya } \\
\text { heat s.th. on fire }\end{array}$ & $\begin{array}{l}\text { wopoyaya } \\
\text { heat s.th. by hand }\end{array}$ \\
\hline tomatoma & be inspired & - & $\begin{array}{l}\text { lutomatoma } \\
\text { talk like forcigner }\end{array}$ & $\begin{array}{l}\text { litomattomaya } \\
\text { lack s.th. (salt) }\end{array}$ & 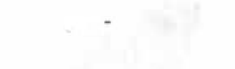 \\
\hline wiwila & go round & - & $\begin{array}{l}\text { luwilawila } \\
\text { ask many questions }\end{array}$ & - & $\begin{array}{l}\text { wowilawilaya } \\
\text { mix things together }\end{array}$ \\
\hline (yadaga) & - & - & $\begin{array}{l}\text { luyadagi } \\
\text { hil s.th. blindly }\end{array}$ & - & $\begin{array}{l}\text { woyadaga } \\
\text { scarch in the dark }\end{array}$ \\
\hline yagiyagina & quickly & $\begin{array}{l}\text { wiyagiyagincya } \\
\text { bring s.th. fast }\end{array}$ & $\begin{array}{l}\text { luyagiyagina } \\
\text { do s.th. in a hurry }\end{array}$ & - & $\begin{array}{l}\text { woyagiyagineya } \\
\text { carry s.th. quickly }\end{array}$ \\
\hline
\end{tabular}




\subsection{SUMMARY}

A semantic continuum of data has been presented in this section. At one extreme, data were presented from homogenous semantic fields, with the prototypical example being the number roots (4.5). At the other extreme, data were presented from heterogenous semantic fields which had little in common with each other, the prime examples being four roots illustrated in the residue section (4.7). In between these two extremes were numerous semantic fields within which roots show varying degrees of homogeneity of semantic content.

A second and parallel syntactic-semantic continuum has been mapped onto the above semantic continuum (as illustrated in Table 15). The second continuum is parallel to the first in the sense that its degree of predictability has been shown to be in direct proportion to the homogenous nature of the semantic continuum.

TABLE 15: THE RELATIONSHIP BETWEEN THE SEMANTIC FIELDS OF ROOTS AND THEIR DERIVED VERBS

1st continum
semantic fields of roots
predictable
2nd continum
syntactic-semantic function
of derived verbs

The second continuum involves predictable patterns in the use of the four derivational prefixes ( $w i, l u, l i$ and $w o$ ) in common use with Tawala roots. Attempts to find a general meaning for these prefixes resulted in only vague and not very useful definitions. However, once the focus of attention was concentrated on the meaning of the prefixes with specific word classes, common meanings were found to which the majority of the data bear recognisable resemblance. Thus even at this stage we observed a confirmation of the thesis that 'in so far as two words share significant semantic components, so their syntax overlaps'.

At one extreme of the second continuum are sets of derived verbs which share identical syntactic-semantic functions. The prototypical examples are the derived verbs which are formed from the semantic field containing number roots (4.5). Thus the highly predictable end of the derived verb continuum corresponds to the homogenous end of the semantic field continuum.

The other extreme of the second continuum consists of derived verbs from isolated roots with unique syntactic-semantic functions. The prime examples are the derived verbs associated with the residue. Little or no correspondence is found to exist between these derived forms (4.7). It is no accident that these unpredictable sets of derived verbs correspond to the heterogenous semantic fields of their roots, for in both the irregular data and the regular data we see clear evidence for the thesis stated above, and a confirmation that there is indeed a priority of semantics in the operation of Tawala verb derivation. 


\section{CONCLUSION}

It has not been possible in a paper of this size to handle all aspects of Tawala derivational prefixes. The main casualty has been the syntactic treatment of the derived verbs. However, insights have been gained into even this aspect of the subject, pointing to fruitful avenues for future research.

The main advance has been in the systemisation of derived verbs in relation to the semantic fields of their roots; for, while efforts directed at finding the 'general' meanings for the derivational prefixes proved only marginally successful, the meaning of each prefix when combined with roots from a specific semantic field were found to be highly predictable. In addition, the general agreement of these meanings within the various word classes enabled me to successfully posit 'common' meanings for each prefix as used with all the roots within a word class. Divergences from this common meaning were noted where appropriate, however these divergences were found only in a minority of data, and of ten only one or two idiomatic examples. Thus the data were reduced from chaotic to manageable proportions, making language learning within the grasp of the outsider.

Besides unlocking some of the mysteries of Tawala data, I hope that this paper may also inspire some of my colleagues working on Milne Bay languages, and perhaps even further afield, to take up the challenge and pay more rigorous attention to an area of language so easily dismissed in a trite fashion. I am sure that such studies will be amply rewarded, for I am aware that this paper is far from being the last word on the subject.

APPENDIX 1: Muyuw derivational prefixes

Material culled from Lithgow (1974) (stress omitted).

(a) $v / v a^{1}$

\begin{tabular}{|c|c|c|c|}
\hline vasus (vses) & suckle a child & (sus & breast) \\
\hline vatow (vtow) & stand it up & (tow & stand, stand away) \\
\hline vvag & keep doing it & (vag & do, make) \\
\hline vtok & $\begin{array}{l}\text { criticise, slander, complain } \\
\text { about him }\end{array}$ & (tok & $\begin{array}{l}\text { bury, lead by } \\
\text { hand) }\end{array}$ \\
\hline vtam & ask permission for it & (tam & agree, consent) \\
\hline vnavek & become a senior/old woman & (tovek & grow old) \\
\hline vapel & $\begin{array}{l}\text { cross it on foot, step over } \\
\text { something }\end{array}$ & (pel & jump) \\
\hline vakun & tread in his footprints & (kun & trade in kula) \\
\hline vanoy & farewell him on foot & (noy & go on that road) \\
\hline $\operatorname{vap}(w)^{\cdot}$ & step on it and break it & & \\
\hline vapwapwel & $\begin{array}{l}\text { stand on it and squeeze } \\
\text { stuff out of it }\end{array}$ & (pwapwas & soft, easy) \\
\hline
\end{tabular}

$1_{v a-m a y}$ be simply a classificatory prefix and $v$-a derivational prefix. 
(b) ya

\begin{tabular}{|c|c|c|c|}
\hline yakawn & praise & (kaves & praise) \\
\hline yabin & crowd round and force & (sibin & $\begin{array}{c}\text { force into a } \\
\text { corner) }\end{array}$ \\
\hline yabik & dirty it & (bik & to be dirty) \\
\hline yabol & make a mistake and spoil it & (bol & confused, wrong) \\
\hline yadumwal & to discipline & (dumwal & go straight) \\
\hline yagay & scoff, jeer & (yeg & scoff, jeer) \\
\hline yageg & spoil, damage & (geg & to be bad) \\
\hline yamlik(w) & start something moving & $(\operatorname{lik}(w)$ & untie) \\
\hline yamov & save someone's life & (katimov & $\begin{array}{l}\text { hit but not kill } \\
\text { someone) }\end{array}$ \\
\hline yamwen & lift & (mwen & ascend) \\
\hline yasiblut & startle someone & (sibilut & startle) \\
\hline yatapip & sleep on floor & (tapip & lie on floor) \\
\hline
\end{tabular}

(c) $k a$

\begin{tabular}{|c|c|c|c|}
\hline kabak & bald & (bak & baldness) \\
\hline kabut & summons, call for work & (but & make noise) \\
\hline kalag & harvested food & (lag & go up) \\
\hline kalog & gather food & $(\log (w)$ & $\begin{array}{l}\text { pile in heaps for } \\
\text { distribution) }\end{array}$ \\
\hline kawot & wave breaks & (wot & cut big logs) \\
\hline kabalawein & mad, senseless, stupid & (balawein & mad) \\
\hline kabayay & wide opening & (babayay & wide opening) \\
\hline kadumwal & show the right path & (dumwal & go straight) \\
\hline kalgutan & $\begin{array}{l}\text { one pile divided in portions } \\
\text { for distribution }\end{array}$ & (lagutan & one pile) \\
\hline kalouvat & meet & (louvat & meet) \\
\hline \multicolumn{4}{|l|}{ kata } \\
\hline atabuyav & make to bleed & (buyav & blood) \\
\hline atadumwal & make it straight, go straight & (dumwal & go straight) \\
\hline katagayay & scatter & (gayay & $\begin{array}{l}\text { disintegrate, } \\
\text { disappear) }\end{array}$ \\
\hline atageg & not hit him properly & (geg & to be bad) \\
\hline katagimeg & clean dirt off something & (gimagim & clean) \\
\hline katagulek & wreck, destroy & (katagulek $(w)$ & wreck, destroy) \\
\hline katakin & choose, sort out & (kin & look at) \\
\hline kataligen & listen & (ligen & hear, heed) \\
\hline katamkul & make something sink & (mukul & submerge) \\
\hline katavis & burst open & (vis & $\begin{array}{l}\text { strip something } \\
\text { into shreds) }\end{array}$ \\
\hline
\end{tabular}


(e) ta

\begin{tabular}{|c|c|c|c|}
\hline tamav & do nothing & $\begin{array}{l}\text { (simav } \\
\text { (mav }\end{array}$ & $\begin{array}{l}\text { stay doing nothing) } \\
\text { without reason) }\end{array}$ \\
\hline tabod & block it off & (sibod & block, obstruct) \\
\hline taboul & cut a hole in it & (kayboul & $\begin{array}{l}\text { poke a hole through } \\
\text { it) }\end{array}$ \\
\hline tabwed & block it & (sibwed & $\begin{array}{l}\text { block, obstruct, } \\
\text { stand in road of) }\end{array}$ \\
\hline tadadog & $\begin{array}{l}\text { weigh him down with } \\
\text { heavy load }\end{array}$ & (dadog & crooked) \\
\hline tadamoms & stand erect & (damoms & $\begin{array}{l}\text { taut, straight, } \\
\text { unsagging) }\end{array}$ \\
\hline tadidul & scratch it & (kaydidul & scratch) \\
\hline tagiyeil & demolish hill & (giyeil & landslide) \\
\hline $\operatorname{takop}(w)$ & scrape rubbish into heaps & $(k o p(w)$ & get pregnant) \\
\hline takwen & exchange & (kwen & $\begin{array}{l}\text { catch with rope or } \\
\text { sorcery) }\end{array}$ \\
\hline $\operatorname{tamumug}(w)$ & leader & (mug & go ahead) \\
\hline tasinal & avoid someone & (sinal & avoid someone) \\
\hline tasiyas & those people & (siyas & those) \\
\hline tawlat & teenage boy & (wlat & teenager dressed up) \\
\hline \multicolumn{2}{|c|}{ Multiple use of a single root: } & & \\
\hline dumwal & go straight & & \\
\hline kadumwal & show the right path & & \\
\hline $\begin{array}{l}\text { katadumwal } \\
\text { yadumwal }\end{array}$ & $\begin{array}{l}\text { make something go straight } \\
\text { to discipline }\end{array}$ & & \\
\hline
\end{tabular}

APPENDIX 2: Iduna derivational prefixes

Material culled from Huckett (1982).

(a) ve

\begin{tabular}{|c|c|c|c|}
\hline ve?abaga & live with someone & (abaga & place of doing things) \\
\hline ve?afa & go down into soil & (afana & seed) \\
\hline ve?agetoga & become a servant & (agetoga & menial servant) \\
\hline ve?avalana & load someone up & (avalana & carry on shoulder) \\
\hline vebalauma & become a spirit & (balauma & spirit, ghost) \\
\hline vebe?una & drop something from hand & $\left(b e^{?} u\right.$ & fall down) \\
\hline vebulubulu & get black (of yam) & (bulubulu & black pig) \\
\hline vebwaneni & become dirty & (bwanene & dirt) \\
\hline vedamana & adopt, copy & (damana & to cross river etc.) \\
\hline vehifuga & conceive & (hifuga & pregnant) \\
\hline vekaliva & become a man & (kaliva & $\operatorname{man})$ \\
\hline
\end{tabular}


(b) $1 u$

\begin{tabular}{|c|c|c|c|}
\hline lu?afo?ano & charm (yams) & $(a f o ? a$ & magic charm) (sung) \\
\hline lu?afuna & hold something big under arm & (afuna & put handle on knife) \\
\hline lu?alala & sing & (alala & songs) \\
\hline lu?avala?eya & carry on shoulder & (avalana & carry on shoulder) \\
\hline lubaiba & put in crosswise log & (bai & crosswise stick) \\
\hline lubaibodana & close of $f$ with bai & (boda & close off) \\
\hline lubaikuna & pierce something upright & (kuna & push stick in) \\
\hline lubalena & make terraces & (balebalena & $\begin{array}{l}\text { lying down } \\
\text { horizontal) }\end{array}$ \\
\hline lubodana & close book & (boda & enclose, block) \\
\hline lufifina & draw circle & (fifi & curl round) \\
\hline lufuwana & hatch, break open (egg) & (fuwana & break, crush) \\
\hline
\end{tabular}

(c) $k i$

\begin{tabular}{|c|c|c|c|}
\hline ki?amo?amona & mould, fashion with hands & (amana & mould (clay)) \\
\hline kibahina & throttle, strangle & (bahibahi & small clam) \\
\hline kibakabakalina & pick to pieces (bird, of nest) & (bakalina & disintegrate) \\
\hline kibalebalena & hold horizontally & (balebalena & $\begin{array}{l}\text { lying down } \\
\text { horizontal) }\end{array}$ \\
\hline kibodana & $\begin{array}{l}\text { enclose underpart of house, } \\
\text { blot out (sun) }\end{array}$ & (boda & enclose, block) \\
\hline kibwadina & patch a hold & (bwadina & patch) \\
\hline kibwa?ena & touch something & (bwa?ena & touch) \\
\hline kidalina & make dam & (dalina & plaster nest) \\
\hline kifanina & misjudge & (fanifani & ignorant) \\
\hline kihawahawa & count & (hawana & count) \\
\hline kihobuye & $\begin{array}{l}\text { turn lamp down, lower } \\
\text { (of reputation) }\end{array}$ & (hobu & go down) \\
\hline & & & \\
\hline aiyega & clearing & (yegayega & get clean) \\
\hline aibabala & accusation of flirting & (babala & charm) \\
\hline aibawe & crawl & (bawe & pig) \\
\hline aiboda & cover drum with skin & (boda & close in, block) \\
\hline aibo?u & stack bundle & $(b o ? u$ & bundle, stack) \\
\hline aibubuna & creation, making & (bubuna & make, create) \\
\hline aidaba(na) & bring to a close & (dabana & bring to end) \\
\hline aidaka & break away, divide (bananas) & (dakana & $\begin{array}{l}\text { break away, divide } \\
\text { (banana)) }\end{array}$ \\
\hline aidobo & break off (of tree) & (dobona & break off) \\
\hline
\end{tabular}


(e) luve

\begin{tabular}{|c|c|c|c|}
\hline luvealika & kill & (alika & die) \\
\hline luvebowana & dark brown & (bowabowana & black) \\
\hline luvedamana & $\begin{array}{l}\text { switch promised gift, remake } \\
\text { something }\end{array}$ & (damana & $\begin{array}{l}\text { to cross } \\
\quad(\text { river etc.)) }\end{array}$ \\
\hline luvedayagina & cause blood to flow & $\begin{array}{l}\text { (dayaga } \\
\text { (dayagana }\end{array}$ & $\begin{array}{l}\text { blood) } \\
\text { his blood) }\end{array}$ \\
\hline luvedubana & sprinkle (something) & (dubadubana & wet) \\
\hline luvefota & be dependent on someone & (fotana & $\begin{array}{l}\text { stick to } \\
\text { (something) }\end{array}$ \\
\hline luvehayahayana & (to) dry hands & (hayahayana & dry) \\
\hline luve?ivaguna & make new & (ivaguna & new) \\
\hline luvekilumina & decorate & (kilumina & $\begin{array}{l}\text { decorate } \\
\text { something) }\end{array}$ \\
\hline luvelakavina & pile up & (lakavina & $\begin{array}{l}\text { climb (tree), break } \\
\text { out on skin) }\end{array}$ \\
\hline
\end{tabular}

(f) kive

\begin{tabular}{|c|c|c|c|}
\hline kivebwadina & kill (by rough handling) & (bwadina & patch) \\
\hline kivebalana & stop, prevent from going & (bala & $\begin{array}{l}\text { walk along, cross } \\
\text { over) }\end{array}$ \\
\hline kivebelona & be bent, bend something & (belo & bend, wrap) \\
\hline kivebe?una & drop from hand & $\left(b e^{?} u\right.$ & fall down) \\
\hline kivebutana & make wet by hands & (butabutana & wet) \\
\hline kivebwanenena & defile, make dirty & (bwanene & dirt) \\
\hline kivedubana & make wet & (dubadubana & wet) \\
\hline kivefotana & stick together (with glue) & (fotana & $\begin{array}{l}\text { stick to) (of } \\
\text { plaster) }\end{array}$ \\
\hline kivehelolona & drain liquid & (helolona & drain liquid) \\
\hline kivefaiwalana & make someone strong & (faiwala & hold strongly) \\
\hline kive?ihayana & make easy & (ihayana & easy) \\
\hline \multicolumn{4}{|c|}{ ive - (general causative) } \\
\hline ivebikana & calm (heart) & (bikana & become pliable) \\
\hline ivedigagina & sweeten food & (digadigagina & sweet (taste)) \\
\hline ivehifugana & make pregnant & (hifugana & abdomen) \\
\hline ivehobu & $\begin{array}{l}\text { break power of spell } \\
\text { (love potion) }\end{array}$ & (hobu & go down) \\
\hline ivekabi?ona & to make small & (kabi?ona & small) \\
\hline ivekoyona & spoil, make bad & (koyona & bad, wrong) \\
\hline ivekwe?una & to go out (of firebrand) & (kwe?una & extinguish) \\
\hline ivelakahina & increase (of possessions) & (lakahina & great, large) \\
\hline ivelaube?una & level a hilly area & (laube?u & flat land) \\
\hline ivemanavina & tame & (manavina & pliable) \\
\hline
\end{tabular}


(h) Multiple use of single roots:

\begin{tabular}{|c|c|c|c|}
\hline boda & close in, block & & \\
\hline aiboda & cover drum with skin & & \\
\hline lubodana & close book & & \\
\hline kibodaboda & rescue & & \\
\hline kibodana & blot out (sun), block (ears) & & \\
\hline lauboda & wait for & & \\
\hline vealaboda & cook to seal blood & (ala & fenc \\
\hline dobona & break off & & \\
\hline aidobo & break off (of tree) & & \\
\hline udobona & break on or by something & & \\
\hline kidobona & break firewood (with hands) & & \\
\hline
\end{tabular}

APPENDIX 3: Dobu derivational prefixes

Material culled from J. W. Dixon (1970). General meanings are those supplied by Dixon.

(a) $e / p$

\begin{tabular}{|c|c|c|c|}
\hline eqare & to begin something & (qare & source) \\
\hline ?ebotana & become hungry (through fasting) & (botana & $\begin{array}{c}\text { become hungry } \\
\text { (normally)) }\end{array}$ \\
\hline ?eboda & to place food in baskets & (boda & group) \\
\hline edebadebana & $\begin{array}{l}\text { to argue about who will go } \\
\text { first (i.e. appoint a leader?) }\end{array}$ & (deba & $\begin{array}{l}\text { head } \\
\qquad>(\mathrm{ADJ}) \text { debadeba) }\end{array}$ \\
\hline egagara & to withhold something & (gagara & be barren) \\
\hline ?egesi & to miss mark & (gesi & (ADV) wrongly) \\
\hline enatuna & to give birth to... & (natu & child) \\
\hline ebunina & to capsize & (buni & to roll) \\
\hline ?egesi & to miss the mark & (gesi & wrongly) \\
\hline emanua & become an animal & (manua & an animal?) \\
\hline edena & cause to escape & (dena & flee) \\
\hline
\end{tabular}

(b) 10

\begin{tabular}{|c|c|c|c|}
\hline loaga & debt & (aga & article got on credit) \\
\hline lobau & replant yams & (bau & yam mound) \\
\hline lobelulu & make 'pshaw' sound & (belubelulu & to roar) (of bullroarer) \\
\hline loboda & $\begin{array}{l}\text { knot for fastening fish } \\
\text { through gills }\end{array}$ & (boda & group) \\
\hline lobware & eye of needle & (bware & to pierce) \\
\hline lobu?una & incestuous marriage & (bu?una & person of same totem) \\
\hline lodakadaka & be rough to the touch & $\begin{array}{l}\text { (daka } \\
\text { (dakadaka }\end{array}$ & $\begin{array}{l}\text { rough) } \\
\text { scratch something) }\end{array}$ \\
\hline lodobwadobwa & speak language badly & (dobwa & cut food into pieces) \\
\hline loetana & be above & (etana & place above) \\
\hline loguguya & to exhort & (guguya & to exhort) \\
\hline
\end{tabular}


(c) gi - (1) by hand, (2) by sundry means

\begin{tabular}{|c|c|c|c|}
\hline giapwesa & protrude from something & (apwesa & put something out) \\
\hline giata & to do four things & (ata & four) \\
\hline gianua & to repair house & (anua & house) \\
\hline gibaula & pinch (and hold) & (baula & still) \\
\hline gibibi & squeeze something & (bibi & squeeze something) \\
\hline gibuni & $\begin{array}{l}\text { invert, translate something } \\
\text { to answer riddle }\end{array}$ & (buni & roll canoe) \\
\hline gibubu & to prepare & (bubu & to make) \\
\hline gibwage & break portion of pot & (bwage & spoil edge) \\
\hline gidari & sexual abuse & (dari & sexual abuse) \\
\hline
\end{tabular}

(d) loe-(1) to cause to be, (2) to become

\begin{tabular}{|c|c|c|c|}
\hline $\begin{array}{l}\text { loegumwara } \\
\text { loegogona }\end{array}$ & $\begin{array}{l}\text { finish task or something } \\
\text { band together }\end{array}$ & $\begin{array}{l}\text { (gumwara } \\
\text { (gogona }\end{array}$ & $\begin{array}{l}\text { be finished) } \\
\text { gather weapons for } \\
\text { fighting) }\end{array}$ \\
\hline loegesi & do things wrongly & (gesi & wrongly) \\
\hline loemwawasa & to kill & (mwawasa & die, faint) \\
\hline loeowana & cause bewilderment & (owana & be bewildered) \\
\hline loeparu & make straight & (paruparu & straight) \\
\hline loesae & place food in pot & (sae & $\begin{array}{l}\text { come ashore to lay } \\
\text { eggs (of turtle)) }\end{array}$ \\
\hline & suspend something & (sanana & be suspended) \\
\hline loesalutua & happen suddenly & (salutua & grow rapidly) \\
\hline
\end{tabular}

(e) gie - (1) cause by hand or finger, (2) cause by other means

\begin{tabular}{|c|c|c|c|}
\hline giebaila & to make dirty & (baila & be dirty) \\
\hline giebobo?ana & repair, make good & (bobo?ana & be good) \\
\hline gieboi & work morning till night & (boi & become dark/light) \\
\hline giedada & force one's head back & (dada & stare up) \\
\hline giedau & cause to flow & $(d a u$ & run (water)) \\
\hline giededoni & cause to cry & (dedoni & to cry) \\
\hline giegwamumu & do something difficult & (gwamumu & $\begin{array}{l}\text { render someone } \\
\text { helpless) }\end{array}$ \\
\hline ienua & to defecate & (nua & soft) \\
\hline ienuana & waver in decision & (nuana & his mind) \\
\hline ietabe & carry something suspended & (tabe & $\begin{array}{l}\text { something to hang } \\
\text { suspended) }\end{array}$ \\
\hline
\end{tabular}

(f) Multiple use of single roots:

$\begin{array}{ll}\text { buni } & \text { to roll } \\ \text { gibuni } & \text { to turn something over, to translate } \\ \text { lobunibuni } & \text { to cause to roll, to roll (transitive) } \\ \text { ebunina } & \text { to capsize } \\ \text { ebunibuni } & \text { to roll (intransitive) }\end{array}$


APPENDIX 4: Mota verb prefixes

Data on possible derivational prefixes selected from Codrington (1885:282-284).

va causative .

vaesu to make to live, to save (esu to live)

vaga causative

vagaqoqo to multiply (qoqo many)

ge causative (lit. to make, do, act)

$\begin{array}{llll}\text { me ge esua } & \text { saved him } & \text { (me vaesua } & \text { saved him) } \\ \text { vat ge lot } & \text { make a pestle } & \text { (lot } & \text { pestle) }\end{array}$

ni we gege lologou he acts like a fool

na causative (lit. to make)

va causative (lit. to go $)^{2}$

vailo to visit

vatutu to encounter

var reciprocal

varvus beat each other

ma passive (Codrington means 'stative' not a true passive.)

$\begin{array}{llll}\text { masare } & \text { be tom } & \text { (sare } & \text { to tear) } \\ \text { malate } & \text { be broken } & \text { (late } & \text { to break) } \\ \text { mawora } & \text { to come apart } & \text { (wora } & \text { asunder) } \\ \text { maluqe } & \text { folded } & \text { (luqe } & \text { to fold) } \\ \text { malakalaka } & \text { to rejoice } & \text { (laka } & \text { kick up heels) }\end{array}$

ta be thought to have more the meaning of spontaneity

tatiotio to stagger

taavaava to miss footing

sa

sasaroro to come or sink down

tava (tama) the condition has come about by itself

$\begin{array}{llll}\text { tavaul } & \text { to come untied } & \text { (ul } & \text { to untie rope) } \\ \text { tavamesu } & \text { to fall down } & \\ \text { tavaroro } & \text { to sink down } & \\ \text { tavaraka } & \text { to rise up } & \\ \text { tavsare } & \text { torn } & \end{array}$

2 Presumably Codrington distinguished this use of vafrom the first va causative on the semantic grounds of movement. 
APPENDIX 5: Arosi verb prefixes

Definitions according to Fox (1978) with examples culled from dictionary.

?a prefix forming adjectives and verbs; rarely past participles

?a?ahi incline towards (?ahi bank up earth)

?ahiro keep coming and going (hiro go to and fro)

ha prefix to verbs and adjectives

\begin{tabular}{|c|c|c|c|}
\hline hat & tight, taut (of line) & (roro & pull tight) \\
\hline guru & chatter & (nguru & hum a song or chorus) \\
\hline
\end{tabular}

ha?a causative prefix, forming causative verbs, adverbs and adjectives. Not all verbs can take it; and of ten the meaning appears to be unaltered by the prefix, but in other cases the meaning of the verb is considerably altered. In the remaining cases the meaning is causative.

\begin{tabular}{|c|c|c|c|}
\hline $\begin{array}{l}\text { ha?a?a?ahi } \\
\text { ha?a?adu }\end{array}$ & $\begin{array}{l}\text { make incline } \\
\text { to rake }\end{array}$ & $\begin{array}{l}\text { (?a?ahi } \\
\text { (?adu }\end{array}$ & $\begin{array}{l}\text { incline towards) } \\
\text { rake garden) }\end{array}$ \\
\hline
\end{tabular}

hari reciprocal prefix...but in some cases the sense is altered...

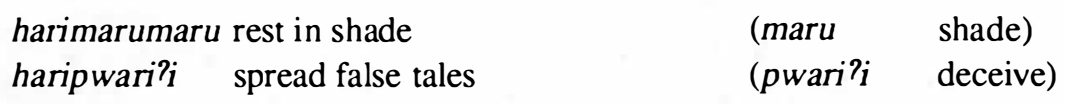

ma (reduplication maa) conditional prefix often forming a past participle (cf. mwa and mai)

\begin{tabular}{|c|c|c|c|}
\hline $\begin{array}{l}\text { maangia } \\
\text { maagari }\end{array}$ & $\begin{array}{l}\text { be distressed } \\
\text { to go and see }\end{array}$ & $\begin{array}{l}\text { (angi } \\
\text { (gari }\end{array}$ & $\begin{array}{l}\text { cry, sound off) } \\
\text { to go) }\end{array}$ \\
\hline
\end{tabular}

tai prefix of condition with adjectives and verbs (cf. ta)
taihiro to stir up (water)
(hiro
go to and fro (water))
taiduruduru to be entangled
(duru tie a knot)

tari a prefix to adjectives and verbs

tarihisia be narrow, confined

tariho?a take lone strides

tata a prefix of condition or continuous action

\begin{tabular}{|c|c|c|c|}
\hline $\begin{array}{l}\text { tatarahi } \\
\text { tatarau }\end{array}$ & $\begin{array}{l}\text { to sweep } \\
\text { creep along branch etc. }\end{array}$ & $\begin{array}{l}\text { (rahi } \\
(r a u\end{array}$ & $\begin{array}{l}\text { take/pick up from) } \\
\text { leaf) }\end{array}$ \\
\hline
\end{tabular}

wai a prefix to nouns, adjectives and verbs
waiasinga to fish or hunt
wai?atenga?i to drive away
(asinga
(atengi
to fish or hunt)
to send)
fish with coconut leaves)
(ho?a sit with legs apart)
(hisi fish trap, shutting in

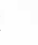


APPENDIX 6: Duke of York verb prefixes

Material culled from Brown and Danks (1882). General meanings supplied from the dictionary.

(a) wa causative particle

\begin{tabular}{|c|c|c|c|}
\hline wabalamati & comfort, control the passion & (balamat & restful, lazy (ADJ)) \\
\hline wabaraga & look kindly upon & (baraga & friendly (ADV)) \\
\hline wabenbeni & to lead & (benbeni & to lead) \\
\hline wadaraka & to lift up the face & (daraka & look up, lift up head) \\
\hline adokoi & to kill & (dokoi & $\operatorname{dead}(\mathrm{ADJ}))$ \\
\hline wagagai & to hasten & (gagai & quickly (ADV)) \\
\hline wagap & to wound & (gap & blood) \\
\hline wagarop & to joke, deceive & (garop & characterless, soft) \\
\hline agoi & strike a drum & (goigoi & dance) \\
\hline & & (goi & strike) \\
\hline agopi & to clothe & (gopi & bind, clothe) \\
\hline akaka & to spread/increase & (kaka & creep, crawl) \\
\hline
\end{tabular}

(b) ta prefix making some verbs passive

\begin{tabular}{|c|c|c|c|}
\hline tabanot & finish $(A D J)$ & (banotoi & to finish) \\
\hline taboro & to be broken & (bori & to break) \\
\hline tabongi & cover with smoke & (bongi & to cover) \\
\hline tadaraka & openly (ADV) & (daraka & look up) \\
\hline tadoko & to die (polite term) & (dokoi & dead) \\
\hline tagago & crawl (snake), be swift & (gago & swift (ADJ)) \\
\hline takaba & to split & $(k a b a$ & a cluster) \\
\hline takado & $\begin{array}{l}\text { straight, be straight } \\
\text { (passive of } k a d o \text { ) }\end{array}$ & (kado & straight (ADJ)) \\
\hline takudul & broken & (kudul & broken? (ADJ)) \\
\hline takuop & capsized, keel up (ADJ) & (kuopi & upside down) \\
\hline
\end{tabular}

(c) we (1) reciprocal particle prefixed to verbs, (2) nominaliser

\begin{tabular}{|c|c|c|c|}
\hline wedokoi & choke by twining around & (dokoi & dead) \\
\hline webarat & meeting place & (barat & in place of) \\
\hline webolo & carry stick between two & $\begin{array}{l}\text { (bolobolo } \\
\text { (boloi }\end{array}$ & $\begin{array}{l}\text { cross to other side) } \\
\text { across anything) }\end{array}$ \\
\hline webukula & to crowd upon & (bukulai & crowd together) \\
\hline webuta & carry on the back & (buta & carry child on back) \\
\hline wedaun & one on top of another (ADV) & (dauni & $\begin{array}{l}\text { be on top of } \\
\text { something) }\end{array}$ \\
\hline wedok & payment & (dok & repayment?) \\
\hline wekalik & tickle each other & (kalik & to tickle) \\
\hline wekoro & assemble in a place & (koro & assemble) \\
\hline welapang & $\begin{array}{l}\text { (1) give betel nut to visitors } \\
\text { (2) exchange betel nut }\end{array}$ & (lapanga & $\begin{array}{l}\text { give betel nut to } \\
\text { visitors) }\end{array}$ \\
\hline
\end{tabular}


(d) pam work, do, hold, take hold of

\begin{tabular}{|c|c|c|c|}
\hline pam a kabangpai & whiten & (kabang & white) \\
\hline pam a kotoi & hold fast & (kotoi & hold fast) \\
\hline pam a pulatai & blinded & (pula & blind person) \\
\hline pam ruai & finish & (ruai & finish) \\
\hline pam banotoi & make complete, finish & (banotoi & finish) \\
\hline pam kadoi & make straight & (kadoi & stretch out) \\
\hline pam kadopi $i$ & try to do & (kadopoi & try) \\
\hline pamkingera & catch & (kingera & be caught) \\
\hline pam kopoi/kopotai & leave some undone & (kopo/tai & miss something) \\
\hline
\end{tabular}

(e) pet about to do

$\begin{array}{llll}\text { pet bati } & \text { enclose } & \text { (bati } & \text { espouse) } \\ \text { pet biling } & \text { go or do slowly } & \text { (bilbiling } & \text { slow (ADV) } \\ \text { pet garanai } & \text { backbite/slander } & \text { (garanai } & \text { backbite, slander) } \\ \text { pet gati } & \text { cause to be taken out } & \text { (gati } & \text { pull up) } \\ \text { pet lele } & \text { bother/importune woman } & \text { (lele } & \text { good) } \\ \text { pet lukani } & \text { have a grudge } & \text { (lukan } & \text { hold a grudge) } \\ \text { pet paling } & \text { rich person } & \text { (paling } & \text { have property) } \\ \text { pet papai } & \text { be able to do } & \text { (papai } & \text { able (ADV)) } \\ \text { pet pilaka } & \text { redeem } & \text { (pilakai } & \text { wrench open the hand) }\end{array}$

(f) Multiple meanings with a single root:

$\begin{array}{ll}\text { dokoi } & \text { dead (ADJ) } \\ \text { wadokoi } & \text { to kill } \\ \text { wedokoi } & \text { to choke by twining around } \\ \text { pam doko } & \text { kill, extinguish } \\ \text { takoko } & \text { to die (polite term) }\end{array}$

\section{REFERENCES}

BECKER, A.L. and I Gusti Ngurah OKA, 1974, Person in Kawi: exploration of an elementary semantic dimension. Oceanic Linguistics 13:229-256.

BERLIN, B. and P. KAY, 1969, Basic color terms. Berkelcy: University of California Press.

BLOOMFIELD, Leonard, 1935, Language. London: Allen and Unwin. (1933 Amcrican Edition.)

BROWN, G. and B. DANKS, 1882, A dictionary of the Duke of York language, New Britain Group. MS placed on computer with preliminary cditing by Dean Moorc.

CAllister, Bill and Sandra CAllister, 1979, Grammar essentials of Misiman. MS.

CAPELL, A., 1943, The linguistic position of south-eastern Papua. Sydney: Australasian Medical Publishing Co.

1976, General picture of Austronesian languages, New Guinca arca . In S.A. Wurn, ed. New Guinea area languages and language study, vol 2, 5-52. PL, C-39.

CHOMSKY, Noam, 1957, Syntactic structures. The Hague: Mouton.

1965, Aspects of the theory of syntax. Cambridge: M.I.T. Press. 
CODRINGTON, R.H., 1885, The Melanesian languages. Reprint 1974. Netherlands: Philo Press.

DEMPWOLFF, Otto, 1927, Das austronesische Sprachgut in den indanesischen Sprachen. Folia Ethnoglossica 3:32-43.

1937, Vergleichende Lautlehre des austronesischen Wortschatzes. Band 2: Deduktive Anwendung des Urindonesischen auf austronesische Einzelsprachen. ZES Beiheft 17. Berlin: Dietrich Reimer.

DIXON, J.W., 1970, Dobu-English dictionary. Duplicated and bound at Salamo, P.N.G.

DIXON, R.M.W., 1971, A method of semantic description. In Danny D. Steinberg and Leon A. Jakobovits eds Semantics: an interdisciplinary reader in philosophy, linguistics and psychology. Cambridge: the University Press.

1976, Syntactic orientation as a semantic property. In James D. McCawly, ed. Syntax and semantics, vol.7: Notes from the linguistic underground, 347-363.

1977, Where have all the adjectives gone? Studies in Language 1/1:19-80. Reprinted in Dixon 1982. 1982, Where have all the adjectives gone? Berlin: Walter de Gruyter.

DUTTON, T.E., 1973, A checklist of languages and present-day villages of central and south-east mainland Papua. PL, B-24.

DYEN, Isidore, 1965, A lexicostatistical classification of the Austronesian languages. International Journal of American Linguistics, Memoir 19, 31/1.

ELSON, Ben jamin and Velma PICKETT, 1964, An introduction to morphology and syntax. Santa Ana: Summer Institute of Linguistics.

EZARD, Bryan, 1977, Tubetube's place among the Milne Bay Province languages: a synchronic study. Workpapers in Papua New Guinea Languages 21:135-153.

1978, Classificatory prefixes of the Massim Cluster. In S.A. Wurm and Lois Carrington, eds Second International Conference on Austronesian Linguistics: proceedings, 1159-1180. PL, C-61.

1980a, Reduplication in Tawala: including a comparison with Motu. Kivung 12/2:145-160.

1980b, Tawala verb classes: a pilot study. MS.

EZARD, Bryan and Janet EZARD, 1974, Tawala phonology. MS.

EZARD, Janet, 1970, Yamalele phonemics. MS.

FOX, Charles E., 1978, Arosi dictionary. Revised edition with English-Arosi index prepared by Mary Craft. $P L, \mathrm{C}-57$.

HAAS, Mary R., 1978, Linguistics and history. In Anwar S. Dil, ed. Language, culture and history, Chapter 20. Stanford: Stanford University Press.

HALLE, Morris, 1973, Prolegomena to a theory of word formation. Linguistic Inquiry 4/1, 3-16.

HOOLEY, Bruce A., 1970, Mapos Buang - Territory of New Guinea. PhD thesis, University of Pennsylvania.

HUCKETT, J.A., 1982, Iduna-English dictionary. MS.

JACKENDOFF, R.S., 1972, Semantic interpretation in generative grammar. Cambridge: M.I.T. Press.

LEHRER, Adrienne, 1974, Semantic fields and lexical structure. North-Holland Linguistic Series 11. Amsterdam: North-Holland.

LITHGOW, D., 1974, Muyuw dictionary. Ukarumpa: Summer Institute of Linguistics.

1976, Austronesian languages: Milne Bay and adjacent islands (Milne Bay Province). In S.A. Wurm, ed. New Guinea are languages and language study, vol.2, 441-523. PL, C-39.

LYNCH, John, 1973, Verbal aspects of possession in Melanesian languages. Oceanic Linguistics 12:69102.

LYONS, John, 1977, Semantics. London: Cambridge University Press.

McElHANON, K.A., 1971, Classif ying New Guinea languages. Anthropos 66:120-144.

NIDA, E., 1949, Morphology. Ann Arbor: University of Michigan Press.

PAISAWA, Elsie, Louise PAGOTTO and Joan KALE, 1976, A short sketch of Are (or Mukawa), Milne Bay, Papua New Guinea. UPNG Department of Language Occasional Paper No.2. 
PAWLEY, Andrew, 1972, On the internal relationships of Eastern Occanic languages. In R.C. Green and M. Kelly, eds Studies in Oceanic Culture History, vol.3, 1-142. Pacific Anthropological Records 13. Honolulu: Bishop Museum.

1973, Some problems in Proto-Occanic grammar. Oceanic Linguistics 12: 103-188.

ROSS, Malcolm D., 1983, Milnc Bay lexicon. Computer print-out.

1988, Proto Oceanic and the Austronesian languages of western Melanesia. PL, C-98.

SAPIR, Edward, 1921, Language: an introduction to the study of speech. New York: Harcourt, Brace \& World.

SCHACHTER, Paul, 1985, Parts of speech systems. In Timothy Shopen, ed. Language typology and syntactic description, 3-61. Cambridge University Press.

SIMONS, Gary F., 1982, Word taboo and comparative Austronesian linguistics. In Amran Halim, Lois Carrington and S.A. Wurm, eds Papers from the Third International Conference on Austronesian Linguistics, vol.3, 157-226. PL, C-76.

SPENCE, N.C.W., 1961, Linguistic fields, conceptual systems, and the Wcltbild. Transactions of the Philosophical Society, 1961, 87-106.

WEINREICH, Uriel, 1966, Explorations in semantic theory. In T.A. Scbcok, ed. Current Trends in Linguistics, vol.3: 395-477. The Hague: Mouton.

WIERZBICKA, Anna, 1980, The case for surface case. Ann Arbor: Karoma. 


\section{GUMAWANA (AMPHLETT ISLANDS, PAPUA NEW GUINEA): GRAMMAR SKETCH AND TEXTS \\ CLIF OLSON}

\section{INTRODUCTION ${ }^{1}$}

\subsection{BACKGROUND}

The Gumawana language is the native language of approximately 350 people located on the Amphlett Islands of the Milne Bay Province of Papua New Guinea. There are some 28 islands that make up the Amphletts, four of which are inhabited: Nubogeta, Gumawana, Omea and Bituma. (See Map 4). The Amphletts are a part of the D'Entrecasteaux group of islands some 65 kilometres north of the easternmost tip of Papua New Guinea. Most maps do not show all the Amphletts because of their small size. The four main islands are each no bigger than ten square kilometres, and Nubogeta is the smallest with an area of approximately one square kilometre. Because they are so small there are no airstrips, and therefore they are only accessible by boat.

The Amphlett people are renowned for their clay pot making, which has been the focus of most research in the Amphletts thus far. They are also a major link in the well-known Kula ring made famous by Malinowski's research in the early 1900s. Because of their extensive trading, they have some knowledge of many of the neighbouring languages such as Kilivila, Dobu, Basima, Bosalewa, Yamalele, Kalokalo and Bwaidoka. (See Map 5). The language that has had the greatest influence on Gumawana has been Dobu, which is the language used by the United Church. Both Dobu and Gumawana are used in church services, but most people tend to mix many Dobu words into their Gumawana, sometimes citing both the Dobu and the Gumawana. In everyday speech, the Dobu component greatly decreases; however, Dobu syntax continues to affect it. The Gumawana language is in the midst of change possibly due to this influence from Dobu.

\footnotetext{
${ }^{1}$ Editor's note: This paper was written by Clif Olson as part of his language program with the Summer Institute of Linguistics. The purpose of this program is the translation of the New Testament into the Gumawana language. The paper has been edited quite heavily for publication purposes, but the author's analysis remains basically unchanged.
} 


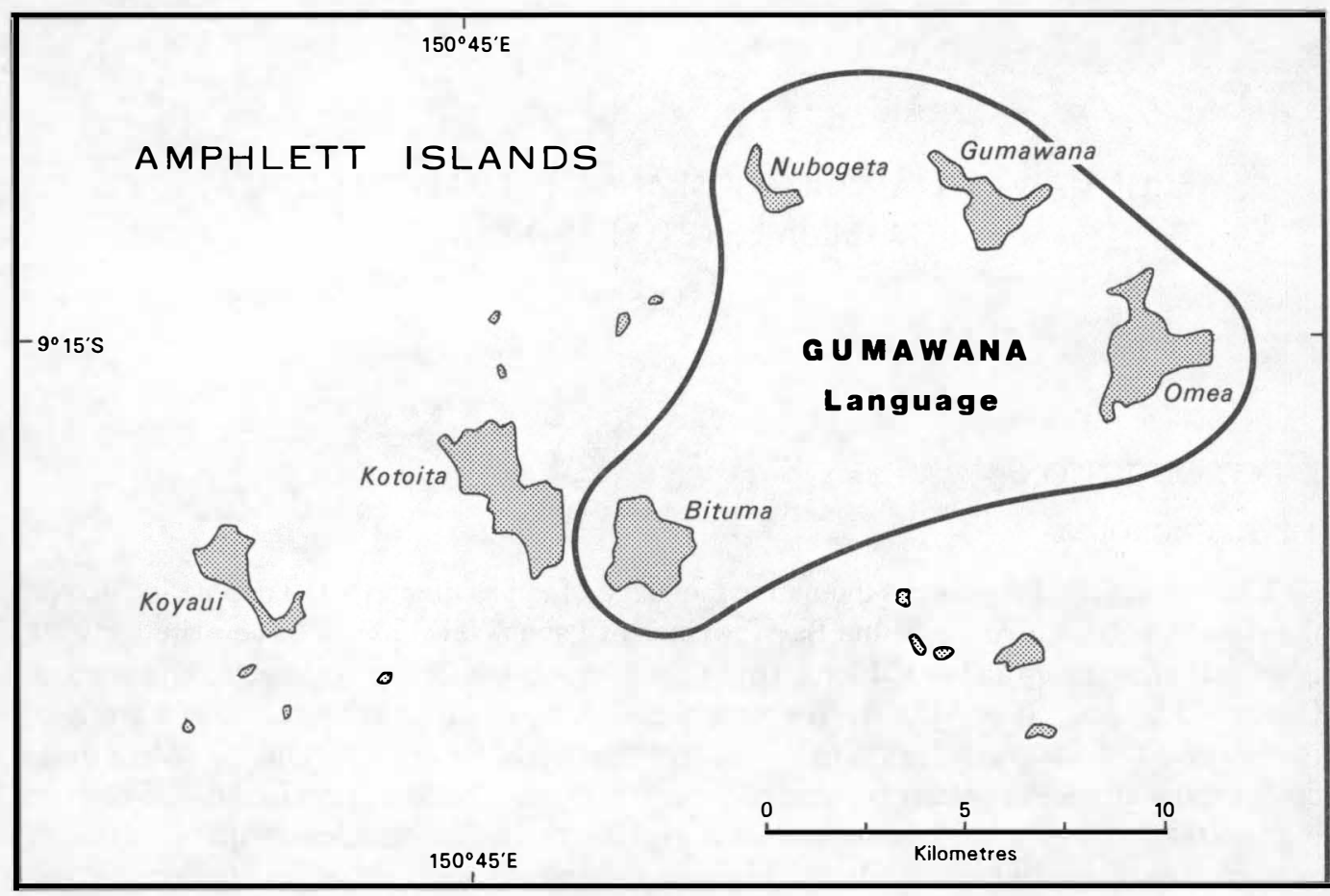

MAP 4: THE GUMAW ANA LANGUAGE AREA

\subsection{LINGUISTIC RESEARCH}

In the literature the Gumawana language is referred to as 'Gumasi'. However, 'Gumasi' is what the Trobriand Island people to the north call the language. It is agreed amongst the people that their language should be called Gumawana, and I therefore refer to it as such.

Gumawana belongs to the large Oceanic subgroup of Austronesian languages, but is considered by Lithgow (1976) to be an isolate in relation to its Austronesian neighbours in the Milne Bay Province. In comparing Gumawana with both Dobu to the south and Kilivila to the north, it appears that there are significant grammatical differences between them. Lithgow lists Gumawana as being $47 \%$ cognate with the Dobu family and $38 \%$ with the Muyuw family. There are similarities in the pronominal system with languages on the mainland. Ross (1988:212) tentatively suggests that Gumawana belongs to the North Mainland/D'Entrecasteaux linkage of the Papuan Tip cluster; that is, that it is more closely related to the languages of the D'Entrecasteaux Islands to the south than to Kilivila, although it has been influenced within the latter.

The first recorded work by someone who visited the Amphletts is by Bronislaw Malinowski in 1920. His work in Argonauts of the Western Pacific gives a small amount of data which he collected during his visit in 1915. No other work to my knowledge was carried on or recorded until Lauer (1974) did his fairly extensive research of pottery in the D'Entrecasteaux group. Lauer included a word list comparing the Omea, Gumawana and Nubogeta dialects with Bituma (see section 11.2), and a list of the key terms used in pottery making. Lithgow (1976) also gives a word list and a small amount of data. Lauer's word list is compared with mine in section 11 . 


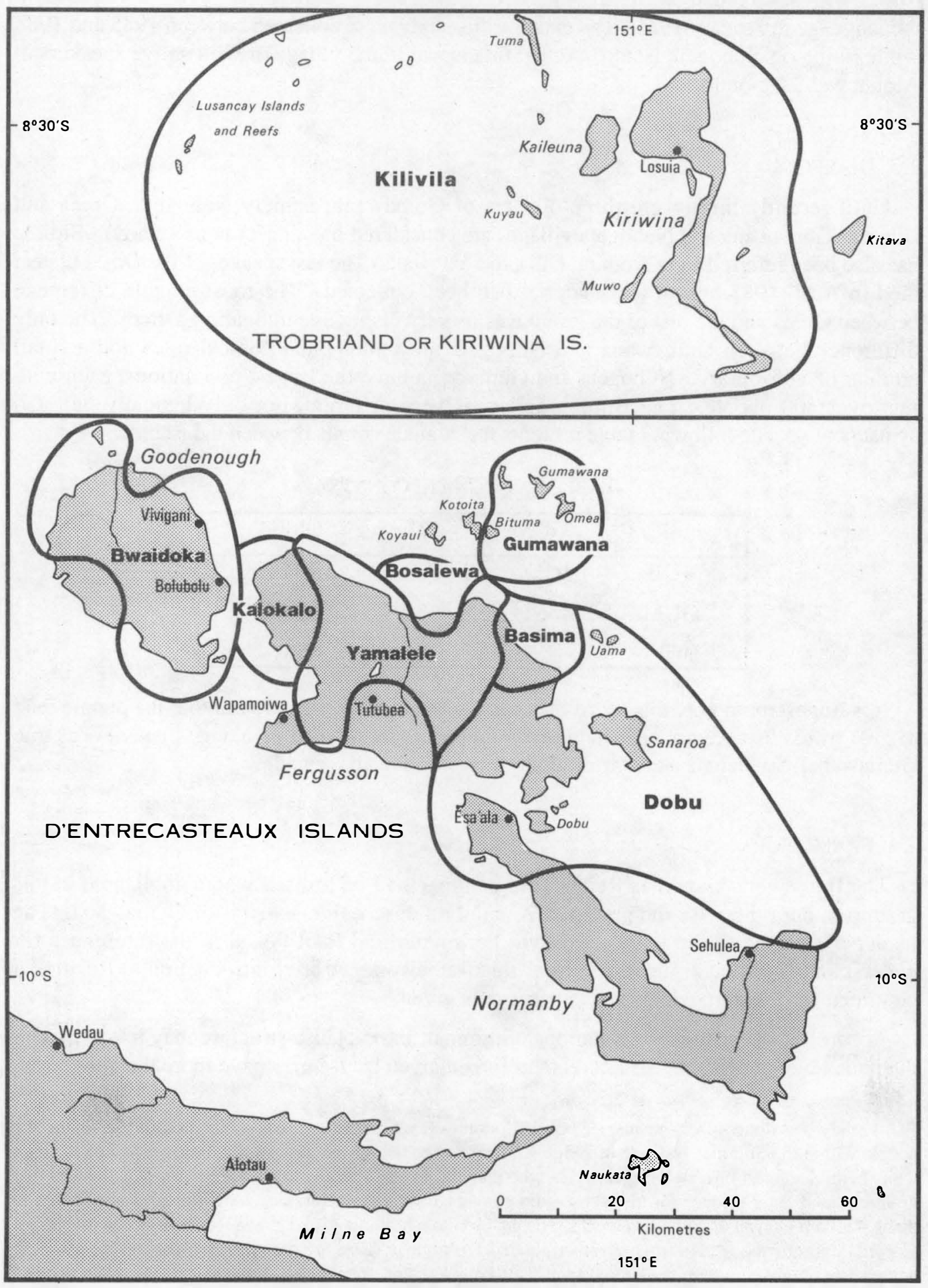


My wife and I did an initial survey in September 1984, before actually beginning to learn the language in January 1985. The data for this study were collected between 1985 and 1988 while living on Nubogeta Island. Actual time spent in the village or with native speakers in Alotau was 24 months. $^{2}$

\subsection{DiALECTS}

Until recently there were three dialects of Gumawana, namely Nubogeta, Omea and Bituma (Gumawana and Nubogeta villages are considered one dialect in this study). Bituma has also been referred to as Kotoita, Dilia and Yabwaia. The last speaker of the Omea dialect died in April 1988 but no text material had been collected. The most notable difference between Omea and the rest of the group was its very distinctive intonation pattern. The only difference between Gumawana and Nubogeta are minor phonological rules and a small amount of vocabulary. Nubogeta and Gumawana have the largest populations, each with just over 100 people. The Bituma dialect is very different, not only lexically but also syntactically. The following table presents the cognate counts between the islands.

TABLE 1: COGNATE COUNTS

\begin{tabular}{|llll|}
\hline & GUM & BIT & OMEA \\
\hline NUB & $92 \%$ & $73 \%$ & $80 \%$ \\
GUM & & $67 \%$ & $82 \%$ \\
BIT & & & $66 \%$ \\
\hline
\end{tabular}

It is important to note that word lists can be deceiving. I have found that the people tend to give words that are not used in everyday speech; instead they give what they view as true Gumawana. So there is a certain amount of error in the above table.

\subsection{FRAMEWORK}

The framework known as Relational Grammar will be utilised where applicable in this grammar, but otherwise the grammar is mainly a descriptive analysis of Gumawana. The reader is referred to the works of David Perlmutter and Paul Postal in the references for understanding of and argumentation for this framework. A brief introduction to Relational Grammar for the purposes of this paper is now given.

According to Perlmutter's Relational Grammar, basic clause structure may involve more than one level of syntactic structure; therefore, a given clause may have more than one level.

\footnotetext{
${ }^{2}$ This study was done under the auspices of the Summer Institute of Linguistics. I would like to thank two people within the Summer Institute of Linguistics who have helped me in writing this paper and have given many helpful suggestions: Bob Bugenhagen, who read through the paper and gave me many new insights into grammar, and Russ Cooper for his many radio conversations and discussions. Most of all I would like to thank Kalitoni Gaiyau of Nubogeta Island. His understanding of how his language works has been invaluable to me. Many of the ideas in his paper originated with him. There are many more people who could be named from Nubogeta who have taught me their language and spent hours working on text material. My good friend Topiyo Mulolu was an excellent language teacher and extremely patient with me as he taught me how to speak his language. Finally, thanks go to my wife, Roxanne, for having put up with my linguistics and frustrations for the last three years and for patiently listening to my ideas.
} 
These levels are referred to as initial and final. It is at the initial level that the grammatical relations of subject, direct object and indirect object are determined by the semantic roles. In other words, agents are initial subjects, patients initial direct objects, recipients indirect objects, etc.

Relational Grammar claims that a clause is underlyingly neither transitive nor intransitive, rather each stratum or level is described as either transitive or not. Therefore, a transitive stratum is one that has a subject and a direct object. There are two types of intransitive strata. One has a subject but no direct object, the other has a direct object but no subject. In the case of the latter, the direct object advances to subject. It should also be noted here that grammatical relations are taken as primitives in Relational Grammar. Argumentation for these notions is given by Perlmutter (1978) and Rosen (1981).

The phonological analysis is phonemic, but I have used Clements and Keyser's (1983) autosegmental framework to describe syllabification. A more complete phonology is in preparation.

All examples are written in the orthography currently proposed. Where phonemic rules are widespread throughout the language I account for these: for example, the phoneme $/ \mathrm{k} /$ has two allophones that are quite predictable, therefore only $k$ is written. This is true of $/ a / a s$ well since its allophones are predictable. The syllable $m u$ is also written as such because the rule for $/ \mathrm{u} /$ deletion is widespread throughout the language. Although there are a number of morphophonemic rules, I have not tried to base the orthography on the morphophonemic level, due to native speaker preference for a more phonetic orthography.

\subsection{TYPOLOGY}

In this section I give a brief typological sketch of Gumawana in relation to Greenberg's (1966) universals.

\subsubsection{MORPHOLOGICALLY}

Gumawana could be classified, morphologically, as an agglutinative language with a propensity toward being fusional. Example (1) illustrates this point. ${ }^{3}$

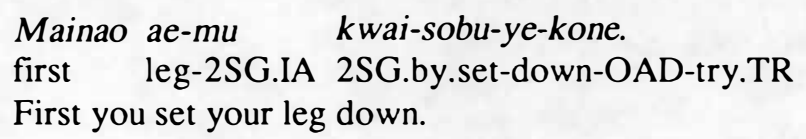

\footnotetext{
${ }^{3}$ Abbreviations used in the glosses are as follows: AGT - agentive nominaliser, BEN - benef active, CAUS causative, CERT - certainty, CL - classifier, COM - comitative, CON - control relationship, DEM demonstrative, DEV - devclopmental marker, DIR - directional, EAT - eating - intention to consume, EXC - exclusive, EXCL - exclamation, IA - inalienable, IMPER - imperfective aspect, INC - inclusive, INCH inchoative, INST - instrument, IRR - irrealis, LIM - limiter, LOC - locative, LOC.ADV - locational adverb, NEG - negation, NOM - nominaliser, NONDEV - non-developmental marker, OAD - oblique advancement to direct object, OI - old information, PASS - passive relationship, PER - perfective aspect, PL - plural, PLA.ADV - place adverb, PN - pronoun, POSS - possession, PP - postposition, PRF perfect aspect morpheme, PRO - prospective aspect, PUR - purpose, REA - reason, RECP - reciprocal, RDP - reduplication, REF - reference marker, REFL - reflexive, SG - singular, ST - stative, SW - switch of attention, TEMP - temporal, TM - tag marker, TR - transitive, UNCRT - uncertainty.
} 


\subsubsection{WORD ORDER TYPOLOGY}

Comrie (1981:89-96) identifies two major groups of languages on the basis of Greenberg's (1966) word order typology, namely Object-Verb languages (where the object precedes the verb) and Verb-Object languages (where the object follows the verb). The basic word order typology for an Object-Verb language is:

(a) object + verb;

(b) noun phrase + postposition;

(c) possessor noun phrase + possessed noun phrase;

(d) either adjective + noun or noun + adjective.

The basic word order of Gumawana is Subject-Object-Verb and it follows Greenberg's predictions for an Object-Verb language, with the pattern of noun + adjective rather than adjective + noun.

(a) subject + object + verb
$\mathrm{S}$
$\mathrm{O}$
$\mathrm{V}$

(2) Topiyo iyana badabada-i-di i-ginubasi-di.

Topiyo fish many-?-3PL.IA 3SG-spear-3PL

Topiyo speared many fish.

(b) noun phrase + postposition

(3)

Vada goi i-siu.

house PP 3SG-enter

He entered the house.

(c) possessor noun phrase + possessed noun phrase

(4)
I-tomo
vavina i-na-bayao
i-kabi.
3SG-next.day woman CON-3SG-basket 3SG-get
The next day the woman got her basket.

(d) noun + adjective
Steve i-na-buki gagai-na
Steve CON-3SG-book big-3SG
Steve's big book

\section{PHONOLOGY}

This section provides a brief and tentative description of Gumawana phonology. A more detailed phonological analysis is in preparation. The rules are provided as the basis for the grammatical analysis, and no formal rule ordering is given, although rules are presented roughly in their sequence of application. 


\subsection{PHONEMES}

The following chart illustrates the phonemes for Gumawana.

CONSONANTS

$\begin{array}{lcccc} & \text { Bilabial } & \text { Labio-dental } & \text { Alveolar } & \text { Velar } \\ \text { Stops voiced } & b & & d & g \\ \quad \text { voiceless } & p & & t & k \\ \text { Fricatives } & & v & s & \\ \text { Nasals } & m & & n & \\ \text { Lateral } & & & l & \end{array}$

\section{VOWELS}

Front Central Back

High close

Mid close

Low close

$\begin{array}{ll}i & u \\ e & o\end{array}$

\subsubsection{STOPS}

a

The stops contrast at labial, alveolar and velar points of articulation. All are unaspirated. $/ \mathrm{k} /$ has two allophones, $[\mathrm{k}]$ and $[\mathrm{x}] ; / \mathrm{k} /$ is realised as [x] between a non-high vowel or initial word boundary, and a non-high, back vowel. All the stops occur both word initially and word medially. $/ \mathrm{t}$ has the allophones $[\mathrm{t}]$ and $[\mathrm{s}]$; $/ \mathrm{t} /$ is realised as $[\mathrm{s}]$ before $[\mathrm{i}]$.

\subsubsection{NASALS}

The nasals contrast at labial and dental points of articulation. Both are voiced and can occur word initially and medially.

\subsubsection{FRICATIVES}

The fricatives contrast at labio-dental and alveolar points of articulation. Both $/ \mathrm{v} /$ and $/ \mathrm{s} /$ can occur word initially and word medially. The [s] is produced with tongue tip on the lower teeth and with the blade of the tongue in the alveopalatal area. / $/$ / has two allophones, [v] and $[w] ; / v /$ is realised as $[w]$ before front vowels.

\subsubsection{LATERAL}

The lateral $\Lambda /$ is in free fluctuation with the flap [r]. It is alveolar and may occur word initially or word medially. Some people place the tongue tip on the lower teeth using the blade to produce the sound, while others use the tongue tip in the alveolar position. 


\subsubsection{VOWELS}

The vowels contrast in high, mid and low tongue positions. The allophones of $/ \mathrm{a} /$ are [a] and [ə]. The latter occurs in unstressed syllables.

\subsubsection{SEMIVOWELS}

The semivowels [y] and [w] occur phonetically in Gumawana, but are not phonemic. When $/ \mathrm{i} /$ and / $\mathrm{u} /$ are assigned to a $\mathrm{C}$ in the skeletal tier of Gumawana syllable structure (see section 2.2) they are realised phonetically as [y] and [w]. All examples beyond this section are written using $y$ and $w$ for clarity.

The [y] has two phonetic shapes. The first is palatal and the second is fronted between a non-high vowel and a non-high, back vowel.

\subsubsection{CONTRASTIVE PAIRS}

The following pairs of words are contrastive.

\begin{tabular}{|c|c|c|c|}
\hline \multirow[t]{2}{*}{$\mathrm{b}: \mathrm{p}$} & $\begin{array}{l}\text { /tabo/ } \\
\text { /tapo/ }\end{array}$ & $\begin{array}{l}\text { ['tabo] } \\
\text { ['tapo] }\end{array}$ & $\begin{array}{l}\text { shoot } \\
\text { height }\end{array}$ \\
\hline & $\begin{array}{l}\text { /biu/ } \\
\text { /piu/ }\end{array}$ & $\begin{array}{l}\text { ['biu] } \\
\text { ['piu] }\end{array}$ & $\begin{array}{l}\text { pull } \\
\text { break wind }\end{array}$ \\
\hline \multirow[t]{2}{*}{$\mathrm{b}: \mathrm{v}$} & $\begin{array}{l}\text { /beba/ } \\
\text { /beva/ }\end{array}$ & $\begin{array}{l}\text { ['beba] } \\
\text { ['beva] }\end{array}$ & $\begin{array}{l}\text { butterfly } \\
\text { insides of fish }\end{array}$ \\
\hline & $\begin{array}{l}\text { /bala/ } \\
\text { /vala/ }\end{array}$ & $\begin{array}{l}\text { ['bala] } \\
\text { ['vala] }\end{array}$ & $\begin{array}{l}\text { across } \\
\text { message }\end{array}$ \\
\hline \multirow[t]{2}{*}{$\mathrm{b}: \mathrm{m}$} & $\begin{array}{l}\text { /iaban/ } \\
\text { /iaman/ }\end{array}$ & $\begin{array}{l}\text { ['yabana] } \\
\text { ['yamana] }\end{array}$ & $\begin{array}{l}\text { heaven } \\
\text { outrigger }\end{array}$ \\
\hline & $\begin{array}{l}\text { /boku/ } \\
\text { /moku/ }\end{array}$ & $\begin{array}{l}\text { ['boku] } \\
\text { ['moku] }\end{array}$ & $\begin{array}{l}\text { cough } \\
\text { bait }\end{array}$ \\
\hline \multirow[t]{2}{*}{$\mathrm{m}: \mathrm{n}$} & $\begin{array}{l}\text { /tamal } \\
\text { /tana/ }\end{array}$ & $\begin{array}{l}\text { ['tama] } \\
\text { ['tana] }\end{array}$ & $\begin{array}{l}\text { we (inclusive) come } \\
\text { we (inclusive) go }\end{array}$ \\
\hline & $\begin{array}{l}\text { /meta/ } \\
\text { /neta/ }\end{array}$ & $\begin{array}{l}\text { ['meta] } \\
\text { ['neta] }\end{array}$ & $\begin{array}{l}\text { braid } \\
\text { if }\end{array}$ \\
\hline \multirow[t]{2}{*}{$\mathrm{d}: \mathrm{n}$} & $\begin{array}{l}\text { /vada/ } \\
\text { /vana/ }\end{array}$ & $\begin{array}{l}\text { ['vada] } \\
\text { ['vana] }\end{array}$ & $\begin{array}{l}\text { house } \\
\text { skin disease }\end{array}$ \\
\hline & $\begin{array}{l}\text { /deba/ } \\
\text { /neba/ }\end{array}$ & $\begin{array}{l}\text { ['deba] } \\
\text { ['neba] }\end{array}$ & $\begin{array}{l}\text { bald } \\
\text { scar }\end{array}$ \\
\hline \multirow[t]{2}{*}{$\mathrm{t}: \mathrm{d}$} & $\begin{array}{l}\text { /tala/ } \\
\text { /dala/ }\end{array}$ & $\begin{array}{l}\text { ['tala] } \\
\text { ['dala] }\end{array}$ & $\begin{array}{l}\text { year } \\
\text { clan }\end{array}$ \\
\hline & $\begin{array}{l}\text { /neta/ } \\
\text { /neda/ }\end{array}$ & $\begin{array}{l}\text { ['neta] } \\
\text { ['neda] }\end{array}$ & $\begin{array}{l}\text { if } \\
\text { lice eggs }\end{array}$ \\
\hline
\end{tabular}




$\begin{array}{llll}\text { s:t } & \text { /masa/ } & \text { ['masa] } & \text { doubt } \\ & \text { /mata/ } & \text { ['mata] } & \text { die } \\ & \text { /sasa/ } & \text { ['sasa] } & \text { mad } \\ & \text { /tatav/ } & \text { ['tatava] } & \text { shake } \\ \text { l:d } & \text { /liu/ } & \text { ['liu] } & \text { to lift up } \\ & \text { /diu/ } & \text { ['diu] } & \text { to cut } \\ & \text { /vala/ } & \text { ['vala] } & \text { message } \\ & \text { /vada/ } & \text { ['vada] } & \text { house } \\ \text { n:l } & \text { /nava/ } & \text { ['nava] } & \text { still } \\ & \text { /lava/ } & \text { ['lava] } & \text { ame } \\ & \text { /sena/ } & \text { ['sena] } & \text { divide } \\ & \text { /sela/ } & \text { ['sela] } & \text { dig } \\ \text { i:e } & \text { /diu/ } & \text { ['diu] } & \text { dig out } \\ & \text { /deu/ } & \text { ['deu] } & \text { raft } \\ & \text { /kivi/ } & \text { ['kivi] } & \text { root of pandanus } \\ & \text { /kive/ } & \text { ['kive] } & \text { toward ocean } \\ \text { u:o } & \text { /baluma/ } & \text { [ba'luma] } & \text { type of sugarcane } \\ & \text { /baloma/ } & \text { [ba'loma] } & \text { spirit } \\ & \text { /tabu/ } & \text { ['tabu] } & \text { taboo } \\ & \text { /tabo/ } & \text { ['tabo] } & \text { sprout } \\ & \text { /ago/ } & \text { ['ago] } & \text { new information } \\ \text { a:e } & \text { ['ego/ } & \text { ['ego] } & \text { old information } \\ & \text { /niga/ } & \text { ['niga] } & \text { afterwards } \\ & \text { /nige/ } & \text { ['nige] } & \text { grub worm } \\ \text { a:o } & \text { /patu/ } & \text { ['patu] } & \text { enclose } \\ & \text { /potu/ } & \text { ['potu] } & \text { sore } \\ & & & \end{array}$

\subsection{SYLLABLE STRUCTURE}

Gumawana syllable structure may be conveniently described within Clements and Keyser's (1983) autosegmental framework, which views the syllable as a hierarchic structure of three tiers.

(1)

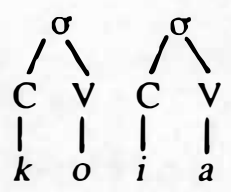

$$
\begin{aligned}
& \text { syllable tier } \\
& \text { skeletal tier } \\
& \text { segmental tier }
\end{aligned}
$$

Ito (1986) suggests that each language has a syllable template by which all possible syllable patterns may be derived for that particular language. For Gumawana the syllable template is very simple: $[(\mathrm{C}) \mathrm{V}]$, from which both a $[\mathrm{CV}]$ and a $[\mathrm{V}]$ pattern may be generated, as in $(2 b)$. 
$\begin{array}{lllll}\text { (2) a. /vada/ } & \text { ['vada] } & \text { [CV.CV] } & \text { house } \\ \text { b. lebulu/ } & \text { [e'bulu] } & \text { [V.CV.CV] } & \text { pandanus }\end{array}$

Autosegmental theory also gives a satisfactory account of words such as /kotal/.

(3) [kotal/ ['xotala] north-west wind

Because / kotal/ with its final consonant does not fit the syllable template, Gumawana requires the vowel [a] to be epenthesised. Ito refers to this as "stray epenthesis" (see 2.3.8). Syllable assignment is from left to right, placing a to the right of the final consonant.

(4)

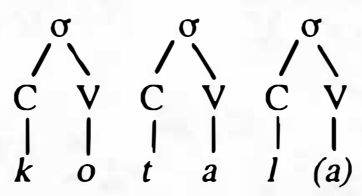

When underlying / $\mathrm{u} /$ and $/ \mathrm{i} /$ are assigned to a $\mathrm{C}$ at the sketetal tier they become phonetically $[w]$ and $[y]$. For example in (5) the $/ \mathrm{u} /$ receives a $C$ assignment, resulting in $[w]$.

(5)

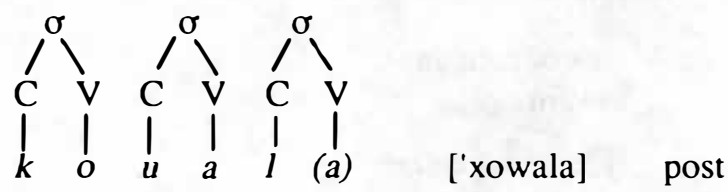

\subsection{PHONOLOGICAL AND MORPHOPHONEMIC RULES}

\subsection{1 $i$ AND $u$ DELETION RULES}

/i/ is optionally deleted between /s/ and voiceless stops (6a-b), and word finally following /s/ (6c).

(6) a. /si-paiseua/

[spai'sewa] / [sipai'sewa] they worked

3PL-work
b. /si-tagona/
[sta'gona] / [sita'gona]
they allowed
3PL-permit
c. /i-kapusi/
[ika'pus] / [ika'pusi]
he/she travelled
3SG-trip

/i/ is also optionally deleted between /n/, and /d/ (7a-b) or /s/ (7c).
(7) a. /i-vini-di/
[i'vindi] / [ivi'nidi]
he/she gave them
3SG-gave-3PL
b. /a-kani-di/
1SG-eat-3PL
[a'xandi] / [axa'nidi]
I ate them
c. /a-ginisi-mu/
1SG-pinch-2SG
[agin'sim] / [agini'sim]
I pinched you

$/ \mathrm{u} /$ is optionally deleted word finally after $/ \mathrm{p} /(8 \mathrm{a})$ and obligatorily after $/ \mathrm{m} /(8 \mathrm{a}-\mathrm{b})$ except in the syllable sequence /mumu/ (9d).
(8) a. /i-kakapu/
[ika'xap] / [ika'xapu]
it is easy
b. /sabamugo/
[sa'bamgo]
night 

c. /a-nimu/
[a'nim]
I drink
d. /i-tamumu/
[ita'mumu]
he hides

\subsection{2 a RAISING RULE}

In the environment _ $\mathrm{CV}$, where $\mathrm{V}$ is [i] or [e], /a/ is raised to [e] or [o], depending on the backness of the preceding vowel.
(9) a. /a-giual-i/
1SG-spit-TR
[agi'woli]
I spit at him
b. /a-vatetal-i/
[avate'teli]
I story about him
1SG-story-TR

\subsection{3 a TO o RULE}

/a/ become [o] word finally. Only in a small number of words does this rule apply.
(10) a. /a-dudua/
1SG-call
[adu'duo]
I call out
b. /a-diga/
1SG-say
[a'digo]
I say

When these verbs are transitive, we find the stem-final vowel /a/ coalescing with the transitive marker/-i/ to give [-e] (2.3.4). This indicates that the stem-final vowel is indeed /a/:
(11) a. /a-dudua-i/
[adu'due]
I call out to him
b. /a-diga-i/
[a'dige]
I talk about him

\subsubsection{THE TRANSITIVE MARKER -i: COALESCENCE}

There are various rules that apply to the transitive marker /-i/. These depend on the stemfinal vowel of the verb.

The only environment in which the transitive marker is realised as [-i] is when the stemfinal vowel is [o] followed by an object marker other than third person singular (in (12) the rules in 2.3.9 and 2.3.11 have applied to give [o]).
(12)
/a-kupuan-i-di/
[aku'poidi]
I cut them
1SG-cut-TR-3PL
b. /a-kupuan-i/
[a'kupo]
I cut it

If the stem-final vowel is $/ a /$, it obligatorily coalesces with the transitive marker /-i/ to become [-e], as in (13b) and (14b).
(13) a. /a-gita/
[a'gita]
I see
b. /a-gita-i/
[a'gite]
I see it
1SG-see-TR 

(14) a. /a-lusala/
[alu'sala]
I search
b. /a-lusala-i/
[alu'sale]
I search for it
1SG-search-TR

The only verb with stem-final /a/ to which this process does not apply is /tala/ 'to cut'.
(15) a. /a-tala/
[a'tala]
I cut
b. /a-tala-i/
[ata'lai]
I cut it
1SG-cut-TR

A possible explanation of this exception is that an underlying consonant has been deleted. Because / $/$ / deletion before /i/ or /e/ is so prominent, / $/$ / seems at first sight the most probable candidate for deletion here (2.3.13). That is, we posit the underlying transitive form /talav-i/, which does not undergo coalescence because / $/$ / deletion occurs after coalescence. However, I have not yet found any evidence for this hypothesis. ${ }^{4}$

\subsection{5 $i$ DELETION}

/i/ is deleted between non-high, non-front vowels ([e] is generated by the coalescence rule in 2.3.4).

$\begin{array}{lll}\text { (16) a. /a-taoia/ } & \text { [a'taoya] } & \text { I stood } \\ \text { 1SG-stand } & \text { [ava'taoe] } & \text { I stood it up } \\ \begin{array}{l}\text { b. /a-va-taoia-i/ } \\ \text { 1SG-CAUS-stand-TR }\end{array} & \text { I make it sway } \\ \begin{array}{l}\text { c. /a-kimoiamoia-i/ } \\ \text { 1SG-sway-TR }\end{array} & \text { [iomae'mae] } & \text { he's embarrassed } \\ \begin{array}{l}\text { d. /i-omaiamaia-i/ } \\ \text { 3SG-embarrass-TR }\end{array} & \text { [amwe'rae] } & \text { I climb with it } \\ \text { e. /a-muela-ia-i/ } & & \end{array}$

This rule also applies over morpheme boundaries, as exemplified in (16e).

\subsection{6 $k$ - DELETION RULE}

$/ \mathrm{k} /$ is deleted word initially before $/ \mathrm{a} /(17 \mathrm{~b}$ and $18 \mathrm{~b})$.

$\begin{array}{rll}\text { (17) a. /a-kauanoi/ } & \text { [axawa'noi] } & \text { I beg } \\ \text { 1SG-beg } & \text { [awa'noi] } & \text { beg } \\ \text { b. } \text { /kauanoi/ } & \text { [ikana'mimi] } & \text { he dreamed } \\ \text { (18) a. } / \text { i-kanamimi/ } & \text { 3SG-dream } & \text { dream } \\ \text { b. /kanamimi/ } & \text { [ana'mimi] } & \end{array}$

\footnotetext{
${ }^{4}$ Editor's note: Gumawana -tala 'cut' is derived from Proto Oceanic/Proto Papuan Tip *taRaq 'chop, adze'. Since * $q$ - is preserved in a number of Gumawana's neighbours as [?], $[\gamma]$ or [ $v$ ], a historical explanation for this exception is that a segment reflecting ${ }^{*}-q$ - has been deleted rclatively recently; that is, Olson's argument is diachronically valid, even if it is not supported synchronically.
} 
$/ \mathrm{k} /$ is also optionally deleted between $/ \mathrm{u} /$ and $/ \mathrm{a} /$. When this rule applies $/ \mathrm{u} /$ is realised as [w] (see 2.3.7).

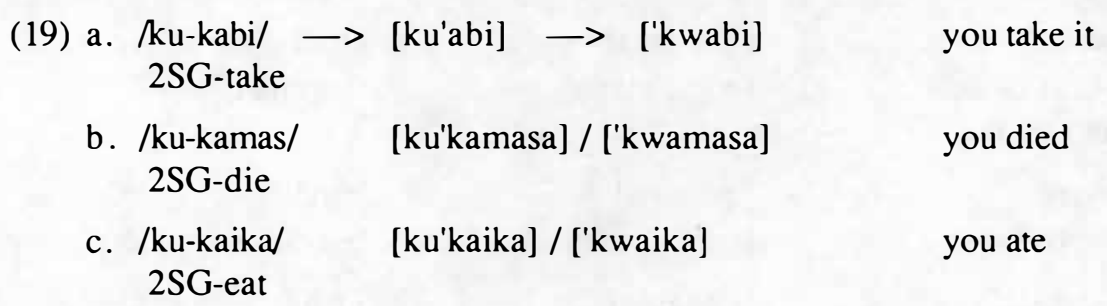

\subsection{7 $u$ TO $w$ RULE}

The sequences [pw bw mw kw gw] occur phonetically in Gumawana:

$\begin{array}{llll}b w & \text { /bobuala/ } & \text { ['bobwara] } & \text { to talk } \\ p w & \text { /puaiiuiu/ } & \text { [pwai'yuyu] } & \text { to smoke } \\ k w & \text { /vatulukuana/ } & \text { [vatu'lukwana] } & \text { to teach } \\ g w & \text { /neguasa/ } & \text { ['negwasa] } & \text { ocean } \\ m w & \text { /muela/ } & \text { ['mwera] } & \text { to climb }\end{array}$

I analyse the above sequences as underlyingly $C u$, where $/ \mathrm{u} /$ becomes $[\mathrm{w}]$ obligatorily between a bilabial or velar consonant and /a/ or /e/. There are almost no phonetic Cua or Cue sequences in the language where $\mathrm{C}$ is either a bilabial or a velar consonant. There are also no [twa] or [dwa] sequences.

So far I have found only two words which appear to contradict this analysis: [gabuaine] 'god' and [vatupue] 'push over'.

The former has also been heard as [gabwaine]. The latter is readily accounted for by examining the Omea dialect. Where in the Nubogeta dialect we find the intransitive form [vatupuo] and the transitive [vatupue], in Omea the [v] is retained, and we find the intransitive form [vatupuva] and the transitive [vatupuve]. It is clear that in Nubogeta the [wa] to [o] rule (2.3.11) has applied to the intransitive form and [v] deletion (2.3.13) to the transitive, which is underlyingly /vatupuva+i/ (2.3.4). Since the /u/ to [w] rule applies before the rules mentioned in this paragraph, the [pue] sequence is accounted for and is not an exception.

\subsubsection{EPENTHESIS}

Certain verbs and nouns are underlyingly consonant final. Since the syllable template for Gumawana is [CV] (see section 2.2), a word's syllable structure must conform on the surface to the template. In order for those nouns and verbs which are consonant final in their underlying form to match the template the vowel [-a] is added. Thus the syllable template explains the allomorphy found in the Gumawana verbs and nouns in (21) - (26); in each of these examples the underlying root is /CVCVC/. In the (b) and (c) parts of these examples, the root occurs followed by a vowel-initial suffix and the syllable structure therefore conforms to the template. In the (a) examples there is no suffixation, and the allomorph ends in $[-\mathrm{a}]$ resulting from epenthesis. 


\begin{tabular}{|c|c|c|}
\hline $\begin{array}{l}\text { (21) a. /iaman/ } \\
\text { b. /iamani-na/ }\end{array}$ & $\begin{array}{l}\text { ['yamana] } \\
\text { [yama'nina] }\end{array}$ & $\begin{array}{l}\text { outrigger } \\
\text { its outrigger }\end{array}$ \\
\hline $\begin{array}{l}\text { (22) a. /goman/ } \\
\text { b. /goman-ia-na/ } \\
\text { child-REF-3SG }\end{array}$ & $\begin{array}{l}\text { ['gomana] } \\
\text { [goma'niana] }\end{array}$ & $\begin{array}{l}\text { child } \\
\text { that child }\end{array}$ \\
\hline $\begin{array}{l}\text { (23) a. /patum/ } \\
\text { b. /patumi-na/ }\end{array}$ & $\begin{array}{l}\text { ['patuma] } \\
\text { [patu'mina] }\end{array}$ & $\begin{array}{l}\text { bundle } \\
\text { bundle of something }\end{array}$ \\
\hline $\begin{array}{l}\text { (24) a. /a-bagul/ } \\
\text { b. /a-bagul-i/ } \\
\text { c. /a-bagul-i-di/ }\end{array}$ & $\begin{array}{l}\text { [a'bagula] } \\
\text { [aba'guli] } \\
\text { [abagu'lidi] }\end{array}$ & $\begin{array}{l}\text { I plant } \\
\text { I plant it } \\
\text { I planted them }\end{array}$ \\
\hline $\begin{array}{l}\text { (25) a. /a-ginubasin/ } \\
\text { b. /a-ginubasin-i/ } \\
\text { c. /a-ginubasin-i-di }\end{array}$ & $\begin{array}{l}\text { [aginu'basina] } \\
\text { [aginu'basi] } \\
\text { [aginuba'sidi] }\end{array}$ & $\begin{array}{l}\text { I speared } \\
\text { I speared it } \\
\text { I speared them }\end{array}$ \\
\hline $\begin{array}{l}\text { (26) a. /a-ginin/ } \\
\text { b. /a-ginin-i/ } \\
\text { c. /a-ginin-i-di/ }\end{array}$ & $\begin{array}{l}\text { [a'ginina] } \\
\text { [a'gini] } \\
\text { [agi'nidi] }\end{array}$ & $\begin{array}{l}\text { I write } \\
\text { I write it } \\
\text { I write them }\end{array}$ \\
\hline
\end{tabular}

Examples (25b), (25c) and (26b), receive their surface shape through the application of $/ \mathrm{n} /$ deletion (2.3.9).

Further evidence of epenthesis is given in section 2.6, where stress placement is presented.

\subsection{9 $n$ DELETION RULE}

$/ \mathrm{n} /$ is deleted before the transitive marker /-i/, as illustrated by (25b), (25c) and (26b), in the previous section.

\subsubsection{0 v TO $w$ RULE}

$/ \mathrm{v} /$ may become $[\mathrm{w}]$ preceding $/ \mathrm{a} /$ at the end of a word.
(27) a. /a-seva-i-di/
[ase'vedi]
I gathered them
1SG-gather-TR-3PL
b. /a-seva/
[a'seo]
I gather
1SG-gather

In (27b) two rules are applied to the stem /seva/. The first is the rule which allows / $/$ to become $[w]$ and then the [wa] to [o] rule of section 2.3.11.

\subsubsection{1 wa TO o RULE}

[wa] become [o] word finally (27b) or before a CV sequence word finally where the $\mathrm{V}$ is a non-low vowel. This rule appears only to apply to verbs, and applies to [wa] resulting from the rules in section 2.2, 2.3.7 and 2.3.10. The non-low vowel of the environment may be [e] resulting from the coalescence rule in section 2.3.4. In each of the (a) examples 
below, the rule does not apply since the final vowel is low. However in the (b) examples the conditions for the rule are met.

(28) a. /a-uiauana/

$$
\text { [au'yawana] }
$$

I rejoice

1SG-rejoice

b. /a-uiauana-i/ [auiauane] $\rightarrow$ [auyawane] $\rightarrow$ [auya'one] I rejoice in him 1SG-rejoice-TR

(29) a. /a-bobuala/

1SG-speak

[a'bobwara]

I speak

b. /a-bobuala-i/ [abo'buare] $\rightarrow$ [abo'bware] $\rightarrow$ [abo'bore] 1SG-speak-TR

I speak about it

(30) a. /a-vainauan/

[avai'nawana]

I steal

1SG-steal

b. /a-vainauan-i/ [avainauai] $\rightarrow$ [avainawai] $\rightarrow$ [avainaoi] $\rightarrow$ [avai'nao] 1SG-steal-TR

I steal it

In (30b) deletions of $/ \mathrm{n} /(2.3 .9)$ and of $/-\mathrm{i} /$ (2.3.12) have also occurred.

\subsubsection{THE TRANSITIVE MARKER -i: DELETION}

The transitive marker /-i/ is always deleted after [u] (31) and [i] (32), and is also deleted after [o] when it occurs word finally (34).
(31) a. /a-gabu-i/
b. /a-gabu-i-di/
[a'gabu]
I burn it
[aga/budi]
I burn them
(32) a. /a-ginin-i/
b. /a-ginin-i-di/
[a'gini]
I write it
[agi'nidi]
I write them
(33) a. /a-kupuan-i/
[a'kupo]
I cut it
b. /a-kupuan-i-di/
1SG-cut-TR-3PL
[aku'poidi]
I cut them

Note that (32) also reflects [n] deletion (2.3.9), whilst (33) reflects [n] deletion and the [wa] to [o] rule (2.3.11).

Phonetically the sequences [ui] and [oi] do occur, but they are the result of $/ v /$ deletion (2.3.13), which applies after the deletion of the transitive marker. Note the following examples.
(34)
a. /a-lauv/ 1SG-hit
b. /a-lauv-i/
(35) a. /a-saioiov/ [alauva
[a'laui]
[asayo'yova]
b. /a-saioiov-i/
[asayo'yoi]
I hit him
I rinsed
I hit
I rinsed it

In $(34 a) / v /$ is not realised because of the application of the $/ v /$ to [w] rule (2.3.10) and [wa] to [o] rule (2.3.11), and in (34b) because of the $/ \mathrm{v} /$ deletion rule (2.3.13). The rule for deleting the transitive marker evidently precedes / $/$ deletion, and this explains why the transitive marker has not been deleted. In (35a) the intransitive form (with epenthetic [-a] 
shows that the $/ v /$ is present underlyingly, whilst for the transitive form in $(35 b) / v /$ deletion again accounts for the survival of the transitive marker.

\subsubsection{3 $v$ DELETION RULE}

$/ \mathrm{v} /$ is deleted before [e] and [i]. In some words it is optional, as in (36a-c), and in others it is obligatory, as in (36d).

(36)
a. /dedevi-na/ good-3SG
b. /a-nava-i/ 1SG-take-TR
c. /a-kauvisi-i/ 1SG-break-TR
d. /i-taligav-i/ 3SG-untie-TR

$$
\text { [de'deina] / [dede'vina] it is good }
$$
[a'nae] / [a'nave]
I took it
[axa'uis] / [axa'uvis] I broke it
[itali'gei]

In each of the above examples $/ \mathrm{v} /$ is deleted before /e/ or /i/. The coalescence rule feeds this rule, as in (36b).

\subsection{MORPHOPHONEMIC RULES AFFECTING SPECIFIC MORPHEMES}

As well as the rules affecting the transitive marker /-i/, presented above in their rough order of application, Gumawana has a number of morphophonemic rules which affect other specific morphemes.

\subsection{1 - mo}

The verbal suffix /-mo/ 'only, just' has the allomorphs [-yamo] and [-mo]. [-yamo] occurs on transitive verbs with third person singular objects. [-mo] occurs everywhere else. It appears that [-yamo] is underlyingly /-ia-mo/, where /-ia/ is historically the third person singular object marker.

$$
\begin{aligned}
& \text { /ku-tu-sobu-mo/ } \\
& \text { 2SG-by.sit-down-just } \\
& \text { Just sit down! }
\end{aligned}
$$$$
\text { [kutuso'bumo] }
$$

$$
\begin{aligned}
& \text { /a-gita-i-di-mo/ } \\
& \text { 1SG-see-TR-3PL-just } \\
& \text { I just watch them. }
\end{aligned}
$$

(39) /ku-kalava-i-ia-mo/ 2SG-leave-TR-3SG-just

You just leave it!

[agite'dimo]

\section{[kukalave'yamo]}




\subsubsection{LIMITER -ita}

The suffix /-ita/, which limits the scope of negation, has the allomorphs [-eta], [-yeta], [-ta] and [-ita]. The morpheme-initial /-i-/ of /-ita/ is treated similarly to the transitive marker /-i/, as discussed in sections 2.3.4 and 2.3.12 above.

Vowel coalescence (cf. 2.3.4) applies to sequences of /-a/ and the morpheme-initial /-i-/ of /-ita/. The [-a] may be the stem-final [-a] of an intransitive verb or the [-a] of an object suffix. Note that in (40) epenthesis of [-a] takes place, resulting in $/ \mathrm{kamasa} /$, before [-ita] is suffixed, giving - by coalescence - [eta].

$$
\begin{aligned}
& \text { /geia a-kamas-ita/ [ge axama'seta] } \\
& \text { NEG 1SG-die-LIM } \\
& \text { I didn't die }
\end{aligned}
$$

Example (41) illustrates coalescence of the [-a] of an object suffix.

$$
\begin{aligned}
& \text { /geia ku-gita-i-ma-ita/ } \\
& \text { NEG } 2 S \text { [geya kugite'meta] } \\
& \text { you didn't see us }
\end{aligned}
$$

The allomorph [-yeta] occurs only on transitive verbs which have third person singular objects. It appears that [-yeta] is underlyingly /-ia-ita/, where /-ia/ is again historically the third person singular object marker (cf. 2.4.1). Vowel coalescence again applies, producing [-yeta].
/geia a-iagoi-ia-ita/
NEG 1SG-know-3SG-LIM
[ge ayagoi'yeta]
I don't know it
/geia a-gabu-ia-ita/
NEG 1SG-burn-3SG-LIM
I didn't burn it
[ge agabu'yeta]

The allomorph [ita] occurs in all other instances except where the stem-final vowel of the verb is /u/or /i/; here the [-i] of [-ita] is deleted in the same way as the transitive marker /-i/ (cf. 2.3.12), resulting in [-ta].

NEG 1SG-sleep-LIM

I didn't sleep

/geia a-puaiiuiu-ita/

NEG 1SG-smoke-LIM

I don't smoke

$$
\begin{aligned}
& \text { /geia a-siu-ita/ } \\
& \text { NEG 1SG-enter-LIM } \\
& \text { I didn't enter }
\end{aligned}
$$

[ge amasi'sitą]

[ge apwaiyu'yuta]

[ge a'siuta]

\subsubsection{PLURAL MORPHEME}

The plural suffix /-iao/ has two allomorphs, [-yao] and [-ao]. /-iao/ is realised as [-ao] on nouns with inalienable suffixes ending in $/ a /$, and the resulting /a-a/ sequence becomes simply [a]. 
(47)

(48) /magi-iao/

/sina-da-iao/ mother-1PL.INC.IA-PL

/tama-ma-iao/ father-1PL.EXC.IA-PL [magi'yao] betel nut

[sina'dao] our mothers

[tama'mao] our fathers -

\subsection{STRESS}

With a few exceptions, stress falls on the penultimate syllable. Examples (50) - (53) illustrate stress placement in non-suspect words.

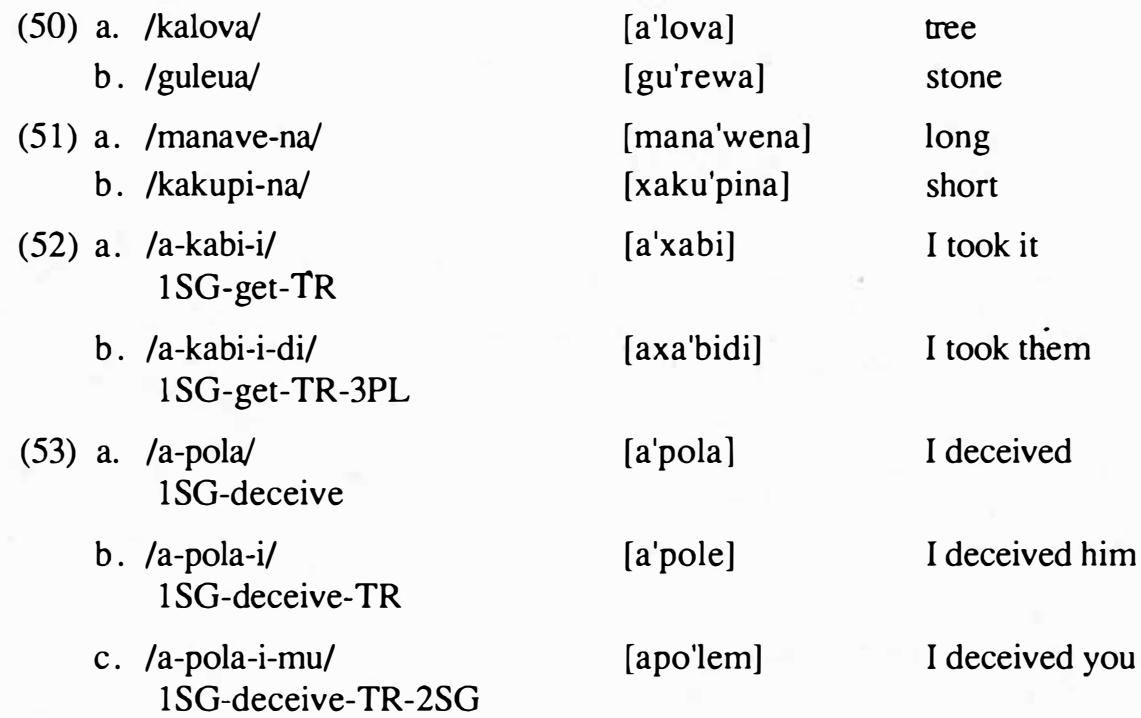

Phonetically there are many words that appear not to follow the above stress pattern; instead of the stress falling on the penultimate syllable it falls on the antepenult. Examples of antepenultimate stress are given in the (a) examples below. The (b) examples show penultimate stress with suffixation.

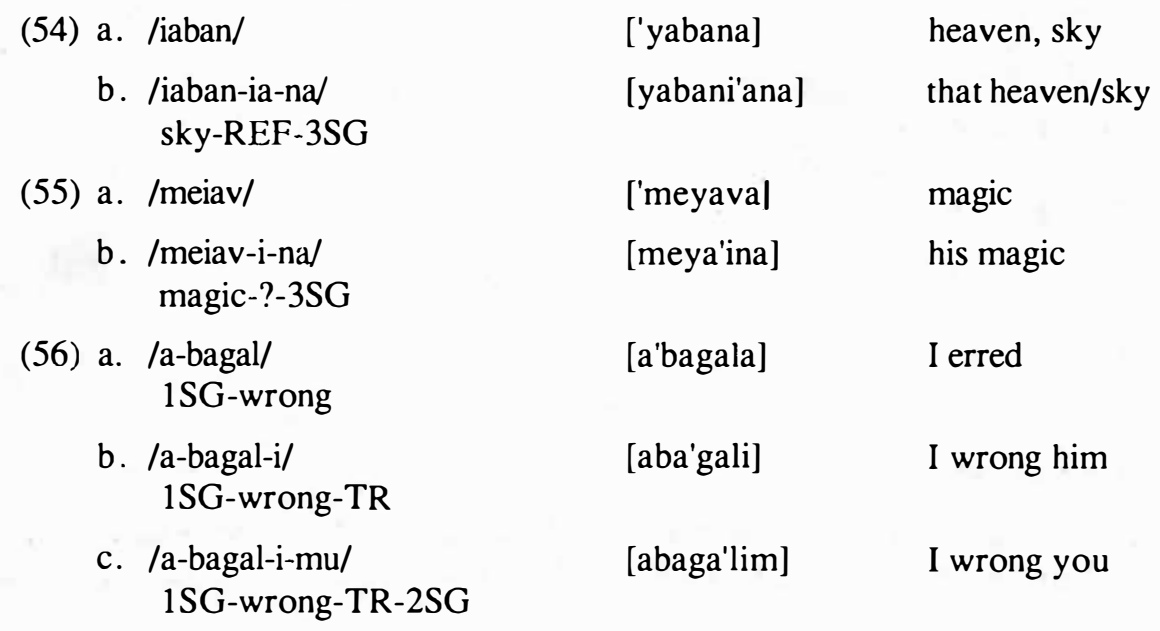


(57) a. /a-ioit/

1SG-hold.on

b. /a-ioit-i/

1SG-hold-TR

c. /a-ioit-i-di/ [a'yoita]

[ayo'isi]

[ayoi'sidi]
I held on

I held it

I held them

However, if it is recognised that stress placement occurs after suffixation but before the epenthetic vowel [-a] is added (2.3.8), then all these examples are accounted for.

There are a few exceptions to the regular stress pattem. In (58a) and (59a) the intransitive forms have stress on the antepenultimate syllable but the transitive forms follow the normal stress rule. The underlying form is not consonant final, so epenthesis does not occur, and yet the stress placements in (58a) and (59a) behave as if the final [-a] were epenthetic, and thus violate the rule. These are the only exceptions that have been found.

$(58)$
a. /a-bobuala/
b. /a-bobuala-i//
c. /a-bobuala-i-di/
b. /a-uiauana-i/
c. /a-uiauana-i-di//

(59) a. /a-uiauana/ [a'bobwara]

[abo'bore]

[abobo'redi]

[au'yawana]

[auya'one]

[auyao'nedi]
I talk

I talk about it

I talk about them

I rejoice

I rejoice in him

I rejoice in them

This concludes my brief description of the phonology, which requires further investigation.

\section{MORPHOLOGY}

\subsection{WORD CLASSES}

The major word classes of Gumawana are nouns, verbs, adjectives and adverbs. In addition to these, there are a number of minor word classes. The major classes are presented first, followed by a description of the minor classes.

\subsubsection{NOUN CLASSES}

A noun is a word that cannot be inflected with verbal morphology and may function as the sole argument of a verb. There are several classes of nouns in Gumawana, and these are described next. The classification of nouns interacts with the possessive system, which is presented in more detail in section 4.

\subsubsection{INALIENABLY POSSESSED NOUNS}

There is a class of nouns that is obligatorily inalienably possessed and require suffixes which mark the person and number of their possessor (see also section 4.1). This class includes items encoding body parts (1a), kinship terms (1b), partitives (1c) and spatial relationships (1d). 


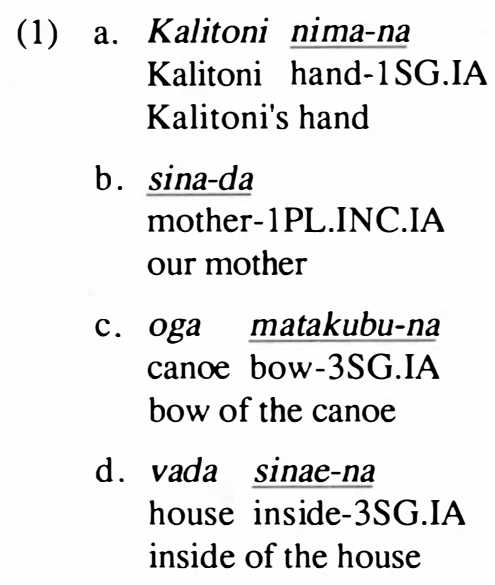

\subsubsection{INALIENABLY POSSESSED QUANTIFIER NOUNS}

Gumawana has four inalienably possessed quantifier nouns whose suffix marks the person and number of the noun which is being quantified.

$\begin{array}{ll}\text { badabada } & \text { many/number } \\ \text { manie } & \text { some } \\ \text { madabiki } & \text { all } \\ \text { liliu } & \text { all }\end{array}$

I have not been able to find any difference between madabiki and liliu.

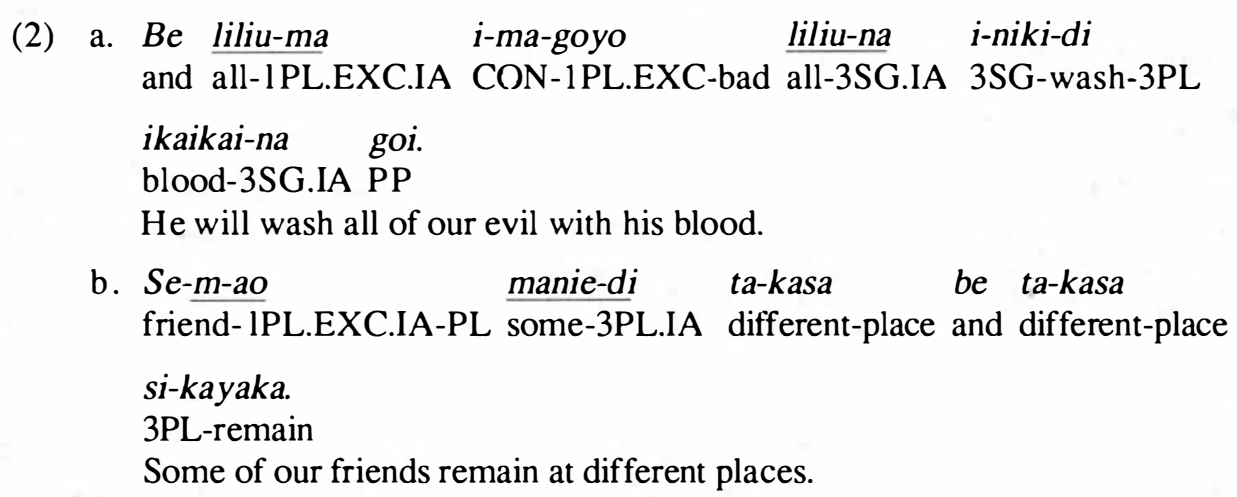

\subsubsection{ALIENABLY POSSESSED NOUNS}

Alienably possessed nouns (see also section 4.2 ) that are potentially consumable may occur with the 'eating' alienable possession marker a- (3a), as opposed to the controlled possession marker $i-(3 b)$.

(3) a. A-na-iyana i-ginubasina.

EAT-3SG-fish 3SG-spear

He speared his fish (for eating, non-referential). 


\section{b. Tau-ya-na i-na Kalitoni i-na-vada. person-REF-3SG 3SG-go Kalitoni CON-3SG-house He went to Kalitoni's house.}

\subsubsection{PERSON, PLACE OR THING}

Nouns can also be classed according to whether they encode persons, places or things. When people cannot remember the name of a thing they will pause with dogoi 'thing' (4a). For the name of a person they will use toi (4b) for a male and nai for a female. If the name of a place is forgotten (4c) nuwoi 'place' is used.

(4) a. Ka-sowodo ka-ma dogoi awoinu-ya-di bogina si-meo. 1PL.EXC-arrive 1PL.EXC-come thing food-REF-3PL PRF 3PL-be.done We arrived and came, (What?) the food was already cooked.

b. Kidi se-m-ao toi Dipastin i-katowana... 3PL.PN friend-1PL.EXC.IA-PL man Dipastin 3SG-be.sick As for them, our friends, (what's his name) Dipastin was sick...
c. Si-kabi si-na si-sou-ye nuwoi Nupaipoya. 3PL-take(TR) 3PL-go 3PL-descend-OAD.TR place Nupaipoya They took it and went and descended with it to (where?) Nupaipoya.

The distinction between male toi and female nai is being lost. It is common to hear a woman referred to as toi. A reduced form of these words is found prefixed to the names of men and women to make a distinction between them.

$\begin{array}{lll}\text { Kauseo } & \text { Nakauseo } & \text { The woman Kauseo } \\ \text { Bwaina } & \text { Tobwaina } & \text { The man Bwaina }\end{array}$

\subsubsection{COUNT/MASS NOUNS}

Nouns can also be divided into count nouns and mass nouns. Mass nouns do not allow third person plural agreement on the verb (5a); instead, they require third person singular verb agreement and third person singular inalienable possession (5b) on the quantifier noun badabada 'number, much' (3.1.1.2).

(5) a. *Ediedila si-dimodimo. sand 3PL-be.hot The sand is hot.

b. Loulou badabada-i-na i-kaiaka. coral much-?-3SG.IA 3SG-be.there Thre is much coral.

\subsubsection{HUMAN NOUNS}

The use of question words reveals the distinction between human and non-human nouns. When referring to humans the question word is ava-tau 'who/which person' (6a) and to nonhumans kaga 'what' (6b). 
(6) a. Go ava-tau geya i-na-vaega-mo, e i-kailova. SW which-person NEG CON-3SG-clay-any DEV 3SG-depart And whoever does not have any clay, then he departs.

b. Kaga vavagi-mu?

what desire-2SG.IA

What do you want?

\subsubsection{ADVERBS}

Adverbs can be distinguished from other words by the fact that they do not take nominal or verbal morphology. They "function as modifiers of constituents other than nouns" (Schachter 1985:20). In this section certain limited categories of adverbs are described. Adjectives may also function adverbially (see 5.3). Location adverbs form part of the demonstrative system and are discussed in 3.1.7.2.

\subsubsection{TIME ADVERBS}

The difference between time adverbs and time nouns is that time adverbs are not marked with the postposition goi whereas time nouns are (5.2.1.3).

Time adverbs normally occur clause initially. The following are some of the time adverbs found in Gumawana.

$\begin{array}{ll}\begin{array}{l}\text { boi(nimatu) } \\ \text { niga }\end{array} & \begin{array}{l}\text { long ago/before/last } \\ \text { afterwards } \\ \text { nava }\end{array} \\ \text { maine } & \text { still/later } \\ \text { boile } & \text { earlier today } \\ \text { kaitaga } & \text { yesterday } \\ \text { koneyuwe } & \text { recent past } \\ \text { konavasie } & \text { day after/before yesterday/tomorrow } \\ \text { konanima } & \text { four days after/before yesterday/tomorrow } \\ & \text { five days after/before yesterday/tomorrow }\end{array}$

(7)
a. Boi ka-na ka-uwo-uwata ame bei a-vatetel-i.

before 1PL.EXC-go 1PL.EXC-IMPER-net today PRO 1SG-story-TR

Today I will tell a story about the last time we went netting.

b. Maine nobuyana ka-taoya.

earlier moming 1PL.EXC-arise

Earlier, in the morning, we got up.

The perfect aspect marker bogina 'already' (8.2.2.1), which may occur either before or after the verb phrase, may also be regarded as a special category of adverb. The negation marker geya (8.5.1) has a similar distribution. 


\subsubsection{MODALITY MARKERS 5}

Modality markers are also conveniently treated as a kind of adverb, since they are not structurally part of the verb phrase in Gumawana, and may occur before the subject, between the subject and object, or before the verb phrase. Markers in this category are listed below, with references to the sections in which they are described.

$\begin{array}{ll}\text { bei } & \text { prospective (8.2.2.2) } \\ \text { be } & \text { uncertainty (8.3.1.1) } \\ \text { bego } & \text { irrealis }(8.3 .1 .2) \\ \text { tabe } & \text { marker of irony (9.1.7) }\end{array}$

\subsubsection{VERBS}

Verbs are words that are inflected with verbal morphology and may function in isolation to encode a full predication. On the basis of their relational valence three main classes of verbs may be recognised in Gumawana.

Within the framework of Relational Grammar, clauses may consist of more than one level of structure. It is at the initial level that grammatical relations are determined in accordance with semantic roles. In her dissertation, Rosen (1981) proposes the need for what she refers to as the 'relational valence' of a predicate. She writes that "A predicate's relational valence specifies which of the central relations must or can be assigned in the initial stratum of a clause with that predicate". Hence a verb like eat in English has a relational valence of [Obligatory Subject, Optional Direct Object] since (8) is possible.

(8) a. I eat.

b. I eat the sandwich.

Within this kind of framework, Gumawana has three distinct verb classes on the basis of relational valence. These are presented next. From this point onward, 'subject' is abbreviated as S and 'direct object' as DO when referring to the relational valence of the verb. Parentheses are used to indicate that an element is optional. Thus $[(\mathrm{S}), \mathrm{DO}]$ indicates that the subject is optional and the direct object is obligatory.

\subsubsection{1 [S, DO]}

There are a large number of verbs which make up this class. Even though they are initially transitive, they are not necessarily finally transitive, and in section 5 I discuss the relation-changing device of the antipassive. The following examples (9) illustrate verbs which are both initially and finally transitive.

(9)
a. Go-gomanea-di ava-di PL-child.REF-3PL food-3PL.IA
tayamo tayamo si-kabi-di.
The children each took their food.
one one 3PL-take-3PL
b. Bei bao i-kani-mu.
PRO pig 3SG-bite-2SG
The pig will bite you.

${ }^{5}$ Editor's note: This section is an editorial addition. 


\subsubsection{2 [(S), DO]}

There are two classes of verbs that have a relational valence of $[(S), D O]$. One class requires the verbal prefix ta- when the verb is finally intransitive. The prefix ta- appears to indicate that the initial DO is in a particular state. In (10a) the verb upa 'to break' is finally transitive. However, in (10b) it is finally intransitive ([topa] $=/$ ta-upa/).
a. (oga) i-lokoina Gilibo i-saiko,
canoe 3SG-run Gilibo 3SG-bump
i-kali-upe.
canoe 3SG-run Gilibo 3SG-bump(TR) 3SG-by.INST-break.TR

The canoe ran and bumped Gilibo, and it broke it.

\section{b. Gilibo i-topa go, si-lokoina... \\ Gilibo 3SG-ST.break SW 3PL-run \\ Gilibo broke and they ran on...}

The second class lacks the ta-prefix. So in the (a) examples below the verbs are finally transitive whereas in the (b) examples they are finally intransitive. Because in the (b) examples the verbs lack an S, the DO advances to subject.

(11) a. Iyana a-kone-di.

turtle 1SG-trap.TR-3PL

I trapped the turtles.

b. Iyana si-kona.

turtle 3PL-trap

The turtles were trapped.

(12) a. Niboda a-katupaeve-di.

door ISG-open.TR-3PL

I opened the doors.

b. Niboda si-katupaeva.

door 3PL-open

The doors are open.

(13) a. Maini-na

kubu-gu

i-gede.

odour-3SG.IA nose-1SG.IA 3SG-hurt.TR

The odour hurts my nose.

b. Kubu-gu i-geda.

nose-1SG.IA 3SG-hurt

My nose hurts.

\subsubsection{INTRANSITIVES}

There are two types of intransitive verbs. The first has a relational valence of [DO]. These verbs which always have only a DO initially obligatorily advance the DO to $\mathrm{S}$. These verbs include statives, where the final subject has no control and is of ten the notional patient. As we see in section 3.2.2, verbs with a relational valence of [DO], [S] and [S, DO] may acquire the causative prefixes vai-, va- and $l u$, which derive transitive verbs from intransitives. In (14a) and (15a) the verbs are finally intransitive. In (14b) and (15b) the causative prefixes occur and the verbs are finally transitive. 
(14) a. Awoinu i-meo.

food 3SG-be.cooked

The food is cooked.

b. Kuvi a-va-meve-di.

yam 1SG-CAUS-cook.TR-3PL

I cooked the yams.

(15) a. Kuvi si-polu.

yam 3PL-boil

The yams boiled.

b. Kuvi a-vai-polu-di.

yam 1SG-CAUS-boil-3PL

I boiled the yams.

The second type of intransitive verb has a relational valence of [S]. These verbs are event verbs, in which the final subject does the action. Verbs that have an initial $S$ but no initial DO may take one of the suffixes $-(y) e^{6}$ or $-k o$, which derive transitive verbs from intransitives, whereby certain oblique noun phrases become DO (see 6.9.2 and 6.9.3). Examples (16a) and (17a) illustrate verbs with a valence of [S]. The (b) examples show the corresponding derived transitive verbs, with an oblique advancement to DO.

(16) a. Ma-(i)-gu-sisi a-tuko.

COM-CON-1SG-machete 1SG-ascend

I went up with my machete.

b. Sisi a-tuko-e.

machete 1SG-ascend-OAD.TR

I ascended with the machete.

(17) a. A-siya a-o yai-mu.

1SG-flee 1SG-go GOAL-2SG

I flee to you.

b. A-siya-ko-i-mu.

ISG-flee-DIR-TR-2SG

I flee to you.

Some verbs like siu 'to go through' have a relational valence of either [DO] or [S]. In the case of [DO], the final subject is the notional patient and has no control or volition; it also allows the causative prefixes.

(18) a. Buyala i-siu.

vine 3SG-go.though

The vine went through.

b. Buyala a-vai-siu-di.

vine 1SG-CAUS-go.through-3PL

I put the vines through.

If $s i u$ is initially [S], then its final subject is the animate agent and has control; it also allows the oblique advancement suffix $-y e$.

${ }^{6}$ Editor's note: See 2.3.5 regarding deletion of $/ \mathrm{i} /$. 
(19) a. Vada goi a-siu. house PP 1SG-go.through

I enter into the house.

b. Buki a-siu-ue-di.

book 1SG-go.through-OAD.TR-3PL

I entered with the books.

\subsubsection{ADJECTIVES}

The underived adjective in Gumawana is unmarked, and follows the noun it modifies. Thus far only two members of this catgegory have been found: vau 'new' (20) and bogo 'old' (21).
Yau
guna-vada
moe vada bogo.
1SG.PN 1SG.POSS-house DEM house old
My house is an old house.

(21)
Naveya, ame weniya vau.
friend this dog new
Friend, this is a new dog.

Other adjectives are derived from verbs or are morphologically different from the underived form. The following adjectives require person and number agreement with the noun they modify (each is here marked with third person singular -na; see 4.1).

$\begin{array}{ll}\text { dedevi-na } & \text { good } \\ \text { manawe-na } & \text { long } \\ \text { kakupi-na } & \text { short } \\ \text { gagai-na } & \text { big } \\ \text { giyai-na } & \text { small }\end{array}$

What makes these adjectives different is not only the fact that they have agreement suffixes but also that some of them retain the -na when functioning as verbs. Compare (23) with (22). Note that (23b) entails transitive marker coalescence (see section 2.3.4).

(23) a. Bogina i-dedevina.

PRF 3SG-good

He is already well.

b. A-ta-gagaine.

1SG-by.cut-big.TR

I cut it long.

Others of these adjectives do not keep the third person singular -na when functioning as verbs.

$$
\begin{aligned}
& \text { Alova i-kakupi. } \\
& \text { stick 3SG-short } \\
& \text { The stick is short. }
\end{aligned}
$$

Those adjectives that retain the suffix -na when functioning as verbs, as in (24), also retain it when functioning as nouns. 
A-mu-dedevina bei ku-babane.

PASS-2SG-good PRO 2SG-find.TR

You are going to find your goodness.

\subsubsection{PRONOUNS}

There are two types of pronouns in Gumawana: personal and reflexive. Personal pronouns are words that may stand alone as the argument of a verb and may replace a noun phrase. They may also function as the possessor in a possessive construction. They are used as topic and for emphasis. Pronouns are inflected with neither nominal nor verbal morphology.

TABLE 2: FREE PERSONAL PRONOUNS

\begin{tabular}{|c|c|c|}
\hline \multirow[t]{2}{*}{ Person } & \multicolumn{2}{|c|}{ Number } \\
\hline & Singular & Plural \\
\hline 1 & yau & $\begin{array}{l}\text { INC } k i t a \\
\text { EXC } \\
k a i\end{array}$ \\
\hline 2 & komu & komi \\
\hline 3 & kina/iya 1 & kidi \\
\hline
\end{tabular}

${ }^{1}$ Gumawana village has iya and Nubogeta village has kina.

In (26a, b) the pronoun is used emphatically, and in (c) it is the topic.

(26) a. Ago neta komu i-mu-poyapoya i-kaiaka... SW if 2SG.PN CON-2SG-land 3SG-exist But if your land exists...

b. Yau a-na ava-gu a-lusala.

1SG.PN 1SG-go food-1SG.IA 1SG-look.for I'm going food-searching.

c. E kina go vavina i-nuwo-nuwona...

DEV 3SG.PN SW woman 3SG-IMPER-think

So as for the woman, she was thinking...

The reflexive pronoun is toini- and requires agreement suffixes (4.1). It is used in reflexive clauses where the action is unintentional.

(27) a. Toini-na i-ta-guyala.

REFL-3SG 3SG-ST-break

It broke itself (on its own).

b. Toini-gu a-guinuwe.

REFL-1SG 1SG-do.TR

I did it myself.

(For further discussion of toini-, see section 6.6.) 


\subsubsection{QUANTIFIERS}

Quantifier nouns are discussed in 3.1.1.2; other quantifier morphemes include the various forms of the numerals and the words tamotamo 'each' and aditaiyuwomo 'several'. The last two words appear to be morphosyntactically similar to the underived adjectives referred to in section 3.1.4.
Tomota tamotamo a-da-kaiguyau i-vini-da. people each.one PASS-1PL.INC-apportion 3SG-give-1PL.INC He gives each of us our portion.

\subsubsection{CARDINAL NUMERALS}

The cardinal numbers in Gumawana are used to specify quantities of objects. The cardinal numerals from 'one' to 'five' are all bimorphemic, but 'one' (29a) is morphologically different from the numerals 'two' to 'five' (29b), which are formed by means of the prefix ai-. ${ }^{7}$ The morpheme nima 'five' is also the noun 'hand'. The numeral 'ten' appears to be morphologically simple (29c), while other cardinal numbers are compounds $(29 \mathrm{~d})$.

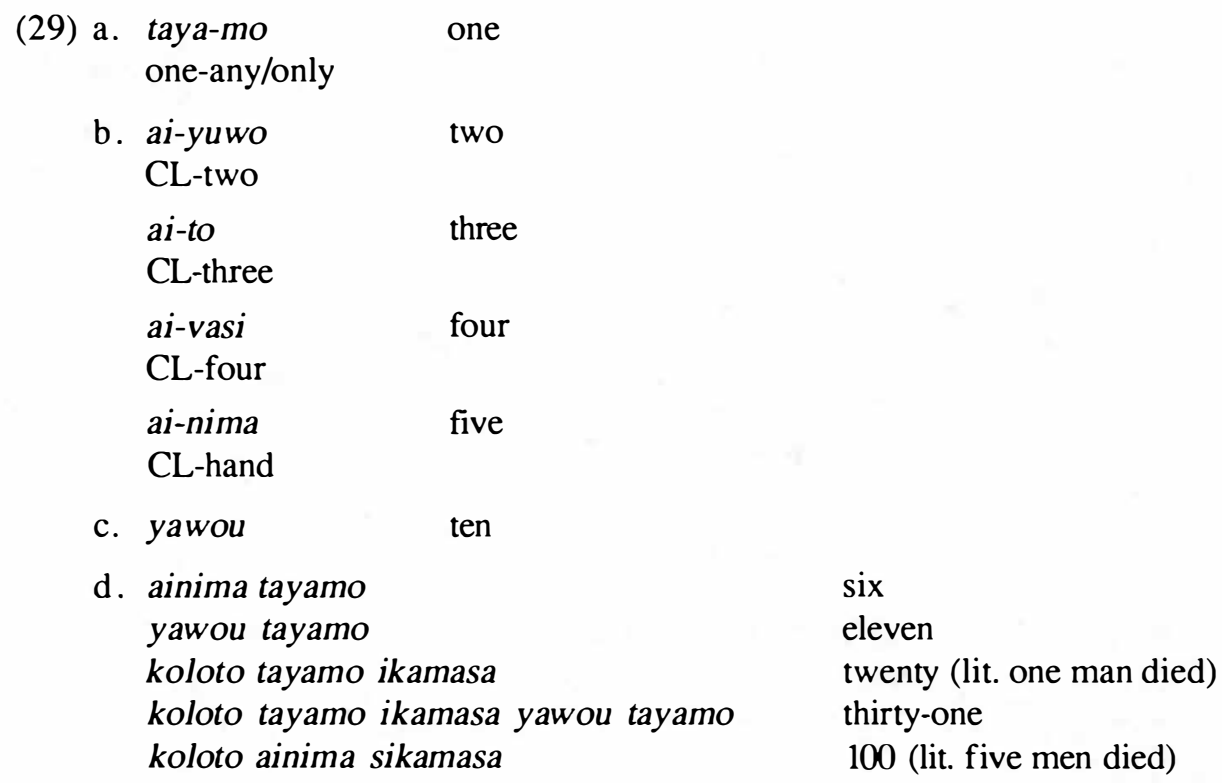

Presently the above cardinal-numerals are being replaced with borrowed words from English. The first five are still used frequently in everyday speech but numerals greater than five are rarely used.

\subsubsection{ORDINAL NUMERALS}

The ordinal numerals from 'second' to 'fifth' are derived from the cardinals by adding the agreement suffixes (4.1). The numeral for 'first' is a suppletive form.

\footnotetext{
${ }^{7}$ Editors note: Historically ai- is a numeral classifier, derived from the Proto Oceanic noun * $k a i u$ 'wood, tree'. A full-blown numeral classifier system exists in Kilivila, to the north of Gumawana.
} 
(30)

$\begin{array}{ll}\begin{array}{l}\text { boigimaino } \\ \text { ai-yuwo-i-na } \\ \text { CL-two-?-3SG } \\ \text { ai-toni-na }\end{array} & \begin{array}{l}\text { first } \\ \text { CL-three-3SG } \\ \text { ai-vasi-na }\end{array} \\ \begin{array}{l}\text { CL-four-3SG } \\ \text { ai-nima-na } \\ \text { CL-hand-3SG }\end{array} & \text { third } \\ & \text { fourth } \\ & \text { fifth }\end{array}$

\subsubsection{COUNTING NUMERALS}

For purposes of counting, the stem forms of the numerals are used.

$\begin{array}{ll}\text { taya } & \text { one } \\ \text { yuwo } & \text { two } \\ \text { toi } & \text { three } \\ \text { vasi } & \text { four } \\ \text { nima } & \text { five }\end{array}$

When counting units of quantity such as baskets or bundles, the reduced forms are suffixed to the noun, which changes stress.

$\begin{array}{ll}\text { 'patuma } & \text { bundle } \\ \text { patu'ma-to } & \text { three bundles } \\ \text { patuma-'nimapatuma-'tamo } & \text { six bundles } \\ \text { bayao-'yuwo } & \text { two baskets }\end{array}$

To count people,the alienable possessive marker a- (see 4.2.1) occurs with its (plural) person and number suffix, followed by tai 'person/man' and a suffixed numeral.

\begin{tabular}{|c|c|c|}
\hline $\begin{array}{l}\text { /a-di-tai-yuwo/ } \\
\text { PASS-3PL-man-two }\end{array}$ & [adite'yuwo] & two of them \\
\hline $\begin{array}{l}\text { /a-da-tai-to/ } \\
\text { PASS-1PL.INC-man-three }\end{array}$ & [ada'taito] & three of us \\
\hline $\begin{array}{l}\text { /a-ma-tai-nima/ } \\
\text { PASS-1PL.EXC-man-five }\end{array}$ & [amatai'nima] & three of us \\
\hline
\end{tabular}

Formally related to these structures are those with the limiter -ita (2.4.2).

$\begin{array}{lll}\text { (34) } & \text { [a-tu-ita/ } & \text { only me } \\ \text { PASS-1SG-LIM } & \text { ['amta] } & \text { only you } \\ \text { /a-mu-ita/ } & & \\ \text { PASS-2SG-LIM } & \text { [a'neta] } & \text { only him/her } \\ \text { /a-na-ita/ } & & \\ \text { PASS-3SG-LIM } & \text { [a'deta] } & \text { only us } \\ \text { /a-da-ita/ } & & \\ \text { PASS-1PL.INC-LIM } & & \end{array}$


The counting of canoes is similar to the counting of people except that instead of tai,we find $k a i$ 'canoe'. 8

$\begin{array}{lcc}\text { /a-di-kai-yuwo/ } & \text { [adikai'yuwo] } & \text { two canoes } \\ \text { PASS-3PL-canoe-two } & & \\ \text { /a-di-kai-vasi/ } & \text { [adikai'vasi] } & \text { four canoes } \\ \text { PASS-3PL-canoe-four } & & \end{array}$

When counting specific numbers of coconuts or betel nut (areca nuts) a different system is used. However, the numerals listed below have never been heard in normal conversation and are probably no longer current. This type of numeral is formed by reduplicating the reduced form of the cardinal number.

$\begin{array}{ll}\text { tayataya } & \text { one } \\ \text { yuwoyuwo } & \text { two } \\ \text { otaito } & \text { three } \\ \text { vasivasi } & \text { four } \\ \text { nimanima } & \text { five }\end{array}$

When referring to coconuts uri- is prefixed to the cardinal number to count bundles of four coconuts. I have been unable to find any independent meaning for uri-.
uri-taya-mo
CL-one-only
one bundle
uri-vasi
four bundles
CL-four
uri-taya-mo yuwoyuwo one bundle plus two coconuts
CL-one-only two

If betel nut is counted the numerals are prefixed with yaule-.

(38)

$\begin{array}{lc}\text { yaule-nima } & \text { five } \\ \text { CL-hand } & \\ \text { yaule-vasi } & \text { four } \\ \text { CL-four } & \\ \text { yaule-nima yaule-tayamo } & \text { six } \\ \text { CL-five CL-one } & \end{array}$

Gumawana has a few collective nouns which are used in enumeration:
yawo
aitowo
group of fish, dog, birds
guguna
forest of trees
pile of sheels, yams etc.

\footnotetext{
${ }^{8}$ The morpheme $k a i$ is found in ncarly all words dealing with canoes. Note the following words:

$\begin{array}{lll}\text { kai-lova } & \text { canoe-leave } & \text { to depart } \\ \text { kai-vau } & \text { canoe-new } & \text { new canoe } \\ \text { kai-bogo } & \text { canoe-old } & \text { old canoe } \\ \text { kai-dedea } & \text { canoe-float } & \text { canoc } \\ \text { kai-moloya } & \text { canoe-?? } & \text { canoc }\end{array}$
}

The two words meaning 'new canoe' and 'old canoe' have been lexicaliscd to mean 'new' and 'old'. They require agreement with the noun they modify in person and number. 


$\begin{array}{ll}\text { patala } & \text { fleet of canoes } \\ \text { kisi } & \text { hand of bananas } \\ \text { sipula } & \text { bunch of coconuts, mangoes } \\ \text { uyama } & \text { plantation of betel nut palm, coconut trees } \\ \text { popo } & \text { stack of books, cartons etc. }\end{array}$

\subsubsection{DEMONSTRATIVES}

Demonstratives are used both in isolation as pronouns and as modifiers of nouns (demonstrative adjectives). The same forms are used as demonstrative pronouns and adjectives, but word order indicates whether a demonstrative is functioning as an adjective or as a pronoun.

Gumawana has a six-place demonstrative system which is person-oriented. This is presented in Table $3(\mathrm{SP}=$ speaker, $\mathrm{HR}=$ hearer $)$.

TABLE 3: DEMONSTRATIVES

\begin{tabular}{|c|c|c|c|c|}
\hline $\begin{array}{c}\mathrm{DEM} \\
\text { pronoun/adjective }\end{array}$ & $\begin{array}{l}\text { PLACE } \\
\text { adverb }\end{array}$ & $\begin{array}{l}\text { LOCAT } \\
\text { visible }\end{array}$ & $\begin{array}{l}\text { ADVERB } \\
\text { invisible }\end{array}$ & MEANING \\
\hline ame & ameko & goame & ameni & this/here near SP \\
\hline moe & moeko & gomoe & moeni & that/there near HR \\
\hline amo & amoko & goamo & amoni & $\begin{array}{l}\text { ther/there distant from SP } \\
\text { and HR }\end{array}$ \\
\hline kive & kiveko & gokive & kiveni & that/there toward ocean \\
\hline mae & maeko & gomae & maeni & that/there above SP \\
\hline tono & tonoko & gotono & tononi & that/there below SP \\
\hline
\end{tabular}

\subsubsection{REFERENTIAL FUNCTION}

The demonstrative pronouns and adjectives given in Table 3 may be used to refer to various items in a discourse. They can also be used in conjunction with a noun to refer to the physical object in the real world. In (40) the demonstratives are used in gestural ways to point out physical objects in the real world; that is, they function as deictic pronouns.

(40) a. Amo kaga?

that what

What is that?

b. Geya, amo moteta.

NEG that.away snake

Nothing, that is a snake.

c. Go semu moe a-mu-moku ku-dabe-di.

but however that.near.you EAT-2SG-fish 2SG-cut.TR-3PL

However, those are your fish near you, you cut them. 
These demonstratives may also be used in symbolic ways. This is especially true of time expressions, where ame means 'today'.

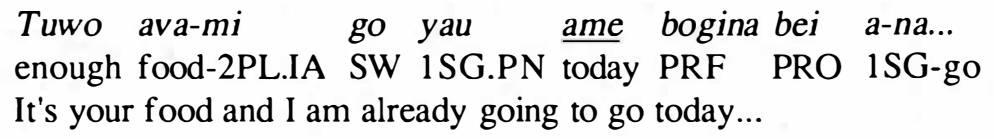

The item moe may be used to indicate anaphoric reference in a discourse. In (42) it is possible that moe is used anaphorically because its basic meaning is 'that near hearer' and therefore 'known to both speaker and hearer'; it refers back to a referent in a previous clause not given in the example.

$$
\begin{aligned}
& \text { Yemesa moe i-lawoiwoi-ye. } \\
& \text { James that 3SG-deny-OAD.TR } \\
& \text { James rejects that [which was earlier claimed]. }
\end{aligned}
$$

The item ame may be used cataphorically. Normally this is found at the beginning of a story, as in (43) where ame signals that the discourse coming up is about their marriage.

$$
\begin{aligned}
& \text { Yau Opa i-ma-nai } \frac{\text { ame nakae. }}{\text { 1SG.PN Opa CON-1PL.EXC-marry this like }} \\
& \text { Mine and Opa's marriage was like this. }
\end{aligned}
$$

\subsubsection{LOCATION ADVERBS}

There are two ways in which the demonstratives are encoded as location adverbs.

\subsection{VISIBLE OBJECTS}

The prefix go-indicates that the object is visible to both speaker and hearer.
(44) a. Komu i-mu-vada
go-mae do-yava.
2SG.PN CON-2SG-house LOC.ADV-above by.head-to.bush
Your house is up there toward the bush.
b. E vayavaya go-tono.
DEV turtle LOC.ADV-below
There is a turtle down there.

\subsection{NON-VISIBLE OBJECTS}

When a referent is not visible to speaker or hearer or is new information, the demonstrative is affixed with the inalienable suffixes; however, the third person singular is -ni rather than -na. I have not been able to find any reason for this difference. In $(45 a, b)$ the suffixed demonstrative indicates that the object is unseen by both speaker and hearer.

(45) a. I-mu-buyala
CON-2SG-necklace there-3SG

Is your necklace over there? (not seen by speaker or hearer) 

b. Ame-ni, kai
ka-kabi.
here-3SG 1PL.EXC.PN 1PL.EXC-take(TR)
$\mathrm{He}$ is here, we took him (but not seen by either hearer or speaker).

\subsubsection{PLACE ADVERBS}

Place adverbs are derived from the demonstratives by means of the suffix $-k o$. This type of construction is used to indicate places and directions towards places.
(46) a. Si-na amo-ko si-kaika.
3PL-go there-PLA.ADV 3PL-eat
They went there to eat.
b. Ka-tuko ka-na tanuwo mae-ko.
1PL.EXC-ascend 1PL.EXC-go garden above-PLA.ADV
We went up to the garden there above.
c. Yau mae-ko a-kaiaka.
1SG.PN above-PLA.ADV 1SG-live
I live there above.
d. Koloto i-na-kasa ame-ko Tamoidu. man CON-3SG-place here-PLA.ADV Tamoidu The man's village was here at Tamoidu.

\subsubsection{DETERMINERS}

A demonstrative (as noted in 3.1.7.2.2) may be used to indicate that a nominal is given or old information. The number tayamo 'one' may be used as the indefinite article. This occurs at the beginning of a story to introduce the main participants and other new information.

(47) a. Gwalabeyai gomana tayamo.

Gwalabeyai child one

Gwarabeyai was a child.

The reference marker - ya- $^{9}$ is used to mark a noun as referential and specific (i.e. referring to a specific item whose identity the speaker assumes is known to the hearer). It is suffixed directly to the noun, and is always followed by a possessive suffix marking the number of the noun, as in (48a,b), or occasionally agreeing with its (alienable) possessor, as in $(48 \mathrm{c})$.
(48) a. Go anamimi-ya-na tupwana aba-matoita. SW dream-REF-3SG little NOM-fear
But the dream was a fearful thing.

\footnotetext{
${ }^{9}$ Editor's note: The remainder of this section is an editorial addition (the examples are culled from other sections).
} 
b. Go-gomanea-di ava-di tayamo tayamo si-kabi-di.

PL-child.REF-3PL food-3PL.IA one one 3PL-take-3PL

The children each took their food.

c. Ka-na yau tanuwo-ya-gu goi ka-paisewa.

1PL.EXC-go 1SG.PN garden-REF-1SG PP 1PL.EXC-work

We went to my garden where we worked.

Occasionally the reference marker -ya- is suffixed to the possessive suffix of an inalienably possessed noun. Since -ya- is always followed by its own agreement suf fix, this means that there can be two agreement suffixes attached to the same noun.

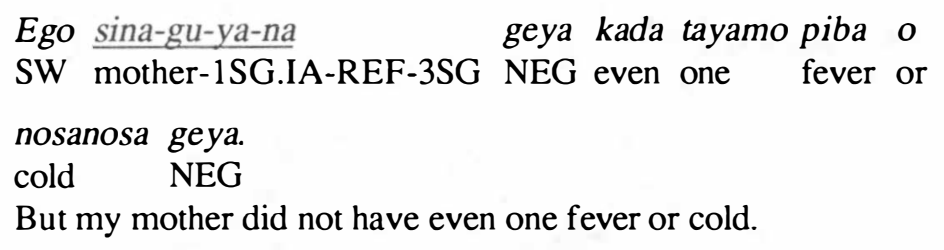

Note that the reference marker may be added to a proper noun as well as to a common noun.

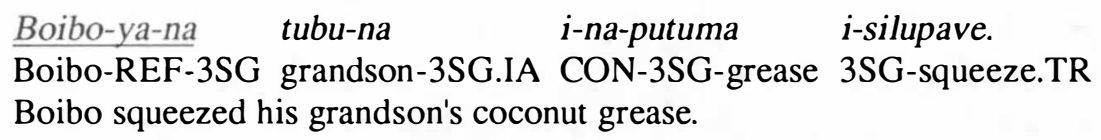

Almost all uses of the reference marker -ya- are with nouns which are definite, but occasionally it occurs with a noun marked with tayamo 'one', indicating that its function has to do with reference and specificity, not with definiteness (see section 5.1.7).

The usage of nouns marked with the reference marker is discussed in section 5.1.7.

\subsubsection{INTERROGATIVES}

An interrogative takes the place of a noun as the argument of a verb or as the head of an adpositional phrase. The following are the interrogatives found in Gumawana. (Their use is described in 8.4.3.)

\begin{tabular}{|c|c|c|}
\hline ava- & & which \\
\hline ava-tau & which-person & who \\
\hline ava-tuta & which-time & when \\
\hline ai-vina & CL-how.many & how many/much \\
\hline ma-nakae & COM-like & what do you want/what? \\
\hline ma-nakae-na & $\begin{array}{l}\text { COM-like-3SG } \\
\text { (marked for person and nu }\end{array}$ & $\begin{array}{l}\text { how, what...like? } \\
\text { mber of noun) }\end{array}$ \\
\hline nako & & where \\
\hline kaga & & what \\
\hline kaga una-na & what source-3SG & why \\
\hline kaga pasi-na & what reason-3SG & why $=$ what is the reason \\
\hline kagagoi & & what for \\
\hline kaga manu-na & what BEN-3SG & what for \\
\hline
\end{tabular}

The interrogative nako may also agree with the children in person and number. Compare (52c) with (52d). Nako is the only interrogative (other than manakaena) which allows 
agreement suffixes. The natural question is: what is the difference between the two forms? I have not yet been able to ascertain this.

(52) a. Kaga amo i-dige-dige?

what that 3SG-IMPER-talk.TR

What is that he is talking about?

b. Ava-tuta ku-ma?

which-time 2SG-come

When did you come?

c. Go-gomana ai-yuwo nako?

PL-child CL-two where

Where are the two children?

d. Go-gomana ai-yuwo nakoi-di?

Pl-child CL-two where-3PL

Where are the two children?

\subsubsection{POSTPOSITIONS}

Postpositions mark the various oblique relations (described in 5.2). Two of them are unmarked: goi, which marks locatives ((53a) and 5.2.1.1), instruments ((53b) and 5.2.1.2) and temporals (5.2.1.3) and taiyao, marking the comitative (5.2.3.1). The other postpositions require an agreement suffix (4.1).

(53) a. Ka-na yau tanuwo-ya-gu goi ka-paisewa.

1PL.EXC-go 1SG.PN garden-REF-1SG PP 1PL.EXC-work

We went to my garden where we worked.

b. Giya kawala goi i-dabi-dabi i-kau-mate.

INST pole PP 3SG-IMPER-slap 3SG-by.force-kill.TR

He was hitting her with a pole and he killed her.

c. Yau Opa tama-na be sina-na taiyao ka-tuko

1SG.PN Opa father-3SG.IA and mother-3SG.IA COM 1PL.EXC-ascend

ka-ma.

1PL.EXC-come

I and Opa's mother and father ascended together.

d. A-va-tetala Opa be yau i-ma-nai manu-na.

1SG-CAUS-story Opa and 1SG.PN CON-1PL.EXC-marriage about-3SG I will tell about mine and Opa's marriage.

\subsubsection{INTERJECTIONS}

There are a number of interjections in Gumawana.

$\begin{array}{ll}\text { ia! } & \text { exclamation of digust or shock at something } \\ \text { oiyoi! } & \text { exclamation of amazement or when in pain } \\ \text { uu! } & \text { yes } \\ \text { go! } & \text { yes (emphatic) }\end{array}$




$\begin{array}{ll}\text { o! } & \text { what? } \\ \text { ooo! } & \text { I understand } \\ \text { ma-nakae! } & \text { What do you want/what (3.1.9) } \\ \text { ma-nakae-da! } & \text { What about us (3.1.9) } \\ \text { seki! } & \text { What! (3.1.9) } \\ \text { kaga! } & \text { What! (3.1.9) } \\ \text { moitamo! } & \text { That's right } \\ \text { i! } & \text { used when a mistake is made } \\ \text { ade! } & \text { oops }\end{array}$

(55) a. Oiyoi guna-gomana!

EXCL 1SG.POSS-brother

Oh my brother!
b. Ia amo kaga!
Wow that what
Wow, what is that?

\subsubsection{CONJUNCTIONS}

\subsubsection{COORDINATING CONJUNCTIONS}

There are three coordinating conjunctions in Gumawana, namely go, be and $o$. The use of go and be as clause coordinators is presented in section 7.1 and the use of $o$ in section 8.4.2. Also described in section 7.1 are the uses of baige and gobe, which serve to coordinate clauses in temporal sequence.

The conjunction be joins both clauses and noun phrases of equal rank. Its use in noun phrases is exemplified below. (Note that in (56c) each of the conjoined noun phrases contains a relative clause.)

(56) a. Lava tayamo Tomasi Siyokila be yau oga time one Tomasi Siyokila and 1SG.PN canoe

ka-lu-sobu-ye.

1PL.EXC-by.lift-descend-OAD.TR

One time Tomasi, Siyokila and I launched the canoe.

b. Tuta liliu-na sabamgo be maliyalina nakae i-tai-taiya. time all-3SG.IA night and day like 3SG-IMPER-cry All of the time like night and day he was crying.

c. Kaga ka-gite-di be nakae kaga ka-paisewe-di... what 1PL.EXC-see.TR-3PL and like what 1PL.EXC-work.TR-3PL What we see and also what we worked on...

\subsubsection{SENTENCE INTRODUCERS}

Gumawana has a number of morphemes which serve as sentence introducers. They indicate the discourse status of what is to follow in relation to what has preceded, and are discussed in section 7.2. 
(57)

$\begin{array}{ll}\text { ago } & \text { switch of attention } \\ \text { ego } & \text { switch of background } \\ \text { tuwo } & \text { enough } \\ e & \text { marker of new development } \\ \text { tauna } & \text { therefore - marker of result or conclusion }\end{array}$

\subsubsection{SUBORDINATING CONJUNCTIONS}

Gumawana has a number of words which function as subordinating conjunctions (their uses are described in section 7.3).

$\begin{array}{ll}\text { tuteana } & \text { time: 'when' (lit. 'the time') } \\ \text { laveana } & \text { time: 'when' (lit. 'the time') } \\ \text { anatuwana } & \text { duration: 'until' (lit. 'its boundary') } \\ \text { namuliyeta } & \text { sequence: 'afterwards' } \\ \text { nako } & \text { place: 'where' } \\ \text { unana } & \text { reason = new information: 'because' (lit. 'its base/source') } \\ \text { kutoto } & \text { reason = presupposed information: 'because' } \\ \text { balito } & \text { reason = contrary to expectation: 'because' } \\ \text { neta } & \text { unreal condition: 'if' } \\ \text { kaikoma } & \text { real condition: 'when, as soon as' }\end{array}$

\subsection{DERIVATIONAL MORPHOLOGY}

In order to discuss derivational and inflectional morphology it is necessary to establish some criterion for making a distinction between them. For the purposes of this paper derivational morphemes may change the syntactic categories or class of the stems on which they occur, or may change the valency of a verb. They are restricted to a certain class of words. If a morpheme produces a significant meaning change of the stem, it is considered derivational.

\subsubsection{INSTRUMENTAL PREFIXES}

Certain verbs in Gumawana allow prefixes which indicate the instrument used to perform a particular action, or the manner in which the action is performed. They are found mainly on initially transitive verbs, but there are a few cases where a transitive verb is derived from an intransitive. These instrumental prefixes (1) derive new verbs, (2) increase valency, (3) are fairly predictable in meaning, and (4) are restricted to certain verb roots. For these reasons I have grouped them with the derivational affixes. These have been referred to as 'classificatory prefixes' (see Ezard, this volume; Bradshaw 1982). Some of the instrumental prefixes are:
bisi-
by touch
ka- with teeth
kai- by setting down
kali- with pointed instrument
kana-
(1) by lying down
(2) with speech 


$\begin{array}{ll}k a u- & (1) \text { with rock, axe } \\ & (2) \text { with force } \\ k i- & \text { with hand } \\ k o- & \text { by bending or stretching } \\ s a- & \text { with water } \\ \text { sai- } & \text { by joining } \\ \text { sala- } & \text { with loud voice } \\ \text { samu- } & \text { by smell } \\ t a- & \text { (1) with paddle } \\ & \text { (2) with machete } \\ \text { tu- } & \text { by sitting } \\ \text { va- } & \text { with foot } \\ \text { vaka- } & \text { with fire } \\ \text { vata- } & \text { (see 6.7) } \\ \text { vatu- } & \text { by dropping (see also 6.7) }\end{array}$

The instrumental prefixes cannot co-occur with the causative prefixes va-, lu-or vai-, and those verbs which allow the causative prefixes normally do not allow instrumental prefixes. Some verbs obligatorily take an instrumental prefix while others take them optionally (60).

(60) a. Alova a-(ki)-guyal-i. wood 1SG-with.hand-break-TR I break the wood (with my hand).

b. Alova ku-(ka)-sesel-i. wood 2SG-with.teeth-split-TR You split the wood (with your teeth).

Other verb stems, such as those in (61), require one of the instrumental prefixes.

(61) a. Vaega a-vatu-visi. clay.pot 1SG-with.drop-break(TR) I broke the clay pot by dropping it.

b. Vevana si-ta-upe-upe. seed 3PL-with.knife-IMPER-cut.TR They are cutting the seed yams with knives.

c. Aleko a-ki-ise. cloth 1SG-with.hand-tear.TR I tear the cloth with my hand.

A third group consists of initially intransitive verbs which are transivitised by the addition of an instrumental prefix. In both (62a) and (63a) the verb is intransitive. The (b) examples illustrate the same verbs with the instrumental prefixes.

(62) a. A-mata.

1SG-die

I die.

b. A-ki-mate.

ISG-with.hand-die.TR

I kill it with my hand. 
(63) a. Gomana i-taiya.

child 3SG-cry

The child cries.

b. Ku-ki-tai-taiye.

2SG-with.hand-IMPER-cry.TR

You make him cry with my hand.

Some of these prefixes are clearly reduced forms of verbs. The verbs in (64a) and (65a) illustrate two prefixes derived from the verbs illustrated in the (b) examples.

(64) a. Bwae a-sai-damane.

water 1 SG-join-across.TR

I cross over the water.

b. A-savi.

1SG-join(TR)

I join it.

(65) a. A-bu-sobu-ye.

1SG-pull-descend-OAD.TR

I pull it down/I down it by pulling.

b. Buyala a-biu.

rope 1SG-pull(TR)

I pulled the rope.

\subsubsection{CAUSATIVE PREFIXES}

The four causatives in Gumawana are ve-, va-, vai- and lu-. The differences between them are unclear. Very few cases of $l u$-, vai- or ve-have been found. However, ve- is used to derive verbs from nouns, specifically kinship terms.

(66) a. natu-na

of fspring-3SG.IA

his/her of fspring

b. i-ve-natune

3SG-CAUS-of fspring.TR

she gave birth to him

By far the most common one is va-. The causatives increase the valence of the verb by one argument.

(67) a. Alova a-va-taoe.

tree 1SG-CAUS-stand.TR

I stand the tree/stick up.

b. A-va-taoe-mu.

1SG-CAUS-stand.TR-2SG

I help you to stand up. (you are unable to stand $=$ non-control)

(68) Awoinu a-vai-polu.

food 1SG-CAUS-boil(TR)

I boiled the food. 
(69)

\section{Guna-paisewa a-lu-kavave.}

1SG.POSS-work 1SG-CAUS-be.finished.TR

I finished my work.

(The valency-changing role of these prefixes is described in section 6.8. The prefix va-also serves as a reciprocal marker, discussed in section 6.5.)

\subsubsection{INCHOATIVE PREFIX $k a-$}

The $k$ a- prefix derives verbs from nouns and has the meaning of 'to become'. The derived verbs are always finally intransitive.

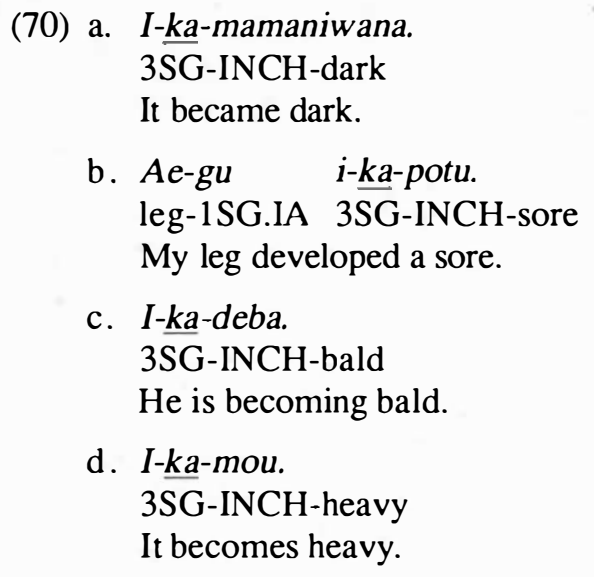

\subsubsection{TRANSITIVE SUFFIX $-i$}

The morpheme $-i$ marks the transitivity of a verb which has a final direct object. As noted previously, $-i$ coalesces with stem-final vowel $a$ as $-e$ (2.3.4) and is deleted after $i$ and $u$ (2.3.12).

(71) a. Tomota a-gite-di. people 1SG-see.TR-3PL I see the people.

b. Ku-ma ku-vatuluko-i-gu. 2SG-come 2SG-show-TR-1SG Come and show me.

When an initially intransitive verb allows the advancement to direct object of an oblique argument, the verb is marked with either $-k o$ or $-(y) e$, but the transitive marker is still required. In (72a) the verb is intransitive. However, in (72b) $-(y)$ e indicates that there is an advancement.

(72) a. Ka-tuko.

1PL.EXC-ascend

We ascended. 
b. Ka-tuko-e-di.

1PL.EXC-ascend-OAD.TR-3PL

We ascended with the things.

\subsubsection{DIRECTIONAL SUFFIX -ko}

The suffix -ko derives a transitive verb whose object results from the advancement of a directional (further discussed in 6.9.2). The suffix -ko is of ten found on motion verbs in Gumawana and on a few other verbs. It is derivational because it changes the valency of the verb.
(73) a. Ku-ma (yai-gu).
2SG-come GOAL-1SG
You come to me.
b. Ku-me-ko-i-gu.
2SG-come-DIR-TR-1SG
You come to me.

(74) a. A-siya a-o yai-mu.

ISG-flee 1SG-go GOAL-2SG

I flee to you.

b. A-siya-ko-i-mu.

I SG-flee-DIR-TR-2SG

I flee to you.

(75) a. I-lokoina i-na yai-di.

3SG-run 3SG-go GOAL-3PL

He ran to them.

b. I-lokoina-ko-i-di.

3SG-run-DIR-TR-3PL

He ran to them.

\subsection{6 -ko AND -(y)e AS REASON SUFFIXES}

The suffixes $-k o$ and $-(y) e$ are also used in questions which ask the reason for or the purpose of something. If the verb is transitive then in a question construction it takes $-k o$ as in the (a) examples below. If the verb is intransitive it is transitivised by means of $-(y) e$ as in the (b) examples below.

(76) a. Kaga ko-talai-ko?

what 2PL-cut.TR-REA.TR

What did you cut it for?

b. Kaga ko-tala-e ?

what 2PL-cut-REA.TR

What are you cutting for?

(77) a. Kaga ku-luma-dade-ko-i-gu?

what 2SG-ask-unseen.TR-REA-TR-1SG

What do you ask me for? 


\section{b. Kaga ku-luma-dadana- $\underline{e}$ ? what 2SG-ask-unseen-REA.TR What do you ask for?}

Compare (76a) and (77a) with (74b). In (74b) the verb is initially intransitive and -ko marks the verb as transitive. In (76a) and (77a), however, $-k o$ is added to verbs which are already transitive, and this is indicated by the presence of the transitive marker $-i$ before $-k o$ (in (77a) the transitive marker has coalesced with the final -a of the verb stem).

In (74b) and (77a) the resulting transitive verb has a pronoun object suffix, and so the transitive marker is suffixed after $-k o$. In the case of $(77 \mathrm{a})$, this means that there are two transitive markers.

Compare (78a) and (b) where the verb mwela is used to illustrate both uses of the suffix $-k o$.

(78) a. Alova kaga ku-mwele-ko?

tree what 2SG-climb.TR-REA.TR

What did you climb up?

b. Ku-mwela-ko-i-gu.

2SG-climb-DIR-TR-1SG

Climb up to me.

\subsubsection{NOMINALISATION}

Nouns can be formed from verbs in a variety of ways. Some involve nominalisers affixed to the verb. Table 4 gives a summary of the various types of nominalisation in Gumawana.

TABLE 4: FORMS OF NOMINALISATION

\begin{tabular}{|l|l|}
\hline Affix & Noun type \\
\hline- & action.non-process \\
to- & agentive \\
goma- & experiencer \\
$(k) a b a-$ & instrument/locative \\
- & objective \\
$k a-$ & stative \\
\hline
\end{tabular}

The types of nominalisation found in Table 4 are discussed in the following sections. Nominalisation is a very important aspect of Gumawana, and more research is needed in this area.

\subsubsection{ACTION NOMINALISATION}

The simplest form of nominalisation is where the stem simply occurs without affixation to encode a noun. 
(79) a. Taya gagai-na i-guinuwe.

cry big-3SG 3SG-do.TR

He had a big cry.

b. Paisewa i-mou-mou.

work 3SG-IMPER-heavy

The work is hard.

These forms are what Comrie and Thompson (1985:351) refer to as action non-process nouns.

\subsubsection{OBJECTIVE NOMINALISATION}

Objective nominalisation derives names of things. Like action nominalisations, objective nouns derived from verbs do not have any special marking. They must, however, be the intransitive form of the verb as in (80).

Iyoni i-na-ginina

John CON-3SG-write

John's writing

$\begin{array}{ll}\text { tala } & \text { to cut } \\ \text { kupo } & \text { to cut } \\ \text { beuta } & \text { to paddle } \\ \text { kawala } & \text { to pole } \\ \text { vailowana } & \text { to anchor }\end{array}$

$\begin{array}{ll}\text { tala } & \text { cut, i.e. injury or year } \\ \text { kupwana } & \text { piece } \\ \text { beuta } & \text { paddle } \\ \text { awala } & \text { pole for canoe } \\ \text { vailowana } & \text { anchor }\end{array}$

\subsubsection{AGENTIVE NOMINALISATION}

The nominaliser to- derives an agentive noun from a verb. Agentive nominalisation is the traditional term for this process but, as Comrie and Thompson (1985:351) point out, "strictly speaking, the noun need not be in an 'agent' relationship with the verb from which it is derived". The term refers to the fact that underlyingly the 'one who does' the action is the agent of the verb. When a verb is nominalised with to-it indicates that the person does the particular action habitually.

(82) a. To-paisewa-yao loga si-kamasa.

AGT-work-PL hunger 3PL-die

The workers are starving.

b. Nava bei to-kamasa si-valiwoge.

later PRO AGT-die 3PL-grave.TR

Later they will bury the deceased.

c. To-vainawana si-siya si-na i-tuli ta-kasa.

AGT-steal 3PL-flee 3PL-go 3SG-be.different different-village

The thieves fled to a different village.

Verbs which only allow non-human subjects or are always finally transitive will not allow the agentive nominalisation. 


\subsubsection{EXPERIENCER NOMINALISATION}

Just as in the agentive nominalisation the verb is nominalised and the underlying subject is encoded by means of the prefix to-, so an underlying object may be encoded on nominalised verbs by means of the prefix goma-. However, this is no longer a productive construction (borrowings are used instead), and it has been found only on the two verbs in (83) and (84).

(83) a. liwola to exhort

b. gomaliwola obedient = one who is exhorted and does what he is told
a. etune
to send
b. gomaetuna
one who is sent

Goma- probably derives from gomana 'child', and so the meaning of verbs nominalised with goma- is literally 'the child whom something is done to or who experiences'. In practice, however, these nominalisations refer to adults as well.

\subsubsection{INSTRUMENT/LOCATIVE NOMINALISATION}

The nominaliser ( $k$ )aba- ${ }^{10}$ derives both instruments and locative nouns from verbs. For example, tulaga 'sit down on something higher than the ground' can be nominalised to form (k)aba-tulagalaga meaning either 'an instrument for sitting on' or 'place for sitting'. But actually both ideas mean the same thing, that is 'sitting is done here = chair'. These derived nouns are normally generic in meaning.

(85) a. Bei aba-vakakona si-kabi.

PRO NOM-test 3PL-get(TR)

They are going to get a test.

b. Go anamimi-ya-na tupwana aba-matoita.

SW dream-REF-3SG little NOM-fear

But the dream was a fearful thing.

c. Lamupa si-kaiako be nakae aba-isiwo aba-busa.

light 3PL-exist and like NOM-wash NOM-defecate

There were lights and also showers and toilets.

d. Tau-ya-na i-na i-na-kaba-paisewa.

person-REF-3SG 3SG-go CON-3SG-NOM-work

He went to his work place.

(86) a. masisi

abamasisi

to sleep

b. tulaga

thing/place for sleeping (on) = bed(room)

abatulagalaga

to sit above

thing/place for sitting (on) = chair

c. kupwana

to cut

abakupwana

thing/place for cutting $=$ knife

d. tuko

to go up

abatuko

thing/place for going up

\footnotetext{
10Initial $(k$-) is written in parentheses because of the application of $k$-deletion whenever the prefix is word initial (see section 2.3.6).
} 

e. siu
to go in
abasiu
thing/place for entering $=$ entrance
f. kaika
to eat
abakaika
thing/place for eating $=$ spoon $/$ table
g. takuku
to erase
abatukuku
thing/place for erasing $=$ eraser

\subsubsection{STATIVE NOMINALISATION}

Certain nouns in Gumawana may be verbalised with the inchoative ka- prefix (3.2.3). These derived verbs can then be nominalised and the new noun indicates a state. In the (a) examples below there is a simple noun. In the (b) examples the same noun has been made into a verb via the $k a$ - prefix. Finally, the (c) examples illustrate nominalisation of the verbs from (b).

(87) a. mamaniwana i-saki

dark 3SG-too.much

it is too dark

b. i-ka-mamaniwana

3SG-INCH-dark

it is becoming dark/darkening

c. A-mamaniwana bogina i-ma.

INCH-dark PRF 3SG-come

Darkness has come.

(88) a. Guna-potu i-geda.

1SG.POSS-sore/ulcer 3SG-hurt

My sore/ulcer hurts.

b. Ae-gu i-ka-potu.

leg-1SG.IA 3SG-INCH-sore/ulcer

My leg is ulcerating.

c. a-potu

INCH-ulcer

ulceration

(89) a. deba

bald

b. kadeba

to become bald

c. adeba

baldness

(90) a. mou

hard

b. kamou

to become hard

c. amou

hardness

\subsubsection{POSSESSION AND NOMINALISATION}

A noun formed by nominalisation may occur as the head of a possessive noun phrase, where the possessor is semantically either the agent or the patient of the nominalised verb. If 
the possessor is semantically the agent (the initial subject), then the nominalised verb is marked with the active or control marker $i$ - (4.2.2.2). However, if the possessor is semantically the patient (the initial direct object) of the verb, then we find the passive marker a- (4.2.1.1).

(91) a. a-gu-yala

PASS-1SG-believe

my belief (i.e. someone believes in me)

b. $\underline{\text { i-gu-yala }}$

CON-1SG-believe

my belief (i.e. I believe)

This kind of construction is used, like passive constructions in many languages, where the agent is unspecified. The initial direct object of the verb tagona is (92) is 'me', encoded as -gu. The fact that it is the initial direct object is indicated by a-, the passive alienable possessive marker. (Such forms are further illustrated in sections 4.2 and 4.3.)

$$
\begin{aligned}
& \text { A-gu-tagona Kalitoni i-na-vada a-mwela. } \\
& \text { PASS-1SG-permit Kalitoni CON-3SG-house } 1 \text { SG-climb } \\
& \text { I have permission to go up into Kalitoni's house. }
\end{aligned}
$$

When the initial subject and direct object are both encoded on the nominalised verb, the control marker $i$ - marks the initial subject, and inalienable possessive marking (4.2) marks the object.

$$
\begin{aligned}
& \text { oga } \underline{i-m a-p a i s e w a-i-n a} \\
& \text { canoe CON-1PL.EXC-work-?-3SG.IA } \\
& \text { our work of canoe(-making) }
\end{aligned}
$$

Inalienable possessive marking is also used to encode the relationship of reference (4.5).

\subsubsection{NOUNS FORMED FROM NOUNS}

New nouns can be formed from nouns by means of the derivational prefix toni-, which is similar in meaning to the agentive nominaliser to- described in section 3.2.7.2. The prefix toni- forms an agentive noun meaning 'one who owns'.

$$
\begin{aligned}
& \text { Ku-na toni-poyapoya ku-lituwoko... } \\
& \text { 2SG-go owner-land 2SG-tell(TR) } \\
& \text { You go tell the landowner... }
\end{aligned}
$$

The markers da- 'the people of' and guma- 'one from' are affixed to nouns to make new nouns from place names.

(95) a. E se-gowo da-Nubogeta...

DEV friend-1SG.IA.PL people.of-Nubogeta

So my friends of Nubogeta...

b. Boi nimatu da-Isireri i-di-lovina yoi-na Yudi.

last before people.of-Isreal CON-3PL-rule name-3SG.IA Judea

A long time ago, the name of the people of Israel's kingdom was Judea. 
(96) a. E vavina guma-Kotanunu i-na

DEV woman one.from-Kotanunu 3SG-go

So the woman from Kotanunu went.

b. guma-Nubogeta i-mamai-ma

one.from-Nubogeta 3SG-IMPER-come

the Nubogetan is coming

Another morpheme which creates nouns from nouns is ana- 'language of'. When prefixed to a locative nominal its new meaning is the language of the place indicated.
ana-Dobu
Dobu language
ana-Kiriwina
Kiriwina language

The prefix si-creates new nouns from place names and has the meaning of 'grass skirts of'. The prefix ko- means 'the food of'.
Kinanava
Fergusson Island
si-Kinanava
Fergusson Island grass skirts
ko-Kinanava
Fergusson Island food (yams)

\subsubsection{DEVERBAL ADJECTIVES}

Deverbal adjectives are formed from the imperfective aspect of the verb, either through reduplication or lengthened vowel (3.3.1.5), together with the suffix $-i$ and an agreement suffix (4.1).

(99) a.
Kunaya ta:oya-i-na
i-ta-taoya.
mast stand.IMPER-?-3SG 3SG-IMPER-stand

The vertical mast was standing.

b. Kunaya kana:-balabala-i-na si-sou.

mast by.lay.IMPER-across-?-3SG 3PL-descend

The horizontal mast came down.

Where a deverbal adjective is formed from a $k$-initial verb (e.g. ka:mas-i-na 'dead', from kamasa 'die') $k$-deletion (2.3.6) does not occur. Instead, $k$-is retained, as it would be on a verb stem preceded by its subject prefix, in contrast to the nominalised form amasa, where the $/ \mathrm{k} /$ is deleted and there is no vowel lengthening.
$(100)$
Tubu-gu
ka:mas-i-na
a-va-tetel-i.
I'll tell about my dead grandparent.

\subsection{INFLECTIONAL MORPHOLOGY}

Morphemes which indicate grammatical relations or do not change the syntactic category of the word are considered inflectional. This account of inflectional morphology is divided into two sections, the verb (3.3.1) and the noun (3.3.2). 


\subsubsection{VERB MORPHOLOGY}

\subsubsection{AGREEMENT}

The verb in Gumawana agrees with the final subject and object (if there is one) in person and number. Subject agreement prefixes are obligatory on all verbs. Table 5 lists the subject prefixes in Gumawana.

TABLE 5: SUBJECT PREFIXES

\begin{tabular}{|c|cc|}
\hline Person & \multicolumn{2}{|c|}{ Number } \\
& Singular & Plural \\
\hline 1 & $a^{-}$ & INC ta- \\
& & EXC ka- \\
2 & $k u-$ & $k o-$ \\
3 & $i-$ & $s i-$ \\
\hline
\end{tabular}

(101) a. Yau a-na.

1SG.PN 1SG-go

I go.

b. Gomana i-taoya.

child 3SG-stand

The child stood up.

c. ka-lokoina

1 PL.EXC-run

we run

A finally transitive verb must also agree in person and number with its final direct object. The direct object suffixes are the same as those used to cross-reference the possessor on inalienably possessed nouns. Table 6 lists the direct object suffixes found in Gumawana.

TABLE 6: DIRECT OBJECT SUFFIXES

\begin{tabular}{|c|c|c|c|}
\hline \multirow[t]{2}{*}{ Person } & \multicolumn{3}{|c|}{ Number } \\
\hline & Singular & & \\
\hline 1 & $-g u$ & INC & \\
\hline & & $\mathrm{EXC}$ & $-m a$ \\
\hline 2 & $-m u$ & & $-m i$ \\
\hline 3 & $-\theta$ & & $-d i$ \\
\hline
\end{tabular}

(102) a. Si-lumadade-di. 3PL-ask.TR-3PL

They asked them.

b. I-pole-gu.

3SG-lie.TR-1SG

She lied to me. 
c. I-kabi-ma.

3SG-get-1 PL.EXC

He got us.

d. Si-lau-i-mi.

3PL-kill-TR-2PL

They kill you.

\subsubsection{LIMITER -ita}

The limiter -ita only occurs on verbs when they are negated. It limits the scope of the negation; negation without -ita means 'never', whereas negation with -ita refers to a single non-occurrence (8.5.1). -ita occurs on the outer periphery and other morphemes may not be suf fixed to it. (The allomorphs of -ita are discussed in section 2.4.2.)

(103) a. Geya i-toboine-gu-ta.

NEG 3SG-suitable.TR-1SG-LIM

It was not suitable for me.

b. Geya si-kaiketa.

NEG 3PL-eat.LIM

They did not eat.

c. Koloto gagai-di geya si-sou-ta.

man big-3PL NEG 3PL-descend-LIM

The men who are big ones did not descend.

\subsubsection{3 -mo 'only'}

The morpheme -mo and its allomorph -yamo (2.4.1) occur on the outer periphery of predicates and, like -ita, do not allow any other morpheme to be suffixed after them. The morpheme -mo of ten used in an imperative sense as exemplified in (104).

(104) a. Ku-siya-mo!

2SG-flee-only

Flee!

b. Ku-kabi-yamo!

2SG-take-only

Take it!

However, its meaning is not restricted to the imperative. It has the meaning of 'just' or 'only'.

(105) a. A-paisewa-mo.

1SG-work-only

I only worked.

When a nominal predicate is negated in a stative clause of possession (6.4.2), the suffix -mo is attached to that nominal, which also must be possessed. It appears to have the same function as -ita does on the verbs, that of limiting the scope of the negation (8.5.2). I have glossed -mo here as 'any'. 
(106) a. Guna-gomana geya a-na-bwae-mo.

1SG.POSS-brother NEG EAT-3SG-water-any

My brother does not have any water.

b. Guna-gomana geya a-na-kinale-mo.

1SG.POSS-brother NEG EAT-3SG-rations-any

My brother does not have any rations.

c. Geya a-gu-kaipata-mo.

NEG PASS-1SG-ability-any

I am not able.

d. Geya ava-tau i-na-vaega-mo...

NEG which-person CON-3SG-clay-any

Whoever does not have any clay...

\subsubsection{ADVERBIAL SUFFIXES}

The adverbial suffixes occur closest to the verb.

$\begin{array}{ll}\text { (107) beso } & \text { any, carelessly } \\ \text { dokana } & \text { true, properly } \\ \text { ko } & \text { repeatedly } \\ \text { kova } & \text { a little } \\ \text { masala } & \text { all night } \\ \text { muna } & \text { again } \\ \text { ponapona } & \text { fast, quickly } \\ \text { popoita } & \text { boldly } \\ \text { save } & \text { total, all } \\ \text { vata } & \text { indefinite time } \\ \text { wowoil } & \text { hurry } \\ \text { yaba } & \text { completed }\end{array}$

(108) a. I-bobwala-ponapona.

3SG-talk-fast

He talks fast.

b. I-pola-muna.

3SG-lie-again

He lied again.

c. I-pole-mune-i-mu.

3SG-lie.TR-again-TR-2SG

He lied to you again.

d. A-kaiaka-yaba.

1SG-remain-completed

I've finished staying.

e. Ka-masisi-vata.

1PL.EXC-sleep-indefinite.time

We sleep forever. 
Evidence that these adverbials are suffixes is found in the fact that they behave morphophonemically as part of the verb stem when the transitive suffix $-i$ is added. Compare the following intransitive (a) examples with the transitive (b) examples (in (109b) the rules in 2.3.9 and 2.3.11 have applied).

(109) a. A-gita-dokana.

1SG-see-proper

I see properly.

b. Oga a-gite-doko-i-di.

canoe 1SG-see.TR-proper-TR-3PL

I see the canoes properly.

(110) a. A-kaluvila-muna.

1SG-return-again

I return again.

b. A-kaluvile-mune-i.

1SG-return.TR-again-TR

I retumed with it again.

Also the stress shifts according to the suffixes. The verb in (110) has the stress pattem given in (111).

(111) [axalu'vila]

I return (unsuffixed verb)

[axaluvi'lamna]

I retum (110a)

[axaluvilem'nei]

I retumed with it again $(110 \mathrm{~b})$

Not all of the adverbials occur on both transitive and intransitive clauses. In (109b) and (110b) the transitive marker $-i$ occurs twice, once on the verb stem and once on the adverbial. It is probable that these adverbials were separate words at one time, and have become part of the verb. This would account for the double occurrence of the transitive marker.

Another possibility is that the adverbial suffixes are affixed to the verb after coalescence has taken place. However, the transitive marker is still required on the adverbial suffix before the object marker may be affixed. This same phenomenon also occurs with transitive verbs which have been reduplicated (see 3.3.1.5). Compare (112) with (109b) and (110b). The reduplicated form of the verb retains the transitive marker on the reduplicated part.

$$
\begin{aligned}
& \text { Oga a-gite-gite. } \\
& \text { canoe ISG-IMPER-see.TR } \\
& \text { I am watching the canoe. }
\end{aligned}
$$

Some of the adverbials do occur separately from the verb when they function as the stems of adjectives or nominals.

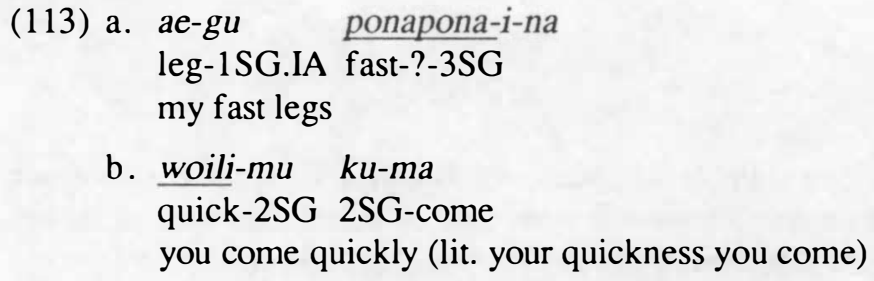




\subsubsection{IMPERFECTIVE PREFIX}

The imperfective prefix has two allomorphs, CVCV- and CV-, where the consonants and vowels are unspecified. When affixed to the verb root, the prefix copies the features of the first CVCV or CV in the root, as illustrated in (114) with the verb $k a b i$ 'to get'.
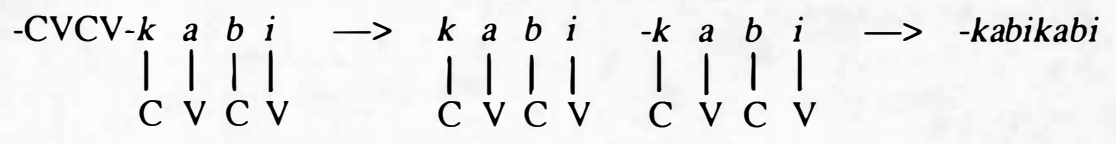

\section{TWO-SYLLABLE VERB ROOTS}

Two-syllable verb roots like -kabi, taking the allomorph $\mathrm{CVCV}$-, are by far the most common.

(115) a
a. ka-bani-bani
we are fishing for it
1PL.EXC-IMPER-fish.TR
b. i-yova-yova 3SG-IMPER-fly
he is flying
c. i-kani-kani
he is eating it 3SG-IMPER-eat.TR

With two-syllable roots, the CV-allomorph occurs when the verb root has the syllable structure $(\mathrm{CV})_{1}(\mathrm{CV})_{1}$, that is where the first two syllables are identical, as in tutu 'to pound'.

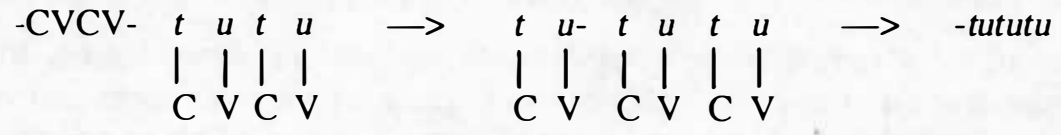

(117) a. a-lu-lulu

1SG-IMPER-pull.out(TR)
b. $i$-ta-pu-pupu it is falling out
3SG-ST-IMPER-fall.out
c. i-sa-sasa it is angry (as in a dog)
3SG-IMPER-angry
d. a-pa-papala
1SG-IMPER-play
I am playing
e. i-ta-tatava
3SG-IMPER-shake
he is shaking

I am pulling it out

Note that in (117d-e) the verb roots have two syllables underlyingly, with epenthetic $-a$ (see section 2.2).

\section{ONE-SYLLABLE VERB ROOTS}

When a verb root has only one syllable, the imperfective prefix copies the root twice, adding the vowel $-i$ - before the root. I have not been able to determine the source of $-i$ Example (118) shows how one-syllable verbs like ma 'to come' reduplicate. 
(118)

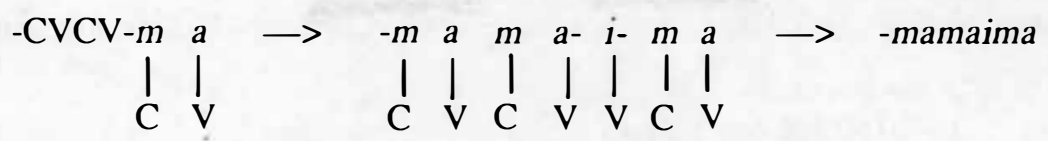

(119) a. i-vavai-va 3SG-IMPER-do

b. i-memei-me 3SG-IMPER-come.TR

c. i-nonoi-na 3SG-IMPER-go (va) he is doing (me) he is bringing it

(na) he is going

\section{THREE-SYLLABLE VERB ROOTS}

Verb roots with three or more syllables take the allomorph CV-.

(120)
a. i-ma-masisi
3SG-IMPER-sleep
b. a-ka-kaika 1SG-IMPER-eat
c. ku-bo-bobwala 2SG-IMPER-talk
d. so-bo-bolagu 3PL-IMPER-scold
e. i-lo-lokoina 3SG-IMPER-run
he is sleeping
I am eating
you were talking
they are scolding
he is running

\section{BLOCKAGES TO IMPERFECTIVE REDUPLICATION}

Derivational prefixes block reduplication, so that (121) is ungrammatical.

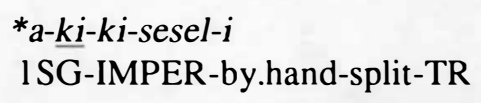

Transitive verb stems may be reduplicated only if the object is third person singular (a zero morpheme - see section 3.3.1.1). Thus any object suffix blocks reduplication. In (122a) and (b) reduplication is acceptable. However, (c) is ungrammatical since an object suffix is present.

(122) a. a-gita-gita

ISG-IMPER-see

I am seeing/watching

b. a-gite-gite

ISG-IMPER-see.TR

I am seeing/watching it

c. *a-gite-gite-di 
Adverbial suffixes (3.3.1.4) also block reduplication. Hence (123) is ungrammatical.

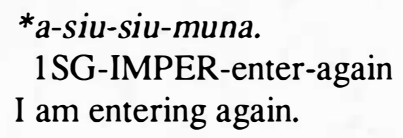

There are also a number of verbs, like - paisewa 'to work', that never reduplicate.

A question that arises from the above facts is: how is imperfective aspect marked on forms which do not reduplicate? The answer is that imperfectivity is encoded by lengthening the syllable of the inflected verb form which occurs two syllables before the stressed syllable. So a verb stem like paisewa will show imperfectivity as in (124). In this case the syllable on which lengthening occurs is the subject prefix.

$$
\begin{aligned}
& \text { a:-pai'sewa } \\
& \text { I SG.IMPER-work } \\
& \text { I am working }
\end{aligned}
$$

With longer verb stems the lengthened vowel falls in the middle of the word, as in (125).

$$
\begin{aligned}
& \text { a-saboku:li'ye-di } \\
& \text { 1SG-follow.IMPER.TR-3PL } \\
& \text { I am following them }
\end{aligned}
$$

A suffixed stem encodes imperfectivity in exactly the same way.

(126) a. a:-gi'te-di

1SG.IMPER-see.TR-3PL

I am seeing/watching them

b. a:-siu-'muna

1SG.IMPER-enter-again

I am entering again

If the verb form is too short - that is, it lacks two syllables before the stressed syllable, as in $i$-'me-di 'he brings them' - then the verb root is reduplicated.

$$
\begin{aligned}
& \text { i:-me-'me-di } \\
& \text { 3SG.IMPER-RDP-come.TR-3PL } \\
& \text { he is bringing them }
\end{aligned}
$$

There are some finally intransitive verbs which allow either reduplication or the lengthened vowel.
(128) a. i:-kaiaka
3SG.IMPER-stay
he is staying
b. i-ka-kaiaka
3SG-IMPER-stay
he is staying
(129) a. i:-lokoina
3SG.IMPER-run
he is running 


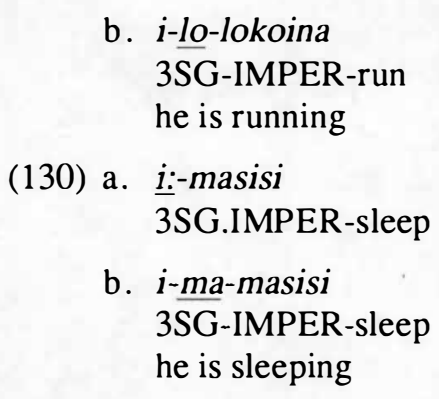

In each of the above (a) examples the verb encodes imperfectivity via vowel lengthening. In the (b) examples imperfective aspect is marked by means of reduplication. The question arising is what the difference between these two constructions is. Some native speakers give (131) to illustrate the difference. In (131a) the subject is unspecified, whereas in (b) the subject is known.

(131)
a. Ava-tau i:-lokoina?
which-person 3SG.IMPER-run
Who is running?
b. Geya, Kelebi i-lo-lokoina.
NEG Kelebi 3SG-IMPER-run
No, Kelebi is running.

The lengthened vowel is often found in the asking of questions, which would support the above hypothesis. However, many speakers do not seem to make a distinction between the two forms. Further study is need.

\subsubsection{NOUN INFLECTION}

\subsubsection{COMITATIVE ma-}

The morpheme ma- indicates either ownership or a comitative relationship. Nouns prefixed with ma- must have possession marked on the noun. The alienable possessive markers a- and $i$ - (4.2) are deleted when ma-occurs, as illustrated in (132a,b). The prefix ma- is also used with an inalienably possessed noun to express a contents-container relationship, illustrated in (132d) (cf. 4.1.3).

(132) a. Maniye-di ma-*(i)-di-vaega. some-3PL.IA COM-CON-3PL-clay

Some of them have clay.

b. ma-*(a)-na-magi

COM-EAT-3SG-betel.nut

with his betel nut/he has betel nut

c. tayamo vavina ma-natu-na

a woman COM-child-3SG.IA

a woman with/and her child

d. vevana ma-bayao-i-di

seed COM-basket-?-3PL.IA

basket of seeds $=$ basket containing seeds 


\subsubsection{ADVERBIAL ta-}

The morpheme ta- can be prefixed to any noun; it means 'different' or 'another'.
Ava-gu a-lusala
ta-kasa.
food-1SG.IA 1SG-search different-village
I will search for my food at a different village.

\subsubsection{LIMITER -va}

The limiter -va has the meaning of 'only' or 'just'.

$$
\begin{aligned}
& \text { I-gweniya-va a-duduwe-di. } \\
& \text { CON-1SG.dog-LIM 1SG-call.TR-3PL } \\
& \text { I called only my dogs. }
\end{aligned}
$$

\subsubsection{PLURAL - (y)ao}

The plural morpheme $-(y)$ ao suffixes to the noun (its allomorphs are discussed in section 2.4.3).

$$
\begin{aligned}
& \text { (135) a. } \text { weniya-yao } \\
& \text { dog-PL } \\
& \text { dogs } \\
& \text { b. } \text { magi-yao } \\
& \text { betel.nut-PL } \\
& \text { betel nut } \\
& \text { c. } \text { natu-nao } \\
& \text { child-3SG.IA.PL } \\
& \text { his/her children }
\end{aligned}
$$

The occurrence of the plural marker is not obligatory, and I have yet to determine when it is necessary for it to occur.

\section{POSSESSION}

As in many Oceanic Austronesian languages, the encoding of possession in Gumawana is quite complex. There are three different types of possessive constructions in Gumawana. The first one, which consists of an affix suffixed directly to the head, is referred to as inalienable (4.1). The other two are normally referred to as alienable (4.2) and are encoded with the morphemes a- and $i$ -

The possessive system allows some nouns to utilise two or all three construction types with distinctive meanings depending on which construction is used. In (1a) the noun nunu is possessed with the inalienable form and has the meaning of 'breast'; in (b) it is possessed with the alienable $i$-form and the meaning changes to 'lineage'.

(1) a. Esteli nunu-na

Esteli breast-3SG.IA

Esteli's breast 


\section{b. $i$-gu-nunu}

CON-1SG-lineage

my matrilineage (to which I belong)

The word bao 'pig' allows all three forms with differing meanings as in (2a-c). Note that the a-form can be interpreted in two different ways.

(2) a. Kalitoni bao-i-na

Kalitoni pig-?-3SG.IA

Kalitoni's pig (his in-laws raise and eat it, but they do so because of Kalitoni)

b. Kalitoni a-na-bao

Kalitoni EAT-3SG-pig

Kalitoni's pig (for consuming) / his pig which was given to him

c. Kalitoni i-na-bao

Kalitoni CON-3SG-pig

Kalitoni's pig (he owns it)

As the above examples indicate, the normal order for possessive constructions is PossessorHead. The difference between these three constructions is discussed next.

\subsection{INALIENABLE POSSESSION}

Inalienable possession is associated with those nominals which are obligatorily possessed or those nominals that are inseparable semantically from their head.

Lynch (1982:249) notes that "in many languages...possessive suffixes to nouns and person/number-of-object suffixes to transitive verbs are formally similar or, in many cases, identical". This is true of Gumawana, and Table 7 shows that the object suffixes (3.3.1.1) and possessive suffixes differ only in third person singular.

TABLE 7: OBJECT AND POSSESSIVE SUFFIXES

\begin{tabular}{|lcc|}
\hline Person/number & Object suffixes & Possessive suffixes \\
\hline 1SG & $-g u$ & $-g u$ \\
2SG & $-m u$ & $-m u$ \\
3SG & $-\emptyset$ & $-n a$ \\
1PL.INCL & $-d a$ & $-d a$ \\
1PL.EXCL & $-m a$ & $-m a$ \\
2PL & $-m i$ & $-m i$ \\
3PL & $-d i$ & $-d i$ \\
\hline
\end{tabular}

The inalienable possessive suffixes mark a number of forms of agreement, as well as agreement of the head noun with its possessor (as described below), and it is therefore of ten convenient to speak simply of 'agreement suffixes' and 'agreement'.

In the following sections the functions of inalienable possession are described. A number of the terms used to describe possessive functions are taken from Beekman and Callow (1974:251-256). 


\subsubsection{PART-WHOLE RELATIONSHIP}

Inalienable possession encodes a part-whole relationship between a possessor noun and a head (possessum) noun. There are three subcategories of part-whole relationship: constituent-whole, quantitative-whole and spatial-whole.

\subsubsection{CONSTITUENT-WHOLE}

The constituent-whole relationship includes body parts and parts of things. The word for 'name' is also in this group.

(3) a. Ku-na kewou matakubu-na... 2SG-go canoe bow-3SG.IA You go to the bow of the canoe...

b. $\underline{\text { Ae-mu }} \quad k w a i-s o b u-y e$. leg-2SG.IA 2SG.by/set-descend-OAD.TR You set your leg down.

\subsubsection{QUANTITATIVE-WHOLE}

The second relationship is quantitative-whole. In (4a) liliu 'all' is inalienably possessed and in (4b) manie 'some' is inalienably possessed. These morphemes belong to the class of quantifier nouns described in section 3.1.1.2.

(4)
a. Liliu-ma
ka-siu
vada ame.
all-1PL.EXC.IA 1PL.EXC-enter house this
All of us entered this house.

b. Tomota manie-di si-katowana. people some-3PL.IA 3PL-be.sick

Some of the people are sick.

\subsubsection{SPATIAL-WHOLE}

Nouns of spatial relationships such as sinae 'inside' (5a) and kiki 'next to, near' (5b) obligatorily take the inalienable possession.

(5) a. I-siu vada sinae-na.

3SG-enter house inside-3SG.IA

He entered the inside of the house.

b. Latuwo-na bego i-na-tuwowo-na kiki-na. desire-3SG.IA IRR 3SG-go-older.brother-3SG.IA next.to-3SG.IA He intended to go next to his brother.

Other nouns also allow inalienable possession to express a spatial relationship.

(6) a. tanuwo vada-i-di

garden house-?-3PL.IA

garden house (i.e. houses located in the garden) 


\section{b. Nubogeta udodana-i-na Nubogeta bush-?-3SG.IA bush located on Nubogeta}

There is an important distinction which should be noted between (6a) and (7a). In (7a) the meaning would be something like 'a greenhouse', i.e. a house for a garden, which in Amphlett culture is unfelicitous. In (7b) the meaning is clearly 'a house for yams': the house is used for storing yams.

(7) a. *tanuwo a-na-vada garden PASS-3SG-house greenhouse (i.e. a house for a garden)

b. kuvi a-na-vada yam PASS-3SG-house yam house (i.e. a house for yams)

\subsubsection{KINSHIP}

Kinship terms are normally inalienably possessed, except the term for 'younger sibling of same sex', a-na-gomana (lit. 'his child'). ${ }^{11}$

(8) a. Vavina mone-na i-sou i-ma. woman spouse-3SG.IA 3SG-go.down 3SG-come The woman's spouse came down.

b. Natu-na i-digo... child-3SG.IA 3SG-say Her child said...

\subsubsection{CONTENTS-CONTAINER}

In a contents-container relationship the possessor noun is contained in the head. This type of construction requires the prefix ma- 'comitative' on the head noun (3.4.2.1).

(9) a. vevana ma-bayao-i-di

seed COM-basket-?-3PL.IA

basket of seeds $=$ basket containing seeds

b. bwae ma-vedi-na

water COM-coconut.shell-3PL.IA

shell of water $=$ shell containing water

c. iyana ma-uwos-i-di

fish COM-net-?-3PL.IA

net of fish

${ }^{11}$ Some speakers feel this term is more of a generic term indicating someone who goes and does things for someone. 


\subsubsection{REFERENCE}

In some constructions the head noun is about or refers to the possessor noun.
(10) a. sina-gu a-na-kamasa vatetel-i-na mother-1SG.IA PASS-3SG-death story-?-3SG.IA the story about my mother's death
b. Kelebi buki-na
Kelebi book-3SG.IA
book about Kelebi

\subsection{ALIENABLE POSSESSION}

The alienable possession involves two different morphemes, $i$ - and a-. Both require agreement with the possessor in person and number.

\subsection{1 a-POSSESSION}

The a-possessive marker has two main functions. Firstly, it indicates a relationship in which a possessor intends to consume the possessum. This has been traditionally referred to as 'edible' in the literature. Lynch (1982) rightly states that "the important thing in these constructions is the fact or intention of eating, not the edibility of the referent of the head nominal, and hence the name eating rather than edible possession". Therefore, where applicable I have labelled a- as EAT for eating. ${ }^{12}$

The second function Lynch refers to as 'passive', in the sense that the possessor has no control over (or has a passive relationship with) the possessum. (In section 4.3.1 I present the semantic relationships in a more general way.)

\subsubsection{EATING}

As stated above, the a-form can indicate intention to consume an item. The following examples are given to illustrate:

(11) a. a-gu-iyana
EAT-1SG-fish
My fish for eating

b. A-mu-magi a-vini-mu.

EAT-2SG-betel.nut 1SG-give-2SG

I give you your betel nut (for chewing).

\subsubsection{PATIENT}

This relationship deals with nominalised verbs where the possessor could be described as the direct object of the underlying verb (cf. section 3.2.7.7).

12Lynch (1982) suggests that this form of possession was derived from the Proto Oceanic verb *kani 'to eat'. Historically, Gumawana a- is derived from Proto Oceanic *ka- (cf. Lichtenberk 1986). 
(12) a. a-ma-yabobona

PASS-1PL.EXC-love

our love $=$ (someone) loves us

b. vaega a-na-elina

clay PASS-3SG-dig

digging of clay $=($ someone $)$ digs clay

\subsubsection{RECIPIENT}

The recipient relationship refers to an implicit event that entails the head and in which the possessor is the recipient of the head.

(13) a. Tomasi a-na-gita

Tomasi PASS-3SG-spear

Tomasi's spear $=$ the spear which will be used to spear Tomasi

b. a-mu-ten

PASS-2SG-ten

your ten (which I will give you)

Example (13b) was heard during a card game where to get a ten was not good. This is all that was uttered, yet the meaning in parentheses was clearly intended.

\subsection{2 i-POSSESSION}

The $i$-form of possession indicates that the possessor has some control over the possessum.

\subsubsection{OWNERSHIP}

When the possessor owns or can manipulate the possessum we find the $i$-form of possession.

(14) a. I-na-weniya-yao i-duduwe-di.

CON-3SG-dog-PL 3SG-call.TR-3PL

He called his dogs (which belong to him).

b. Si-kaiaka i-di-vada.

3PL-remain CON-3PL-house

They are at their house (which belongs to them).

\subsubsection{AGENT}

When a verb is nominalised with the $i$-form of possession the relationship is one where the possessor is the underlying agent of the nominalised verb as in (15a,b) (cf. 3.2.7.7).

(15) a. i-da-yabobona

CON-1PL.INC-love

our love $=$ we love 
b. yau Opa i-ma-nai

1SG.PN Opa CON-1PL.EXC-marriage

mine and Opa's marriage $=$ Opa and I married

\subsubsection{ROLE}

The $i$ - possession may be used to indicate a role relationship fulf illed by the possessum in relation to the possessor:

(16) a. Kelebi i-gu-to-bowou.

Kelebi CON-1SG-AGT-sorcery

Kelebi is my sorcerer (he works for me).

b.

CON-1PL.EXC-minister

our minister

\subsection{SUBJECT-OBJECT NOMINALISATION/POSSESSION}

In relation to nominalised verbs, an important generalisation was noted in 3.2.7.7, namely that if the possessor is semantically the agent (the initial subject), then the nominalised verb is marked with the active or control marker $i$-, whereas if the possessor is semantically the patient (the initial direct object) of the verb, then we find the passive marker a-. The following diagram presents these underlying relationships between the subject and object in relation to the verb in graphic form:

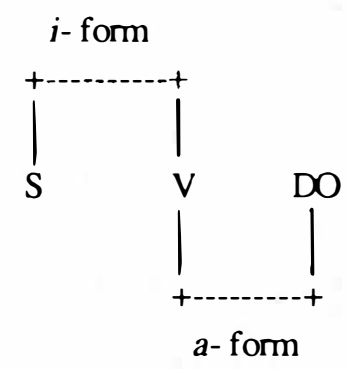

(17) a. a-mu-pola = (i)-pole-mu

PASS-2SG-lie 3SG-lie.TR-2SG

your lie (which was told to you) = someone lied to you

b. $\underline{i-m u}$-pola $=\underline{k u}$-pola

CON-2SG-lie 2SG-lie

your lie $($ which you told $)=$ you lie

This notion, which is essentially the notion of control, also accounts for the distinction between the $a$-form and the $i$-form of the alienable possession when the possessum is not a nominalised verb. The utterance in (19a) is logically an answer to (18), but is infelicitous because the possessor marked by a-has no control over the fire; instead the possessor is in some sense the patient of the action involving the fire. In contrast (19b) is acceptable because it indicates that the fire will be used on the pig; that is, the pig is the patient and has 
no control over the fire. The utterance in (19c) is a felicitous answer to the question in (18) because the possessor is in control of the fire.

Kaga a-na-yeu?

what PASS-3SG-fire

What is the fire for?

(19) a. ? Geya, a-gu-yeu.

NEG PASS-1SG-fire

Nothing - my fire (which I will eat). / Nothing - my fire (which is to be used to burn me).

b. Geya, bao a-na-yeu.

NEG pig PASS-3SG-fire

Nothing - the pig's fire (which will be used to roast it).

c. Geya, i-gu-yeu.

NEG CON-1SG-fire

Nothing - it is my fire (I decide what it will be used for).

It is clear from contrasting pairs that the distinction is one of control.

(20) a. Kelebi a-gu-to-bowou.

Kelebi PASS-1SG-AGT-sorcery

Kelebi is my sorcerer (who is doing sorcery to me).

b. Kelebi i-gu-to-bowou.

Kelebi CON-1SG-AGT-sorcery

Kelebi is my sorcerer (i.e. I tell him who to do sorcery to - he belongs to me).

Examples (21a) and (21b) given by my informant, illustrate the difference in meaning, and show that the distinction between these two forms is important.

(21) a. Ame Yeisu a-na-kelose bei i-vailai.

this Jesus PASS-3SG-cross PRO 3SG-accident

This is Jesus' cross with which he will have an accident.

b. Ame Yeisu i-na-kelose.

this Jesus CON-3SG-cross

This is Jesus' cross (which he made and owns).

Some speakers, however, make no difference in meaning and use the $i$ - and $a$ - forms indiscriminately, indicating that this distinction is being neutralised.

\subsection{NEUTRALISATION OF INALIENABLE POSSESSION}

Nouns which are normally inalienably possessed may also occur in an altermative form, with an invariant suffix -na and a shift in stress one syllable to the left. The (a) examples below contain an inalienably possessed noun, the (b) examples the alternative form.

(22) a. Yau ma'ta-gu si-goyo.

1SG.PN eye-1SG.IA 3PL-bad

My eyes are bad. 

b. Yau 'matana si-goyo.
ISG.PN eye 3PL-bad
My eyes are bad.

(23) a. Yau da'ba-gu i-geda.

1SG.PN head-1SG.IA 3SG-hurt

My head hurts.

b. Yau 'dabana i-geda.

1SG.PN head 3SG-hurt

My head hurts.

Although not immediately obvious from the examples above, a noun with the alternative -na form functions as if it were not inalienable. Hence a form like ['nimana] 'hand' can be possessed with the a-form of alienable possession. Thus example (24a) is grammatical because stress falls on the first syllable. However, (24b) is ungrammatical because it carries both the alienable a-form and the inalienable suffix.

(24) a. a-mu-'nimana

PASS-2SG-hand

your hand (which I will hit you with)

b. *a-mu-ni'ma-na/-mu

PASS-2SG-hand-3SG/2SG

(25)
a. 'yawana
life, breath
b. ya'woigu
my life, my breath

(26) a. 'konana

thing, possession

b. ko'nagu

my thing, my possession

\subsection{ATTRIBUTION OF INALIENABLE POSSESSION}

Just as nouns which are usually inalienably possessed may occur without inalienable possession, so conversely a noun that is not normally inalienably possessed may have inalienable possession attributed to it. In such cases an $-i$ - suffix occurs before the agreement markers. In (27) bao and ikaika do not require any form of possession, but when they do take the inalienable form, they require the $-i$ - suffix.

(27) a. bao- $\underline{-}-g u$

pig-?-1SG.IA

my pig = the pig which exists because of me

b. ikaika-i-gu

blood-?-1SG.IA

my blood

Nominalised verbs which are inalienably possessed to indicate a reference relationship (4.1.4) also require $-i$-. When a man does marriage work, he does work because of his wife-to-be, and in (28a) she is implicitly the possessor. In $(28 \mathrm{~b}, \mathrm{c})$ the verbs are nominalised and require $-i$ - 
(28) a. paisewa- $\underline{i}-g u$

work-?-1SG.IA

my work $=$ the work done because of me

b. sina-gu vatetel-i-na

mother-1SG.IA story-?-3SG.IA

the story about my mother

c. bagal-i-gu

mistake-?-1SG.IA

my wrong

I have not been able to determine any semantic function for the suffix $-i-$, which seems to occur for phonological reasons.

\subsection{SUMMARY}

To summarise the possessive system the following diagram is given:

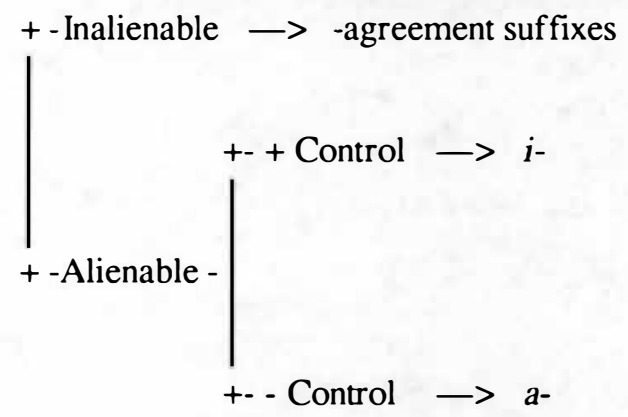

The diagram illustrates the different types of possessive encoding in Gumawana. Alienable possession distinguishes between controlled and non-controlled possession. Consumability is a form of non-control because nouns possessed with this form imply the possessor's intention to consume, but not his control. In (29) there is no evidence that 'you' have control over the object marked as consumable.

(29) Maine a-mu-iyana a-ginubasi be, a-vai-polu. earlier EAT-2SG-fish 1SG-spear and 1SG-CAUS-boil Earlier I speared your fish (for eating) and I will boil it.

\section{PHRASE STRUCTURE}

In this section simple phrases are presented; these include noun phrases, adpositional phrases and verb phrases.

\subsection{NOUN PHRASE}

The order of constitutents in the noun phrase is:

(possessor) head noun (attribute noun) (adjective) (numeral) (demonstrative) 
where a constituent in brackets is optional. An attribute may be another noun, an adjective, a numeral or a relative clause.

\subsubsection{SIMPLE NOUN PHRASE}

A simple noun phrase consists minimally of a head noun or pronoun.

(1) a. Tanuwo mainao ka-tala-i. garden first 1PL.EXC-cut-TR

First we cut the garden.

b. Go kai ka-kaluvila-muna.

SW 1PL.EXC.PN 1PL.EXC-return-again

But we retumed again.

\subsubsection{POSSESSIVE NOUN PHRASE}

The possessive constructions are described in detail in section 4 .

The only constituent which comes before the head is the possessor. Note that in (2b) two genitive constructions occur together.

(2) a. Patiseba i-na-kewou ka-biu.

Patiseba CON-3SG-canoe 1PL.EXC-pull

We pulled Patiseba's canoe.

b. Boibo-ya-na tubu-na i-na-putuma i-silupave.

Boibo-REF-3SG grandson-3SG.IA CON-3SG-grease 3SG-squeeze.TR

Boibo squeezed his grandson's coconut grease.

When the head is a quantifier noun, it has a partitive meaning.

(3) Iyana giyai-di badabada-i-di ka-ginubasi-di.

fish small-3PL many-?-3PL.IA 1PL.EXC-spear-3PL

We speared many of the small fish.

\subsubsection{NOUN ATTRIBUTES}

A noun may serve as an attribute to modify the head noun. The attributive noun is semantically more specific than the head noun.

(4) a. E gomana Botuliu i-ma-masisi.

DEV child Botuliu 3SG-IMPER-sleep

The child Botuliu was sleeping.

b. E gomana koloto i-digo...

DEV child man 3SG-say

So the boy said...

c. E tuta tayamo natu-na koloto toi-na i-latuwoko... DEV time one child-3SG.IA man real-3SG 3SG-tell.TR So one time she told her real son... 


\subsubsection{ADJECTIVES}

The morphology of adjectives is described in 3.1.4. An attributive adjective follows any attributive noun (see (4c)) and precedes the numeral (see examples in 3.1.4). Example (5) illustrates the uninflected adjective.

(5)

$$
\begin{aligned}
& \text { Yau guna-vada moe vada } \frac{\text { bogo. }}{\text { old }} \\
& \text { ISG.PN 1SG.POSS-house DEM house } \\
& \text { My house is an old house. }
\end{aligned}
$$

\subsubsection{HEAD-NUMERAL}

The numeral is the next to last constituent in the noun phrase. This does not include tayamo 'a, one', which may function as an indef inite article. In example (6) the order is noun-adjective-numeral.

(6) a. Koloto gagai-di a-di-tai-yuwo a-gite-di.

man big-3PL PASS-3PL-man-two 1SG-see.TR-3PL

I saw the two big men.

b. Gulewa giyai-di ai-yuwo i-babane-di. stone small-3PL CL-two 3SG-find.TR-3PL

He found two small stones.

If the order of constituents in (6b) is changed to that of (7) so that the numeral comes before the adjective, there is a change in intonation. This type of construction is a leftdislocation.

$$
\begin{aligned}
& \text { Gulewa } \frac{\text { ai-yuwo, giyai-di i-babane-di. }}{\text { CL-two }} \text { small-3PL } 3 \text { SG-find.TR-3PL } \\
& \text { stone } \\
& \text { The two stones, they were small ones he found. }
\end{aligned}
$$

The numeral tayamo 'a, one' functions as an indefinite article when it begins the noun phrase, as in (8a), and as the numeral 'one' when it occurs after the head noun, as in (8b) (see also 3.1.8).

(8) a. Tayamo nubasidi gagai-na i-ginubasi.

one fish.type big-3SG 3SG-spear.TR

He speared a big nubasidi fish.

b. Nubasidi tayamo gagai-na i-ginubasi.

fish.type one big-3SG 3SG-spear.TR

He speared one big nubasidi fish.

\subsubsection{HEAD-DEMONSTRATIVE}

Demonstratives (section 3.1.7) are normally the last constituent in the noun phrase.

$$
\begin{aligned}
& \text { Vada tayamo giyai-na amo si-yowo-yowo. } \\
& \text { house one small-3SG that 3PL-IMPER-build } \\
& \text { They were building that one small house. }
\end{aligned}
$$

If the demonstrative comes between the noun and modifying adjective as in (10b), it is a left-dislocation construction. In (10a) the demonstrative comes last in the noun phrase - that 
is, in the normal word order. The meaning is that all the fish are big and all are being given. In (10b) there is an intonation difference. The comma indicates a pause. The implied meaning of the noun phrase in (10b) is that there are perhaps small fish which were not given.

(10) a. Iyana gagai-di ame a-vini-mu.

fish big-3PL this $1 \mathrm{SG}$-give-2SG

I give you these big fish.

b. Iyana ame, gagai-di a-vini-mu.

fish this big-3PL 1SG-give-2SG

These fish, I give you the big ones.

\subsubsection{HEAD-REFERENCE MARKER ${ }^{13}$}

The reference marker -ya- (3.1.8) and its attendant possessive suffix are, like the demonstrative, always the last items of the noun phrase (although a relative clause may follow). Since they are suffixed directly to the noun, this means that they are used only where no other attributes (attributive noun, adjective, numeral, demonstrative) follow the noun.

Although the reference marker is only used when the semantic conditions (referentiality, specificity) and the structural conditions (no attributes) for its use are met, these are apparently only necessary, but not sufficient, conditions for its use. There are occasions when the conditions are met and the reference marker is not used. The reasons for this evidently have to do with discourse considerations, and it appears that there is normally only one case of -ya- in a clause. We may say tentatively that -ya- marks the topic of the clause (i.e. the referent about which the speaker wishes to say something). This in (1la) koloto-ya-di 'the men' is marked with the reference marker, but weniya 'the dog' is not. Similarly in (11b) dokanikani-ya-na 'the giant' has the reference marker, but noko 'the plate' does not. The distinction in each case between the noun marked with -ya- and the noun not thus marked is not a difference in referentiality or specificity, but apparently a difference in topicality. Note that, as (11c) illustrates, the topic is not necessarily the subject; here it is the possessor.

(11) a. Koloto-ya-di weniya si-duduwe.

man-REF-3PL dog 3PL-call.TR

The men called the dog.

b. Dokanikani-ya-na noko i-kavale.

giant-REF-3SG plate 3SG-carry.TR

The giant carried the plate.
c. Vatutea-na yoi-na kakavaku.
legend.REF-3SG name-3SG.IA worm
The name of this legend is 'worm'.

Similarly, when a temporal clause is introduced by tuteana /tuta-ya-na/ or laveana /lava-iana/ 'when, the time', the time reference ('the time you go to America') is the topic of the sentence.

${ }^{13}$ Editor's note: This section is an editorial addition, with examples derived from other sections of this work. 


\section{Tutea-na komu ku-na America ta-va-tai-taiya.}

time.REF-3SG 2SG.PN 2SG-go America 1PL.INC-RECP-IMPER-cry

(At) the time you go to America we will cry for each other.

The concept of topic is not to be confused with that of 'old information'. In (13) ame dogoi-ya-na 'this, the thing' is evidently receiving its first mention, but is topic.
Ame dogoi-ya-na kaga manu-na?
this thing-REF-3SG what BEN-3SG
What is this thing for?

There are also cases where the topic noun marked with -ya- is clearly referential and specific, but not definite.

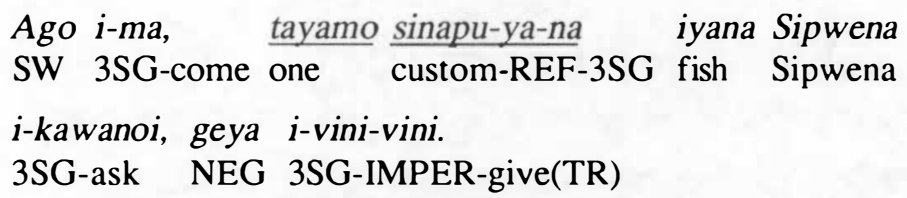

And he (the giant) came, and one of his customs was that Sipwena would ask for fish but he never gave to him.

Finally, note that a topic noun is only marked with -ya- if it is not followed by an attribute; that is, not every topic is marked with -ya-.

\subsubsection{RELATIVE CLAUSES}

Since Gumawana is a verb-final language, we would expect the relative clause to precede the head noun. But that is not the case.

Subjects, objects and locatives may be relativised in Gumawana. The head may be analysed either as internal to the relative clause or as extemal to and preceding the relative clause:

[head + relative clause] OR head + [relative clause]

It is difficult to determine which is the better analysis, but for convenience of presentation I treat the head as intemal to the relative clause.

In (15) the head and the relative clause are enclosed in square brackets and the head is underlined. In (15a) the head is the relativised subject Daniana monena. In (15b) there are two relative clauses: the head of the first is the relativised subject $C$ lif, of the second the relativised locative Guest House.

(15) a. Kai [Dania-na mone-na i-dalaiba] ka-ma.

1PL.EXC Dan.REF-3SG wife-3SG.IA 3SG-drive 1PL.EXC-come We and Dan's wife, who drove, came.

b. Teside yau Kelebi Tomasi [Clif i-iwo i-ma Thursday 1SG.PN Kelebi Tomasi Clif 3SG-seaward 3SG-come
i-kabi-ma]
ka-yava
ka-na
[Guest House goi
3SG-get-1PL.EXC 1PL.EXC-to.bush 1PL.EXC-go Guest House PP
ka-mwela].
1PL.EXC-climb 
On Thursday Kelebi, Tomasi, I and Clif, who came and got us, went to the Guest House where we went up.

When the subject of the matrix clause is the head noun, the subject remains in its normal (clause-initial) position. But when the object of the matrix clause is the head noun, the object and its accompanying relative clause are shifted to the position after the verb.

(16) a. Kelebi i-modugu-di [kewou-ya-di si-salili].

Kelebi 3SG-make-3PL canoe-REF-3PL 3PL-sink

Kelebi built the canoes which sank.

b. Clif i-na i-leuye-di i-me-di [temba gabula

Clif 3SG-go 3SG-gather.TR-3PL 3SG-come.TR-3PL timber under.house

i-yato-i-di].

3SG-set-TR-3PL

Clif went to gather and bring the timber which he set under the house.

c. E a-ma a-lituwoko [tubu-gu

DEV 1SG-come 1SG-tell.TR grandmother-3SG.IA

i-kali-taoe].

3SG-with.point.INST-stand.TR

So I went and told my grandmother who made one.

Gumawana speakers only allow the locative of a matrix clause to be the head of a relative clause if the verb in the relative clause is imperfective. In (17) the head noun is abatulagalaga.

$$
\begin{array}{lll}
\text { [Aba-tulagalaga } & \text { i:-ta-guyala } & \text { goi] } i \text {-tu-sobu. } \\
\text { NOM-chair } & \text { 3SG.IMPER-ST-break PP } & \text { 3SG-by.sit-down }
\end{array}
$$

He sat down on the chair which was breaking.

A distinction is made between a relative clause and the complement clause of a verb of perception. This difference is seen in the verb agreement with the object. In (18a) and (18b) koloto is the head noun internal to the relative clause, and the object-marking of the verb 'see' agrees with it in person and number (with zero-marking for third person singular in (18a), -di for third person plural in (18b). In (18c) the clause in brackets is a complement clause and the verb 'see' has zero-marking because it agrees not with 'many men' but with the complement clause as a whole. In other words the object of gite 'see' is the clause in brackets.

(18) a. Kelebi i-gite [koloto-ya-na bao i-ginubasi].

Kelebi 3SG-see.TR man-REF-3SG pig 3SG-spear.TR

Kelebi saw the man who speared the pig.

b. Kelebi i-gite-di

[koloto badabada-i-di bao si-ginubasi].

Kelebi 3SG-see.TR-3PL man many-?-3PL.IA pig 3PL-spear.TR

Kelebi saw the men who speared the pig.

c. Kelebi i-gite [koloto badabada-i-di bao si-ginubasi.]

Kelebi 3SG-see.TR man many-?-3PL.IA pig 3PL-spear.TR

Kelebi saw the men spear the pig. 
Also found in Gumawana is a construction of the kind which Keenan (1985) labels 'co-relative'.

(19) a. Vavina i-kamasa, moe yau tubu-gu. woman 3SG-die that ISG.PN aunt-1SG.IA

The woman who died was my aunt. (lit. The woman died, that one was my aunt.)

b. Kelebi i-na-kewou i-modugu, kewou-ya-na i-salili.

Kelebi CON-3SG-canoe 3SG-make.TR canoe-REF-3SG 3SG-sink

Kelebi built his canoe which sank. (lit. Kelebi built his canoe, that canoe sank.)

In (19) the first clause is followed by a second clause introduced by either moe, a demonstrative used anaphorically, or tauyana 'that person' also used anaphorically. The second clause is a description of one particular noun in the first clause.

\subsubsection{COORDINATE NOUN PHRASES}

Noun phrases may be coordinated with be to form compound noun phrases.
a. Tama-di
be sina-di
father-3PL.IA and mother-3PL.IA PRF 3PL-die
Their father and mother had already died.
b. Losui tayamo be niu si-kaiaka.
banana one and coconut 3PL-be.there
A banana and coconut were there.
c. Yau Ediliki be Siyokila a-lituwoko-i-di.
1SG.PN Ediliki and Siyokila ISG-tell-TR-3PL
I told Ediliki and Siyokila.

bogina si-kamasa.

It is not yet clear to me when be is necessary. Normally when listing several nominals, be is not used.

(21) a. Ka-ma,

kona-ma

ka-vadoda a-ma-poasi

1PL.EXC-come thing-1PL.EXC.IA 1PL.EXC-load PASS-1PL.EXC-bar

a-ma-weniya.

PASS-1PL.EXC-dog

We came and loaded our things, our steel rods and our dogs.

b. E yau Ediliki ka-tuko.

DEV 1SG.PN Ediliki 1PL.EXC-go.up

So Ediliki and I went up.

\subsection{ADPOSITIONAL PHRASES}

All adpositions in Gumawana are postposed, with the exception of ma- (5.2.3). The most common postposition is goi, which is used in various types of phrasal constructions such as temporal, locative and instrumental. Similarity is encoded with nakae 'like'. The notions of benefactive, reason and content phrases are encoded by means of manu- 'benefactive' or 'purpose', and pasi- 'reason'. Source and goal are encoded with yai-. Each of these takes 
suffixes (4.1) agreeing with the head noun of the phrase in person and number. Two other adpositional phrases discussed in this section are those formed with ma- and taiyao 'comitative'.

\subsubsection{PhRASES MARKed WITH goi}

\subsubsection{LOCATIVE PHRASES}

Locative phrases include a head with the postposition goi. The clause following the locative phrase indicates what took place at that location.

(22) a. Tamogibeli natu-na taiyao si-kawala Musuwo goi tomota Tamogibeli child-3SG.IA COM 3PL-pole Musuwo LOC people manie-di si-lumadade-di... some-3PL.IA 3PL-ask.TR-3PL Tamogibeli poled with his child to Musuwo where he asked some of the people...

b. Yau a-na Bogili i-na-kasa goi tau-ya-na 1SG.PN 1SG-go Bogili CON-3SG-hamlet LOC person-REF-3SG a-gite. 1SG-see.TR I went to Bogili's hamlet to see him.

\subsubsection{INSTRUMENT PHRASES}

Goi is also used to encode the instrument with which an action is performed.

(23) a. Neta kokona, si-yagoi bei gita goi i-ginubasi-di. if crazy.person 3SG-know.TR PRO spear INST 3SG-spear-3PL If the crazy person is there, they know he will spear them with a spear.

b. ...ediedila goi yagila i-vayamu-di. sand INST wind 3SG-cover-3PL ...the wind covered them with sand.

\subsubsection{TEMPORAL PHRASES}

Temporal phrases consist of the postposition goi and a temporal noun phrase.

(24) a. Maliyalina $\frac{\text { ame goi uya-ma }}{\text { day }}$ TEMP thank-1PL.EXC.IA big-3SG On this day we thank you very much...

b. Nobuyana ame goi liliu-ma ka-siu ka-ma... morning this TEMP all-1PL.EXC.IA 1PL.EXC-enter 1PL.EXC-come On this morning all of us have entered... 


\subsubsection{PHRASES MARKED WITH OTHER POSTPOSITIONS}

\subsubsection{BENEFACTIVE PHRASES}

The notion of benef active is encoded by manu- 'benefactive', which takes an inalienable possessive suffix agreeing with the head in number and person (4.1).

(25) a. A-bobwala manu-mu o tuwo?

1SG-speak BEN-2SG or enough

Shall I speak for you or not?

b. Si:-paisewa Kalitoni manu-na.

3PL.IMPER-work Kalitoni BEN-3SG

They are working for Kalitoni.

\subsubsection{CONTENT PHRASES}

The notion of content (or reference) is also encoded by manu.
(26) a. Be ma-nakae-da go-gomana ame manu-di.
UNCRT COM-like-1PL.INC PL-child this CON-3PL
What might we do about these children.

$\begin{array}{lll}\text { b. Ta-vatetala } & \text { i-mi-sinapu } & \text { manu-na } \\ \text { 1 PL.INC-story } & \text { CON-2PL-custom } & \text { CON-3SG }\end{array}$

Let's talk about your customs.

\subsubsection{REASON PHRASES}

Reason phrases are characteristically marked by pasi 'reason' which, like manu, takes an inalienable possessive suffix agreeing with the head in number and person (4.1).
(27) a. Kaga pasi-na sinitu yai-na ko-numisa? what reason-3SG satan GOAL-3SG 2PL-trust What is the reason you trust in the evil being?
b. Yau pasi-gu siya-gu i-lau-i.
1SG.PN reason-1SG friend-1SG.IA 3SG-hit-TR
I am the reason he hit my friend.

\subsubsection{SOURCE AND GOAL PHRASES}

Both source and goal phrases are marked with yai-, which also takes an inalienable possessive suffix agreeing with the head in number and person (4.1). In (28a) yai-marks the goal and in (28b) it marks the source.
(28) a. I-vayali
i-na Tomasi yai-na.
3SG-walk.on.shore 3SG-go Tomasi GOAL-3SG
He walked along the shore to Tomasi.
b. Yaubada yai-na si-ma.
God SOURCE-3SG 3PL-come
They come from God.




\subsubsection{SIMILARITY}

Similarity is encoded with the postposition nakae (for examples, see section 9.1.1).

\subsubsection{PHRASES MARKED WITH ma-}

\subsubsection{COMITATIVE PHRASES}

There are two ways comitative phrases are constructed. One utilises the affix ma-, which is prefixed to the head of the comitative phrase.
(29) a. Nabodimomu Silekaleka ma-nubai-na i-di-kasa
Nabodimomu Silekaleka COM-cousin-3SG.IA CON-3PL-hamlet
Tuluviluvi si-kaiako.
Tuluviluvi 3PL-live
Nabodimomu and her cousin Silekaleka lived at their hamlet Tuluviluvi.
b. Tau-ya-na ma-niu-na si-kaiako.
person-REF-3SG COM-sister-3SG.IA 3PL-be.there
$\mathrm{He}$ and his sister were there.

A second construction consists of a noun phrase followed by the posposition taiyao. Note that in (30d) the comitative phrase is clause final and the head is not included in the subject as in (30a-c).

(30) a. $\frac{\text { Nubai-gu }}{\text { cousin-1SG.IA }} \frac{\text { taiyao }}{\text { COM }}$ 1PL.ma 1 EX-come 1 1PL.EXC-gather.shells

Together with my cousin we came to gather shells.

b. Nabodimomu nubai-na Silekaleka taiyao si-na vada giyai-na.

Nabodimomu cousin-3SG.IA Silekaleka COM 3PL-go house little-3SG Nabodimomu and her cousin Silekaleka went to the toilet.

c. Mone-na taiyao si-kawala si-wo si-vaiu.

spouse-3SG.IA COM 3PL-pole 3PL-go 3PL-arrive

With his wife they poled and arrived.

d. ...go se-gowo si-na si-paisewa Clif taiyao.

SW friend-1SG.IA.PL 3PL-go 3PL-work Clif COM

...but my friends went and worked with Clif.

When an inanimate object is carried only ma-may be used.

(31) a. Ma-i-gu-buki a-siu.

COM-CON-1SG-book 1SG-enter

With my book I entered.

b. *Guna buki taiyao a-siu.

\subsubsection{MANNER PHRASES}

Manner phrases consist of a nominalised verb with the prefix ma-. 
(32) a. Go-gomana ma-i-di-taiya si-bobwala.

PL-child COM-CON-3PL-cry 3PL-talk

The children spoke weeping. (lit. The children with crying spoke.)

b. Ma-i-na-matoita pola-pola i-tuma-bala.

COM-CON-3SG-fear IMPER-lie 3SG-beckon-across

With false fear he beckoned.

\subsection{VERB PHRASE}

The constituents of the verb phrase are simply:

verb (adverb)

A simple verb phrase minimally consists of a finite verb - that is, a verb stem with attendant affixes (3.3.1).

(33) a. Ku-sou!

2SG-go.down

Go down!

b. Tamogibeli natu-na bwae i-nimu.

Tamogibeli child-3SG.IA water 3SG-drink

Tamogibeli's child drank water.

The other (optional) constituent of the verb phrase is the adverbial (distinct from the adverbial suffix, which is part of the verb itself; cf. 3.3.1.1). Adjectives such as toina 'very' and gagaina 'big' may function as adverbials. These are considered as part of the verb phrase because of their strict ordering and the fact that nothing else may come between them. In (34a) and (35a) the finite verb is followed by gagaina and toina, both of which modify the verb. Both (b) examples show that it is not possible to place any other constituent between the adjectival noun and the verb.

(34) a. Ka-matoita gagai-na.

1PL.EXC-fear big-3SG

We were very afraid.

b. *Ka-matoita moteta gagai-na.

1PL.EXC-fear snake big-3SG

(35) a. Ai-yuwo-i-na ka-uyawana gagai-na toi-na.

CL-two-?-3SG 1PL.EXC-rejoice big-3SG real-3SG

Again we two rejoiced very much.

b. *Ka-uyawana ai-yuwo-i-na gaga-i-na toi-na.

It is possible to have more than one occurrence of toina, which intensifies the verb.
Kelebi i-matoita toi-na toi-na.
Kelebi 3SG-afraid real-3SG real-3SG
Kelebi was very very afraid. 


\section{CLAUSE STRUCTURE}

In this section the clause structure of Gumawana is presented. The basic order of constituents in a Gumawana clause is:

(subject noun phrase) (direct object noun phrase) (oblique noun phrase) verb phrase Note that the bracketed constituents are not obligatory. Normally only one or two are found.

Grammatical relations in Gumawana are presented in section 6.1. The basic clause structures of intransitive and transitive clauses are discussed in 6.2 and 6.3. In 6.4 the various predicate types found in Gumawana are described. Reflexive clauses and reciprocal clauses are discussed in 6.5 and 6.6. Impersonal constructions are examined in 6.7 and causatives in 6.8. The various relation-changing devices in Gumawana are described in 6.9.

\subsection{GRAmmatical RELATIONS}

\subsubsection{SUBJECT}

The subject in Gumawana is identified by the subject agreement prefix on the verb and by word order. All verbs in Gumawana agree with their final subject in both person and number (3.3.1.1). In (la) the intransitive verb paisewa agrees with the third person singular subject Kalitoni. In (1b) the intransitive verb nai has a plural subject and is thus marked with the third person plural prefix si-. Examples (1c) and (1d) illustrate a change in person which is marked on the verb.

(1) a. Kalitoni i-paisewa.

Kalitoni 3SG-work

Kalitoni worked.

b. Kalitoni be Opa si-nai.

Kalitoni and Opa 3PL-marry

Kalitoni and Opa married.

c. $\underline{Y a u} \underline{a}-$-mwela.

1SG.PN 1SG-climb

I climbed up.

d. Komu ku-mwela.

2SG.PN 2SG-climb

You climbed up.

Word order is another way of distinguishing the subject from other constituents of the clause. Overt subjects precede both the object (if there is one) and the verb.

(2) a. Topiyo alova i-tala-i.

Topiyo tree 3SG-cut-TR

Topiyo cut the tree.

b. Topiyo Kelebi i-lau-i.

Topiyo Kelebi 3SG-hit-TR

Topiyo hit Kelebi. 


\subsubsection{DIRECT OBJECT}

The object noun phrase is cross-referenced on the verb with a suffix agreeing in person and number with the object (3.3.1.1). In (3) the verb agrees in person and number with the final direct object. Note that in (3c) and (3d) it is not necessary for there to be an overt direct object: just the agreement suffix is sufficient if the object has been previously given in the discourse.

(3) a. Koloto-ya-di weniya si-duduwe. man-REF-3PL dog 3PL-call.TR

The men called the dog.

b. Koloto weniya-yao i-duduwe- $\underline{\text { it. }}$. man dog-PL 3SG-call.TR-3PL

The man called the dogs.

c. Koloto i-duduwe-mu. man 3SG-call.TR-2SG

The man called you.

d. Koloto i-duduwe-gu. man 3SG-call.TR-1SG The man called me.

The direct object follows the subject and precedes the verb in basic word order. In (4b) the direct object is found closest to the verb.

(4) a. Kiwelu weniya i-kabi-di.

Kiwelu dog 3SG-take-3PL

Kiwelu took the dogs.

b. Dokanikani-ya-na noko i-kavale. giant-REF-3SG plate 3SG-carry.TR

The giant carried the plate.

A change in word order is found in various types of construction. If the object is in focus (of ten marked with (-yana) and it is clear which nominal is the subject then the object may precede the subject. Objects may come after the main verb when they are relativised (see section 5.1.8).

\subsubsection{INDIRECT OBJECT}

Because (in the Relational Grammar framework used here) grammatical relations are determined at the initial level, it is possible for the indirect object to occur initially but not finally, due to its advancement to direct object. This is the case in Gumawana. The indirect object obligatorily advances to direct object. As a result, the final object in (5a-c) is semantically the recipient, that is, initially the indirect object. However, it is finally a direct object of the clause.

(5) a. A-latuwoko-i-mu.

1SG-tell-TR-2SG

I tell you. 
b. Buki a-vini-mu.

book 1SG-give-2SG

I give you the book.

c. Ame a-vatuluko-i-di.

this 1SG-teach/show-TR-3PL

I teach/show them this.

\subsubsection{OBLIQUE RELATIONS}

Table 8 summarises the oblique relations which are found (the phrase structure of each is examined in 5.2).

TABLE 8: OBLIQUE RELATIONS

\begin{tabular}{|l|l|}
\hline Form & Semantic Role \\
\hline ma- & Comitative \\
taiyao & Comitative \\
yai & Source \\
& Goal \\
manu & Purpose \\
& Benefactive \\
& Content \\
goi & Instrumental \\
& Temporal \\
& Locative \\
pasi & Reason \\
\hline
\end{tabular}

Nouns marked by the above postpositions cannot be the arguments of a verb. This is the main difference between the above oblique relations and the relations of subject and object.

(6) a. Buyala a-madagi Topiyo manu-na.

necklace 1SG-make(TR) Topiyo BEN-3SG

I make the necklace for Topiyo.

b. Si-na bwanala goi si-tamumu.

3PL-go food.storage LOC 3PL-hide

They went to the food storage area where they hid.

c. Nima-na goi i-lau-i-di.

hand-3SG INST 3SG-hit-TR-3PL

He hit them with his hand.

d. Tapwae i-kawanoi-ye

tobacco 3SG-request-OAD.TR SOURCE-1SG

He requested tobacco from me.

e. Komu yau taiyao ta-paisewa.

2SG.PN 1SG.PN COM 1PL.INC-work

You and I will work together. 


\subsection{INTRANSITIVE CLAUSES}

Finally intransitive clauses must agree with the final subject in number and person (3.3.1.1). Minimally a finally intransitive clause includes a finite verb which agrees with the final subject. Other constituents of the clause have the basic word order but without the direct object. The word order may be changed due to topicalisation or focus.
(7) a. Ta-mogibeli natu-na taiyao si-lokoina. male-mogibeli child-3SG.IA $\overline{\mathrm{COM}}$ 3PL-run Tamogibeli and his child ran.
b. Teside sabamugo a-kanamimi. Thursday night 1SG-dream On Thursday night I dreamed.

c. Sipwena a-neta Moninito goi i-kaiako.

Sipwena PASS-3SG.LIM Moninito PP 3SG-remain Sipwena stayed by himself at Moninito.

d. Teside sabamugo boda manie-di si-vesi-vesi Josephine Thursday night people some-3PL.IA 3PL-IMPER-sing Josephine i-na-kamasa manu-na.

CON-3SG-death PUR-3SG

On Thursday night some people were singing because of Josephine's death.

e. Nukoto-di i-mou gagai-na Josephine i-na-kamasa pasi-na. throat-3PL.IA 3SG-heavy big-3SG Josephine CON-3SG-death REA-3SG They were very sad because of Josephine's death.

\subsection{TRANSITIVE CLAUSES}

A finally transitive verb must agree in person and number with the final subject and direct object (3.3.1.1). Minimally a finally transitive clause need only consist of a finite verb agreeing with subject and direct object. The order of other constituents for finally transitive clauses is the basic order. In both (8a) and (8b) there is an overt subject and an overt object. In $(8 \mathrm{c})$ there is no overt subject or object.

(8) a. Ta-mogibeli natu-na(S) bwae(O) i-nimu. male-mogibeli child-3SG.IA water 3SG-drink(TR) Tamogibeli's child drank the water.

b. Kiwelu natu-na taiyao(S) kewou (O) si-kabi.

Kiwelu child-3SG.IA COM canoe 3PL-get(TR)

Kiwelu and his child got the canoe.

c. Niga vanuwo i-tomo valiwoga goi si-yato.

later village 3SG-tomorrow grave PP 3PL-set(TR)

Later the next day they set her in the grave. 


\subsection{PREDICATE TYPES}

In this section I illustrate how Gumawana encodes various types of predication, such as equatives, statives and location/position.

\subsubsection{EQUATIVE CLAUSES}

Equative clauses consist of two noun phrases in juxtaposition.

(9) a. I-suma i-ve-natuna, natu-na bobokata. 3SG-pregnant 3SG-CAUS-child child-3SG.IA crab She was pregnant and gave birth, her child was a crab.

b. Vatutea-na yoi-na kakavaku. legend-REF-3SG name-3SG.IA worm The name of this legend is Worm.

c. Sina-na nauli toi-na go i-ve-natuna natu-na mother-3SG.IA woman real-3SG SW 3SG-CAUS-child child-3SG.IA bunabuna.

dove Her mother was a real woman and she gave birth, her child was a dove.

Whenever a demonstrative is followed by a noun phrase the construction is equational (a demonstrative within a noun phrase occurs as its final constituent).

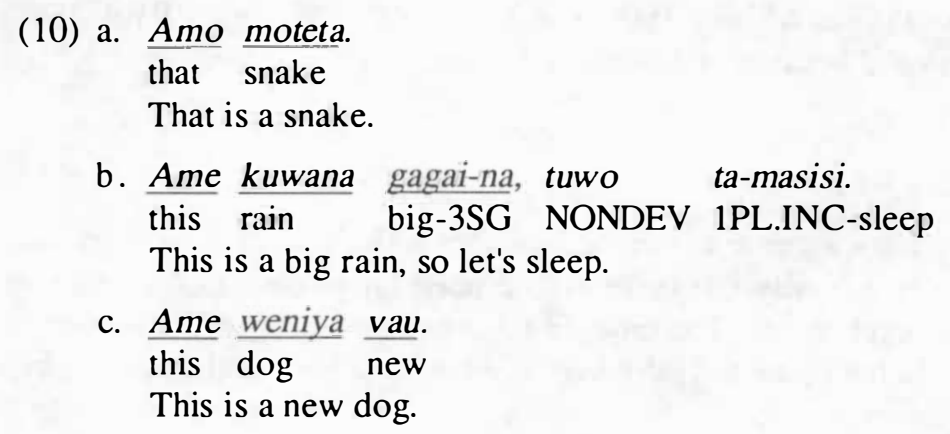

\subsubsection{POSSESSIVE CLAUSES}

Possessive clauses are verbless. The subject of a possessive clause is the possessor, the predicate is an alienably possessed noun phrase expressing the thing possessed. If the clause is not negative, comitative ma- (3.3.2.1) is prefixed to the predicate. If it is negative, the predicate is suffixed by -mo 'only' (3.3.1.3). A possessive clause expresses the relationship encoded by English 'have'.

(11) a. Ma-(a)-mu-magi o geya?

COM-EAT-2SG-betel.nut or NEG

Do you have any betel nut or not?

b. Yau ma-(i)-gu-buki ai-yuwo.

1SG.PN COM-CON-1SG-book CL-two

I have two books. 


\section{c. Guna-gomana geya a-na-bwae-mo. \\ 1SG.POSS-brother NEG EAT-3SG-water-any \\ My brother does not have any water.}

\subsubsection{STATIVE CLAUSES}

There are a few stative verbs such as -goyo 'to be bad' (12a) and -togaga 'to be strong' (12b) in Gumawana, but most stative verbs are derived from adjectives, as in (12c).

(12) a. Awoinu ame i-goyo.

food this 3SG-be.bad

This food is bad.

b. Ku-na ku-togaga.

2SG-go 2SG-be.strong

You go and be strong.

c. Maisi-na i-kaya-kaya.

face-3SG.IA 3SG-IMPER-be.red

His face is red.

Note that when certain adjectives occur as verbs, they are reduplicated. However, this is not the case with all adjectives. In (13) the adjective kakupi 'short' is verbalised yet without reduplication.
Alova i-kakupi. stock 3SG-be.short The stick is short.

\subsubsection{LOCATIVE CLAUSES}

\subsubsection{STATIVE LOCATIVE CLAUSES}

A stative locative clause normally consists of a noun phrase followed by a demonstrative which is either prefixed with go- (indicating location of an object visible to speaker and hearer) or suffixed with person and number suffixes (if the object is unseen) (3.1.7.2). In (14c) it is not clear to me why the third person singular suffix is - $n$ i rather than -na. Only in this type of construction does it appear. Notice that in each example the locative agrees with the head noun.

(14) a. Kinale ame-di. rations DEM-3PL

There are rations here.

b. Yau ame-gu.

1SG.PN here-1SG

I am here.

c. Guna-sisi amo-ni.

ISG.POSS-machete there-3SG

My machete is over there.

In location questions of ten there is only a question word and a noun phrase. 
(15)

Go-gomana ai-yuwo nako-i-di?

PL-child CL-two where-?-3PL

Where are the two children?

\subsubsection{CLAUSES WITH POSITION VERBS}

Certain verbs indicate location, such as -kaiaka in (16); -kaiaka can mean 'to remain, to stay, to live' or 'to exist, to be there'.
Topiyo i-kaiaka
i-na-vada
gabula-i-na.
Topiyo 3SG-be.there CON-3SG-house under-?-3SG
Topiyo is under the house.

The following verbs are location or position predicates:

$\begin{array}{lll}\text {-tusobu } & \text { sit down } & \text { + Animate Subject } \\ \text {-tulaga } & \text { sit higher up } & \text { + Animate Subject } \\ \text {-taoya } & \text { stand/arise } & \text { +/- Animate Subject } \\ \text {-masisi } & \text { lie down/sleep } & \text { +/- Animate Subject } \\ \text {-kanabalabala } & \text { lie horizontally } & \text { +/- Animate Subject }\end{array}$

They take experiencers as subjects. Some allow animate or inanimate subject while others allow only animate subjects.

(18) a. E Sipwena i-kapusi i-sou i-kana-bala-bala.

DEV Sipwena 3SG-stumble 3SG-down 3SG-by.lay-IMPER-across

So Sipwena fell down and lay horizontally.

b. E koloto i-taoya i-na-kudula i-kavale.

DEV man 3SG-stand CON-3SG-spear 3SG-carry.TR

So the man stood up and carried his spear.

c. Dokanikani-ya-na bosima goi i-tu-laga.

giant-REF-3SG platform PP 3SG-by.sit-up

The giant sat up on the platform.

\subsubsection{Clauses WITH MOTION VERBS}

\subsubsection{DIRECTION}

There are two types of motion verbs in Gumawana: those that indicate a spatial direction travelled by the subject of the verb and those that indicate direction in relation to speaker and hearer location or deictic centre.

The following motion verbs indicate a spatial direction travelled by their subject:

$\begin{array}{ll}\text {-sou } & \text { to move down } \\ \text {-tuko } & \text { to move up } \\ \text {-yava } & \text { to move towards bush } \\ \text {-iwo } & \text { to move towards ocean } \\ \text {-bala } & \text { to move across (parallel to ocean and bush) } \\ \text {-kailova } & \text { to depart } \\ \text {-kaluvila } & \text { to return }\end{array}$


Each of these normally occurs in a serial construction before one of the following directional verbs indicating direction in relation to speaker/hearer location or deictic centre:

$\begin{array}{ll}\text {-na } & \text { move away from speaker/hearer location } \\ \text {-ma } & \text { move towards speaker } \\ \text {-wo } & \text { move towards hearer }\end{array}$

In this kind of serial construction, the second (deictic directional) verb modifies the first, telling the hearer which direction the event is moving in with respect to the deictic centre. This type of construction does not allow any other word to occur between the two verbs, which are both finite.

(21) a. Dokanikani-ya-na bogina i-sou i-ma. giant-REF-3SG PRF 3SG-go.down 3SG-come The giant had moved down (toward deictic centre).

b. Sipwena i-bala i-na...

Sipwena 3SG-move.across 3SG-go.away

Sipwena went across (toward new deictic centre)...

c. ...tauna a-yava a-ma ame-ko a-siboila. result 1 SG-to.bush 1 SG-to.hearer here-PLA.ADV 1SG-enter ...therefore I moved towards the bush to here where I entered.

d. Sipwena i-iwo i-na pusa goi i-yoita. Sipwena 3SG-seaward 3SG-move.away bow PP 3SG-hold Sipwena moved seaward to the bow where he held on.

e. Ka-kailova ka-ma i-ma-kasa. 1PL.EXC-depart 1PL.EXC-come CON-1PL.EXC-village We departed (coming) to our village.

f. Niga amo-ko Oyayu goi i-kaluvila-muna i-ma. afterwards there-PLA.ADV Oyayu PP 3SG-return-again 3SG-come Afterwards he returned (coming) from there at Oyayu.

In the above examples the spatial direction verbs indicate the direction in which the subject has moved in terms of three dimensional movement, whilst the deictic direction verbs 'come' and 'go' give the direction of the activity with regard to the speaker and hearer.

A third set of motion verbs indicates manner of motion:

$\begin{array}{ll}\text { lokoina } & \text { to run } \\ \text { vabebeo } & \text { to walkabout } \\ \text { ketoiya } & \text { to walk (with intent of destination) } \\ \text { loiteta } & \text { to skip } \\ \text { pela } & \text { to jump } \\ \text { dala } & \text { to crawl }\end{array}$

All three types of motion verb may occur together serially. In (23) the motion verb of manner comes first, followed by two verbs indicating spatial direction, then finally a deictic direction verb indicating direction with regard to speaker position.

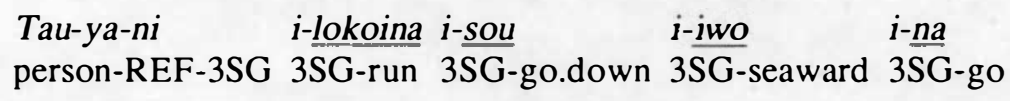


negwasa goi i-kaya-sobu.

ocean PP 3SG-swim-down

He ran down to the ocean where he swam in.

The 'come' and 'go' motion verbs may be suffixed to another verb, but this is not a common construction. In (24) the verb ma 'motion towards speaker' is suffixed to the preceding verb. Normally the 'come' and 'go' verbs are finite verbs.

(24) a. Ku-bale-ma ${ }^{14}$ guna-kewou ta-li-sobu-ye.

2SG-go.across-come 1SG.POSS-canoe 1PL.INC-?-down-OAD.TR

You come here and we will launch my canoe.

b. Kina go dokanikani...tukubu goi i-sowoduwo-ma.

3SG.PN SW giant cave PP 3SG-arrive-come

As for the giant...he arrived back at the cave.

Those motion verbs which indicate a direction may also be suffixed to other verbs to form compound verb stems.

(25) a. E i-di-kewou si-lu-sobu-ye.

DEV CON-3PL-canoe 3PL-lift-go.down-OAD.TR

So they launched their canoe.

b. Kina go i-sowodo i-do-iwo oga geya.

3SG.PN SW 3SG-appear 3SG-with.head-seaward canoe NEG

As for him, he appeared and looked to the ocean, no canoe.

c. I-vaiu, i-tuma-yava, ka-na...

3SG-arrive 3SG-beckon-to.bush talk-3SG

He arrived, then beckoned toward the bush saying...

\subsubsection{DEICTIC CENTRE}

The verbs of motion used to describe motion in relation to speaker/hearer location (the 'come' and 'go' motion verbs) are also used to indicate the deictic centre, of ten the main participant in a third person narrative. In other words, if the main character of a story is the subject, then na 'motion away from speaker and hearer' is used. If, however, the main character is the goal, then the motion verb ma 'motion toward speaker' is used.

In the folktale entitled Sipwena (see section 10.1) the following clauses illustrate this use of 'come' and 'go'. The main character is Sipwena and the dokanikani 'giant' is a secondary participant. The deictic centre is near the ocean because that is where Sipwena lives. So the giant moves toward the deictic centre and the verb -ma 'to come' is used.

$$
\begin{aligned}
& \text { E lava tayamo i-na-kabela konana-i-na i-kabi-di } \\
& \text { DEV time one CON-3SG-fish thing-?-3SG } 3 S G-t a k e-3 P L \\
& \text { i-sou negwasa. } \\
& \text { 3SG-go.down } 3 \text { SG-to.hearer ocean }
\end{aligned}
$$

So one time he (giant) took his fishing gear and went down to the ocean.

\footnotetext{
${ }^{14}$ It is not clear why the verb bala occurs as bale with an $e$ when compounded with ma 'to come'.
} 
In (27) Sipwena is moving parallel to the ocean. He is the main character so -na is used. In fact in the story of Sipwena -na is found with Sipwena in every occurrence.
Sipwena i-bela
i-na...
Sipwena 3SG-move.parallel 3SG-go
Sipwena went across...

The giant occurs with both -ma and -na because when Sipwena is not in focus the giant becomes the main character. In (28) the giant is moving away from the deictic centre which is Sipwena.

$$
\begin{aligned}
& \text { Kina go dokanikani i-na i-kabela. } \\
& \text { 3SG.PN SW giant 3SG-go 3SG-fish } \\
& \text { As for the giant, he went fishing. }
\end{aligned}
$$

Within quotes the deictic centre again shifts to the speaker. In (29) the woman is speaking to her husband so she becomes the centre.

$$
\begin{aligned}
& \text { I-digo ka-na, "Toi } k u-m a \text { memea } \\
& \text { 3SG-mata-kavate } \\
& \text { go, yau talk-3SG man 2SG-come baby } 2 \text { SG-by.eye-hold.TR } \\
& \text { SW 1SG.PN 1SG.go Sipwena food-3SG.IA } 1 \text { SG-give(TR) } \\
& \text { She (giant's wife) said, "Hey, come and watch the baby and I will go give } \\
& \text { Sipwena his food". }
\end{aligned}
$$

\subsubsection{METAPHORICAL USES OF MOTION VERBS}

The motion verbs - na and -ma may also be used to indicate passing of time. In (30) the subject of -ma is tuta 'time'.

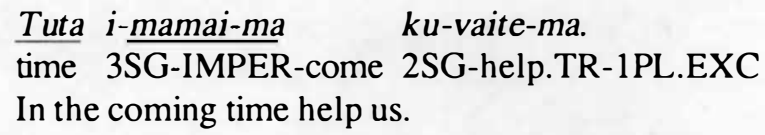

Another means of expressing the passing of time entails repetition of the verb -na or -ma. It is usually associated with the lengthening of the final vowel to mean 'until'.

$$
\begin{aligned}
& \text { Ka-kailova ka-ma ka-ma: e: enao goi, } \\
& \text { 1PL.EXC-depart 1PL.EXC-come 1PL.EXC-come until road PP } \\
& \text { e talaka... } \\
& \text { DEV truck... } \\
& \text { We departed and came and came until we came to the road, then a truck... }
\end{aligned}
$$

The distance of something may also be indicated by means of the verb -na. In (32) the subject of na is dumiya 'flatland' and the verb is used to indicate the distance of the flatland.

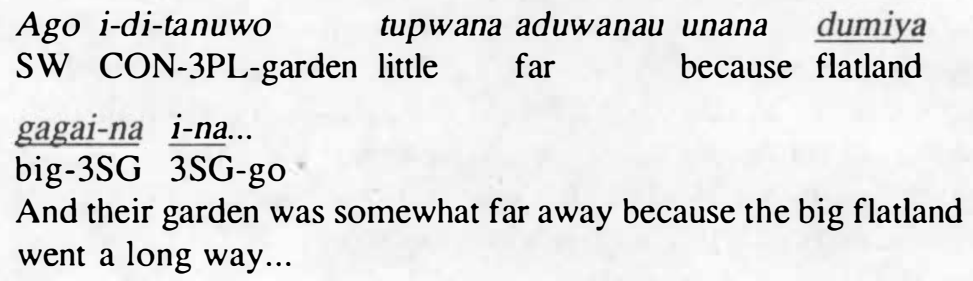


One other metaphorical use of -na is in referring to death:

$$
\begin{aligned}
& \text { Yau bogina bei a-nonoi-na. } \\
& \text { ISG.PN PRF PRO 1SG-IMPER-go } \\
& \text { I am already going. (lit. I am dying.) }
\end{aligned}
$$

\subsubsection{CARDINAL TRANSITIVES}

Cardinal transitive verbs are those verbs which have an agent as subject and a patient as direct object which is highly affected by the agent in some way. Typical verbs which fall into this category are given in (34) and examples in (35). Some of these verbs may be detransitivised (discussed in 6.9.4).

$\begin{array}{ll}\text {-laui } & \text { to hit/kill } \\ \text {-kabi } & \text { to get/take } \\ \text {-babane } & \text { to find } \\ \text {-yani } & \text { to do } \\ \text {-ginubasi } & \text { to spear } \\ \text {-gabu } & \text { to roast/burn } \\ \text {-kani } & \text { to eat/bite }\end{array}$

(35) a. Topiyo iyana badabada-i-di i-ginubasi-di.

Topiyo fish many-?-3PL.IA 3SG-spear-3PL

Topiyo speared many fish.
b. ...i-gabu-di
i-vai-polu-di i-kani-di.
3SG-roast-3PL 3SG-CAUS-boil-3PL 3SG-eat-3PL ...he roasted, boiled and ate them.
$\begin{array}{ll}\text { c. I-ma-kadi } & k a-k a b i-d i . \\ \text { CON-1PL.EXC-card } & \text { 1PL.EXC-get-3PL }\end{array}$
We got our cards.

\subsubsection{VERBS OF TRANSFER}

Some of the verbs of transfer are as follows:

$\begin{array}{ll}- \text { vini } & \text { to give } \\ -m e & \text { to bring (-ma-i 'to come-TR') } \\ -v e & \text { to take } \\ \text {-etune } & \text { to send } \\ \text {-yabobona } & \text { to give free }\end{array}$

Each of these verbs takes an agent as subject, but they differ in the type of direct object they take. In the case of vini 'give' and yabobona 'give free' the direct object is the recipient rather than the patient, unlike the other predicates. The verb -etune 'send' $(37 \mathrm{c}, \mathrm{d})$, and verbs of throwing, dropping and the like, require that a deictic direction verb (in these examples, -ma and -wo) be present in serial construction to indicate the direction of the object sent. This serial construction is thus the transitive equivalent of the intransitive (motion) serial constructions (discussed in 6.4.5). In (37a) yai-gu 'to me' is optional with the verb -me because the latter inherently means 'come with to the speaker'. 
(37) a. Sisi kwabi ku-me (yai-gu). machete 2SG.get(TR) 2SG-come.TR GOAL-1SG

Get the machete and bring it to me.

b. Ka-na vada sinae-na kwinini si-vini-ma. 1 PL.EXC-go house inside-3SG.IA quinine 3PL-give-1 PL.EXC We went inside the house and they gave us quinine.

c. A-mu-magi ku-etune i-ma yai-gu.

EAT-2SG-betel.nut 2SG-send.TR 3SG-come GOAL-1SG Send your betel nut to me.

d. Leta a-etune i-wo yai-mu. letter ISG-send.TR 3SG-go GOAL-2SG I sent the letter to you.

\subsubsection{EXPERIENTIAL VERBS}

The following are experiential verbs in Gumawana:

$\begin{array}{ll}\text {-matoita } & \text { to be afraid } \\ \text {-nuwe } & \text { to think } \\ \text {-lotowo } & \text { to feel (as in feelings) } \\ \text {-kamasa } & \text { to die } \\ \text {-kapusi } & \text { to stumble } \\ \text {-sowoduwo } & \text { to appear/arrive/happen }\end{array}$

Body-part idioms also can be grouped with experiental verbs:

$\begin{array}{llll}\text { nukotogu imou } & \text { my neck is heavy } & = & \mathrm{I} \text { am sad } \\ \text { nukotogu igoyo } & \text { my neck is bad } & = & \mathrm{I} \text { feel sorry } \\ \text { gamogu igoyo } & \text { my stomach is bad } & = & \mathrm{I} \text { am angry } \\ \text { dabana ilokoina } & \text { his head runs } & = & \text { he is smart }\end{array}$

Each of these verbs takes an experiencer as subject. However, they are grammatically very different (these differences are discussed in 6.9.1). Some may be transivitised while some may not be.

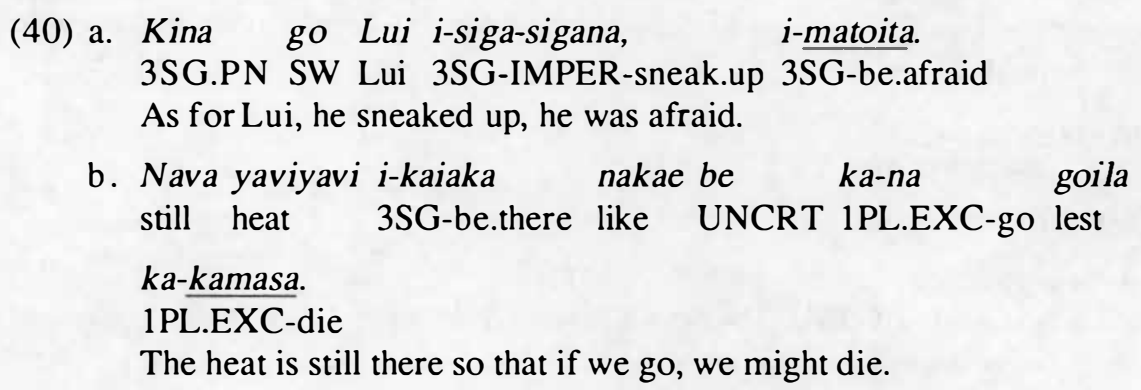

\subsection{RECIPROCAL ClaUSES}

When va- is prefixed to the verb stem, it encodes the verb for reciprocity. All reciprocal constructions require a plural subject and the verb must be finally intransitive. 
(41) a. Kidi Ron be Wagowago si-va-lau-lauwo. 3PL.PN Ron and Wagowago 3PL-RECP-IMPER-hit Ron and Wagowago are hitting each other.

b. Tutea-na komu ku-na America ta-va-tai-taiya. time.REF-3SG 2SG.PN 2SG-go America 1PL.INC-RECP-IMPER-cry When you go to America we will cry for each other.

c. Komu Kelebi a-gite-mi ko-va-siya-siya. 2SG.PN Kelebi 1SG-see.TR-2PL 2PL-RECP-IMPER-flee I saw you and Kelebi fleeing each other.

Two constructions which are related to the reciprocal va-involve the prefixes gi-and vagi-; gi-indicates some type of contest between the subjects. The verb root must be reduplicated when $g i$ - is affixed.

(42) a. Boile ta-gi-pota-pota go komu ku-kalisave-gu. yesterday 1PL.INC-RECP-IMPER-stare SW 2SG.PN 2SG-win.TR-1SG Yesterday we stared at each other (as in a contest) and you won.

b. Nava bei ta-gi-lo-lokoina. later PRO 1PL.INC-RECP-IMPER-run Later we will run against each other.

The prefix vagi- has an alternative form vagili- which is used when the verb is not reduplicated. Vagi-indicates a plurality of subjects that do something at the same time.
Maine tomota si-vagi-pota-pota.
earlier people 3PL-RECP-IMPER-stare
Earlier the people were staring.

E go-gomana i-bowo-i-di si-vagili-siya.

DEV PL-child 3SG-scold-TR-3PL 3PL-RECP-flee

Then he scolded the children and they all fled at one time.

\subsection{REFLEXIVE CLAUSES}

Two types of reflexive clause occur in Gumawana. The first type is the reflexive clause in which the subject volitionally does something to him/herself. It requires a human subject coreferential with the direct object.

(45) a. Ko-tagone-mi.

1PL-submit.TR-2PL

You submit yourselves.

b. A-vata-yave-gu a-na a-gite.

1SG-?-to.bush.TR-1SG 1SG-go 1SG-see.TR

I will move myself to the bush and see it.

c. ?Yeu goi â -gabu-gu.

fire PP 1SG-burn-1SG

I bumed myself with the fire (intentionally).

Example (45c) would mean that I wanted to burn myself, and it therefore sounds rather unfelicitous. To indicate that the event was an accident a reflexive construction is not 
acceptable. Compare (45c) with (46), where the fire, which is an inanimate object, is acting upon the direct object.
Yeu i-gabu-gu.
fire 3SG-burn-1SG
The fire burned me.

A second type of reflexive clause is marked with the word toini- 'itself', a reflexive pronoun (3.1.5). This is often used with verbs that take the prefix ta- (3.1.3.2). Only a certain class of verbs dealing mainly with the destruction or some type of change of state in the object takes the prefix ta-.
(47) a. Buyala toini-na i-topa (ta-upa). vine itself-3SG 3SG-ST.break (ST-break) The vine broke itself.
b. Gune-kaleko toini-na i-ta-isa.
1SG.POSS-clothing itself-3SG 3SG-ST-tear
My clothing tore itself.

\subsection{IMPERSONAL CONSTRUCTIONS}

Certain clauses in Gumawana allow a subject which does not refer to anything in the discourse. These are of ten referred to as dummy subjects. These types of constructions are marked by the instrumental prefixes vatu- or vata- (3.2.1). In example (48) the verbs with the third person singular subjects (underlined) have no reference to anything in the real world. For example, in (48b) the verb $i$-vatayaegu 'it goes to the bush with me' can also be stated as ayava, and native speakers agree that it has the same meaning as with the dummy subject.
a. Nakae i-kosavalimo
be kita
ta-sou
like 3SG-jump.on.fours UNCRT 1PL.INC.PN 1PL.INC-go.down
gamo-da i-vatu-pave-di.
stomach-1PL.INC.IA 3SG-by.fall-pop.TR-3PL
He jumps on all fours so we might go down and our stomachs will pop
by dropping. (lit. ...there will be popping of our stomachs.)

b. E kwaiaka be i-vata-yae-gu mae-ko a-taoya.

DEV 2SG.remain and 3SG-??-to.bush.TR-1SG above-PL.ADV 1SG-stand So you stay and I will go to the bush there above and stand. (lit. ...there will be going to the bush with me...)

c. Doiya-gu kwaluvile guna-loseyana be muli-gu nephew-1SG.IA 2SG.return.TR 1SG.POSS-heir UNCRT behind-1SG

\section{ko-saku:rikuri ko-kapusi gomana i-vatu-mate.}

2PL-follow.IMPER 2PL-fall child 3SG-by.drop-die.TR

Return my nephew, my heir. If you follow behind me and you fall he will die. (lit. ...there will be killing of him by dropping.) 


\subsection{Causative Clauses}

In Gumawana there are four causative prefixes: va-, vai-, ve- and lu-. It is unclear exactly what the differences are between them and whether or not there are restrictions on which prefix may occur with which verb stems. ${ }^{15}$ There are two types of verbs which allow the causatives - those with an initial valence of [DO] (3.2.3.3) and certain initially transitive verbs. In examples (49a), (50a) and (51a) the underlined verb initially has a direct object without a subject. In the (b) examples the same verb occurs with the causative prefix making the verb finally transitive.

(49) a. A-kapusi a-sou a-sipula. 1SG-stumble 1SG-go.down 1SG-roll I stumbled and rolled down.

b. Bolo a-va-sipul-i.

ball 1SG-CAUS-roll-TR

I rolled the ball.

(50) a. Kubu-gu i-patu. nose-1SG 3SG-be.enclose

My nose is plugged.

b. Vada a-va-patu-di. house 1SG-CAUS-enclose-3PL

I enclose the houses.

(51) a. Yau a-togaga.

1SG.PN 1SG-be.strong

I am strong.

b. A-va-togage-mu.

1SG-CAUS-be.strong.TR-2SG

I strengthen you.

Most of these verbs allow the transitive marker $i$ - when the causative prefix occurs. Some verbs require the co-occurrence of -ye with the causative prefix.

(52) a. A-na udodana goi a-tagau.

1SG-go bush PP 1SG-be.lost

I went to the bush and was lost.

b. I-gu-buki a-va-tagau-ye.

CON-1SG-book 1SG-CAUS-be.lost-OAD.TR

I lost my necklace.

(53) a. Gomana i-tu-sobu.

child 3SG-by.sit-down

The child sat down.

b. Gomana a-va-tu-sobu-ye.

child 1SG-CAUS-by.sit-down-OAD.TR

I sat the child down. 
The causative vai- has only been found on the verbs -polu 'boil' and -siu 'enter/go through'.

(54) a. Vaega i-polu.

pot 3SG-boil

The pot boiled.

b. Kuvi a-vai-polu-di.

yam 1SG-CAUS-boil-3PL

I boiled the yams.

(55) a. Nima-na i-siu.

hand-3SG 3SG-go.through

His hand went through.

b. Dogoi i-vai-siu.

thing 3SG-CAUS-go.through(TR)

He put the thing through.

Likewise the causative lu- has only been found on a few verbs such as -kavava "be finished'.

(56) a. A-paisewa i-kavava...

1SG-work 3SG-be.finished

When I finish my work...

b. Guna-paisewa a-lu-kavave...

1SG.POSS-work 1SG-CAUS-be.finished.TR

I finished my work...

The last causative prefix, ve-, appears to derive verbs from nouns.

(57)
a. Vavina natu-na
i-kamasa.

woman child-3SG.IA 3SG-die

The woman's child died.

b. Vavina i-ve-natuna.

woman 3SG-CAUS-child

The woman gave birth.

c. Sina-gu i-ve-natun-i-gu.

mother-1SG 3SG-CAUS-TR-1SG

My mother gave birth to me.

(58) a. Ame tama-gu.

this father-1SG

This is my father.

b. Tau-ya-na i-ve-tamane-mu.

person-REF-3SG 3SG-CAUS-father.TR-2SG

He fathered me.

The second type of causative construction involves those verbs that are initially transitive. The causative prefix has the meaning of 'help' rather than of causation on these verbs. The verb is detransitivised with the antipassive (6.9.4), then the causative construction is applied, 
increasing the verb's valence by one. The initial subject is the final direct object, as in the (b) examples below. The (a) examples illustrate the intransitive form of the verbs.

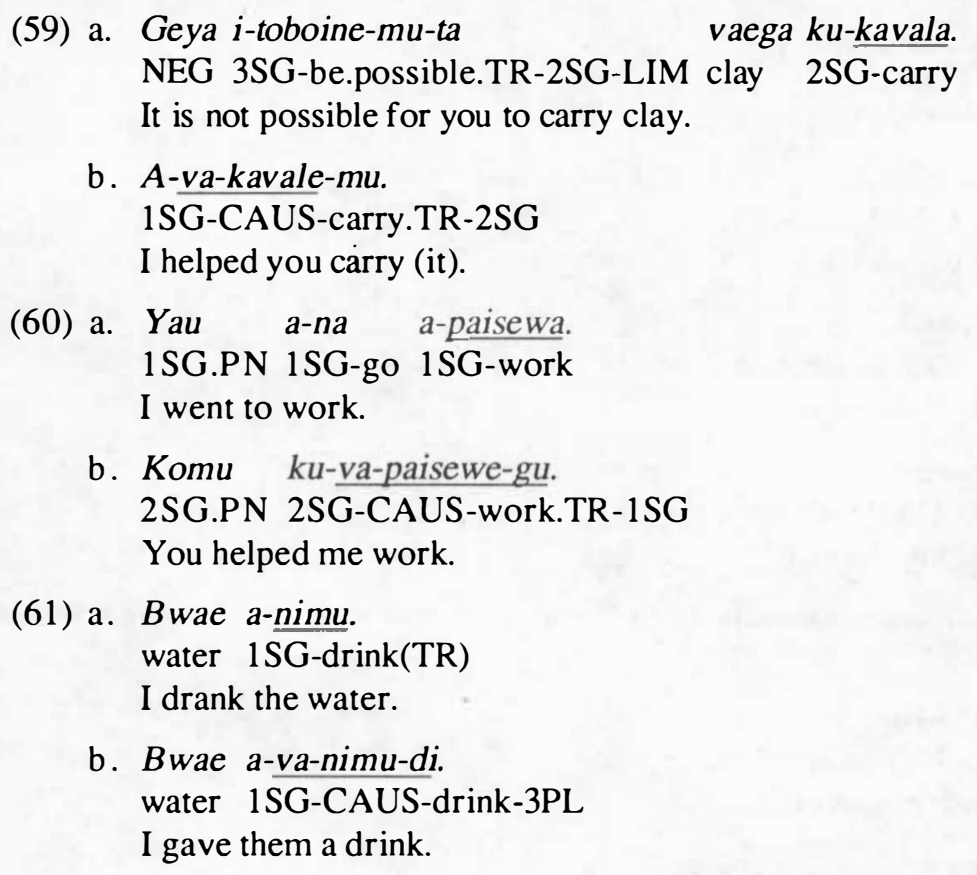

\subsection{RELATION-CHANGING DEVICES}

There are various relation-changing devices in the clause structure of Gumawana. In referring to these, those grammatical relations which move up on the following hierarchy are said to have 'advanced', those that move down are said to 'retreat':

$$
\text { subject }>\text { direct object }>\text { indirect object }>\text { obliques }
$$

\subsubsection{POSSESSOR ASCENSION}

In this section I present a construction known as possessor ascension. The (a) examples below illustrate typical body-part idioms. In the (b) examples the body part is incorporated into the verb and the possessor is the subject. In (62c) possessor ascension results in a new finally transitive verb whose direct object indicates what the person is afraid of.

(62) a. Ate-gu i-yova.

liver-1SG.IA 3SG-fly

I am worried/afraid. (lit. My liver flies.)

b. A-kate-yova.

1SG-liver-fly

I am worried.

c. Moteta a-kate-yova-e.

snake 1SG-liver-fly-OAD.TR

I am afraid of the snake. 
(63) a. Nuwo-na i-mou.

mind-3SG.IA 3SG-heavy

He is sad. (lit. His mind is heavy.)

b. I-nuwo-mou.

3SG-mind-heavy

He is sad.

In 'possessor ascension' the possessor of a possessive construction is raised to become the argument of the verb. In Gumawana, a rule of noun incorporation is required when the possessor ascends. This is (63a) ( $k$ )ategu 'my liver'16 is the subject of -yova 'to fly'. In (63b) the possessor of (63a) is raised or ascends (thus possessor ascension) to become the subject and the bare noun stem kate is incorporated. This is no longer a very productive construction in Gumawana and is restricted to body parts. A number of body-part idioms allow both forms, while the majority are fixed as idioms or lexicalised in the incorporated verbal state. This use of possessor ascension to promote the affected participant in a bodypart idiom into a "primary case role" is cross-linguistically quite common, according to Mithun (1984:858-860).

Some forms that have been lexicalised are still transparent. In (64a) and (64b) the noun incorporation is transparent but the idioms from which they must be derived $(64 c, 64 \mathrm{~d})$ are not longer heard.

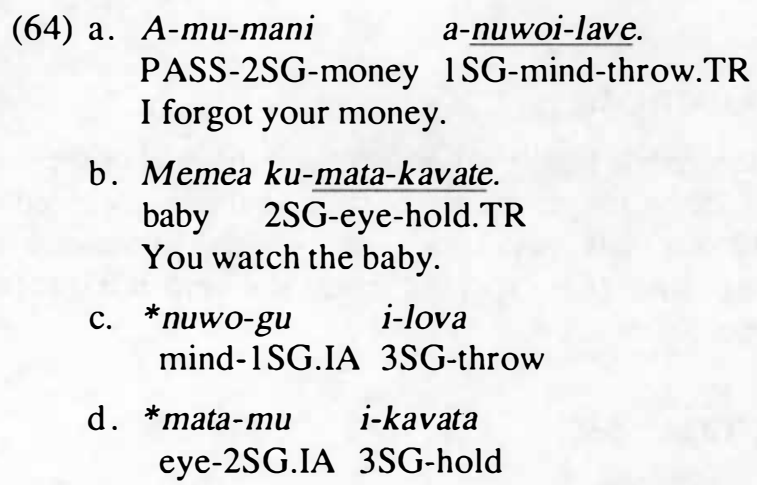

Other body-part idioms will not allow incorporation of the overt noun but do allow the incorporation of another noun to give the same meaning. For example, (65a) is a typical body-part idiom. Both ( $65 \mathrm{a})$ and $(65 \mathrm{~b})$ have the same meaning, but the incorporated noun in (b) is different from that of the free form in (a), whilst (c) and (d) do not occur.

(65) a. Sopa-na i-makimaki.

lip-3SG.IA 3SG-be.firm

He argued/persisted. (lit. his lip was firm)

b. I-kao-makimaki.

3SG-mouth-be.firm

He argued/persisted.

c. *I-sopa-makimaki.

d. *Ao-gu i-makimaki.

${ }^{16}$ See the rule of $k$ - deletion in section 2.3.6. 
It is interesting to note that in the body-part idioms a closer bond than usual is found between the subject (body part) and the verb. When the body-part idiom is negated, two possible word orders are found. The negative particle geya normally occurs next to the verb (see 8.5 ), but in body-part idioms we find it can occur either before the verb (66a) or before the body part (66b).

(66) a. Ate-mu geya i-yoveta.

liver-2SG.IA NEG 3Sg-fly.LIM

Don't be afraid.

b. Geya ate-mu i-yoveta.

NEG liver-2SG.IA 3SG-fly.LIM

Don't be afraid.

In other constructions it is ungrammatical for the negation particle to occur before the subject, as it does in (66a) above. This is indicative of a closer than usual relationship between the subject and the verb in a body-part idiom, and it is apparently this relationship which results in the fact that possessor ascension occurs only with body-part idioms.

In summary, Gumawana manifests two historical stages of the noun incorporation process. Firstly, there are those body-part idioms which allow incorporation and possessor ascension. Secondly, there are those that are lexicalised as verbs with a transparent prefix being a body part.

\subsubsection{OBLIQUE ADVANCEMENTS TO DO WITH -ko}

In examples (67a), (68a) and (69a) the verb is finally intransitive and the goal of the verb is marked by yai. In the (b) examples yai no longer occurs and the goal has advanced to direct object. For examples such as (69b) the verb mwera 'to climb' is initially transitive but is detransitivised by means of the antipassive (6.9.4). This leaves the verb intransitive, allowing an oblique advancement to direct object.

(67) a. A-lokoina a-na Kelebi yai-na. 1SG-run 1SG-go Kelebi GOAL-3SG I run to Kelebi.

b. Kelebi a-lokoina-ko.

Kelebi 1SG-run-GOAL(TR)

I run to Kelebi.

(68) a. A-siya a-na tomota yai-di.

1SG-flee 1SG-go people GOAL-3PL

I flee to the people.

b. Tomota a-siya-ko-i-di.

people 1SG-flee-GOAL-TR-3PL

I flee to the people.

(69) a. Alova a-mwela a-o yai-mu.

tree 1SG-climb 1SG-go GOAL-3SG

I climb on the tree to you. 
b. Alova a-mwela-ko-i-mu.

tree 1SG-climb-GOAL-TR-2SG

I climb up to you on the tree.

\subsubsection{OBLIQUE ADVANCEMENTS TO DO WITH -ye}

In this section advancements which involve the oblique advancement (OAD) marker -ye are examined. In examples (70a) and (71a) the verb is intransitive and the oblique is flagged with either yai or ma-. In the (b) examples -ye registers the verb for oblique advancement.

(70) a. A-siya yai-mu.

1SG-flee SOURCE-2SG

I flee from you.

b. A-siya-e-mu.

1SG-flee-OAD.TR-2SG

I flee from you.

(71) a. Ma-(i)-gu-sisi a-siya.

COM-CON-1SG-machete 1SG-flee

I flee with my machete.

b. Sisi a-siya-e.

machete 1SG-flee-OAD.TR

I flee with my machete.

The advancement must occur out of an intransitive stratum. Thus certain verbs that allow antipassive will also allow an oblique advancement. In (72a) the verb liwola is both initially and finally transitive. In (72b) it is finally intransitive due to antipassivisation. However, in (72c) there is a n advancement of the oblique argument to direct object.

(72) a. Tomota a-liwole-di.

people 1SG-exhort.TR-3PL

I exhort the people.

b Paisewa manu-na a-liwola.

work CONTENT-3SG 1SG-exhort

I exhorted about the work.

c. Paisewa a-liwola-e.

work 1SG-exhort-OAD.TR

I exhorted about the work.

Note that the third person singular transitive suffix in $(72 c)$ is zero. However, three tests can be applied to show clearly that verbs in -ye are transitive.

In (73a) the verb is intransitive and the object taken in is marked with the comitative ma-; (73b) is ungrammatical because finally intransitive verbs do not allow object markers; (73c) illustrates the advancement to direct object.

(73) a. Ma-i-gu-buki a-siu.

COM-CON-1SG-book 1SG-enter

I entered with my book. 
b. ${ }^{* B}$ Buki a-siu-di.
book 1 SG-enter-3PL

c. I-gu-buki a-siu-ye-di.

CON-1SG-book 1SG-enter-OAD.TR-3PL

I entered with my books.

The second test entails negation constructions which require the suffix -ita on the verb to limit the scope of negation to a single occasion (8.5.1). One of the allomorphs of -ita is -yeta /-ia-i-ta/, where /-ia-/ is the third person singular object marker (see 2.4.2). If in fact such verbs as those in (70b), (71b) and (72c) are finally transitive we would expect to find -yeta on them when the third person singular occurs. In (74a) the verb takes the negative suffix -yeta, indicating that there is a third person singular object - that is, that the verb in -ye is transitive. In (74b) note that the suffix -ita has coalesced with the final stem vowel -a of siya to form -e-. Both (74c) and (74d) are ungrammatical since the wrong allomorph of /-ita/ occurs.

(74) a. Kalitoni geya a-siya-e-yeta.

Kalitoni ṆEG 1SG-flee-OAD.TR-LIM

I didn't flee from Kalitoni.

b. Geya a-siyeta Kalitoni yai-na.

NEG 1SG-flee.LIM Kalitoni SOURCE-3SG

I didn't flee from Kalitoni.

c. *Kalitoni geya a-siya-e-ta.

d. *Geya a-siya-yeta Kalitoni yai-na.

The third transitivity test entails the reason suffixes (discussed in 3.2.6). These are not fully understood at this time, but they do provide a test of final transitivity. If the verb is finally intransitive the suffix is -ye and if transitive $-k o$. Those verbs that allow the advancement marker -ye should therefore allow the reason suffix $-k o$. The verb in (75a) takes $-k o$, indicating that it is finally transitive. In (75b) the verb is finally intransitive and therefore takes the suffix -ye. Note that $(75 c)$ is ungrammatical, since the verb is finally transitive but has the reason suffix for finally intransitive verbs.

(75) a. Sisi kaga ku-mwela-e-ko? machete what 2SG-climb-OAD-REA(TR)

Why did you go up with the machete?

b. Kaga ku-mwela-e?

what 2SG-climb-REA

Why did you climb up?

c. *Sisi kaga ku-mwera-e-ye?

From the above arguments it is clear that those verbs which take the -ye advancement marker have increased their valence by one, thus making them finally transitive. The same arguments can be applied to the final transitivity of verbs showing advancement with $-k o$.

One last aspect of the advancement of obliques to direct object is their function. When the oblique is advanced to direct object, the subject of the verb exercises more control over the object in question. Example (76a) indicates that the subject must have used some degree of 
force or at least exercised his own volition to get the child into the house, whereas (76b) indicates that the child went in under his own volition.

(76) a. Gomana vada goi a-siu-ye.

child house PP 1SG-enter-OAD.TR

I entered the house with the child. (lit. I entered the child into the house.)

b. Vada goi ka-siu gomana taiyao.

house PP 1PL.EXC-enter child COM

The child and I entered the house together.

\subsubsection{ANTIPASSIVE}

Certain transitive verbs may be detransitived by means of the antipassive. ${ }^{17}$ Loss of the transitive marker - $i$ signals the antipassive. The purpose of the antipassive in Gumawana is to place the focus of the clause on the action of the verb rather than on the object. Verbs which are antipassive indicate that the action is done in a very general way to indef inite, nonspecific objects. The definiteness of the nominal determines whether the verb is finally transitive or whether it is antipassive. Definiteness is marked in Gumawana by means of a demonstrative, a numeral or the reference marker -ya (5.1.7).

Examples (77) - (80) illustrate the differences between the antipassive and its transitive counterpart. In the (a) examples the nominal is definite and requires the verb to agree with it in person and number. In contrast, the (b) examples illustrate the antipassive verb, which indicates a general non-specific activity with the verb finally intransitive. Mithun (1984) shows that of ten languages will allow this kind of construction only with institutionalised events, and this may well also be the case in Gumawana.

(77) a. Iyana tayamo a-ginubasi.

fish one 1SG-spear(TR)

I speared a fish.

b. Iyana a-ginubasina.

fish 1SG-spear

I fish-speared.

(78) a. Kuvi amo a-bagul-i.

yam that 1SG-plant-TR

I planted that yam.

b. A-na a-bagula.

1SG-go 1SG-plant

I am going to (yam) plant.

(79)
a. Simwai-ya-na bogina a-teui.
sweet.potato-REF-3SG PRF 1SG-peel(TR)
I have peeled the sweet potato.

b. A-teuina i-kavava, bei a-vai-polu.

1SG-peel 3SG-be.finished PRO 1SG-CAUS-boil

When I am done (yam) peeling, then I am going to (yam) boil.

${ }^{17}$ See Postal (1977) for arguments that accusative languages may have an antipassive. 
(80) a. Magi tayamo a-lusale.

betel.nut one 1SG-search.for.TR

I searched for one betel nut.

b. Magi a-lusala.

betel.nut ISG-search.for

I searched for betel nut.

There are many verbs which allow the antipassive construction, some of which are:

$\begin{array}{ll}\text { akatubayasina } & \text { I prepare } \\ \text { agiwala } & \text { I spit } \\ \text { abagala } & \text { I wrong } \\ \text { asayoyova } & \text { I rinse } \\ \text { atuyawata } & \text { I wait } \\ \text { ayoita } & \text { I hold } \\ \text { aginina } & \text { I write } \\ \text { avainawana } & \text { I steal } \\ \text { akatuyaivina } & \text { I read/count } \\ \text { asopuna } & \text { I plant } \\ \text { avatulukwana } & \text { I teach } \\ \text { awowokana } & \text { I accuse }\end{array}$

The antipassive construction is very productive in Gumawana. However, I have found that for verb roots ending in [n] most speakers are no longer using the unmarked antipassive form. Those verbs require an epenthetic [-a] (2.3.8). The transitive form has a rule of $/ \mathrm{n} /$ deletion (2.3.9). From the data I have collected it is apparent that in the antipassive forms the final syllable -na may be disappearing. Most speakers agree that (82a) and (82b) are the same and that (82c) is different. What has happened in (a), I believe, is that the final syllable -na has been lost. Both (a) and (b) are heard but (a) is becoming more common. Speakers also agree that $(c)$ is transitive.

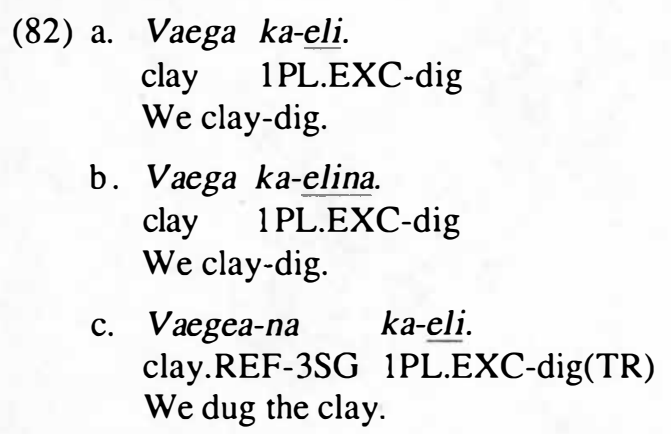

Negation constructions shed light on the changes; -ita is suffixed to verbs when negated (8.5). The allomorph -yeta is found only on finally transitive verbs with the third person singular objects. According to native speakers, (83a) and (83b) mean the same. Notice the negation on (83a) is that for finally intransitive verbs as in (83b). In (83c), however, we find -yeta and the meaning is different as well. The differences may be accounted for by loss of the syllable -na. 
(83) a. Vaega geya ka-eli-ta.

clay NEG 1PL.EXC-dig-LIM

We didn't clay-dig.

b. Vaega geya ka-elineta.

clay NEG 1PL.EXC-dig.LIM

We didn't clay-dig.

c. Vaegea-na geya ka-eli-yeta.

clay.REF-3SG NEG 1PL.EXC-dig-LIM

We didn't dig the clay.

(84) a. I-vayali i-na dobala Omanao goi a-na-iyana i-ginubasina. 3SG-walk.shore 3SG-go there Omanao PP EAT-3SG-fish 3SG-spear He walked along the shore and went to Omanao where he fish-speared.

b. Ka-paisewa vatuta ka-ki-totomoina.

1PL.EXC-work folktale 1PL.EXC-by.hand-straight

We worked on folktale straightening.

c. I-ma-kadi ka-kabi-di, ka-tu-tuyawata.

CON-1PL.EXC-card 1PL.EXC-get-3PL 1PL.EXC-IMPER-wait

We got our cards and were waiting.

\subsubsection{DIRECT OBJECT TO SUBJECT ADVANCEMENT}

A certain class of verbs in Gumawana have the relational valence of [(S), DO] (3.1.3.2). When there is no subject initially, the direct object obligatorily advances to subject; thus the notional direct object is referenced on the verb as subject.

In examples (85a), (86a) and (87a), the verb is finally transitive. However, in the (b) sentences the notional direct object is marked on the verb as subject and the verb is finally intransitive, as the absence of the transitive marker indicates.

(85) a. Boile iyana ka-kone-di. yesterday fish 1PL.EXC-trap.TR-3PL

Yesterday we trapped many fish.

b. Iyana bogina si-kona.

fish PRF 3PL-trap

The fish are already trapped.

(86) a. Totomu ku-katupaeve. doorway 2SG-open.TR Open the door.

b. Totomu bogina i-katupaeva. doorway PRF 3SG-open The door is already open.

(87) a. Moe kubu-gu i-gede. that nose-1SG.IA 3SG-hurt.TR That there hurts my nose. 


$$
\begin{aligned}
& \text { b. Ae-gu i-geda. } \\
& \text { leg-1SG.IA 3SG-hurt } \\
& \text { My leg hurts. }
\end{aligned}
$$

A further test of their final intransitivity is the negation affix. If finally intransitive, we would expect -ita to coalesce with the final vowel of the verb stem, and this is the case.
a. Ae-gu geya i-gedeta.
leg-1SG.IA NEG 3SG-hurt.LIM
My leg does not hurt.
b. Totomu geya i-katupaeveta. doorway NEG 3SG-open
The doorway is not open.

When (86a) and (87a) are negated we would expect -yeta to occur, marking final transitivity. This is indeed what occurs.

(89) a. Totomu geya a-katupaeve-yeta. doorway NEG 1SG-open.TR-LIM I did not open the door.

b. Kubu-gu geya i-gede-yeta. nose-1SG.IA NEG 3SG-hurt.TR-LIM It did not hurt my nose.

There are many areas of Gumawana clause structure that need further investigation. The above analysis is only a beginning to understanding the structure of Gumawana clauses.

\section{COMBINATIONS OF PREDICATIONS}

This section is an account of the various ways in which clauses are combined. (Note, however, that relative clauses, which always function as part of a noun phrase, are described under phrase structure in 5.1.7.)

\subsection{COORDINATION}

The morphemes used to coordinate clauses are be, go, baige, gobe and the negative morpheme geya (8.5).

The coordinating conjunctions $b e$ and go tend to be attached to the verb which precedes them, rather than to the followng clause. In other words, there is of ten a pause after the conjunction rather than before it, unlike English. Schachter (1985) holds that coordinating conjunctions can be characterised as either postpositional or prepositional in character, and that their character is "quite systematically associated with the language's general word-order characteristics" (1985:47). This association holds true for Gumawana: it has verb-final clause structure and postpositions in adpositional phrases, and its coordinating conjunctions also behave postpositionally.

The first coordinating conjunction is $b e$. It joins clauses or noun phrases of equal rank. 
(1)

...komu Ulogu dadavi-na goi ku-na be ta-lusala moku.

2SG.PN Ulogu side-3SG.IA PP 2SG-go and 1PL.INC-search bait

...you go to the Ulogu side and we will search for bait...

In the following examples a comma indicates where the pause occurs in relation to the conjunction.

(2) a. Noko i-kalave go, i-kaluvila mone-na.

plate 3SG-leave.TR SW 3SG-return spouse-3SG.IA

He left the plate and he retumed to his wife.

b. I-vakau go, dokanikani-ya-na bogina i-sou i-ma.

3SG-tie SW giant-REF-3SG PRF 3SG-descend 3SG-come

He tied (it) and the giant had descended.

The main function of $g o$ is 'switch of attention' (SW); this may be a change of either subject or event. It is most commonly used to indicate a switch of event.

(3) a. Kwaiyaka go yau a-na.

2SG.stay SW 1SG.PN 1SG-go

You stay but I'm going.

b. ...a-vai-polu go a-va-nunu.

1SG-CAUS-boil SW 1SG-CAUS-nurse(TR)

...I will boil (the food) and I will nurse him.

c. Yau bego a-na Wadalei go tama-gu i-katowana.

1SG.PN IRR 1SG-go Wadalei SW father-1SG.IA 3SG-be.sick

I intended to go to Wadalei but my father is sick.

$G o$ is also used when there is a switch from a positive to a negative clause.
Sabamugo tayamo koloto si-na si-mwela, Nabodimomu
night one man 3PL-go 3PL-climb Nabodimomu
\begin{tabular}{lll} 
ma-buwo-na & go nubai-na & Silekaleka geya \\
\hline COM-gift-3SG.IA & SW cousin-3SG.IA & Silekaleka NEG
\end{tabular}
ma-buwo-na-mo.
COM-gift-3SG.IA-any
One night men went and climbed up (in the house); Nabodimomu had a gift
but her cousin Silekaleka did not have any gift.

The conjunction go is also used to encode the notion of contrast where English would use a comparative construction.

(5) a. Yau manawe-gu (go) komu kakupi-mu.

1SG.PN tall-1SG SW 2SG.PN short-2SG

I am taller than you. (lit. I am a tall but/and you are short.)

b. Komu i-mu-vada gagai-na (go) yau giyai-na.

2SG.PN CON-2SG-house big-3SG SW 1SG.PN small-3SG

Your house is bigger than mine. (lit. Your big house but/and mine small.)

The coordination of clauses in temporal sequence (English 'and then') is marked in Gumawana by one of two morphemes: 


$$
\begin{array}{ll}
\text { baige } & \text { 'then' + presupposed information } \\
\text { bobe } & \text { 'then' + new information }
\end{array}
$$

If baige is used, it signals that the information in the preceding clause is new, while that in the clause introduced by baige is given. If gobe is used, it signals that the information in the preceding clause is given, while that in the clause introduced by gobe is new. Gobe probably consists of the morphemes go, marking a switch of attention, and be 'uncertainty' (8.3.1.1). They are written together since speakers consider them one word.

In (6a) the speaker responds to the comment 'Let's work'. The first clause is thus new information and baige introduces given information. In (6b) the person is responding to the comment 'Give me your cigarette to smoke', and so the first clause is given information and gobe introduces new information.

(6) a. A-pwaiyuyu i-kavava, baige ta-paisewa.

1SG-smoke 3SG-be.finished then 1PL.INC-work

We will work after I have smoked.

$$
\begin{aligned}
& \text { b. Ku-pwaiyuyu i-kavava, gobe ta-na ta-uwata. } \\
& \text { 2SG-smoke 3SG-be.finished then 1PL.INC-go 1PL.INC-net } \\
& \text { After you smoke, then we will go netting. }
\end{aligned}
$$

The negative marker geya is used to conjoin clauses, and in such cases it functions as 'or'.

$$
\begin{aligned}
& \text { Be ku-ma geya } k \text { ku-kaiyaka? } \\
& \text { UNCRT } 2 \text { SG-come or 2SG-remain } \\
& \text { Are you coming or are you staying? }
\end{aligned}
$$

\subsection{SENTENCE INTRODUCERS}

Gumawana has several sentence introducers. These are similar in function to coordinating conjunctions, but begin new sentences rather than conjoining them to the preceding clause.

There are two sentence introducers derived from go (7.1), namely ago and ego. Like go, they mark switch of attention, and sometimes, as in (8), go is used sentence initially where ago is expected. Intonation drops at the end of the first clause, indicating a new sentence in the second.
I-kapatu go dokanikani-ya-na i-na i-kaisikoko go 3SG-close SW giant-REF-3SG 3SG-go 3SG-gather SW
vavinea-na bebegula sinae-na goi i-kaiaka.
woman.REF-3SG cave inside-3SG.IA PP 3SG-remain
Go dokanikani-ya-na i-kaluvila i-ma...
SW giant-REF-3SG 3SG-return 3SG-come
It closed and the giant went to gather (food) but the woman remained inside of the cave. And the giant returned...

In (9) ago marks a switch of action.

$\begin{array}{llll}\text { Lava liliu-na } & \text { (dokanikani) } & \text { i-nonoi-na } & \text { i-kabela. } \\ \text { time all-3SG.IA (giant) } & \text { 3SG-IMPER-go } & \text { 3SG-fish }\end{array}$


Ago i-ma, tayamo sinapu-ya-na...

SW 3SG-come one custom-REF-3SG

All of the time the giant was going fishing. But he would come, his one custom...

The form ego introduces flashback - that is, a switch to significant background information. Thus the event after ego in (10) took place at the same time or earlier than the preceding event.

(10) Bogina niyala i-saliu, vanuwo i-ka-mamaniwana, go-gomanea-di

PRF sun 3SG-set village 3SG-INCH-dark PL-child.REF-3PL

alovea-na una-na goi si-masisi. Ego kidi

tree.REF-3SG base-3SG.IA PP 3PL-sleep SW 3SG.PN

sina-di be tama-di si-tuma-dadana geya,

mother-3PL.IA and father-3PL.IA 3PL-beckon-unseen NEG

si-lusala.

3PL-search

The sun had set, the village became dark and the children slept at the base of the tree. And meanwhile their mother and father beckoned - but nothing they searched.

In order to indicate a switch in subject a pronoun coreferential with the subject is sometimes fronted before go.

(11) a. Kina go dokanikani i-na i-kabela.

3SG.PN SW giant 3SG-go 3SG-fish

Now the giant went fishing.

b. ...go Silekaleka kewou i-siya-e go maiine

SW Silekaleka canoe 3SG-flee-OAD.TR SW earlier

niu bogina i-nonom-i i-kabi, i-kalisobuye.

coconut PRF 3SG-tie 3SG-get(TR) 3SG-drop.TR

Iya go Nabodimomu nimowo-ya-na i-kabi, i-ma...

3SG.PN SW Nabodimomu shell-REF-3SG 3SG-get(TR) 3SG-come ...and Silekaleka fled with the cane and she got the coconuts which she had tied earlier and dropped it. As for Nabodimomu, she got the shell and came...

The same type of construction is used when indicating a switch in the temporal setting. In (12) the temporal word niga 'afterwards' is fronted before go, changing the temporal setting from that of the preceding clauses.

$\begin{array}{llll}\text { (Weniya) } & \text { si-gou-gou } & \text { si-gou-gou, } & \text { koloto } \\ \text { dog } & \text { 3PL-IMPER-bark } & \text { 3PL-IMPER-bark man } & \text { 3SG-come } \\ \text { i-na-numonuwona ka-na, } & \text { "Nakona bao". } \\ \text { CON-3SG-thinking talk-3SG.IA perhaps pig }\end{array}$

Niga go i-ma i-gite-di go-gomanea-di.

afterwards SW 3SG-come 3SG-see.TR-3PL PL-child.REF-3PL

The dogs were barking and the man came thinking, "Perhaps it is a pig".

But afterwards he came and saw the children. 
In (13) niga is again used, and a new temporal setting (lavilavi 'evening') is also stated overtly after go.

$$
\begin{aligned}
& \text { Ago (dokanikani) i-ma, tayamo sinapu-ya-na iyana } \\
& \text { SW giant } \quad \text { 3SG-come one custom-REF-3SG fish } \\
& \begin{array}{l}
\text { Sipwena i-kawanoi, geya i-vini-vini. } \\
\text { Sipwena 3SG-ask NEG 3SG-IMPER-give(TR) }
\end{array} \text { afterwards } \\
& \text { go lavilavi si-vai-polu ava-na, nakae. } \\
& \text { SW evening 3PL-CAUS-boil food-3SG.IA like } \\
& \text { And he (the giant) came, and one of his customs was that Sipwena would } \\
& \text { ask for fish but he never gave to him. Afterwards, however, in the evening } \\
& \text { they (the giant and his wife) would cook his (Sipwena's) food, thus (it was). }
\end{aligned}
$$

A strong adversative is encoded by means of go followed by semu 'however'.

(14) a. Yau be Siyokila kokona ka-gite-gite, neta

ISG.PN and Siyokila crazy.person 1PL.EXC-IMPER-see if

i-ma bei ka-yois-i.

3SG-come PRO 1PL.EXC-catch-TR

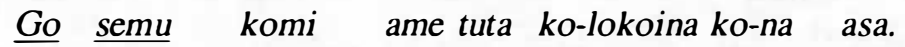

SW however 2PL.PN this time 2PL-run 2PL-go village

Siyokila and I are watching for the crazy person; if he comes we are going

to catch him. But right now you run to the village.

b. ...masigava ku-yato-i-di. Go semu i-mu-nuwonuwona

far.away 2SG-set-TR-3PL SW however CON-2SG-thought

ku-vini-ma.

2SG-give-1PL.EXC

...put them far away. However, give us your thoughts.

c. O dedei-na tuwo. Go semu pakiki moe giyai-na

oh good-3SG enough SW however fish.name that small-3SG

ku-vini-gu.

\begin{tabular}{|c|c|c|c|c|c|}
\hline $\begin{array}{l}\text { "Sina-da } \\
\text { mother- }\end{array}$ & I PL.INC.IA & $\begin{array}{l}\text { ku-gite-gite } \\
\text { 2SG-IMPE }\end{array}$ & $\begin{array}{l}\text { e. } \\
\text { R-watch.TR }\end{array}$ & $\begin{array}{ll}\text { Ago yau } \\
\text { SW } 1 \text { ISG.PN }\end{array}$ & \\
\hline nc & Boleig & a-gite & Ago gomana & $i-n$ & i-taiya. \\
\hline 1SG & Boleigana & 1 SG-see.TR & SW child & 3SG-be.afraid & 3SG-cry \\
\hline
\end{tabular}

2SG-give-1SG

Oh that's fine. However, give me that small pakiki fish.

The negation word geya may function not only as a coordinating conjunction (7.1) but also as a sentence introducer. It indicates that the expectation of the previous sentence is negated. In (15) the child is told to stay. The last sentence is introduced with geya indicating that this event took place instead of what was proposed in the preceding sentences.

$$
\begin{array}{lllll}
E & \text { yau } & \text { gomanea-na } & \text { a-lituwoko } & k a-g u, \\
\text { DEV } & \text { ISG.PN } & \text { child.REF-3SG } & \text { ISG-tell(TR) } & \text { talk-1SG.IA }
\end{array}
$$


Geya, taiyao ka-sou ka-na.

NEG COM 1PL.EXC-go.down 1PL.EXC-go

So I told that child: "You watch our mother. And I will go and see Boleigana".

But the child was afraid and cried. So instead we went down together.

The sentence introducer tuwo 'enough' is used to mark new units of information unrelated to previous sentences. Thus in the last sentence of (16) the giants go off, but this is not a direct result of what took place in the preceding sentences.
(Dokanikani) si-digo ka-di,
"Sina-ma
i-tomo
(giant)
3PL-say talk-3PL.IA
mother-1PL.EXC.IA
3SG-be.tomorrow
nakae. Ku-na ku-isiwo go a-ma
iyana si-kamasa
like 2SG-go 2SG-wash SW EAT-1PL.EXC fish 3PL-die
ku-kabi-di ku-kaivae-di ka-ma bogina ka-kaika”.
2SG-get-3PL 2SG-dry.TR-3PL 1PL.EXC-come PRF 1PL.EXC-eat
Sina-di i-digo ka-na, "I-tomo baige".
mother-3PL.IA 3SG-say talk-3SG.IA 3SG-be.tomorrow then
Tuwo dokanikani-ya-di si-mwela i-di vada goi si-kaivesi.
well giant-REF-3PL 3PL-climb CON-3PL house PP 3PL-sing
The giants said, "Our mother, tomorrow the same. You go wash and when our
fish die, you get them and dry them. When we have come, we'll eat them".
Their mother said, "Tomorrow then (I will)". Well, the giants climbed up into their houses to sing.

Tuwo also marks expected information within an episode. In (17) the house opens as would be expected.
Vanuwo i-tomo
dokanikani-ya-na ka-na,
"Yau
village 3SG-be.tomorrow
giant-REF-3SG
talk-3SG.IA ISG.PN
a-na a-kaisikoko". $\quad \underline{\text { Towo }}$ ka-na, "Bolakanaikanai".
1SG-go 1SG-gather(food) NONDEV talk-3SG.IA open
Tuwo vada i-kanai.
NONDEV house 3SG-open
The next day the giant said, "I am going to go gather (food)". So he said, "Open". So the house opened.

Another sentence introducer found in Gumawana is e 'so'. It introduces-new, significant or distinct information. In a story about a giant that has a woman captive, the woman tries to open the cave door in the same way that the giant has (see example (17) above). Because it is the first time it occurs it is new and distinct information. The result is given in (18).
(Nabodimomu) ka-na,
"Bolakanai". $\underline{E} \quad$ vadea-na
i-kanai.
Nabodimomu talk-3SG.IA open
DEV house.REF-3SG 3SG-open
(Nabodimomu) she said, "Open!" And the house (door) opened.

The sentence introducer $e$ is glossed 'DEV', for developmental marker, because it introduces a new step in the development of a story, in contrast to tuwo in (17), glossed 'NONDEV' because the event is expected and not a new development. 
The morpheme tauna introduces a concluding statement. It is functionally similar to English 'therefore'. It states the result of or conclusion to a command or proposal, as in the following excerpt from a story called Silekaleka. It is conclusive in that the sentences which follow are picking up the story at a different point. This contrasts with the use of tuwo, which expects more to follow, whereas tauna does not.

In (19a) the adverbial clause is introduced with tauna. Note that in (19b) the final sentence begins with $e$, the developmental marker, indicating that the story is moving to new and significant information. Thus tauna in the previous sentence is conclusive.

(19) a. Ate-ma i-yova gagai-na unana vanuwo liver-1PL.EXC.IA 3SG-fly big-3SG because place

madaboki-na i-mamaniwan. Tauna ka-matoita gagai-na... all-3SG.IA 3SG-be.dark RESULT 1PL.EXC-be.afraid big-3SG We were worried a lot because all of the village was dark, therefore we were very afraid...

b. Gumasai-ya-na geya tayamo niu-na o siya-na Gumasai-REF-3SG NEG one sister-3SG.IA or brother-3SG.IA

geya. Tauna sina-na taiyao a-di-tai-yuwo

NEG RESULT mother-3SG.IA COM PASS-3PL-man-two

si-kaiaka. E lava tayamo Guyau bao i-yois-i...

3PL-live DEV time one Guyau pig 3SG-catch-TR

Gumasai didn't have any sisters or brothers. Therefore he and his mother, the two of them, lived together. Now one time Guyau caught a pig...

If the result is already known by the hearer, tauna is used. When used in this way chiasmus of ten occurs as in (20), where $\left(b^{\prime}\right)$ and ( $\left.a^{\prime}\right)$ repeat in reversed sequence information from (a) and (b). In (b') tauna introduces the given information.

(20) a. E go toni-kasa si-taiya,

DEV SW owner-village 3PL-cry

b. nukoto-di i-mou

throat-3PL.IA 3SG-be.heavy

c. unana kunumana bego ka-kalae-di

because sago IRR 1PL.EXC-leave.TR-3PL

b'. tauna nukoto-di i-mou,

RESULT throat-3PL.IA 3SG-be.heavy

$\mathrm{a}^{\prime}$. si-taiya.

3PL-cry

So the residents cried, they were sad because we were going to leave the sago, therefore they were sad and they cried.

\subsection{ADVERBIAL CLAUSES}

Thompson and Longacre (1985:177) find two basic types of adverbial clauses in the world's languages: (1) "clauses substitutable for by a single word"; and (2) "clauses not substitutable for by a single word". The first group consists of time, location and manner 
adverbial clauses. The latter includes purpose clauses, conditionals and others. The distinction between these two (p.177) is that "languages have monomorphemic nonanaphoric adverbs expressing the time, location, and manner relationships, but they do not have such adverbs expressing purpose, reason, concession, etc.". Those in the first group are discussed in section 7.3.1. In section 7.3.2 those in group two are presented.

\subsubsection{SubSTITUTABLE CLAUSES}

\subsubsection{TIME}

There are several subordinating conjunctions which introduce temporal adverbial clauses:

$\begin{array}{lll}\text { tuteana } & \text { when } & \text { (lit. the time) } \\ \text { laveana } & \text { when } & \text { (lit. the time) } \\ \text { anatuwana } & \text { until } & \text { (lit. its boundary) } \\ \text { namuliyeta } & \text { afterwards } & \end{array}$

Example (22) illustrates time adverbial clauses introduced by tuteana /tuta-ia-na/ and laveana /lava-ia-na/ 'time-REF-3SG'. The subordinate clause is in square brackets and could be replaced by a temporal adverb in (a) and (b).

(22) a. E [tutea-na guna-bobwala si-nove], bogina si-taiya. DEV time.REF-3SG 1SG.POSS-talk 3PL-hear.TR PRF 3PL-cry So when they had heard my talk, they had cried.

b. [Tutea-na go-gomanea-di bogina si-siboila], Siyokila time.REF-3SG PL-child.REF-3PL PRF 3PL-enter Siyokila i-ma yau i-latuwoko-i-gu... 3SG-come 1SG.PN 3SG-tell-TR-1SG

When the children had entered, Siyokila came to tell me...

$\begin{array}{lllll}\text { c. [Lavea-na bogina vavina } & \text { i-nai], dokanikani ivatowo bei } \\ \text { time.REF-3SG PRF woman } & \text { 3SG-marry giant } & \text { 3SG-begin PRO }\end{array}$ iyana i-lusala.

fish 3SG-look.for

When the woman had married, the giant began to look for fish.

Another means of introducing a temporal adverbial is with anatuwana 'until' (lit. 'its border'). The notion of 'until' can also be encoded by means of e... (extra long [e:]) placed at the end of the first clause.

(23) a. I-kaiaka i-na-vada [a-na-tuwana i-boboina]. 3SG-remain CON-3SG-house PASS-3SG-border 3SG-well He remains in his house until he is well.

b. Si-lokoina [e... Yagumatabu goi si-sobu]. 3PL-run until Yagumatabu PP 3PL-bring.sail.down They sailed until at Yagumatabu they brought the sail down.

The notion of 'before' is encoded by means of a clause introduced by the sequence namuliyeta 'afterwards' plus bei 'prospective marker' (8.2.2.2): 
(24)
[Namuliyeta bei si-kaika], tau-ya-na
i-kawanoi.
afterward PRO 3PL-eat person-REF-3SG 3SG-ask
Before they ate, he prayed.

\subsubsection{LOCATIVE}

Locative adverbial clauses are introduced using the question word nako 'where'. Location clauses may be replaced by locative adverbs. This type of clause may be marked with the postposition goi.

(25) a. Go-gomana a-latuwoko-i-di ka-gu, "Go-gomana, wasale PL-child 1SG-tell-TR-3PL talk-1SG PL-child basket

\section{ame ko-nave [nako Kalitoni i-kaiaka] ko-vini".}

this 2PL-take.TR where Kalitoni 3SG-remain 2PL-give(TR)

I told the children, "Children, take this basket to where Kalitoni is and give it to him".

b. Yeu ko-nave [nako i-yabuyabu goi] ko-dimili.

fire 2PL-take.TR where 3SG-be.dry PP 2PL-build.fire(TR)

You take the fire to where it is dry and build it.

\subsubsection{MANNER}

Manner adverbial clauses are characteristically marked with a nominal and the postposition nakae 'like, as'.

$\begin{array}{llll}E \quad \text { tutea-na } & k a-s o w o y a & k a-t o-i w o, \\ \text { DEV time.REF-3SG } & \text { 1PL.EXC-embark } & \text { 1PL.EXC-embark-seaward } \\ \text { siya-gu } & \text { i-na } & \text { i-na-dadava, yau } & \text { a-na } \\ \text { friend-1SG.IA } & \text { 3SG-go CON-3SG-side } & \text { 1SG.PN } & \text { 1SG-go } \\ \text { guna-dadava } \quad \text { [maine nakae } & \text { i-loina } & \text { bogina]. } \\ \text { lSG.POSS-side earlier same } & \text { 3SG-decide PRF }\end{array}$

So when we embarked out toward the sea, my friend went to his side and I went to my side as he had decided earlier.

\subsubsection{Clauses NOT SUBSTITUTABLE}

There are several types of clauses in this category. As indicated these clauses cannot be replaced by adverbials. (Purpose clauses are discussed separately in section 7.4.)

\subsubsection{REASON CLAUSES}

Reason clauses are introduced by unana 'because' (lit. 'its base/source'), kutoto 'because = presupposed information' or balito 'because = counter to expectation'. Unana indicates that the reason clause is new information to the hearer. A clause introduced with unana may either precede or follow the main clause. 
In (27a) and (27b) the reason clause follows the independent clause whereas in (27c) the reason clause precedes the independent. Normally, if the reason clause precedes the independent clause it begins with go ' $\mathrm{SW}$ '. This makes it clear that the reason clause is not related to the previous clause.

(27) a. Si-kaika [unana loga si-kamasa].

3PL-eat because hunger 3PL-die

They ate because they were starving.

b. Ka-sina-laga [unana niyala bogina i-kavava].

1PL.EXC-?-up because sun PRF 3SG-be.finished

We came up (out of the water) because the sun had set.

c. Go [unana yau guna-kewou tau-ya-na

SW because 1SG.PN 1SG.POSS-canoe person-REF-3SG

i-na-yowoyowana goi i-siko], neta i-talige-i, yau

CON-3SG-rope PP 3SG-tie(TR) if 3SG-untie-TR 1SG.PN

guna-kewou i-doiye.

1SG.POSS-canoe 3SG-drift.TR

But because he tied my canoe with his rope, if he untied it my canoe would drift.

Reason clauses introduced by kutoto indicate that the information is given or presupposed. As with reason clauses introduced by unana, those with kutoto may be initial or final.

(28) a. Yau bego a-na go [kutoto kuwana geya a-no-ita]. 1SG.PN IRR 1SG-go SW because rain NEG 1SG-go-LIM I intended to go but because of rain (as you know) I didn't go.

b. Boile geya a-paiseweta [kutoto i-kuwana]. yesterday NEG 1SG-word.LIM because 3SG-rain Yesterday I didn't work because (as you know) it rained.

The third type of reason clause is introduced by balito, which indicates the clause is counter to what is expected. Clauses of this type can also come first or last.

a. A-tuyawata geya, kewou a-lu-sobuye bego a-beuta

1SG-wait NEG canoe 1SG-lift-down.TR IRR 1SG-paddle

a-na Gumawana goi tau-ya-na a-gite go, [balito

1SG-go Gumawana PP man-REF-3SG 1SG-see.TR SW because

i-kali-woduwo], geya a-kaiaka.

3SG-by.pole-appear NEG 1SG-remain

I waited - nothing - so I launched the canoe in order to paddle to Gumawana

to see him but because he unexpectedly appeared, I didn't, I remained.

b. A-kaluvila-muna [balito a-gite komu bogina ku-mamai-ma].

1SG-return-again because 1SG-see.TR 2SG.PN PRF 2SG-IMPER-come I returned again because (surprised) I saw you were already coming. 


\subsubsection{CONDitional ClaUSES}

Thompson and Longacre (1985) divide unreality conditions into 'predictive' and 'imaginative'. They further divide imaginative conditions into 'hypothetical' and 'counterfactual'.

All unreal conditions in Gumawana are introduced by neta 'if'. What Thompson and Longacre refer to as predictive conditions Gumawana expresses with bei 'prospective aspect' in the apodosis.

(30) a. [Neta i-ma], bei ka-yois-i. if 3SG-come PRO 1PL.EXC-catch-TR

If he comes, we are going to catch him.

b. [Neta meyava ku-kalave], bei loga ku-kamasa.

if magic 2SG-leave.TR PRO hunger 2SG-die

If you leave magic, you are going to starve.

The notion 'if and only if' is expressed by the addition of go geya, geya 'if not, no'.

[Neta tau-ya-na i-tagona], nakae, go geya, geya.
if person-REF-3SG 3SG-offer like SW NEG NEG
If he offers then alright, but if not, no.

Hypothetical conditions are similar to predictive conditions, but bei 'prospective aspect' does not occur in the apodosis.

(32) a. [Neta i-kuwana], guna-kaleko ku-vai-siu-di.

if 3SG-rain 1SG.POSS-clothing 2SG-CAUS-go.through-3PL

If it should rain, (you would) put my clothes in.

b. [Neta i-tagona], e dedei-na, ta-tupa. if 3SG-offers, DEV good-3SG 1PL.INC-sail

If he offered, then good, we would sail.

Counterfactual conditions are similar to hypothetical conditionals, but there must be an indication that the clause refers to a non-occurring event in the past. This may take the form of the context provided by a previous clause or of a temporal adverb in the protasis.

(33) a. [Neta boile komu ku-ma], e ta-paisewa. if yesterday 2SG.PN 2SG-come DEV 1PL.INC-work If you had come yesterday, then we would have worked.

b. [Maine sisi neta ku-mwela-e]. earlier knife if 2SG-climb-OAD.TR Earlier, if you had climbed up with the knife.

In (33b) the apodosis ('you could have cut them') is not given, but is implied.

A few examples occur in the data of apparent conditionals introduced by kaikoma. I have not been able to determine its exact use, but the few examples indicate that it introduces predictive conditions.

(34) a. KKaikoma

soroti i-me]

bei a-vini-mu.

?

salt 3SG-come.TR PRO 1SG-give-2SG

As soon as/if he brings it, I am going to give you (some). 
$\begin{array}{llll}\text { b. [Kaikoma } & \text { i-ma] bei ta-vatowo } & \text { ta-paisewa. } \\ \text { ? } & \text { 3SG-come PRO } & \text { 1PL.INC-being } & \text { 1PL.INC-work }\end{array}$ As soon as/if he comes, we are going to start to work.

However, kaikoma is also used to introduce a concessive conditional.

$\begin{array}{ll}\text { Kaikoma } & \text { i-kuwana, tuwo bei a-paisewa. } \\ ? & \text { 3SG-rain enough PRO 1SG-work } \\ \text { Even if it rains, that's alright I'm going to work. }\end{array}$

\subsection{PURPOSE}

The use of deictic directional verbs ('go, 'come') in serial constructions is described in sections 6.4.5 and 6.4.7. In the cases described there, the directional verb occurs in final position in a sequence of verbs. However, there are other cases where one of these verbs occurs first in a sequence, and the second verb expresses a purpose. It is not entirely clear whether these constitute serialisations.
(36) a. Ka-uwo-uwata, toni-kasa si-ma si-bolagu.
1PL.EXC-IMPER-net owner-village 3PL-come 3PL-rebuke
While we were netting, the village owners came to rebuke (us).
b. I-ma bego i-duduwo go kai ka-katae.
3SG-come IRR 3SG-call SW 1PL.EXC.PN 1PL.EXC-refuse.TR
He came intending to call but we refused him.

\subsection{COMPLEMENT CLAUSES}

There are various types of complement clauses in Gumawana. Sentence-like complements are discussed in section 7.5.1, while in section 7.5.2 nominalised complements are examined.

\subsubsection{SENTENCE-LIKE COMPLEMENTS}

A sentence-like complement is one that has a finite verb such that the complement clause could stand alone as an independent clause. In (37a) be sikamasa is an independent clause but in (37b) it is the object of the verb matoita 'fear'. The complement clause is in brackets.

(37) a. Be si-kamasa.

UNCRT 3PL-die

They might die.

b. A-matoite [be si-kamasa].

1SG-afraid.TR UNCRT 3PL-die

I am afraid they might die.

This type of complement can be either the subject or the object of the matrix verb. As for word order, normally object complements follow the matrix verb whereas subject complements precede it. Only a few verbs allow subject complements of this type. 
Constructions with -kavava 'finish' indicate completion of the event in the first clause, with a new event occurring in the following clause. Syntactically the first clause is the subject of kavava.

(38) a. [Tanuwo-ya-na si-katuguyal-i] i-kavava...

garden-REF-3SG 3PL-cut-TR 3SG-be.finished

When their cutting of the garden was finished...

b. [Ka-paisewa] i-kavava baige ka-na.

1PL.EXC-work 3SG-be.finished then 1PL.EXC-go

When our work is finished, then we will go. (lit. We work it finishes, then we go.)

The following examples illustrate object complements.

(39) a. A-yagoi [bei June 19 goi a-na Nubogeta].

1SG-know(TR) PRO June 19 PP 1SG-go Nubogeta

I know that on June 19 I will go to Nubogeta.

b. A-nuwopeye [totomu woi bogina a-katunibode].

1SG-remember.TR doorway CERT PRF ISG-close.TR

I remembered I definitely had closed the door.

c. A-nuwe [geya i-toboine-gu-ta bei a-vaite-mu].

1SG-think.TR NEG 3SG-suitable.TR-1SG-LIM PRO 1SG-help.TR-2SG

I think it is not suitable for me that I help you.

To demonstrate that the above clauses are indeed complement clauses compare examples (40) and (41) with example (39).
(40) a. Kelebi i-nove [kamukamu si-taiya].
Kelebi 3SG-hear.TR chicken 3PL-cry
Kelebi heard the chickens cry.
b. Kelebi kamukamu i-nove-di si-taiya.
Kelebi chicken 3SG-hear.TR-3PL 3PL-cry
Kelebi heard the chickens (and they) cried.

(41) a. A-yagoi [Manawale be Dimi si-katowana].

1SG-know(TR) Manawale and Jimmy 3PL-be.sick

I know Manawale and Jimmy are sick.

b. Manawale be Dimi a-yagoi-di si-katowana.

Manawale and Jimmy 1SG-know-3PL 3PL-be.sick

I know Manawale and Jimmy are sick.

In the (a) examples in (40) and (41) the verb agrees with a third person singular object, namely the complement clause. In the (b) examples the word order has changed and the verbs now agree with a third person plural $(-d i)$ object. The difference between the (a) and (b) clauses is that in the (b) clauses subject-to-object raising has taken place. In other words, the subject of the complement clause has been raised to become the object of the matrix clause.

In some cases the raising rule is obligatory, as in the following examples. 
(42) a. Kalitoni ku-latuwoko i-ma.

Kalitoni 2SG-tell(TR) 3SG-come

You tell Kalitoni to come.

b. Ku-tagone-ma [ka-nonoi-na].

2SG-permit.TR-1PL.EXC 1PL.EXC-IMPER-go

Permit us to go.

\subsubsection{NOMINALISED COMPLEMENTS}

Nominalised complements are numerous in Gumawana. In this type of construction a nominalised verb of the active type (see section 3.2.7.1) is an argument of the matrix verb.

(43) a. [Taiya gagai-na] i-guinuwe.

cry big-3SG 3SG-do.TR

He did a lot of crying.

b. Yau [beuta] a-katae.

ISG.PN paddle ISG-refuse.TR

I refuse to paddle.

c. [Vanama-i-gu] i-geda a-na-kaigigita goi.

laugh-?-1SG 3SG-hurt PASS-3SG-appearance PP

I laughed until I hurt over his appearance. (lit. My laughing hurt at his

appearance.)

\section{MODALITY}

In this section the area of modality is examined: tense (8.1), aspect (8.2), mood (8.3), questions (8.4), negation (8.5) and quotative constructions (8.6).

\subsection{TENSE}

Tense is not morphologically marked in Gumawana, but time reference may be indicated by means of temporal adverbs like maine 'ealier', verbs like itomo 'it is tomorrow/next day' or temporal nouns like maliyalina 'day', sabamugo 'night', and so on. The temporal adverbs are normally found at the beginning of a story to set the time reference for the scene. However, folktales and legends often give no indication of time reference. They may indicate absolute time or relative time.

(1)
a. Teside boi ka-na
ka-ka-kaika
a-vatetel-i.
Thursday last 1PL.EXC-go 1PL.EXC-IMPER-eat 1SG-story-TR
I will tell about us going and eating last Thursday.

b. Boi nimatu tayamo gomana koloto, gomanea-na yoi-na before long a child man child.REF-3SG name-3SG.IA

Gumasai.

Gumasai.

Long ago there was a boy, the child's name was Gumasai. 
c. Boile Palaide yau Ediliki Patimo ma-namoya yesterday Friday 1SG.PN Ediliki Patimo COM-old.woman

Lisi taiyao ka-na...

Lisi COM 1PL.EXC-go

Last Friday Ediliki, Patimo and I along with the old woman Lisi went...

Future tense is implied when the prospective aspect marker bei is used (see 8.2.2).

(2)

$$
\begin{aligned}
& \text { Yau bei a-na. } \\
& \text { 1SG.PN PRO 1SG-go } \\
& \text { I am going to go. }
\end{aligned}
$$

\subsection{ASPECT}

Gumawana makes a distinction between perfective and imperfective aspects (8.2.1) as well as a distinction between the prospective and perfect aspects (8.2.2).

\subsubsection{IMPERFECTIVE/PERFECTIVE}

Imperfective aspect is marked on the verb by means of a reduplicative prefix or by means of vowel lengthening (both are described in 3.3.1.5). The terms 'imperfective' and 'perfective' are used here in Comrie's (1976:16) sense: "perfectivity indicates the view of a situation as a single whole, without distinction of the various separate phases that make up that situation; while the imperfective pays essential attention to the internal structure of the situation".

Comrie subdivides imperfectivity into habitualness and continuousness, both of which Gumawana marks by means of reduplication or vowel lengthening. Thus the context determines whether the imperfective is habitual or continuous. Concerning the habitual Comrie (1976:27-28) writes that "the feature common to all habituals...is that they describe a situation which is characteristic of an extended period of time, so extended in fact that the situation referred to is viewed not as an incidental property of the moment but, precisely, as a characteristic feature of a whole period". So for the habitual to be used it must refer to an event that takes place over an extended period of time. Examples (3a) and (3b) are both appropriate responses to the questions 'do you eat bananas?' and 'do you climb coconut palms?' respectively.

(3) a. Losui a-kani-kani. banana 1SG-IMPER-eat I eat bananas.

b. Niu a-mwela-mwela. coconut 1SG-IMPER-climb I climb coconut palms.

Habitual constructions may have the phrase tuta liliuna 'all the time'.

$$
\begin{array}{llll}
\text { Tuta } & \text { liliu-na } & \text { si-nonoi-na a-di-vayakuyana } & \text { si-kaisikoko } \\
\text { time } & \text { all-3SG.IA } & \text { 3PL-IMPER-go PASS-3PL-rations } & \text { 3PL-gather }
\end{array}
$$


yawalea-na goi.

old.garden.REF-3SG PP

All the time they were going to their garden to gather their rations.

When two events either overlap or are simultaneously taking place, both clauses are imperfective.

(5) a. Lisi i-bu-bubuna, kai ka-sela-sela.

Lisi 3SG-IMPER-pull.weeds 1PL.EXC.PN 1PL.EXC-IMPER-dig

While Lisi was pulling weeds, we were digging.

b. Kai ka-sela-sela, siya-ma Patimo niu

1PL.EXC.PN 1PL.EXC-IMPER-dig friend-1PL.EXC.IA Patimo coconut

i-mwela.

3SG-climb

While we were digging, our friend Patimo climbed a coconut palm.

The unmarked form of the verb indicates perfective aspect. The perfective aspect may indicate the completion of an event with no reference to time, as in (6). The context determines the time reference.

(6)
a. Si-kaluvila
si-na
vada si-mwela.
3PL-return(PER) 3PL-go(PER) house 3PL-climb(PER)

They retumed/will retum to the house where they went/go up.

b. I-ginubaku-di i-kalave-di i-me-di

3SG-spear(PER)-3PL 3SG-carry.TR(PER)-3PL 3SG-come.TR(PER)-3PL

asa i-gabu-di i-kani-di.

village 3SG-roast(PER)-3PL 3SG-eat(PER)-3PL

He speared, carried and brought them to the village where he roasted them, then ate them.

Often the first of two clauses is imperfective and the second perfective, expressing a durative/punctiliar relationship.

(7)
a. Dada-i-na
ka-sela-sela
Ediliki a-na-daima
side-?-3SG.IA 1PL.EXC-IMPER-dig Ediliki PASS-3SG-spade
i-ta-guyala.
3SG-ST-break(PER)
While we were digging the other side, Ediliki's spade broke.
b. Ka-uwo-uwata toni-kasa si-ma si-bolagu.
2PL.EXC-IMPER-net owner-village 3PL-come(PER) 3PL-scold(PER)
While we were netting, the village owners came and rebuked (us).

\subsubsection{PERFECT/PROSPECTIVE}

Aspect, according to Comrie (1976:52), is "concemed with different ways of representing the internal temporal constitution of a situation". He writes that the perfect (distinct from the perfective) does not fit into this definition "since it tells us nothing about the situation in itself, but rather relates some state to a preceding situation". Traditionally, however, the perfect has been included with discussions on aspect. This is also the case with what Comrie 
refers to as "prospective". This difference can be seen in Gumawana since the truly aspectual markers are found on the verb whereas both the perfect and prospective are external to it.

Comrie defines the perfect as indicating "the continuing present relevance of a past situation”. The perfect is marked by bogina 'already' in Gumawana. In each example in (8) the clause with bogina has relevance to the following situation.
a. Tutea-na
vavina bogina i-nai,
dokanikani i-vatowo
time.REF-3SG woman PRF 3SG-marry giant
3SG-begin
be iyana i-lusala.
and fish 3SG-search

When the woman had married, the giant began to look for fish.

b. Maliyalina manawe-na bogina a-vaite-mu go aika geya. day long-3SG PRF 1SG-help.TR-2SG SW meal NEG For a long time I have helped you but (there is) no food.

c. Ago Sipwena bogina i-katubayasi, bei i-ketoiya. SW Sipwena PRF 3SG-prepare PRO 3SG-walk But Sipwena had prepared and he was about to walk.

Although in (8) bogina precedes the verb, it is possible for it to follow the verb.

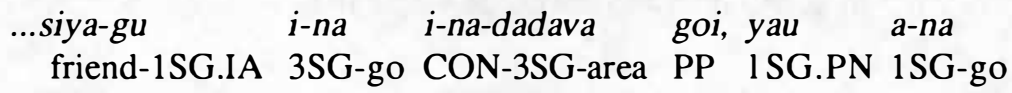

guna-dadava goi maine nakae i-loina bogina.

1SG.POSS-area PP earlier like 3SG-decide PRF

...my friend went to his area, I went to my area as he had decided earlier.

The perfect may occur in conjunction with the continuous aspect.

\section{Bogina si-nonoi-na. \\ PRF 3PL-IMPER-go \\ They are already going.}

Bogina may occur by itself when someone asks whether a particular event is done or not.

$$
\begin{aligned}
& \text { Boginae? } \\
& \text { PRF.TM } \\
& \text { All done, right? }
\end{aligned}
$$

The prospective may be seen as the flip side of the perfect, that is "where a state is related to some subsequent situation, for instance where someone is in a state of being about to do something" (Comrie 1976:64). The prospective aspect is marked by the word bei which means 'about to do something' or 'be going to do something'.

(12) a. Kelebi i-na Gumawana goi bei tapwae i-gimona. Kelebi 3SG-go Gumawana PP PRO tobacco 3SG-buy Kelebi went to Gumawana and he is going to buy tobacco.

b. Niu-mu bei i-na yawala goi a-mi-vilava gurewa sister-2SG.IA PRO 3SG-go old.garden PP EAT-2SG-taro stone 
una-na goi i-kabi.

base-3SG.IA PP 3SG-get(TR)

Your sister is going to go to the old garden and get your taro at the base of the stone.

The prospective and perfect may be used together.

c. Bogina bei si-ma.

PRF PRO 3PL-come

They are already about to come.

\subsection{MOOD}

Mood is expressed by a variety of devices in Gumawana.

\subsubsection{IRREALIS/REALIS}

\subsubsection{THE UNCERTAINTY MARKER be}

The marker be indicates uncertainty in questions, as in (13a), or in statements when the speaker is not sure of what is to take place, as in (13b).

(13) a. Be i-kuwana o geya?

UNCRT 3SG-rain or NEG

Might it rain or not?

b. Kelebi i-na Gumawana goi be tapwae i-gimona.

Kelebi 3SG-go Gumawana PP UNCRT tobacco 3SG-buy

Kelebi went to Gumawana where he might buy tocaboo.

It appears that some speakers are collapsing be and the prospective marker bei.

Note that there is also the conjunction be which means 'and'. This is homophonous with the uncertainty marker, but apparently distinct from it.

\subsubsection{THE IRREALIS MARKER bego}

The irrealis marker bego has various functions. It may be made up of the two morphemes be 'uncertainty marker' and go 'switch of attention conjunction'. 18

The irrealis is used to indicate frustrated intent, as in (14b). In (14a) the giant takes the plate of food with no problem. In (14b) the giant intends to take the plate but is stopped by the dog. Bego indicates that the giant's desire was unfulfilled. When bego is used as in (14b), a clause introduced by go is expected at the end of the clause to introduce the reason why the action did not take place.

(14) a. Ago dokanikani-ya-na i-bisi-sobu vilava be iyana

SW giant-REF-3SG 3SG-by.hand-downward taro and fish

${ }^{18}$ Editor's note: There is some evidence that some instances of bego contain be 'uncertainty marker', others be 'conjunction', but this requires further investigation. 
ma-noko-i-na i-kavale.

COM-plate-?-3SG.IA 3SG-carry.TR

And the giant reached down and carried the plate with taro and fish.

b. Ago dokanikani-ya-na i-bisi-sobu bego noko

SW giant-REF-3SG 3SG-by.hand-downward IRR plate

i-kavale $\quad$... go weniya i-gou.

3SG-carry.TR SW dog 3SG-bark

And the giant reached down intending to carry the plate...but the dog barked.

$B e g o$ is also used with dreams (15a), indirect speech (15b), daydreaming (15c), requests (15d) and desire (15e), all of which are uncertain or unreal. Indirect speech is in a sense not real since the words have been changed from what the person originally said.
a. I-kanamimi bego sina-di i-ma i-digo ka-na... 3SG-dream IRR mother-3PL.IA 3SG-come 3SG-say talk-3SG.IA He dreamed that his mother came and said...
b. Maine sina-da i-digo-digo bego losui ta-gabu. earlier mother-1PL.INC.IA 3SG-IMPER-say IRR banana 1PL.INC-roast Earlier our mother had said that we would roast the banana...
c. Yau bego a-na Gumawana. 1SG.PN IRR 1SG-go Gumawana I might go to Gumawana.
d. A-kawanoi yai-mu bego magi ku-vini-gu. 1SG-request GOAL-2SG.IA IRR betel.nut 2SG-give-1SG I ask from you that you give me betel nut.
e. Ago dokanikani-ya-na i-kao-makimaki latuwo-na bego i-kaika. SW giant-REF-3SG 3SG-by.mouth-strong desire-3SG.IA IRR 3SG-eat And the giant persisted desiring to eat.

\subsubsection{REALIS}

In contrast to clauses marked with be or bego, the 'unmarked' clause expresses realis.
(16) a. Ka-na
Tukwaukwa vaega ka-gimona.
1PL.EXC-go(REALIS) Tukwaukwa clay.pot 1PL.EXC-sell(REALIS)
We went to Tukwaukwa to sell clay pots.

\subsubsection{ABILITY}

Ability may be expressed by one of the nouns yoiya- 'ability, fit' and kaipata 'ability' in a genitive construction. The noun yoiya means 'ability, fit' in the sense that something fits such as clothing. It obligatorily takes the inalienable possessive suffix. The idea is 'my arm is big enough for the armband'. One does not say that the armband is too small.

$$
\begin{aligned}
& \text { I-mu-nipuna yoiya-gu a-valiliv-i. } \\
& \text { CON-2SG-armband fit-1SG.IA ISG-slip.on-TR } \\
& \text { I am able to slide your armband on. }
\end{aligned}
$$


Kaipata 'ability' is used with regard to one's physical ability and takes the a-form of alienable possession.
(18) a. Bogina a-ma-kaipata ka-kaika.
PRF PASS-1PL.EXC-able 1PL.EXC-eat
We have the ability to eat (it).
b. A-gu-kaipata alova a-kavale.
PASS-1SG-able wood 1SG-carry.TR
I am able to carry the wood.

\subsubsection{DESIRE/INTENT}

Desire is expressed through the inalienably possessed nouns vavagi- or latuwo-, both meaning 'desire, want'. There appears to be no difference in their use. Often this construction is followed by bego, the irrealis marker (8.3.1.2).
(19) a.
$\begin{array}{lll}\text { Vavagi-mi } & k o-n a & \text { Alotau o geya? } \\ \text { desire-2PL.IA } & \text { 2PL-go Alotau or NEG }\end{array}$
Do you want to go to Alotau or not?

$\begin{array}{lllll}\text { b. Bobokata i-poikikina. } & \text { Latuwo-na bego i-na tuwowo-na } \\ \text { crab } & \text { 3SG-try } & \text { desire-3SG.IA IRR } & \text { 3SG-go old.brother-3SG.IA }\end{array}$

kiki-na.

next.to-3SG.IA

The crab tried. His desire was to be next to his older brother.

\subsubsection{POSSIBILITY/NECESSITY}

Possibility is expressed by means of the modal verb -kakapu 'easy, be able, be possible' followed by the goal/source marker yai- (20). The verb -toboina is also used for the notion of possibility, and takes as its object the animate agent of the possible action (21).

(20) a. I-kakapu yai-gu a-katuyaina.

3SG-be.easy GOAL-1SG.IA 1SG-read

I can read. (lit. It is easy to me to read.)

b. Paisewa ame i-kakapu yai-da.

work this 3SG-be.easy GOAL-1PL.INC.IA

We can do this work. (lit. This work is easy to us.)

(21) a. I-toboine-gu a-liwola.

3SG-possible.TR-1SG 1SG-preach

It is possible for me to preach.

b. Ame dogoi-ya-na i-toboine-mu ku-kavale.

this thing-REF-3SG 3SG-possible.TR-2SG 2SG-carry.TR

It is possible for you to carry this thing.

The verb -toboina is also used to express necessity, but in this case the direct object is an unspecified third person singular, as in (22). According to informants, this unspecified object is understood to be lovina 'rule, law, order'. 
(22) a. I-toboine a-na a-paisewa.

3SG-must.TR 1SG-go 1SG-work

I must go work.

b. I-toboine ta-takisi.

3SG-must.TR 1PL.INC-tax

We must pay taxes.

\subsubsection{PRESCRIPTION}

The notion of prescription is expressed by means of the word $k a-d a$ 'our (inclusive) talk' preceding the switch marker go (7.1). It may carry a slight rebuke when used in this way. It indicates that the listener should have or should do a particular task. The intonation on such clauses is different.

(23) a. Ka-da go ma-(a)-mu-magi!

talk-1PL.INC.IA SW COM-PASS-2SG-betel.nut

You should have your own betel nut!
b. Ka-da go ma-(a)-mu-mani ku-sowoya! talk-1PL.INC.IA SW COM-PASS-2SG-money 2SG-embark You should have embarked with your money!

\subsubsection{DOUBT}

The notion of doubt is introduced with the particle masa.
(24) a. Masa bei yau a-togaga.
doubt PRO 1SG.PN 1SG-be.strong
I doubt I am going to be strong.
b. Masa bei tala si-mamai-ma i-gu-kaiaka bei dedei-na. doubt PRO year 3PL-IMPER-come CON-1SG-stay PRO good-3SG I doubt my existence in the coming years is going to be good.

\subsection{QUESTIONS}

In this section the various types of questions are examined: yes/no (8.4.1), alternative (8.4.2), content (8.4.3), confirmation (8.4.4), embedded (8.4.5) and rhetorical (8.4.6).

\subsubsection{YES/NO QUESTIONS}

$\mathrm{A}$ rise in intonation at the end of a clause indicates a yes/no question.

(25) a. Bogina i-ma?

PRF 3SG-come

Has he come?

b. Mata-mu i-masisi? eye-2SG.IA 3SG-sleep

Are you tired? 
The appropriate answer to the above yes/no questions would either be geya 'no' or a positive answer in the form of the following:

(26) a. $U u$ 'yes'

b. Go 'emphatic yes'

c. sharp breath taken in

d. raising of eyebrows + closing of eyes momentarily

\subsubsection{ALTERNATIVE QUESTIONS}

In alternative questions the hearer must decide between a delimited set of alternatives given by the speaker. Intonation rises before $o$ 'or' and falls clause finally. In (27) gea 'no' may be used in place of $o$ 'or' with the same meaning.

(27) a. Ame dedei-na o i-goyo?

this good-3SG or 3SG-be.bad

Is this a good one or is it bad?

b. Si-vini-mi o si-vagagala?

3PL-give-2PL or 3PL-keep

Did they give you (it) or did they keep (it)?

Another common usage is adding o geya 'or not' to the clause.

(28) a. Be ku-na o geya?

UNCRT 2SG-go or NEG

Are you going to go or not?

b. Ku-tagona i-mu-kaimoloiya goi a-sowoya o geya?

2SG-permit CON-2SG-canoe PP 1SG-embark or NEG

Do you allow that I embark on your canoe or not?

c. A-mu-potu i-geda o geya?

PASS-2SG-sore 3SG-hurt or NEG

Does your sore hurt or not?

\subsubsection{CONTENT QUESTIONS}

Any constituent of a clause may be questioned. Minimally an interrogative clause need only have a question word (listed in 3.1.9).

(29)

$$
\begin{aligned}
& \text { Nako? } \\
& \text { where } \\
& \text { Where? }
\end{aligned}
$$

In an interrogative equative clause the question word occurs clause finally as the predicate.

(30) a. Komu ava-tau?

2SG.PN which-person

Who are you? 
b. Go-gomana nako?

PL-children where

Where are the children?

c. Amo kaga?

that what

What is that?

The interrogative expression nako nakae 'what kind of' (more literally 'like where?') is used to ask for further specification of an object.
Manuwo nako nakae?
bird where like
What kind of bird?

\subsubsection{SUBJECT QUESTIONS}

Human subjects may be questioned with (a)va-tau 'which person, who' or with ava'which' in conjunction with some other human nominal. Non-human nouns are questioned with ava- plus some non-human noun, or with kaga 'what'.

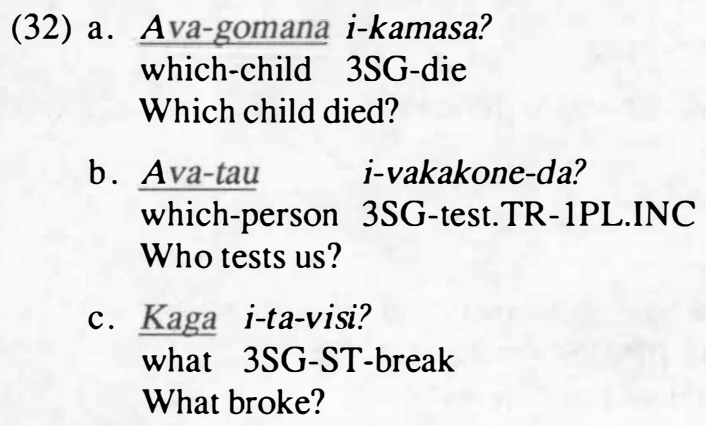

\subsubsection{DIRECT OBJECT QUESTION}

Objects are questioned with the same forms as subjects. The only difference is in the placement of the question word, which occurs in the object position. In (33a) an inanimate object is the direct object. In (33b) an animate object is questioned.

(33) a. Kelebi kaga i-gite?

Kelebi what 3SG-see.TR

What did Kelebi see?

b. Ava-tau-wa bei a-lituwoko-i-di?

which-person-PL PRO 1SG-tell-TR-3PL

Whom am I going to tell?

\subsubsection{OBLIQUE QUESTIONS}

Goal and source are encoded with yai- (5.2.2.4). When questioning, the goal/source ava-tau occurs with yai-. 
(34) a. Buki ku-etune i-na ava-tau yai-na?

book 2SG-send.TR 3SG-go which-person GOAL-3SG

To whom did you send the book?

b. Ku-liwola ava-tau-wa yai-di?

2SG-preach which-person-PL GOAL-3PL

To which people did you preach?

Benefactive constructions consist of a head nominal and the benef active manu- (5.2.2.1). Thus, when benefactives are questioned, the question word is followed by manu-. The question word reflects whether the head is human or non-human (8.4.3.1).

(35) a. Ku-paisewa ava-tau manu-na?

2SG-work which-person BEN-3SG

For whom do you work?

b. Ame dogoi-ya-na kaga manu-na?

this thing-REF-3SG what BEN-3SG

What is this thing for?

Benefactives may also be encoded with the postposition goi (5.2.1).

$$
\begin{aligned}
& \text { Kaga goi? } \\
& \text { what PP } \\
& \text { What for? }
\end{aligned}
$$

Manner may be questioned with the question word manakae- 'how', which agrees in person and number with the questioned word and is made up of the comitative prefix maand the postposition nakae 'like'.

(37) a. Niboda ma-nakae-gu a-katupaeve? door COM-like-1SG 1SG-open.TR How do I open this door?

b. Koloto ma-nakae-na i-ketoiya? man COM-like-3SG 3SG-walk How did the man walk?

When questioning how someone is, manakae does not agree with the clausal topic.

$$
\begin{aligned}
& \text { Ma-nakae, dedei-mi? } \\
& \text { COM-like good-2PL } \\
& \text { How are you, good? }
\end{aligned}
$$

Manakae is also used when someone comes to the door. Instead of asking kaga vavagimu 'what do you want', which would be considered impolite, one simply asks Manakae?

Location is questioned with the question word nako 'where', which normally occurs preceding the verb.

(39) a. Komu nako goi ku-ma?

2SG.PN where PP 2SG-come

Where did you come from?

b. Noko nako i-yato-i-di?

plate where 3SG-set-TR-3PL

Where did he set the plates? 
c. Nako ku-na bei?

where 2SG-go PRO

Where are you going to go?

It is possible to form equative clauses with nako (40a). Nako may also be inflected to agree with the head (40b).

(40) a. Nako koloto-i-mu?

where man-?-2SG

Where are you from? (lit. Where are you a man from?)

b. Nako-i-na?

where-?-3SG

Where is he?

Time is questioned with the expression ava tuta 'which time?'.
Clif, komu bei ava-tuta ku-ma Nubogeta?
Clif 2SG.PN PRO which-time 2SG-come Nubogeta
Clif, when are you going to come to Nubogeta?

There are three types of constructions used for questioning the reason for something. One consists of kaga 'what' and pasi-na 'its reason'. Reason question words normally precede the verb.

(42) a. Nubai-gu, kaga pasi-na ku-kalave-gu?

cousin-1SG.IA what reason-3SG 2SG-leave.TR-1SG

Cousin, why did you leave me?

b. Libetina Jimi kaga pasi-na si-kaimumuna?

Libetina Jimi what reason-3SG 3PL-slow

Why are Libetina and Jimi so slow?

A second construction involves kaga 'what' and una-na, which literally means 'its base/source' but which I gloss as 'because' (7.3.2.1). The question in (43a) is asking what the source of the crying is. The implication is that there is no reason. The answer (43b) is that Tomasi hit the child; however, the negation word geya introduces the answer by negating the implication of (43a). In (43c) the question is asking Tomasi for his reason for hitting the child, with the same implication as in (43a). The answer in (43d) is betel nut.

(43) a. Kaga unana gomana amo i-tai-taiya? what because child that 3SG-IMPER-cry Because of what is that child crying?

b. Geya, unana Tomasi i-lau-i.

NEG because Tomasi 3SG-hit-TR

Nothing - because Tomasi hit him.

c. Go Tomasi, kaga pasi-na gomana ku-lau-i?

SW Tomasi what reason-3SG child 2SG-hit-TR

And Tomasi for what reason did you hit the child?

d. Geya, magi pasi-na, unana magi a-kawanoi-ye

NEG betel.nut reason-3SG because betel.nut 1SG-request-OAD.TR 
i-vagagale tauna a-lau-i.

3SG-hold.back therefore 1SG-hit-TR

Nothing - betel nut is the reason, because I asked for betel nut and he kept it back, so I hit him.

Finally, depending on the transitivity of the clause, reason questions can be registered on the verb by means of $-k o(6.9 .2)$ and $-y e(6.9 .3)$. Verbs which are transitive take $-k o$, whereas those that are intransitive take -ye thus making them finally transitive.

(44) a. Komu kaga kwaiako-e?

2SG.PN what 2SG.remain-OAD.TR

Why are you here?

b. Gomana kaga i-taiya-e?

child what 3SG-cry-OAD.TR

Why did the child cry?

c. Kaga ku-luma-dadana-e ?

what 2SG-ask-unseen-OAD.TR

Why do you ask?

d. Kaga ku-luma-dade-ko-i-gu?

what 2SG-ask-unseen.TR-REA-TR-1SG

Why do you ask me?

e. Komi bao kaga ko-tala-i-ko-i?

2PL.PN pig what 2PL-cut-TR-REA-TR

Why did you cut the pig?

Answers to reason questions may begin with unana 'because'. Examples (45a) and (45b) are possible answers to the question in (44b).

(45) a. Unana gomana vavagi-na bwae.

because child desire-3SG.IA water

Because the child wants water.

b. Bego bwae i-nimu.

IRR water 3SG-drink

He wants water to drink.

c. Unana koloto madaboki-di i-di-nuwo-nuwona komu go

because man all-3PL.IA CON-3PL-IMPER-think 2SG.PN SW

yau si-katae-gu.

1SG.PN 3PL-refuse.TR-1SG

Because all the men want you but they refuse me.

\subsubsection{QUALITY QUESTIONS}

The quality of an object is elicited with interrogative expression kaganakae 'like what'.

(46) a. Maisi-na kaga nakae?

face-3SG.IA what like

What did he look like? (lit. What was his face like?) 


\section{b. I-na-vada kaga naka? \\ CON-3SG-house what like \\ What is his house like?}

\subsubsection{QUANTITY QUESTIONS}

Quantity is questioned with the question word aivina 'how many, how much?'. The head (if overt) usually precedes the question word, but a reverse order is possible.

(47) a. $\frac{\text { Oga }}{\text { canoe }} \stackrel{\text { a-di-kai-vina }}{\text { PASS-3PL-canoe-how.many }} \stackrel{\text { a-na-badabada si-kailova? }}{\text { PASS-3SG-number 3PL-depart }}$ How many is the number of canoes that left?

b. Ai-vina buki si-kaiaka?

CL-how.many book 3PL-remain

How many books are left?

c. Ai-vina a-na-maisa?

CL-how.much PASS-3SG-debt

How much does it cost?

When questioning the number of people the word tai 'man' or 'person' occurs with vina 'how many', which is alienably possessed. This is the construction for counting people (3.1.6.3).

(48) a
A-mi-tai-vina ko-ma?
PASS-2PL-man-how.many 2PL-come
How many of you came?
b. A-di-tai-vina si-vaite-mu?
PASS-3PL-man-how.many 3PL-help.TR-2SG
How many of them helped you?

To answer the questions in (48) the following constructions are used.
(49) a. A-ma-badabada ai-nima tayamo.
PASS-1PL.EXC-number CL-five one
Our number was six.
b. A-ma-tai-nima.
PASS-1PL.EXC-man-five
We were five.

\subsubsection{CONFIRMATION QUESTIONS}

Confirmation questions are marked by the clitic ae which occurs clause finally and bears rising intonation. Note that in each case the initial $a$ of $a e$ is deleted and it becomes phonologically part of the final word of the sentence.

(50) a. Boginae?

PRF.TM

Done, right? 
b. Ta-mogibeli ame bei i-mae?

MALE-Mogibeli today PRO 3SG-come.TM

Tamogibeli is going to come today, isn't he?

c. Moitamoe?

true.TM

That's right, isn't it?

d. Moe ku-digoe?

that 2SG-say.TM

You said that, didn't you?

\subsubsection{EMBEDDED QUESTIONS}

With certain verbs it is possible to embed a question. Many of the questions discussed thus far may be embedded. They normally follow the main verb.

(51) a. Ku-yagoi ava-tuta be i-ma?

2SG-know which-time UNCRT 3SG-come

Do you know when he will come?

b. Ku-yagoi $\frac{\text { ava-tau }}{\text { 2SG-know }} \stackrel{\text { i-kamasa? }}{\text { wSh-die }}$

Do you know who died?

\subsubsection{RHETORICAL QUESTIONS}

Rhetorical questions are not marked with any morpheme. They have the same basic pattem as content questions. It is mainly the context that determines a rhetorical question.

(52) a. Kaga pasi-na sinitu yai-na ko-numisa?

what reason-3SG evil.one GOAL-3SG 2PL-trust

Why do you trust in the evil one? = You trust in the evil one.

b. Bego tau-ya-na ava-mi i-vini-mi?

IRR person-REF-3SG food-2PL.IA 3SG-give-2PL

Will he give you your food? = So that he will give your food.

A common way of forming a rhetorical question is to start the question with nakona 'perhaps' as in (53).

(53) a. Geya, nakona yau geya a-lovinae-mu-ta?

NEG perhaps 1SG.PN NEG 1SG-command.TR-2SG-LIM

Perhaps I have not commanded you? = I have commanded you.

b. Nakona geya a-vini-mu-ta?

perhaps NEG 1SG-give-2SG-one

Perhaps I didn't give you it? = I did give you it.

Rhetorical questions are used mainly in exhortations or when someone is angry. 


\subsection{NEGATION}

There are two negation morphemes in Gumawana, geya and gebu. It appears that gebu is used only when answering polar questions; it is not found in the context of a clause. Two other morphemes used for negation are tabu 'taboo' and boma- 'ban'. The latter requires inalienable possession.

\subsubsection{Clause NEGATION}

The negation particle geya immediately precedes the verb:

(subject) (object) geya verb phrase

When the scope of the negation is a single event, the limiter suffix -ita (3.3.1.2) is necessary.

(54) a. Go niya-di geya si-sowodo-ita.

SW voice-3PL.IA NEG 3PL-come.out-LIM

And their voices did not come out.

b. Go iyana geya ka-koneta.

SW fish NEG 1PL.EXC-trap.LIM

And we didn't trap any fish.

If the limiter -ita is not present the meaning becomes 'never' and the verb must be imperfective in aspect (8.2.1).

(55) a.
...go negwasa geya ta-gite-gite
geya.
SW ocean NEG 1PL.INC-IMPER-see.TR NEG
...but we never saw the ocean.

b. Geya ku-mamai-ma.

NEG 2SG-IMPER-come

You don't/never come.

Emphasis may be placed on the negation of a clause by repeating geya at the end of the clause or adding geya toina 'very no'. It seems that this type of construction can only be used with a completed event.

(56) a. Kina go Kakavaku i-sou geya i-kayeta geya, 3SG.PN SW worm 3SG-go.down NEG 3SG-swim.LIM NEG i-salili.

3SG-sank

Now the worm who went down didn't swim, he sank.

b. Bao geya i-ginubasi-yeta geya.

pig NEG 3SG-spear-LIM NEG

He didn't spear the pig, no.

The scope of the negative particle geya may embrace more than one finite verb. In example (57) the negative particle geya comes before both verbs, yet only the final verb has the limiter-ita. 
(57) a. ...yau geya a-na a-tapwalolo-ita.

1SG.PN NEG 1SG-go 1SG-worship-LIM

...I didn't go to church.

b. Geya ta-na ta-kaiketa.

NEG 1PL.INC-go 1PL.INC-eat.LIM

We don't go and eat.

Ellipsis is allowed in negation clauses. In example (58) the phrase go geya occurs with the verb elided.

(58) a. Kunuwo ku-mata-kavate go geya, bei ta-tomova.

rudder 2SG-by.eye-hold.TR SW NEG PRO 1PL.INC-run.aground

You watch the rudder but if not, we will run aground.

b. ...go mae-ko yata-na si-gite-gite go geya,

SW above-PLA.ADV on.top-3SG.IA 3PL-IMPER-see.TR SW NEG

ka-eli-eli, geya ka-yagoi-yeta i-ta-guyala.

1PL.EXC-IMPER-dig NEG 1PL.EXC-know-LIM 3SG-ST-break

...and we (habitually) watch up above, but if not, when we are digging, we

don't know if it will break.

The prohibitive tabu 'taboo' is used in conjunction with the imperfective apsect of the verb (8.2.1), indicating that a certain event is forbidden by taboo.

Niu tabu ku-mwela-mwela.

coconut taboo 2SG-IMPER-climb

It is taboo for you to climb the coconut tree. / Don't climb coconut trees.

Boma-, which agrees in number and person with the person to whom a ban applies, occurs in sentences such as (60). The prohibitive boma- differs from tabu in that bomaforms a noun phrase and indicates that a particular person has a restriction on doing something. Tabu is used at clause level indicating that the event is taboo. Compare (60) with (59). In example (60) the clause geya ku-kani-kani 'you don't eat fish' explains that the fish is forbidden for me.
Iyana boma-mu, geya ku-kani-kani.
fish forbidden-2SG.IA NEG 2SG-IMPER-eat(TR)
You are forbidden fish: you do not eat fish.

\subsubsection{PHRASE LEVEL NEGATION}

The following examples illustrate negation of noun phrases. In examples (61a) - (61c) the phrase geya (kada) tayamo 'not (even) one' occurs. This is a common construction when showing the intensity of the negation.

(61) a. Ego sina-gu-ya-na geya kada tayamo piba o nosanosa geya. SW mother-1SG.IA-REF-3SG NEG even one fever or cold NEG But my mother did not have even one fever or cold.

b. Geya tayamo monaga ka-babane geya, geya toi-na. NEG one squid 1PL.EXC-find.TR NEG NEG very-3SG Not one squid did we find, no, definitely not. 
c. Geya kada tayamo iyana ka-kone geya, geya toi-na. NEG even one - fish 1PL.EXC-trap NEG NEG very-3SG

Not even one fish did we trap, no, definitely not.

d. Ae-mu kwai-sobu-ye, dimodimo geya, moe bogina leg-2SG.IA 2SG.by.set-down-TR heat NEG that PRF i-sawala.

3SG-disperse

Put your leg down (in the hole), if (you feel) it is not hot, then it (the heat/odour) has dispersed.

e. Go ka-eli ka-me asa goi moe poisoni geya. SW 1PL.EXC-dig 1PL.EXC-come.TR village PP that poison NEG And we dig and bring it to the village where there is no poison.

f. Geya tayamo kaga i-kaiaka.

NEG one what 3SG-remain

Not one thing was there.

In constructions where the idea is 'not any', the nominal suffix -mo (3.3.1.3) occurs.

(62) a. I-poikiki, geya a-na-kaipata-mo.

3SG-try(TR) NEG PASS-3SG-able-any

He tried it but did not have any ability.

b. Go yau a-gu-ta geya i-gu-vaega-mo...

SW 1SG.PN PASS-1SG-LIM NEG CON-1SG-clay-any

But if I do not have any clay...

\subsection{QUOTATIONS}

There are two quotation formulas in Gumawana. The normal order is as follows:

Indirect speech: speech verb (IMPER) IRR quotation

Direct speeech: (speech verb) ka-na quotation (kaena)

\subsubsection{INDIRECT SPEECH}

Indirect speech has restricted use in Gumawana. Normally indirect speech is expressed by the imperfective form of the verb digo 'to say' followed by the irrealis marker bego, then the quotation. It is normally used in requests but may be found in other contexts as well.

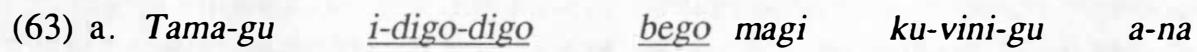
father-1SG.IA 3SG-IMPER-say IRR betel.nut 2SG-give-1SG 1SG-go a-vini.

1SG-give(TR)

My father says that you (must) give me betel nut, and I will go give it to him.

$\begin{array}{lll}\text { b. Tuwowo-gu } & \text { maine sina-da } & \frac{\text { i-digo-digo }}{3 \text { SG-IMPER-say }} \\ \text { old.brother-1SG.IA } & \text { earlier mother-1PL.INC.IA }\end{array}$ 
losui ta-gabu.

banana 1PL.INC-roast(TR)

Older brother, earlier our mother said that we were to roast a banana.

Indirect speech is used to encode mild requests where the speaker considers himself only to be giving a message. Direct speech is used to encode more forceful requests, in which the speaker is asking on behalf of the one whom he is quoting.

\subsubsection{DIRECT SPEECH}

In direct speech the quotation formula contains the inalienably possessed quotation noun $k a$ - 'talk', which agrees in person and number with the quoted person. Ka- may come before the quoted material or after. In direct speech any verb of speech may be used followed by $k a$ -

(64) a. I-sou i-ma i-digo ka-na, "Iva-gu, 3SG-go.down 3SG-come 3SG-say talk-3SG.IA brother.in.law-1SG.IA

kaga ku-vavai-va?"

what 2SG-IMPER-do

He went down and said, "Brother-in-law, what are you doing?".

b. I-vaiu, i-tuma-yava ka-na, "Sipwena, ku-ma 3SG-arrive 3SG-beckon-to.bush talk-3SG.IA Sipwena 2SG-come

kewou ta-yagasi”.

canoe 1PL.INC-slip

He arrived, he beckoned toward the bush, "Sipwena, come and let's slip the canoe".

Direct speech is very common, and quotations within quotations are found.

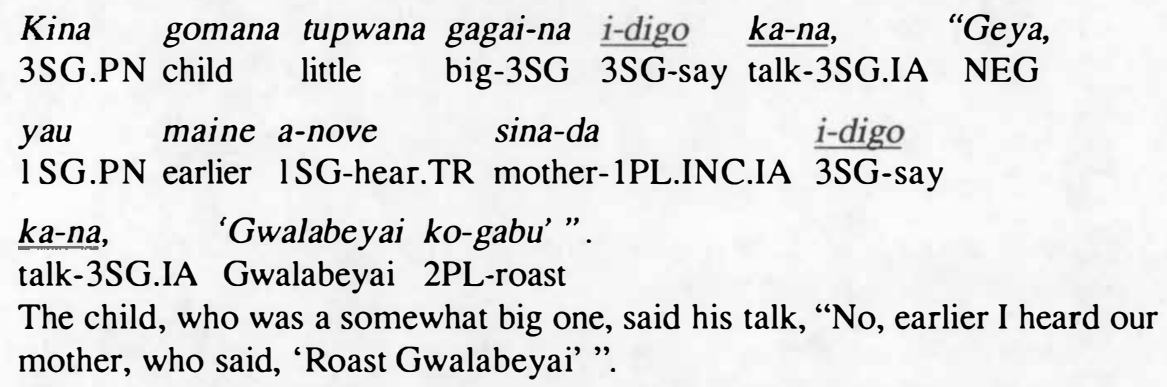

The direct speech formula may be reversed so that the quoted material comes first, followed by the quotation noun $k a-$. In such constructions it is necessary to affix $k a-$ with $-e$ 'old information'.

(66) a. "Geya, a:-kaiako", Sipwena ka-e-na.

NEG ISG.IMPER-remain Sipwena talk-OI-3SG.IA

"Nothing, I'm just here", said Sipwena.

b. "Komu nako koloto-i-mu? Yoi-mu ma-nako-yoi-na?", 2SG.PN where man-?-2SG.IA name-2SG.IA COM-where-name-3SG.IA 


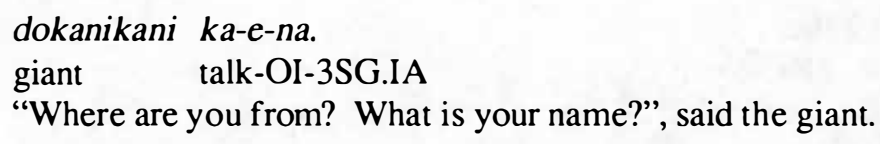

It is possible to combine the two different direct speech formulae into one sentence.

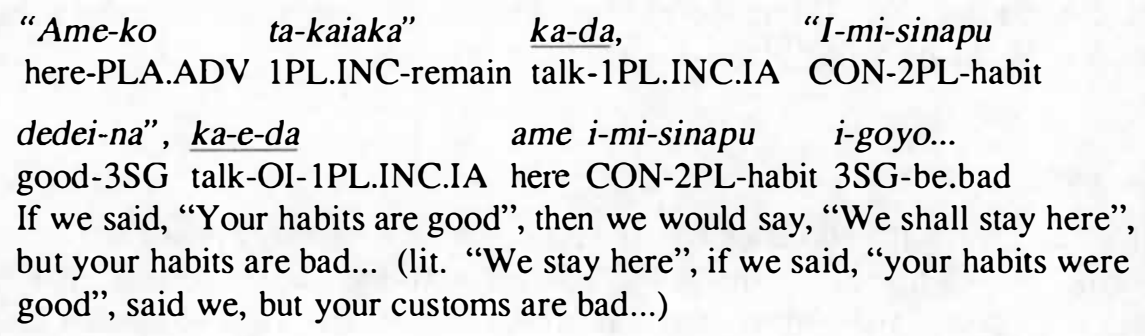

\section{MISCELLANEOUS DEVICES}

In this section I discuss various devices in Gumawana, including abstractions and figures of speech.

\subsection{FIGURES OF SPEECH}

\subsubsection{SIMILE}

Simile in Gumawana is expressed using the word nakae 'same, like'.

(1) a. Vaega moumou-na simenti nakae. clay heavy-3SG cement like The heavy clay is like cement.

b. Moe nakae geya ku-nuwo-nuwona geya. DEM like NEG 2SG-IMPER-think NEG You are not to think (habitually) like that.

\subsubsection{METAPHOR}

Metaphors are quite numerous in Gumawana. The characteristics of certain animals are used in describing people in the village.

If someone is wearing a shirt which is too big someone might label that person as being magiaweda 'flying fox' because the flying fox has wings which appear to be too big for the animal.

An unfriendly person is called viviya 'wasp' because the wasp stings for no reason and will attack without warning. Viviya may also refer to someone who builds without removing the old part but rather adds on. The similarity is that the wasp builds a mud house which he continually adds on to.

A person who is always wearing someone else's clothing is called giloilo 'land crab' because the land crab or hermit crab always takes various shells as his home. 
If a person comes and visits but stays for a long time he is referred to as yaowana 'clam' because the yaowana attach themselves to large rocks in the ocean and remain there indefinitely.

A person called kulasi has the characteristics of the kulasi fish, which keeps its mouth open all the time and just stares.

Metaphor is sometimes used to hide the speaker's meaning from some listeners. The question in (2) is asked after a meal when betel nut is being divided up.
Gaota si-loiteta si-sou
koya giyai-di o geya?
cloud 3PL-skip 3PL-go.down mount small-3PL or NEG
Are the clouds skipping down to the small mountains or not?

The gaota 'clouds' are the betel nut, the koya giyaidi 'small mountains' are small children and the loiteta 'to skip' refers to the dividing up of the betel nut. What they are asking is, 'Is there enough betel nut so that the small children can have some?'.

\subsubsection{EUPHEMISM}

Euphemisms deal with death and sexual ideas.

(3) a. Tama-gu i-tagau.

father-1SG.IA 3SG-lost

My father was lost. = My father died.

b. A-na-tuta i-babane.

PASS-3SG-time 3SG-find.TR

He found his time. $=$ He died.

c. Ka-kaiaka nakae five minutes yawo-i-na i-kavava.

1PL.EXC-remain like five minutes life-?-3SG.IA 3SG-be.finished

We remained for five minutes and her life was finished. $=$ We were there for five minutes and then she died.

d. Bogina a-nonoi-na.

PRF ISG-IMPER-go

$\mathrm{I}$ am already going. = I am dying.

e. A-masisi-ye.

1SG-sleep-OAD.TR

I slept with her. = I had intercourse with her.

f. Sakava-i-na i-bisi-kone.

skin-?-3SG.IA 3SG-touch-try.TR

He touched her skin. = He had intercourse with her.

\subsubsection{HYPERBOLE}

Hyperbole is found in Gumawana with the quantifier nouns such as madaboki 'all' and verbs like kamasa 'to die'. 
(4) a. Boda madaboki-di si-na Wadalei Synod manu-na. people all-3PL.IA 3PL-go Wadalei Synod for-3SG

All the people went to Wadalei for the synod. = Most of the people went...

b. Loga a-kamasa.

hunger 1SG-die

I'm starving. (lit. Hunger I die.)

c. Gogou a-kamasa.

cold 1SG-die

I'm freezing to death. (lit. Cold I die.)

\subsubsection{APOSTROPHE}

Apostrophe occurs in Gumawana.

(5)
$O$ bolimana
ku-ma!
o south-east.wind 2SG-come
$\mathrm{O}$ south-east wind, come!

\subsubsection{PERSONIFICATION}

Personification is mainly found in legends or folktales about non-human beings which have the features of humans attributed to them.

(6)
a. Utunea-di ka-di, "Kai bei ka-na i-tuli". star.REF-3PL talk-3PL.IA 1PI.EXC.PN PRO 1PL.EXC-go 3SG-different The stars said, "We are going to go to a different place".

b. Ame gulewea-di ai-to Duau goi si-lokoina si-ma. this rock.REF-3PL CL-three Duau PP 3PL-run 3PL-come These are three stones which came sailing from Duau.

\subsubsection{IRONY}

Irony is found extensively in Gumawana. Characteristically irony is indicated using the mood marker tabe or kada go 'talk but' and a change of the intonation, but tabe is not required.

In (7a) the intonation rises on $e$ and falls on moe. But when the intonation rises on $e$ and drops on mo with a rise at the end of the word (7b) the meaning is the opposite of what is said.

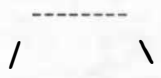

(7) a. E moe!

DEV that

That's it! 


$$
\begin{aligned}
& \text { b. E moe! } \\
& \text { so that } \\
& \text { That's right! = No, that's wrong! }
\end{aligned}
$$

Example (8a) is used in complaining about someone coming and taking something without asking. In (8b) the person attempts to carry off the lime belonging to someone else. The owner makes the statement in (8b) and he gets his lime back. Example (8c) was heard in the middle of a game where people draw for a number. When it was not the right number the opponent came out with (8c) to be funny. The intonation patterns on $(8 \mathrm{a}-\mathrm{c})$ are the same as (7b).

(8) a. Moe tabe kona-na i-kabi. that MOOD thing-3SG.IA 3SG-take(TR) He certainly took his thing. = He took my thing.

b. Siya-gu tabe moe i-mu-yaguma ku-me a-kauli. friend-1SG.IA MOOD that CON-2SG-lime 2SG-come.TR 1SG-chew My friend, bring your lime so I can chew. = That's my lime you are taking so bring it back so I can chew.

c. Ka-da go i-kaiaka.

talk-1PL.INC.IA SW 3SG-remain

It should be there. $=$ You wish it was there but it's not.

\subsubsection{SYNECDOCHE}

Synecdoche is also possible.

(9) a. Maisi-na nako?

face-3SG.IA where

Where is he from? (face = person)

b. Ame tau-ya-na Nubogeta daba-na.

this person-REF-3SG Nubogeta forehead-3SG.IA

This $\operatorname{man}$ is the leader of Nubogeta. (forehead $=$ leader)

\subsection{BORROWING}

Words borrowed from English are incorporated into the Gumawana grammatical system. Gumawana speakers make verbs from English nouns just as they do from native nouns. In (10a) the noun bolo 'ball' has the subject prefix ta- and now has the extended meaning of 'soccer'.

(10) a. Ta-na ta-bolo.

1PL.INC-go 1PL.INC-ball

Let's go play soccer. 
b. A-talaim. 19

1SG-try

I try.

c. Ka-mikisi.

1PL.EXC-mix(TR)

We mix it.

d. I-na-mitini Kwadima i-na-lokoina manu-na si-mitini. 3SG-go-meeting Kwadima CON-3SG-run BEN-3SG 3PL-meet He went to a meeting where they met for the running of Kwadima.

Example (11) shows the verbalisation of an English preposition/adverbial.
...Labe wopi goi ka-lousaidi.
Rabe wharf PP 1PL.EXC-alongside
...we came alongside of the Rabe wharf.

Phonologically, words borrowed from English will normally add $-i$ finally if the English word ends with a consonant.

Gumawana
buki
keseti
pati
yusi
lampa
kanseti
toti
mikisi

\subsection{ELLIPSIS}

There are various occurrences of ellipsis (indicated by '-') in Gumawana. A single nominal may be deleted anaphorically.

(13) a. Siya-gu bao ai-yuwo i-yois-i-di friend-1SG.IA pig CL-two 3SG-catch-TR-3PL SW 1SG.PN

gayamo a-yois-i.

one 1SG-catch-TR

My friend caught two pigs and I caught one.

b. Iyana giyai-di pepeko pinada si-vini go fish small-3PL pepeko pinada 3PL-give(TR) old.woman.REF-3SG SW

- gagai-di Mogibeli natu-na taiyao a-di-iyana.

big-3PL Mogibeli child-3SG.IA COM EAT-3PL-fish

They gave the old woman the fish which were small ones, such as pepeko and pinada, but the big ones were Mogibeli's and his son's fish.

\footnotetext{
${ }^{19}$ Editor's note: The presence of -im on talaim 'try' indicates that it has been borrowed from Tok Pisin (New Guinea Pidgin) or from the now extinct Papuan Pidgin English.
} 
When two clauses are conjoined with go, it is normal for the subject or object noun phrase to be omitted in the second clause.

(14) a. Silekaleka kewou i-siya-e Silekaleka canoe 3SG-flee-OAD.TR SW earlier coconut bogina i-nonomi i-kabi i-kalisobuye.

PRF 3SG-collect(TR) 3SG-take(TR) 3SG-drop.TR

Silekaleka fled with the canoe, and the coconuts she had collected earlier, she took them to drop them.

b. Iva-gu a-mu-iyana go golao moe giyai-na brother.in.law-1SG.IA EAT-2SG-fish SW fish.name that small-3SG

ku-vini-gu a-na - a-gabu.

2SG-give-1SG 1SG-go 1SG-roast(TR)

Brother-in-law, it is your fish, but that golao, you give me a little of it and I will go and roast it.

It is also possible to omit the entire verb along with its subject or object.

(15) a. Ku-wo ku-kaya-laga go geya -, i-doiye-mu. 2SG-go 2SG-swim-upwards SW NEG 3SG-drift.TR-2SG You go swim ashore but if you don't, you will drift.

b. Iyana badabada-i-di i-ginubasina go yau geya fish many-?-3PL.IA 3SG-spear SW 1SG.PN NEG He speared many fish, but me nothing (I didn't get any).

Exampe (16b) is the answer to the question in (16a) and the object and the verb from the question have been omitted.

(16) a. Kalitoni, ai-vina moku ku-ginubasi-di?

Kalitoni CL-how.many bait 2SG-spear-3PL

Kalitoni, how many fish for bait did you spear?

b. Yau ka-gu, "Geya, go komu ai-vina - -?"

1SG.PN talk-1SG.IA NEG SW 2SG.PN CL-how.many

I said, "None, but how many did you?".

Example (17) could possibly also be considered to show ellipsis. In this case the verb $-v i n i$ 'to give' has been omitted.

$\begin{aligned} & \text { Da-Bosalewa } \quad \begin{array}{l}\text { kunumana } \\ \text { people.of-Bosalewa sago }\end{array} \\ & \text { 3PL-give-1PL.EXC food }\end{aligned}$
magi - luwasi -
betel.nut pepper
The people of Bosalewa gave us sago and food and betel nut and pepper.

Clausal ellipsis allows an entire clause to be omitted. As in many languages, this is common with answers to questions. Consider the following questions (a) and answers (b). Note that in (19b) the answer consists only of $u$ 'yes' and the perfect marker bogina.

(18) a. Be ku-paisewa o geya?

UNCRT 2SG-work or NEG

Are you going to work or not? 
b. $U$.

yes

Yes.

(19) a. Kelebi bogina ku-latuwoko?

Kelebi PRF 2SG-tell(TR)

Have you told Kelebi?

b. $U$, bogina.

yes PRF

Yes, already.

(20) a. Oga a-di-kai-vina si-mamai-ma?

canoe PASS-3PL-canoe-how.many 3PL-IMPER-come

How many canoes are coming?

b. - a-di-kai-nima.

PASS-3PL-canoe-five

Five.

\subsection{IDIOMS}

Most idioms in Gumawana involve body parts of some kind. The most common body part used is nukoto- 'neck'.

(21) a. E Sipwena nukoto-na i-topa.

DEV Sipwena neck-3SG.IA 3SG-ST.break

So Sipwena gave up.

b. Nukoto-gu i-molaela.

neck-1SG.IA 3SG-nauseous

That makes me sick to my stomach.

c. Nukoto-mu i-kabi.

neck-2SG.IA 3SG-get(TR)

You like it.

There are also several idioms involving daba- 'forehead'.

(22) a. Daba-na i-patu.

forehead-3SG.IA 3SG-enclosed

He is stupid.

b. Daba-gu i-lokoina.

forehead-1SG.IA 3SG-run

I am smart.

c. Daba-mu i-kasa.

forehead-2SG.IA 3SG-hard

You are stubbom.

The centre of emotions in Gumawana is the neck and that is the place where nuwo'thought' resides. 
(23) a. Nuwo-gu i-mou.

thought-1SG.IA 3SG-heavy

I am sad.

b. Nuwo-mu i-gini.

thought-2SG.IA 3SG-write(TR)

You lie.

Other body parts are also used in idiomatic expressions.

(24) a. O-gu i-kai.

body-1SG.IA 3SG-tired

I don't like it.

b. Ate-da i-yova.

liver-1PL.INC.IA 3SG-fly

We were worried/af raid.

c. Gamo-na i-goyo.

stomach-3SG.IA 3SG-be.bad

$\mathrm{He}$ is mad.

\section{TEXTS}

Two texts are given below. The first is by Kalitoni Gaiyau of Nubogeta Island, and is a traditional narrative entitled Sipwena. The second is a narrative of recent events by Bunore, also of Nubogeta.

\subsection{TEXT 1: SIPWENA}

Xoroto tayamo yoina

koloto tai-mo yoi-na

Sipwena, tauyana maniuna

man one-only name-3SG.IA Sipwena person-REF-3SG COM-sib.opp.sex-3SG.IA

sikayaxa

si-kaiaka

3PL-live

There was a man whose name was Sipwena who lived with his sister.

$\begin{array}{llll}\text { Sinadi } & \text { be tamadi } & \text { bogina } & \text { sikamasa. } \\ \text { sina-di } & \text { be tama-di } & \text { bogina } & \text { si-kamas } \\ \text { mother-3PL.IA and father-3PL.IA } & \text { PRF } & \text { 3PL-die } \\ \text { Their mother and father had died. } & & \end{array}$
Ago kina maniuna
ago kina ma-niu-na
sikayaxa aditaiyuwo

$\begin{array}{lll}\text { adikasa } & \text { yoina } & \text { Moninita. } \\ \text { a-di-kasa } & \text { yoi-na } & \text { Moninita }\end{array}$

PASS-3PL-place name-3PL.IA Moninita

But he and his sister lived, the two of them at their place called Moninita. 


$\begin{array}{lllll}\text { Sikayaxa, } & \text { niuna } & \text { inai } & \text { monena } & \text { doxanikani. } \\ \text { si-kaiaka } & \text { niu-na } & \text { i-nai } & \text { mone-na } & \text { dokanikani } \\ \text { 3PL-remain } & \text { sib.opp.sex-3SG.IA } & \text { 3SG-marry } & \text { spouse-3SG.IA } & \text { giant } \\ \text { They lived on and his sister married; } & \text { her husband was a giant. }\end{array}$

$\begin{array}{lllll}\text { Doxanikaniyana inaxasa } & \text { xoya, } & \text { aseana } & \text { yoina } & \text { Ayona. } \\ \text { dokanikani-ia-na } \text { i-na-kasa } & \text { koia } & \text { kasa-ia-na } & \text { yoi-na } & \text { Aiona } \\ \text { giant-REF-3SG CON-3SG-place } & \text { mountain } & \text { place-REF-3SG name-3SG.IA Ayona } \\ \text { The giant's place was on a mountain the name of which was Ayona. } & \end{array}$

$\begin{array}{llllll}E & \text { vavineana } & \text { ituko } & \text { ina } & \text { doxanikani inaxasa } & \text { goi } \\ e & \text { vavina-ia-na } & \text { i-tuko } & \text { i-na } & \text { dokanikani } \text { i-na-kasa } & \text { goi } \\ \text { DEV } & \text { woman-REF-3SG } & \text { 3SG-ascend } & \text { 3SG-go giant } & \text { CON-3SG-place } & \text { PP }\end{array}$

sikaiaxa.

si-kaiaka

3PL-live

So the woman ascended to the giant's place where they lived.

$\begin{array}{lllll}\text { Ago } & \text { Sipweneana } & \text { aneta } & \text { Moninita goi ikayaxo. } \\ \text { ago } & \text { Sipwena-ia-na } & \text { a-na-ita } & \text { Moninita goi i-kaiaka } \\ \text { SW } & \text { Sipwena-REF-3SG } & \text { PASS-3SG-LIM } & \text { Moninita } & \text { PP } \\ \text { 3SG-live }\end{array}$

But Sipwena lived by himself at Moninita.

$\begin{array}{lllllll}\text { Laveana } & \text { bogina } & \text { vavina } & \text { inai, } & \text { doxanikani } & \text { ivatowo } & \text { bei iyana } \\ \text { lava-ia-na } & \text { bogina } & \text { vavina } & \text { i-nai } & \text { dokanikani } & \text { i-vatowo bei iian } \\ \text { time-REF-3SG } & \text { PRF } & \text { woman } & \text { 3SG-marry giant } & \text { 3SG-begin } & \text { PRO fish }\end{array}$

ilusala.

i-lusala

3SG-look.for

When the woman had married, the giant began to look for fish.

$\begin{array}{llllll}\text { E } & \text { lava tayamo } & \text { inaxabela } & \text { xonanina } & \text { ikabidi, } & \text { isou } \\ \text { e } & \text { lava taia-mo } & \text { i-na-kabela } & \text { konan-i-na } & \text { i-kabi-di } & \text { i-sou }\end{array}$

DEV time one-only CON-3SG-fish thing-?-3SG.IA 3SG-take-3PL 3SG-descend

ima negwasa.

i-ma neguas

3SG-come ocean

So on one occasion he took he fishing gear and came down to the ocean.

$\begin{array}{llllll}\text { Inakewou } & \text { ikayaxa } & \text { aolao } & \text { Sipwena } & \text { inavada } & k i k i n a . \\ \text { i-na-keuou } & \text { i-kaiaka } & \text { kaolao } & \text { Sipwena } & \text { i-na-vada } & k i k i-n a \\ \text { CON-3SG-canoe } & \text { 3SG-remain } & \text { slip } & \text { Sipwena } & \text { CON-3SG-house } & \text { next-3SG.IA }\end{array}$ His canoe was on a slip next to Sipwena's house.

E doxanikani-yana isou.

e dokanikani-ia-na i-sou

DEV giant-REF-3SG 3SG-descend

So the giant went down. 
$\begin{array}{llllll}\text { Isou, } & \text { ima } & \text { idigo } & \text { xana, } & \text { "Ivagu, } & \text { xaga } \\ \text { i-sou } & \text { i-ma } & \text { i-diga } & \text { ka-na } & \text { iva-gu } & \text { kaga } \\ \text { 3SG-descend } & \text { 3SG-come } & \text { 3SG-say } & \text { talk-3SG } & \text { brother.in.law-1SG.IA } & \text { what }\end{array}$

kuvavaiva?".

$k u$-RDP-va

2SG-IMPER-do

He came down and said, "Brother-in-law, what are you doing?".

"Geya, a:хауаха",

Sipwena xaena.

geia a:-kaiaka

Sipwena ka-e-na

NEG 1SG.IMPER-be.there Sipwena talk-OI-3SG.IA

"Nothing, I'm just sitting here", said Sipwena.

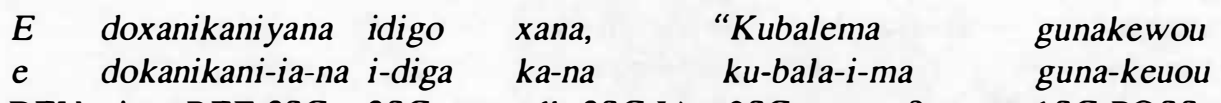

DEV giant-REF-3SG 3SG-say talk-3SG.IA 2SG-across-?-come 1SG.POSS-canoe

talusobuye ana axabela".

ta-lu-sobu-ia-i a-na a-kabela

1PL.INC-lift-down-OAD-TR 1SG-go 1SG-fish

Then the giant said, "Come here; let's launch my canoe so I can go fishing".

E Sipwena ibala ina, doxanikaniyana idigo xana,

e Sipwena i-bala i-na dokanikani-ia-na i-diga ka-na

DEV Sipwena 3SG-across 3SG-go giant-REF-3SG 3SG-say talk-3SG.IA

"Kuna kewou matakubuna kukibode".

ku-na keuou matakubu-na ku-ki-boda-i

2SG-go canoe bow-3SG.IA 2SG-by.hand-block-TR

So Sipwena went across and the giant said, "Go and hold the bow of the canoe".

$\begin{array}{lllll}\text { E } & \text { Sipwena } & \text { iiwo } & \text { ina } & \text { pusa goi iyoita. } \\ \text { e } & \text { Sipwena } & \text { i-iva } & \text { i-na } & \text { pusa goi i-ioit }\end{array}$

DEV Sipwena 3SG-seaward 3SG-go bow PP 3SG-hold

So Sipwena moved seaward to the bow, where he held on.

Iyoita, doxanikaniyana imeyava xana, "Kupi yamam kupi

i-ioit dokanikani-ia-na i-meiav ka-na kupi yama-mu kupi

3SG-hold giant-REF-3SG 3SG-magic talk-3SG.IA ? ?-2SG ?

kaikemu kupaa butuu".

kaike-mu kupaa butuu

?-2SG ? ?

He held on and the giant did magic and said, "[giant's language: not translatable]".

E Sipwena ikapusi isou, ikanabalabala naxae nawala.

e Sipwena i-kapusi i-sou i-kana-RDP-bala nakae naual

DEV Sipwena 3SG-fall 3SG-descend 3SG-by.lay-IMPER-across same slip.support

Then Sipwena fell down and lay horizontal like a slip support pole. 
Ago doxanikaniyana kewou ivaseseli $\begin{array}{lll}\text { ina } & \text { isou } & \text { negwasa. } \\ \text { i-na } & \text { i-sou } & \text { neguas }\end{array}$

ago dokanikani-ia-na keuou i-va-seseal-i

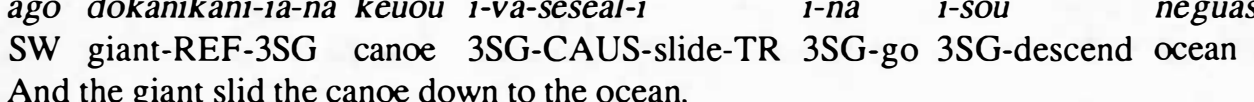
And the giant slid the canoe down to the ocean.

$\begin{array}{lllllll}\text { E } & \text { kina } & \text { Sipwena } & \text { imeyava } & \text { xana, } & \text { "Soinu yamagu } & \text { soinu kaikegu } \\ \text { e } & \text { kina } & \text { Sipwena } & \text { i-meiav } & \text { ka-na } & \text { soinu yama-gu } & \text { soinu kaike-gu } \\ \text { DEV } & \text { 3SG.PN } & \text { Sipwena } & \text { 3SG-magic } & \text { talk-3SG.IA } & \text { ? } & \text { ?-ISG ? }\end{array}$
sososoinusoinu".

sososoinusoinu

?

Then Sipwena did magic and said, "[magic formula: not translatable]".

$\begin{array}{llllll}\text { E } & \text { Sipweneana } & \text { itaoya } & \text { isapinunuwo, } & \text { ibala } & \text { ina } \\ \text { e } & \text { Sipwena-ia-na } & \text { i-taoia } & \text { i-sapi-nunuv } & \text { i-bala } & \text { i-na } \\ \text { DEV Sipwena-REF-3SG } & \text { 3SG-stand.up } & \text { 3SG-slap-brush } & \text { 3SG-across } & \text { 3SG-go } \\ \text { inavada } & \text { isiu } & \text { ikayaxa. } & & \\ \text { i-na-vada } & \text { i-siu } & \text { i-kaiaka } & & \\ \text { CON-3SG-house } & \text { 3SG-enter } & \text { 3SG-remain }\end{array}$

Then Sipwena stood up to brush himself and crossed over to his house, entered it and remained there.

Kina go doxanikani ina ikabela.

kina go dokanikani i-na i-kabela.

3SG.PN SW giant 3SG-go 3SG-fish

Now the giant went fishing.

Ikabela, lavilavi bogina ima ivayu.

i-kabela lavilavi bogina i-ma i-vaiu

3SG-fish evening PRF 3SG-come 3SG-arrive

He fished, and in the evening he arrived back.

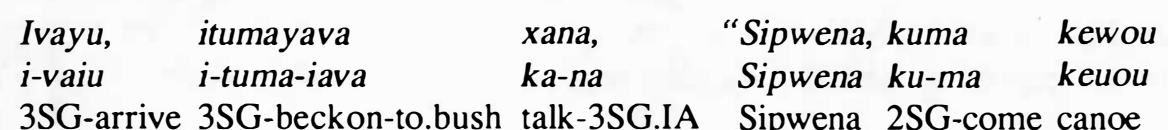

tayagasi".

ta-iagat-i

IPL.INC-beach-TR

He arrived and he beckoned to the shore, "Sipwena, come let's beach the canoe".

Sipwena ibala ina, doxanikaniyana idigo xana, "Kuna

Sipwena i-bala i-na dokanikani-ia-na i-diga ka-na ku-na

Sipwena 3SG-across 3SG-go giant-REF-3SG 3SG-say talk-3SG.IA 2SG-go

kewou matakubuna kukibode".

keuou matakubu-na ku-ki-boda-i

canoe bow-3SG.IA 2SG-by.hand-block-TR

Sipwena crossed over and the giant said, "Go and hold the bow of the canoe". 


\section{E Sipwena ina pusa goi iyoita. \\ e Sipwena i-na pusa goi i-ioit}

DEV Sipwena 3SG-go bow PP 3SG-hold

So Sipwena went to the bow, where he held on.

Iyoita, doxanikani-yana imeyava xana, "Kupi yamamu kupi

i-ioit dokanikani-ia-na i-meiav ka-na kupi yama-mu kupi

3SG-hold giant-REF-3SG 3SG-magic talk-3SG.IA ? ?-2SG ?

kaikemu kupaa butuu".

kaike-mu kupaa butuu

?-2SG ? ?

He held on and the giant did magic and said, "[giant's language: not translatable]".

E Sipwena ikapusi isou, ikanabalabala.

e Sipwena i-kapusi i-sou i-kana-RDP-bala

DEV Sipwena 3SG-fall 3SG-descend 3SG-by.lie-IMPER-across

Then Sipwena fell down and lay horizontal.

$\begin{array}{lllll}\text { Ago doxanikaniyana } & \text { kewou } & \text { ivaseseli } & \text { ina } & \text { mamaya. } \\ \text { ago dokanikani-ia-na } & \text { keuou } & \text { i-va-sesal-i } & \text { i-na } & \text { mamaia } \\ \text { SW giant-REF-3SG canoe } & \text { 3SG-CAUS-slide-TR } & \text { 3SG-go shore } \\ \text { And the giant slid the canoe down to the shore. } & & \end{array}$

$\begin{array}{lllllll}\text { E } & \text { Sipwena } & \text { kina } & \text { imeyava } & \text { xana, } & \text { "Soinu yamagu soinu } \\ \text { e } & \text { Sipwena } & \text { kina } & \text { i-meiav } & \text { ka-na } & \text { soinu yama-gu soinu } \\ \text { DEV } & \text { Sipwena } & \text { 3SG.PN } & \text { 3SG-magic talk-3SG.IA ? } & \text { ?-1SG ? }\end{array}$

kaikegu sososinusoinu".

kaike-gu sososinusoinu

?-1SG ?

Then Sipwena did magic and said, "[magic formula: not translatable]".

Sipwena itaoya, idigo xana, "Ivagu, amiyana

Sipwena i-taoia i-diga ka-na iva-gu a-mu-iiana

Sipwena 3SG-stand.up 3SG-say talk-3SG.IA brother.in.law-1SG.IA EAT-2SG-fish

go, golao moe giyaina kuvinigu ana agabu".

go golao moe giiai-na ku-vini-gu a-na a-gabu

SW fish.name that small-3SG 2SG-give-1SG 1SG-go 1SG-roast

Sipwena stood up and said, "Brother-in-law, it's your fish but give me a little of that golao and I will go roast it".

Doxanikaniyana idigo xana, "Geya, ame go, nium

dokanikani-ia-na i-diga ka-na geia ame go niu-mu

giant-REF-3SG 3SG-say talk-3SG.IA NEG this SW sib.opp.sex-2SG.IA

nunuona go ame".

nunuo-na go ame

desire-3SG.IA SW this

The giant said, "No, as for this one, your sister wants this one". 
"O, dedevina tuwo.

o dedevi-na tuua

"Oh fine, that's fine.

Go sem, pakiki moe giyaina kuvinigu ana agabu." go semu pakiki moe giiai-na ku-vini-gu a-na a-abu

SW however fish.name that small-3SG 2SG-give-1SG 1SG-go 1SG-roast However, give me that small pakiki and I will go and roast it."

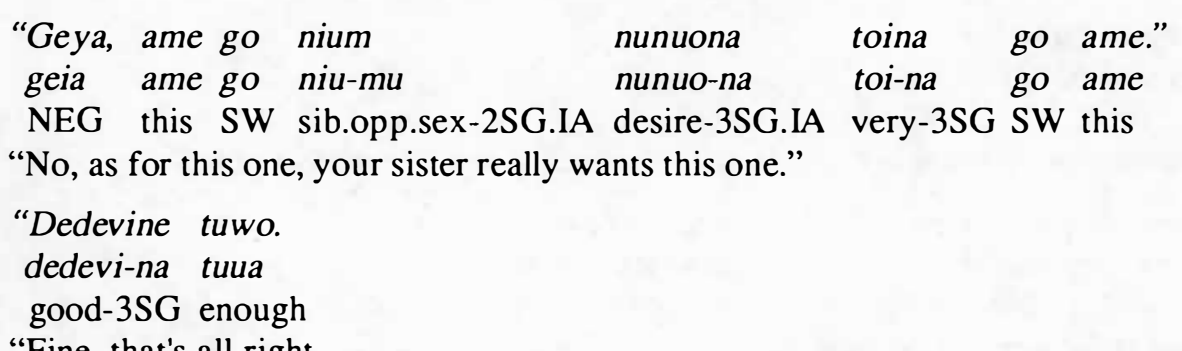

"Fine, that's all right.

Go sem, moe ammoku kudabedi go, bulubuludi kuvinigu go semu moe a-mu-moku ku-daba-i-di go bulubulu-di ku-vini-gu

SW however that EAT-2SG-bait 2SG-cut-TR-3PL SW head-3PL.IA 2SG-give-1SG

ana boxoyo axaigabu."

a-na bokoio a-kai-gabun

1SG-go necessitate 1 SG-set-roast

But those there are your bait; cut them and give me the heads and I will even go and roast them."

$\begin{array}{llll}\text { "Geya, ame go, nium } & \text { nunuona } & \text { toina } & \text { toina go ame." } \\ \text { geia ame go niu-mu } & \text { nunuo-na } & \text { toi-na }\end{array}$

NEG this SW sib.opp.sex-2SG.IA desire-3SG.IA very-3SG very-3SG SW this "No, as for this, your sister really really wants this.'

E Sipwena nukotona itopa.

e Sipwena nukoto-na i-ta-upa

DEV Sipwena neck-3SG.IA 3SG-ST-break

So Sipwena gave up.

Ibala ina inavada isiu.

i-bala i-na i-na-vada i-siu

3SG-across 3SG-go CON-3SG-house 3SG-enter

He crossed to his house and went in.

Geya tayamo xaga ikayaxa bei ikaika.

geia taia-mo kaga i-kaiaka bei i-kaika

NEG one-only what 3SG-remain PRO 3SG-meal

There was not one thing remaining for him to eat.

$\begin{array}{llll}\text { Avana } & \text { tauna nona } & \text { kewoina. } \\ \text { kava-na } & \text { tauna nona } & \text { keuo-i-na } \\ \text { food-3SG.IA that's.it } & \text { fruit.name fruit-?-3SG.IA } \\ \text { His food was only the fruit of the nona. }\end{array}$


Tayamo ikabi ikani, imasisi.

taia-mo i-kabi i-kani i-masisi

one-only 3SG-get 3SG-eat 3SG-sleep

He got one to eat then slept.

Doxanikaniyana anaiyana ikavala ituko ina monena.

dokanikani-ia-na a-na-iian i-kavala i-tuko i-na mone-na

giant-REF-3SG EAT-3SG-fish 3SG-carry 3SG-ascend 3SG-go spouse-3SG.IA

The giant carried his fish up to his wife.

Ina monena, iyana ivini ivaipolu.

i-na mone-na iian i-vini i-vai-polu

3SG-go spouse-3SG.IA fish 3SG-give 3SG-CAUS-boil

He went to his wife, and he gave her the fish for her to boil.

$\begin{array}{lll}\text { Ivaipolu, } & \text { ivameo } & \text { ivaideda. } \\ \text { i-vai-polu } & \text { i-va-meva } & \text { i-vai-deda }\end{array}$

3SG-CAUS-boil 3SG-CAUS-cook 3SG-CAUS-serve

She boiled and cooked it, then she dished it out.

$\begin{array}{lllllll}\text { Idigo } & \text { xana, } & \text { "Toi } & \text { kuma } & \text { memeya } & \text { kumataxavate } & \text { go, yau } \\ \text { i-diga } & \text { ka-na } & \text { toi } & \text { ku-ma } & \text { memeia } & \text { ku-mata-kavata-i } & \text { go iau } \\ \text { 3SG-say } & \text { talk-3SG.IA } & \text { man } & \text { 2SG-come baby } & \text { 2SG-with.eye-hold-TR } & \text { go } & \text { 1SG.PN } \\ \text { ana } & \text { Sipwena } & \text { avana } & \text { avini". } & & \\ \text { a-na } & \text { Sipwena } & \text { kava-na } & \text { a-vini } & & \\ \text { 1SG-go } & \text { Sipwena } & \text { food-3SG.IA } & \text { 1SG-give } & & \end{array}$

She said, "Hey, come and watch the baby and I will go give Sipwena his food".

Go kina doxanikaniyana idigo xana, "I kwayaxamo.

ago kina dokanikani-ia-na i-diga ka-na i ku-kaiaka-mo

SW 3SG.PN giant-REF-3SG 3SG-say talk-3SG.IA hey 2SG-stay-only

But the giant said, "Hey, you just stay.

$\begin{array}{lllllll}\text { Kume } & \text { yau } & \text { toinigu } & \text { anava } & \text { xom } & \text { bei } & \text { govila } \\ \text { ku-ma-i } & \text { iau } & \text { toini-gu } & \text { a-nava-i } & \text { komu } & \text { bei } & \text { govila }\end{array}$

2SG-come-TR 1SG.PN REFL-1SG 1SG-take-TR 2SG.PN PRO lest

kwaimumuna memeya itaiya.

ku-kaimumuna memeia i-taiia

2SG-be.slow baby 3SG-cry

Bring it so I can take it myself lest you are slow and the baby cries.

Kume, yau xoroto aegu ponaponaina ana avini”.

ku-ma-i iau koloto kae-gu ponapona-i-na a-na a-vini

2SG-come-TR 1SG.PN man leg-1SG.IA fast-?-3SG 1SG-go 1SG-give

Bring it and I who am a man with fast legs will go and give it to him".

E doxanikaniyana noxo ikavale isou.

e dokanikani-ia-na noko i-kavala-i i-sou

DEV giant-REF-3SG wood.plate 3SG-carry-TR 3SG-descend

So the giant carried the plate down. 
$\begin{array}{llllll}\text { Isou } & \text { ima } & \text { ima } & \text { aaa } & \text { kenao tolobona } & \text { goi awoinu ikani. } \\ \text { i-sou } & \text { i-ma } & \text { i-ma } & \text { aaa } & \text { kenao tolobo-na goi kauoinu i-kani }\end{array}$ 3SG-descend 3SG-come 3SG-come until path middle-3SG PP food 3SG-eat He went down and down until half way down the path he ate the food.

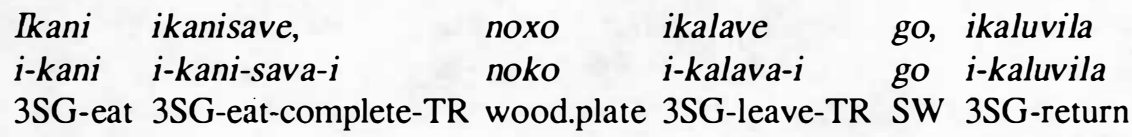

monena goi avadi sikaika.

mone-na goi kava-di si-kaika

spouse-3SG.IA PP food-3PL 3PL-meal

He ate it and he finished it, then left the plate and retumed to his wife where they ate their food.

Sikaika ikavava, simasisi.

si-kaika i-kavava si-masisi

3PL-meal 3SG-be.finished 3PL-sleep

After they ate, they slept.

$\begin{array}{llll}\text { Vavina inanuwonuwona xana, } & \text { "Bogina niugu } & \text { ikaika". } \\ \text { vavina i-na-nuuonuuona ka-na } & \text { bogina niu-gu } & \text { i-kaika } \\ \text { woman CON-3SG-think talk-3SG.IA PRF sib.opp.sex-1SG.IA 3SG-meal }\end{array}$

The woman was thinking, "My brother has eaten".

Go geya, awoinuyadi doxanikani ikanidi.

ago geia kauoinu-ia-di dokanikani i-kani-di

SW NEG food-REF-3PL giant 3SG-eat-3PL

But that was not the case; the giant had eaten the food.

E simasisi, vanuwo itomo naxae.

e si-masisi vanuuo i-tomo nakae

DEV 3PL-sleep place 3SG-be.next.day same

So they slept, and the next day it was the same.

Doxanikaniyana inapaisewa abela.

dokanikani-ia-na i-na-paiseua kabela

giant-REF-3SG CON-3SG-work fish

The giant's work was fishing.
Lava liliuna
inonoina
ikabela.
lave liliu-na
i-nonoi-na
i-kabela
time many-3SG.IA 3SG-IMPER-go 3SG-fish
Many times he went fishing.
Ago ima, tayamo sinapuyana; iyana Sipwena ikawanoi, geya
ago i-ma taia-mo sinapu-ia-na iian Sipwena i-kauanoi geia
SW 3SG-come one-only habit-REF-3SG fish Sipwena 3SG-beg NEG
ivinivini.

i-RDP-vini

3SG-IMPER-give

But he came, and one of his customs was that when Sipwena would ask for fish, he would never give any to him. 
Niga go lavilavi sivaipolu avana, naxae.

niga go lavilavi si-vai-polu kava-na nakae

afterwards SW evening 3PL-CAUS-boil food-3SG.IA same

Afterwards, in the evening they would cook their foods, and it was the same.

$\begin{array}{llllll}\text { Doxanikaniyana } & \text { ikabidi } & \text { imedi } & \text { kenao } & \text { tolobona } & \text { goi } \\ \text { dokanikani-ia-na } & \text { i-kabi-di } & \text { i-ma-i-di } & \text { kenao } & \text { tolobo-na } & \text { goi } \\ \text { giant-REF-3SG } & \text { 3SG-get-3PL } & \text { 3SG-come-TR-3PL } & \text { path } & \text { middle-3SG.IA } & \text { PP }\end{array}$

$\begin{array}{lllll}\text { ikanidi } & \text { go, Sipwena manaloga } & \text { imasisi } & \text { lava badabadaina. } \\ \text { i-kani-di } & \text { go Sipwena ma-a-na-loga } & \text { i-masisi } & \text { lava badabada-i-na }\end{array}$

3SG-eat-3PL SW Sipwena COM-PASS-3SG-hunger 3SG-sleep time many-?-3SG.IA

The giant took them and went half way down the path where he ate them, and Sipwena went to sleep hungry many times.

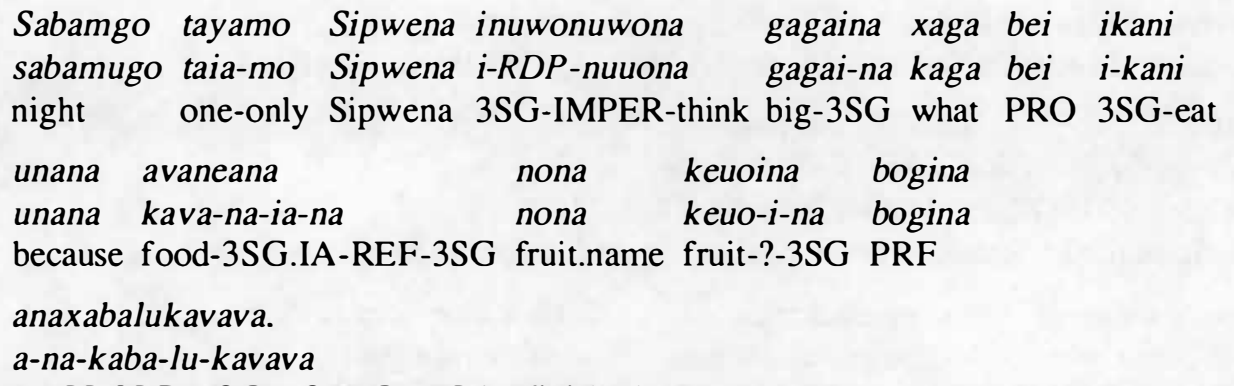

PASS-3SG-LOC.NOM-CAUS-be.finished

One night Sipwena was thinking a lot about what he would eat because his food, the fruit of the nona, had come to an end.

Tayamo toito ikayaxo, bei nobuyana ikani, ikavava.

taia-mo toito i-kaiaka bei nobuiana i-kani i-kavava

one-only only 3SG-remain PRO moming 3SG-eat 3SG-be.finish

Only one remained and he would eat it in the moming, and it would be finished.

$\begin{array}{llll}\text { Sipwena inanamsa xana, } & \text { "O apoikiki be } & \text { asa ame axalave } \\ \text { Sipwena i-nanamus ka-na } & o \text { a-poikiki be } & \text { kasa ame a-kalava-i }\end{array}$

Sipwena 3SG-think talk-3SG.IA oh 1SG-try UNCRT place this 1SG-leave-TR

$\begin{array}{lll}\text { ana } & \text { alusala } & \text { avagu. } \\ \text { a-na } & \text { a-lusala } & \text { kava-gu }\end{array}$

1SG-go 1SG-search.for food-1SG.IA

Sipwena thought, "Oh, I will try to leave this place in order to go and look for my food.

Govila akayaxa amexo, bei amasa ababane”.

govila a-kaiaka ame-ko bei kamas a-babana-i

lest ISG-stay this-PLA-ADV PRO die 1SG-meet-TR

If I remain here, I am going to meet death".

Nobuyana itaoya, inakudula ivakau.

nobuiana i-taoia i-na-kudula i-vakau

morning 3SG-get.up CON-3SG-spear 3SG-tie

In the morning he got up and tied his spear. 
Ivakau go, doxanikaniyana bogina isou ima.

i-vakau go dokanikani-ia-na bogina i-sou i-ma

3SG-tie SW giant-REF-3SG PRF 3SG-descend 3SG-come

He tied it, but the giant had come down.

Idigo xana, "Ivagu, kuma gunakewou

i-diga ka-na iva-gu ku-ma guna-keuou

3SG-say talk-3G.IA brother.in.law-1SG.IA 2SG-come 1SG.POSS-canoe

talusobuye".

ta-lu-sobu-ia-i

1PL.INC-CAUS-down-OAD-TR

He said, "My brother-in-law, come and let's launch my canoe".

Go Sipwena idigo xana, "Siagu, anuwe geya

ago Sipwena i-diga ka-na sia-gu a-nuua-i geia

SW Sipwena 3SG-say talk-3SG.IA friend-1SG.IA 1SG-think-TR NEG

itoboineguta bei avaitem.

i-toboina-i-gu-ita bei a-vaita-i-mu

3SG-possible-TR-1SG-LIM PRO 1SG-help-TR-2SG

But Sipwena said, "My friend, I don't think it is possible for me to help you.

$\begin{array}{lll}\text { Maliyalina manawena } & \text { bogina avaitemu } & \text { go, aika geya. } \\ \text { maliialina manave-na } & \text { bogina a-vaita-i-mu } & \text { go kaika geia }\end{array}$

day long-3SG.IA PRF 1SG-help-TR-2SG SW meal NEG

For a long time I have helped, but with no food.

Gunatogaga madaboikina bogina ikavava”.

guna-togaga madaboiki-na bogina i-kavava

1SG.POSS-strong all-3SG.IA PRF 3SG-be.finished

All of my strength has finished".

$\begin{array}{llllll}\text { Doxanikaniyana } & \text { ibolagu } & \text { idigo } & \text { xana, } & \text { "Kuma, iyana aika } \\ \text { dokanikani-ia-na } & \text { i-bolagu } & \text { i-diga } & \text { ka-na } & \text { ku-ma } & \text { iian kaika } \\ \text { giant-REF-3SG } & \text { 2SG-rebuke } & \text { 3SG-say } & \text { talk-3SG.IA } & \text { 2SG-come fish meal }\end{array}$

naxae ae?

nakae ae

same TM

The giant rebuked him and said, "Come, (you don't want) fish like (you don't want)

food, right?

Poila bomadi go, xoxaobodaboda kuma!".

poila boma-di go ko-kao-RDP-boda ku-ma

hunt forbidden-3PL.IA SW 2PL-by-mouth-IMPER-block 2SG-come

All hunting is forbidden and so stop answering back and come!".

Sipwena bogina ikawowoteya gagaina toina go, tuwo

Sipwena bogina i-ka-uouo-teia gagai-na toi-na go tuua

Sipwena PRF 3SG-INCH-body-tire big-3SG very-3SG SW NONDEV 
ipoikikina ina ivaite.

i-poikikin i-na i-vaita-i

3SG-try 3SG-go 3SG-help-TR

Sipwena was really tired out but he tried anyway and went to help him.

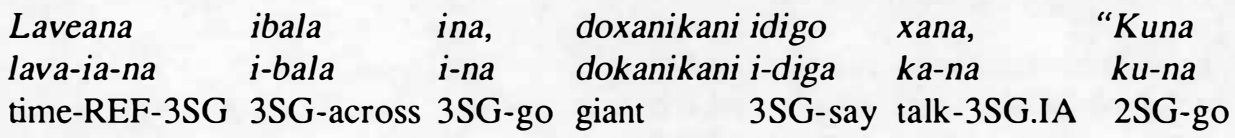

kewou matakubuna kukibode".

keuou matakubu-na ku-ki-boda-i

canoe bow-3SG.IA 2SG-by.hand-block-TR

When he went over, the giant said, "Go and hold the bow of the canoe".

E Sipwena iiwo ina pusa goi iyoita.

e Sipwena i-iva i-na pusa goi i-ioit

DEV Sipwena 3SG-seaward 3SG-go bow PP 3SG-hold

So Sipwena moved seaward to the bow, where he held on.

Iyoita, doxanikaniyana imeyava xana, "Kupi yamam kupu

i-ioit dokanikani-ia-na i-meiav ka-na kupi yama-mu kupu

3SG-hold giant-REF-3SG 3SG-magic talk-3SG.IA ? ?-2SG ?

kaikem kupaa butuu".

kaike-mu kupaa butuu

?-2SG ? ?

He held on and the giant did magic saying, "[giant's language: not translatable]".

E Sipwena ikapusi isou, i-kanabalabala naxae nawala.

e Sipwena i-kapusi i-sou i-kana-RDP-bala nakae naual

DEV Sipwena 3SG-trip 3SG-descend 3SG-by.lie-IMPER-across same slip.support Then Sipwena fell down and lay horizontally like a slip support pole.
Ago doxanikaniyana kewou ivaseseli
ina isou
negwasa.
ago dokanikani-ia-na keuou i-va-sesal-i
i-na i-sou
neguas

SW giant-REF-3SG canoe 3SG-CAUS-slide-TR 3SG-go 3SG-descend ocean But the giant slid the canoe down to the ocean.
E kina
Sipwena imeyava xana,
$\begin{array}{lllllll}\text { e } & \text { kina } & \text { Sipwena } & \text { i-meiav } & \text { ka-na } & \text { soinu iama-gu soinu kaike-gu } \\ \text { DEV } & \text { 3SG.PN } & \text { Sipwena 3SG-magic } & \text { talk-3SG.IA ? ?-1SG ? ?-1SG }\end{array}$
$\begin{array}{lllllll}\text { e } & \text { kina } & \text { Sipwena i-meiav } & \text { ka-na } & \text { soinu iama-gu soinu kaike-gu } \\ \text { DEV } & \text { 3SG.PN } & \text { Sipwena 3SG-magic talk-3SG.IA ? ?-1SG ? ?-1SG }\end{array}$
$\begin{array}{lllllll}\text { e } & \text { kina } & \text { Sipwena } & \text { i-meiav } & \text { ka-na } & \text { soinu iama-gu soinu kaike-gu } \\ \text { DEV } & \text { 3SG.PN } & \text { Sipwena 3SG-magic } & \text { talk-3SG.IA ? ?-1SG ? ?-1SG }\end{array}$
"Soinu yamagu soinu kaikegu sososoinusoinu".

sososoinusoinu

?

Then Sipwena did magic saying, "[magic formula: not translatable]".

$\begin{array}{llllll}\text { E } & \text { Sipweneana } & \text { itaoya } & \text { isapinunuwo, } & \text { ibala } & \text { ina } \\ \text { e } & \text { Sipwena-ia-na } & \text { i-taoia } & \text { i-sapi-nunuv } & \text { i-bala } & \text { i-na } \\ \text { DEV } & \text { Sipwena-REF-3SG } & \text { 3SG-stand.up } & \text { 3SG-slap-brush } & \text { 3SG-across } & \text { 3SG-go }\end{array}$




$\begin{array}{llll}\text { inagabula } & \text { isiu, } & \text { anakudula } & \text { ivaxau. } \\ \text { i-na-gabula } & \text { i-siu } & \text { a-na-kudula } & \text { i-vakau }\end{array}$

CON-3SG-under.house 3SG-enter PASS-3SG-spear 3SG-tie

Then Sipwena got up and brushed himself off and went across to the under part of the house, went in and tied his spear.

Kina go doxanikaniyana ina ikabela.

kina go dokanikani-ia-na i-na i-kabela

3SG.PN SW giant-REF-3SG 3SG-go 3SG-fish

As for the giant, he went fishing.

E kina go vavina inuwonuwona xana, "Yau apoikiki

e kina go vavina i-RDP-nuwona ka-na iau a-poikiki

DEV 3SG.PN SW woman 3SG-IMPER-think talk-3SG.IA ISG.PN ISG-try

be ana Sipwena avadade.

be a-na Sipwena a-va-dada-i

UNCRT ISG-go Sipwena 1SG-by.foot-unseen-TR

But as for the woman, she was thinking, "I will try and go visit Sipwena.

Xaga unana noxo geya i:memedi?

kaga una-na noko geia i:-ma-ma-i-di

what base-3SG.IA wood.plate NEG 3SG.IMPER-RDP-come-TR-3PL

Why is he not bringing back the wooden plates?

Noxo naxo iyatoidi?".

noko nako i-iata-i-di

wood.plate where 3SG-put-TR-3PL

Where did he put them?".

E vavina awoinu ituwomate, natuna ikabi, awoinuyana

e vavina kauoinu i-tuuomata-i natu-na i-kabi kauoinu-ia-na

DEV woman food 3SG-mash-TR offspring-3SG.IA 3SG-take food-REF-3SG

ikavale isou ima Sipwena igite.

i-kavala-i i-sou i-ma Sipwena i-gita-i

3SG-carry-TR 3SG-descend 3SG-come Sipwena 3SG-see-TR

So the woman mashed food, took her child and carried the food down to see Sipwena.

Ago Sipwena bogina ikatubayasi, bei iketoiya.

ago Sipwena bogina i-katubaiasin bei i-ketoiia

SW Sipwena PRF 3SG-prepare PRO 3SG-walk

But Sipwena had prepared and was about to walk.

Kina vavina iketoiya.

kina vavina i-ketoiia

3SG woman 3SG-walk

As for the woman, she walked.

Iketoiya, isowodo idoiwo Sipwena igite konana

i-ketoiia i-souoduva i-do-iva Sipwena i-gita-i kona-na

3SG-walk 3SG-appear 3SG-with.head-seaward Sipwena 3SG-see-TR thing-3SG.IA 
katubayasi.

katubaiasi

prepare

She walked and when she arrived she looked towards the ocean and saw Sipwena preparing his things.

Idigo xana, "Sipwena naxo kuna bei?".

i-diga ka-na Sipwena nako ku-na bei

3SG-say talk-3SG.IA Sipwena where 2SG-go PRO

She said, "Where are you going?".

"Geya, ana dobala avayali."

geia a-na dobala a-vaiali

NEG 1SG-go there 1SG-walk.on.shore

"Nowhere, I will go walking along the shore over there."

"Ae?

ae

TM

"Is that right?

$O$ dedevina.

o dedevi-na

oh good-3SG

$\mathrm{Oh}$, that is fine.

Kuma avam goame.

ku-ma kava-mu go-ame

2SG-come food-2SG LOC.ADV-this

Come, here is your food.

Kwaika go, kuna kuvayali."

ku-kaika go ku-na ku-vaiali

2SG-meal SW 2SG-go 2SG-walk.on.shore

Eat, then go walk on the shore."

Sipwena idigo xana, "Tuwo, avami xonave xoxani".

Sipwena i-diga ka-na tuua kava-mi ko-nava-i ko-kani

Sipwena 3SG-say talk-3SG.IA enough food-2PL.IA 2PL-take-TR 2PL-eat

Sipwena said, "That's all right, you take your food and eat it".

"Xaga pasina?"

kaga pasi-na

what reason-3SG

"Why?"

"Geya, tuwo avami go, yau ame bogina bei ana avagu geia tuua kava-mi go iau ame bogina bei a-na kava-gu

NEG enough food-2PL SW 1SG.PN today PRF PRO 1SG-go food-1SG.IA 
$\begin{array}{ll}\text { alusala } & \text { axaika. } \\ \text { a-lusala } & \text { a-kaika }\end{array}$

1SG-search.for 1SG-meal

"Nothing, that's all right, it's your food and I'm already going today to look for my food to eat.

$\begin{array}{lllll}\text { Monem } & \text { taiyao avami } & \text { xoxaxaika } & \text { go, aguloga } \\ \text { mone-mu } & \text { taiiao } & \text { kava-mi } & \text { ko-RDP-kaika } & \text { go a-gu-loga } \\ \text { spouse-2SG.IA COM food-2PL.IA } & \text { 2PL-IMPER-meal } & \text { SW PASS-1SG-hunger } \\ \text { amasisi. } & & & & \\ \text { a-masisi } & & & & \end{array}$

1SG.sleep

You and your husband eat your food together but I go to sleep hungry.

Gunanona bogina ikavava.

guna-nona bogina i-kavava

1SG.POSS-fruit.name PRF 3SG-be.finished

My nona fruit is all gone.

Ame aketoiya ana avagu alusala."

ame a-ketoiia a-na kava-gu a-lusala

today 1SG-walk 1SG-go food-1SG.IA 1SG-search.for

Today I will go and look for my food."

"Ago lava liliuna doxanikani manoxoidi

ago lava liliu-na dokanikani ma-noko-i-di

SW time many-3SG.IA giant COM-wood.plate-?-3PL

i:memedi, naxo xo:yatoidi?"

i:-ma-ma-i-di nako ko:-iata-i-di

3SG.IMPER-RDP-come-TR-3PL where 2PL.IMPER-put-TR-3PL

"But every time the giant brought the plates, where did you put them?"

$\begin{array}{lll}\text { "Sekidi } & \text { aminoxo, } & \text { avami. } \\ \text { seki-di } & \text { a-mi-noko } & \text { kava-mi } \\ \text { don't.know-3PL } & \text { PASS-2PL-wood.plate } & \text { food-2PL.IA } \\ \text { "I don't know, they are your wooden plates, your food. }\end{array}$

Yau avagu nona keuwoina bogina ikavava.

iau kava-gu nona keuua-i-na bogina i-kavava

1SG.PN food-1SG.IA fruit fruit-?-3SG.IA PRF 3SG-be.finished

My food which is the fruit of the nona is all finished.

$\begin{array}{llllll}\text { Tauna } & \text { bei } & \text { aketoiya ana } & \text { avagu } & \text { alusala." } \\ \text { tauna } & \text { bei } & \text { a-ketoiia a-na } & \text { kava-gu } & \text { a-lusala }\end{array}$

RESULT PRO 1SG-walk 1SG-go food-1SG.IA 1SG-search.for

Therefore I am going to go look for my food.

$\begin{array}{lllll}\text { E } & \text { xoroto itaoya, } & \text { inakudula } & \text { ikavale, } & \text { iketoiya ivatabale. } \\ \text { e } & \text { koloto i-taoia } & \text { i-na-kudula } & \text { i-kavala-i } & \text { i-ketoiia } \\ \text { i-vata-bala-i }\end{array}$

DEV man 3SG-stand.up CON-3SG-spear 3SG-carry-TR 3SG-walk 3SG-?-across-TR

So the man stood up, carried his spear and walked across. 
Niuna itaiya mlina $\quad$ iketoiya manatuna.

niu-na i-taiia muli-na i-ketoiia ma-natu-na

sib.opp.sex-3SG.IA 3SG-cry behind-3SG.IA 3SG-walk COM-offspring-3SG.IA

His sister cried, walking behind him with her child.

$\begin{array}{llllll}\text { Xoroto ikanidovila } & \text { igitedi } & \text { idigo } & \text { xana, } & \text { "I: } & \text { kwaluvila } \\ \text { koloto } \text { i-kanido-vila } & \text { i-gita-i-di } & \text { i-diga } & \text { ka-na } & \text { ii } & \text { ku-kaluvila }\end{array}$

man 3SG-with.head-tum 3SG-see-TR-3PL 3SG-say talk-3SG.IA hey 2SG-retum

The man looked back and saw them, he said, "Hey, go back.
Doiyagu
kwaluvile
gunaloseyana be mligu
doiya-gu
ku-kaluvila-i guna-loseyana be muli-gu
nephew-1SG.IA 2SG-return-TR 1SG-POSS-heir and behind-1SG.IA
xosaku:rikuri xoxapusi gomana ivatumate".
ko-sakulikuli ko-kapusi gomana i-vatu-mata-i

2PL-follow.IMPER 2PL-fall child 3SG-by.falling-die-TR

Return my nephew, my heir. If you follow me and you fall, the child will die".

$\begin{array}{llllllc}\text { Ago iya } & \text { vavina } & \text { itaiya, } & \text { xana, } & \text { "O niugu, } & \text { kuma } \\ \text { ago iia } & \text { vavina } & \text { i-taiia } & \text { ka-na } & \text { o niu-gu } & \text { ku-ma } \\ \text { SW 3SG.PN } & \text { woman } & \text { 3SG-cry } & \text { talk-3SG.IA oh sib.opp.sex-1SG.IA } & \text { 2SG-come } \\ \text { taxaluvila } & \text { tana } & \text { asa tayamo goi xoroto tayamo anai } & \text { bei } \\ \text { ta-kaluvila } & \text { ta-na } & \text { kasa taia-mo goi koloto taia-mo a-nai } & \text { bei } \\ \text { 1PL.INC-return } & \text { 1PL.INC-go place one-only PP man one-only 1SG-marry PRO }\end{array}$

moexo taxayaxa".

moe-ko ta-kaiaka

that-PLA.ADV 1PL.INC-live

But the woman cried and said, "Oh, my brother, come and let's retum to a place where I will marry a man and there we will live".

Xoroto idigo xana, "Geya, tuwo, xowo doxanikani xogite be koloto i-diga ka-na geia tuua ko-va dokanikani ko-gita-i be man 3SG-say talk-3SG.IA NEG enough 2PL-go giant 2PL-see-TR UNCRT

ima igita geya govila ima ikanimi.

i-ma i-gita geia govila i-ma i-kani-mi

3SG-come 3SG-see NEG otherwise 3SG-come 3SG-eat-2PL

The man said, "No, enough, go and see the giant in order that he comes and sees or otherwise he will come and eat you.

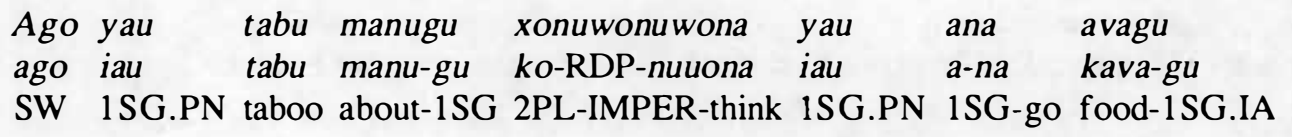

alusala.

a-lusala

1SG-look.for

And it is taboo for you to think about me as I go to look for my food. 


$\begin{array}{llllll}\text { Neta } & \text { awoinu } & \text { xovinigu } & \text { axaxaika, } & \text { taxaiyaxa } & \text { go, unana } \\ \text { neta } & \text { kauoinu } & \text { ko-vini-gu } & \text { 1-RDP-kaika } & \text { ta-kaiaka } & \text { go unana } \\ \text { if } & \text { food } & \text { 2PL-give-1SG } & \text { 1SG-IMPER-meal } & \text { 1PL.INC-remain } & \text { SW because } \\ \text { monem } & \text { taiyao imisinapu } & \text { igoyo, } & \text { avami } & \text { amiiyana } \\ \text { mone-mu } & \text { taiiao } & \text { i-mi-sinapu } & \text { i-goyo } & \text { kava-mi } & \text { a-mi-iian } \\ \text { spouse-2SG.IA COM } & \text { CON-2PL-habit } & \text { 3SG-be.bad food-2PL.IA } & \text { EAT-2PL-fish } \\ \text { xovagagalaxoigu. } & & & & \end{array}$

ko-vagagal-ko-i-gu

2PL-withhold-DIR-TR-1SG

If you gave me food to eat, we would stay, but because you and your husband's custom is bad, you withhold your food which is your fish.

$\begin{array}{llll}\text { Tauna, } & \text { avagu } & \text { alusala } & \text { taxasa". } \\ \text { tauna } & \text { kava-gu } & \text { a-lusala } & \text { ta-kasa }\end{array}$

therefore food-1SG.IA 1SG-search.for different-place

Therefore, I will look for my food in another place".

$\begin{array}{lllll}\text { Vavina itaiya } & \text { isaki, } & \text { geya xoroto idigo } & \text { xana, } \\ \text { vavina i-taiia } & \text { i-saki } & \text { geia koloto i-diga } & \text { ka-na } \\ \text { woman } & \text { 3SG-cry } & \text { 3SG-too.much } & \text { NEG man } & \text { 3SG-say talk-3SG.IA } \\ \text { "Kubalema } & \text { ataoimi". } & & & \\ \text { ku-bala-i-ma } & \text { a-tao-i-mi } & & & \end{array}$

2SG-across-?-come 1SG-delouse-TR-2PL

The woman cried a lot, so the man said, "Come here, and I will delouse you".

Sima i:taoidi.

si-ma 1:-tao-i-di

3PL-come 3SG.IMPER-delouse-TR-3PL

They came and he deloused them.
I:taoidi
simasisi, ikalavedi
go itaoya
i:-tao-i-di
si-masisi i-kalava-i-di
go i-taoia

3SG.IMPER-delouse-TR-3PL 3PL-sleep 3SG-leave-TR-3PL SW 3SG-stand.up

iketoiya.

i-ketoiia

3SG-walk

While he deloused them, they fell asleep; he left them and he stood up and walked.

$\begin{array}{llll}\text { Iketoiya } & \text { Magama idoiwo } & \text { iyana dabatupuna igite } \\ \text { i-ketoiia } & \text { Magama i-do-iva } & \text { iian dabatupuna i-gita-i } \\ \text { 3SG-walk } & \text { Magama 3SG-with.head-seaward fish fish.name } & \text { 3SG-see-TR }\end{array}$

imeyava idigo xana, "E mwako kuduridi yakudukudura yanabwa yanabwa i-meiav i-diga ka-na e mwako kuduridi yakudukudura yanabwa yanabwa 3SG-magic 3SG-say talk-3SG.IA ? ? ? ? ? 
kudurudi yakudukudura saiya sagegege gayave sagegege.

kudurudi yakadukudura saiya sagegege gayave sagegege

?

?

? ?

?

He walked to Magama and saw a fish which was a dabatupuna and he did magic saying, "[magic formula: not translatable]".

$\begin{array}{lllll}\text { Xaimolamola sinam } & \text { taiyao xoma } & \text { amiiyana } & \text { xoxabi } & \text { xoxaluvila". } \\ \text { Kaimolamola sina-mu } & \text { taiiao ko-ma } & \text { a-mi-iian } & \text { ko-kabi } & \text { ko-kaluvila }\end{array}$

Kaimolamola mother-2SG.IA COM 2PL-come EAT-2PL-fish 2PL-take 2PL-retum

Kaimolamola and your mother, come and get your fish and go back".

Gomana yoina xaimolamola.

gomana yoi-na Kaimolamola

child name-3SG.IA Kaimolamola

The child's name was Kaimolamola.

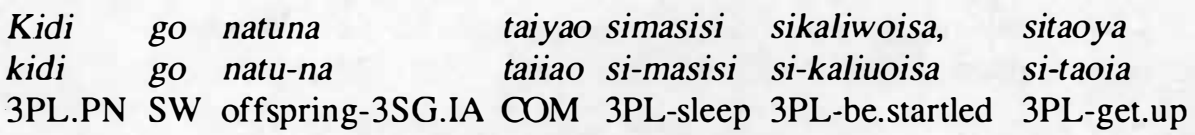

sidobala Gaugaunava, siloxoina.

si-do-bala Gaugaunava si-lokovina

3PL-with.head-across Gaugaunava 3PL-run

As for child and mother who slept, they were startled awake; they stood up and looked across to Gaugaunava and they ran.

$\begin{array}{llll}\text { Si:loxoina, } & \text { si:loxoina, } & \text { idobala } & \text { igitedi } \\ \text { si:-lokovina } & \text { si:-lokovina } & \text { i-do-bala } & \text { i-gita-i-di } \\ \text { 3PL.IMPER-run } & \text { 3PL.IMPER-run } & \text { 3SG-with.head-across } & \text { 3SG-see-TR-3PL }\end{array}$

ituyaosidi.

i-tuiauat-i-di

3SG-wait-TR-3PL

While they were running and running, he looked across and saw them so he waited for them.

$\begin{array}{llllll}\text { Ituyaosidi } & \text { sima } & \text { idigo } & \text { xana, } & \text { "Xoma } & \text { amiiyana } \\ \text { i-tuiauat-i-di } & \text { si-ma } & \text { i-diga } & \text { ka-na } & \text { ko-ma } & \text { a-mi-iian } \\ \text { 3SG-wait-TR-3PL } & \text { 3PL-come } & \text { 3SG-say } & \text { talk-3SG.IA } & \text { 2PL-come } & \text { EAT-2PL-fish }\end{array}$

xoxabi xoxaluvila.

ko-kabi ko-kaluvila

2PL-take 2PL-return

He waited for them to come and said, "Come and get your fish and go back.

$\begin{array}{lllllll}\text { Vanuwo luwaya } & \text { analava } & \text { bei } & \text { aem } & \text { ilabasi } & \text { gomana } \\ \text { vanuuo } & \text { luuaia } & \text { a-na-lava } & \text { bei } & k a e-m u & \text { i-labasi } & \text { gomana } \\ \text { place } & \text { high-tide } & \text { PASS-3SG-time } & \text { PRO leg-2SG } & \text { 3SG-hit child }\end{array}$

kwalisobuye negwasa goi bei inim".

ku-kali-sobu-ia-i neguas goi bei i-nimu

2SG-?-down-OAD-TR ocean PP PRO 3SG-drink

It is time for high tide and it will hit your leg and you will drop the child in the ocean where he will drown". 
Sibala sima itaoidi.

si-bala si-ma i-tao-i-di

3PL-across 3PL-come 3SG-delouse-TR-3PL

They came over and he deloused them.

$\begin{array}{lll}\text { I:taoidi, } & \text { i:taoidi, } & \text { simasisi. } \\ \text { i:-tao-i-di } & \text { i:-tao-i-di } & \text { si-masisi }\end{array}$

3SG-IMPER-delouse-TR-3PL 3SG.IMPER-delouse-TR-3PL 3PL-sleep

He deloused and deloused them, so they slept.

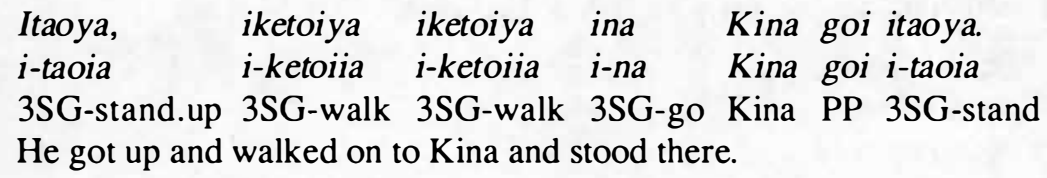

$\begin{array}{lllll}\text { Iiwoiwo } & \text { mayava imeyava, } & \text { "E } & \text { mwako kuduridi yakudukudura } \\ \text { i-RDP-iva } & \text { maiav } & \text { i-meiav } & \text { e } & \text { mwako kuduridi yakudukudura } \\ \text { 3SG-IMPER-seaward point } & \text { 3SG-magic } & ?\end{array}$

yanabwa yanabwa kuduridi yakudukudura saiye sagegege sayava sagegege.

yanabwa yanabwa kuduridi yakudukudura saiye sagegege sayave sagegege

? ? ? ? ? ? ?

He went to the point and he did magic saying, "[magic formula: not translatable]".

Xaimolamola eee xoma.

Kaimolamola eee ko-ma

Kaimolamola VOC 2PL-come

Kaimolamola, come.

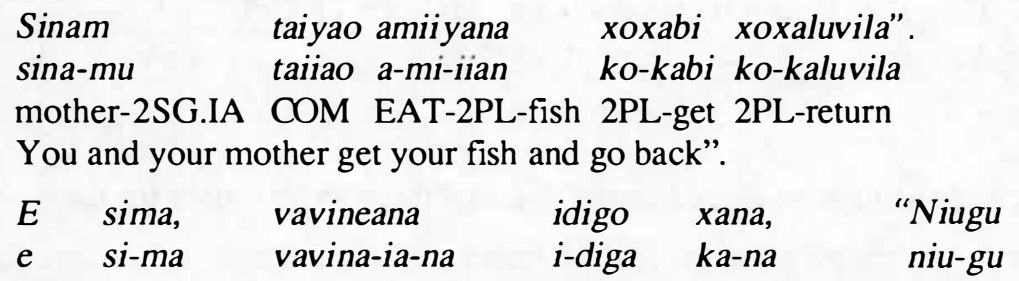

DEV 3PL-come woman-REF-3SG 3SG-say talk-3SG.IA sib.opp.sex-1SG.IA

boxoyo kuma taxaluvila tana idaxasa".

must 2SG-come 1PL.INC-retum 1PL.INC-go CON-1PL.INC-place

So they came and the woman said, "My brother, you must come and we can return to a different place".
Xorotoyana idigo xana,
koloto-ia-na i-diga ka-na
"Geya, niugu
kwalavegu.
man-REF-3SG 3SG-say talk-3SG.IA
geia niu-gu
ku-kalava-i-gu
The man said, "No my sister, leave me.
NEG sib.opp.sex-1SG.IA 2SG-leave-TR-1SG

\begin{tabular}{|c|c|c|c|}
\hline $\begin{array}{l}\text { Tuwo, } \\
\text { tuua }\end{array}$ & $\begin{array}{l}\text { ana } \\
\text { a-na }\end{array}$ & $\begin{array}{l}\text { avagu } \\
\text { kava-gu }\end{array}$ & $\begin{array}{l}\text { alusala. } \\
\text { a-lusala }\end{array}$ \\
\hline gh & ISG-go & food-1SG.IA & \\
\hline
\end{tabular}




$\begin{array}{lllll}\text { Amexo } & \text { taxayaxa } & \text { xada, } & \text { 'Imisinapu } & \text { dedevina' } \\ \text { ame-ko } & \text { ta-kaiaka } & k a-d a & i-m i-s i n a p u & \text { dedevi-na } \\ \text { this-PLA.ADV } & \text { 1PL.INC-remain } & \text { talk-1PL.INC.IA } & \text { CON-2PL-habit } & \text { good-3SG }\end{array}$

xaeda. Ame imisinapu igoyo govila axayaxa bei

ka-e-da ame i-mi-sinapu i-goio govila a-kaiaka bei

talk-OI-1PL.INC.IA this CON-2PL-habit 3SG-be.bad lest 1SG-remain PRO

axamasa".

a-kamas

1SG-die

If we were to say, 'Your custom is good', then we could say, 'We stay here together'. But your custom is bad, and if I stay I will die".

$\begin{array}{llll}\text { E } & \text { situsobu } & \text { go, itaoidi. } \\ \text { e } & \text { si-tu-sobu } & \text { go i-tao-i-di }\end{array}$

DEV 3PL-by.sit-down SW 3SG-delouse-TR-3PL

So they sat down and he deloused them.
I:taoidi
i:taoidi
simasisi.
i:-tao-i-di
i:-tao-i-di
si-masisi

3SG.IMPER-delouse-TR-3PL 3SG-IMPER-delouse-TR-3PL 3PL-sleep

He deloused and deloused them to sleep.
Ago itaoya iketoiya.
ago i-taoia i-ketoiia
SW 3SG-get.up 3SG-walk

And he got up and walked on.

$\begin{array}{llll}\text { Iketoiya } & \text { Nauweta mayaina } & \text { goi itaoya } & \text { itaiya. } \\ \text { i-ketoiia } & \text { Nauueta maiav-i-na } & \text { goi } i \text {-taoia } & \text { i-taiia }\end{array}$

3SG-walk Nauweta point-?-3SG.IA PP 3SG-stand 3SG-cry

He walked to the point of Nauweta where he stood and cried.

$\begin{array}{llllll}\text { Kidi } & \text { go } & \text { simasisi } & \text { sikaliwoisa } & \text { sitaoya, } & \text { sidobala } \\ \text { kidi } & \text { go } & \text { si-masisi } & \text { si-kaliuoisa } & \text { si-taoia } & \text { si-do-bala } \\ \text { 3PL.PN } & \text { SW } & \text { 3PL-sleep } & \text { 3PL-be.startled } & \text { 3PL-stand.up } & \text { 3PL-with.head-across }\end{array}$

sigite mayava goi Gaugaunava.

si-gita-i maiav goi Gaugaunava

3PL-see-TR point PP Gaugaunava

As for the two who slept, they were startled awake, they stood up and looked across and saw him at the point which was Gaugaunava.

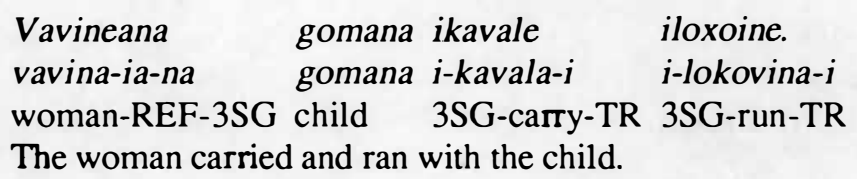

Iloxoine ime

i-lokovina-i i-ma-i

3SG-run-TR 3SG-come-TR

She ran and brought him. 
$\begin{array}{lllll}\text { Ime } & \text { kikina } & \text { goi xorotoyana } & \text { idigo } & \text { xana, } \\ \text { i-ma-i } & k i k i-n a & \text { goi koloto-ia-na } & \text { i-diga } & \text { ka-na }\end{array}$

3SG-come-TR next.to-3SG.IA PP man-REF-3SG 3SG-say talk-3SG.IA

$\begin{array}{cccc}\text { "A } & \text { yau } & \text { muligu } & \text { xosaku:rikuri. } \\ \text { a } & \text { iau } & \text { muli-gu } & \text { ko-sakurikuri }\end{array}$

hey 1SG.PN behind-1SG.IA 2PL-follow.IMPER

She brought him right to him and the man said, "Hey, you are following behind me.

Yau bei oga asowoya xaeda adodoimi.

iau bei oga a-souoia ka-e-da a-dodo-i-mi

1SG.PN PRO canoe 1SG-embark talk-OI-1PL.INC.IA 1SG-load-TR-2PL If I said that I would embark on a canoe, then I would load you.

Ame bei gunaoga ituli.

ame bei guna-oga i-tuli

today PRO 1SG.POSS-canoe 3SG-be.different

Today my canoe is different.

Amexo goi xoxaluvila.

ame-ko goi ko-kaluvila

here-PLA.ADV PP 2PL-return

Go back from here.

Yau gunamayava goamo.

iau guna-maiav go-amo

1SG.PN 1SG.POSS-point LOC.ADV-there

My point is over there.

Amoxo goi bei asowoya".

amo-ko goi bei a-souoia

there-PLA.ADV PP PRO 1SG-embark

There I will embark".

Ago vavineana itaiya gagaina niuna manuna.

ago vavina-ia-na i-taiia gagai-na niu-na manu-na

SW woman-REF-3SG 3SG-cry big-3SG sib.opp.sex-3SG.IA about-3SG

But the woman cried a lot for her brother.

E itaoidi.

e $\quad$ i-tao-i-di

DEV 3SG-delouse-TR-3PL

So he deloused them.

I:taoidi

i:taoidi

i:-tao-i-di

i:-tao-i-di

3SG.IMPER-delouse-TR-3PL 3SG.IMPER-delouse-TR-3PL

itaomasimasisidi.

i-tao-RDP-masisi-di

3SG-delouse-IMPER-sleep-3PL

He deloused and deloused them and he deloused them to sleep. 


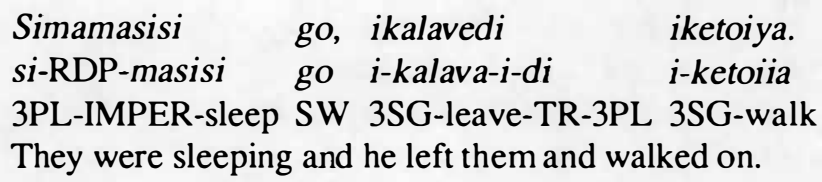

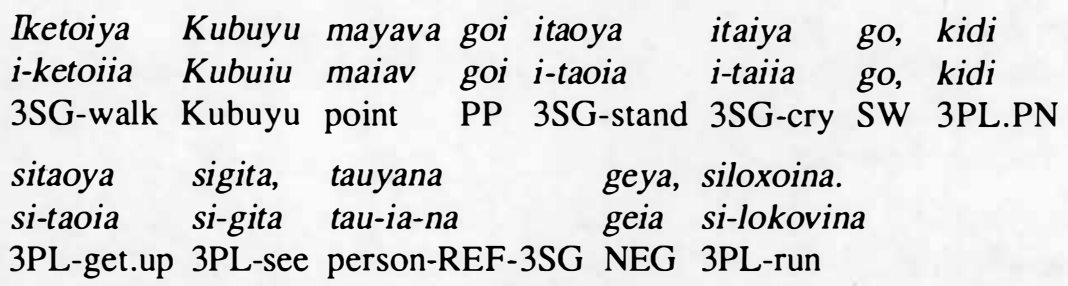

He walked to Kubuyu to the point where he stood and cried and as for them, they got up and looked but he was not here, and they ran.

$\begin{array}{lllll}\text { Si:loxoina } & \text { si-loxoina } & \text { bogina giyaxainava bei } & \text { kikina, } \\ \text { si:-lokovina } & \text { si:-lokovina } & \text { bogina giiakainava bei } & \text { kiki-na } \\ \text { 3PL.IMPER-run } & \text { 3PL.IMPER-run } & \text { PRF soon } & \text { PRO next.to-3SG.IA }\end{array}$

xorotoyana aiyuwoina itaiya.

koloto-ia-na ai-iuuo-i-na i-taiia

man-REF-3SG CL-two-?-3SG 3SG-cry

They ran and ran until they had just about reached him and the man again cried.

$\begin{array}{lllll}\text { Itaitaiya } & \text { go, inaogeana } & \text { ipoiya } & \text { moe iyana gagina. } \\ \text { i-RDP-taiia } & \text { go . i-na-oga-ia-na } & \text { i-poiia } & \text { moe iian gagai-na } \\ \text { 3SG-IMPER-cry } & \text { SW CON-3SG-canoe-REF-3SG } & \text { 3SG-surface that fish big-3SG }\end{array}$
He was crying and he canoe surfaced - it was a big fish.

$\begin{array}{llll}\text { Ipoiya, } & \text { ilokoina ima } & \text { go, vavineana } & \text { iloxoina. } \\ \text { i-poiia } & \text { i-lokovina i-ma } & \text { go vavina-ia-na } & \text { i-lokovina }\end{array}$

3SG-surface 3SG-run 3SG-come SW woman-REF-3SG 3SG-run

It surfaced and swam to him and the woman ran too.

Iyaniana iloxoina.

iian-ia-na i-lokovina

fish-REF-3SG 3SG-run

The fish swam.

$\begin{array}{ll}\text { Vavineana } & \text { iloxoina. } \\ \text { vavina-ia-na } & \text { i-lokovina } \\ \text { woman-REF-3SG } & \text { 3SG-run }\end{array}$

The woman ran.

$\begin{array}{ll}\text { Iyaniana } & \text { iloxoina. } \\ \text { iian-ia-na } & \text { i-lokovina }\end{array}$

fish-REF-3SG 3SG-run

The fish swam.

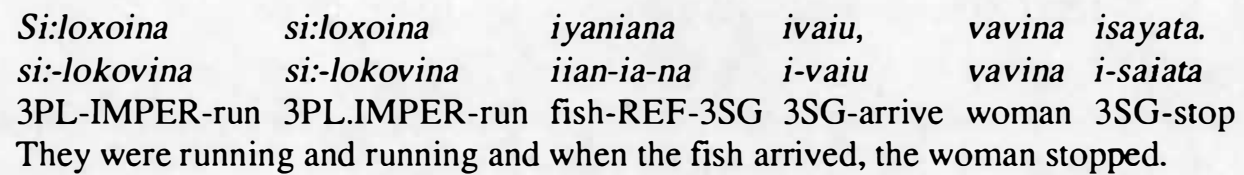


$\begin{array}{lllll}\text { Kina } & \text { xorotoyana } & \text { ipela } & \text { iyana yatana } & \text { itulaga. } \\ \text { kina } & \text { koloto-ia-na } & \text { i-pela } & \text { iian iata-na } & \text { i-tu-laga } \\ \text { 3SG.PN } & \text { man-REF-3SG } & \text { 3SG-jump fish on.top-3SG.IA } & \text { 3SG-by.sit-up } \\ \text { The man jumped on top of the fish and sat on it. } & \end{array}$

Vavineana ibisiiwo.

vavina-ia-na i-bisi-iva

woman-REF-3SG 3SG-by.touch-to.ocean

The woman reached towards the ocean.

Xorotoyana ibisigoyai.

koloto-ia-na i-bisi-goiav-i

man-REF-3SG 3SG-by.touch-be.bad-TR

She missed the man.

$\begin{array}{lllll}\text { Vavineana } & \text { itaiyamsimsi } & \text { go, iyaniana } & \text { bogina iloxina } \\ \text { vavina-ia-na } & \text { i-taiia-RDP-musi } & \text { go iian-ia-na } & \text { bogina i-lokovina } \\ \text { woman-REF-3SG } & \text { 3SG-cry-IMPER-hiccup } & \text { SW fish-REF-3SG PRF 3SG-run } \\ \text { niuneana } & \text { inave } & \text { go, kina } & \text { kanasipusipula } \\ \text { niu-na-ia-na } & \text { i-nava-i } & \text { go kina } & \text { i-kana-RDP-sipul } \\ \text { sib.opp.sex-3SG.IA-REF-3SG } & \text { 3SG-take-TR } & \text { SW 3SG.PN } & \text { 3SG-by.lie-IMPER-roll } \\ \text { imataiyina. } & & & & \\ \text { ma-taii-i-na } & & & & \end{array}$

COM-tear-?-3SG.IA

The woman sobbed but the fish had swam off. He had taken her brother and she rolled on the ground with her tears.

Bogina ikavava.

bogina i-kavava

PRF 3SG-be.finished

It is finished.

\subsection{TEXT 2}

Tiuside goi amexo

xaxailova eee xaloxoina

Tiuside goi ame-ko

ka-kai-lova eee ka-lokovina

Tuesday PP here-PLA.ADV 1PL.EXC-canoe-leave until 1PL.EXC-move

xaloxoina Xotoita xasobu.

ka-lokovina Kotoita ka-sobu

1PL.EXC-move Kotoita 1PL.EXC-down

On Tuesday we departed from here, moving to Kotoita where we brought the sail down:

Xasobu, xayava xana amatapwae

ka-sobu ka-iava ka-na a-ma-tapuae

1PL.EXC-down 1PL.EXC-to.bush 1PL.EXC-go EAT-1PL.EXC-tobacco 
$\begin{array}{llll}\text { xagimone } & \text { ikavava, } & \text { aiyuwoina } & \text { xaxawala. } \\ \text { ka-gimona-i } & \text { i-kavava } & \text { kai-iuuo-i-na } & \text { ka-kauala } \\ \text { 1PL.EXC-buy-TR } & \text { 3SG-be.finish } & \text { CL-two-?-3SG } & \text { 1PL.EXC-pole }\end{array}$

We brought down the sail, then after we had gone towards the bush to buy our tobacco, we again poled (the canoe).

$\begin{array}{llllll}\text { Xasowoya } & \text { xaxawala } & \text { xana } & \text { aaa, aiyuwoina } & \text { tayamo asa } \\ \text { ka-souoia } & \text { ka-kauala } & \text { ka-na } & \text { aaa } & \text { kai-iuuo-i-na taia-mo kasa } \\ \text { 1PL.EXC-embark } & \text { 1PL.EXC-pole } & \text { 1PL.EXC-go until } & \text { CL-two-?-3SG one-only place }\end{array}$

goi Baloina goi aiyuwoina xavayu.

goi Baloina goi kai-iuuo-i-na ka-vaiu

PP Baloina PP CL-two-?-3SG 1PL.EXC-land

We embarked and poled on to a place, to Baloina and again landed.

Xaxaiu, semao maniedi sisou sina,

ka-vaiu siia-ma-ao manie-di si-sou si-na

1PL.EXC-land friend-1PI.EXC.IA-PL some-3PL.IA 3PL-descend 3PL-go

maniema oga goi xaxayaxa.

manie-ma oga goi ka-kaiaka

some-1Pl.EXC.IA canoe PP 1PL.EXC-remain

We landed, then some of our friends got off and went, and some of us remained at the canoe.

Ikavava, sima sisowoya aiyuwoina xaxawala.

i-kavava si-ma si-souoia kai-iuuo-i-na ka-kauala

3SG-be.finish 3PL-come 3PL-embark CL-two-?-3SG 1PL.EXC-pole

After that, they came and embarked and we poled again.

Xaxawala xana aaa Nidula goi xaxailova.

ka-kauala ka-na aaa Nidula goi ka-kai-lova

1PL.EXC-pole 1PL.EXC-go until Nidula PP 1PL.EXC-canoe-leave

We poled on to Nidula, and we departed (again).

Xaxailova, xaloxoina xaloxoina aaa Wadeya goi

ka-kai-lova ka-lokovina ka-lokovina aaa Wadeia goi

1PL.EXC-canoe-leave 1PL.EXC-move 1PL.EXC-move until Wadeya PP

xasobu.

ka-sobu

1PL.EXC-down

We departed and sailed to Wadeya where we brought down our sail.

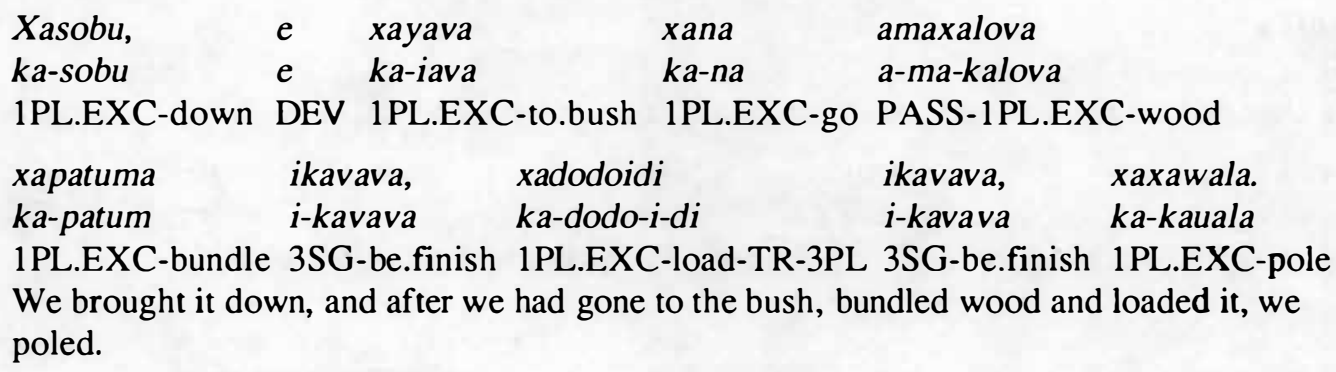


Xaxawala xana Wadarei goi xavaiu niyala bogina sabamgo.

ka-kauala ka-na Wadalei goi ka-vaiu niiala bogina sabamugo

1PL.EXC-pole 1PL.EXC-go Wadalei PP 1PL.EXC-land sun PRF night

We poled to Wadalei where we landed, and it was already dark.

\begin{tabular}{|c|c|c|c|c|}
\hline$E$ & xayava & xama & xavaipolu; & xaxaika \\
\hline$e$ & ka-iava & $k a-n a$ & ka-vai-polu & ka-kaika \\
\hline DEV & 1PL.EXC-to.bush & 1PL.EXC-come & 1PL.EXC-CAUS-boil & 1PL.EXC-eat \\
\hline & $\begin{array}{l}\text { xayava } \\
\text { ka-iava }\end{array}$ & $\begin{array}{l}\text { xana } \\
\text { ka-na }\end{array}$ & $\begin{array}{l}\text { minisita xagite. } \\
\text { minisita } k a-g i t a-1\end{array}$ & \\
\hline
\end{tabular}

3SG-be.finish 1PL.EXC-to.bush 1PL.EXC-go minister 1PL.EXC-see-TR

Then we came to the bush to cook; after we had eaten, we went to the bush to see the minister.

$\begin{array}{llllll}\text { Xagite, } & \text { xana, } & \text { "Vevina } & \text { xoma } & \text { amexo } & \text { vada goi } \\ \text { ka-gita-i } & \text { ka-na } & \text { vevina } & \text { ko-ma } & \text { ame-ko } & \text { vada goi } \\ \text { 1PL.EXC-see-TR } & \text { talk-3SG.IA } & \text { women } & \text { 2PL-come here-PLA.ADV house PP }\end{array}$

xomasisi”.

ko-masisi

2PL-sleep

We saw him, and he said, "You women come here, you will sleep at the house".

Go, vevina sikatae.

ago vevina si-katae

SW women 3PL-refuse.TR

But the women refused.

Sikatae, geya, e yau Opa Lanieta xayava xana

si-katae geia e iau Opa Lanieta ka-iava ka-na

3PL-refuse.TR NEG DEV 1SG.PN Opa Lanieta 1PL.EXC-to.bush 1PL.EXC-go

Opa sinana goi xamasisi.

Opa sina-na goi ka-masisi

Opa mother-3SG.IA PP 1PL.EXC-sleep

They refused, and instead Opa, Laniyeta and I went to the bush to Opa's mother's (place), where we slept.

Xamasisi, itomo nobuyana nave e Solo iwo

ka-masisi i-tomo nobuiana nava e Solo i-va

1PL.EXC-sleep 3SG-next.day morning later time Solo 3SG-go

iwoinima.

i-uoin-i-ma

3SG-awaken-TR-1PL.EXC

We slept and the next morning much later Solo came and woke us up.

$\begin{array}{lllll}\text { Iwoinima, } & \text { xataoya } & \text { xama } & \text { xana, } & \text { "Bei } \\ \text { i-uoin-i-ma } & \text { ka-taoia } & \text { ka-ma } & k a-n a & b e i \\ \text { 3SG-awaken-TR-1PL.EXC } & \text { 1PL.EXC-arise } & \text { 1PL.EXC-come } & \text { talk-3SG.IA } & \text { PRO }\end{array}$




$\begin{array}{ll}\text { xauwata } & \text { vayavaya". } \\ \text { xa-uuat } & \text { vaiavaia } \\ \text { 1PL.EXC-net } & \text { turtle }\end{array}$

He woke us up, so we got up and came and he said, "We are going to go turtle-netting".

E $\quad$ xana.

DEV 1PL.EXC-go

So we went.

Wenisde moexo goi xana aaa xabeuta xana

Weniside moe-ko goi ka-na aa ka-beut ka-na

Wednesday that-PLA.ADV PP 1PL.EXC-go until 1PL.EXC-paddle 1PL.EXC-go

nava mamaniwana.

nava mamaniuana

later dark

On Wednesday we paddled on from there; it was dark.

Sabamgo go, xabeuta xana.

sabamugo go ka-beut ka-na

night SW 1PL.EXC-paddle 1PL.EXC-go

It was night but we paddled on.

$\begin{array}{llll}\text { Xabeuta } & \text { xana } & \text { aaa amoxo, } & \text { dogoi goi manaxoyoina, } \\ \text { ka-beut } & k a-n a & \text { aaa amo-ko } & \text { dogoi goi manakoio-i-na } \\ \text { 1PL.EXC-paddle } & \text { 1PL.EXC-go until that-PLA.ADV thing PP called-?-3SG }\end{array}$

bogina xavailowana xaxayaxa go, bogina vanuwo itomotomo,

bogina ka-vailouan ka-kaiaka go bogina vanuuo i-RDP-tomo

PRF 1PL.EXC-anchor 1PL.EXC-remain SW PRF place 3SG-IMPER-next.day

e xabeuta.

e ka-beut

DEV 1PL.EXC-paddle

We paddled on to what's-its-name, we anchored and remained but it was already dawn, so we paddled on.

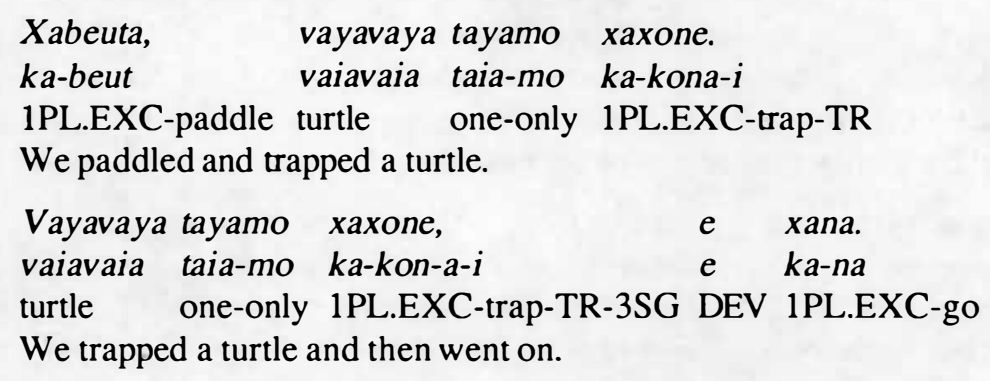

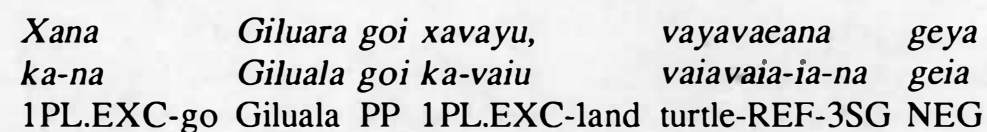


xagabuyeta

ka-gabu-ia-ita

1PL.EXC-roast-3SG-LIM NEG 1PL.EXC-set.down

We went to Giluwala where we landed; we didn't roast the turtle; instead we set it aside.
$\begin{array}{llllll}E & \text { xaxaiaxa } & \text { aaa } & \text { xavaipolu } & \text { xaxaika } & \text { ikavava, } \\ e & \text { ka-kaiaka } & \text { aaa } & \text { ka-vai-polu } & k a-k a i k a & i-k a v a v a\end{array}$

DEV 1PL.EXC-remain until 1PL.EXC-CAUS-boil 1PL.EXC-eat 3SG-be.finish

ka-kaiaka eee lavilavi e kai-iuuo-i-na ka-souoia-muna

1PL.EXC-remain until evening DEV CL-two-?-3SG 1PL.EXC-embark-again

Then we were there for a while and cooked and after we had eaten, we stayed there until evening, then we embarked again.

$\begin{array}{llll}\text { Xasowoyamna } & \text { aiyuwoina } & \text { xabeuta; } & \text { xaxaluvila } \\ \text { ka-souoia-muna } & \text { kai-iuuo-i-na } & \text { ka-beut } & \text { ka-kaluvila } \\ \text { 1PL.EXC-embark-again } & \text { CL-two-?-3SG } & \text { 1PL.EXC-paddle } & \text { 1PL.EXC-return }\end{array}$

xama.

ka-ma

1PL.EXC-come

We embarked again and again we paddled; we went back.

$\begin{array}{lllll}\text { Xama } & \text { Wadalei daiyana } & \text { goi xabeuta } & \text { xama } & \text { aaa } \\ \text { ka-ma } & \text { Wadalei daiia-na } & \text { goi ka-beut } & \text { ka-ma } & \text { aaa }\end{array}$

1PL.EXC-come Wadalei area-3SG.IA PP 1PL.EXC-paddle 1PL.EXC-come until

aiyuwoina iyana aiyuwoina tayamo xaxone.

kai-iuuo-i-na iian kai-iuuo-i-na taia-mo ka-kona-i

CL-two-?-3SG turtle CL-two-?-3SG one-only 1PL.EXC-trap-TR

We came to the Wadalei area where we paddled and again we trapped a second turtle.

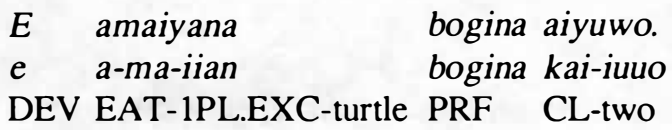

Then we had two turtles.

$\begin{array}{llll}\text { Xama } & \text { aaa } & \text { xavayu } & \text { sabamgo, iyana sigabu. } \\ \text { ka-ma } & \text { aaa } & \text { ka-vaiu } & \text { sabamugo iian si-gabu } \\ \text { 1PL.EXC-come time } & \text { 1PL.EXC-land night turtle } & \text { 3PL-roast } \\ \text { We came and landed at night, and they roasted one of the turtles. }\end{array}$

Tayamo sigabu, moe xai amaiyana.

taia-mo si-gabu-i moe kai a-ma-iian

one-only 3PL-roast-TR that 1PL.EXC.PN EAT-1PL.EXC-turtle

They roasted one, that was our turtle.
E sigabu ikavava, xavaipolu.
xaxaika ikavava,
e si-gabu i-kavava ka-vai-polu ka-kaika i-kavava
DEV 3PL-roast 3SG-be.finish 1PL.EXC-CAUS-boil 1PL.EXC-eat 3SG-be.finish 
xamasisi.

ka-masisi

1PL.EXC-sleep

Then after we had roasted it, we boiled it, and after we had eaten, we slept.

$\begin{array}{llllll}\text { Xamasisi, } & \text { itomo, } & \text { e } & \text { itomo } & \text { Teside, semao } \\ \text { ka-masisi } & \text { i-tomo } & \text { e } & \text { i-tomo } & \text { Teside } & \text { siia-ma-ao } \\ \text { 1PL.EXC-sleep } & \text { 3SG-next.day } & \text { DEV } & \text { 3SG-be.tomorrow } & \text { Thursday } & \text { friend-1PL.EXC-PL }\end{array}$

bogina vevina maniedi bogina sisowoduwo.

bogina vevina manie-di bogina si-souduva

PRF women some-3PL.IA PRF 3PL-arrive

We slept and the next day, Thursday, some of our women friends had arrived.

$\begin{array}{lllll}\text { Dabasima } & \text { dagameta } & \text { sisowoduwo, e } & \text { xatapwaroro. } \\ \text { da-basima } & \text { da-gameta } & \text { si-souoduva } & \text { e } & \text { ka-tapualolo } \\ \text { people.of-Basima people.of-Gameta } & \text { 3PL-arrive } & \text { DEV } & \text { 1PL.EXC-worship }\end{array}$

The people of Basima and Gameta arrived, and then we worshipped.

Nobuyana xasiu xatapwaroro, loina sisimana xadi, nobuiana ka-siu ka-tapualolo lovina si-simana ka-di

moming 1PL.EXC-enter 1PL.EXC-worship decide 3PL-report talk-3PL.IA

$\begin{array}{llllll}\text { "Ame bei } & \text { tasowoduwo, e } & \text { tana } & \text { tapaisewa". } \\ \text { ame bei } & \text { ta-souoduva } & \text { e } & \text { ta-na } & \text { ta-paiseua } \\ \text { today PRO } & \text { 1PL.INC-arrive } & \text { DEV } & \text { 1PL.INC-go } & \text { 1PL.INC-work }\end{array}$

In the moming we went in and worshipped, and they reported the decision saying, "Today we are going to go out, then we will go and work".

Valiwoga xapaisewa.

valivoga ka-paiseua

grave 1PL.EXC-work

We worked on the grave.

Josephine valiwogaina, e moe xana xapaisewa.

Josephine valivoga-i-na e moe ka-na ka-paiseua

Josephine grave-?-3SG.IA DEV that 1PL.EXC-go 1PL.EXC-work

Josephine's grave, it was that which we went and worked on.

Xapaisewa ikavava, e xama.

ka-paiseua i-kavava e ka-ma

1PL.EXC-work 3SG-be.finish DEV 1PL.EXC-come

After we had worked, we came back.

$\begin{array}{lllll}\text { Xaiwo } & \text { xama } & e & \text { vayavaya sigabu, } & \text { amaiyana. } \\ \text { ka-iva } & \text { ka-ma } & \text { e } & \text { vaiavaia si-gabu-i } & \text { a-ma-iian }\end{array}$

1PL.EXC-seaward 1PL.EXC-come DEV turtle 3PL-roast-TR EAT-1PL.EXC-turtle We returned to the beach, then we roasted the turtle, our turtle.

Sigabu ikavava, aiyuwoina xavaipolu.

si-gabu i-kavava kai-iuuo-i-na ka-vai-polu

3PL-roast 3SG-be.finish CL-two-?-3SG 1PL.EXC-CAUS-boil

After we had roasted it, again we boiled it. 


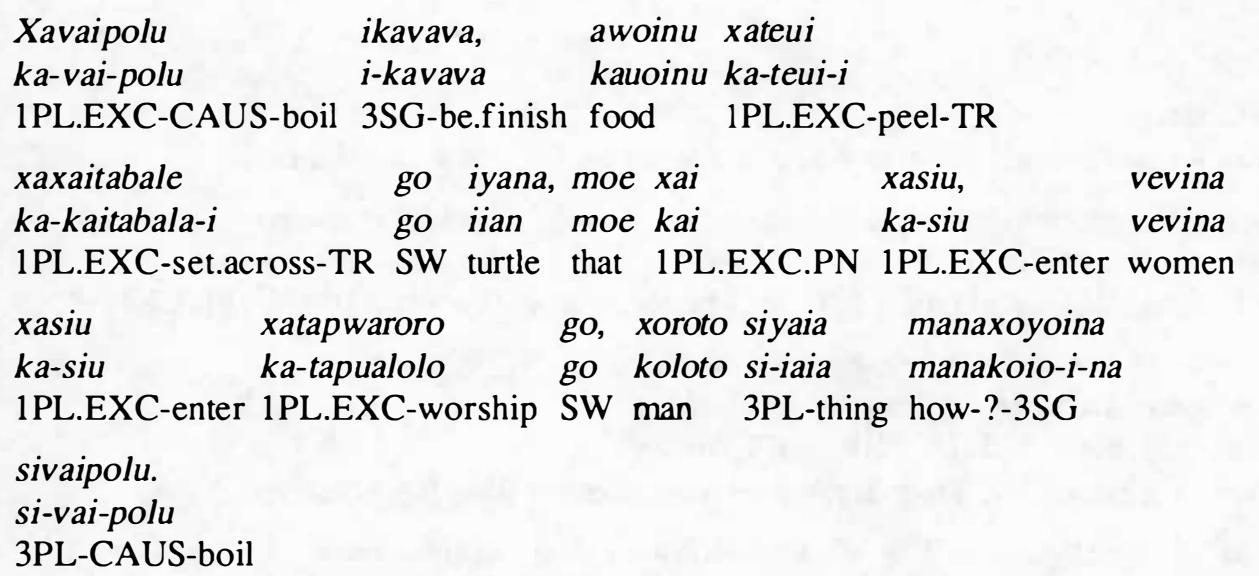

After we had cooked, we peeled the yams and set them aside and as for the turtle, we women went in and worshipped and the men cooked it.
Sivaipolu ikavava e xama.
si-vai-polu i-kavava e ka-ma
3PL-CAUS-boil 3SG-be.finish DEV 1PL.EXC-come
After they had boiled it, we came back.

$\begin{array}{llll}\text { Xai } & \text { xatapwaroro } & \text { ikavava, } & \text { dogoi vevina xaesinua } \\ \text { kai } & \text { ka-tapualolo } & \text { i-kavava } & \text { dogoi vevina ka-esinua }\end{array}$

1PL.EXC.PN 1PL.EXC-worship 3SG-be.finished thing woman 1PL.EXC-choose

dogoi sekiriteri xaesinue.

dogoi sekiliteli ka-esinua-i

thing secretary 1PL.EXC-choose-TR

After we had worshipped, the women chose something, they chose a secretary.

$\begin{array}{lll}\text { Xaesinue } & \text { ikavava, } & \text { xasowoduwo. } \\ \text { ka-esinua-i } & \text { i-kavava } & \text { ka-souoduva }\end{array}$

1PL.EXC-choose-TR 3SG-be.finished 1PL.EXC-appear

After we had chosen her, we came outside.

$\begin{array}{llll}\text { Xaesinue } & \text { Gameta vavinaina } & \text { xadi } & \text { Nebayodi, e } \\ \text { ka-esinua-i } & \text { Gameta vavina-i-na } & \text { ka-di } & \text { Nebayodi } \\ \text { 1PL.EXC-choose-TR Gameta woman-TR-3SG } & \text { talk-3PL.IA } & \text { Nebayodi } & \text { DEV }\end{array}$

$\begin{array}{lll}\text { moe tauyana } & i k a b i & \text { esinua. } \\ \text { moe tau-ia-na } & i-k a b i & \text { esinua } \\ \text { that person-REF-3SG } & \text { 3SG-get } & \text { choose }\end{array}$

We chose a woman from Gameta, they said Nebayodi; that one won the election.
E ikavava, xasowoduwo xama, dogoi awoinuyadi
e i-kavava ka-souoduva ka-ma dogoi kauoinu-ia-di

DEV 3SG-be.finished 1PL.EXC-exit 1PL.EXC-come thing food-REF-3PL

bogina simeo xavadeda.

bogina si-meva ka-va-deda

PRF 3PL-cook 1PL.EXC-CAUS-serve

Then after it was finished, we went out and we dished out the food which had been cooked. 
Xavadeda,

ka-va-deda

1PL.EXC-CAUS-serve

goi udi

vagana

goi udi

vaga-na

xayava

ka-iava

xama

ka-ma

minisita totomna

minisita totomu-na

1PL.EXC-to.bush

1PL.EXC-come minister doorway-3SG.IA

sitaupedi

simedi,

si-ta-upa-i-di

si-ma-i-di

siyeveidi ikavava, awoinuyadi xayatoidi

si-yeve-i-di

i-kavava

kauoinu-ia-di ka-iata-i-di

3PL-spread-TR-3PL 3SG-be.finished food-REF-3PL 1PL.EXC-put-TR-3PL

ikavava, e niyala bogina ina ikamamaniwana.

i-kavava e niiala bogina i-na i-ka-mamaniuana

3SG-be.finished DEV sun PRF 3SG-go 3SG-INCH-be.dark

We served, then we went toward the bush to the minister's doorway where, after they had laid out the branches which they had cut and brought, we set the food down. Then the sun had gone and it became dark.

$\begin{array}{llrl}E & \text { xadi, } & \text { "Xoma } & \text { taxaika". } \\ \text { e } & \text { ka-di } & \text { ko-ma } & \text { ta-kaika }\end{array}$

DEV talk-3PL.IA 2PL-come 1PL.INC-meal

Then they said, "Come, let's eat".
E xayava
xama,
xadi,
"Tamamiyao taiyao
e ka-iava
ka-ma
ka-di
tama-mi-yao taiiao
so 1PL.EXC-to.bush 1PL.EXC-come talk-3PL.IA father-2PL-PL COM
xoyava xoma".
ko-iava ko-ma

2PL-to.bush 2PL-come

So we came and they said, "Come with your fathers".

$\begin{array}{lllllll}\text { Ego xai } & \text { tamamao } & \text { maniedi } & \text { yuti, } & \text { e } & \text { siyava } & \text { sima } \\ \text { ego } k \text { ai } & \text { tama-ma-ao } & \text { manie-di } & \text { iuti } & \text { e } & \text { si-iava } & \text { si-ma }\end{array}$

SW 1PL.EXC father-1PL.EXC-PL some-3PL.IA youth DEV 3PL-to.bush 3PL-come

go, geya xoroto gagaidi geya sivaipolu.

go geia koloto gagai-di geia si-vai-polu

SW NEG man big-3PL NEG 3PL-CAUS-boil

Now some of our fathers were (with the) youth (group), and they came, but there were no big men to boil food.

$\begin{array}{llllll}E & \text { xayava } & \text { xama } & \text { xaxaika } & \text { ikavava, } & e \\ e & \text { ka-iava } & \text { ka-ma } & k a-k a i k a & \text { i-kavava } & \text { e }\end{array}$

DEV 1PL.EXC-to.bush 1PL.EXC-come 1PL.EXC-meal 3SG-be.finished DEV

minisita ibobobwara, ionaoboboma.

minisita $i$-RDP-bobuala i-ona-oboboma

minister 3SG-IMPER-talk 3SG-say-love

So after we had come to eat, the minister spoke and said thanks. 
Ionaoboboma ikavava, e xaiwo xana. i-ona-oboboma i-kavava k ka-iva ka 3SG-say-love 3SG-be.finished DEV 1PL.EXC-seaward 1PL.EXC-go After he had said thanks, we went to the beach.

E ionaoboboma ikavava, idigo xana, Ago avatawa e i-ona-oboboma i-kavava i-diga ka-na ago ava-tau-ua

DEV 3SG-say-love 3SG-be.finished 3SG-say talk-3SG.IA SW which-person-PL vesi vavagimi, e xoyava xoma amexo vada goi xovesi”. vesi vavagi-mi e ko-iava ko-ma ame-ko vada goi ko-vesi song desire-2PL.IA DEV 2PL-to.bush 2PL-come here-PLA.ADV PP 2PL-sing After he had said thanks, he said, "And any of you who want singing, come over here to the house to sing".
E xai xaiwo
xana, xaxayaxa.
e kai ka-iva
ka-na
ka-kaiaka

DEV 1PL.PN 1PL.EXC-seaward 1PL.EXC-go 1PL.EXC-remain

Then we went to the beach and sat there.
Ikavava,
xaxauli
i-kavava
ka-kauli
xapwaiyuyu.
ka-puaiiuiu
3SG-be.finished 1PL.EXC-chew.betel.nut 1PL.EXC-smoke

Then we chewed and smoked.

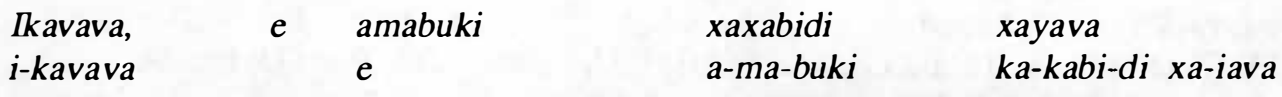

3SG-be.finished DEV PASS-1PL.EXC-book 1PL.EXC-get-3PL 1PL.EXC-to.bush

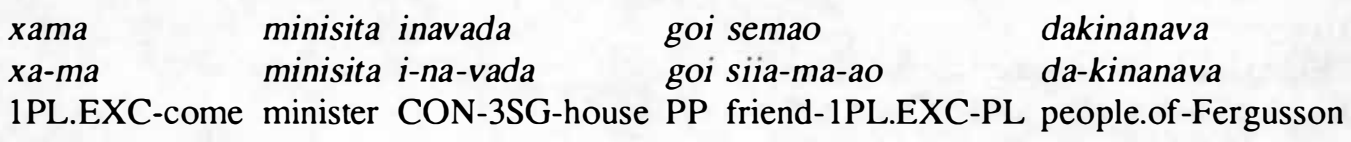

taiyao xavesi.

taiiao ka-vesi

COM 1PL.EXC-sing

After that was finished, then we got our books and came to the minister's house where we sang together with our friends, the people from Fergusson.

$\begin{array}{llllll}\text { Xavesivesi } & \text { iii } & \text { xai } & \text { bogina } & \text { naxona nobunatoina naxae } \\ \text { ka-RDP-vesi } & \text { iii } & \text { kai } & \text { bogina } & \text { nakona nobunatoina nakae } \\ \text { 1PL.EXC-IMPER-sing until } & \text { 1PL.EXC.PN PRF } & \text { perhaps midnight } & \text { same } \\ \text { matama } & \text { simasisi. } & & & \\ \text { mata-ma } & \text { si-masisi } & & & \end{array}$

eye-1PL.EXC.IA 3PL-sleep

We were singing until perhaps midnight and we were tired.

Simasisi, e xaiwo xana.

si-masisi e ka-iva ka-na

3PL-sleep DEV 1PL.EXC-seaward 1PL.EXC-go

We were tired, so we went to the beach. 
$\begin{array}{lll}\text { Xaiwo } & \text { xana } & \text { xamasisi. } \\ \text { ka-iva } & \text { ka-na } & \text { ka-masisi } \\ \text { 1PL.EXC-seaward } & \text { 1PL.EXC-go } & \text { 1PL.EXC-sleep }\end{array}$

We went to the beach to sleep.

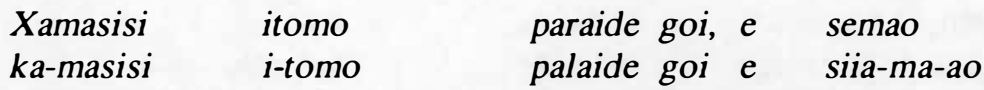

1PL.EXC-sleep 3SG-be.next.day Friday PP DEV friend-1PL.EXC-PL

dakinanava sisawala go, xai aiyuwoina xasowoya,

da-kinanava si-sauala go kia ai-iuuo-i-na ka-souoia

people.of-Fergusson 3PL-disperse SW 1PL.EXC.PN CL-two-?-3SG 1PL.EXC-embark

xaxaluvilamna xana Gilwara goi.

ka-kaluvila-muna ka-na Gilwara goi

1PL.EXC-return-again 1PL.EXC-go Gilwara PP

We slept until the next day, which was Friday, then our friends, the people from Fergusson, dispersed and we embarked again and returned to Gilwara.

$\begin{array}{llllll}X \text { ana } & \text { amoxo } & \text { tamamao } & \text { sikayaxa } & \text { go, } & \text { xai } \\ \text { ka-na } & \text { amo-ko } & \text { tama-ma-ao } & \text { si-kaiaka } & \text { go } & \text { kai }\end{array}$

1PI.EXC-go there-PLA.ADV father-1PL.EXC-PL 3PL-remain SW 1PL.EXC.PN

yuti xasiu xana dogoi woiga xaxavala.

iuti ka-siu ka-na dogoi uoiga ka-kavala

youth 1PL.EXC-enter 1PL.EXC-go thing root 1PL.EXC-carry

We went there where our fathers were and we the youth went in to carry woiga root.

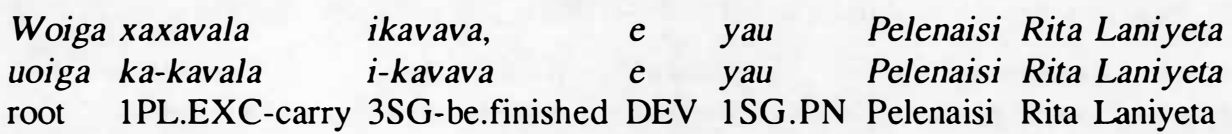

woiga xaxavala, e bwada maniedi sikavaledi xaxaluvila

uoiga ka-kavala e buada manie-di si-kavala-i-di ka-kaluvila

root 1PL.EXC-carry DEV caulk some-3PL.IA 3PL-carry-TR-3PL 1PL.EXC-return

xana Gilwara go, xoroto kidi yuti moe sina aiyuwoina

ka-na Gilwara go, koloto kidi iuti moe si-na kai-iuuo-i-na

1PL.EXC-go Gilwara SW man 3PL.PN youth that 3PL-go CL-two-?-3SG

bwada tuwaina sikavala.

buada tuuaina si-kavala

caulking more 3PL-carry

After we had carried the woiga root, Pelenaisi, Rita, Laniyeta and I carried caulking, then they carried the caulking and we returned to Gilwara and the men who are youth went again to carry more caulking.

Sikavala sima, lailai bogina sima sisowoduwo, e aiyuwoina si-kavala si-ma lavilavi bogina si-ma si-souoduva e kai-iuuo-i-na 3PL-carry 3PL-come evening PRF 3PL-come 3PL-exit DEV CL-two-?-3SG 
xana xabeuta.

ka-na ka-beut

1PL.EXC-go 1PL.EXC-paddle

They carried it and in the evening they came out, then again we paddled on.

\begin{tabular}{|c|c|c|c|c|}
\hline Xasowoya & aiyuwoina & xana & xabeuta, & $x a i$ \\
\hline ka-souoia & kai-iuuo-i-na & ka-na & ka-beut & kai \\
\hline 1PL.EXC-embark & CL-two-?-3SG & 1PL.EXC-go & 1PL.EXC-paddle & 1PL.EXC.PN \\
\hline toinima & amaiyana. & & & \\
\hline toini-ma & a-ma-iian & & & \\
\hline REFL-1PL.EXC & EAT-1PL.EXC- & turtle & & \\
\hline
\end{tabular}

$\begin{array}{lllll}\text { Xana } & \text { xabeubeuta } & \text { aaa } & \text { iyana tayamo } & \text { xaxone. } \\ \text { ka-na } & \text { ka-RDP-beut } & \text { aaa } & \text { iian taia-mo } & \text { ka-kona-i }\end{array}$

1PL.EXC-go 1PL.EXC-IMPER-paddle until turtle one-only 1PL.EXC-trap-TR We were paddling until finally we trapped a turtle.

Tayamo iyana xaxone, xama.

taia-mo iian ka-kona-i ka-ma

one-only turtle 1PL.EXC-trap-TR 1PL.EXC-come

We trapped a turtle, and we continued.

$\begin{array}{llllll}\text { Xama } & \text { xavayu, } & \text { e } & \text { geya } & \text { sigabuyeta } & \text { geya, } \\ \text { ka-ma } & \text { ka-vaiu } & \text { e } & \text { geia } & \text { si-gabu-ia-ita } & \text { geia } \\ \text { ka-masisi }\end{array}$

1PL.EXC-come 1PL.EXC-land DEV NEG 3PL-roast-3SG-LIM NEG 1PL.EXC-sleep

We landed, but then they did not roast it; instead we slept.

Xamasisi, xavaipolu xaxaika ikavava, xamasisi

ka-masisi ka-vai-polu ka-kaika i-kavava ka-masisi

1PL.EXC-sleep 1PL.EXC-CAUS-boil 1PL.EXC-meal 3SG-be.finished 1PL.EXC-sleep

$\begin{array}{llllll}\text { itomo } & \text { Satade, } & \text { e } & \text { xaxaluvilamna } & \text { xama } & \text { Wadalei goi. } \\ \text { i-tomo } & \text { Satade } & \text { e } & \text { ka-kaluvila-muna } & \text { ka-ma } & \text { Wadalei goi }\end{array}$

3SG-next.day Saturday DEV 1PL.EXC-retum-again 1PL.EXC-come Wadalei PP

We slept, and after we had cooked and eaten, we slept until the next day, which was

Saturday, then we retumed again to Wadalei.

Wadalei goi aiyuwoina Satade nobuyana aiyuwoina xama

Wadalei goi kai-iuuo-i-na Satade nobuiana kai-iuuo-i-na ka-ma

Wadalei PP CL-two-?-3SG Saturday moming CL-two-?-3SG 1PL.EXC-come

xabeuta.

$k a-b e u t$

1PL.EXC-paddle

At Wadalei on Saturday we again went and paddled.

Xabeuta aiyuwoina iyana tayamo xaxone.

ka-beut kai-iuuo-i-na iian taia-mo ka-kona-i

1PL.EXC-paddle CL-two-?-3SG turtle one-only 1PL.EXC-trap-TR

We paddled, and we trapped a second turtle. 


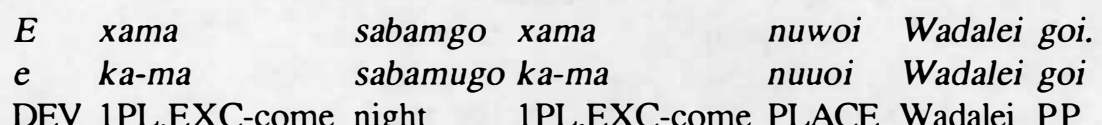

So we came back at night to Wadalei.

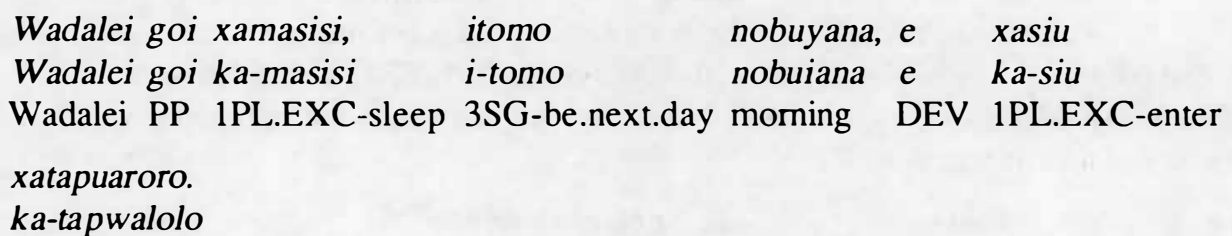

1PL.EXC-worship

At Wadalei we slept; the next day in the moming we went in to worship.

$\begin{array}{llllll}\text { Tapwaroro } & \text { ikavava, } & \text { xama } & & \text { xavaipolu } & \text { xaxaika } \\ \text { tapualolo } & \text { i-kavava } & \text { ka-ma } & \text { ka-vai-polu } & \text { ka-kaika } \\ \text { worship } & \text { 3SG-be.finished } & \text { 1PL.EXC-come } & \text { 1PL.EXC-CAUS-boil } & \text { 1PL.EXC-meal } \\ \text { ikavava, } & \text { aiyuwoina } & \text { dine } & \text { xasiu } & \text { xatapwaroro. } \\ \text { i-kavava } & \text { kai-iuuo-i-na } & \text { dine } & \text { ka-siu } & \text { ka-tapualolo }\end{array}$

3SG-be.finish CL-two-?-3SG afternoon 1PL.EXC-enter 1PL.EXC-worship

After worship, we came and cooked. After we had eaten, we went in again to worship.

Tapwaroro ikavava, xasowoduwo, xamasisi.

tapualolo i-kavava ka-souoduva ka-masisi

worship 3SG-be.finished 1PL.EXC-exit 1PL.EXC-sleep

After we had worshipped, we went out to sleep.

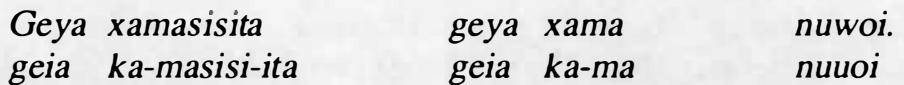

NEG 1PL.EXC-sleep-LIM NEG 1PL.EXC-come PLACE

We didn't sleep, we came to what was the place?

Sande sabamgo goi xama nuwoi.

Sanide sabamugo goi ka-ma nuuoi

Sunday night PP 1PL.EXC-come PLACE

On Sunday night we came to what was the place?

Xama nuwoi moe manaxoyoina Duduwe goi.

ka-ma nuuoi moe manakoioi-na Duduue goi

1PL.EXC-come PLACE that how-3SG Duduwe PP

We came to what place, what's the name of it, to Duduwe.
Xama
Duduwe goi ama-iyana
aiyuwo sigabudi.
ka-ma
Duduue goi a-ma-iian
kai-iuuo si-gabu-i-di
1PL.EXC-come Duduwe PP EAT-1PL.EXC-turtle CL-two 3PL-roast-TR-3PL
We came to Duduwe where we roasted our two turtles.

Sigabudi, xamasisi.

si-gabu-i-di ka-masisi

3PL-roast-TR-3PL 1PL.EXC-sleep

We roasted them, then we slept. 


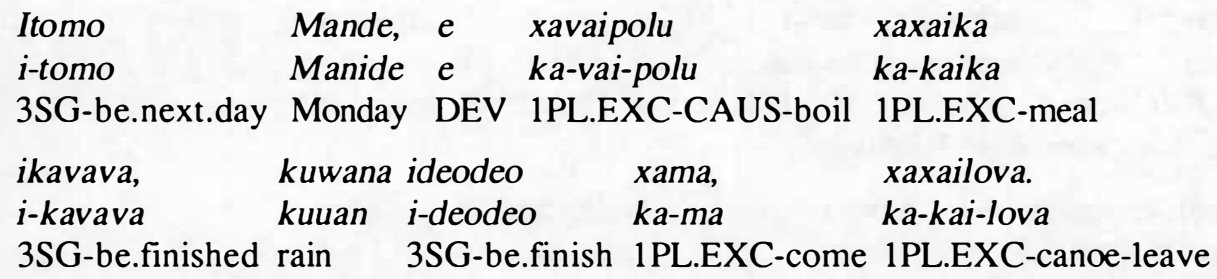

It was the next day, Monday, then we cooked and after we had eaten, the rain had stopped and we continued and departed.

$\begin{array}{lllll}\text { Xaxailova } & \text { xama } & \text { aaa nuwoi } & \text { semao } & \text { sina } \\ \text { ka-kai-lova } & \text { ka-ma } & \text { aaa nuuoi } & \text { siya-ma-ao } & \text { si-na } \\ \text { 1PL.EXC-canoe-leave } & \text { 1PL.EXC-come } & \text { until PLACE } & \text { friend-1PL.EXC-PL } & \text { 3PL-go }\end{array}$

Tuyatana.

Tuiatana

Tuyatana

We departed and came to, our friends came to Tuyatana.

Sina Xotoita, sivayu ikavava, sima nuwoi Tuyatana go, si-na Kotoita si-vaiu i-kavava si-ma nuuoi Tuiatana go 3PL-go Kotoita 3PL-land 3SG-be.finished 3PL-come PLACE Tuyatana SW

$\begin{array}{lllll}x a i & \text { Kina amoxo } & \text { lagaima } & \text { goi xama } & \text { nuwoi } \\ \text { kai } & \text { Kina amo-ko } & \text { laga-i-ma } & \text { goi ka-ma } & \text { nuuoi }\end{array}$

1PL.EXC.PN Kin there-PLA.ADV up-?-1PL.EXC PP 1PL.EXC-come PLACE

Duriduri goi niu Sidoudou imwera, xaxaika ikavava,

Duliduli goi niu Sidoudou i-muela ka-kaika i-kavava

Duriduri PP coconut Sidoudou 3SG-climb 1PL.EXC-meal 3SG-be.finished

e aiyuwoina xabeuta.

e kai-iuuo-i-na ka-beut

DEV CL-two-?-3SG 1PL.EXC-paddle

They came to Kotoita, then after they had landed, they came to Tuyatana but over there on the bush side from Kina we came to Duriduri where Sidoudou climbed a coconut tree. After we had eaten, we again paddled.

$\begin{array}{lllll}\text { Xabeuta } & \text { xama, } & \text { xadi, } & \text { "Tana } & \text { Tuyatana". } \\ \text { ka-beuta } & \text { ka-ma } & \text { ka-di } & \text { ta-na } & \text { Tuiatana }\end{array}$

1PL.EXC-paddle 1PL.EXC-come talk-3PL.IA 1PL.INC-go Tuyatana

We paddled on and they said, "Let's go to Tuyatana".

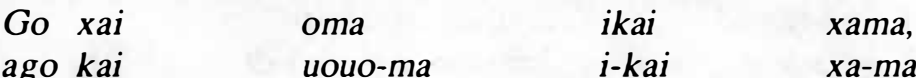

SW 1PL.EXC.PN body-1PL.EXC.IA 3SG-not.want talk-1PL.EXC.IA

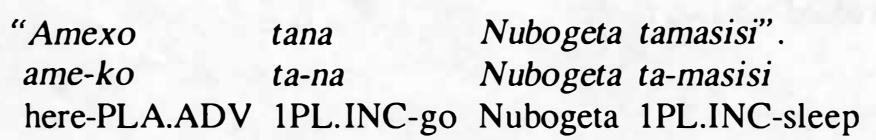

But we didn't want to, we said, "From here let's go to Nubogeta and sleep". 


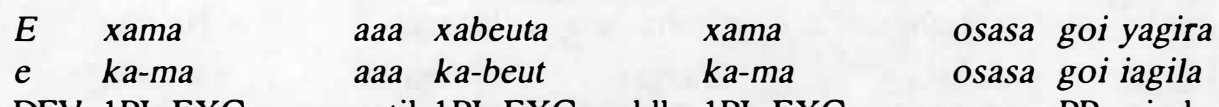

DEV 1PL.EXC-come until 1PL.EXC-paddle 1PL.EXC-come sea PP wind

itowo, xaxailova.

i-touo ka-kai-lova

3SG-land 1PL.EXC-canoe-leave

So we came and paddled to the sea where the wind touched down and we departed.

$\begin{array}{llll}\text { Xaxailova } & \text { xama } & \text { aaa bogina ixamamaniwana sabamgo } \\ \text { ka-kai-lova } & \text { ka-ma } & \text { aaa bogina i-ka-mamaniuana sabamugo } \\ \text { 1PL.EXC-canoe-leave } & \text { 1PL.EXC-come until PRF } & \text { 3SG-INCH-be.dark night } \\ \text { naxae xama } & \text { xasobu. } & & \\ \text { nakae ka-ma } & k a-s o b u & & \\ \text { same 1PL.EXC-come } & 1 \text { PL.EXC-down }\end{array}$

We departed and continued until it had become dark like night; we continued and took down our sail.

$\begin{array}{lllll}\text { Xasobu, } & \text { xavaipolu } & \text { xaxaika } & \text { ikavava, } & e \\ \text { ka-sobu } & \text { ka-vai-polu } & \text { ka-kaika } & \text { i-kavava } & e \\ \text { 1PL.EXC-down } & \text { 1PL.EXC-CAUS-boil } & \text { 1PL.EXC-meal } & \text { 3SG-be.finished DEV }\end{array}$

$\begin{array}{llll}\text { xasawala } & \text { xama } & \text { amavada } & \text { goi xamasisi. } \\ \text { ka-sauala } & \text { ka-ma } & \text { a-ma-vada } & \text { goi ka-masisi }\end{array}$

1PL.EXC-disperse 1PL.EXC-come PASS-1PL.EXC-house PP 1PL.EXC-sleep

We took down the sail, then we cooked. After we had eaten, we dispersed and came to our houses where we slept.

Ame tauna.

ame tauna

this that's.it

That's all.

\section{WORD LISTS}

The only previously published lexical materials for Gumawana are short word lists in Lauer (1974) and Lithgow (1976). Section 11.1 contains the Summer Institute of Linguistics (Papua New Guinea branch) basic word list for each of the four Gumawanaspeaking islands. They are given in phonetic transcription. Section 11.2 reproduces the list from Lauer (1974) and gives Nubogeta equivalents.

\subsection{BASIC WORD LIST FOR FOUR GUMAWANA COMMUNALECTS}

The following word lists were collected by the author at each of the four villages of Nubogeta, Gumawana, Omea and Bituma. They are given in phonetic transcription. Items from the Summer Institute of Linguistics list which are not found in Gumawana (e.g. 62. horn) are omitted. 


\begin{tabular}{|c|c|c|c|c|}
\hline & Nubogeta & Gumawana & Omea & Bituma \\
\hline 1. (his) hair & kununa & kununa & kununa & kununa \\
\hline 2. (his) head & bulubuluna & bulubuluna & bulubuluna & bulubuluna \\
\hline 3. (his) mouth & tobuna & tobuna & tobuna & tobuna \\
\hline 4. (his) nose & kubuna & kubuna & kubuna & kubuna \\
\hline 5. (his) eye & matana & matana & matana & matana \\
\hline 6. (his) neck & nukotona & nukotona & nukotona & nokona \\
\hline 7. (his) belly & gamona & gamona & gamona & gamona \\
\hline 8. (his) skin & saxavaina & saxavaina & saxavaina & sakavaina \\
\hline 9. (his) knee & aetutuna & - & - & - \\
\hline 10. $\operatorname{man}$ & xoroto & xoroto & xoroto & oroto \\
\hline 11. woman & vavina & vavina & vaina & vaina \\
\hline 12. bird & manuo & manuo & manuo & mano \\
\hline 13. $\operatorname{dog}$ & woinia & weinia & wenia & wenia \\
\hline 14 he bites & ikani & $i k a n i$ & - & - \\
\hline 15. he sits & itusobu & itusobu & isisobu & itosobu \\
\hline 16. he stands & itaoya & itaoya & itaoya & itaoya \\
\hline 17. he lies down & imasis & imasisi & - & ikena \\
\hline 18. he walks & iketoia & - & - & - \\
\hline 19. road & enao & kenao & keda & enao \\
\hline 20. stone & gurewa & gurewa & lusa & lusa \\
\hline 21. big & gagaina & gagaina & gagaina & gagaina \\
\hline 22. small & giaina & giaina & gilomwenia & giaina \\
\hline 23. fire & yeu & yeu & xova & yeu \\
\hline 24. smoke & aubowo & aubowo & aubowo & $a u$ \\
\hline 25. ashes & selexa & poxova & aususu & pokoa \\
\hline 26. his ear & taiana & taiana & taiana & teana \\
\hline 27. his tongue & maena & maena & maena & maena \\
\hline 28. his tooth & alana & salana & sakina & salana \\
\hline 29. her breast & nununa & nununa & susuna & nununa \\
\hline 30. his hand & nimana & nimana & nimana & magirina \\
\hline 31. his foot & aena & aena & aena & - \\
\hline 32. sun & niala & alasia & alasia & niala \\
\hline 33. moon & tukowana & tukowana & waikena & wowoina \\
\hline 34. star & utuna & utuna & utuna & utuna \\
\hline 35. cloud & geleo & gaota & gawata & geleo \\
\hline 36. rain & kuwana & kuwana & - & - \\
\hline 37. water & bwae & bwae & bweye & bweye \\
\hline 38. tree & alova & alova & alova & alowa \\
\hline 39. root & lam & lamna & buyala & lamna \\
\hline 40. leaf & yao & yao & yao & yao \\
\hline 41. meat & - & - & goba & esowa \\
\hline 42. fat & sabali & sabali & momona & momonaina \\
\hline 43. egg & pelelemotu & peleleotu & pou & pou \\
\hline 44. he eats & ikaika & ikaika & ikaika & ikani \\
\hline 45. he gives me it & ivinigu & ivinigu & ivinigu & iinigu \\
\hline
\end{tabular}


46. he sees

47. he comes

48. louse

49. one

50. two

51. his back

52. his shoulder

53. his forehead

54. his chin

55. his elbow

56. his thumb

57. his leg

58. his heart

59. his liver

60. his bone

61. his blood

64. wing

65. claw

66. tail

67. boy

68. girl

69. baby

70. old man

71 . old woman

72. person

73. his father

74. his mother

75. brother (older of man)

76. sister (older of man)

77. name

78. pig

81. flying fox

82. rat

83. frog

84. snake

85. fish

86. taro

87. sugarcane

88. yam

89. banana

90. sweet potato

91. bean

92. axe

93. knife

96. house

\begin{tabular}{|c|c|c|c|}
\hline Nubogeta & Gumawana & Ornea & Bituma \\
\hline igite & igite & ipwategu & igite \\
\hline ima & ima & ima & ima \\
\hline kutu & kutu & kutu & kutu \\
\hline tayamo & tayamo & tayamo & tamo \\
\hline aiyuwo & aiyuwo & aiyuwo & aiyuwa \\
\hline toluna & toluna & toluna & ligana \\
\hline valavana & valavana & valavana & vavalana \\
\hline dabana & dabana & dabana & dabana \\
\hline xalaxalena & - & - & - \\
\hline nimatutuna & - & - & - \\
\hline nimatubutubuna & - & - & - \\
\hline aena & aena & aena & aena \\
\hline nuwemagina & - & - & - \\
\hline atena & atena & atena & atena \\
\hline luluna & luluna & luluna & luluna \\
\hline ikaika & ikaika & ikaika & buyai \\
\hline panapanena & panipainena & nipapena & papanena \\
\hline nimadidina & - & - & - \\
\hline yuyuna & yuyuna & duduna & - \\
\hline gomana koroto & - & - & - \\
\hline gomana vavina & - & - & - \\
\hline memea & - & - & - \\
\hline tomoya & - & - & - \\
\hline namoya & - & - & - \\
\hline tomota & - & - & - \\
\hline tamana & tamana & tamana & tamana \\
\hline sinana & sinana & sinana & sinana \\
\hline tuwowona & tuwowona & tuwavana & siyana \\
\hline niuna & niuna & niuna & niuna \\
\hline yoina & yoina & yoina & yoina \\
\hline bao & bao & bao & bao \\
\hline magiaweda & - & - & - \\
\hline kelikeli & kelideli & kwelekwele & kelikeli \\
\hline kwekwe & - & - & - \\
\hline moteta & moteta & mota & mota \\
\hline iyana & iyana & iyana & iyana \\
\hline vilava & - & - & - \\
\hline tou & - & - & - \\
\hline kuvi & - & - & - \\
\hline losui & busisi & busisi & isiwo \\
\hline simwai & - & - & - \\
\hline bini & - & - & - \\
\hline kiyama & - & - & - \\
\hline naipi & - & - & - \\
\hline vada & vada & sibeove & vada \\
\hline
\end{tabular}




\begin{tabular}{|c|c|c|c|c|}
\hline & Nubogeta & Gumawana & Ornea & Bituma \\
\hline 97. earth & роуароуа & роуароуа & роуароуа & poyapoya \\
\hline 98. sand & ediedila & ediedila & nidunidula & lolou \\
\hline 99. mountain & xoya & xоyа & xоyа & koya \\
\hline 100. wind & yaina & yaina & yaina & yaina \\
\hline 101. vine & buyala & - & - & - \\
\hline 104. seed (for planting) & vevana & vevana & uwaina & keuwaina \\
\hline 105. tobacco & tapwae & - & - & - \\
\hline 106. morning & nobuyana & - & - & - \\
\hline 107. afternoon & dine & - & - & - \\
\hline 108. night & sabamgo & sabamgo & sobomgo & boiboi \\
\hline 109. yesterday & boile & - & - & - \\
\hline 110. tomorrow & itomo & - & - & - \\
\hline 111. white & powouna & powouna & wakekena & - \\
\hline 112. black & xalawoina & xalaxovina & alaxowina & - \\
\hline 113. yellow & yaoyaoina & - & - & - \\
\hline 114. red & xayaxayaina & xaxayaina & xaxayaina & katakoina \\
\hline 115. green & xalakalaoina & - & - & - \\
\hline 116. good & dedeina & dedevina & dedewina & gumaboina \\
\hline 117. bad & goyogoyoina & - & - & - \\
\hline 118. long & manawena & manawena & manawena & manawena \\
\hline 119. short & xakupina & kubokuboina & bokubona & kakopina \\
\hline 120. heavy & moumouna & moumouna & moumouna & kamouna \\
\hline 121. light & xaxapuna & - & - & - \\
\hline 122. cold (water) & tulaina & tulaina & tulaina & tulaina \\
\hline 123. hot (water) & dimodimo & dimodimo & - & yaiyai \\
\hline 124. old & bogo & xaibogoina & aibogoina & takanaboga \\
\hline 125. new & vau & vau & vau & - \\
\hline 126. many & badabadaina & badabadaina & bidibadaina & babadaina \\
\hline 127. all & madabokina & - & - & - \\
\hline 128. this & ame & - & - & - \\
\hline 129. that & amo & - & - & - \\
\hline 130. what? & xaga & xaga & xavaga & kadiani \\
\hline 131. who? & avatau & vatau & vatau & avaita \\
\hline 132. when? & avalava & - & - & - \\
\hline 133. where? & naxo & - & - & - \\
\hline 134. round & gumogumoina & - & - & - \\
\hline 135. wet (clothing) & ikanapoiwo & xanapou & xanapowo & ikanapoa \\
\hline 136. dry (clothing) & iyabuyabu & saiyasaiya & - & isaiyasaiya \\
\hline 137. full & ikayaoda & xayaoda & ikayawada & ikayaoda \\
\hline 138. not & geya & - & - & - \\
\hline 139. three & aito & aito & aito & aito \\
\hline 140. four & aivas & aivas & aivas & aivasi \\
\hline 141. five & ainima & ainima & ainima & ainima \\
\hline 142. ten & yauwo & - & - & - \\
\hline 143. yes & $u u$ & - & - & - \\
\hline 144. no & geya & geya & geda & geya \\
\hline 145. he says & idigo & - & - & - \\
\hline
\end{tabular}




\begin{tabular}{|c|c|c|c|c|}
\hline & Nubogeta & Gumawana & Ornea & Bituma \\
\hline 146. he hears & inove & inowo & inowo & inove \\
\hline 147. he knows & iyagoi & - & - & - \\
\hline 148. he drinks & inim & inim & inim & inim \\
\hline 149. he sleeps & imasis & imasis & imasisi & ikena \\
\hline 150. he kills & ikaumate & - & - & - \\
\hline 151. he dies & ikamasa & imata & ikamasa & imata \\
\hline 152. it burns (fire) & ininima & ininima & ininima & ininima \\
\hline 153. it flies & iyova & - & - & - \\
\hline 154. he swims & ikaya & - & - & - \\
\hline 155. he runs & iloxoina & - & - & - \\
\hline 156. he falls down & ikapus & ikapus & - & ibeku \\
\hline 157. he hits & ilauwo & ilauwo & ilauwo & ilauwo \\
\hline 158. he catches & ikalagomota & - & - & - \\
\hline 159. he coughs & iboku/loku & - & - & - \\
\hline 160. he laughs & ivanama & ikolua & ivanama & ianama \\
\hline 161. he dances & ilausa & - & - & - \\
\hline 162. I & yau & yau & yau & уаu/аu \\
\hline 163. thou & xom & xom & xom & kom \\
\hline 164. he & kina & ia & ia & kina \\
\hline 165. we two (EXC) & amateyuwo & - & - & - \\
\hline 166. you two & amiteyuwo & - & - & - \\
\hline 167. they two & aditeyuwo & - & - & - \\
\hline 168. we (PL.EXC) & kita & - & - & - \\
\hline 169. you (PL) & xomi & - & - & - \\
\hline 170. they & kidi & - & - & - \\
\hline
\end{tabular}

\subsection{TERMS USED IN MAKING CLAY POTS}

This section reproduces a word list from Lauer (1974) of terms used in connection with clay pot making. Column 1 is Lauer's list for the villages of Nubogeta, Gumawana, Omea; column 2 his Bituma (or, in his terms, Dilia) list; and column 3 is my list collected at Nubogeta.

1

1. paddle

2. Bailer shell

3. fresh water

4. base board

5. pandanus leaf over the base board

6. grass ring

7. wooden knife

8. shell scraper

9. decorating shell

10. decorating seed

$\begin{array}{ll}\begin{array}{l}\text { ailauwo } \\ \text { keduya } \\ \text { bwoae } \\ \text { aisika }\end{array} & \begin{array}{l}\text { ainena } \\ \text { welego } \\ \text { bwoae } \\ \text { aisika }\end{array} \\ \text { sedula } & \text { sekula } \\ \text { nupaiya } & \text { seniseni } \\ \text { aisisi } & \text { aisisi } \\ \text { vidiala } & \text { sikaka } \\ \text { lokiloki } & \text { lokiloki } \\ \text { meko } & \text { aigini }\end{array}$

3

aipasi/ailauwo

keduya

bwae

aisika

sekula

nupaiya

aisisi

vidiala

lokiloki

meko 
1

11. bumishing pebble

12. burnishing shell

13. digging clay

14. breaking dry clay

15. adding fresh water

16. kneading

17. cleaning

18. rolling the clay

19. heavy roll

20. flattening the roll

21. slab

22. setting slab on the base board

23. joining the slabs

24. drawing clay up from the slabs

25. squeezing heavy rolls

26. adding heavy rolls

27. the opening in the bottom of the unfinished pot

28. covering rim with

29. beating the pot with the paddle

30. decorating

31. turming pot over and setting pot into grass ring

32. scraping

33. scraping with paddle

34 burnishing

35. drying dry by wind dry by sun

36. firing

37. wooden fire place

38. stacking wood around the pot

39. breaking a pot

40. the pot breaks while drying

41. basket for pottery tools

42. pot

43. cooked pot

44. clay $\begin{array}{ll}\text { bwabwaelo } & \text { ulao } \\ \text { didimoko } & \text { didim }\end{array}$

uaegaeli

tutu

wuwui

pie

kutukutu

bili

kavakanabale

tutu

geyabadenamo

sepatuko

katuvayapo

kalitaoe

kule

katuvayapo

kibode

watum

laui

gini

gavile

keli kiposi

kai

ulao

dinala

$-$

gabu

walakone

vataoe

tavisi

pene

pwasale

vaega

kebi

vaega

nene

ulao

tais

kebi
2

3

bwabwaelo

didimoko

vaega ana elina

tutu

wuwui

pie

kutukutu

bili

vakanabala

tutu

vaega geya dadenamo

sepatuko

katuvayapu

kalitaoya

pie

atokula (Gumawana)

katuvayapo

kibode

tapora

kubwase

vatum

eluelu

lauwo

gini

aluile

lugaila

stalaikiposi

balebale

kiposi

ulao

dinala

yagira i sive

niyala i vae

gabu

gabu

kudemeli

valakone

vataoe

vataoya

tavisi

kayau

pene

yavana

wasare

vaega

vaega

kebi

vaega 


\section{REFERENCES}

BEEKMAN, John and John CALLOW, 1974, Translating the Word of God. Grand Rapids: Zondervan.

BRADSHAW, Joel, 1982, Word order change in Papua New Guinea Austronesian languages. PhD dissertation, University of Hawaii.

CLEMENTS, G.N. and S.J. KEYSER, 1983, CV phonology: a generative theory of the syllable. Cambridge: MIT Press.

COMRIE, Bernard, 1975, Aspect: an introduction to the study of verbal aspect and related problems. Cambridge: Cambridge University Press.

1981, Language universals and linguistic typology. Oxford: Blackwell.

COMRIE, Bernard and Sandra A. THOMPSON, 1985, Lexical nominalization. In Shopen, ed. 1985c:349-398.

GREENBERG, Joseph H., 1966, Language universals. The Hague: Mouton.

KEENAN, Edward L., 1985, Relative clauses. In Shopen, ed. 1985b:141-170.

ITO, Junko, 1986, Syllable theory in prosodic phonology. PhD dissertation, MIT.

LAUER, Peter K., 1974, Pottery traditions in the D'Entrecasteaux Islands of Papua. Occasional Papers in Anthropology 3. University of Queensland.

LICHTENBERK, Frantisek, 1986, Syntactic-category change in Oceanic languages. Oceanic Linguistics 24:1-84.

LITHGOW, R. David, 1976, Austronesian languages: Milne Bay and adjacent islands (Milne Bay Province). In S.A. Wurm, ed. New Guinea area languages and language sludy, vol.2, 441-523. $P L$, C-39.

LYNCH, John, 1982, Towards a theory of the origin of the oceanic possessive constructions. In Amran Halim, Lois Carrington and S.A. Wurm, eds Papers from the Third International Conference on Austronesian Linguistics, vol.1, 243-268. PL, C-74.

MALINOWSKI, Bronislaw, 1961, Argonauts of the Western Pacific. (1st edition 1922), London: Routledge and Kegan Paul.

MITHUN, Marianne, 1984, The evolution of noun incorporation. Language 60:847-894.

PERLMUTTER, David M., 1978, Impersonal passives and the unaccusative hypothesis. In Proceedings of the Fourth Annual Meeting of the Berkeley Linguistics Society, 157-189. Berkeley: University of California.

1980, Relational grammar. In Edith A. Moravcsik and Jessica Wirth, eds Syntax and semantics 13: Current approaches to syntax, 195-229. New York: Academic Press.

1982, Syntactic representation, syntactic levels, and the notion of subject. In Pauline Jacobson and Geoffrey Pullum, eds The nature of syntactic representation, 283-340. Dordrecht: Reidel.

PERLMUTTER, David M., ed., 1983, Studies in relational grammar 1. Chicago: University of Chicago Press.

PERLMUTTER, David M. and Paul M. POSTAL, 1983a, Toward a universal characterization of passivization. In Permutter, ed. 1983:3-29.

1983b, Some proposed laws of basic clause structure. In Perlmutter, ed. 1983:81-128.

POSTAL, Paul M., 1977, Antipassive in French. In Proceedings of the Seventh Annual Meeting of the North East Linguistic Society, 273-313. Cambridge, Mass.:M.I.T. Reprinted in Lingvisticae Investigationes 1:333-374.

ROSEN, Carol G., 1981, The relational structure of reflexive clauses: evidence from Italian. PhD dissertation, Harvard University.

ROSS, M.D., 1988, Proto Oceanic and the Austronesian languages of western Melanesia. PL, C-98.

SCHACHTER, Paul, 1985, Parts-of-speech systems. In Shopen, ed. 1985a:3-61.

SHOPEN, Timothy, ed., 1985a, Language typology and syntactic description, vol.1: Clause structure. Cambridge: Cambridge University Press.

1985b, Language typology and syntactic description, vol.2: Complex constructions. Cambridge: Cambridge University Press. 
1985c, Language typology and syntactic description, vol.3: Grammatical categories and the lexicon. Cambridge: Cambridge University Press.

THOMPSON, Sandra A. and Robert E. LONGACRE, 1985, Adverbial clauses. In Shopen, ed. 1985b:171-234. 